\title{
PILOT DEMONSTRATION OF CERIUM OXIDE COATED ANODES
}

DOE/ID/12940--1

DE93 002507

Final Report for the Period

April 1990 to October 1992

October 1992

Work Performed Under Contract No. DE-FC07-90ID12940

\author{
Prepared for the \\ U.S. Department of Energy \\ Under DOE Idaho Field Office \\ Sponsored by the Office of the Assistant Secretary \\ for Conservation and Renewable Energy \\ office of Industrial Technologies \\ Washington, D.C.
Prepared by
ELTECH Research Corporation
Fairport Harbor, $\mathrm{OH}$


Cu cermet anodes were tested for 213 to 611 hours with an in-situ deposited CEROX coating in a pilot cell operated by Reynolds Manufacturing Technology Laboratory. It high bath ratio ( 1.5) and low current density $\left(0.5 \mathrm{~A} / \mathrm{cm}^{2}\right)$, $a \geq 1$ mrn thick denso CEROX coating was deposited on the arodes. At lower bath ratios and higher current density, the CEROX coating was thinner and less dense, but no change in corrosion rate was noted. Regions of low current density on the anodes and sides adjacent to the carbon anode sometimes had thin or absent CEROX coatings. Problems with cracking and oxidation of the cermet substrates led to higher corrosion rates in a pilot cell than would be anticipated from lab scale results. 
CONTENTS

ABSTRACT

SUMMARY

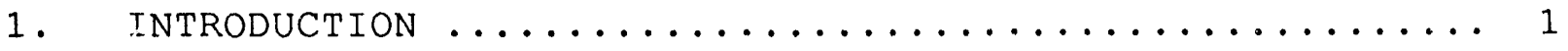

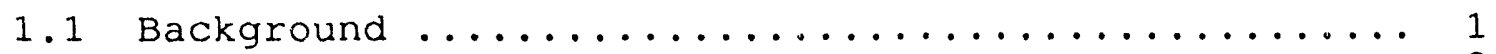

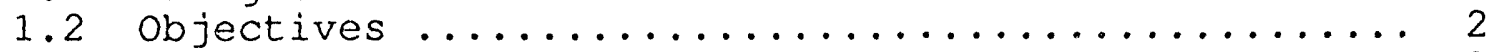

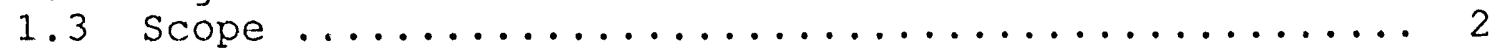

1.4 Accomplishments ..................... 2

2. TEST CELL AND ANODE DESIGN AND PROCEDURES $\ldots \ldots \ldots \ldots \ldots$

2.1 Description of Pilot cell ................. 4

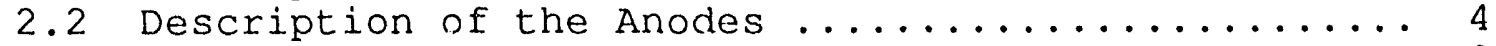

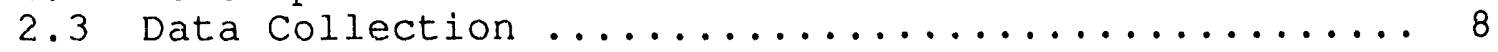

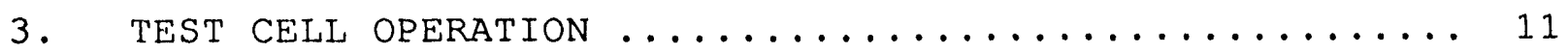

3.1 Target Operating Conditions ................... 11

3.2 Actual Test Conditions and Exchange of Anodes .... 12

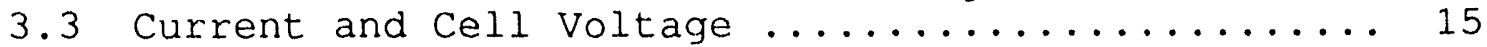

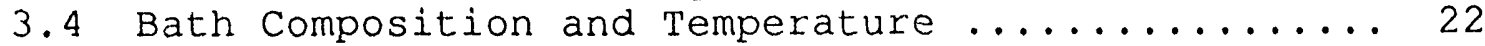

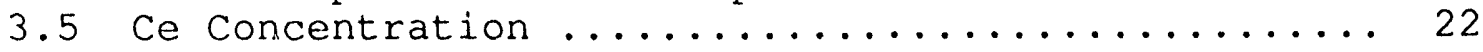

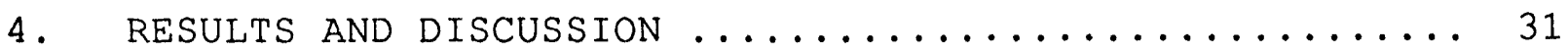

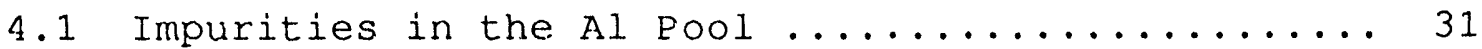

4.2 Macroscopic Examination of Anodes ............. 40

4.2 .1 Description of Anodes ................ 44

4.2.2 Summary of the CEROX Coatings and Cermet

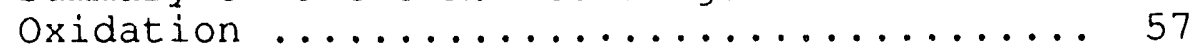

4.3 Microscopic Examination of Anodes ............ 59

4.3.1 Microscopic Evaluation of CEROX Coating ... 59

4.3.2 Microstructures of the Cermet Anodes ...... 71

4.3.3 Microstructure of the Inconel 600 Rod .... 114

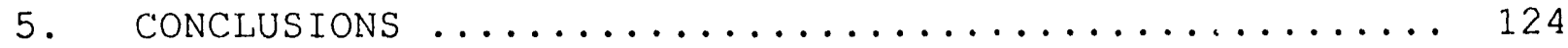

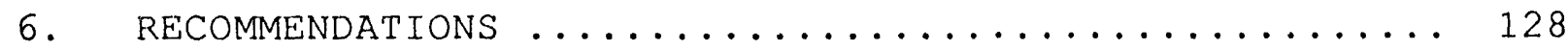

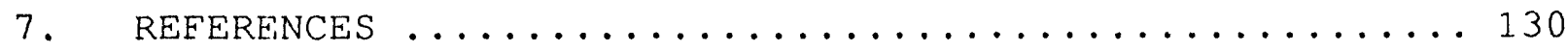

Apperdix 1-Reynolds Manufacturing Technology Laboratory (MTL)

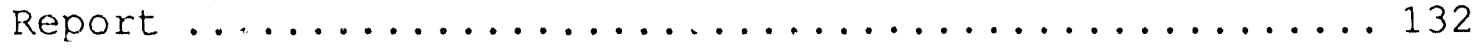




\section{EIGURES}

1. Pilot cell design, plan view ................. 5

2. Pilot cell design, cross section $\ldots \ldots \ldots \ldots \ldots \ldots \ldots \ldots \ldots \ldots \ldots$

3. Position of inert anodes in pilot cell ............7

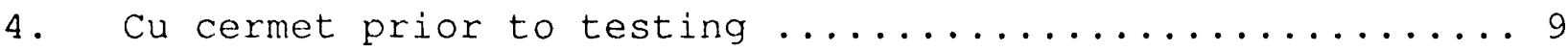

5. Cermet anode design .........................

6. Aluminum impurity with two carbon anodes ........... 14

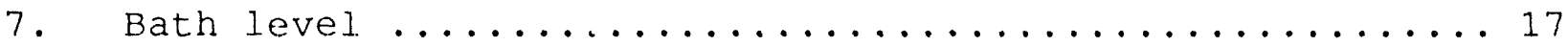

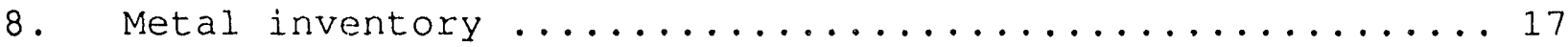

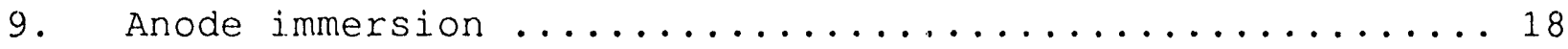

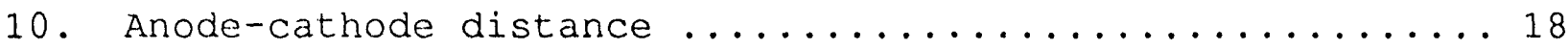

11. Current as a function of time, position $A \ldots \ldots . . . . .19$

12. Current as a function of time, position B.......... 19

13. Current as a function of time, position $c \ldots \ldots \ldots . \ldots 20$

14. Current as a function of time, position D..........20

15. Current as a function of time, position $\mathrm{E} \ldots \ldots . \ldots 21$

16. Current as a function of time, position $F \ldots \ldots . \ldots 21$

17. Cell voltage as a function of time for the cermet anodes 23

18. Bath ratio as a function of time ............... 24

19. Bath temperature as a function of time ............ 24

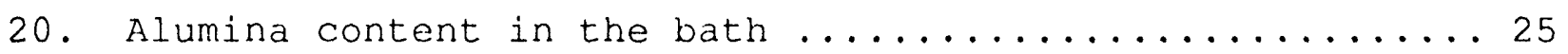

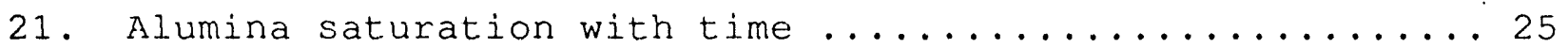

22. $\mathrm{CaE}_{2}$ content in the bath as a function of time $\ldots \ldots \ldots 26$

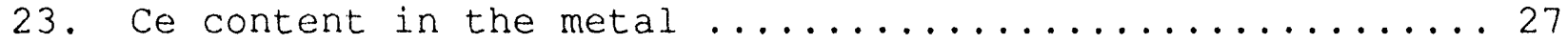

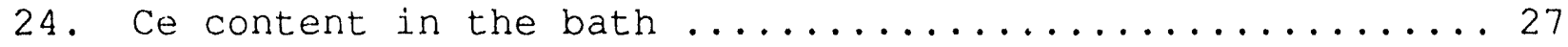

25. Cerium content in bath compared to metal ...........29

26. Ni content in the metal, ELTECH test ............ 32 
27. Cu content in the metal, ELTECH test ............ 32

28. Fe content in the metal, ELtech test ............ 33

29. Ni in the Al metal compared to the model, ELTecil test... 34

30. Cu in the Al metal compared to the model, ELTECH test... 34

31. Fe in the Al metal compared to the model, ELTECH test... 35

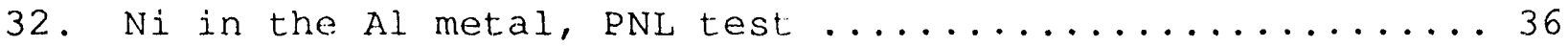

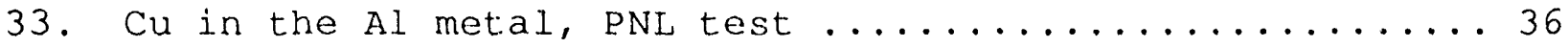

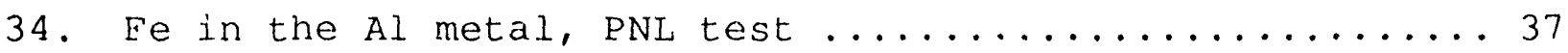

35. $\mathrm{Ni}$ in the Al metal compared to model, eNt test....... 38

36. Cu in the Al metal compared to model, PNI, test .......38

37. Fe in the Al metal compared to model, PNL test ....... 39

38. Alumina saturation, PNL test ................... 41

39. Bath temperature, PNL test ................... 41

40. Sketches of each tested anode $\ldots \ldots \ldots \ldots \ldots \ldots \ldots \ldots \ldots$

41. Untested anodes ....................... 45

42. Anode B1 upon removal from test cell .............46

43. Anode B1 after removal from test cell, cross section.... 46

44. Anode A1, west side, after removal from test cell .....47

45. Anode Al, northeast side, after removal from test cell .. 48

46. Cross sections of anode Al ................. 48

47. Anode $C 1$ after removal from the test cell ...........50

43. Anode A2 after testing ..................... 51

49. Anode A2, west side, after testing ............ 51

50. Anode B2, east side, after testing ............. 52

51. Anode B2, west side, after testing .............. 52

52. Anode $B 2$, cross section along a crack surface ........ 54

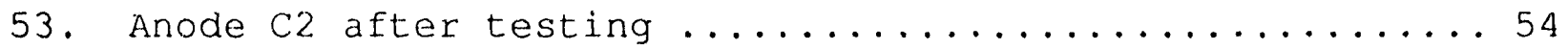




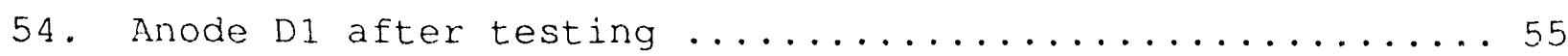

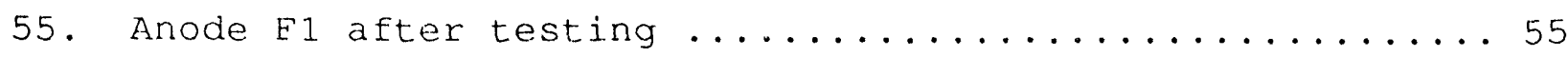

56. Anode E1, cross section along a crack surface ........ 56

57. Inconel 601 connector rod after testing ........... 56

58. CEROX coating on the west side of anode $A 1 \ldots \ldots . \ldots 60$

59. CEROX coating on the northeast side of anode $A 1 \ldots \ldots 66$

60. CEROX coating on the bottom corner of anode A. . . . . . 62

61. CEROX coating on the bottom of anode $\mathrm{C} 1 \ldots \ldots \ldots 63$

62. CEROX coating on the northeast side of anode $\mathrm{C} 1 \ldots \ldots .66$

63. CEROX coating on the northeast bottom corner of anode C1 66

64. CEROX coating on the west side of anode E1 .........667

65a. CEROX coating on the east side of anocie E1, inner section 68

65b. CEROX coating on the east side of anode E1, outer section 69

66. CEROX coating on the bottom of anode $A 2 \ldots \ldots \ldots 70$

67. CEROX coating, anode A2, high magnification ......... 70

68. Low magnification cross section of the untested cermet . 72

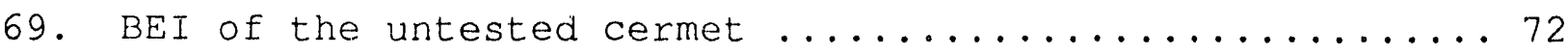

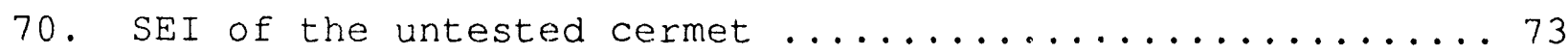

71. Ni cxide-Fe oxide phase diagram $\ldots \ldots \ldots \ldots \ldots \ldots \ldots . \ldots 76$

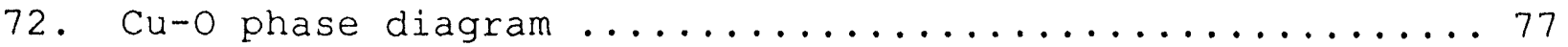

73. Copper depletion $\mathrm{sr}$ am in the untested cermet ........78

74. Exterior bottom corner of anode B1 ............. 80

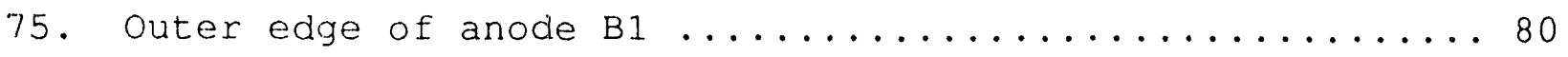

76a. SEI of the $\mathrm{Cu}$ depleted layer, anode $\mathrm{B} 1 \ldots \ldots \ldots . \ldots 81$

76b. BEI of the $\mathrm{Cu}$ depleted layer, anode BI ........... 81

77. Boundary between the porous and dense zones, anode B1 ...83

78. Inner dense zone of anode $B 1 \ldots \ldots \ldots \ldots \ldots \ldots \ldots$ 
79. Outer porous zone of anode BI ............... 84

80. Composition of ferrite and $\mathrm{Cu}$ alloy phase in anode BI ... 86

81. Anode A1, section $40 \ldots \ldots \ldots \ldots \ldots \ldots \ldots \ldots$

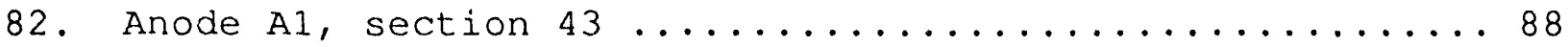

83. Anode $\mathrm{C1}$, section $40 \ldots \ldots \ldots \ldots \ldots \ldots \ldots$

84. Anode Al, section 43, exterior edge of substrate ......990

85. Anode $\mathrm{C} 1$, section 40 , boundary between $\mathrm{Cu}$ metal and

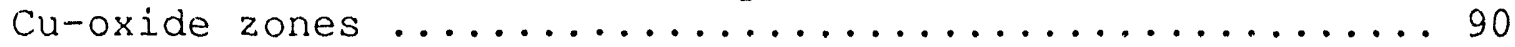

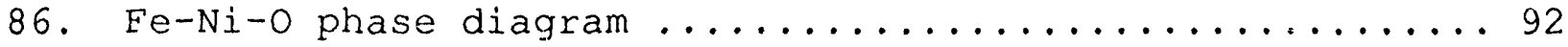

87. Exterior section of anode Al, section $40 \ldots \ldots . \ldots 94$

88. Higher magnification BEI of the dense area in Eigure $87 \quad 94$

89. Aluminate layer next to CERox ................. 96

90. Dense region next to the CEROX in anode A1, section $43 \ldots 98$

91. Anode A1, section 43, at the CEROX-substrate interface .. 98

92. Anode $\mathrm{C} 1$, section 40 , interface between the CEROX and

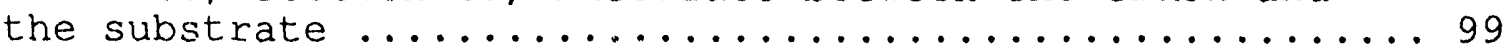

93. Anode C1, section 40, duplex structure next to the CEROX

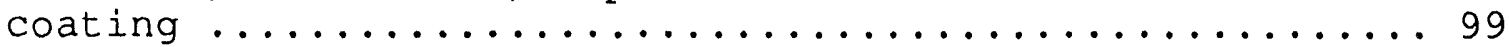

94. Macroscopic section of anode E1, northeast side ...... 101

95. Interface between the CEROX and substrate, anode E1 ... 102

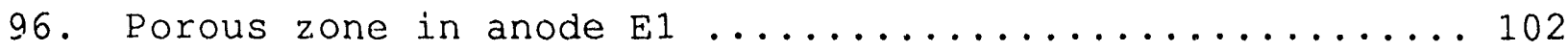

97. Alternating $C u$ depleted and oxidized zones next to the

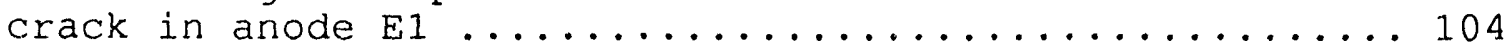

98. Cu depleted zone next to the crack in anode E1.......104

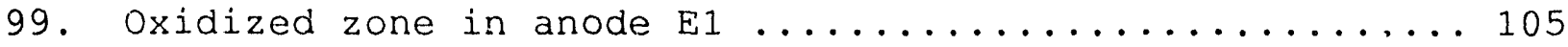

100. Further into the interior of the oxidized zone, anode

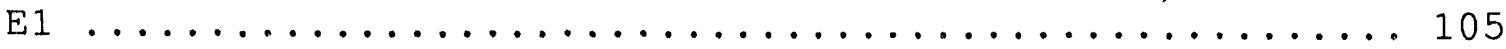

101. Anode $E 1$, further into the interior ............. 107

102. Anode E1, progressing further into the interior than

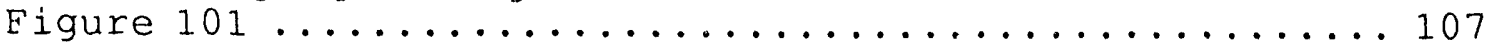


103. Higher magnification of the Cu depleted zone in

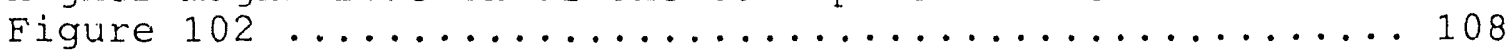

104. BEI of Figure 103, anode E1 ..................... 108

105. Boundary between the fluoride-containing region and the

Cu depletion region, anode $\mathrm{El} \ldots \ldots \ldots \ldots \ldots \ldots \ldots . \ldots . \ldots 109$

106. $\sim 19 \mathrm{~mm}$ into the center of anode $\mathrm{E} 1 \ldots \ldots \ldots \ldots \ldots \ldots \ldots$

107. Higher magnification of Figure $106 \ldots \ldots \ldots \ldots \ldots \ldots$

108. Tip of one of the threads of the Inconel 601 connector 116

109. Base of one of the threads of the Inconel 601 connector 116

110. BEI of the center of the Inconel 601 connector rod .... 117

111. Close-up of the Cr-rich inclusions in Figure $110 \ldots \ldots 117$

112. Edge of the reaction zone in the Inconel 601 rod ...... 118

113. Higher magnification of Figure $112 \ldots \ldots \ldots \ldots \ldots \ldots$

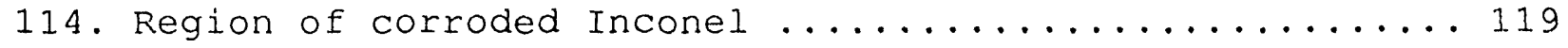

115. Edge of the Inconel rod at the base of the thread ..... 119

116. Higher magnification of Figure $115 \ldots \ldots \ldots \ldots \ldots \ldots \ldots$ 


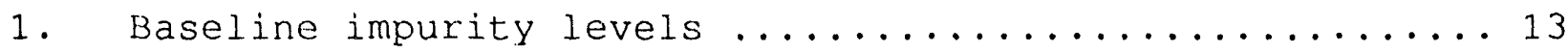

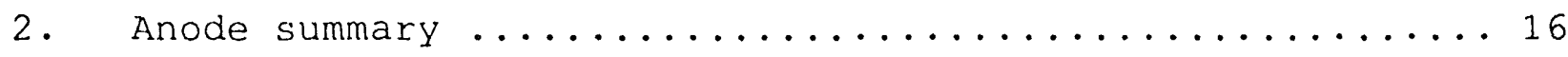

3. Average operating conditions during the four phases of

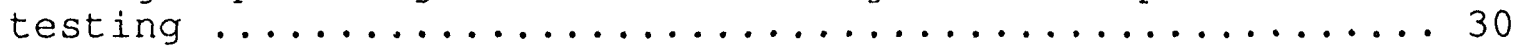

4. Ce concentration and CEROX coating thickness ........558

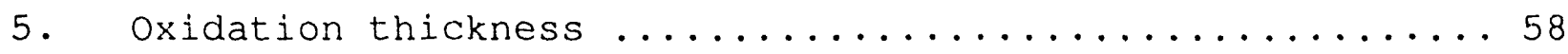

6. Phase compositions in the untested material ........74

7. Average phase compositions in anodes $A 1$ and $C 1 \ldots 93$

8. Compositions of the phases in regions in Figure $104 \ldots 111$

9. Limiting chemical composition of Inconel $601 \ldots \ldots 15$

10. Compositions of $\mathrm{Cr}$ and $\mathrm{Al}$ reaction phases from

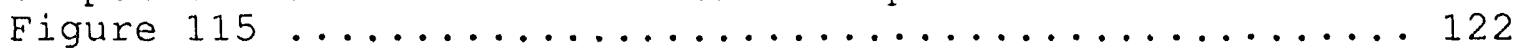




\section{SUMMARY}

Copper cermet anodes for aluminum electrowinning were evaluated in two tests sponsored by DOE, one directed by Battelle Pacific Northwest Laboratories (PNL) and one directed by ELTECH Research Corporation. Both tists were conducted at Reynolds Metals Manufacturing Technology Laboratory (Reynolds) in sheffield, Alabama. The tests were conducted to determine the stability of a $\mathrm{Cu} / \mathrm{NiO} / \mathrm{NiFe}_{2} \mathrm{O}_{4}$ cermet in a pilot aluminum electrowinning cell. The stability of the material was evaluated by the amount of cermet components ( $\mathrm{Ee}, \mathrm{Ni}$, and $\mathrm{Cu}$ ) that accumulated in the $\mathrm{Al}$ metal produced and by examination of the anodes after testing. The performance of the anodes was studied at "optimum" conditions based on laboratory testing and at other bath ratios, current densities, and alumina concentrations. In addition, the stability of the cu cermet material was evaluated both without (PNL) and with (ELTECH) a protective $\mathrm{Ce}(\mathrm{O}, \mathrm{F})_{2}$ layer (CEROX). This report includes the details, results, and conclusions of the ELTECH test, and compares the performance of the uncoated cermets (the PNL test) to the CEROX coated cermets.

The testing of PNL began with two carbon anodes until the operation of the pilot cell was stabilized. One of the carbon anodes was then exchanged for a 6-pack of $\mathrm{Cu}$ cermets manufactured by Ceramic Magnetics Inc. (CM). The Cu cermets operated for a 20 d period, with over $300 \mathrm{~h}$ of testing on some of the cermet anodes.

At the conclusion of the test for PNL, the second test began under the direction of ELTECH. The cell was again operated with two carbon anodes for $13 \mathrm{~d}$ in order to clean the cell of alumina muck and to return the cermet generated impurities in the metal to baseline levels. At the end of that period, another 6-pack of Cu cermet anodes manufactured by CM replaced one of the carbon anodes. The anodes were operated for $26 \mathrm{~d}$ with individual anodes tested for up to $614 \mathrm{~h}$. During the test cerium fluoride was added to the cell to form a CEROX coating on the anodes.

The ELTECH test was conducted for 16 d at "preferred conditions" that were based on the best conditions found in the previous ELTECH laboratory tests: a bath ratio (BR) of 1.5 to 1.6 and a current density (CD) of $0.5 \mathrm{~A} / \mathrm{cm}^{2}$. CD was then increased to $0.65 \mathrm{~A} / \mathrm{cm}^{2}$ for $7 \mathrm{~d}$, and then $B R$ was decreased to $\sim 1.15$ for the remaining $3 \mathrm{~d}$. Bath and metal impurities were monitored throughout the testing to assess the corrosion of the cermet substrate.

During the ELTECH test, as in the PNL test, several problems were encountered. Anodes cracked during introduction to the cell, probably as a result of thermal stress due to temperature gradients and thermal expansion differences between the metal current collector rod and the cermet. Anodes generally remained together and continued operating in spite of the cracks.

A second problem during cell operation was mucking of the cell 
because of high alumina content. The muck tended to accumulate on the bottom of the cell, raising the cathode and reducing cell volume. A third problem during the test was that current to individual cermet anodes was impossible to control, only total current to the 6-pack was controlled. This allowed fluctuations in $C D$ depending on the position of the anode in the cell, and fluctuations in $C D$ during the lifetime of each anode.

Corrosion rates were calculated by Reynolds based on the impurities in the metal. They found corrosion rates during the ELTECH test to be half that of those during the PNL test. The calculated rates are

Iron Increase $(1 \mathrm{~b} / \mathrm{d})$

Nickel increase $(1 b / d)$

Copper increase $(1 \mathrm{~b} / \mathrm{d})$

Surface area loss $(\mathrm{mm} / \mathrm{d})$

$\frac{\text { PNL }}{(0.21)} 0.31$
0.26
0.13
0.2

$\frac{\text { ELTECH }}{(0.12) 0.30}$
0.13
0.075
0.1

In both tests the ratio of $\mathrm{Fe}: \mathrm{Cu}: \mathrm{Ni}$ was higher in the metal than that found in the untested cermet. Therefore, the number in parentheses indicates the amount of $F e$ that would be in the aluminum from the cermet (based on the $\mathrm{Fe}$ ratio in the cermet) and the remainder of the $\mathrm{Fe}$ is believed to be caused by contamination from cell maintenance tools.

Because of the presence of cracks in the anodes and the possibility of chips or pieces of the anode falling into the bath during testing, the corrosion values are probably not representative of those that would occur with an uncoated or CEROX-coated anode.

The CEROX coating was normally 0.5 to $3 \mathrm{~mm}$ in thickness. The thickness was greater on the sides of the anodes than on the bottoms. Bare areas (no CEROX coating) were found on some anodes on the sides adjacent to another cermet anode. The lack of CEROX coating in those areas appears to be a result of low $C D$ in that region. No enhanced corrosion was macroscopically noted in those uncoated areas.

On the sides of some of the cermets adjacent to the carbon anodes there was an indentation in the cermet, which indicates higher corrosion on that side. The side facing the carbon anode sometimes had a CEROX coating and sometimes did not. No microstructural differences were noted in the indented area. The lack of a CEROX coating next to the carbon anode may be a result of either the decreased $C D$ on that side of the cermet anode (the carbon anode draws most of the current) or the increased $\mathrm{CO}_{2}$ and decreased $\mathrm{O}_{2}$ content in that area.

The CEROX coating was densest on the anodes removed after about 200 to $300 \mathrm{~h}$ and operated under "preferred" conditions. The CEROX coating on an anode operated during the second half of testing, when $C D$ was higher and $B R$ was lower, was thinner and less continuous. The CEROX coating formed around the edge of some 
cracks in the anodes and a short distance into the widest cracks; however, much of the cracked surface area was not coated with CEROX.

The three cermet anodes on the side of the cell furthest from the carbon anode operated for over $600 \mathrm{~h}$ but became partially frozen into the crust during the last $300 \mathrm{~h}$. The CEROX coating on that side of the anodes was porous and thick.

All anodes had some oxidation of the $\mathrm{Cu}$ within the outermost bottom layer of the anodes. The thickness of the oxidation ranged up to $10 \mathrm{~mm}$ thick on anodes operated for up to $300 \mathrm{~h}$. On an anode operated for over $600 \mathrm{~h}$, the oxidation thickness was up to $18 \mathrm{~mm}$ thick. Within the oxidized region, there were changes in the phase composition and distribution. Most of the tested anodes were more porous than the untested cermet but local dense regions occurred next to the CEROX coating. Cryolite rich in $\mathrm{AlF}_{3}$ was found in the pores of the tested cermet and local layers of $\mathrm{Ni}$ fluoride were found within the anode operated for over $600 \mathrm{~h}$.

\section{Conclusions}

The test demonstrated that a CEROX coating could be deposited on a $\mathrm{Cu}$ cermet anode in a pilot cell and tiat the coating could be maintained during $600 \mathrm{~h}$ of testing. The thickness of the CEROX coating was reduced in acidic baths and in low $C D$ regions of the anodes. Corrosion rates of $\mathrm{Fe}, \mathrm{Ni}$, and $\mathrm{Cu}$ were calculated for both the uncoated $\mathrm{Cu}$ cermets and the CEROX-coated $\mathrm{Cu}$ cermets. However, because of the cracking of the cermets during both tests, the corrosion rates are not indicative of the corrosion of an intact anode and a comparison between the coated and uncoated cermets can not be made with confidence. Thus, the value of the CEROX coating on the $\mathrm{Cu}$ cermets can not be proven in these tests.

The Cu cermet anodes cracked because of thermal shock during introduction into the cell. In addition, the $\mathrm{cu}$ cermets experienced microstructural changes that included increased porosity and the oxidation of the $\mathrm{Cu}$ metal phase. These changes show that the cu cermet employed in these tests is not suitable for long term inert anode testing.

\section{Recommendations}

Research should be directed toward improving the thermal, oxidation, and corrosion resistance of the $\mathrm{Cu}$ cermet or toward developing an alternative cermet or ceramic as an inert anode. The design of the pilot cell for testing inert anodes could be improved by containing all cermet anodes (no carbon anodes) with individual current control. Careful design of the inert anode and cell should minimize the problem of mucking because of the high alumina concentration. 


\author{
PILOT DEMONSTRATION \\ $O F$ \\ CERIUM OXIDE COATED ANODES
}

\title{
1. INTRODUCTION
}

A great deal of research has been performed on inert anodes to replace carbon anodes for Al electrowinning. This report details the test conditions, results, and conclusions of a pilot cell test directed by ELTECH and conducted by Reynolds. The inert anode materials tested were $\mathrm{Cu}$ cermets fabricated by $\mathrm{CM}$ but coated with a CEROX coating developed and patented by ELTECH. Testing of CEROX coatings on $\mathrm{Cu}$ cermets in the Reynolds pilot cell followed Phase I and Phase II laboratory tests on CEROX coated anodes completed by ELTECH under cooperative agreements with DOE. Phase III laboratory experiments were being completed during the pilot cell testing.

\subsection{Background}

Inert anodes have long been sought to replace carbon anodes and thereby reduce the energy penalty of the carbon anodes and eliminate the costs associated with their production and use.1,2 The key material requirements for an inert anode are:

\footnotetext{
- Low solubility in the molten cryolite bath

- Oxidation resistance

- Thermal shock resistance

- Electrical conductance greater or comparable to carbon

- Low oxygen overpotential

- Adequate mechanical strength.
}

The Aluminum Company of America (AlCoa) developed a $\mathrm{NiFe}_{2} \mathrm{O}_{4} / \mathrm{NiO} / \mathrm{Cu}$ cermet material that was promising in small scale tests. ${ }^{3}$ The material achieved adequate electrical conductivity through the incorporation of 17 wto $C u$ and had resistance to dissolution resulting from the use of oxides with very low solubilities in cryolite. Alcoa discontinued work on this material in 1985 but research on the $\mathrm{Cu}$ cermet was continued by PNL. They operated numerous laboratory experiments and achieved low dissolution rates." In a larger scale test operated by Reynolds with a $15 \mathrm{~cm}$ anode, the cermet was tested for over $100 \mathrm{~h}$ but corrosion rate was unacceptable. ${ }^{5}$

In 1982, ELTECH developed the concept of a cerium oxyfluoride coating on an anode substrate for use in Hall-Heroult cells. DOE supported research in phases I, II, and III to test the CEROX coating on $\mathrm{SnO}_{2}$ and the Alcoa Cu cermet substrate at varying test conditions for up to $100 \mathrm{~h}$. The tests defined the optimum testing conditions for CEROX on a $\mathrm{Cu}$ substrate and showed that corrosion was $\sim 7$ times higher with an uncoated $\mathrm{Cu}$ cermet than with a CEROX coated $\mathrm{Cu}$ cermet under identical test conditions. ${ }^{6}$ 


\subsection{Objectives}

The test at Reynolds was performed to determine the performance advantages of the CEROX coating on $\mathrm{Cu}$ cermet substrates on a pilot scale. A second objective was to gain experience with depositing and maintaining a CEROX coating in an industrial cell.

\subsection{Scope}

The ELTECH pilot cell testing followed pilot cell testing of uncoated $\mathrm{Cu}$ cermets by PNL at Reynolds. The ELTECH test consisted of four main parts. First, Reynolds operated the test cell with two carbon anodes until the $\mathrm{Fe}, \mathrm{Ni}$, and $\mathrm{Cu}$ corrosion from the PNL test reached a stable "baseline" level. During the second part of the test, $6 \mathrm{Cu}$ cermets replaced one of the carbon anodes and were tested for up to 377 h under the ELTECH "optimum" conditions. Several anodes were exchanged and an increased CD was then applied during the third part of the test. Finally, the BR was rodius:i for the final phase of the testing.

The Cu cermets for the ELTECH test were supplied by DOE from CM and the operation of the pilot test cell was performed by Reynolds. Reynolds summarized their test cell operation in a report (see Appendix 1). ELTECH was responsible for setting the test conditinns, overseeing the test and exchanges of anodes, and the analysis of the tested anodes. Reynolds analyzed the bath and metal throughout the testing and calculated corrosion rates from the impurities in the aluminum. The $f$ sures for bath and metal composition and for corrosion were taken from Appendix 1.

\subsection{Accomplishments}

CEROX-coated $\mathrm{Cu}$ cermet anodes were operated in a pilot scale test for 213 to $614 \mathrm{~h}$. Corrosion rates were half that of the uncoated $\mathrm{Cu}$ cermets; however, with the cracking of the cermets during testing and with the mixture of carbon and cermet anodes in the cell, it is difficult to predict what industrial corrosion levels would be and exactly what protection factor the CEROX affords.

It was demonstrated that dense, adherent, 1 to $3 \mathrm{~mm}$ thick CEROX coatings could be deposited and maintained in a pilot cell under optimum conditions. Levels of $\mathrm{Ce}$ in the metal and bath could be maintained near the targeted levels if the cell was kept free from mucking. The influence of low $C D$ on the presence of the CEROX coating wis seen. Increased porosity and thickness of the CEROX coating was found where the cryolite crust froze around the edges of the anode. The CEROX coating was thinner and less continuous at lower BR, although no change in the corrosion rate was noted.

The $\mathrm{Cu}$ cermet substrate was found to undergo a number of changes during testing. The major changes were an increase in porosity throughout the anode and oxidation and loss of the $\mathrm{Cu}$ metal. in the 
outer areas of the anode. In some areas a dense $\mathrm{NiFe}_{2} \mathrm{O}_{4}$ and $\mathrm{NiO}$ layer also was present next to the CEROX coating, and the composition of the cerrite and $\mathrm{NiO}$ were changed in that region. This dense layer was not reported by PNL and thus may be related to the presence of the CEROX coating. 


\section{TFST CELL AND ANODE DESIGN AND PROCEDURES}

The test cell was designed and operated by Reynolds and was located in their facility in Alabama. Anodes were fabricated by $\mathrm{CM}$.

\subsection{Description of Pilot Cell}

The self heated pilot cell had inside dimensions of $44 \times 33 \times$ 17 in., as shown in Figures 1 and 2 . The sidewalls consisted of rammed carbon, prebake carbon blocks, and TR-19 vermiculite insulation. The cell normally operated with two industrial sized carbon anodes ( $15.5 \times 21.5$ in.), one of which was replaced with an inert anode cluster for this test. The cermet anode positions were labeled $A$ through $F$ (Figure 3 ). Each cermet anode could be individually removed.

Alumina was point fed hourly between the carbon anode and the inert anode cluster. The carbon anode and the inert anode cluster were fed by two separate power supplies so that the current to each could be independently controlled. Current to each of the individual cermet anodes could not be independently controlled, but was monitored throughout the test. Additions of $\mathrm{CeF}_{3}$ were made hourly. Cryolite, $\mathrm{NaF}$, and $\mathrm{AlF}_{3}$ were added as needed to maintain the desired BR and bath levels. Aluminum was tapped frequently with a ladle in order to keep a fairly constant metal depth.

\subsection{Description of the Anodes}

The $\mathrm{Cu}$ cermet anodes were fabricated by $\mathrm{CM}$ under the guidance and specifications of PNL.? The cermet anodes for the PNL test and for the ELTECH's test were made in an identical manner. In brief, the

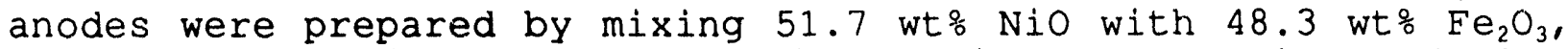
calcining the mixture to form $\mathrm{NiFe}_{2} \mathrm{O}_{4}$ with excess $\mathrm{NiO}$, and then mixing in $1 \%$ polyvinyl alcohol (PVA; binder and spray drying. 17 wt $8 \mathrm{Cu}$ metal was then blended with the spray dried powder. The final composition of the anodes, based on starting components, was 17 wto $\mathrm{Cu}, 42.98 \mathrm{NiO}$, and $40.18 \mathrm{Fe}_{2} \mathrm{O}_{3}$. The powder mixture was then consolidated at 13,000 psi with an isopress. Anodes were sintered at $1200^{\circ} \mathrm{C}$ for $24 \mathrm{~h}$ in an $\mathrm{Ar}-\mathrm{O}_{2}$ atmosphere with an oxygen partial pressure of $150 \mathrm{ppm} \mathrm{O}_{2}\left(1.5 \times 10^{-4} \mathrm{~atm}\right)$.

PNL typically achieved densities of $\sim 6.05$ to $6.10 \mathrm{~g} / \mathrm{cm}^{3}$ with 0laboratory anodes that were consolidated at $20 \mathrm{kpsi}$ (140 MPa). The density of anodes fabricated by $\mathrm{CM}$ ranged from $\sim 5.74$ to 5.85 $\mathrm{g} / \mathrm{cm}^{3}{ }^{7}$ The main reason attributed to this lower density is the lower isopress pressure, which was the maximum pressure that could be achieved with the $\mathrm{CM}$ isopress. Theoretical density has been estimated to be $6.28 \mathrm{~g} / \mathrm{cm}^{3}$ (Alcoa), $6.09 \mathrm{~g} / \mathrm{cm}^{3}$ (from the mixture of the $\mathrm{NiFe}_{2} \mathrm{O}_{4} / \mathrm{NiO}$ powder with 17 wto $\mathrm{Cu}$ ), or higher (see "Microstructure of the Cermet anodes" section). The maximum density of laboratory produced cermets is around $6.11 \mathrm{~g} / \mathrm{cm}^{3}$. 


\section{Pilot Cell Design Plan View}

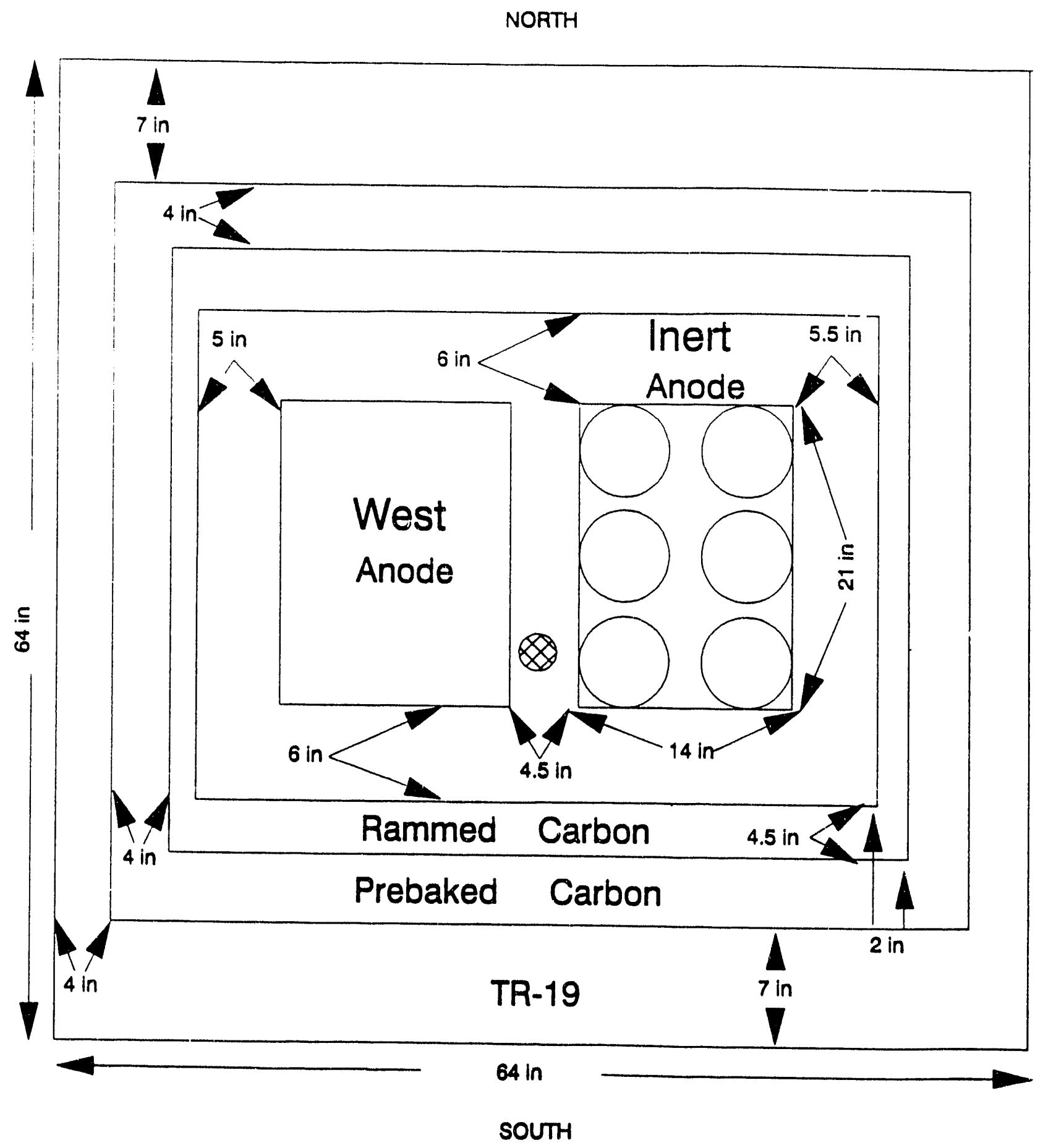

Eigure 1. 


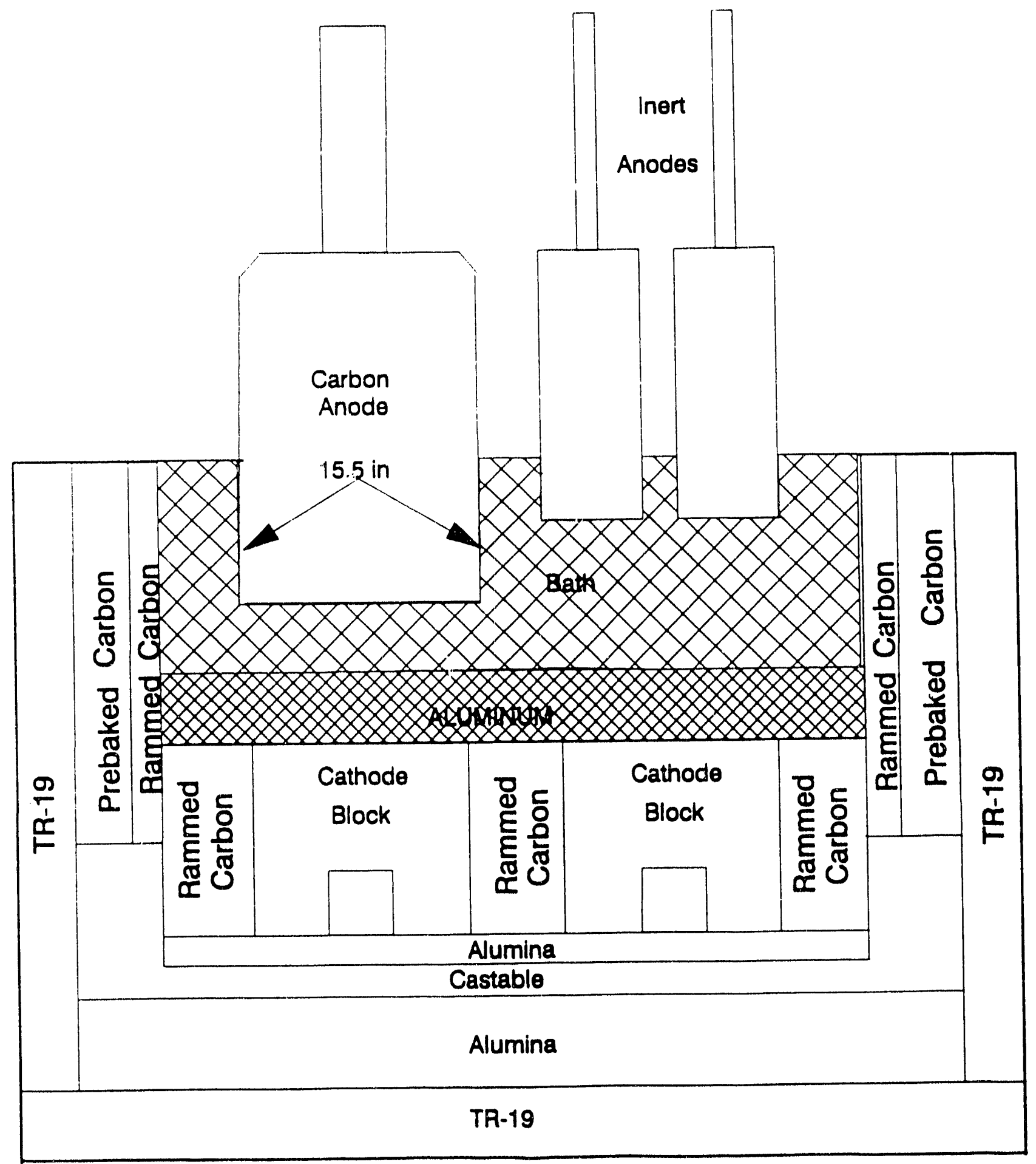

Eigure 2. Pilot cell design, cross section. 


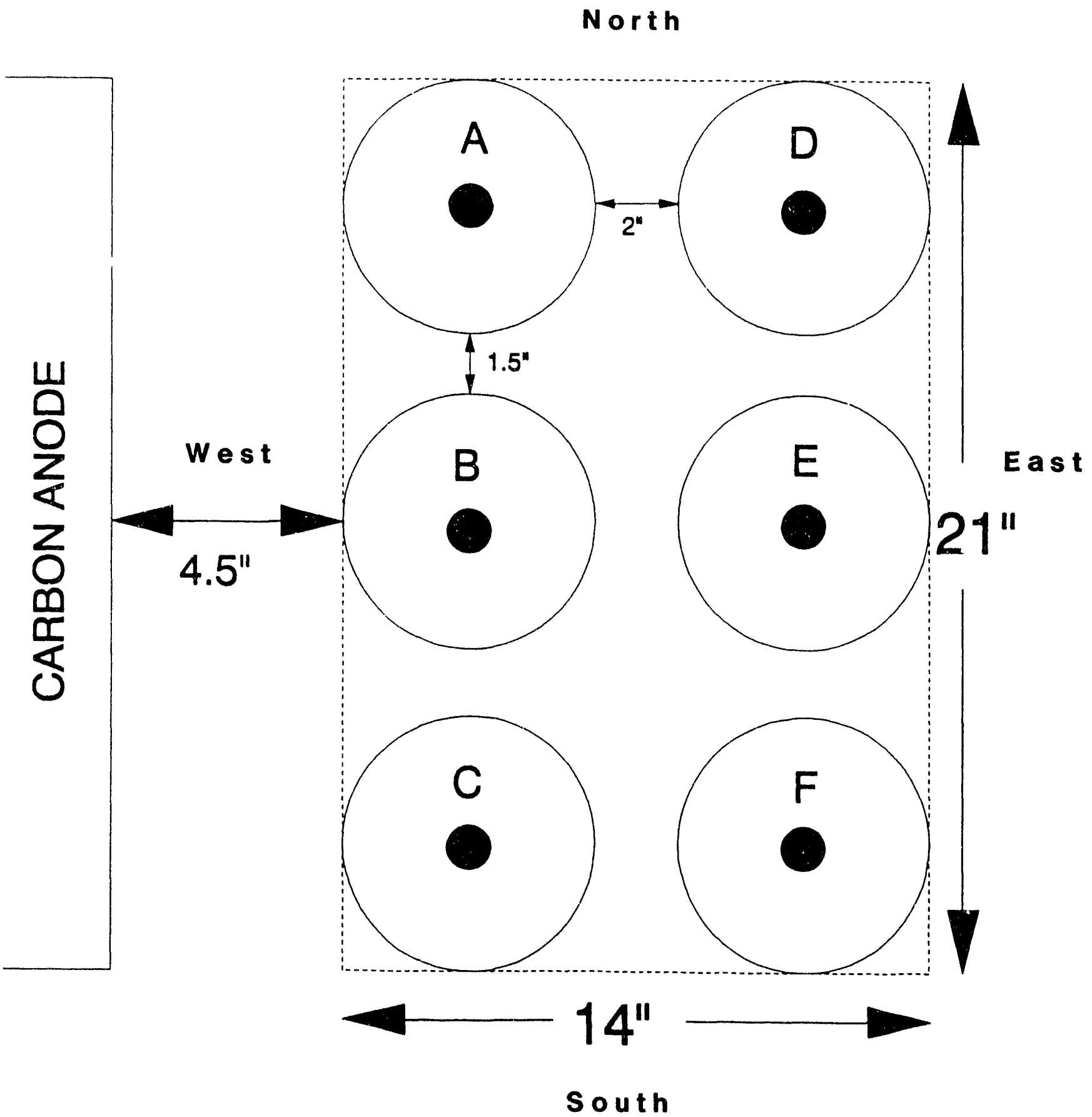

Figure 3. Position of inert anodes in the pilot cell. 
Density on a sample from an untested anode was measured by Archimedes density method (ASTM C 373-72) and found to have a bulk density of $5.74 \mathrm{~g} / \mathrm{cm}^{3}$ and an apparent open porosity of $\sim 0.76 \%$.

The anodes were cylindrical with a diameter of 6 in., a thickness of $3 \mathrm{in.}$ and an additional 1 in. lip on the top as shown in Figures 4 and 5. The bottom was rounded with a radius of 1.5 in. The current connector was an 18-in. long 1-in. diameter Inconel 601 threaded rod that was screwed into the threaded hole in the cermet. This rod was sheathed with a 3-in. long alumina sheath and alumina cement (Fisher 6218 Alundum) covered the sheath; the top of the cermet, and the top of the sheath.

\subsection{Data Collection}

Routine data [collected and recorded hourly (detailed in Appendix 1)] consisted of cell voltages, anode currents, bath and metal depths, bath temperature and anode immersion. In addition, current to each cermet anode, voltage to the two anodes, total current to the carbon anode, and cluster were logged every $30 \mathrm{~s}$ with a data acquisition system. Bath and metal samples were taken every $4 \mathrm{~h}$. The bath was analyzed for $\mathrm{Cu}, \mathrm{Ni}, \mathrm{Fe}, \mathrm{Ce}, \mathrm{Al}_{2} \mathrm{O}_{3}, \mathrm{CaF}_{2}$, and the $\mathrm{BR}$ was determined. Metal was analyzed for $\mathrm{Cu}, \mathrm{Ni}, \mathrm{Fe}$, and $\mathrm{Ce}$. 


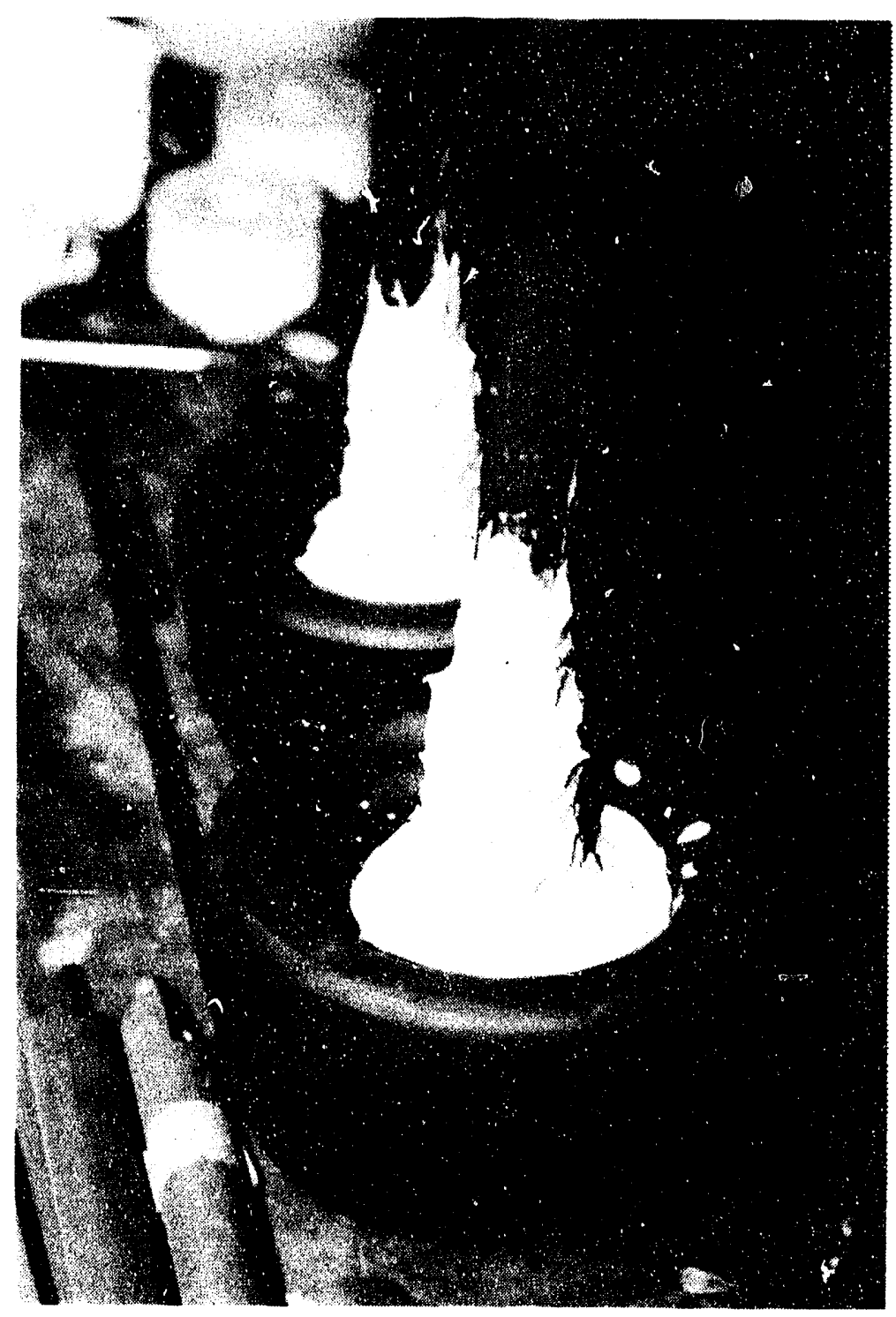

Figure 4. Cu cermet anode prior to testing. Alumina cement coats the bottom of the Inconel connector rod next to the cermet. 


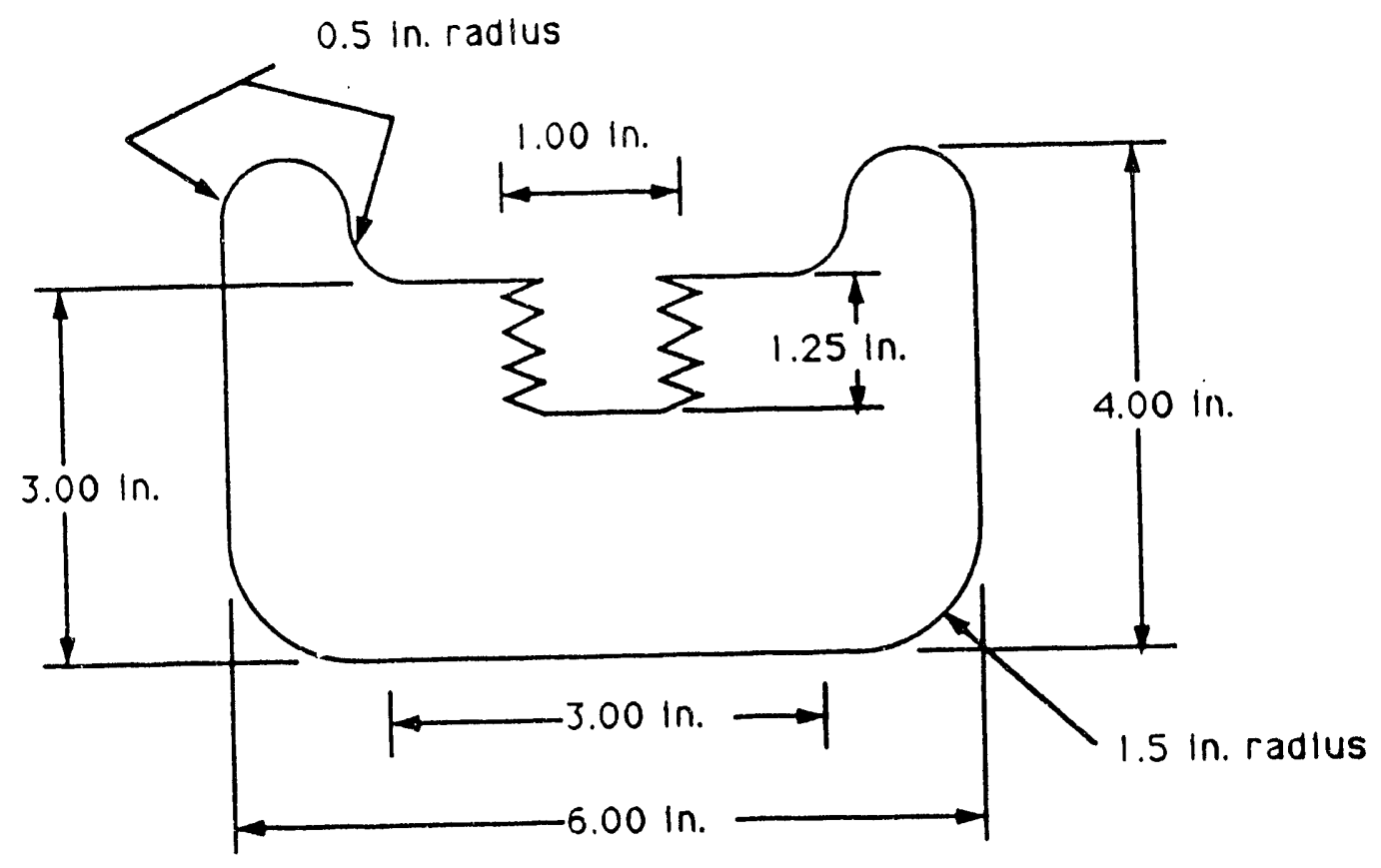

Figure 5. Cermet anode design. 


\section{TEST CELL OPERATION}

The ELTECH test was divided into four main parts: operation with two carbon anodes, operation with a carbon anode and a 6-pack of cermets at our targeted "optimum" conditions, continued operation with the cermets but at a slightly higher $C D$, and continued operation of the cermets but at a lowered BR. Target "optimum" operating conditions were chosen based on the experiments conducted during the ELTECH Phase III laboratory test. During the pilot cell test these target conditions wexe not always achieved.

\subsection{Target Operating Conditions}

During the first part of the test (with the operation of the two carbon anodes) the goal of the testing was to reduce $\mathrm{Fe}, \mathrm{Ni}$, and $\mathrm{Cu}$ impurity levels in the metal to pre-PNL baseline levels. Reynolds proposed to accomplish this by siphoning out much of the metal and by adding additional Al to the cell to dilute the impurities. In addition, anode effects were planned to reduce the muck accumulated in the cell. Bath composition and $\mathrm{Ce}$ concentration would be brought up to the desired levels for the second phase of testing, which would take $\sim 1$ week or less.

The 6 cermet anodes were then to be introduceci into the cell simultaneously (with current on) and operuted at "optimum" conditions. In Phase III laboratory testing CEROX coatings were most dense and continuous, and corrosion was lowest at a BR of 1.5 to 1.6. Therefore, the target "optimum" BR for the second phase of the pilot cell testing was 1.5. In the Phase III laboratory tests there was also a slight decrease in corrosion with decreasing CD. At high CD extensive oxidation of tht: $C u$ and increased porosity led to an increase in cell voltage with time. Therefore, a CD of $0.5 \mathrm{~A} / \mathrm{cm}^{2}$ (equivalent to $\sim 90 \mathrm{~A}$ por anode) ${ }^{7}$ was chosen for the second phase of testing.

Most of the laboratory work was performed with baths saturated with alumina and research has shown that decreasing the alumina concentrations increases the dissolution of the oxide phases and corrosion of the $\mathrm{Cu}$ cermet. ${ }^{3,6}$ Thus, maintaining the bath at 90 to $100 \%$ of alumina saturation $\left(\sim 8\right.$ to $10 \% \mathrm{Al}_{2} \mathrm{O}_{3}$, depending on temperature) was targeted. Operating temperature was targeted at 990 to $1000^{\circ} \mathrm{C}$.

Changes in operating conditions were implemented after $377 \mathrm{~h}$ of operation in order to assess the effect that the $C D$ and $B R$ have on inert anode performance. The $C D$ was raised to a maximum target of $115 \mathrm{~A}$ on any anode $\left(\sim 0.65 \mathrm{~A} / \mathrm{cm}^{2}\right)$; after $\sim 160$ additional hours, the $B R$ was lowered to a target of 1.15 and ran for $77 \mathrm{~h}$ under the lower $B R$ and higher $C D$ conditions.

The target starting $C e$ concentration in the bath for coating the anodes was between 0.5 and 1.0 wto Laboratory testing 
demonstrated that the $\mathrm{Ce}$ concentration in the bath should remain above $0.175 \%$ to maintain a coating, once it is present on an anode. The target concentration for the pilot test for maintenance of the CEROX coating was set between 0.2 and $0.33 \%$. With an expected Ce partition coefficient of between 5 and 12 , the Ce concentration in the metal was expected to be around 1 to $4 \%$.

\subsection{Actual Test Conditions and Exchange of Anodes}

Following the PNL test the cermets were removed and the cell was operated with two carbon anodes. Anode effects were forced to eliminate the muck. The impurities in the metal were monitored with a target impurity level of that before the PNL test

(Table 1), $100 \mathrm{lb}$ of aluminum were added to the cell to help reduce the impurities. After 13 d the impurities had leveled out as shown in Figure 6; but the ELTECH baseline was still higher than the PNL baseline level (Table 1) for $\mathrm{Ni}$ and $\mathrm{Fe}$. $\mathrm{CeF}_{3}$ was then added to the cell.

The inert anodes were preheated by placing them on the deck plate of the cell and covering them with kaowool. The electrodes remained there for $\sim 5$ at which time they were placed into the anode holder over the crust until they reached between 130 and $230^{\circ} \mathrm{C}$. The anodes were covered with kaowool and slowly lowered into the bath for over $26 \mathrm{~h}$ or until they had reached about 600 to $650^{\circ} \mathrm{C}$ (thermocouples were placed at the tops of the anodes). At $1: 30 \mathrm{p} . \mathrm{m}$. September 14, the inert anode cluster was immersed in the bath and the anodes were conducting current.

Upon introduction to the bath, it was observed that anode 2 in position B (Anode BI) was cracked and incapable of carrying any significant amount of current. This anode was removed from the cell after $\sim 1$ hour.

Analysis and observation of a small independently current controlled $4 \mathrm{~cm}$ diameter reference anode was used to determine that the $\mathrm{Ce}$ concentration in the bath was insufficient to form a CEROX coating. Therefore, current to the inert cluster was turned off and additional $\mathrm{CeF}_{3}$ was added to the cell. At 1:00 p.m. September 15, the current was turned back on and anode coating began. Examination of the reference anode showed that a CEROX coating was forming and analysis of the bath showed that the ce had reached $\sim 0.85 \%$.

on september 23, after $213 \mathrm{~h}$ of operation, a piece of anode 1 in posi"ion A (Anode A1) broke off and fell into the bath. The piece was recovered and the rest of A1 was removed. On September 26, anode 3 in position $C$ (Anode C1) was removed from the cell as scheduled after $275 \mathrm{~h}$ of operation. The anode was cracked. 
Table 1. Baseline impurity levels.

PNL

$\begin{array}{ll}\text { Iron } & 0.380 \text { wto } \\ \text { Copper } & 0.050 \text { wt } 8 \\ \text { Nickel } & 0.003 \text { wto }\end{array}$

\section{ELTECH}

\begin{tabular}{ll}
\hline Iron & 0.440 wto \\
Copper & 0.020 wto \\
Nickel & 0.030 wto
\end{tabular}


Fe CONTENT IN METAL

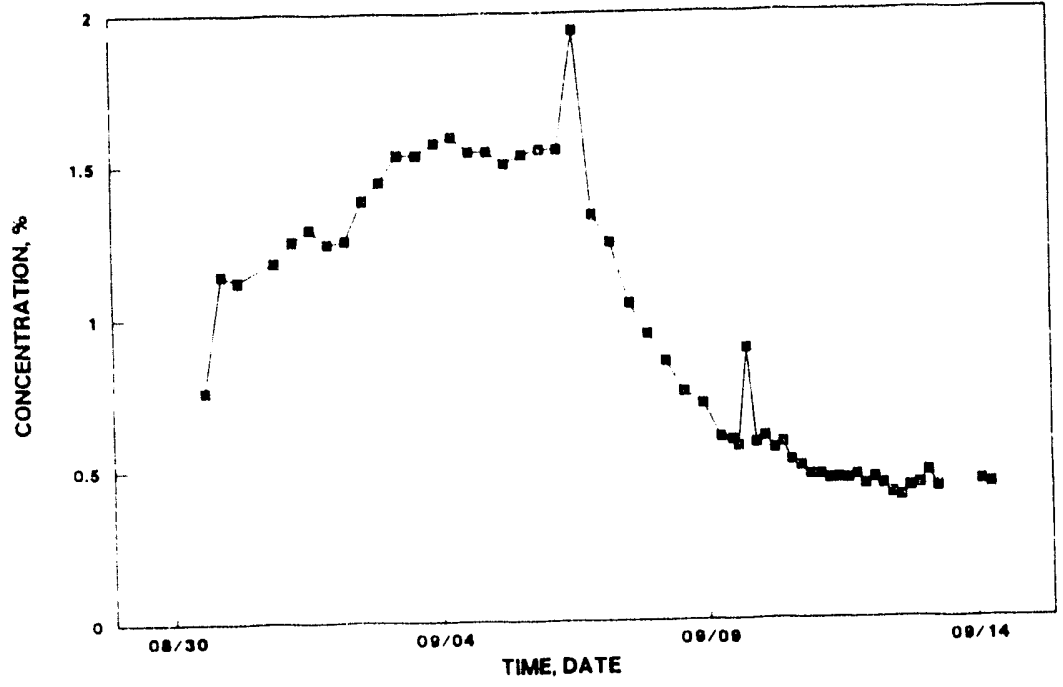

Ni CONTENT IN METAL

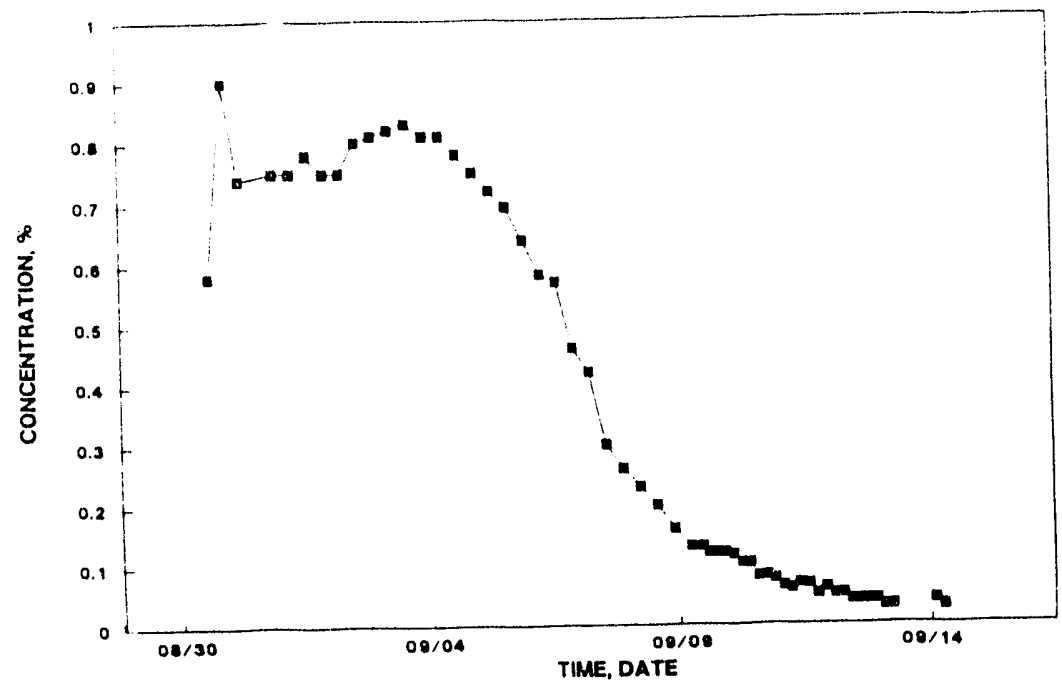

CU CONTENT IN METAL

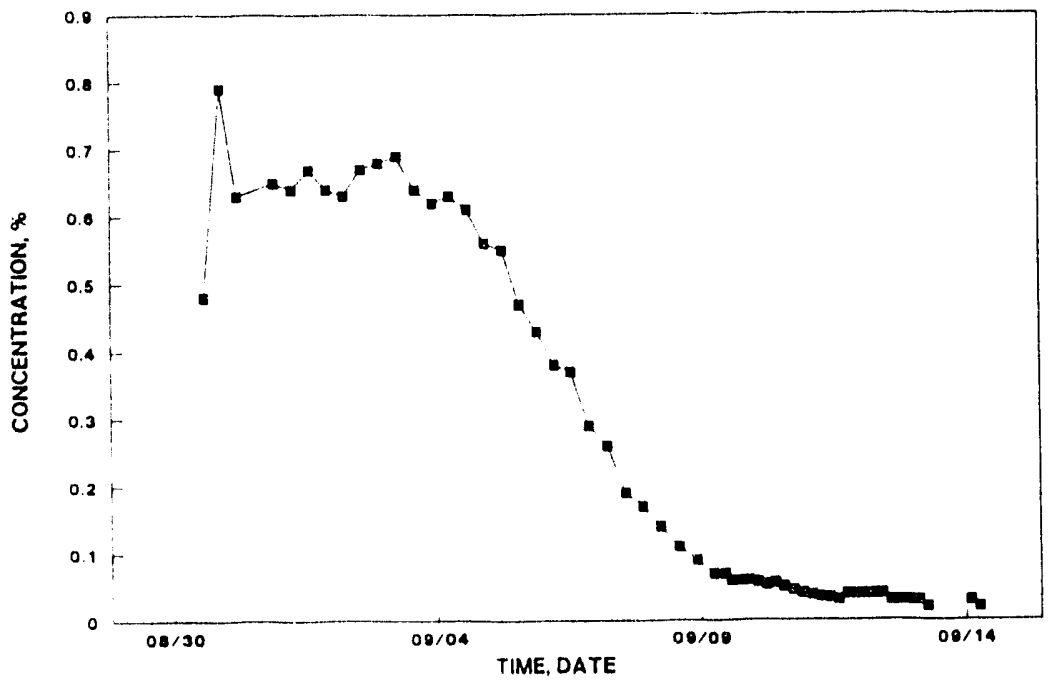

Figure 6. Impurity levels in the aluminum during operation of the pilot cell with two carbon anodes. 
Anodes 7, 8, and 9 were preheated with the same procedure as described for anodes 1 through 6 . Additional. $\mathrm{CeF}_{3}$ was added to the cell, and the anodes were lowered into the cell in positions $A, B$, $C$ (Anodes A2, B2 and C2) September 27 and began conducting current. Because of the problems with cracking of the anodes, no other exchanges of anodes were made during the test.

On september 30, after A2, B2, and C2 had been in the cell for $\sim 74$ hours, the maximum current on any one anode was raised from 90 to 115 A to determine if the increased current would effect anode corrosion. After $\sim 160$ hours of the higher $C D$, the $B R$ was reduced to 1.15 (while $C D$ was maintained at $0.65 \mathrm{~A} / \mathrm{cm}^{2}$ ) to assess its effect on anode corrosion. After $77 \mathrm{~h}$ of further testing, the cermet 6-pack of anodes were removed and the cermet testing was completed. Table 2 summarizes the lifetime of each anode.

The bath level and metal inventory during the test is shown in Figures 7 and 8 . The anode immersion (representative of anodes in position D, E, and $F$ ) is shown in Eigure 9. Anodes A2, B2, and C2 were immersed 1 in. less than $D, E$, and $F$. Anode-cathode distance is shown in Figure 10 and reflects the build-up of muck on the bottom of the cell during the test.

\subsection{Current and Cell Voltage}

Because the current to the cermets couid not be individually controlled, current to the cluster was controlled such that the highest current any individual anode would carry was the target current. For the first part of the cermet testing the maximum current to an anode was $90 \mathrm{~A} ;$ the other anodes carried $\leq 90 \mathrm{~A}$. The current maintained by the individual cermets varied during the length of the test and is shown in Figures 11 through 16 . In general, at the beginning of the test the current carried by anodes in positions $A, B$, and $C$ was lower than the current carried by anodes in positions $D, E$, and $F$. Because the carbon anode carried a larger current in order to maintain a molten electrolyte, the carbon anode was at a higher potential than the cermet anodes. The higher potential of the carbon anode resulted in reduced current through the inert cluster, resulting in anodes $A, B$, and $C$ carrying less current than $D, E$, and $F$ during the first half of the test.

As the experiment progressed, a layer of frozen bath formed under and around the top of the anodes in positions $D, E$, and $F$. This area was the coolest in the cell because most of the heat was generated by the carbon anode. In addition, a frozen ledge may have formed on the bottom of the cell inhibiting current flow at positions $D, E$, and $F$ resulting in increased current to flow to anodes in positions $A, B$, and $C$. Thus, toward the end of the test, positions $A, B$, and $C$ were carrying more current than positions $D$, $E$, and $F$. 
Table 2. Anode summary.

\begin{tabular}{|c|c|c|c|}
\hline Anode & $\begin{array}{c}\text { Cell } \\
\text { Position }\end{array}$ & Operation & Comments \\
\hline 1 & A & $\begin{array}{l}9 / 15-23 \\
213 \mathrm{~h}\end{array}$ & $\begin{array}{l}\text { Section of anode } \\
\text { broke, removed }\end{array}$ \\
\hline 2 & B & $\begin{array}{l}9 / 14 \\
1 \mathrm{~h}\end{array}$ & $\begin{array}{l}\text { Cracked down center } \\
\text { of anode at start-up }\end{array}$ \\
\hline 3 & $\mathrm{C}$ & $\begin{array}{l}9 / 15-26 \\
275 \mathrm{~h}\end{array}$ & Removed on schedule \\
\hline 4 & $\mathrm{D}$ & $\begin{array}{l}9 / 15-10 / 10 \\
614 \mathrm{~h}\end{array}$ & End of test \\
\hline 5 & $\mathrm{E}$ & $\begin{array}{l}9 / 15-10 / 10 \\
614 \mathrm{~h}\end{array}$ & End of test \\
\hline 6 & $\mathrm{~F}$ & $\begin{array}{l}9 / 15-10 / 10 \\
614 \mathrm{~h}\end{array}$ & End of test \\
\hline 7 & A & $\begin{array}{l}9 / 27-10 / 10 \\
312 \mathrm{~h}\end{array}$ & End of test \\
\hline 8 & B & $\begin{array}{l}9 / 27-10 / 10 \\
312 \mathrm{~h}\end{array}$ & End of test \\
\hline 9 & $\mathrm{C}$ & $\begin{array}{l}9 / 27-10 / 10 \\
312 \mathrm{~h}\end{array}$ & End of test \\
\hline
\end{tabular}


BATH LEVEL VERSUS TIME

ELTECH CERMET ANODE PILOT CELL TEST

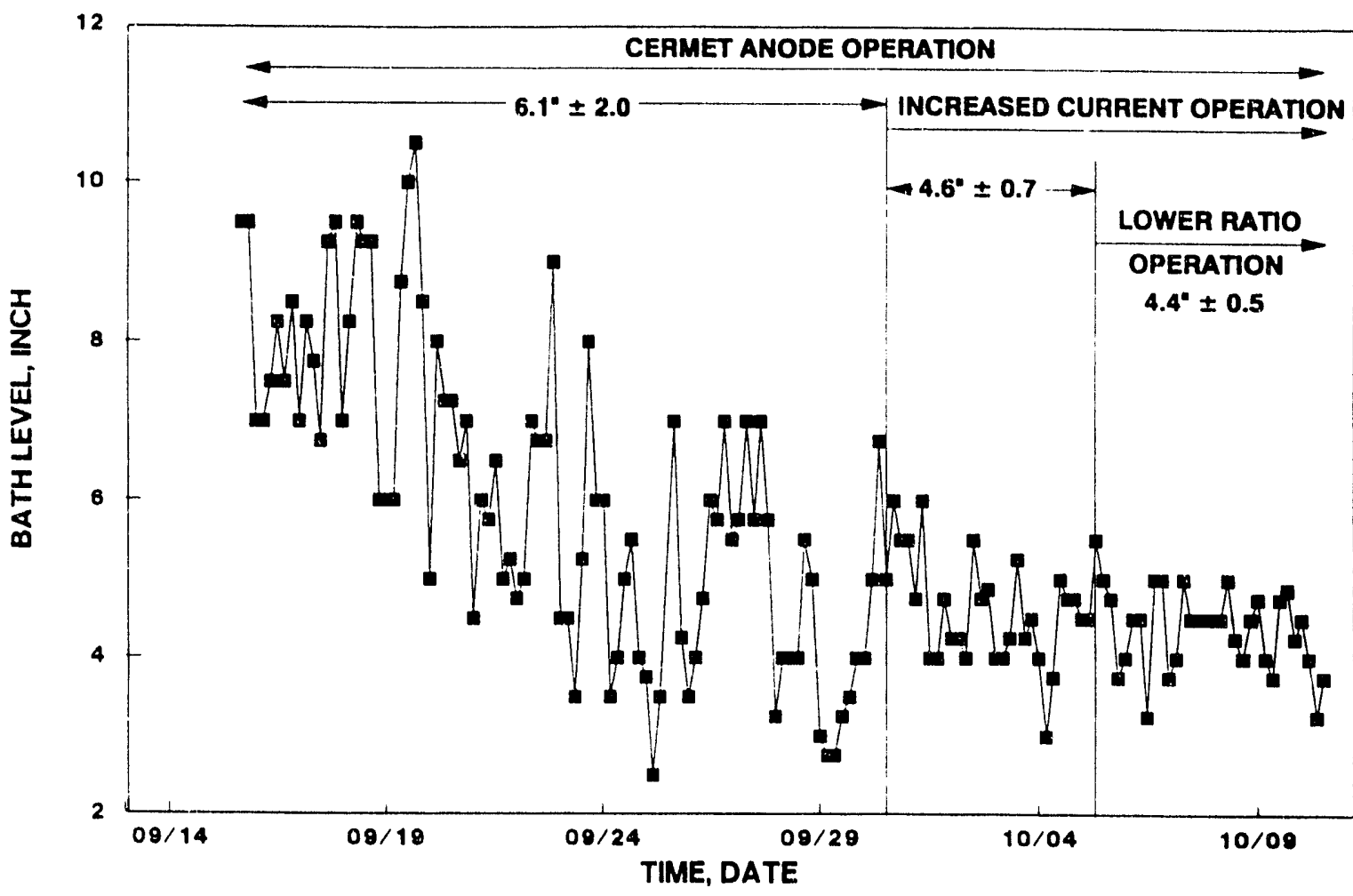

Eigure 7 .

METAL INVENTORY VERSUS TIME

ELTECH CERMET ANODE PILOT CELL. TEST

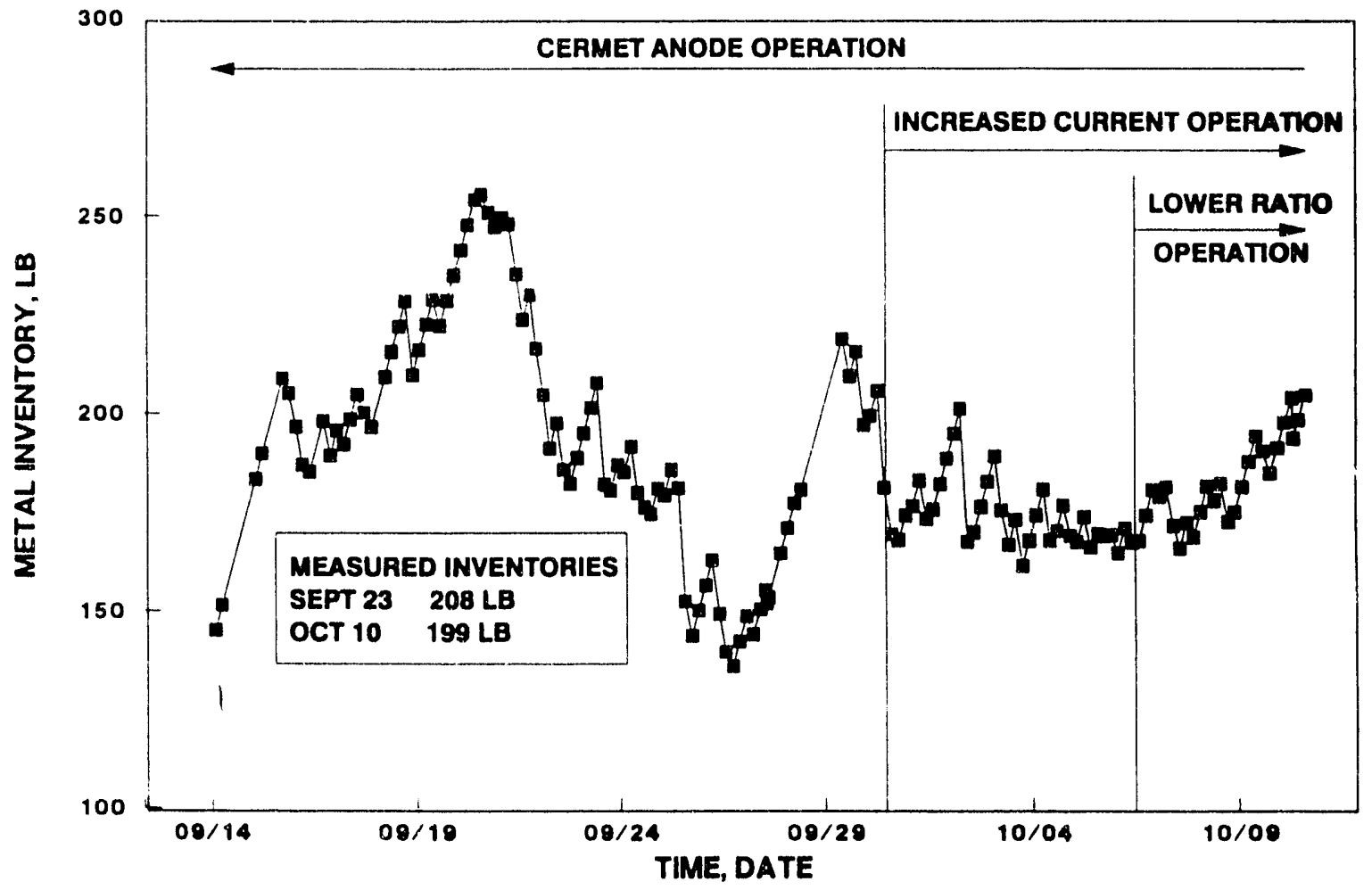

Figure 8 . 


\section{ANODE IMMERSION VERSUS TIME}

ELTECH CERMET ANODE PILOT CELL TEST

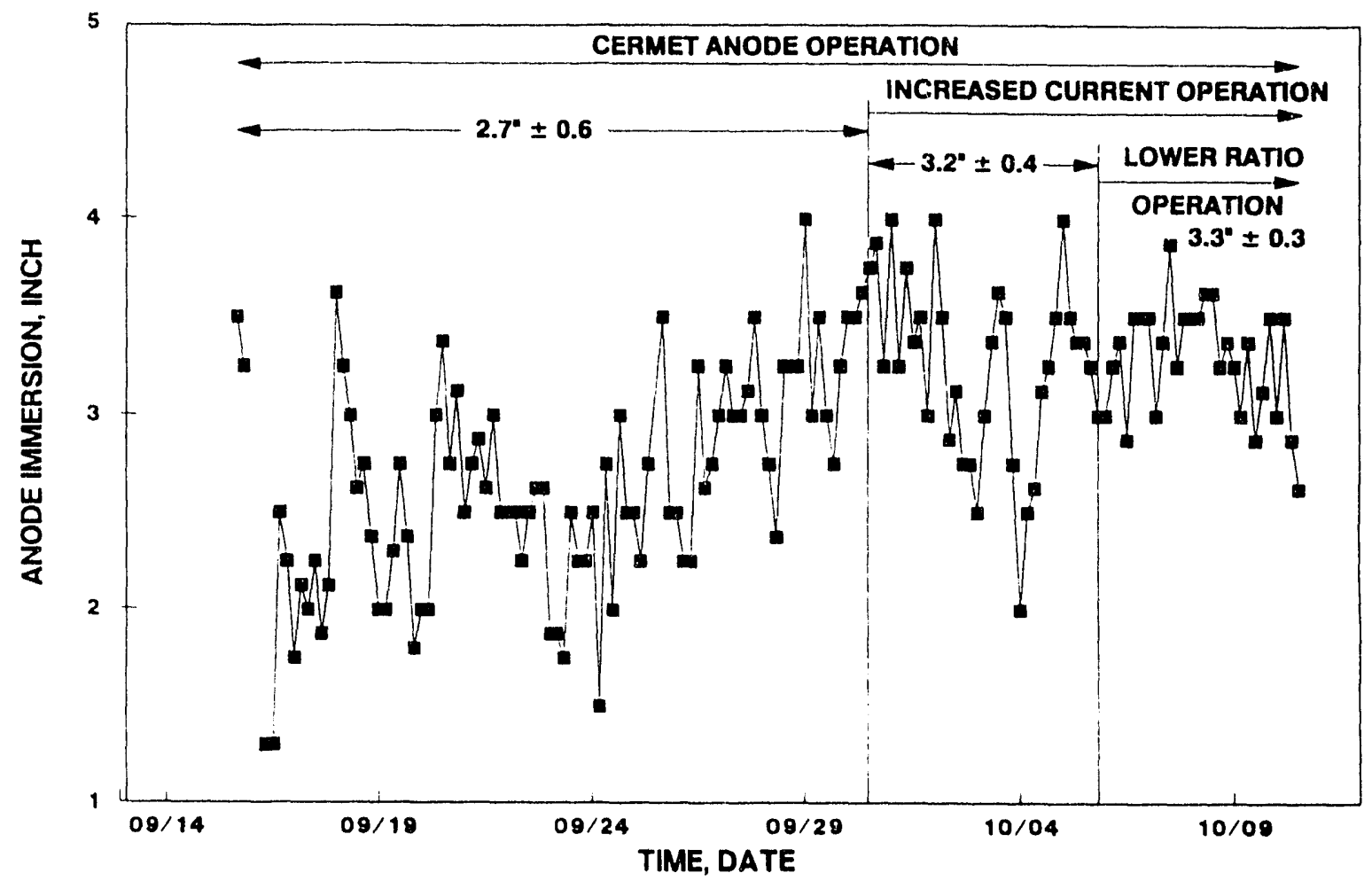

Figure 9.

\section{ANODE-CATHODE DISTANCE VERSUS TIME}

ELTECH CERMET ANODE PILOT CELL TEST

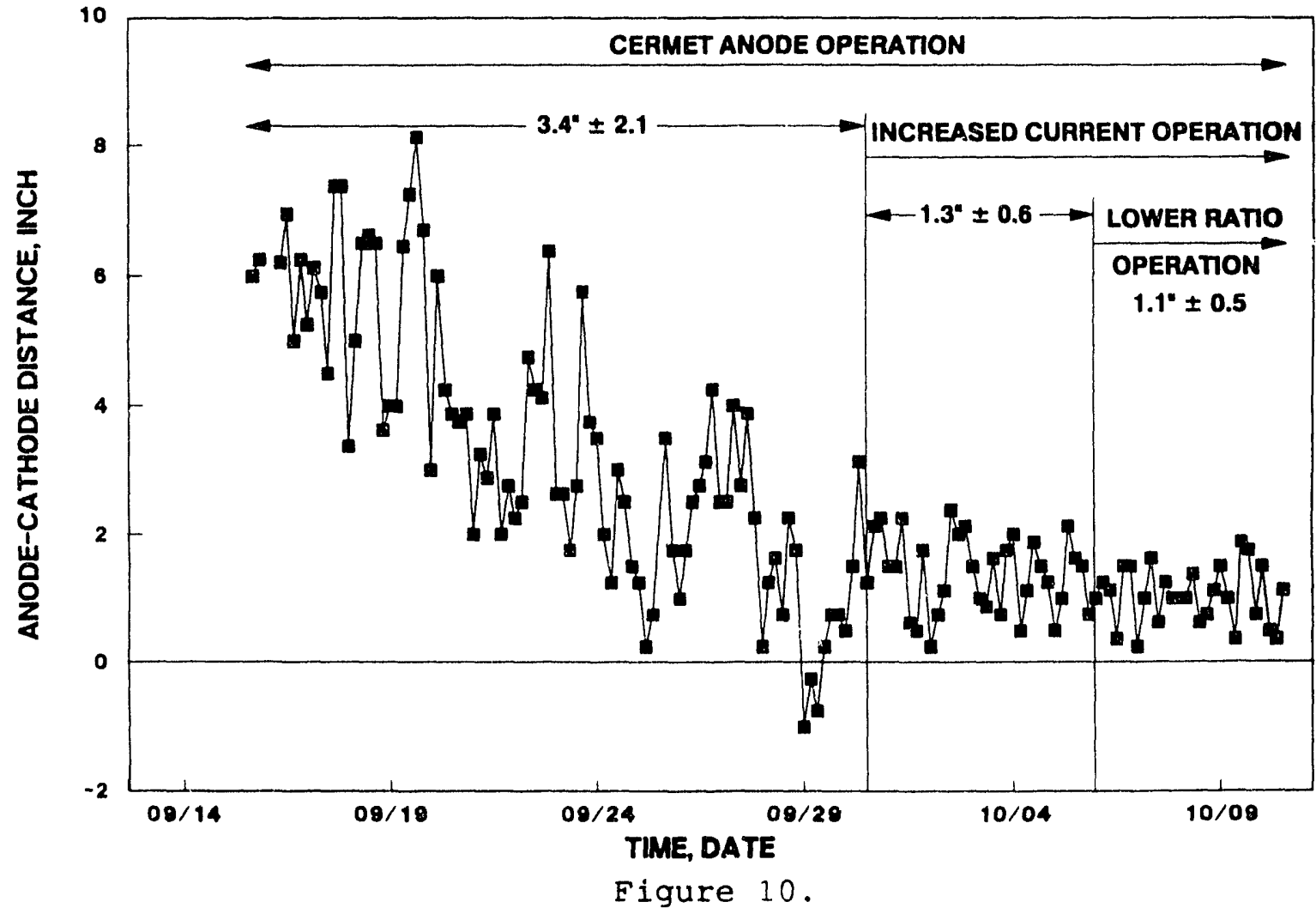



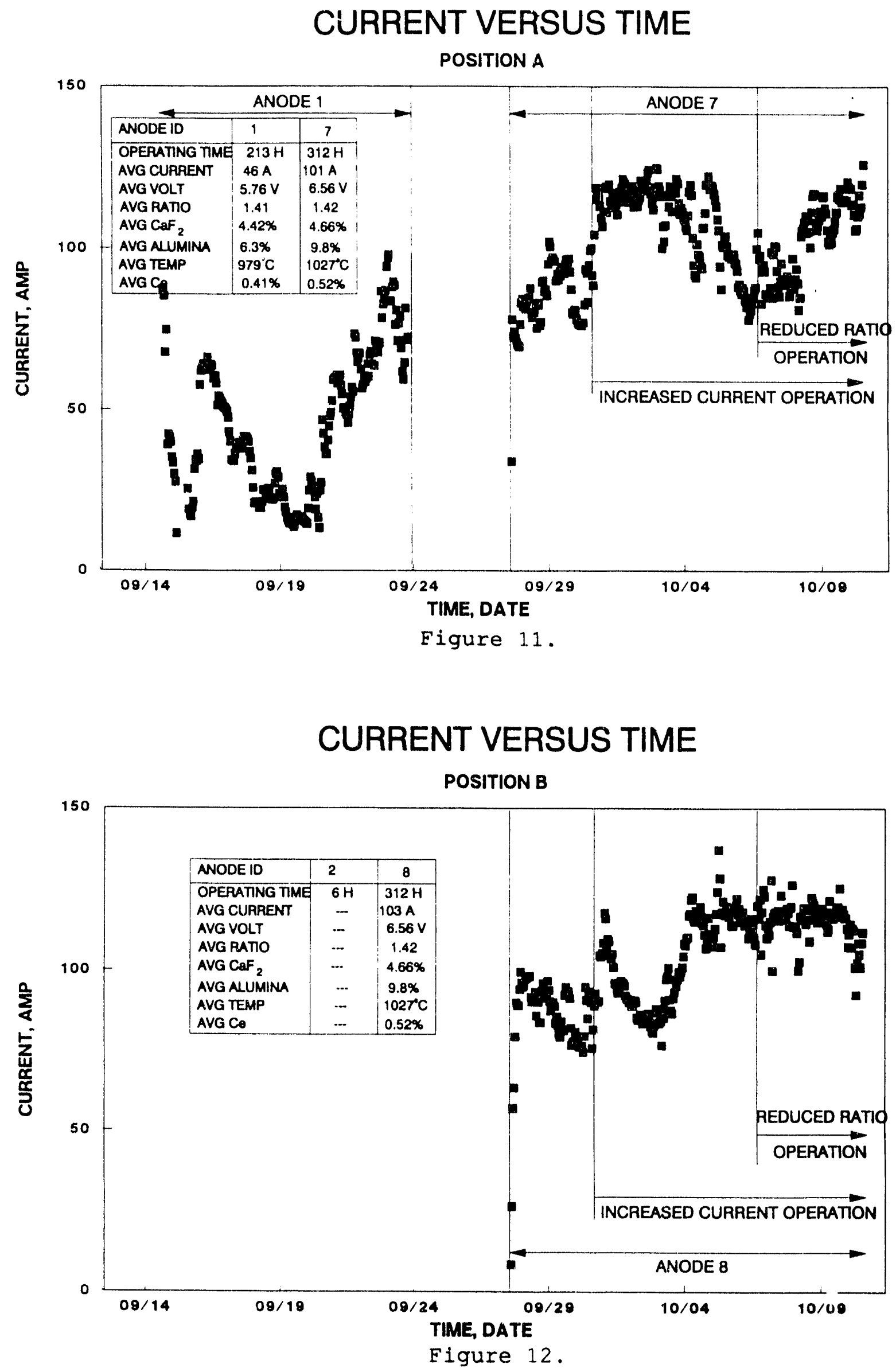


\section{CURRENT VERSUS TIME}

\section{POSITION C}

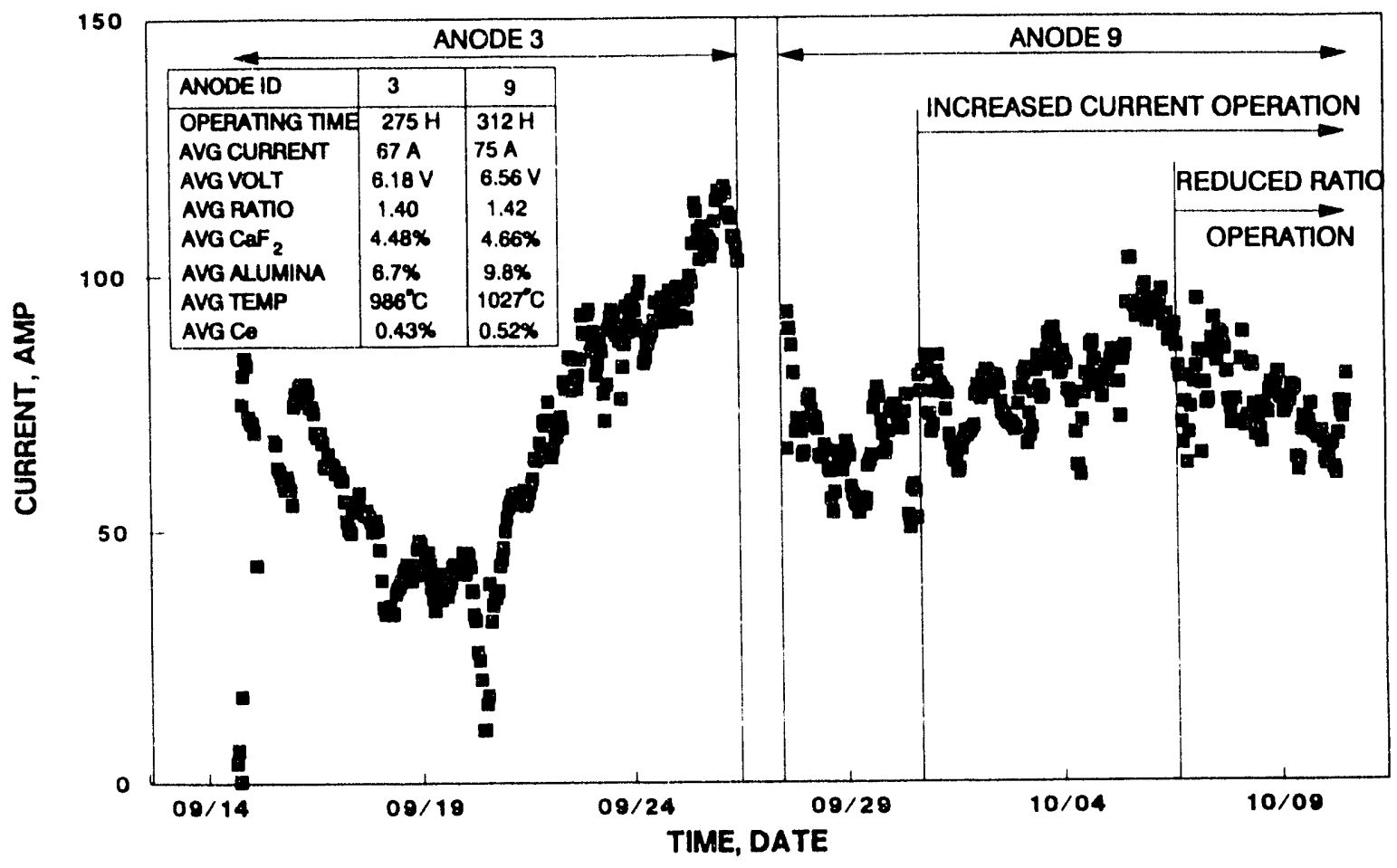

Figure 13 .

\section{CURRENT VERSUS TIME}

POSITION D

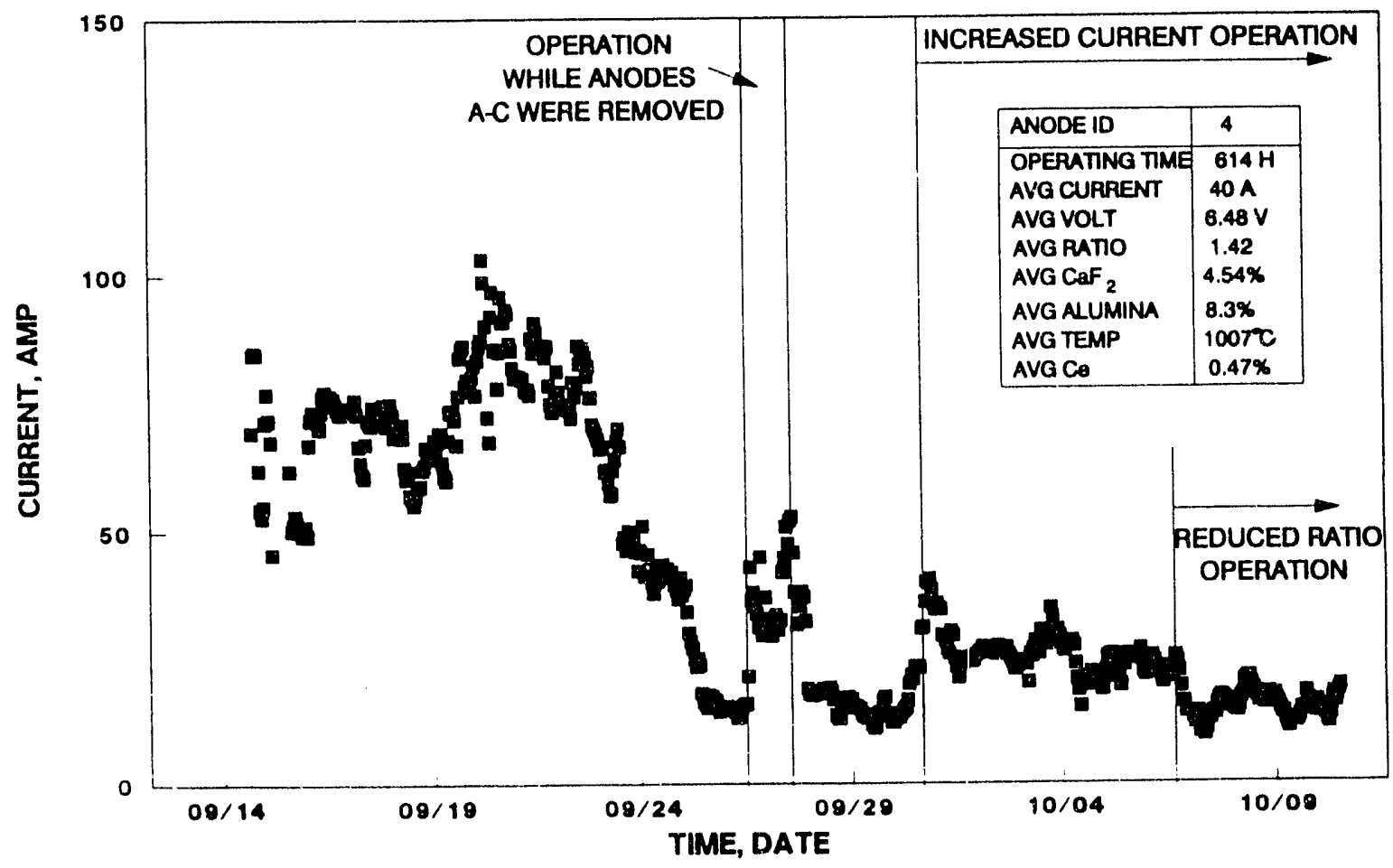

Eigure 14. 

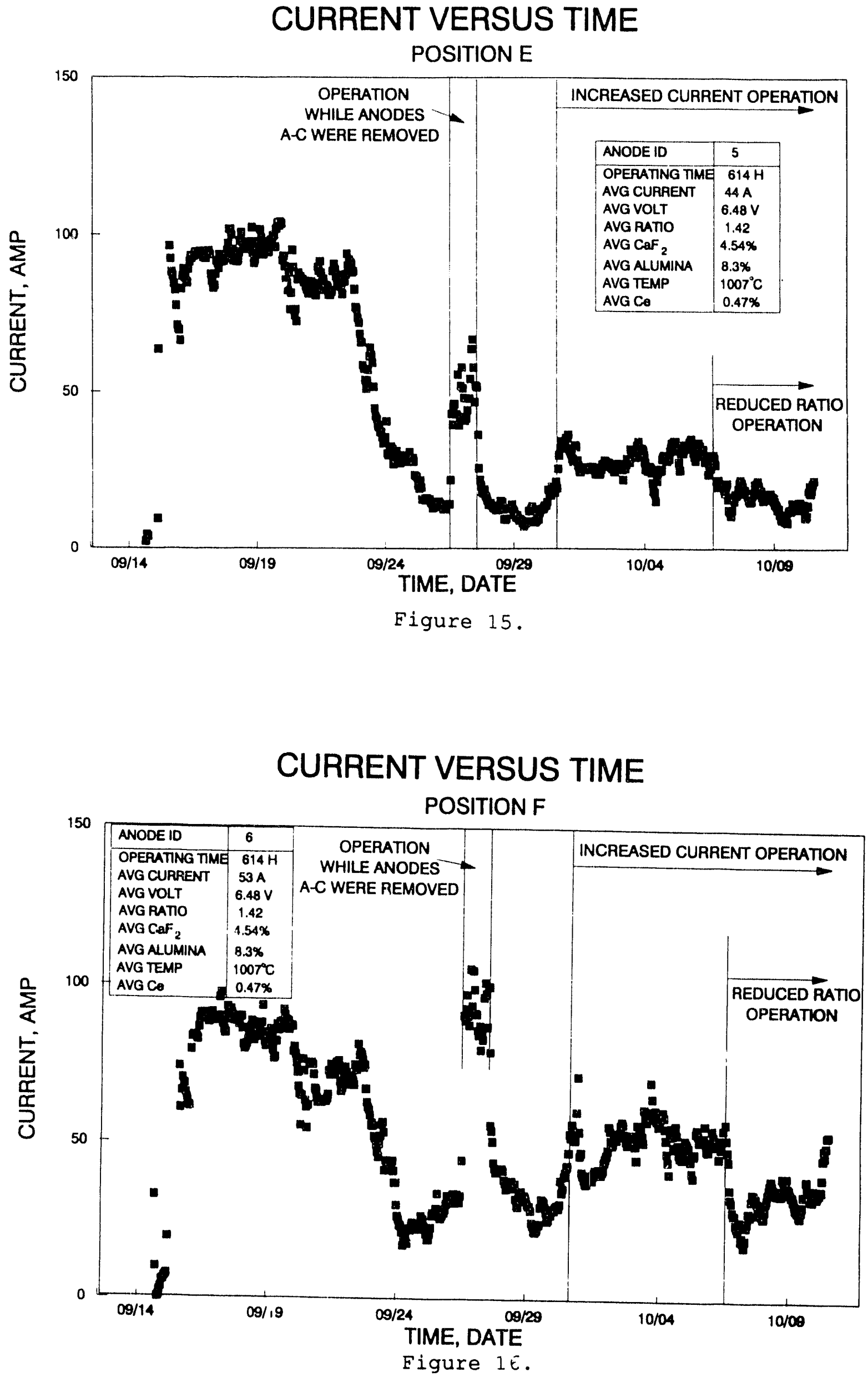
The carbon anode current ranged between 1.8 and $3 \mathrm{kA}$ and was varied during the test in an effort to keep the cell molten and to reduce the effect on the current to the cermet anodes. The voltage on the carbon anode ranged between 7 and $11 \mathrm{~V}$. The cell voltage on the cermet anodes is shown in Figure 17 and averaged around $7 \mathrm{~V}$.

\subsection{Bath Composition and Temperature}

The BR variation during the test is shown in Figure 18 . The BR was very irregular and averaged slightly less than the targeted BR of 1.5 during the first three parts of testing. During the low BR testing, the BR averaged 1.16. The temperature also varied considerably throughout the experiment as shown in Eigure 19. The temperature averaged around $980^{\circ} \mathrm{C}$ during the first half of the testing. However, halfway through the second phase of the test, the temperature became more erratic and reached temperatures of higher than $1050^{\circ} \mathrm{C}$. The temperature variations were forced by MTL to try to dissolve some of the muck on the bottom of the cell so there would be a more even current distribution to the anodes. The temperature variations resulted in bath freezing and melting throughout the latter part of the test.

During the first phase of the cermet testing, the $\mathrm{Al}_{2} \mathrm{O}_{3}$ content averaged $\sim 78$, which was around $70 \%$ of saturation. During the later phases of the test (high $C D$, low $B R$ ), the alumina concentration rose to an average $>10 \%$ and was between 88 to $96 \%$ of saturation as shown in Eigures 20 and 21 . It appears the problems with dissolution of $\mathrm{Al}_{2} \mathrm{O}_{3}$ and mucking began at $80 \%$ of alumina saturation. The percent of saturation is based on the formula of Skybakmoen. ${ }^{8}$ $\mathrm{CaF}_{2}$ content during the testing averaged 4.2 to 4.68 (Figure 22).

\section{6 Ce Concentration}

The $\mathrm{Ce}$ concentration in the bath was the key parameter to control in order to grow and maintain a CEROX coating. Ce content in both the bath and metal is shown in Figures 23 and 24 . A level of about 0.98 Ce was needed in the bath to deposit the CEROX coatings on the first five cermet anodes (September 15, 1991). As the coating formed on the anodes, the ce concentration in the bath rapidly dropped. After coating, the Ce concentration in the bath was then maintained at 0.3 to $0.4 \%$. About halfway through the test (as the cell began to accumulate $\mathrm{Al}_{2} \mathrm{O}_{3}$ muck and cycles of freezing and thawing were experienced with the temperature changes) the $\mathrm{Ce}$ levels became more erratic and more difficult to control. It appeared that $\mathrm{Ce}$ was freezing out with some of the muck, giving lower concentrations in the bath, and then as temperature increased, the $\mathrm{Ce}$ would again dissolve into the bath, giving high bath concentrations. The fluctuating and higher $\mathrm{Ce}$ levels were compounded by the fact that additional $\mathrm{CeF}_{3}$ was added to the cell when anodes A2, B2, and C2 were placed in the cell. Thus, Ce concentration was much more erratic and higher during the second 


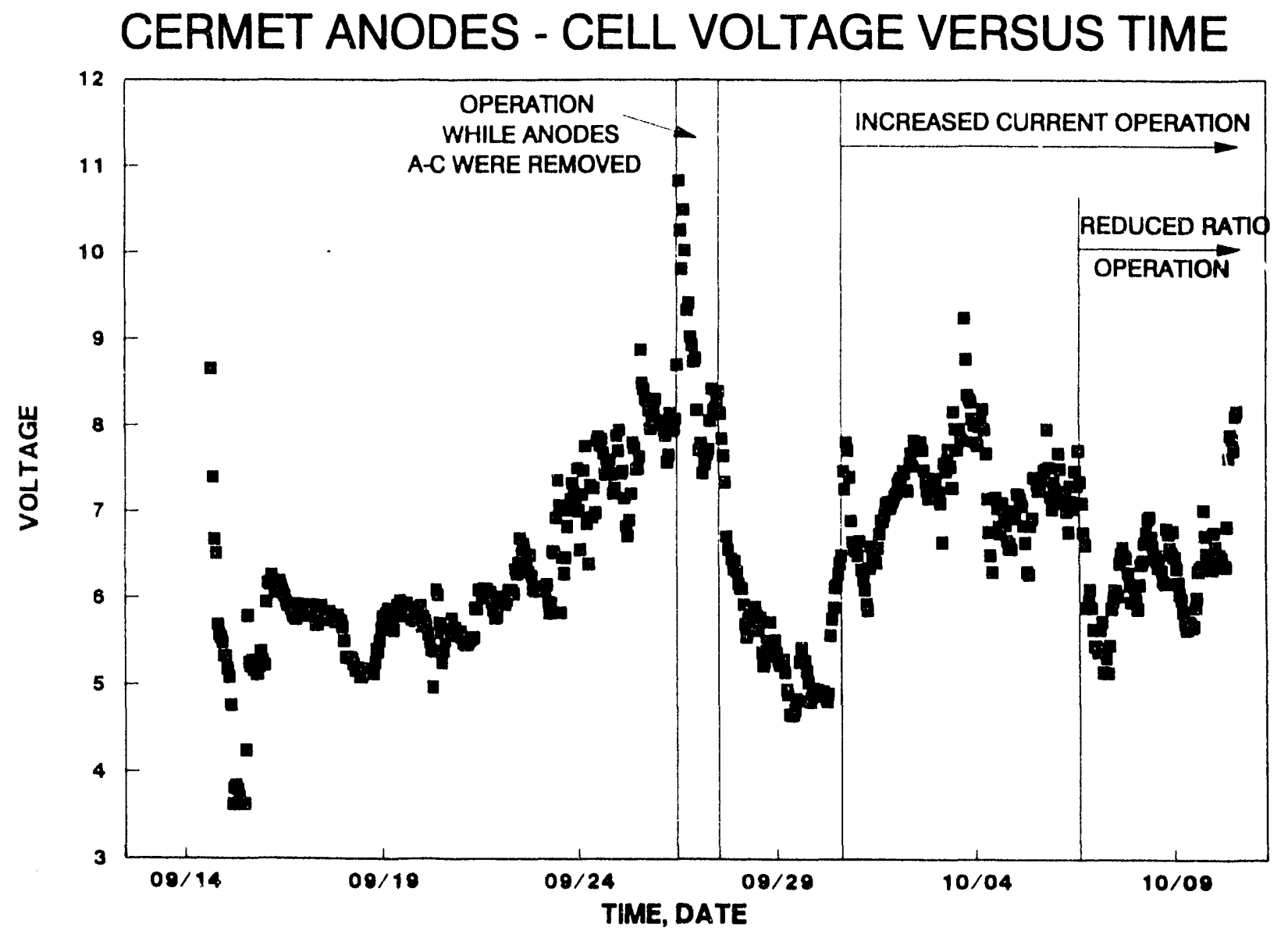

Eigure 17. 
RATIO VERSUS TIME

ELTECH CERMET ANODE PILOT CELL TEST

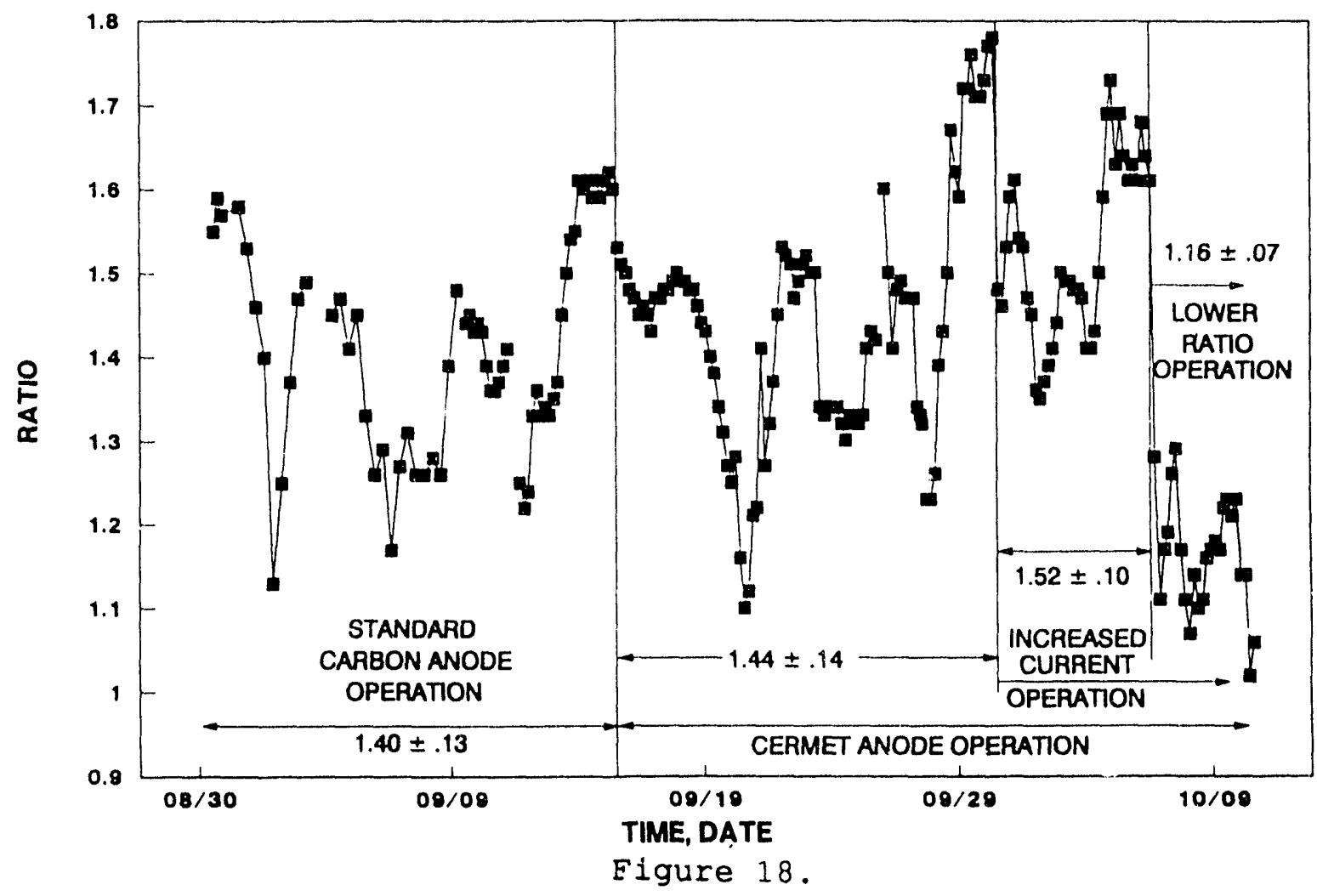

\section{BATH TEMPERATURE VERSUS TIME}

\section{ELTECH CERMET ANODE PILOT CELL TEST}

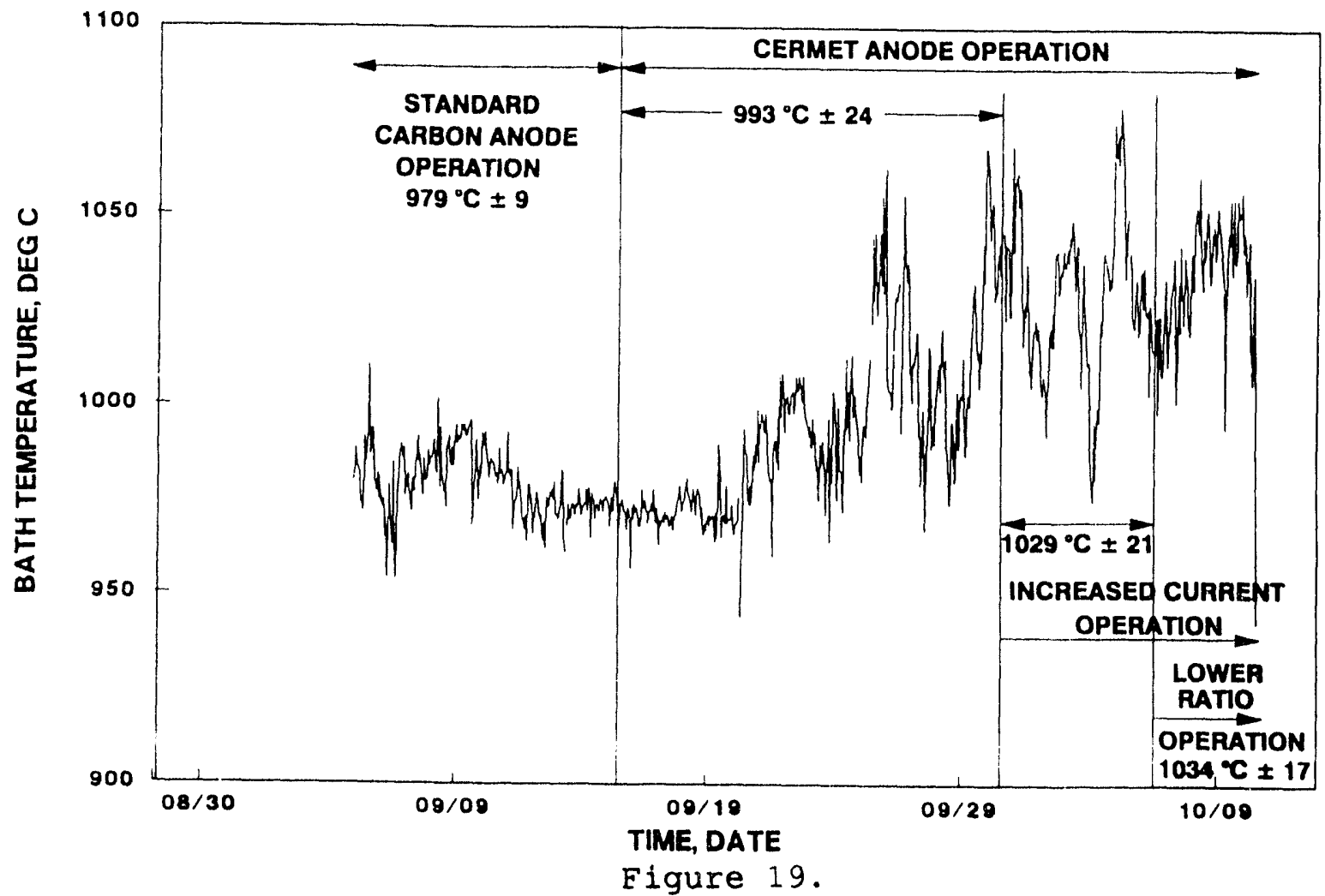




\section{ALUMINA CONTENT IN BATH VERSUS TIME}

ELTECH CERMET ANODE PILOT CELL TEST
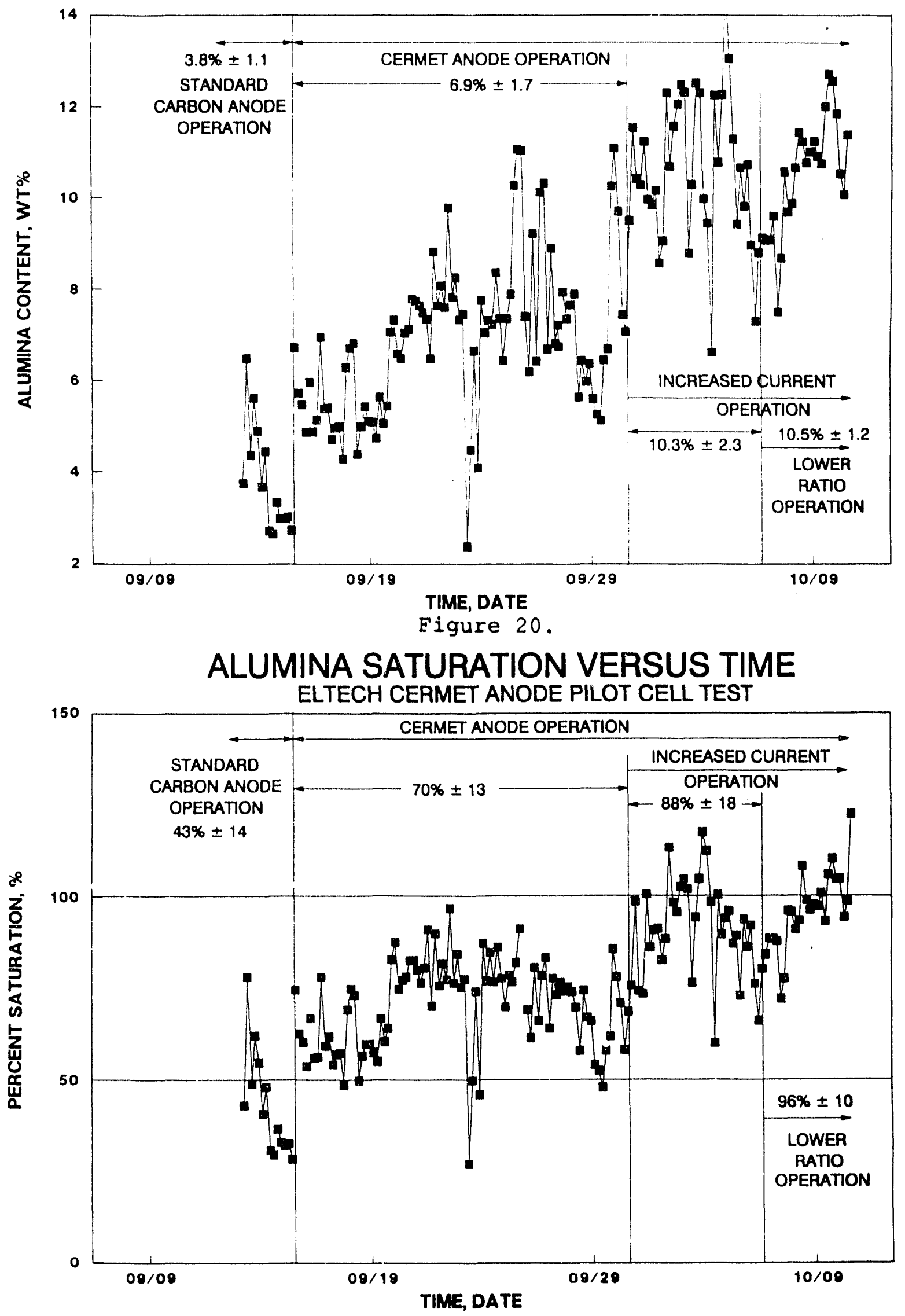

Figure 21. 


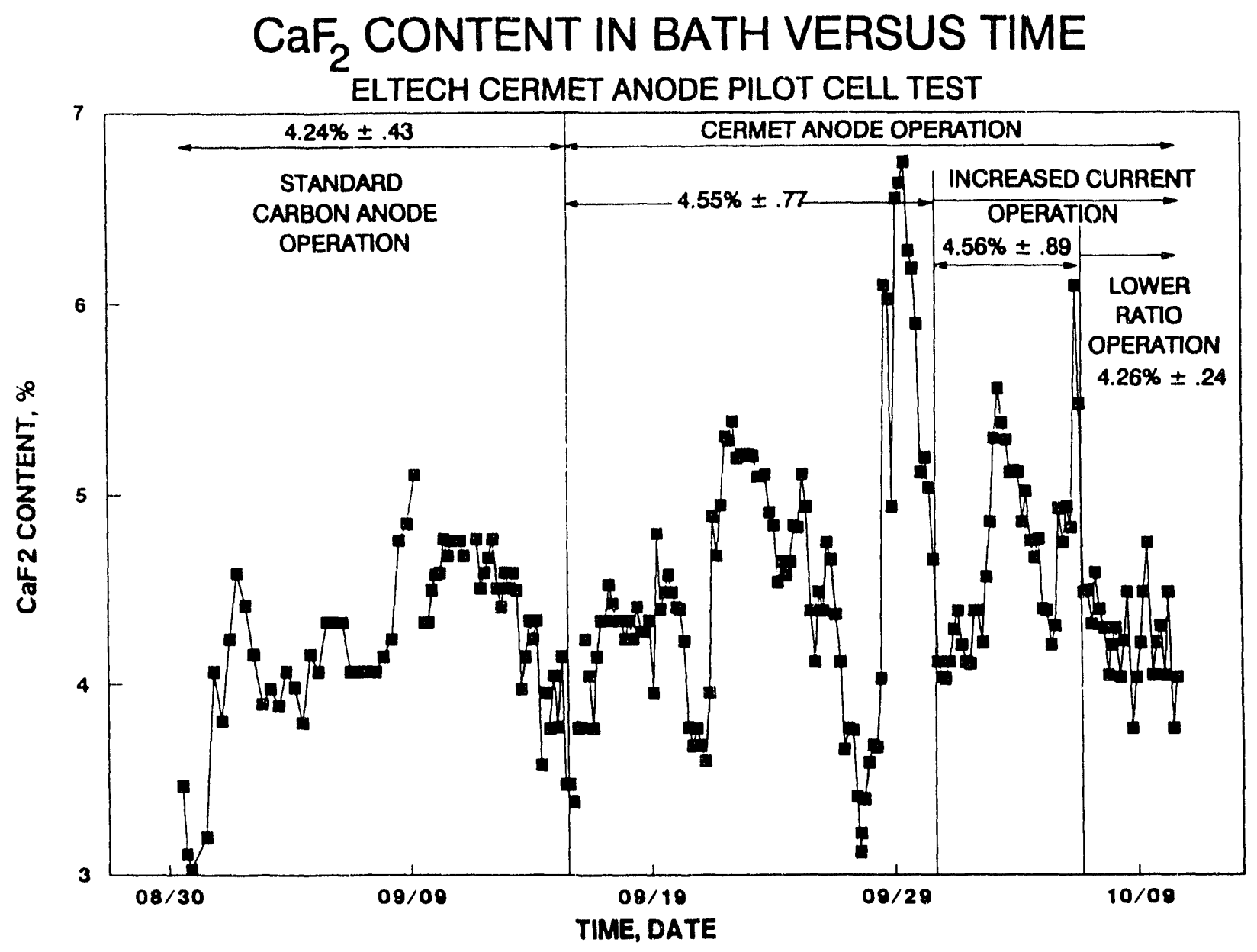

Figure 22. 
Eigure 23. Ce CONTENT IN THE METAL
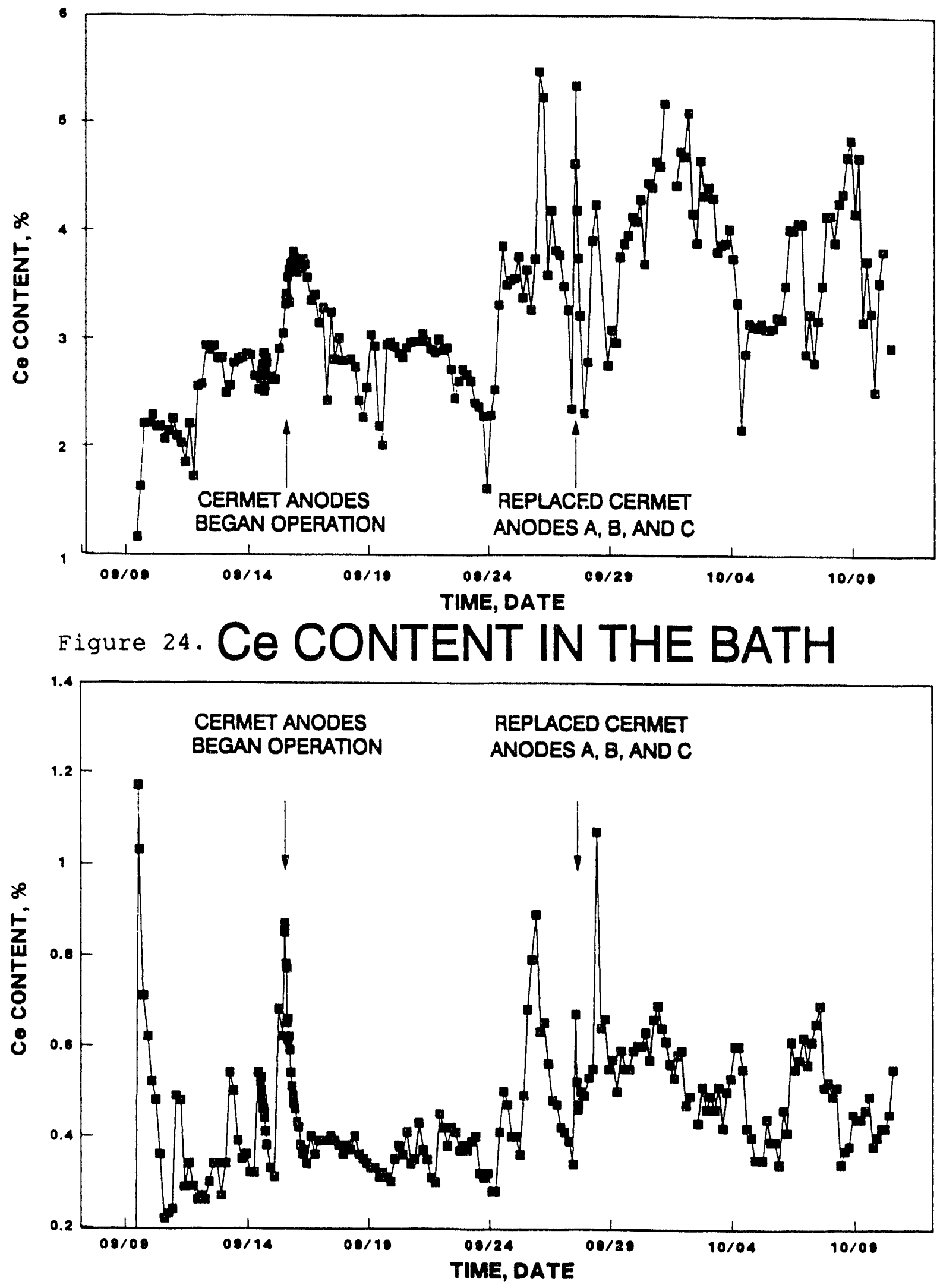
half of the testing than was originally targeted.

The Ce concentration in the metal followed the same trends as that in the bath. In addition (as the bottom of the cell mucked up) it was suspected that the metal pool became segregated into numerous pools, which caused a lack of equilibrium between the pools. As with the Ce bath concentration, the Ce in the metal was much more erratic and higher than was expected, particularly for the second half of the test.

Laboratory tests indicate that the partition coefficient for Ce in the metal and bath (wto $\mathrm{Ce}_{\text {metal }} / \mathrm{wt} \% \mathrm{Ce}_{\text {bath }}$ ) ranges from 8 to 10 for $\mathrm{BR}$ between 1.2 and 1.6 . The Ce wto in the metal versus Ce wto in the bath is shown in Figure 25. The partition coefficient ranged from $\sim 3$ to 10. The scatter in the data is probably partly because of measurements taken when the system was not at equilibrium. In addition, temperature, alumina content, and BR fluctuated during testing and could have lead tc a range of distribution coefficients.

Table 3 summarizes the average bath composition and temperature for each phase of testing. 
CERIUM CONTENT IN BATH VERSUS IN METAL

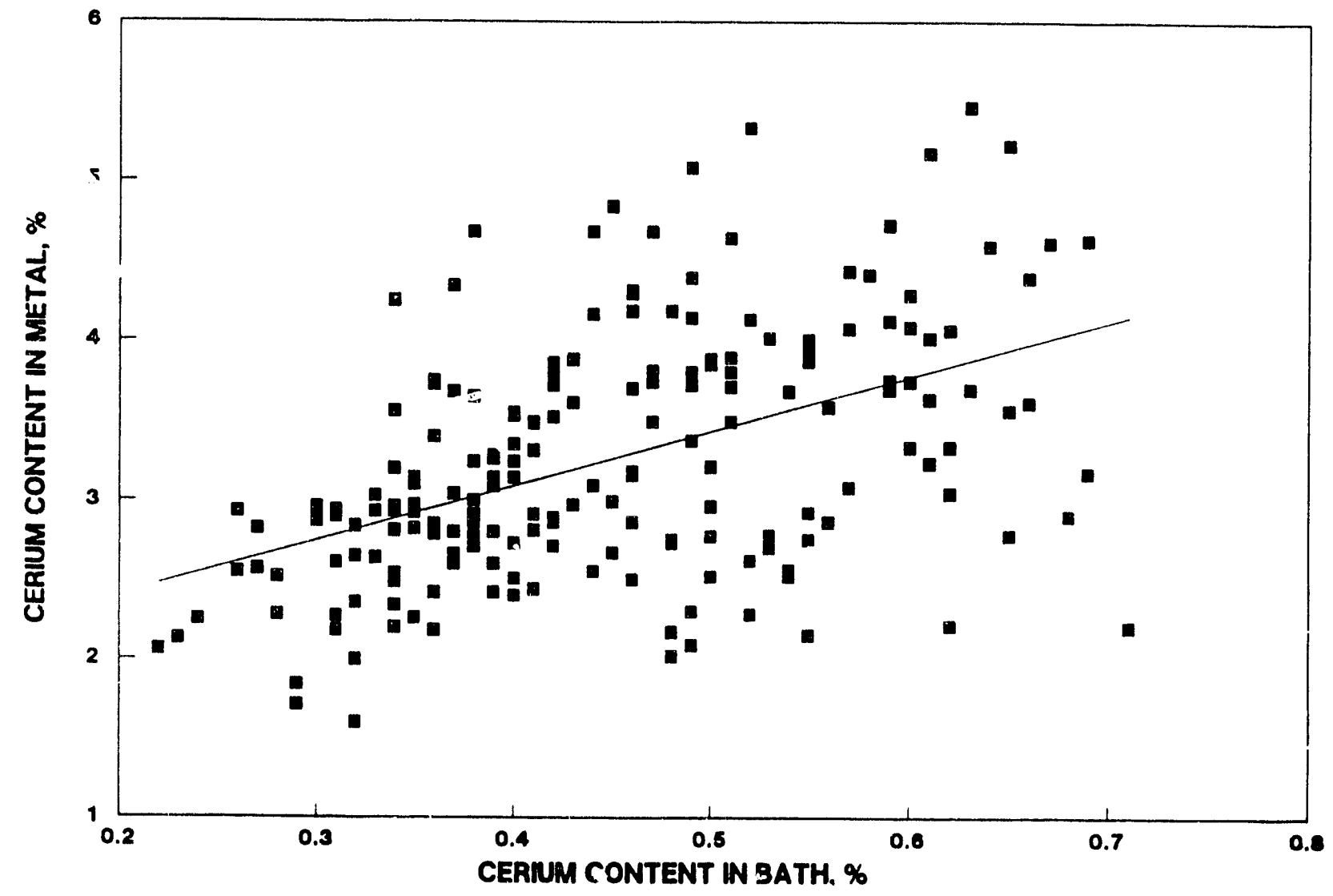

Figure 25. 
Table 3. Average operating conditions during the four phases of testing.

\begin{tabular}{|lllll|}
\hline Date & Sept 1-15 & Sept 15-30 & Sept 30-Oct 6 & Oct 6-10 \\
\hline Current & Carbon anode & Max 90 A & Max 115 A & Max 115 A \\
Ratio & 1.40 & 1.44 & 1.52 & 1.16 \\
$\mathrm{CaF}_{2}$ & $4.24 \%$ & $4.55 \%$ & $4.56 \%$ & $4.26 \%$ \\
$\mathrm{CeF}_{3}$ & $-\cdots .$. & $0.47 \%$ & $0.50 \%$ & $0.49 \%$ \\
$\mathrm{Temp}^{\circ}$ & $979^{\circ} \mathrm{C}$ & $993{ }^{\circ} \mathrm{C}$ & $1029{ }^{\circ} \mathrm{C}$ & $1034^{\circ} \mathrm{C}$ \\
$\mathrm{Al}_{2} \mathrm{O}_{3}$ & $3.8 \mathrm{wt} \%$ & $6.9 \mathrm{w} \%$ & $10.3 \mathrm{wt} \%$ & $10.5 \mathrm{wt} \%$ \\
$\% \mathrm{Sat}$. & $43 \%$ & $70 \%$ & $88 \%$ & $96 \%$ \\
\hline
\end{tabular}




\section{RESULTS AND DISCUSSION}

The anode corrosion and the protection of the CEROX coating were judged from the impurities in the Al pool and from macroscopic and microscopic examination of the anodes. Where data is available, a comparison was made to the uncoated cermets tested by PNI.

\subsection{Impurities in the Al Pool}

The $\mathrm{Ni}, \mathrm{Cu}$, and $\mathrm{Fe}$ impurities measured in the $\mathrm{Al}$ are shown in Figures 26, 27, and 28. The spikes in the data are probably caused by sampling (see Appendix 1) the small, and possibly segregated, metal pool that was present in the cell.

One way to quantify the deterioration of the inert anodes is to calculate a corrosion rate based on these changing impurity levels. By assuming a constant corrosion rate and considering the $A l$ inventory, contamination of the $A l$ can be calculated and compared to the actual impurities found in the bath. Corrosion rates of $0.075,0.13$, and $0.30 \mathrm{lb} / \mathrm{d}$ for $\mathrm{Cu}, \mathrm{Ni}$, and $\mathrm{Fe}$ respectively, fit the data best as shown in Eigures 29, 30, and 31. Assuming the losses are actually $\mathrm{Cu}, \mathrm{NiO}$, and $\mathrm{Fe}_{2} \mathrm{O}_{3}$ and assuming a density of $6 \mathrm{~g} / \mathrm{cm}^{3}$, this amounts to $\sim 0.1 \mathrm{~mm}$ surface area loss/d. There was a period between September 9,1991 and october 10,1991 where the data are substantially lower than the model. During this period there were only three or four cermets present in the bath instead of the usual five or six.

The Fe data show considerably more scatter than the other contaminants and a poorer fit to the model. It is assumed that the use of iron tools for cell maintenance and sampling was responsible. The ratio of $\mathrm{Cu}: \mathrm{Ni}: \mathrm{Fe}$ in the cermet anodes is $1: 1.98: 1.65$. The ratio of the best fit corrosion rates is $1: 1.74: 4$. The $\mathrm{Cu}$ and $\mathrm{Ni}$ contamination correspond fairly well with their relative amounts in the anode material, but the $\mathrm{Ee}$ contamination is much higher. Reynolds assumed that the $\mathrm{Fe}$ in the Al metal from the corrosion of the anodes should be in the correct ratio of the $\mathrm{Fe}$ in the anode; therefore, the $\mathrm{Fe}$ from the anode must be $\sim 0.12 \mathrm{lb} / \mathrm{d}$ and the remainder must be from other sources.

The $\mathrm{Ni}, \mathrm{Cu}$, and $\mathrm{Fe}$ corrosion from the PNL test is shown in Figures 32, 33, and 34. Corrosion models were fit to the data for the time period of under their "optimum" conditions ( $\mathrm{BR} \sim 1.3, \mathrm{CD} \sim 0.5 \mathrm{~A} / \mathrm{cm}^{2}$ or less). For that time period, the corrosion data fit the model very well as shown in Figures 35,36 , and 37 . The calculated corrosion during their test was $0.13,0.26$, and $0.31 \mathrm{lb} / \mathrm{d} \mathrm{Cu}, \mathrm{Ni}$, and Fe, respectively. The calculated surface area loss was $\sim 0.2 \mathrm{~mm} / \mathrm{d}$. The $\mathrm{Fe}$ in their test was also higher than would be expected from the anode. The calculated corrosion was in the ratio of $1: 2: 2.4$ (Cu:Ni:Fe) as compared to the untested anode ratio of $1: 1.98: 1.65$. Fe corrosion, recalculated based on the ratio of Fe in the cermets, was $0.21 \mathrm{lb} / \mathrm{d}$. Corrosion in the PNL test is about 
Ni Content in Metal

ELTECH Cermet Anode Pilot Cell Test

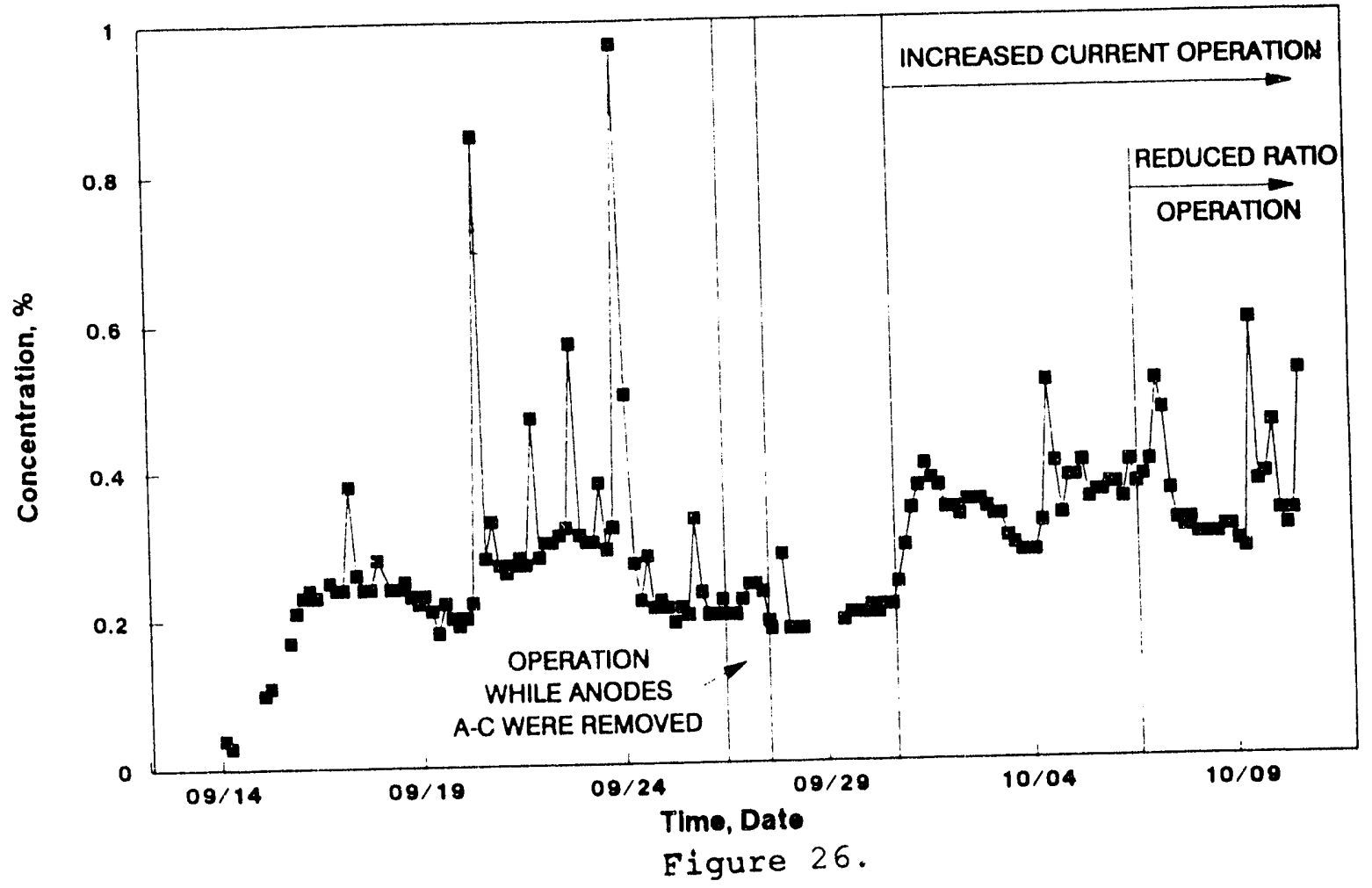

Cu Content in Metal

ELTECH Cermet Anode Pilot Cell Test

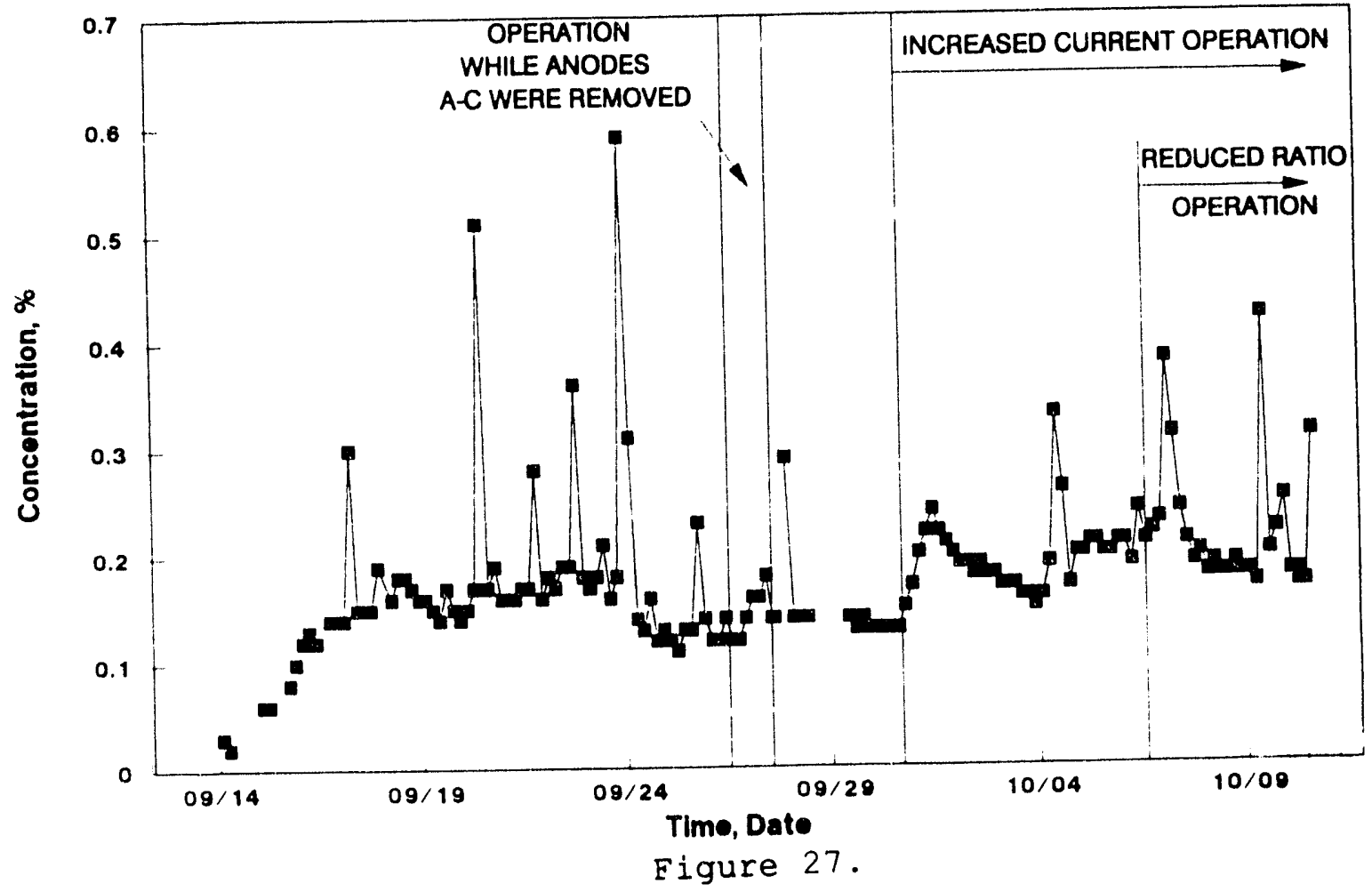




\section{Fe Content in Metal}

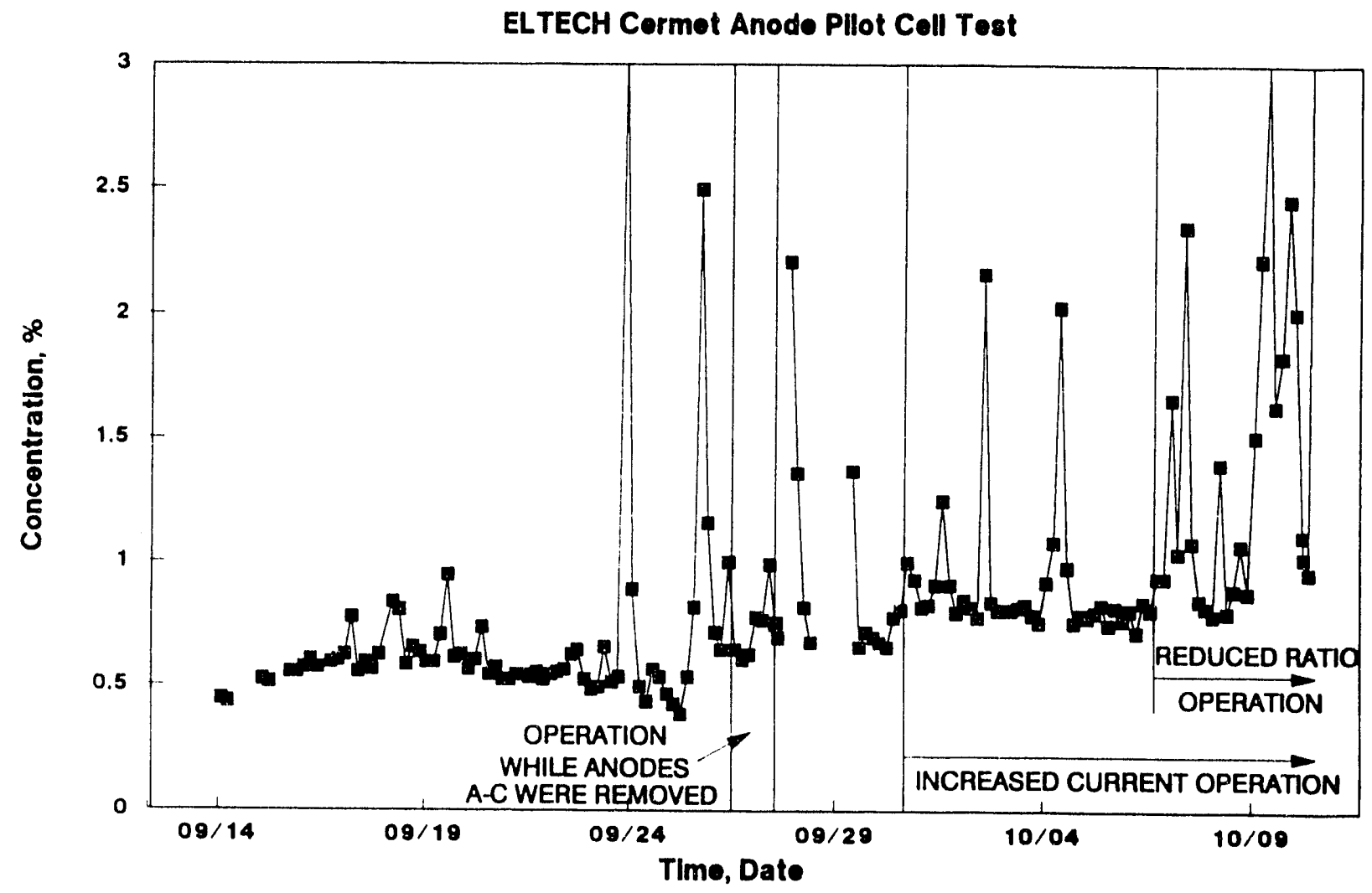

Figure 28. 
Ni CONTENT IN THE METAL

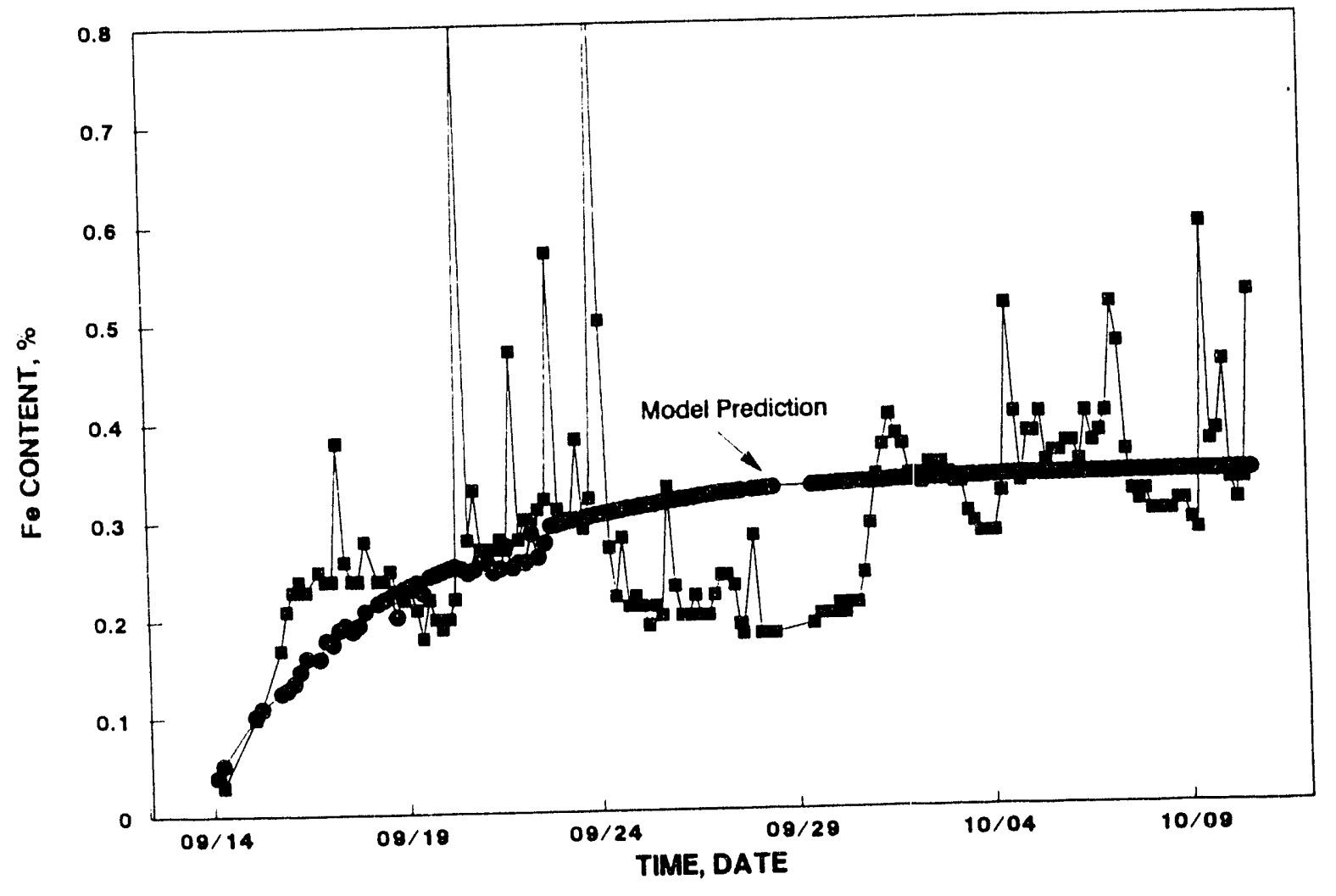

Figure 29.

\section{CU CONTENT IN THE METAL}

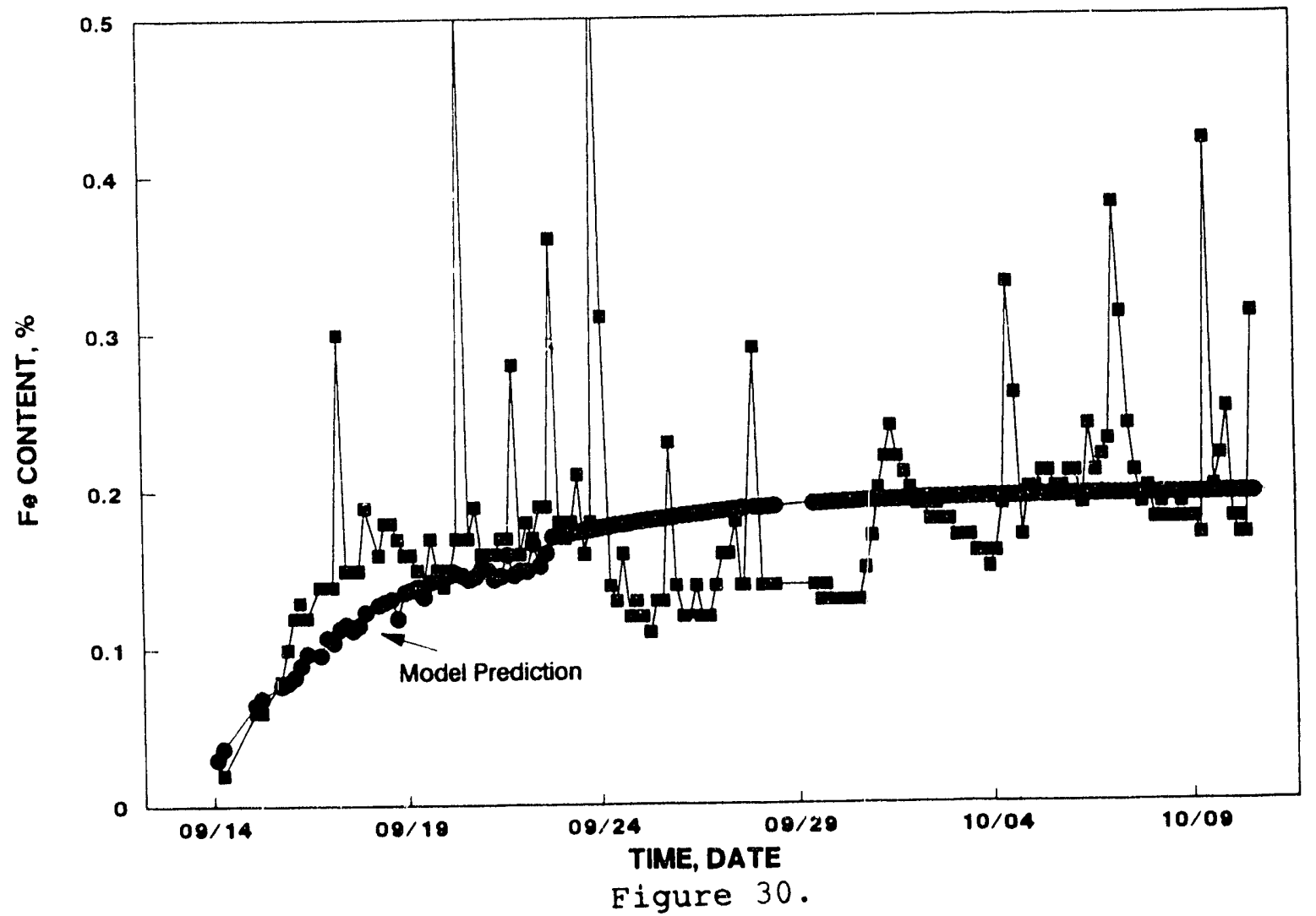


Fe CONTENT IN THE METAL

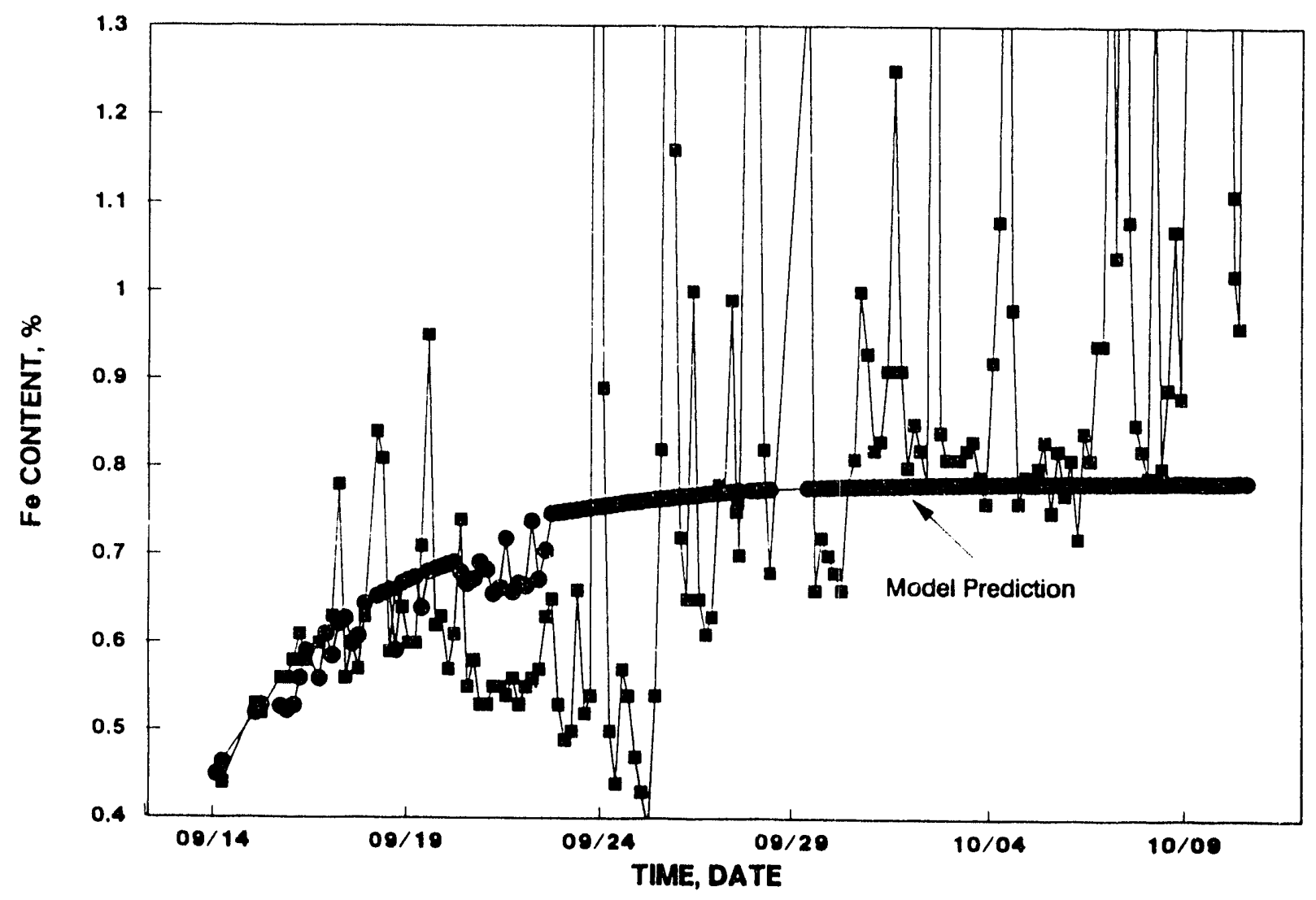

Figure 31. 


\section{PNL Test}

Ni Content in Metal

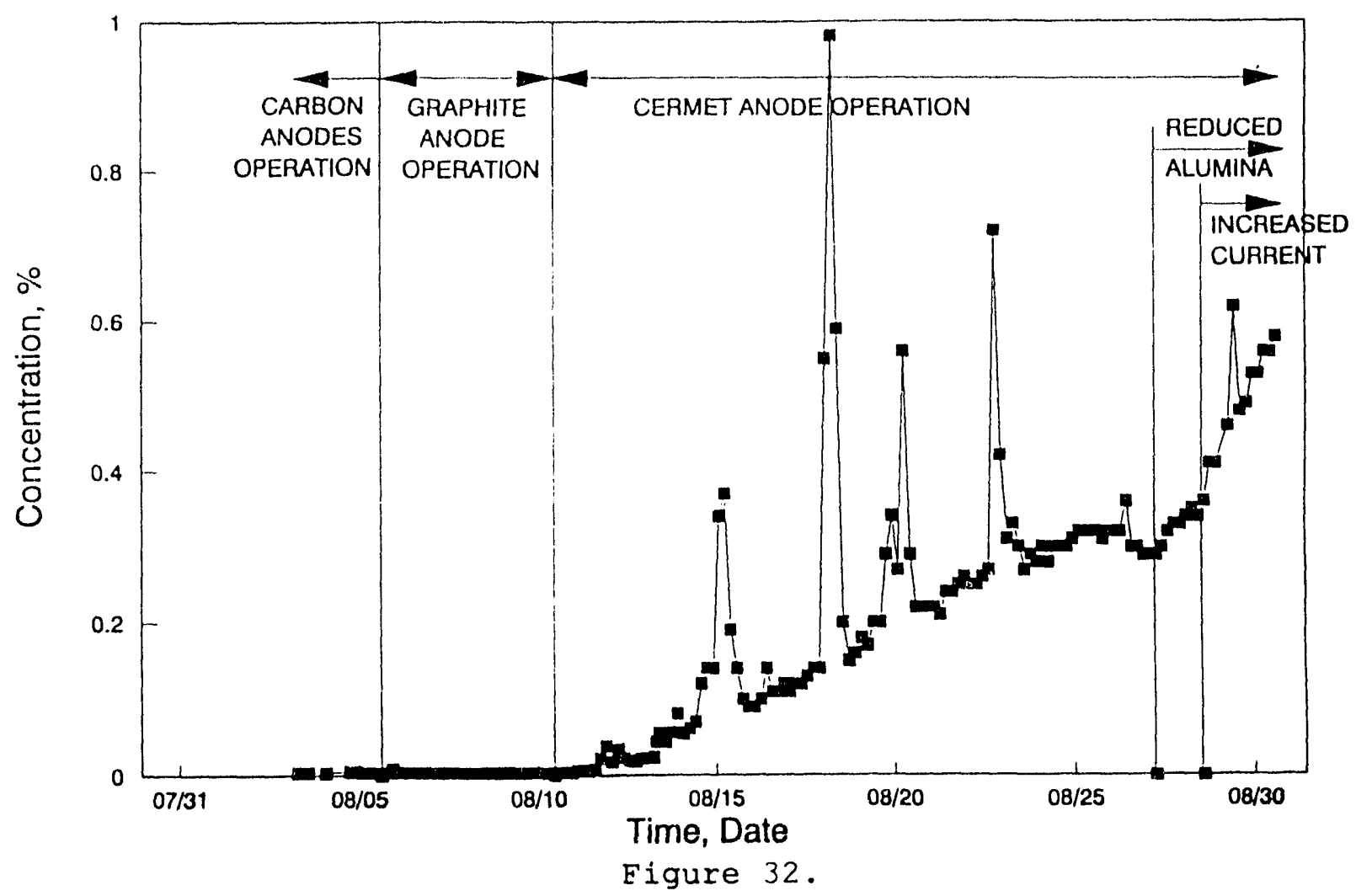

PNL Test

Cu Content in Metal

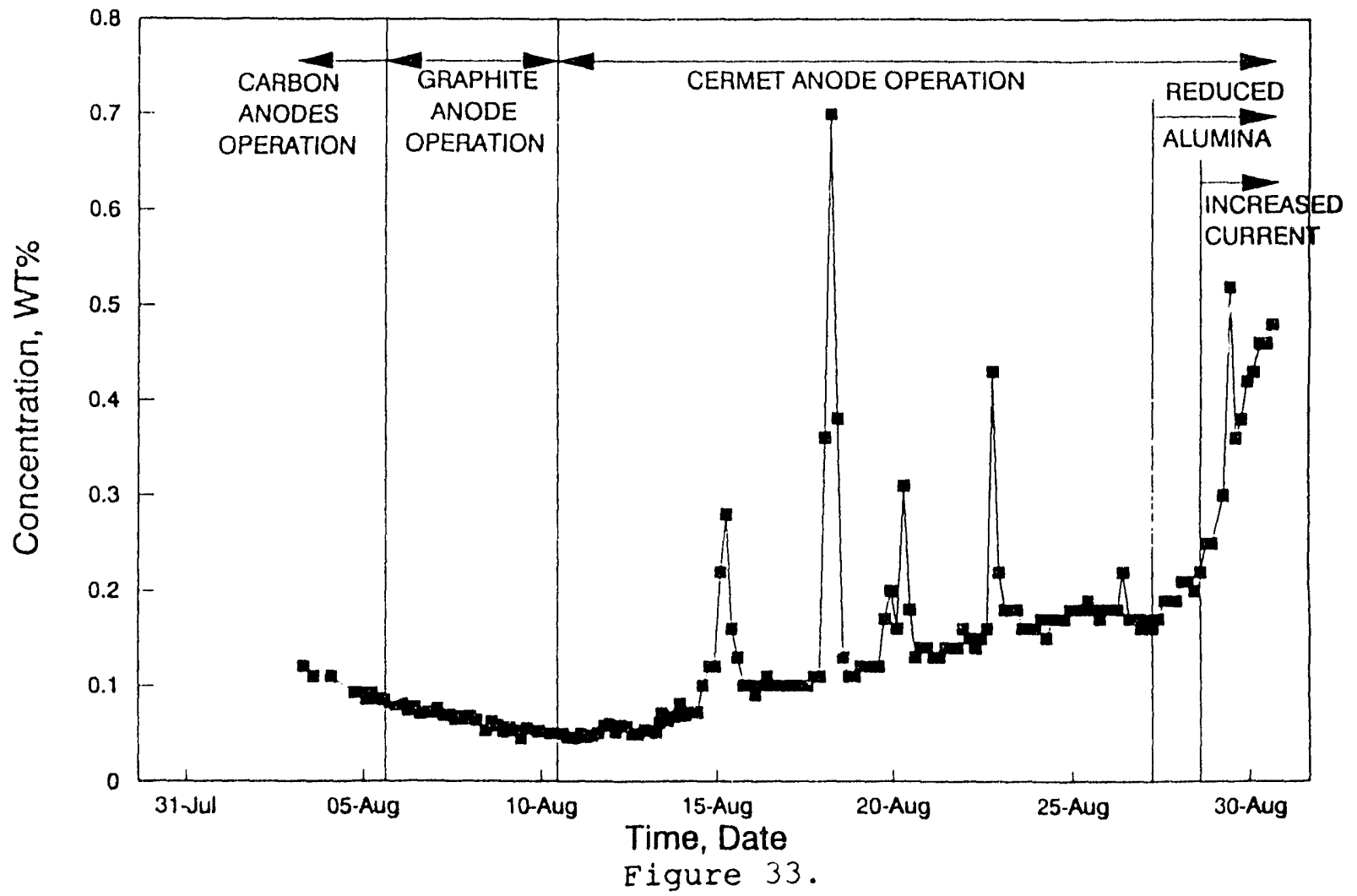




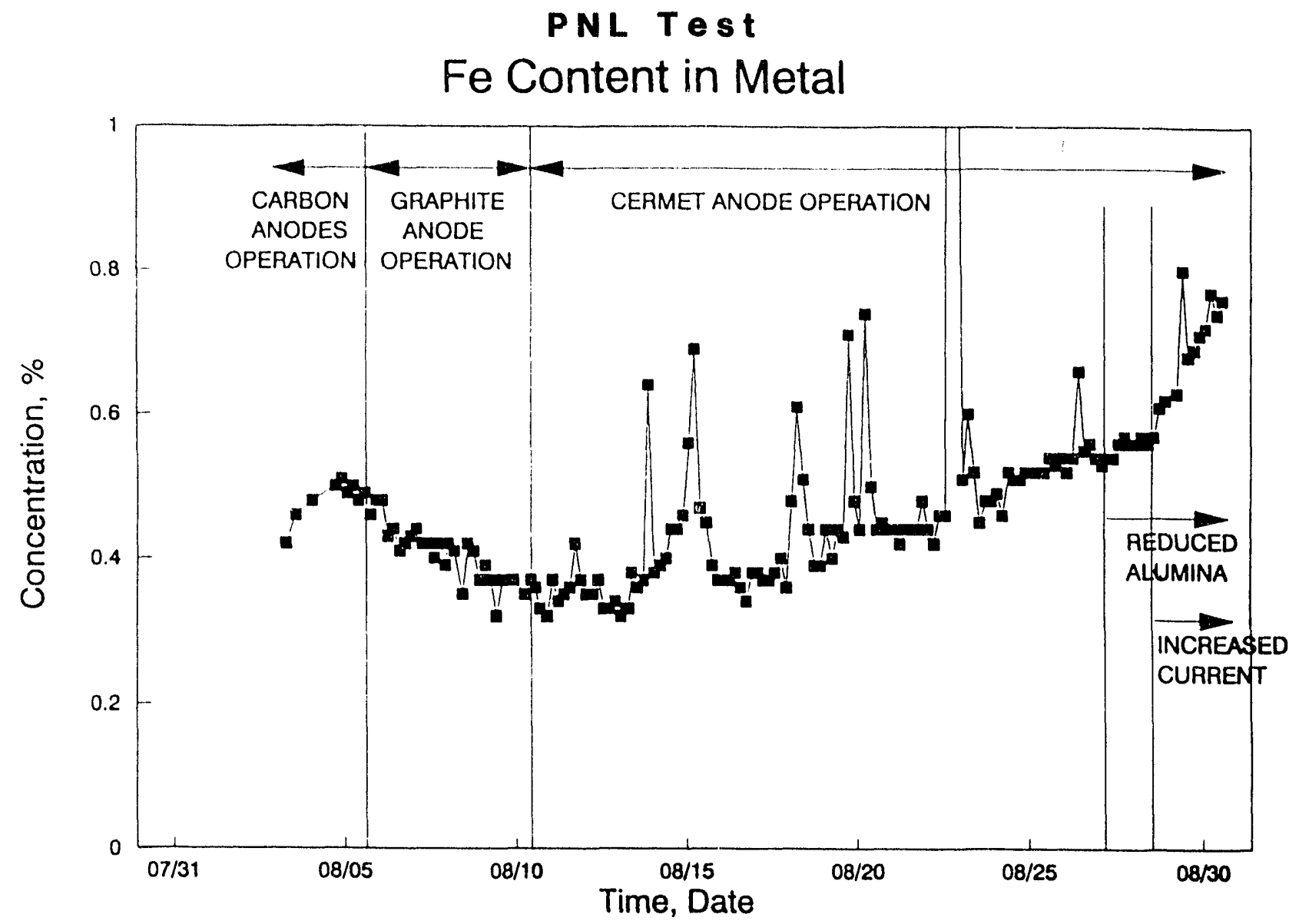

Figure 34. 

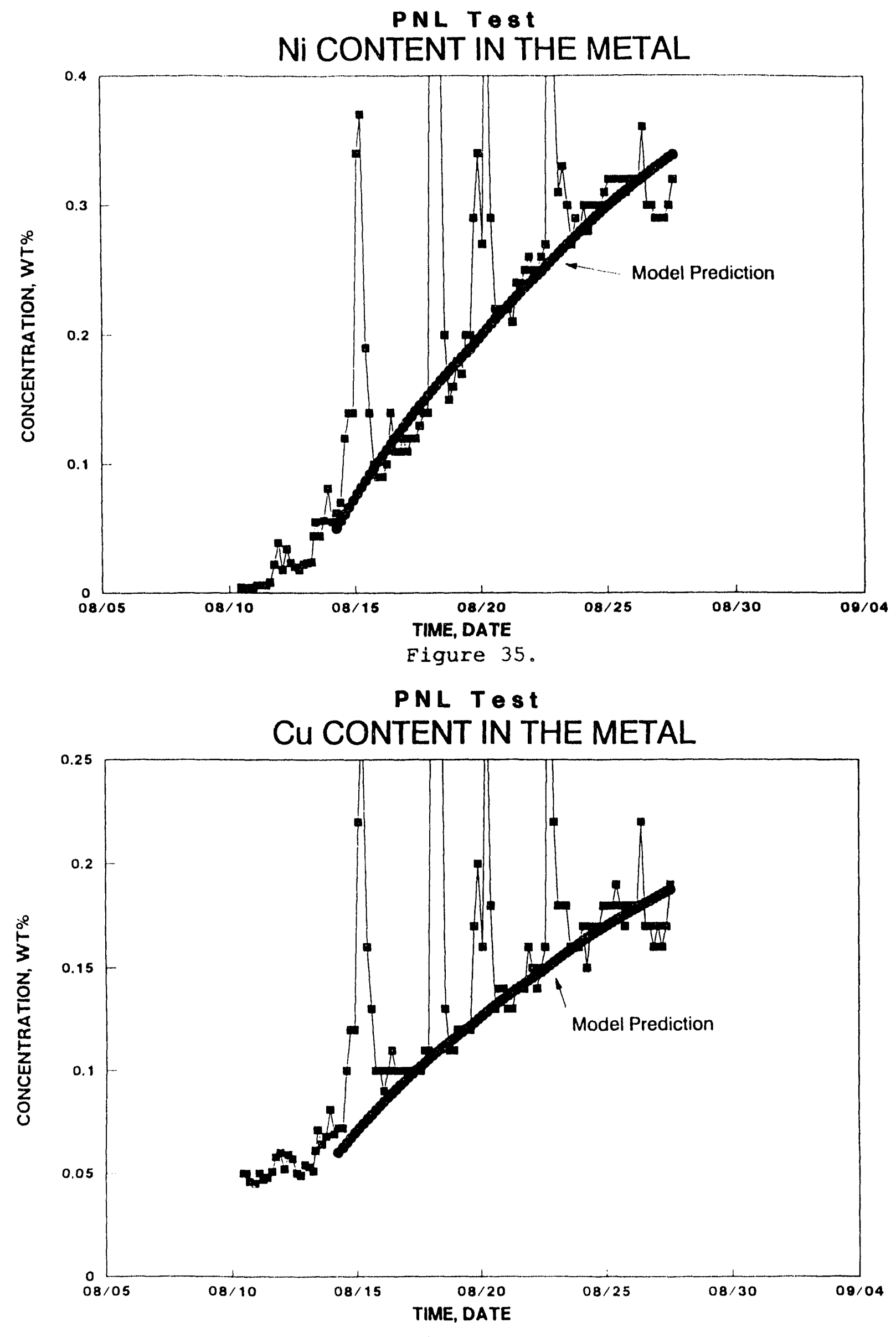

Figure 36. 


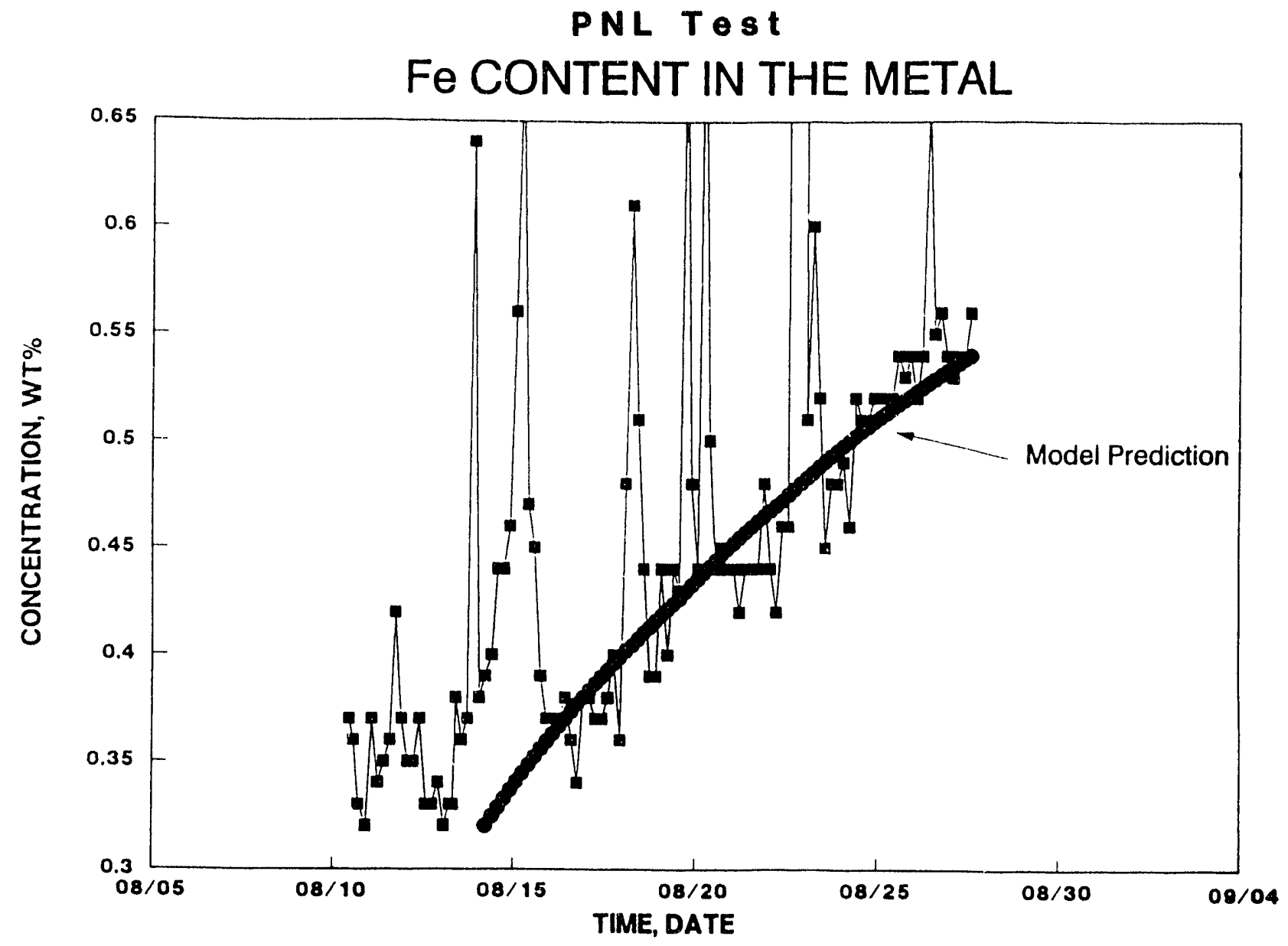

Figure 37. 
twice that of the CEROX-coated anodes.

Because anodes during both tests had cracks, and pieces or chips of the anode fell into the bath (see subsection 4.2), the metal impurities may not be a good measure of the corrosion of the surface of the anodes. Because cracks were present to the center, some cryolite may also have contacted the $\mathrm{Ni}$ (PNL) or Inconel 601 (ELTECH) connector rods. In addition (because of the cracks) much more surface area was exposed to the electrolyte than would be for an intact anode.

The difference in the PNL and ELTECH test conditions also makes it difficult to make a comparison between the cermets operated with and without a CEROX coating. As shown in Figures 38 and 39 , the $\mathrm{Al}_{2} \mathrm{O}_{3}$ concentration was maintained closer to saturation, and the temperature was generally kept below $1000^{\circ} \mathrm{C}$ during the PNL test. During the ELTECH test, the higher temperature and lower $\mathrm{Al}_{2} \mathrm{O}_{3}$ contents may have increased the corrosion. Alcoa has shown that both conditions led to increased dissolution of the oxides. ${ }^{3}$ The effect of temperature on the CEROX coated anodes has not been studied, but labcratory studies on CEROX coated anodes at low $\mathrm{Al}_{2} \mathrm{O}_{3}$ concentrations has shown an increase in corrosion. ${ }^{6}$

The $\mathrm{Fe}, \mathrm{Ni}$, and $\mathrm{Cu}$ levels in the cryolite melt were also monitored throughout the testing period. Average levels during most of the PNL test ranged from 0.001 to $0.003 \% \mathrm{Cu}, 0.005$ to $0.0098 \mathrm{Ni}$, and 0.02 to $0.05 \% \mathrm{Fe}$. Levels were similar during the ELTECH test; 0.001 to $0.006 \% \mathrm{Cu}, 0.001$ to $0.010 \% \mathrm{Ni}$, and 0.020 to $0.080 \% \mathrm{Fe}$. During the tests, some values were lower or higher than these averages; levels are similar to the solubility limits measured by Alcoa for $\mathrm{Ni}$ and $\mathrm{Fe}$ from $\mathrm{NiO}$ and $\mathrm{NiFe}_{2} \mathrm{O}_{4} \cdot{ }^{3}$ Alcoa measured solubilities of 0.01 to $0.028 \mathrm{Ni}$ and 0.05 to $0.08 \% \mathrm{Fe}$ from $\mathrm{NiFe}_{2} \mathrm{O}_{4}$, depending on temperature and bath composition. The solubility of $\mathrm{Ni}$ from $\mathrm{NiO}$ was around 0.02 to $0.08 \%$. It appears that the $\mathrm{Fe}$ and $\mathrm{Ni}$ may be near the solubility limit in the bath during portions of these tests. During the PNL test at the high CD and low alumina concentration, somewhat higher levels were recorded.

\subsection{Macroscopic Examination of Anodes}

The untested and tested anodes were macroscopically and microscopically examined. Each of the tested anodes was cracked upon removal from the cell. The cracks generally radiated from the center of the anode and broke the anode into two or more pieces. In some places, of the top rims of the anodes were chipped off. Each anode will be described in some detail, and then the common features summarized. A sketch of each anode (from the top) is shown in Eigure 40 delineating the cracking orientation. The anode positions in the cell refer to Eigure 3 . The anode locations in the cell and whether the anode was adjacent to another cermet anode or next to the carbon anode had a large effect on the CEROX coating and corrosion of the cermet. 

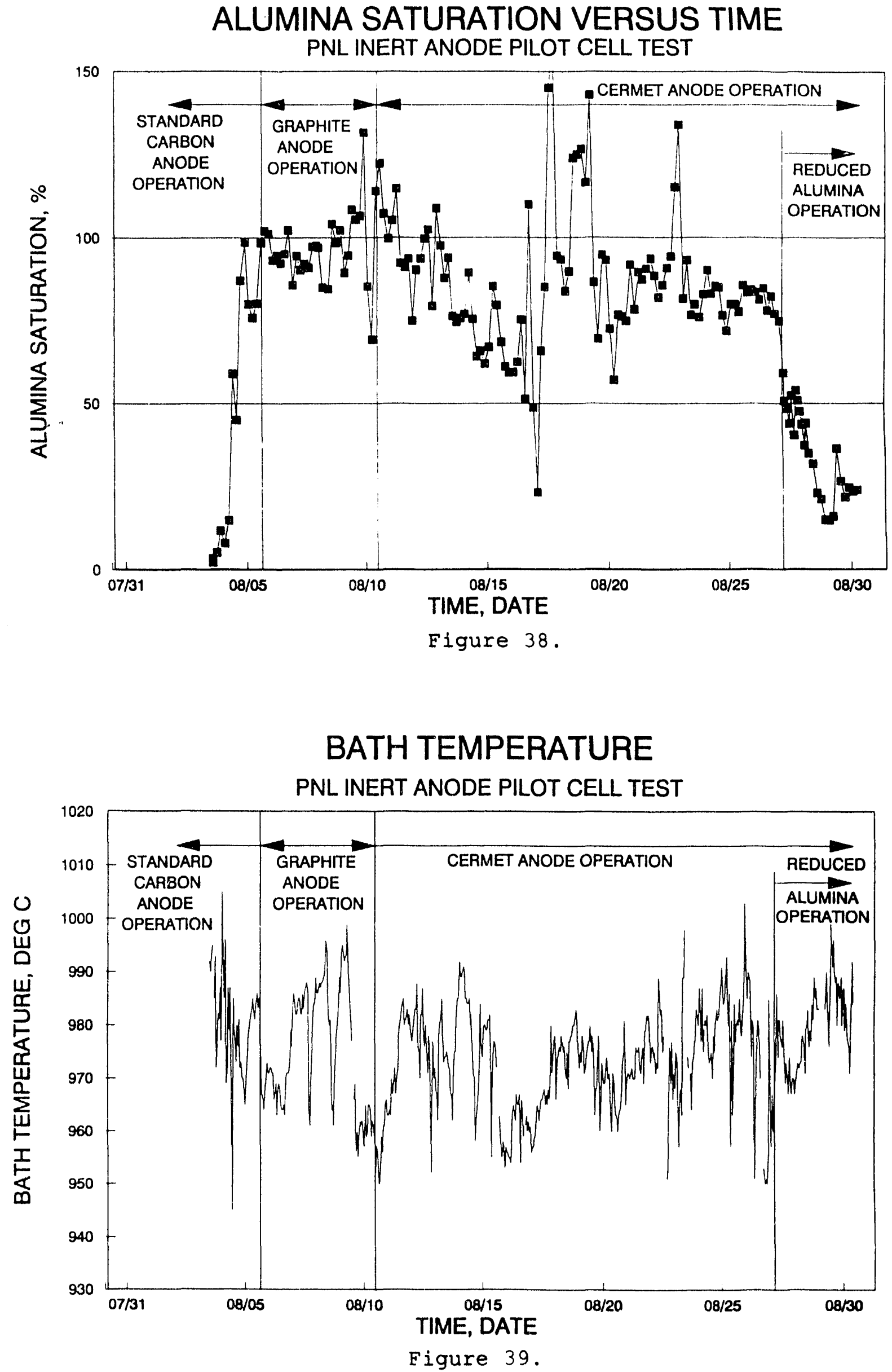

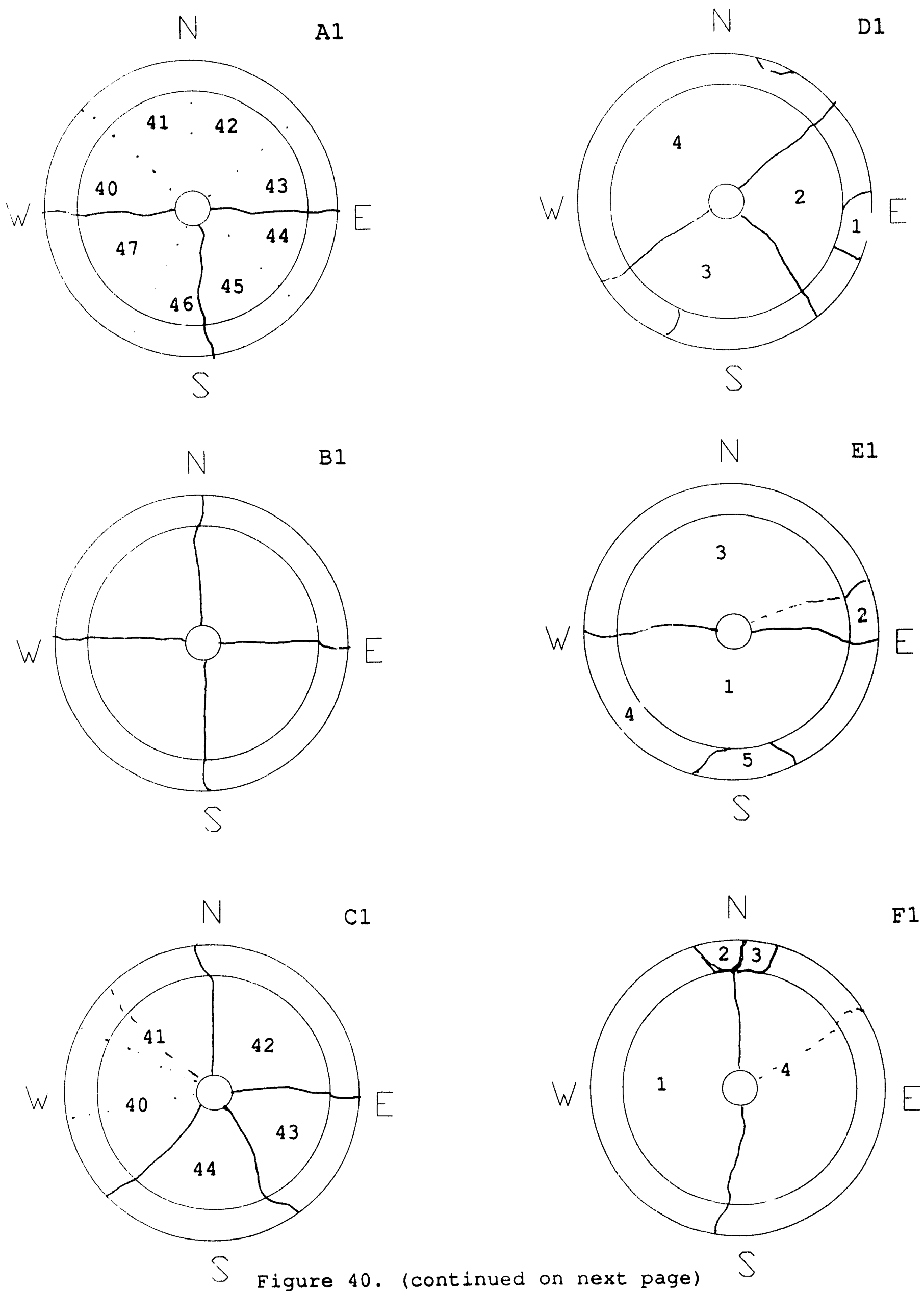


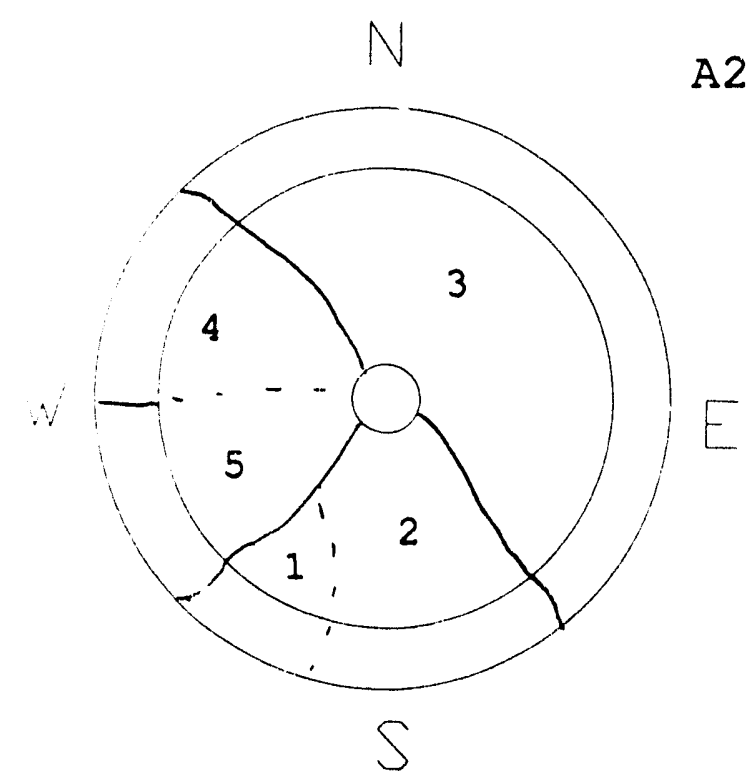

A2
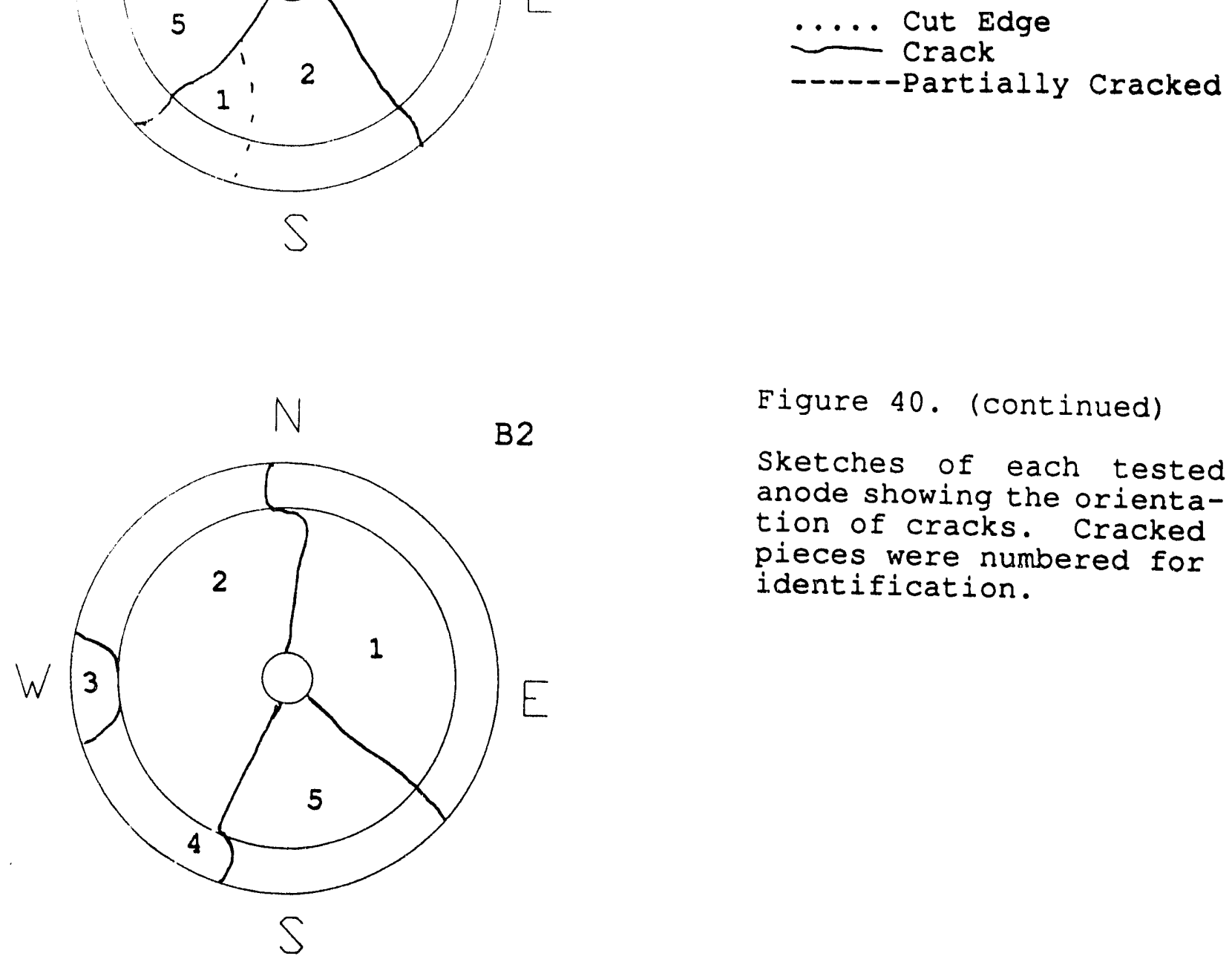

Figure 40. (continued)

Sketches of each tested anode showing the orientation of cracks. Cracked pieces were numbered for identification.

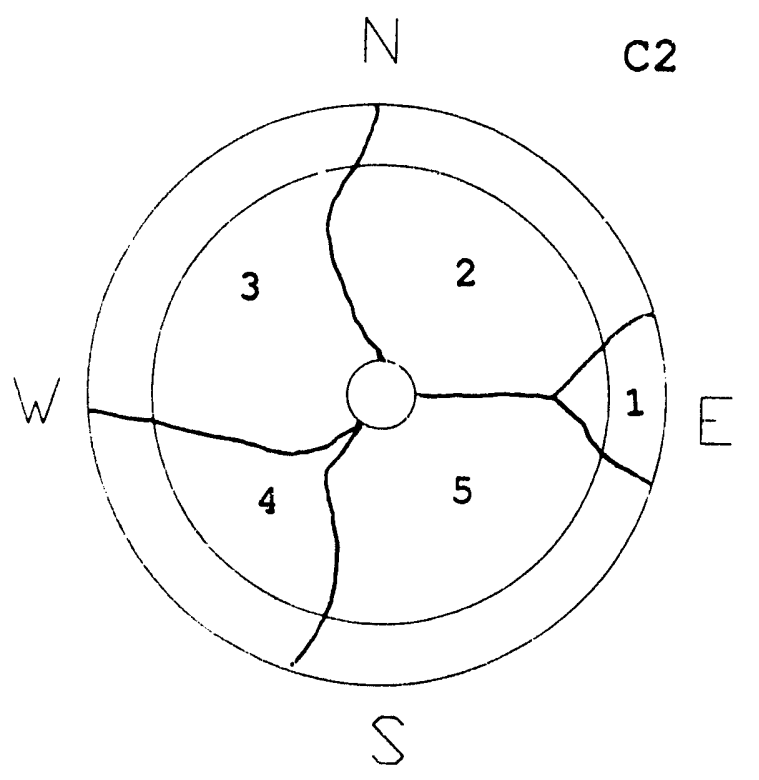




\subsubsection{Description of the Anodes}

Untested Anodes (Anode \#13 cross sectioned for microscopy).

The untested anode shapes were described in subsection 2.2. Two untested anodes are shown in Figure 41. The anodes were generally smooth with a straight side and a radiused bottom. On some of the anodes the surface was slightly rough with scratches, probably formed on the green body. Occasionally a small bead of Cu was squeezed out on the exterior surface. Cross sections of the anodes showed that there were some dark bands parallel to the bottom surface of the anodes. These will be described in detail in the microscopy section.

Anode $B 1^{-\sim 1} \mathrm{~h}$ (Cross sectioned for microscopy).

Anode B1 was removed after $\sim 1 \mathrm{~h}$ in the cell because it was noticeably cracked and not conducting current. The cracks radiated from the center (Figures 40 and 42 ) breaking the anode into four pieces. There was no macroscopic change in the dimensions of the anode or in its appearance. A cross section of the anode is shown in Figure 43.

Anode A1- 213 h, average current $=46 \mathrm{~A}$ (Cross sectioned for microscopy).

Anode Al was cracked into three main pieces that radiated from the center (Figure 40). A $3 \mathrm{~mm}$ dimensional loss was measured from inside the lip to the bottom of the anode. This is probably not significant within our macroscopic measurement capabilities because some anodes showed a small loss while others showed a small increase in size. Only gross dimensional changes could be recorded because of difficulties in measuring the dimensions in the same spot and in measuring a CEROX coated and cryolite covered anode. No gross dimensional changes were noted on any of the anodes.

In general, the CEROX coating was $\sim 0.5$ to $1.5 \mathrm{~mm}$ thick on the sides and the bottom of the anode. On the west side of the anode (facing the carbon anode) the CEROX coating level dipped down and was mostly absent from that side, as shown in Figure 44 . In addition, the bare cermet in that region was covered with roundish corroded areas and the cermet was indented on that side. The corroded areas were also found a short distance into an open crack on that side of the anode. No macroscopic difference was evident in the cermet on the indented side.

On the side of Al facing the east and northeast (Eigure 3) the CEROX coating was up to $8 \mathrm{~cm}$ high and was also thickest on that side ( up to $3 \mathrm{~mm}$ thick, Figure 45). A cross section of the southeast side (no indentation, CEROX coating present) is compared to the west side (indentation, no CEROX coating) in Figure 46 in order to compare the loss of cermet material from the indented 


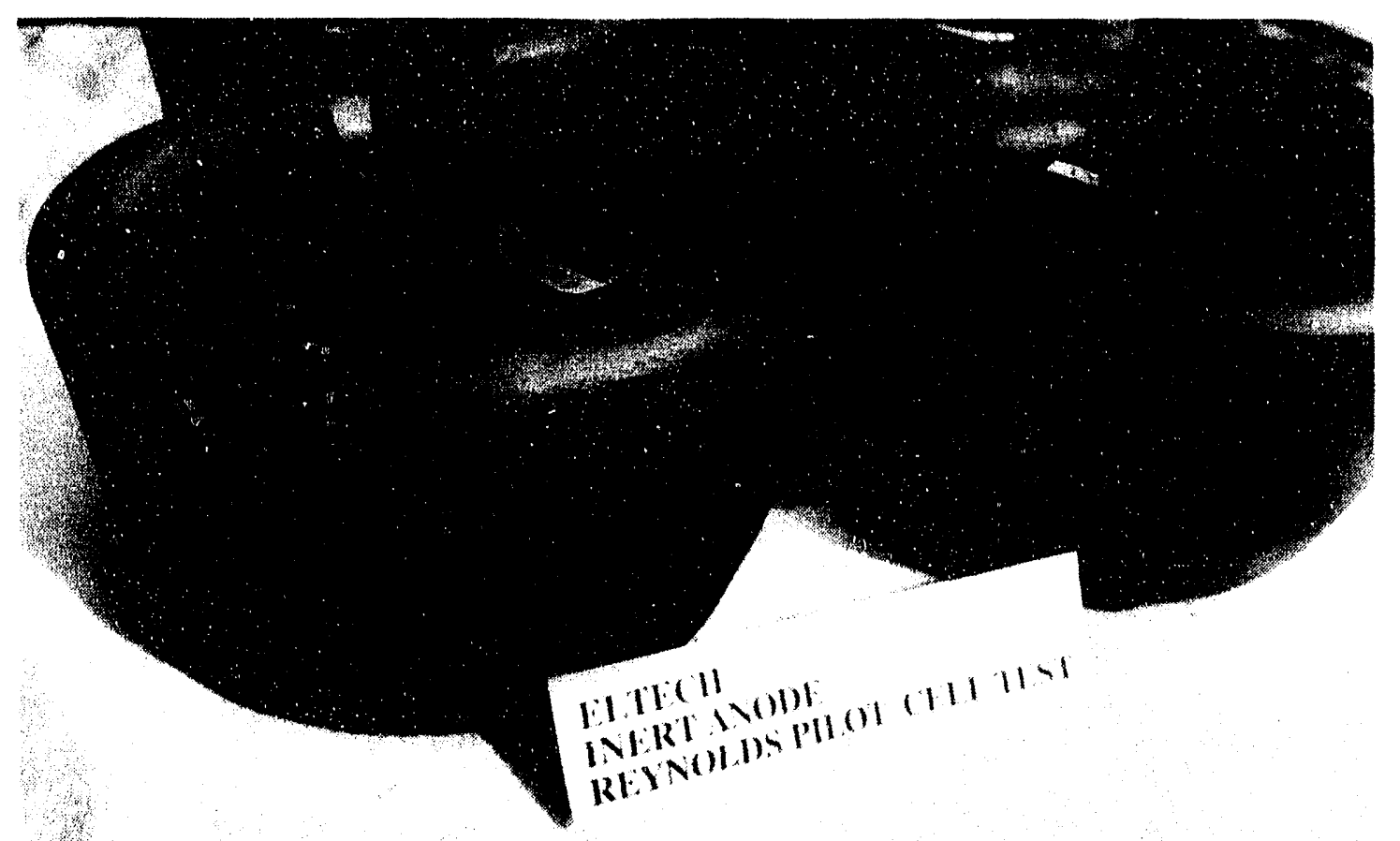

Figure 41. Untested Anodes. 


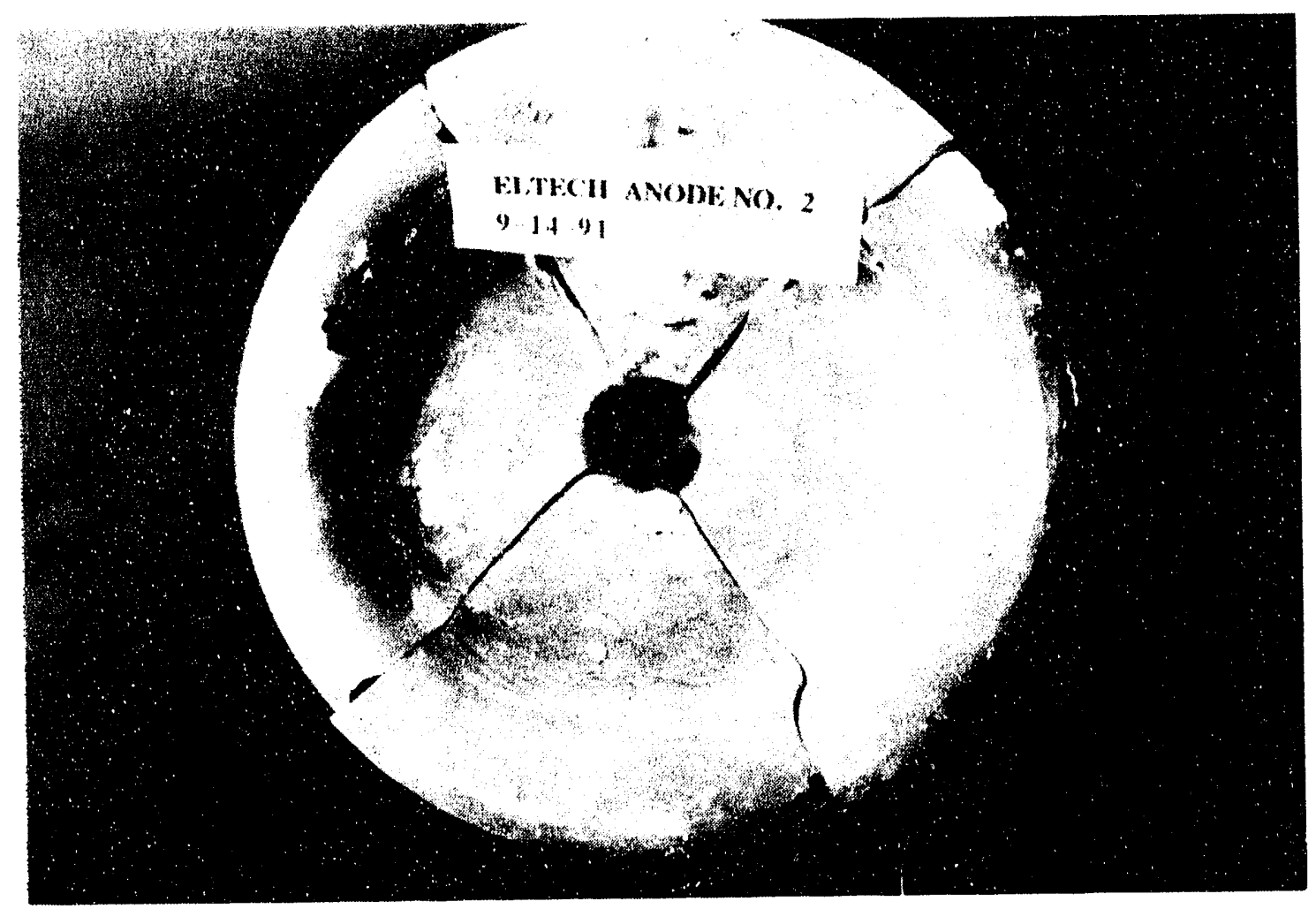

Figure 42. Anode B1 after removal from the test cell. Cracks radiate from the center.

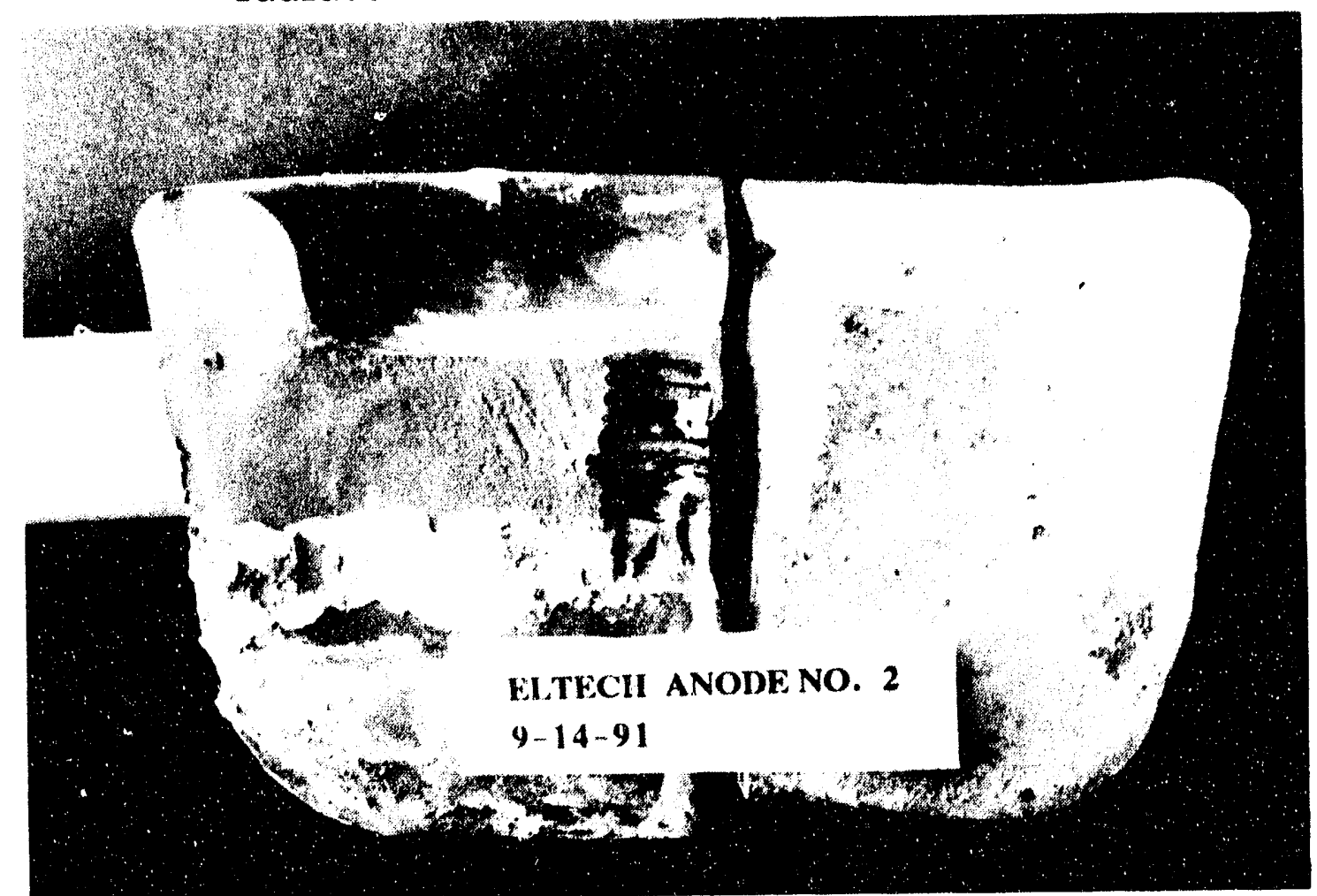

Figure 43. Cross-section of Anode B1 along a crack surface. 


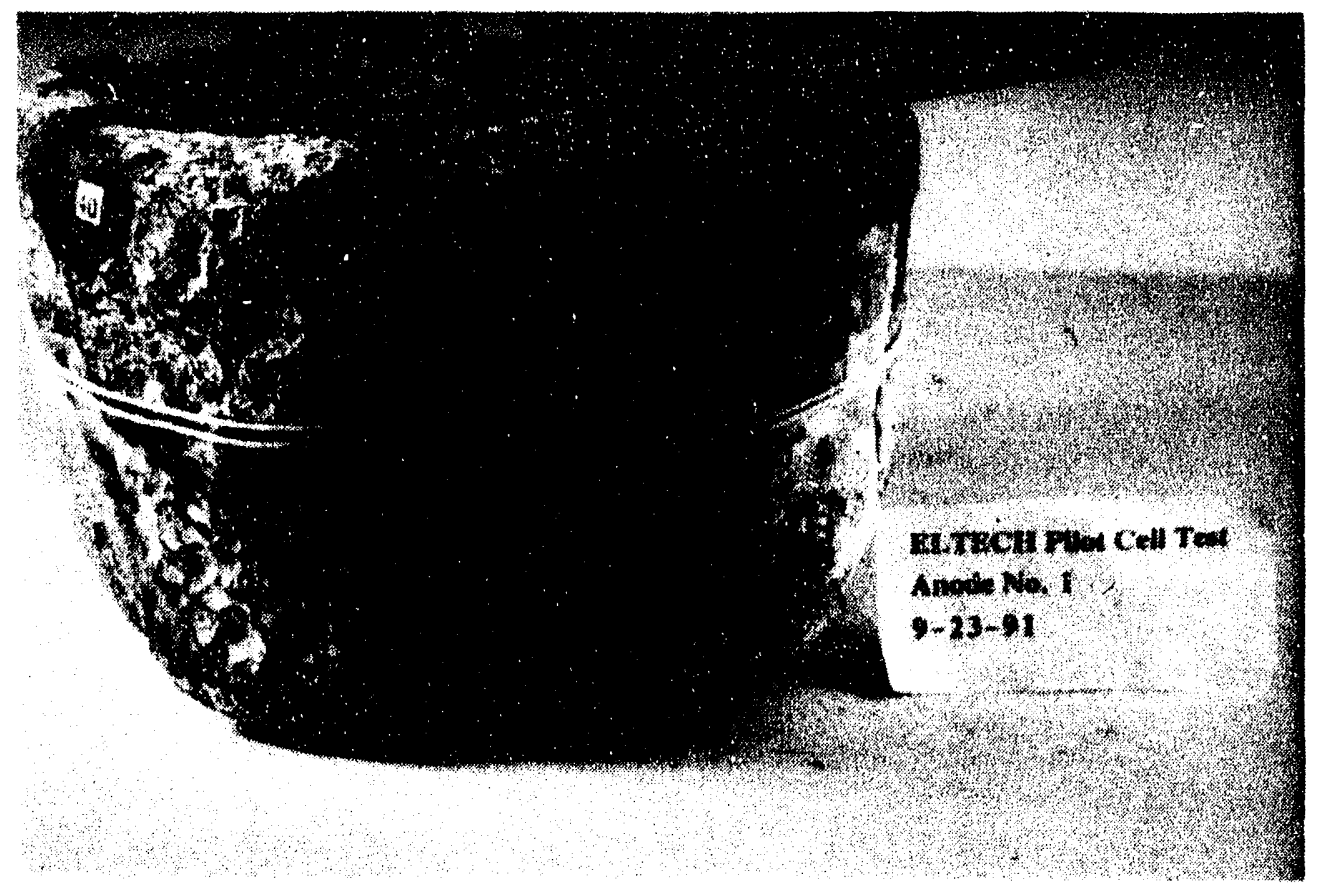

Figure 44. The west side of Anode AI (which was next to the Carbon Anode) shows a dip in the Cerox coating height and also has a pitted corroded region on that side.

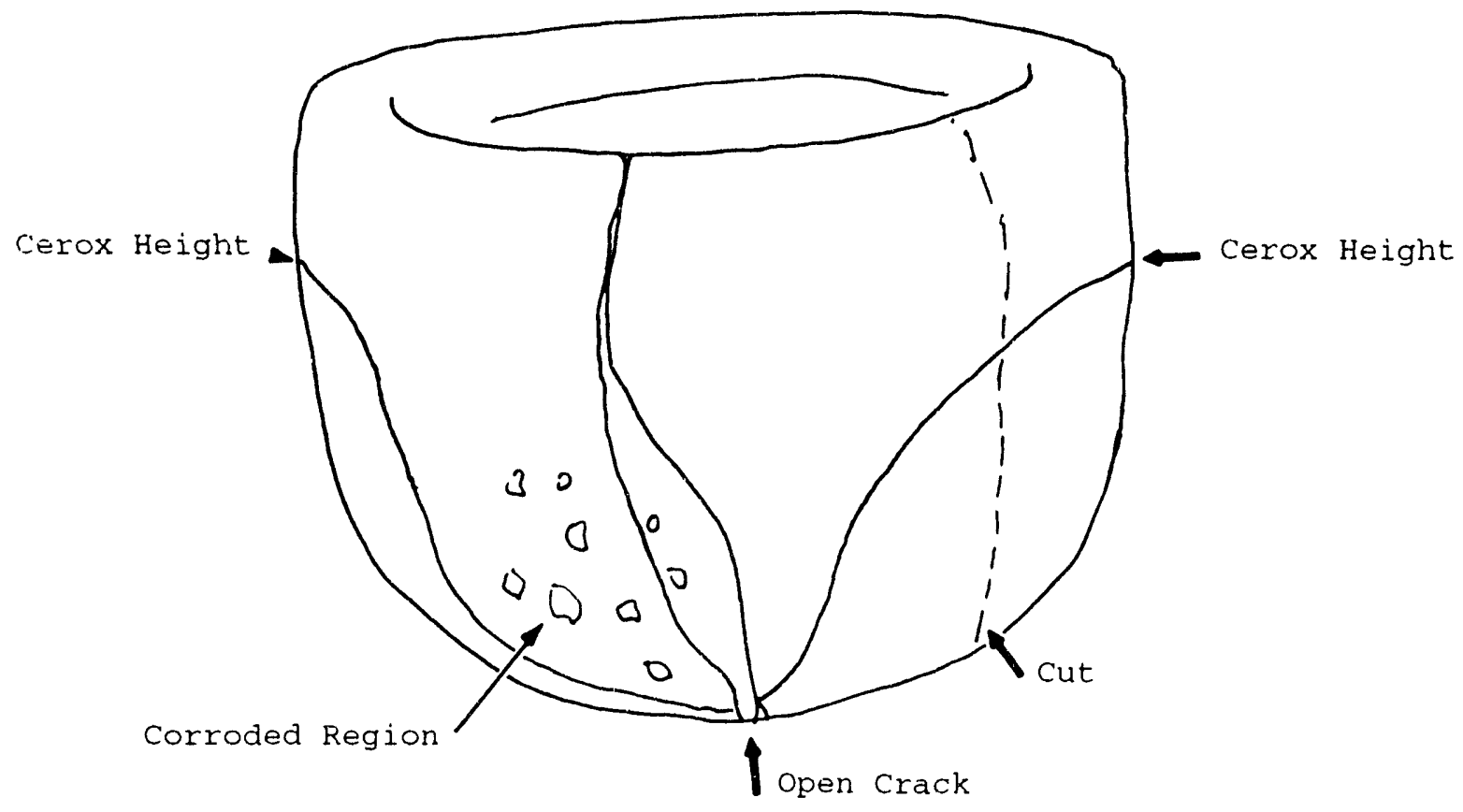

(Sketch of Figure 44 ) 


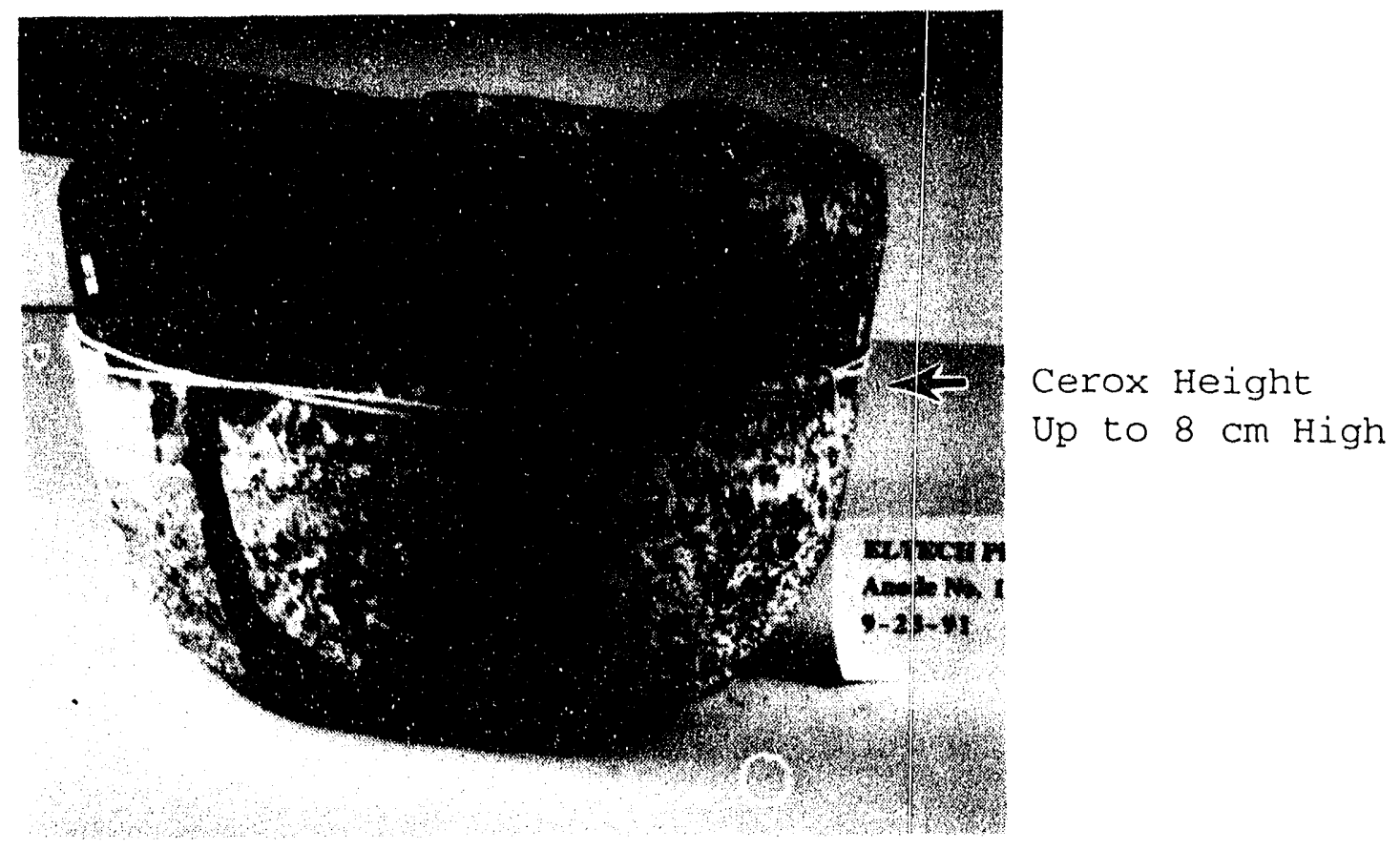

Figure 45. A thick Cerox coating was present on the northeast side of Anode A1.

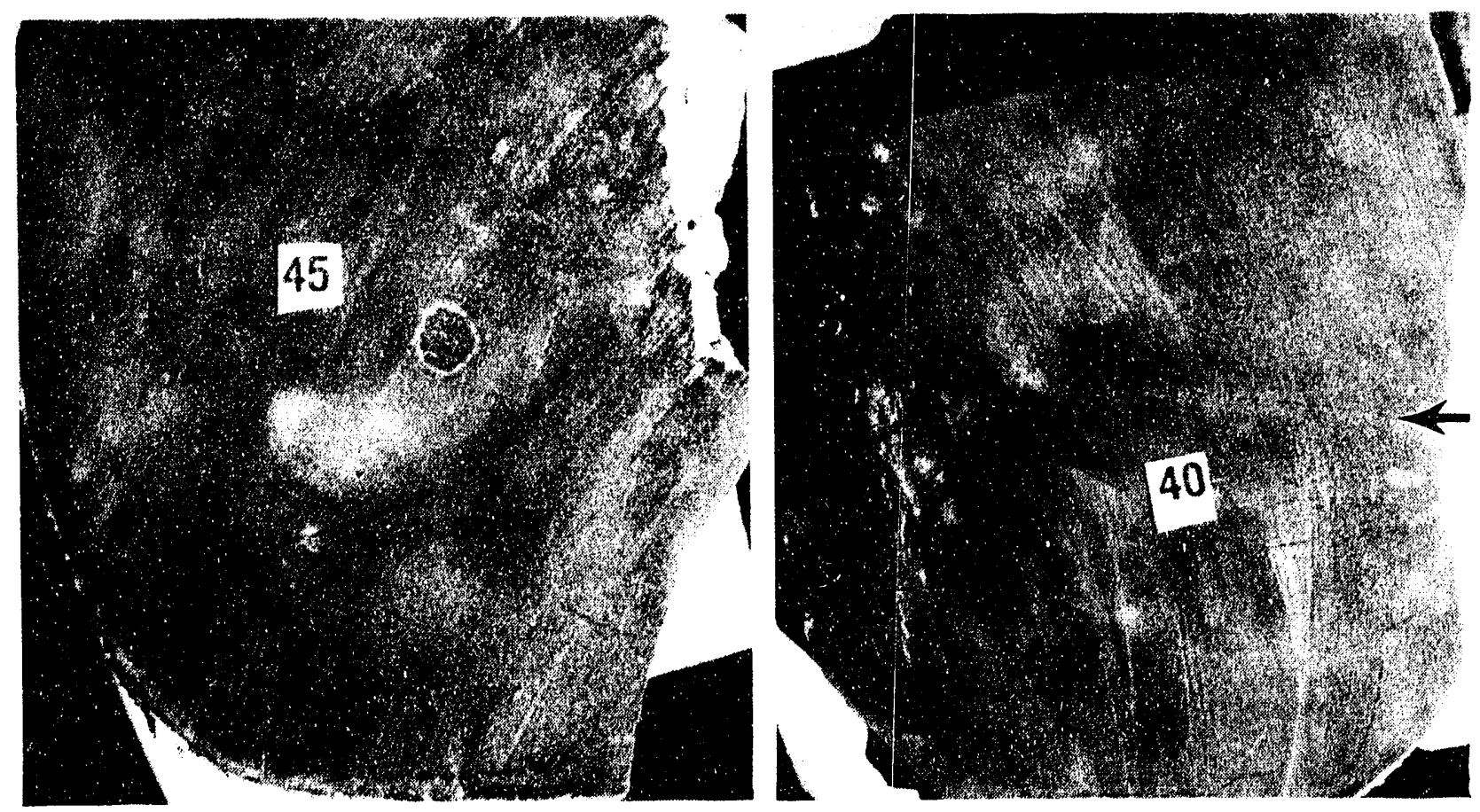

Figure 46. A cross-section of the southeast part of Anode A1 (left) is compared to the west side (right) to show the extent of the indentation (arrow) on the west side facing the carbon anode. 
region.

When the anode was cross sectioned a darker gray area (less Cu colored) was found on the bottom surface of the anode and a short distance up the sides. This region appeared devoid of $\mathrm{Cu}$ metal and was up to $0.5 \mathrm{~mm}$ thick on the side of the anode but up to $7 \mathrm{~mm}$ on the bottom of the anode.

Anode C1- 275 h, average current $=67$ A (Cross sectioned for microscopy).

Anode $\mathrm{Cl}$ was broken into five pieces when it was removed from the cell. There was no macroscopic dimensional change. The CEROX coating was $\sim 11 \mathrm{~cm}$ high on all sides of the anode (Figure 47). The thickness of the CEROX coating was fairly even and averaged 2 to 4 $\mathrm{mm}$ on the side and 1 to $3 \mathrm{~mm}$ thick on the bottom. As seen in Figure 47, the cracks sometimes appear to be wide open and missing chips of the cermet. In one of the open cracks the CEROX coating grew $3 \mathrm{~cm}$ deep into the crack. A gray oxidized layer up to $2 \mathrm{~mm}$ thick on the sides and $6 \mathrm{~mm}$ thick on the bottom and corners was present in the outer surface of the anode. A similar indentation in Al occurred in the side of the anode facing the carbon anode (west side). However, the CEROX coating did cover the indented region on $\mathrm{Cl}$.

Anode A2- 312 h, average current = $101 \mathrm{~A}$ (Cross sectioned for microscopy).

Anode A2 was cracked in three sections upon removal from the cell. Along the cracks there was some evidence of a $\mathrm{Cu}$ metal phase. The CEROX coating and the cryolite level along the side of the anode are at an angle, indicating the anode was probably hanging at an angle in the cell as shown in Figure 48. The CEROX coating angles from about a height of $3.7 \mathrm{~cm}$ to a height of $6.8 \mathrm{~cm}$ up the sides of the anode.

On the west side facing the carbon anode, there was an indentation in the cermet anode as shown in Figure 49 but a CEROX coating was still present. On the south side of the anode, adjacent to anode B2, the CEROX coating dipped down to a height of $1.8 \mathrm{~cm}$ as shown in Figure 49. The coating was thickest on the northeast side of the anode but averaged $\sim 1 \mathrm{~mm}$ thick everywhere it was present. The gray oxidized layer on the bottom of the cermet was 0.6 to $3 \mathrm{~mm}$ thick and was 0.3 to $1.4 \mathrm{~mm}$ thick on the side of the anode.

Anode B2- 312 h, average current $=103 \mathrm{~A}$

Anode B2 was the best example of the absence of a CEROX coating on regions very close to another cermet anode. On the south and east sides (adjacent to cermet anodes C2 and E1), the CEROX coating was very thin to nonexistent as shown in Figure 50. On the west side, facing the carbon anode, a thin CEROX coating was present and no 


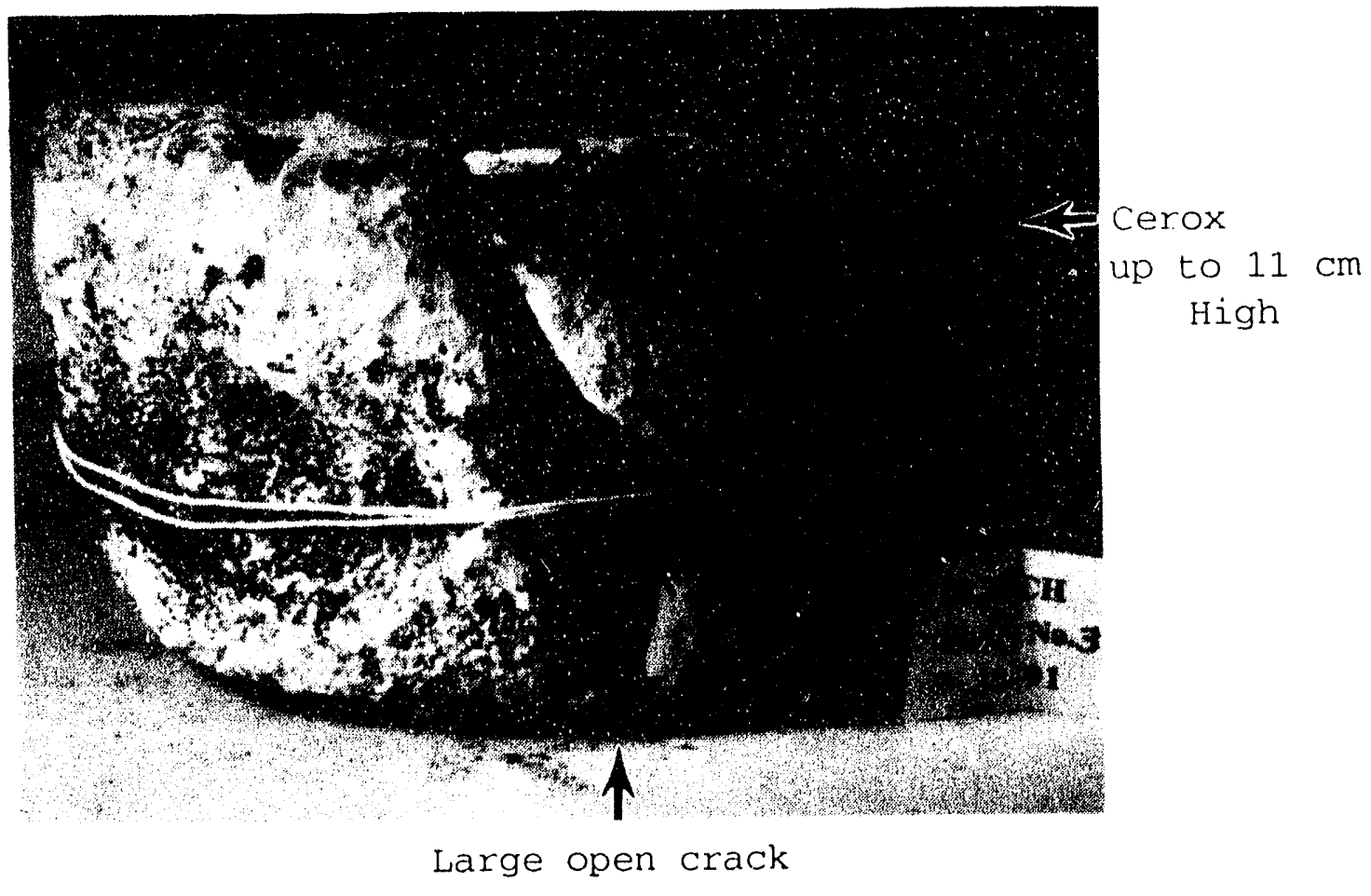

Figure 47. Anode C1 has a thick Cerox coating and a large open crack. 


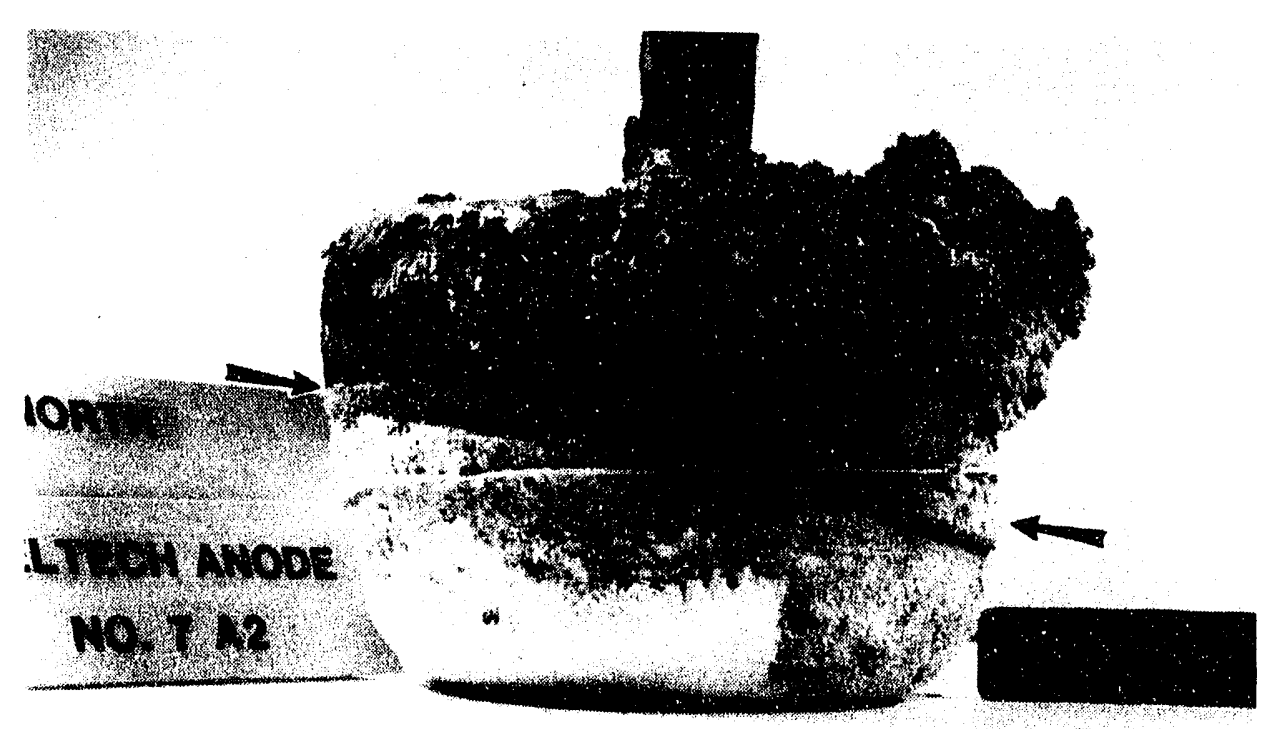

Figure 48. The Cerox coating and cryolite crust are at an angle on Anode A2, indicating the Anode was hanging at an angle during testing.

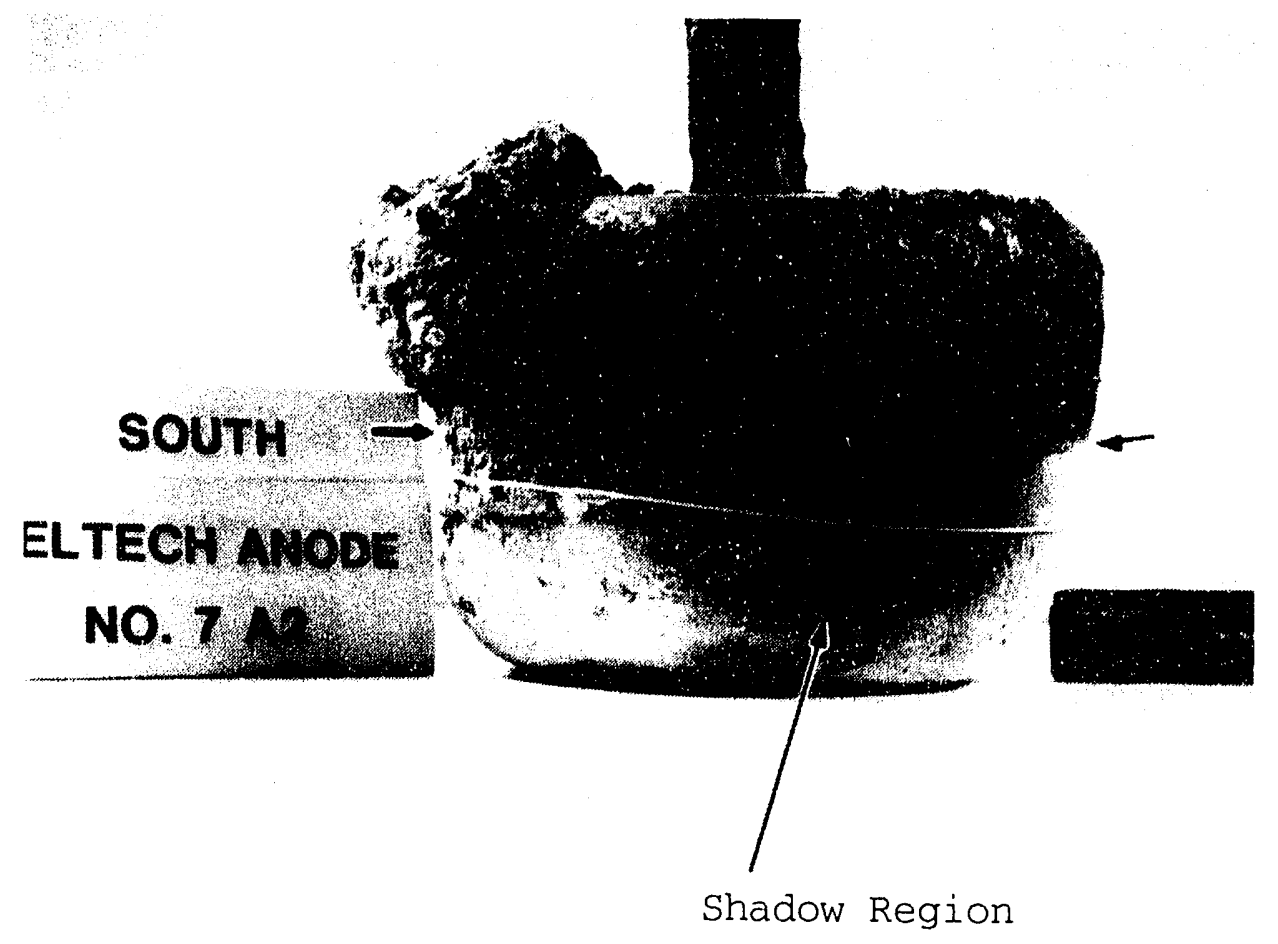

Figure 49. There is an indentation on the west side of Anode A2 (left arrow) facing the Carbon Anode. a "shadow region" where the cerox coating is thin to absent is present on the south side of A2 adjacent to Anode B2. 


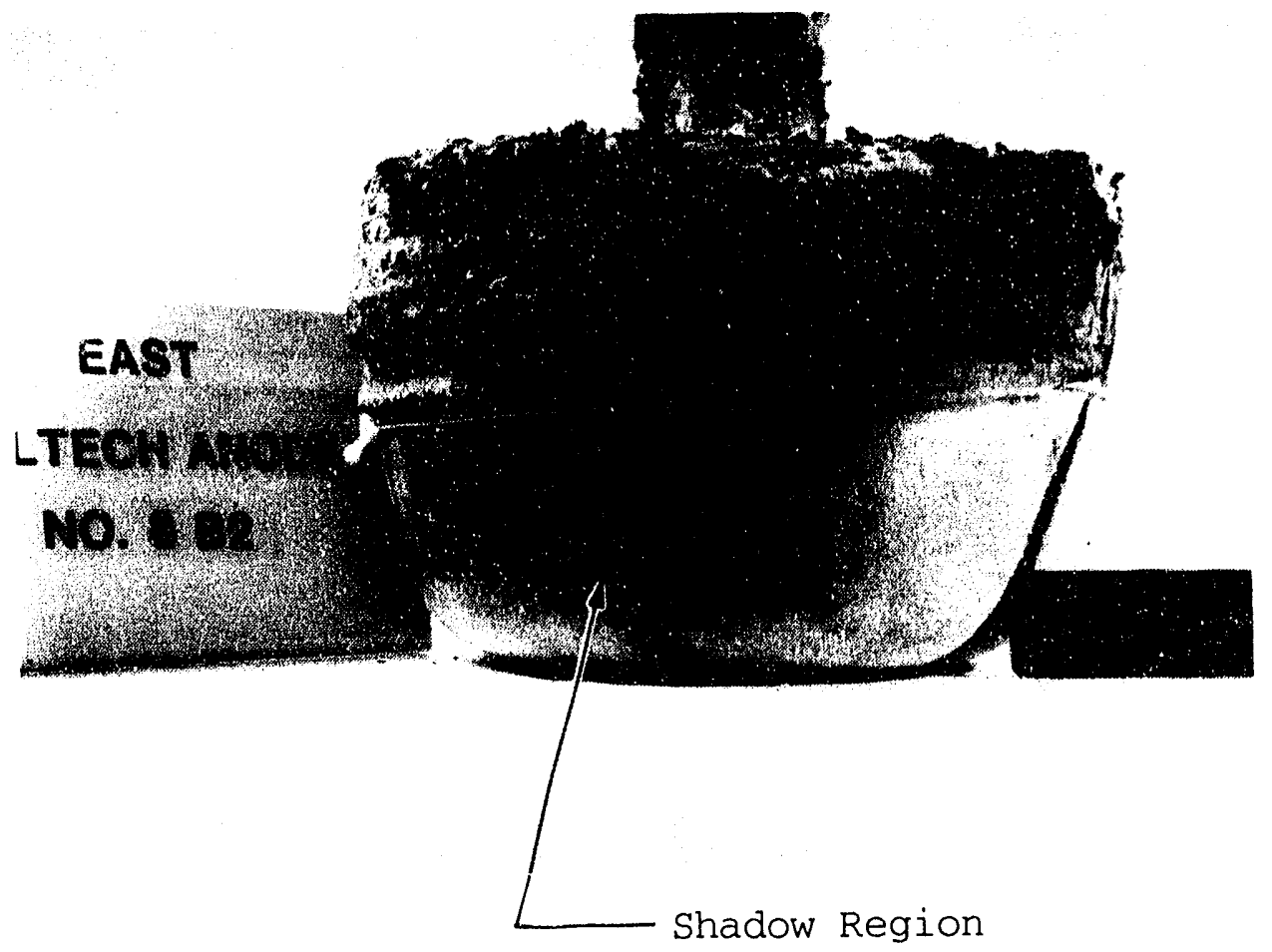

Figure 50. The east side of Anode B2 has a "shadow region" facing Anode E1, where the Cerox coating height dips down.

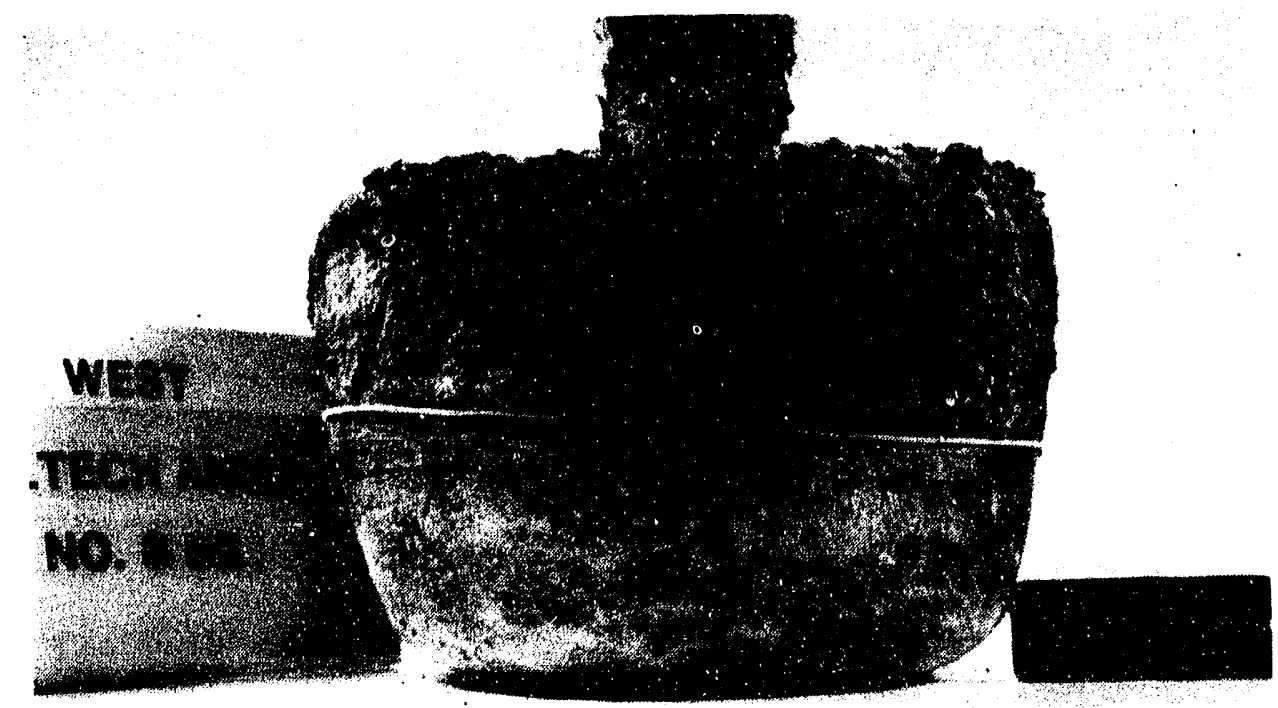

Figure 51. The west side of Anode B2 had a thin Cerox coating. A crack is evident on that side. 
indentation was found as shown in Figure 51. The CEROX coating on the bottom of the anode was $\sim 1 \mathrm{~mm}$ thick. Anode B2 had one main crack running nortin to south in the anode; the CEROX coating grew to a depth of $1.2 \mathrm{~cm}$ into this crack as shown in Figure 52. Along the crack surface, cu metal could be found.

Anode $\mathrm{C} 2-\sim 312 \mathrm{~h}$, average current $=75 \mathrm{~A}$

Anode C2 was cracked into multiple pieces (Figure 40 and 53). The CEROX coating was 1 to $3 \mathrm{~mm}$ thick on all sides and the bottom. Cryolite and some CEROX could be found a short distance into the cracks. The CEROX coating extended up the sides to a height of $8.5 \mathrm{~cm}$ on the southwest side and up to $4 \mathrm{~cm}$ on the northeast side, indicating this anode was also probably tilted slightly during testing. Some cryolite crust was found on the southwest side of the anode (near the sidewall) on top of the CEROX coating, indicating that a frozen crust may have been forming around that side of the anode. A thin layer of $\mathrm{Cu}$ metal was present along the crack surface.

Anodes D1, E1, E1- 614 h, average current $=40 \mathrm{~A}, 44 \mathrm{~A}, 53 \mathrm{~A}$, respectively (E1 cross sectioned for microscopy).

Anodes D1, E1, and F1 became frozen into the cryolite crust during the last half of the testing. The east side of the cell (opposite the carbon anode) became cool, leading to the crusting. When anodes D1 and F1 were removed from the cell, it appeared that each was missing part of the bottom of the anode as shown in Figure 54 and 55. The bottom may have been missing during testing or, more likely, may have broken off during removal from the cell. Parts of the CEROX coating were also missing. Each of the anodes was cracked into two to four main pieces.

Anode El was the most intact of the three anodes tested for $614 \mathrm{~h}$. The anode was cracked into two main halves. Half of the anode is shown in Eigure 56. Some $\mathrm{Cu}$ metal was found along the crack surface.

On the west side of the anode the CEROX coating was 4 to $5 \mathrm{~mm}$ thick while on the east side it was $>5 \mathrm{~mm}$ thick. On the east side the CEROX coating was extremely thick, porous, and mixed with frozen cryolite. A chunk of the CEROX coating and frozen cryolite broke off from the east side and is shown in Eigure 56. The gray oxidized region on the exterior surfaces of the anode is up to 2 to $10 \mathrm{~mm}$ thick on the side and 13 to $18 \mathrm{~mm}$ thich on the bottom of the anode.

\section{Inconel 601 Connector Rods}

A typical Inconel 601 connector rod is shown in Figure 57. The rods maintained their integrity during the testing, but often had 


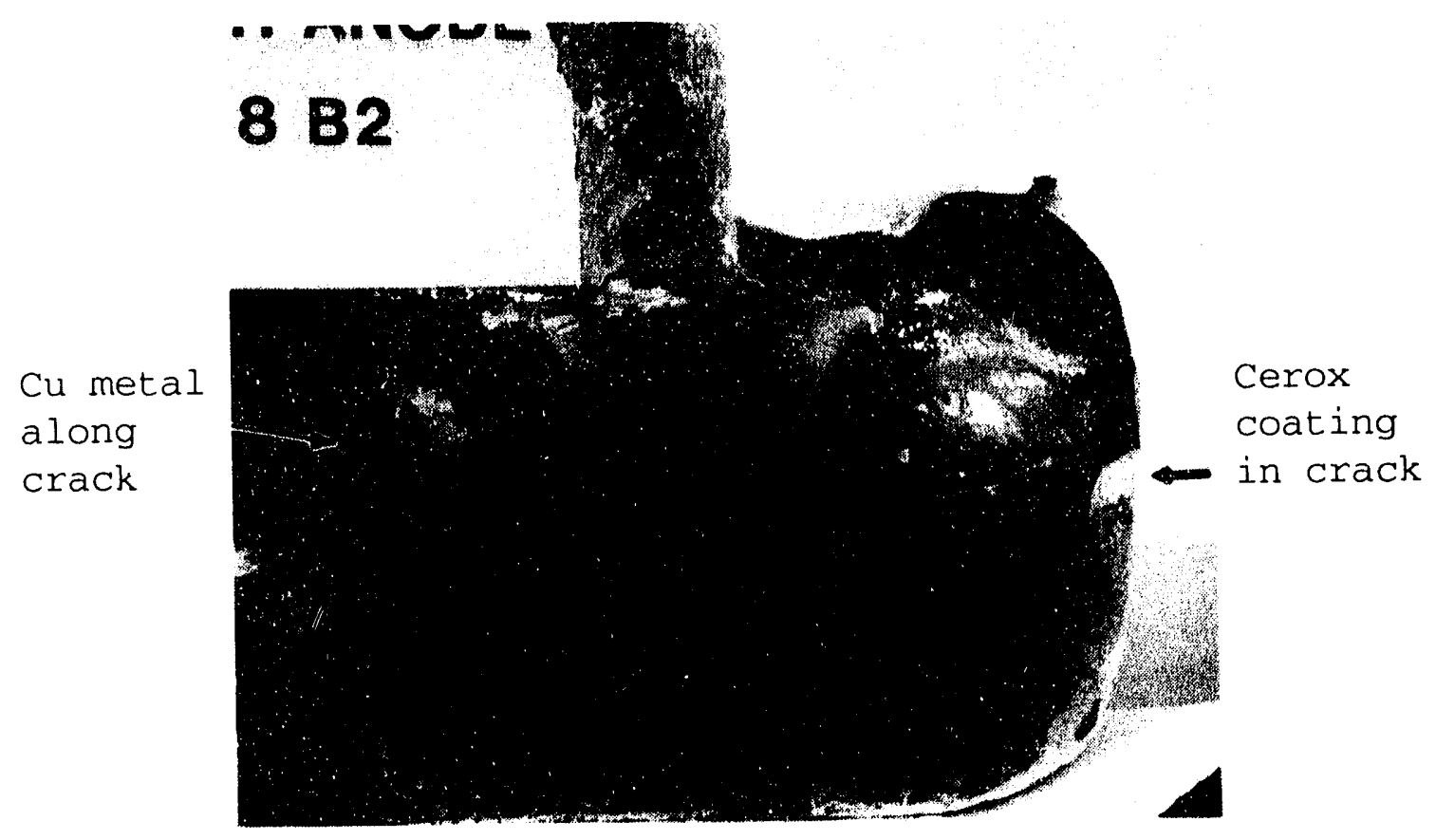

Figure 52. Cross-section of Anode B2 along a cracked surface. The cerox coating grows into the crack and $\mathrm{Cu}$ metal occurs along the crack surface.

\section{NORTH}

\section{ELTECH ANODE NO. $9 \mathrm{C}_{2}$}

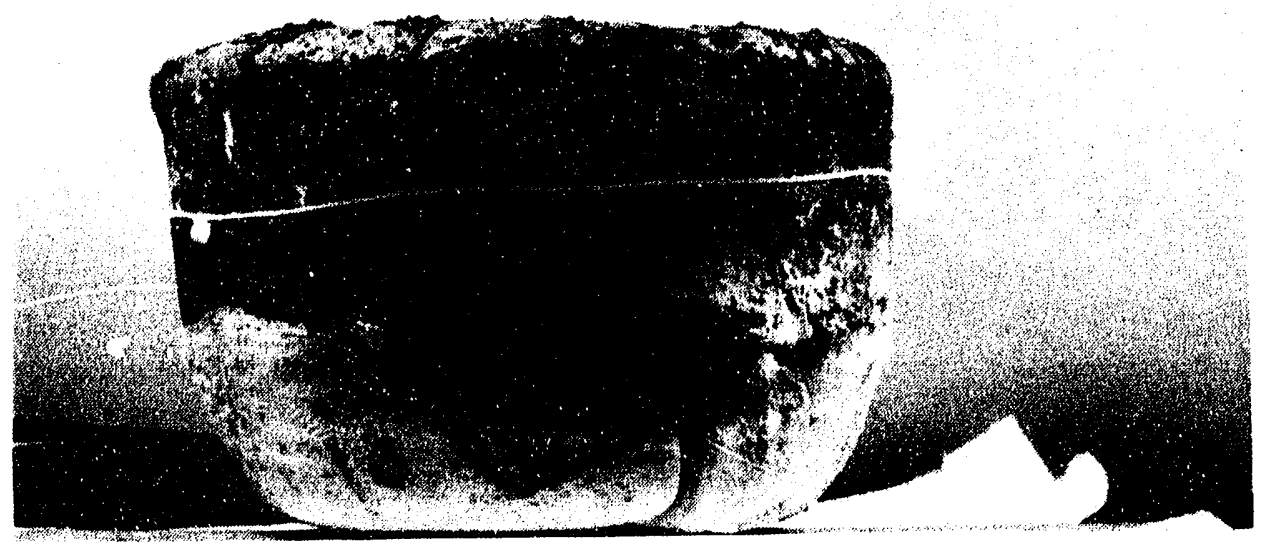

Figure 53. Anode $C 2$ is cracked into multiple pieces. The Cerox coating is present on all sides. 


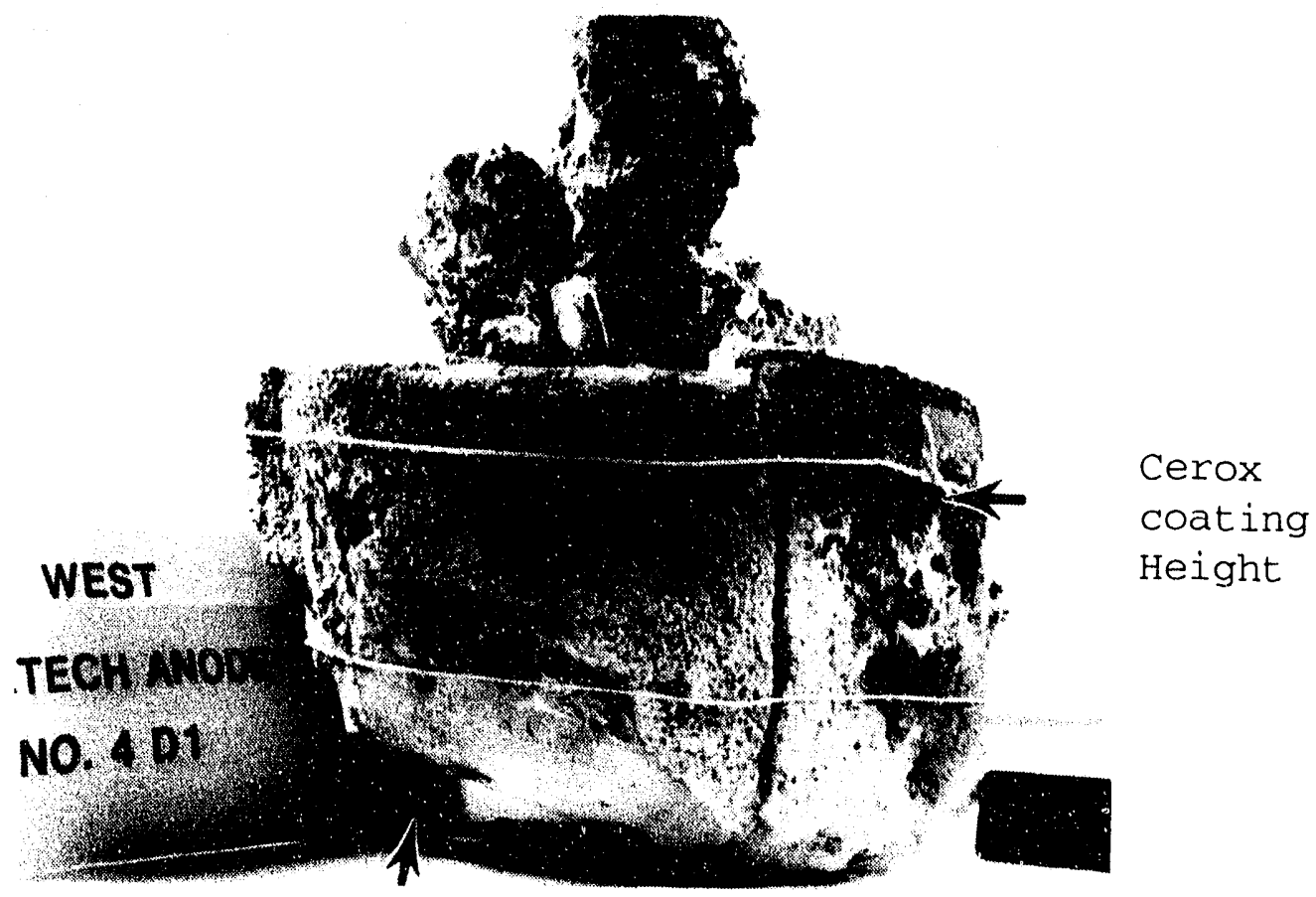

Figure 54. In Anode D1 the north and east sides and part of the bottom of the Anode is missing.

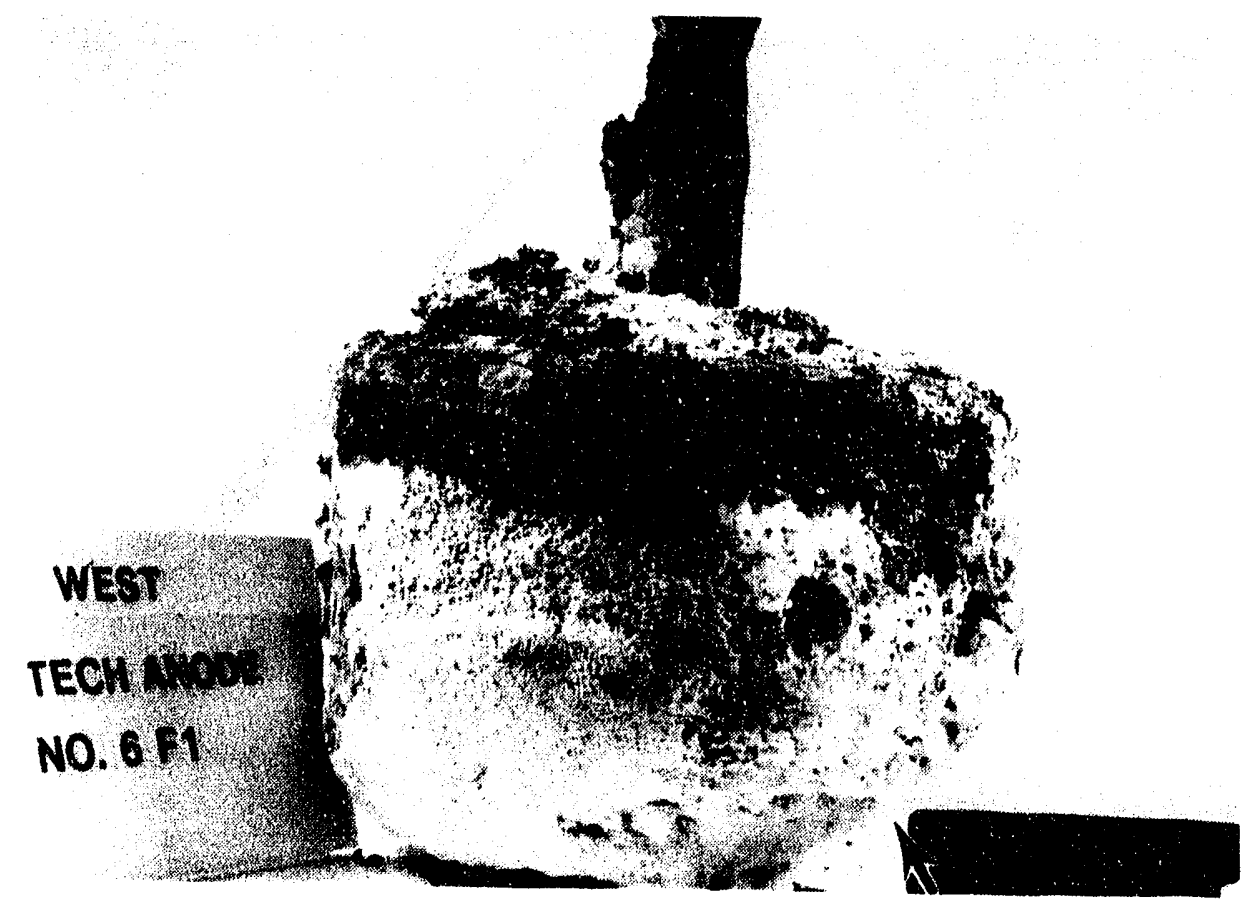

Figure 55. Anode F1. East side bottom of Anode is missing. 


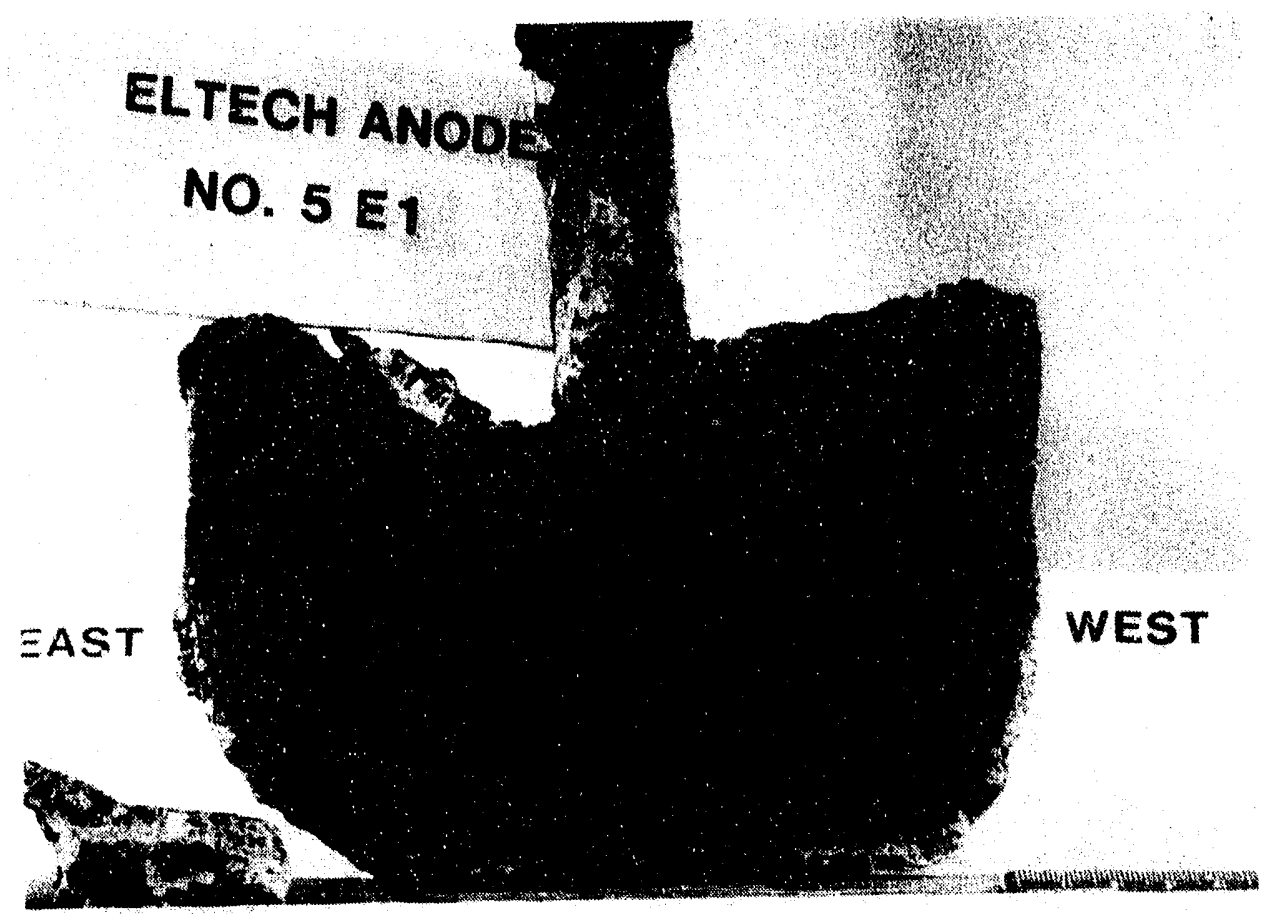

Figure 56. Cross-section of Anode E1 along a crack surface. On the east (left) side, a chunk of the thick cerox and cryolite has fallen off.

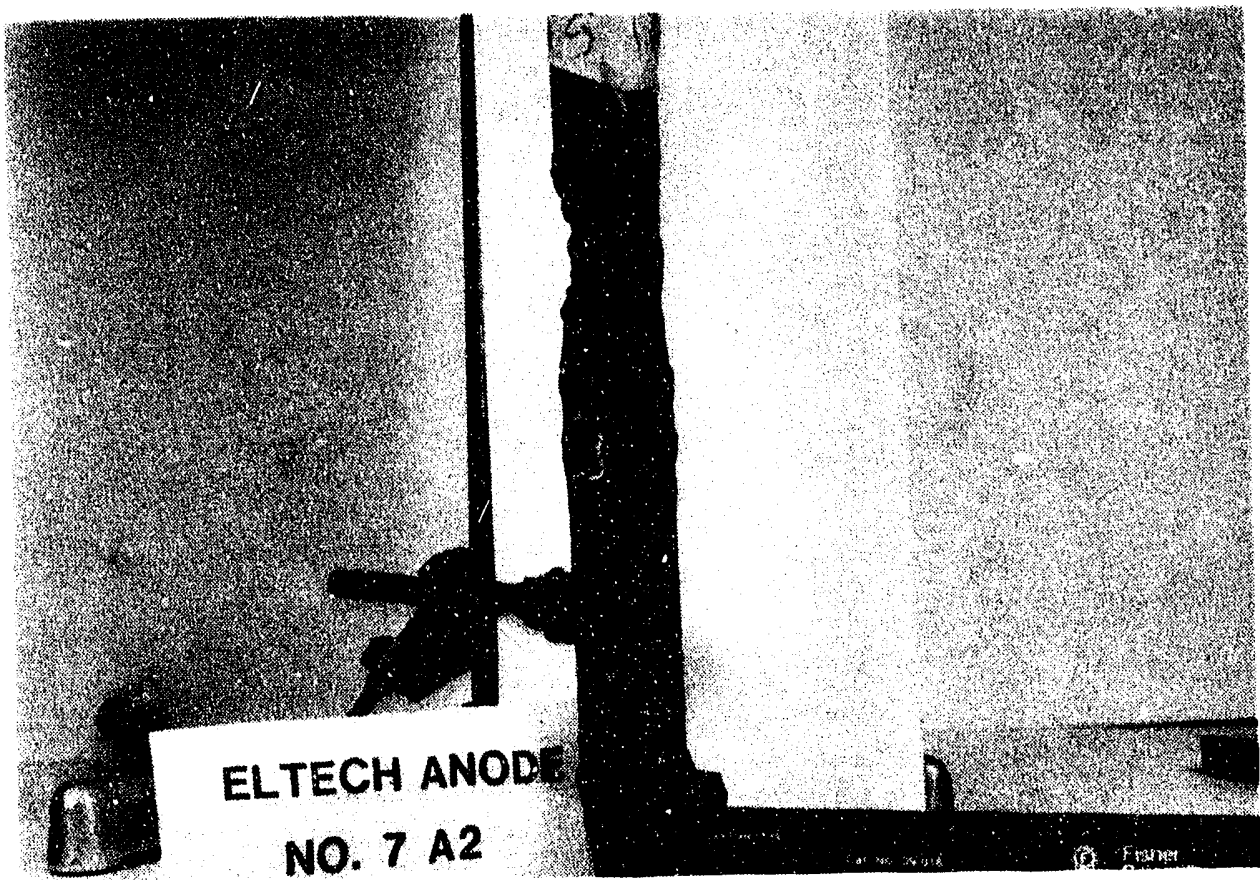

Figure 57. Typical Inconel 601 Anode connector rod after testing for $312 \mathrm{~h}$. 
in indentation in the rod at $\sim 4$ in. above the anode: where the alumina sleeve and alumina cement ended. In some cases there was $\sim 25 \%$ reduction in the diameter of the rod at this point. The microstructure of the rods will be described in subsection 4.3 .

\subsubsection{Summary of CEROX Coating and Oxidation Thickness}

The CEROX coating normally ranged from 0.5 to $3 \mathrm{~mm}$ thick, which was close to the targeted thickness of $\sim 1 \mathrm{~mm}$. It varied in thickness between anodes and around the sides of the individual anodes. The sides of the anodes that were adjacent to the carbon anode or another cermet were expected to carry less current than the sides that were not adjacent to another anode. The distribution of the CEROX coating appears to mimic this current distribution; where CD was very low the CEROX coating was very thin or non-existent, where $C D$ was higher, the CEROX coating was thicker.

Table 4 summarizes the Ce concentrations and $\mathrm{Ce}$ thicknesses when the tested anodes were removed from the cell. Anodes Al and C1 were operated under similar test conditions. However, when Al was removed from the cell the Ce concentration in the bath was around 0.31 wto and the CEROX coating averaged $\sim 1 \mathrm{~mm}$ thick. When $\mathrm{Cl}$ was removed the Ce concentration in the bath was $\sim 0.52 \%$ and the CEROX coating averaged $\sim 2$ to $3 \mathrm{~mm}$ thick. Anodes A2, B2, and C2 were coated with a CEROX coating under the same conditions as $\mathrm{Al}$ and $\mathrm{Cl}$, but after $72 \mathrm{~h}$ the $C D$ was increased and then BR was decreased from $\sim 1.5$ to 1.15 . Laboratory tests by ELTECH have shown that the CEROX coating is thinner in more acidic baths, and the 0.6 to 1.4 $\mathrm{mm}$ thick CEROX coating on A2, B2, and C2 support those tests. During much of the time those anodes were operated the $\mathrm{Ce}$ concentration was high and erratic, when the anodes were removed the concentration in the bath was $\sim 0.5$ wto (similar to C1) yet coatings were thinner. Anodes D1, E1, and F1 were also removed when the Ce concentration was 0.5 wto . Because of the cryolite crusting around the anodes, the cEROX coating was extremely thick $(>4 \mathrm{~mm})$, porous, and mixed with cryolite.

Table 5 summarizes the thickness of the gray oxidation layer on the exterior of the anodes. The oxidized zone will be discussed in more detail in Subsection 4.3. To summarize, the anode operated for the longest time period (E1) had the thickest oxidation layer, up to $18 \mathrm{~mm}$ thick. The amp-hours of that anode was similar to anode A2, which only had a $3 \mathrm{~mm}$ thick oxidation layer. Anodes A1 and $\mathrm{C} 1$ (operated under similar test conditions) had about the same amount of oxidation, even though anode $\mathrm{Cl}$ was operated for a longer period of time and passed more amp-hours. Therefore, oxidation thickness in this test does not seem to be directly relatable to hours of operation, average current, or amp-hours. The oxidation may have more to do with local conditions (in the vicinity of that particular anode) that may cause the oxygen to accumulate or disperse beneath an anode. For example, anode E1, which was 
Table 4. Ce concentration and CEROX coating thickness.

\begin{tabular}{|c|c|c|c|}
\hline \multirow[b]{2}{*}{ Anode } & \multicolumn{2}{|c|}{$\begin{array}{l}\text { Approximate ce concentrations } \\
\text { when the anodes were removed }\end{array}$} & \multirow{2}{*}{$\begin{array}{l}\text { Average } \\
\text { CEROX coating } \\
\text { Thickness (mm) } \\
\end{array}$} \\
\hline & $C e_{\text {bath }}\left(w t^{8}\right)$ & Ce metal (wt 8 ) & \\
\hline A1 & 0.31 & 2.27 & 0.5 to 1.5 \\
\hline $\mathrm{Cl}$ & 0.52 & 3.88 & 2 to $3 \mathrm{~mm}$ \\
\hline E1 & 0.50 & 2.92 & $\begin{array}{l}4 \text { to } 5 \text { on } W \text { side } \\
10 \text { on } E \text {, frozen } \\
\text { side }\end{array}$ \\
\hline $\mathrm{A} 2, \mathrm{~B} 2, \mathrm{C} 2$ & 0.50 & 2.92 & 0.5 to $1.4 \mathrm{~mm}$ \\
\hline
\end{tabular}

Table 5. Oxidation thickness.

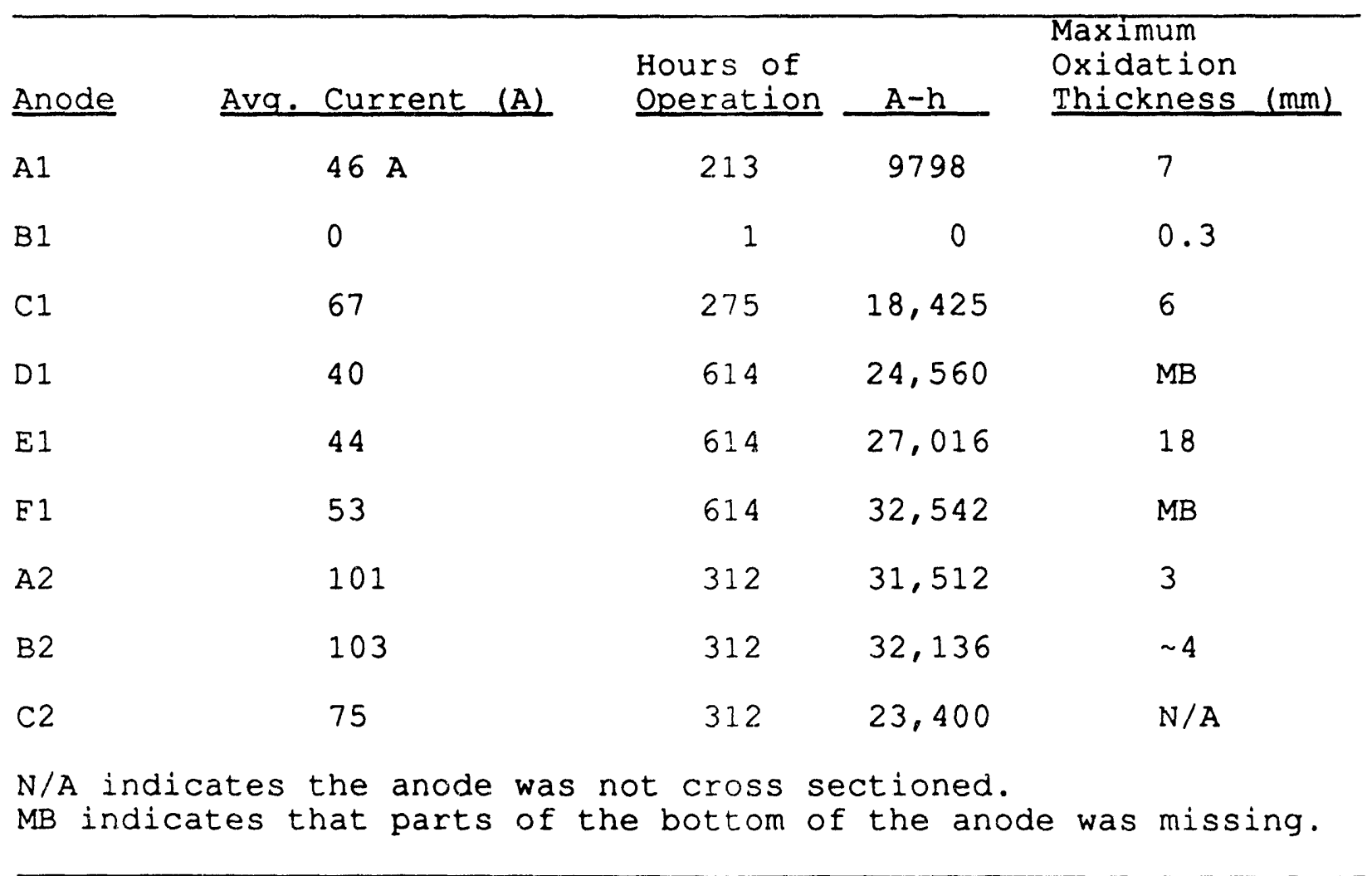


partially frozen with the cryolite had the highest oxidation. Anode A2 operating under a higher $C D$ and lower BR than A1 or C1 had a thin oxidation layer.

PNL also observed oxidation thicknesses of $\sim 1$ to $13 \mathrm{~mm}$ thick in their anodes tested under their standard conditions.7 Their conclusions differ in that they can detect a relationship between the oxidation thickness and the current times time $(A-h)$. They estimated that thickness $(\mathrm{mm})=5 \mathrm{E}-4 \mathrm{x}$ (Current times Time). They also concluded that low alumina content and high $C D$ led to higher oxidation (reaction) layer thicknesses.

\subsection{Microscopic Examination of Tested Anodes}

An untested anode and anodes A1, B1, C1, E1, and A2 were chosen for cross sectioning and microscopic examination. The anodes were examined with an optical microscope (Nikon optiphot) and with a Hitachi S-2300 (both secondary and backscatter imaging) Scanning Electron Microscope (SEM). Phases were analyzed by Energy Dispersive $x$-ray spectroscopy (EDS) analysis with a Noran series II x-ray Analyzer. Phase composition was calculated with the Noran SQ standardless quantitative analysis program. The presence of light elements (i.e., $O, E, C$ ) could be detected with an ultra thin window detector, but only cations could be recalculated for phase composition; the anion $\frac{o}{8}$ in the phase was assumed.

\subsubsection{Microscopic Evaluation of the CEROX Coating}

The density and thickness of the CEROX coating varied from anode to anode and around the sides of the anodes. In Figures 58 through 67 the CEROX coating is labeled with a $\mathrm{C}$, and the cermet substrate is labeled with an S.

On the side of anode Al facing the carbon anode, the CEROX coating was thin to non-existent. Figure 58 shows the beginning of the CEROX coating on the side facing the carbon anode. The coating is $\sim 4.5 \mathrm{~cm}$ up the side of the anode and is $\sim 70 \mu \mathrm{m}$ thick. The coating appears fairly continuous and even in thickness at that point. On the northeast side of anode Al $(\sim 7 \mathrm{~cm}$ up the side), where the CEROX coating was thickest, the coating is up to $3 \mathrm{~cm}$ thick (Eigure 59) and is dense. On both sides, the interface between the CEROX and the substrate appears mostly porefree. On the northeast section of the anode near the curved edge on the bottom, the CEROX coating (Eigure 60) appears more irregular in thickness, less dense, and is generally thinner (up to $\sim 1.3 \mathrm{~mm}$ thick). The interface between the substrate and the CEROX coating is still mostly pore-free, but is much rougher than in the other cases.

Anode $\mathrm{C} 1$ had a more even and thicker CEROX coating than $\mathrm{A} 1$. The CEROX coating on the bottom of the anode near the west side, is shown in Figure 61. The coating is continuous up to $\sim 2.25 \mathrm{~mm}$ in thickness, with a fairly even thickness. Some elongated pores are 


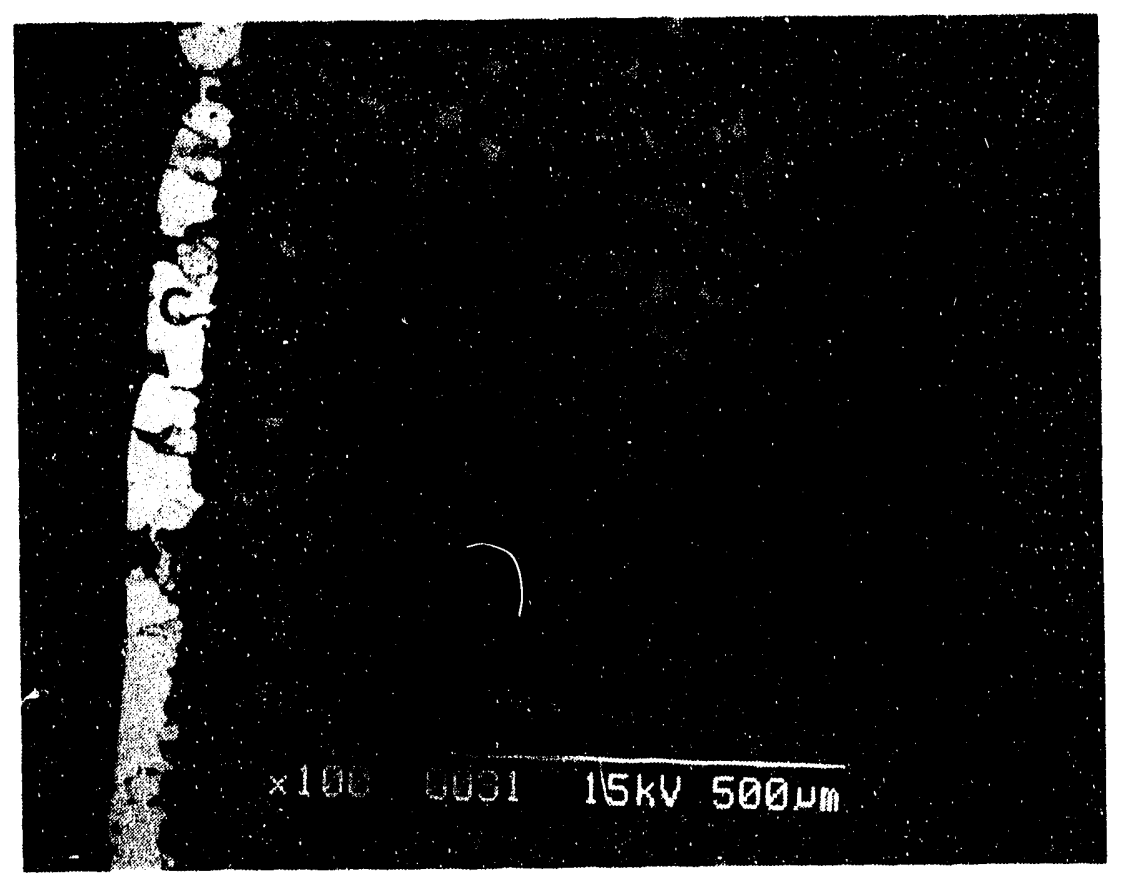

Figure 58. A thin Cerox Coating occurs on the side Al facing the Carbon Anode. 


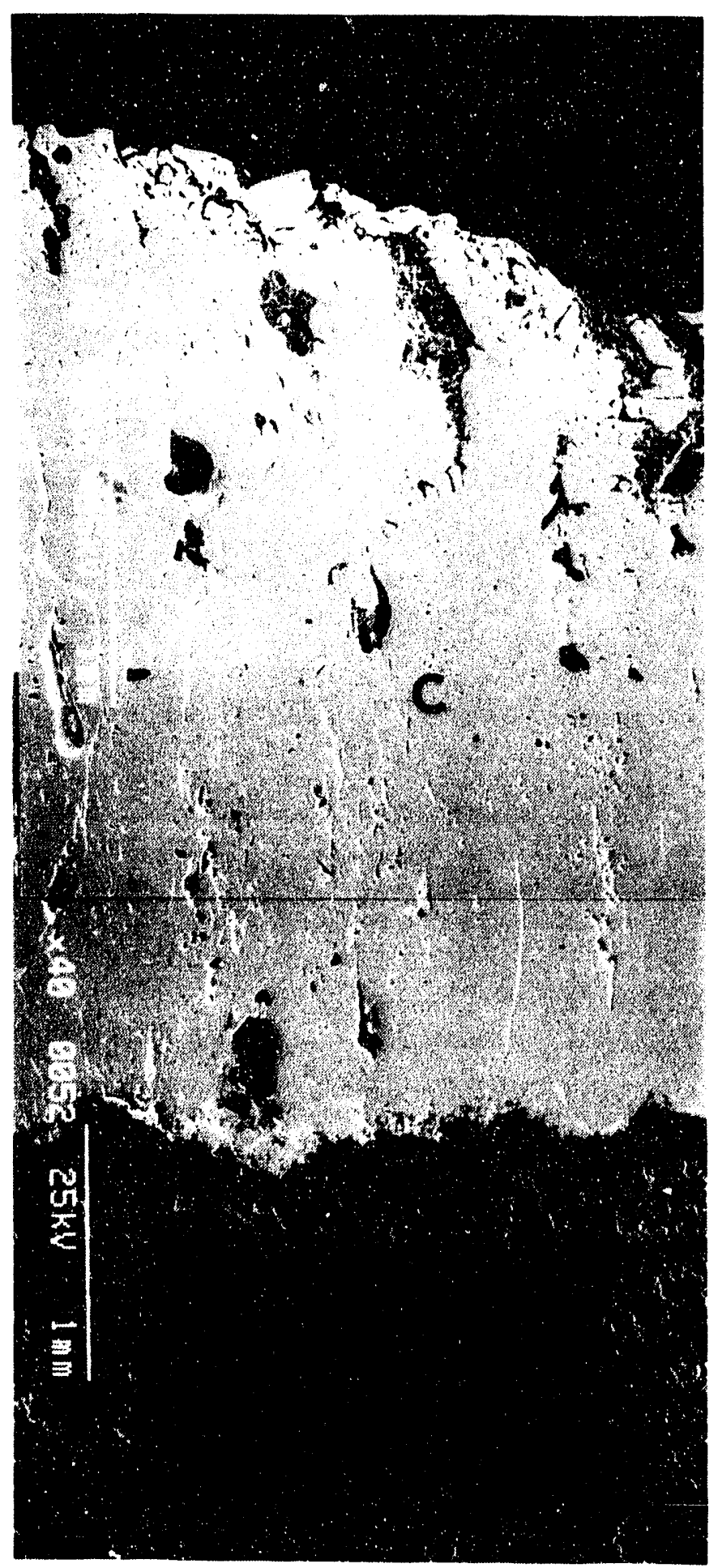

Figure 59. Cerox coating on the northeast side of anode A1. 


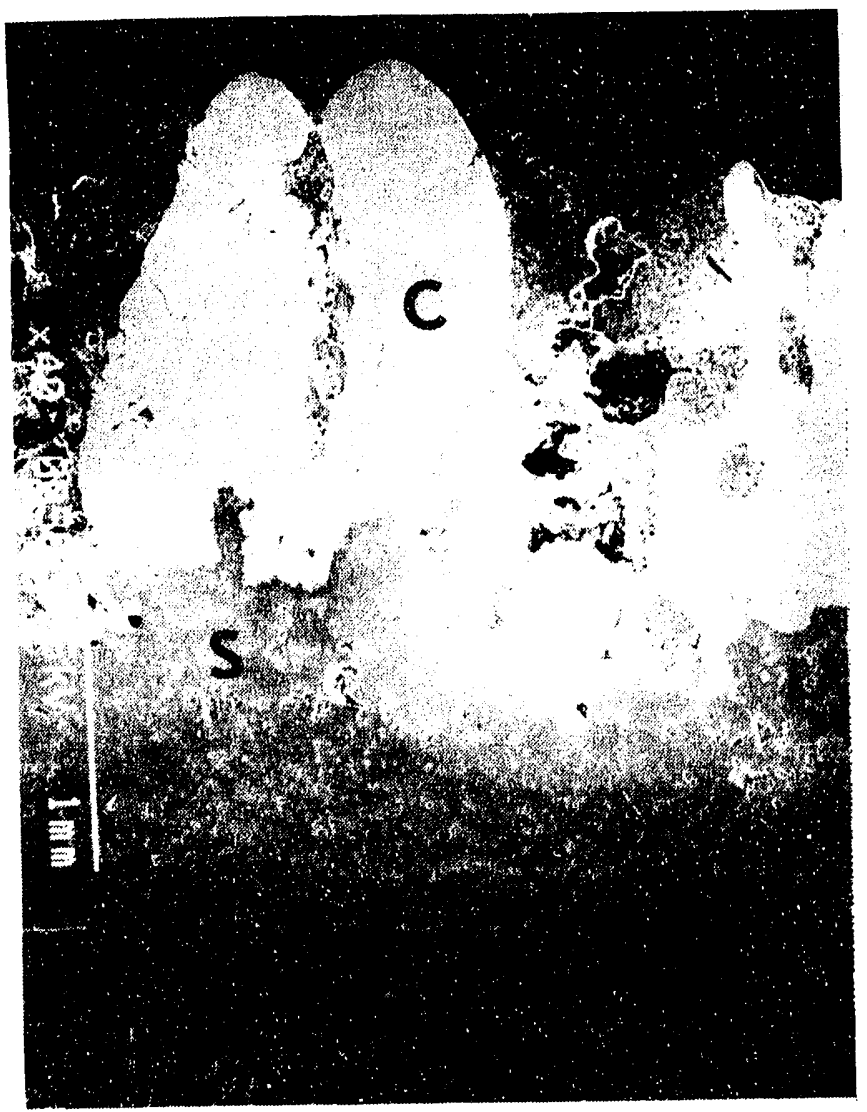

Figure 60. The bottom corner of Anode A1 has a thinner coating than the sides. The coating is also of a more irregular thickness. 


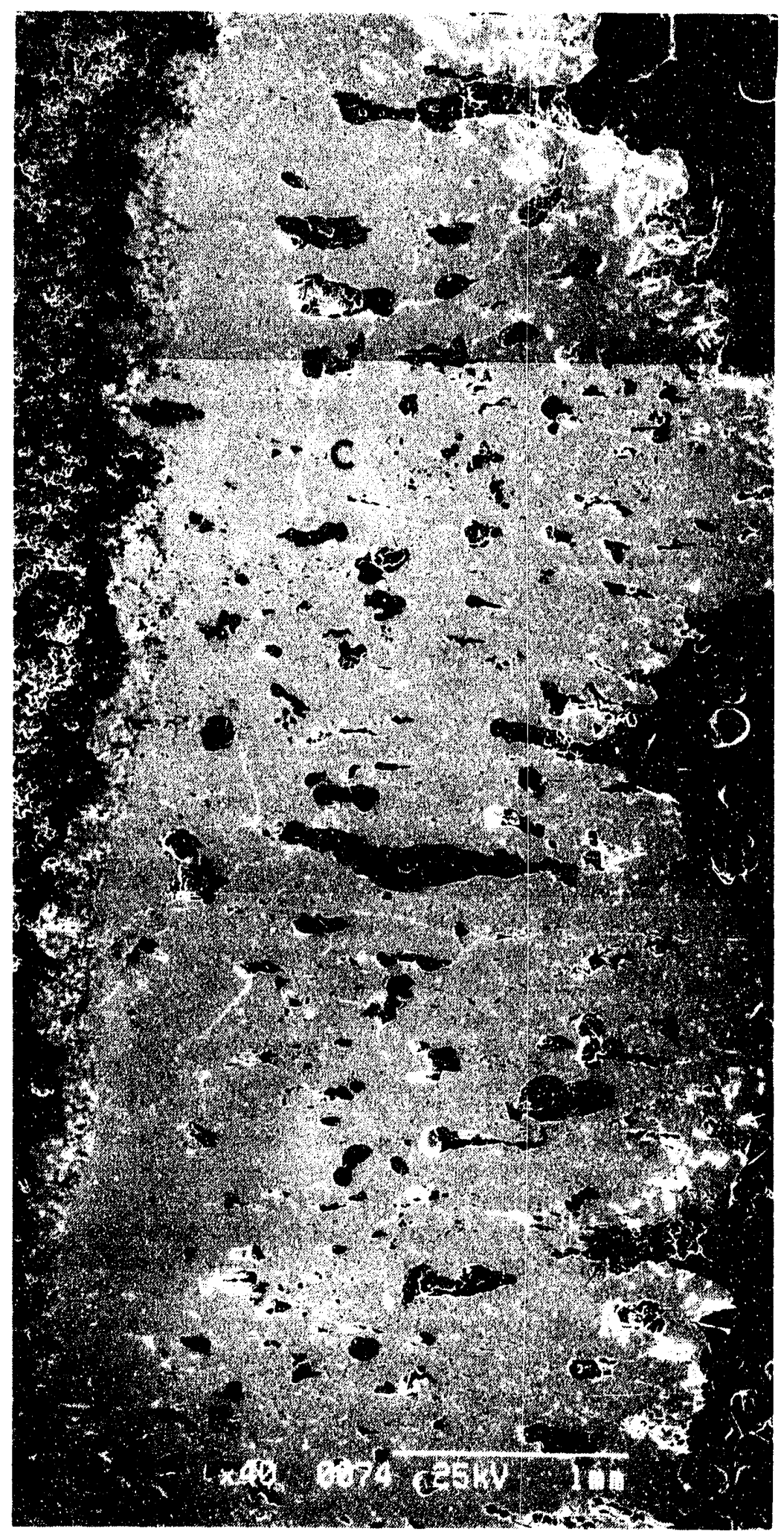

Figure 61. The Cerox coating on the bottom of Anode $\mathrm{Cl}$ is thick and continuous. 
present, but do not appear to penetrate to the substrate. The pores often contain cryolite. The CEROX coating on the northeast side of the anode $\sim 7 \mathrm{~cm}$ up the side is shown in Figure 62. The CEROX coating is $\sim 3 \mathrm{~mm}$ thick, dense, with a smoother, pore-free interface with the substrate. A clump of Al metal (A in Figure 62) is present at the edge of the CEROX coating. The elongated grains within the $\mathrm{Al}$ metal appear to be intermetallics containing $\mathrm{Cu}, \mathrm{Fe}$, and $\mathrm{Ni}$ in addition to $\mathrm{Al}$.

Another region of the CEROX coating on anode Cl (from the northeast bottom corner) is shown in Eigure 63. In that region the CEROX coating is also $\sim 3 \mathrm{~mm}$ thick, but contains some larger pores in the exterior half of the coating. These pores do not appear to penetrate to the substrate. Again, some of the pores contain cryolite.

As described in Subsection 4.2.1, anode E1 experienced different conditions on the east and west sides of the anode. On the west side ( $\sim 3 \mathrm{~cm}$ up from the bottom), where it appeared that current was still flowing at the end of the test period, the CEROX coating (Figure 64) appears similar to that in Eigure 63 (anode C1). The coating is 3 to $3.75 \mathrm{~mm}$ in thickness, with some elongated cryolitefilled pores, particularly in the exterior half of the coating.

On the east side of the anode (where the anode was frozen into the cryolite) the character of the CEROX coating is completely different. The CEROX coating is so thick $(\sim 8.5 \mathrm{~mm})$, that it is shown in Figures 65 (a) and (b). The inner half of the coating [Figure 65 (a)] shows a good, fairly pore-free interface between the CEROX coating and the substrate. The CEROX coating itself has large, roundish pores within it. In the exterior part of the coating [Figure 65 (b)], the coating appears less dense, and many "sawtooth" patterns appear to be present. In addition, numerous small pores occur, which appear to outline $\mathrm{Ce}(O, F)_{2}$ grains within the coating. It is not known if this pattern is from the growth of the coating or from the dissolution of the CEROX coating at some time after it had been deposited.

Anode A2 operated during the last half of testing. The CEROX coating was deposited under the same conditions as those for Al and C1. However, after $\sim 74 \mathrm{~h}$ of testing the $\mathrm{CD}$ was increased, and after another $\sim 160 \mathrm{~h}$ of testing the BR was decreased to $\sim 1.15$ for the remaining testing. During the testing of $\mathrm{A} 2$ the temperature and $\mathrm{Ce}$ concentrations fluctuated and averaged higher than during the first half of the test. The CEROX coating as shown in Figure 66 is much different in character on A2 then that on A1 and $\mathrm{C} 1$. The outer surface of the coating is much rougher, and it appears that the coating is less continuous. The coating is thinner, 1.5 $\mathrm{mm}$ in thickness, and contains some of the "sawtooth" or the porous pattern noted in the exterior portion of the CEROX coating on anode E1. A close-up of this pattern is shown in Figure 67. Because this pattern was observed in both anodes examined that were in the 


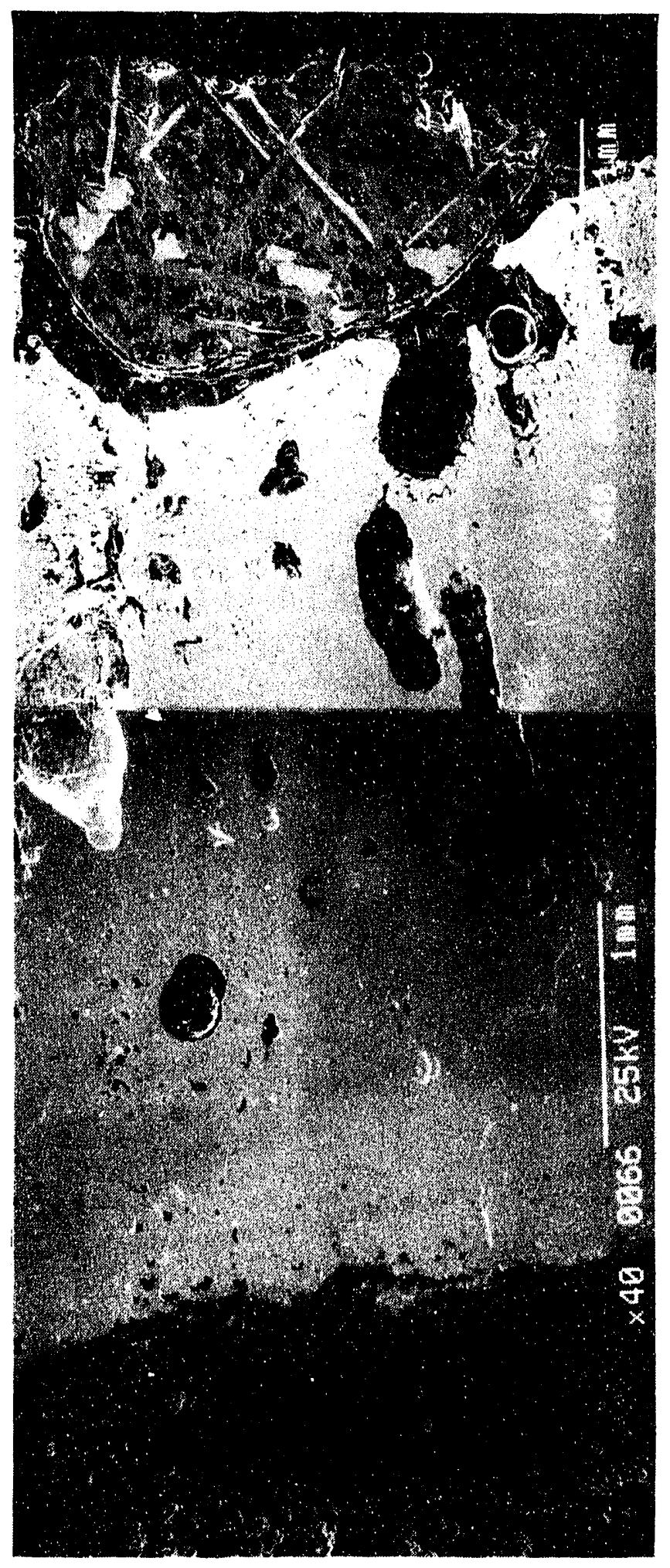

Figure 62. The cerox coating on the northeast side of Anode C1 is up to $3 \mathrm{~mm}$ thick. 


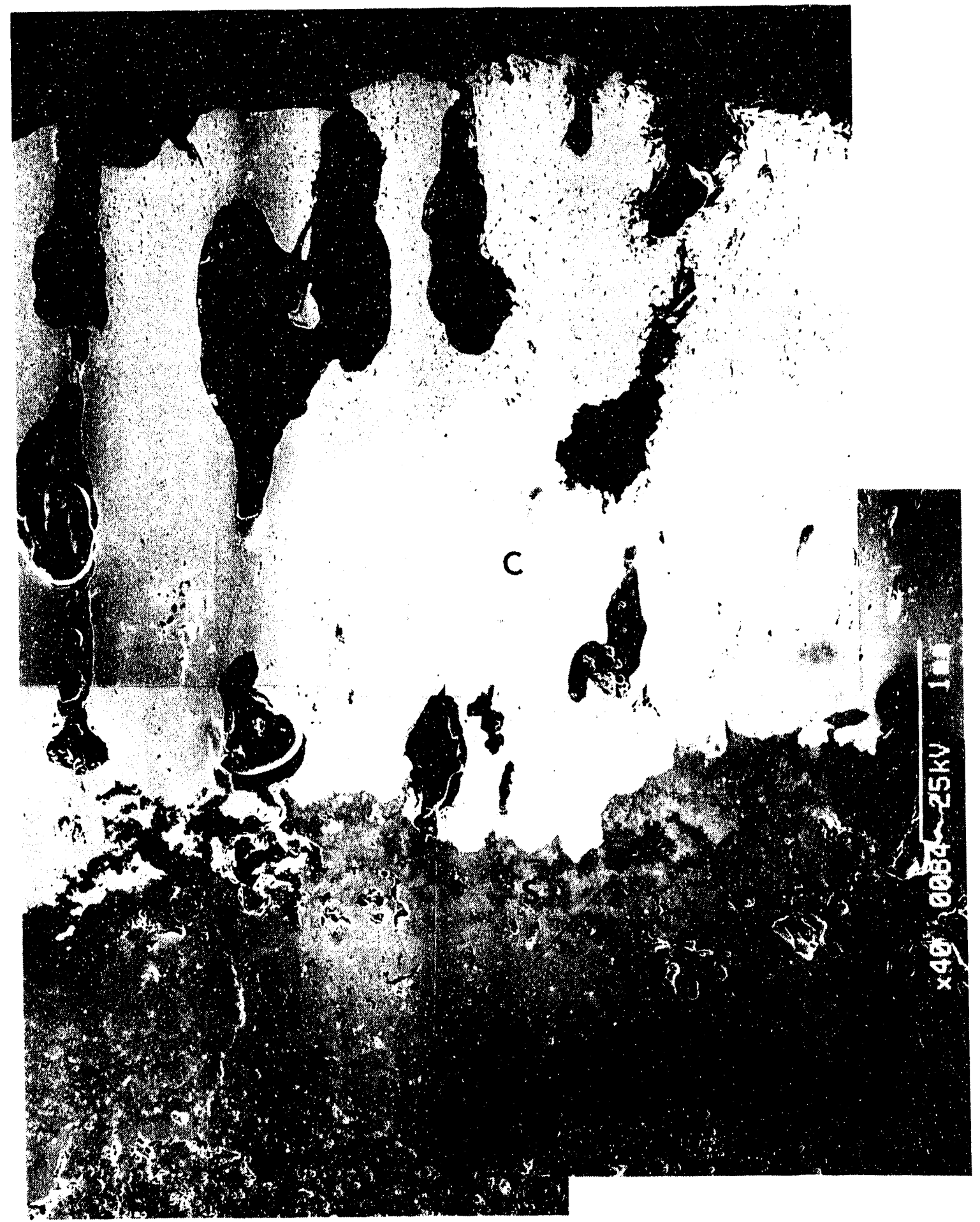

Figure 63. Bottom corner of the northeast side of Anode C1. The cerox coating is thick but contains some pores. 


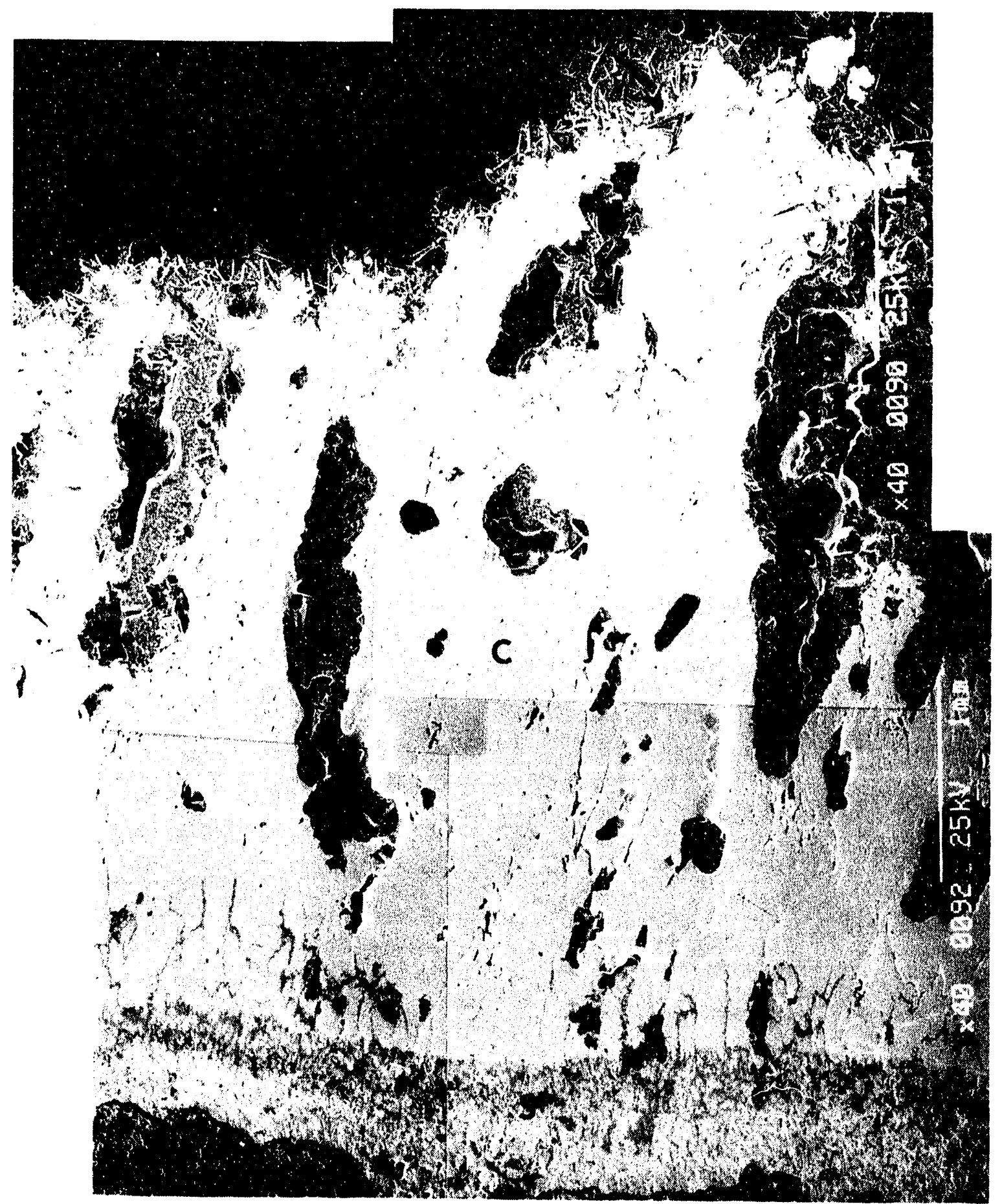

Figure 64. The Cerox coating on the west side of Anode E1 is 3 to $4 \mathrm{~mm}$ in thickness and porous. 


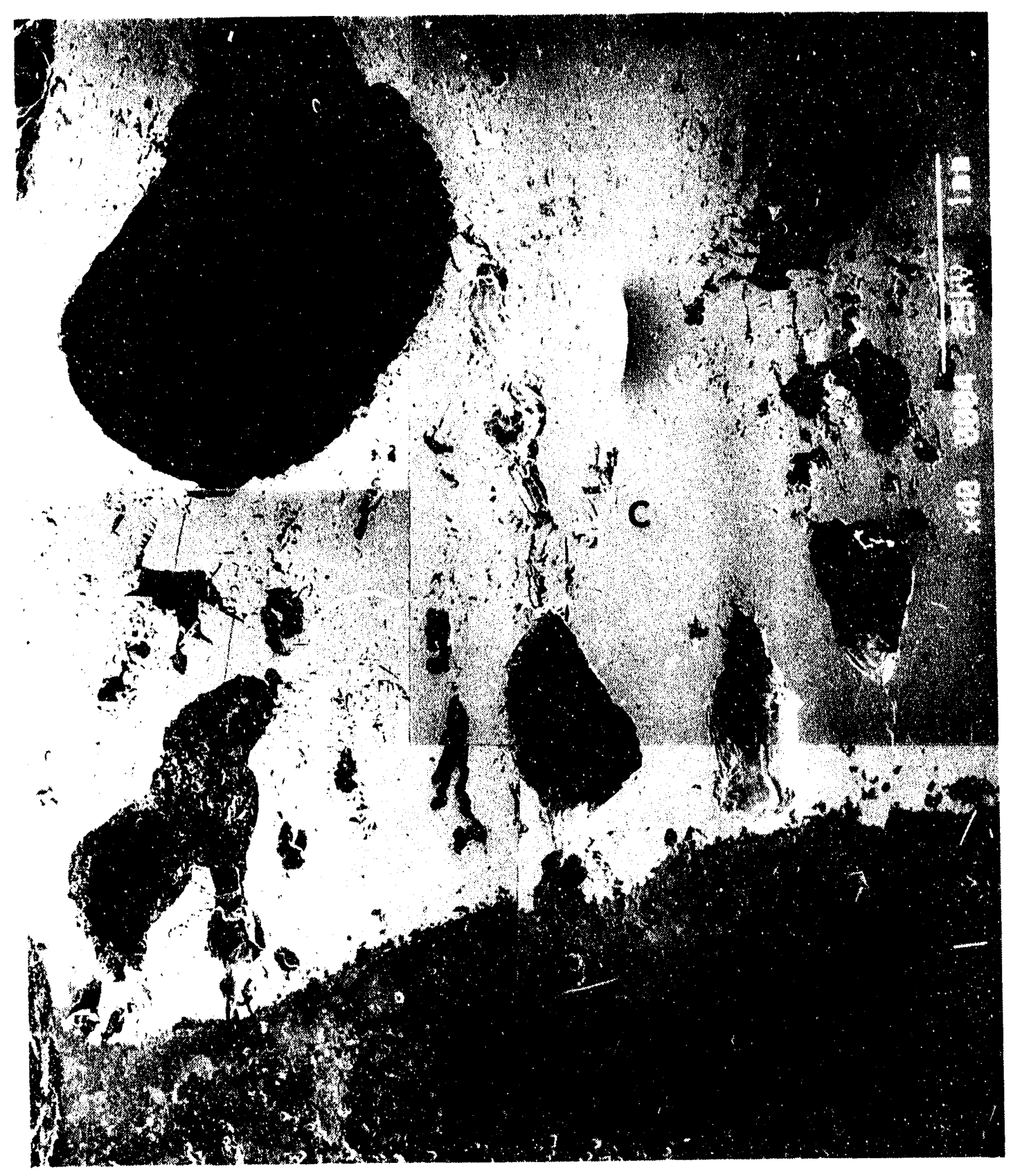

Figure 65a. The inner cerox coating, next to the substrate, on the east side of Anode El. 


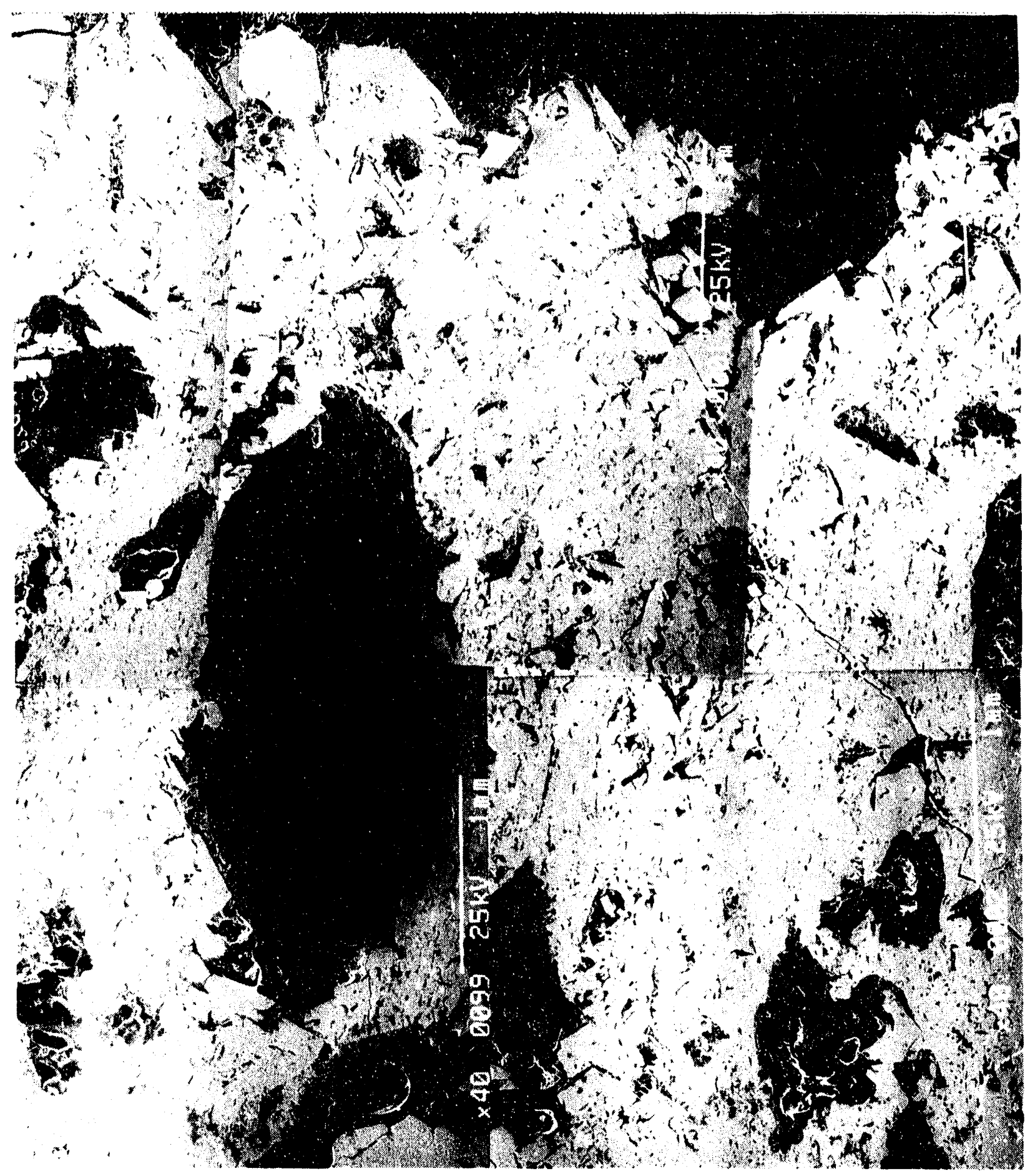

Figure 65b. The outer portion of the cerox coating, on the east side of Anode E1. 


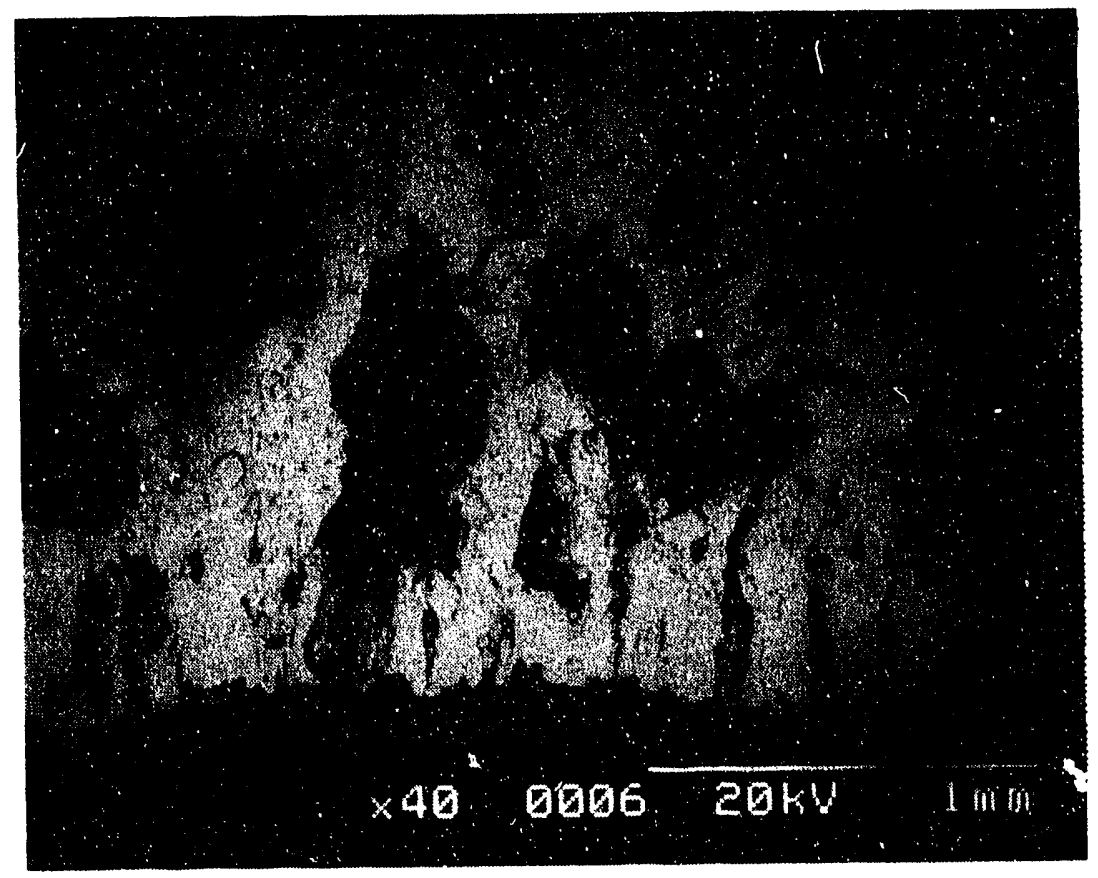

Figure 66. The cerox coating on the bottom of Anode A2 is irregular and less continuous than on the other Anodes.

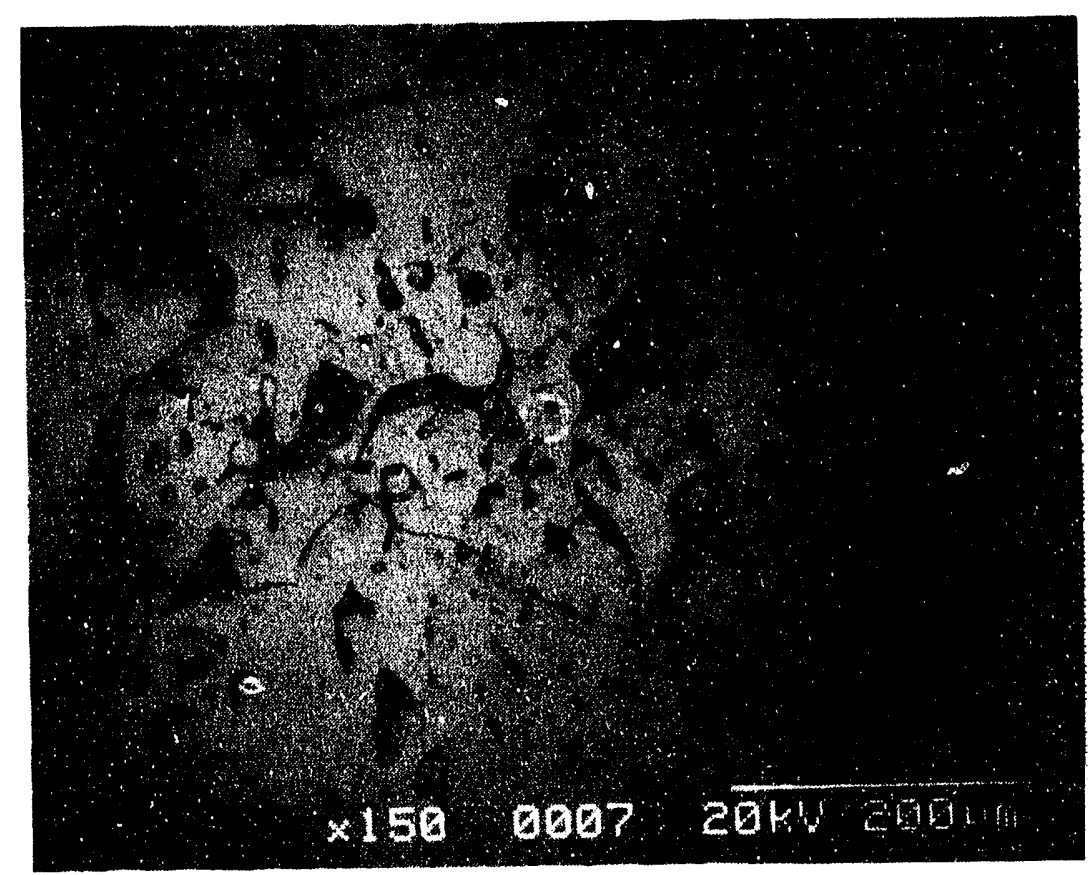

Figure 67. A close-up of the "sawtooth" pattern within the coating on Anode A2. 
cell during the last part of testing, this pattern must result from something in the test conditions dur: 11 that time.

The density and thickness of the CEROX coatings on anodes A1 and C1 are similar to the best coatings obtained in laboratory testing at "optimum" conditions (BR of $\sim 1.5$ to 1.6). Laboratory tests at lower BR have shown that the thickness of the CEROX coating decreases, and this is supported by anode A2. However, the extremely thick CEROX coating on the east side of E1, and the "sawtooth" pattern within the CEROX coatings of anodes A2 and E1 has not been noted in laboratory cells. Therefore, these characteristics are probably the result of the unique conditions that these anodes underwent during the latter phase of testing, with the thick El coating resulting from the cryolite crusting, and the porous pattern was most likely the result of fluctuating temperature and Ce levels.

\subsubsection{Microstructures of the Cermet Anodes}

The microstructure of the cermets were examined before and after testing. The untested cermet is a three-phase mixture that consists of $\mathrm{Ni}$ ferrite (spinel structure), $\mathrm{Ni}$ oxide (rock salt structure), and a $\mathrm{Cu}$ alloy phase. These phases undergo a variety of phase transformations during electrolysis. The original cermet material and the changes it undergoes are described below.

\section{Microstructure of the Untested Substrates}

Figure 68 is a low magnification photograph of the untested material while Figure 69 is a backscatter scanning electron image (BEI) of the sample. The backscatter mode (as compared to the secondary electron image) enhances differences in the atomic number, where phases having heavier elements (higher average atomic number) appear brighter than phases with lighter elements (which appear darker). In Figure 69, the bright features (A) are a Cu-Ni alloy phase, tr. a lighter gray features are the ( $\mathrm{Fe}, \mathrm{Ni}) 0$ phase (B), and the darker gray areas are the $\mathrm{Ni}_{1-x} \mathrm{Fe}_{2+x} \mathrm{O}_{4}$ phase (C). The black spots are pores.

Figure 70 is a higher magnification secondary electron image (SEI) of Eigure 69. The brighter features (A) in both figures are the copper rich phase. The light gray, dense grains are the NiO (B) phase and the darker grains are the $\mathrm{Ni}$ ferrite phase (C). Note that no obvious interphases exist at the grain boundaries of the different phases. The $\mathrm{Cu}$ grains are irregular in shape and range from $\sim 10$ to $125 \mu \mathrm{m}$ in size. The Nio grains are also irregular in shape hut are $\sim 10$ to $25 \mu \mathrm{m}$ long. The $\mathrm{NiFe}_{2} \mathrm{O}_{4}$ occurs as rounded or equant grains, sometimes with a sharp crystal shape, and are $\sim 10$ to $30 \mu \mathrm{m}$ in size.

Average compositions of the three phases are listed in Table 6 . 


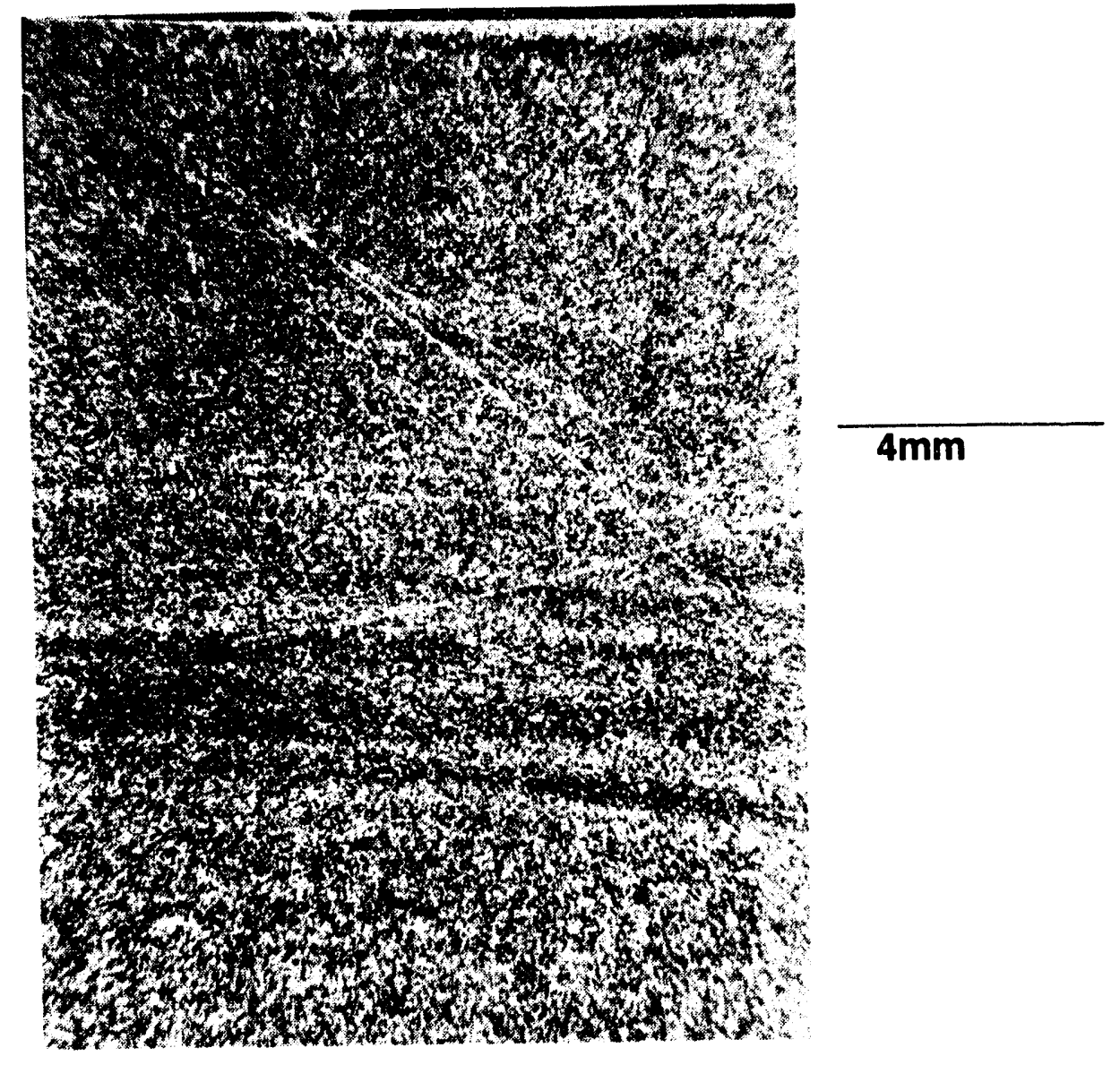

Figure 68. Low magnification cross section of the untested cermet.

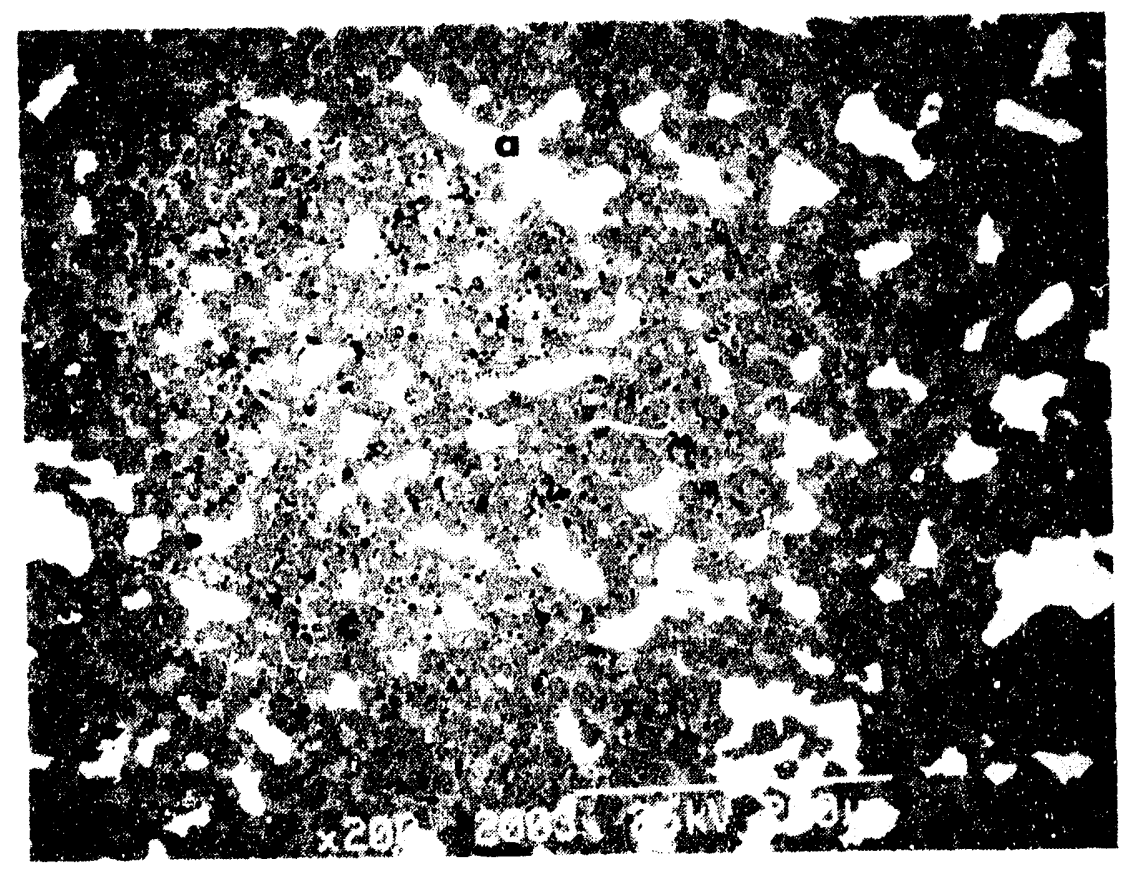

Figure 69. BEI of the untested cermet $(200 \mathrm{X})$. 


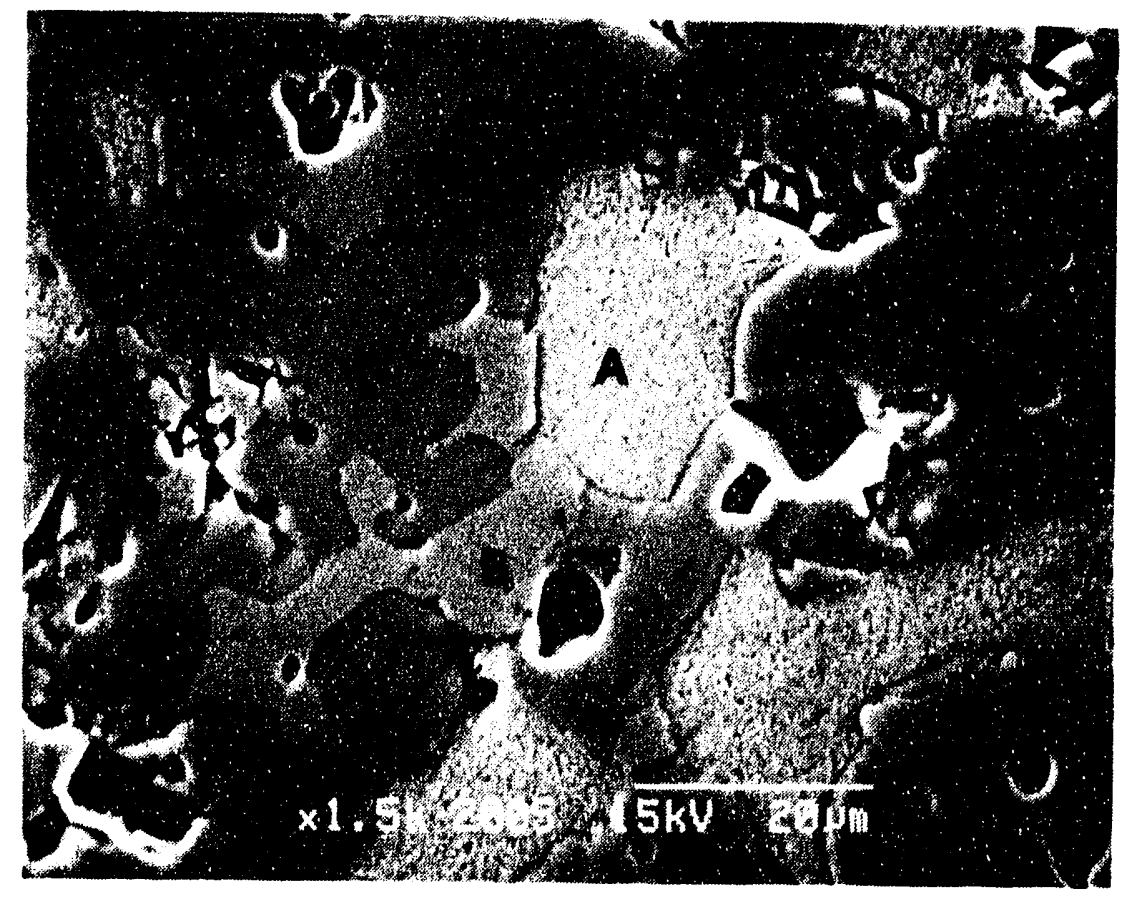

Figure 70. SEI of the untested cermet. $A=C u$ alloy, $B=N i O$,
$C=\mathrm{NiFe}_{2} \mathrm{O}_{4}$. 
Table 6. Phase compositions in the untested material.

\begin{tabular}{lcccc}
\hline Phase & $\frac{8 \mathrm{Fe}}{8 \mathrm{Ni}}$ & $\frac{8 \mathrm{Cu}}{\text { Cation Ratios }}$ & \\
Ferrite & 72.0 & 28.0 & 0 & $\mathrm{Fe} / \mathrm{Ni}=2.57$ \\
Nio & 10.5 & 89.5 & 0 & $\mathrm{Ni} / \mathrm{Fe}=8.52$ \\
Cu Alloy & 1.7 & 15.0 & 83.3 & $\mathrm{Cu} / \mathrm{Ni}=5.61$ \\
Overal1. & 37.4 & 42.7 & 19.9 & \\
& & &
\end{tabular}


The compositions are presented as a molo basis for the metal content of the phase and this convention will be used throughout the report. There are some interesting observations that can be made from Table 6 , one of which is the ferrite phase is not stoichiometric $\mathrm{NiFe}_{2} \mathrm{O}_{4}$. If it were stoichiometric, the $\mathrm{Ni}$ content would be 33.38 . Table 6 shows that the actual $\mathrm{Ni}$ content is $28 \%$, so the ferrite is $\mathrm{Ni}$ deficient and Fe rich. Other observations are that the Nio phase contains $10.5 \% \mathrm{Fe}$ while the copper alloy phase contains $\sim 158 \mathrm{Ni}$ and $1.78 \mathrm{Fe}$.

At the preparation conditions of $1200^{\circ} \mathrm{C}$ and $1.5 \times 10^{-4}$ atm of oxygen, the resultant compositions of the $\mathrm{NiFe}_{2} \mathrm{O}_{4}$ and $\mathrm{NiO}$ phases agree extremely well with the equilibrium compositions that are predicted using the published thermodynamic data for the Fe-Ni-O system. ${ }^{3,9,10,11}$ Figure 71 shows the $\mathrm{NiO}-\mathrm{Fe}_{2} \mathrm{O}_{3}$-temperature phase diagram in air. At $1200^{\circ} \mathrm{C}$, the ferrite is slightly $\mathrm{Fe}$ rich compared to $\mathrm{NiFe}_{2} \mathrm{O}_{4}$ and the NiO contains $\sim 108 \mathrm{Fe}_{2} \mathrm{O}_{3}$. Decreasing the $\mathrm{PO}_{2}$ moves both the $\mathrm{NiFe}_{2} \mathrm{O}_{4}$ and the $\mathrm{NiO}$ phase composition toward the $\mathrm{Fe}$ side of the diagram; both compositions become enriched in $\mathrm{Fe}$.

Published phase diagrams for the Cu-O system ${ }^{12,13}$ show that pure, unalloyed $\mathrm{Cu}$ metal is not the thermodynamically stable phase under the cermet fabrication conditions. Instead, the stable composition consists of a two phase mixture of solid $\mathrm{Cu}_{2} \mathrm{O}$ and a solution of oxygen dissolved in liquid copper (Figure 72). The phase equilibria of the $\mathrm{Cu}-\mathrm{O}$ system dramatically changes when the temperature is raised by $25^{\circ} \mathrm{C}$ and the oxygen pressure is doubled.

Examination of Figures 69 and 70 show that the $\mathrm{Cu}$ phase appears as isolated grains and no evidence of $\mathrm{Cu}_{2} \mathrm{O}$ is present, unless it is on such a small scale that the SEM cannot detect it. Figure 69 also shows that porosity is present in the anode. There appears to be a bimodal distribution of pore sizes where the pores range from 2 to 5 and 10 to $20 \mu \mathrm{m}$ in size. As discussed in subsection 2.2, the measured density on this sample was $\sim 5.74 \mathrm{~g} / \mathrm{cm}^{3}$, which may be from 92 to 948 of the theoretical density (TD). Based on mass balance considerations and using the compositions in Table 6, a TD of $6.53 \mathrm{~g} / \mathrm{cm}^{3}$ was calculated. This would mean that the sample is only $\sim 88.5 \%$ of TD and would suggest that porosity is much higher than previously assumed. Which ever TD is correct, it suggests that some open porosity is present in the untested cermet. Image analysis of Figure 69 showed that the area percent of porosity was 4 to $5 \%$ and the area percent of the $\mathrm{Cu}$ alloy was $14 \%$. As discussed in subsection 2.2, the porous nature of the samples is a result of the low densification pressure. Because some open porosity may exist in the untested anodes, it would be easy for the cryolite electrolyte to penetrate into the sample and attack the grain boundaries.

$\mathrm{Cu}$ depletion seams are found in the cermets (Figure 73) and tend to run parallel to the bottom surface of the anode. These seams can be observed in Figure 68 and are often easily visible 


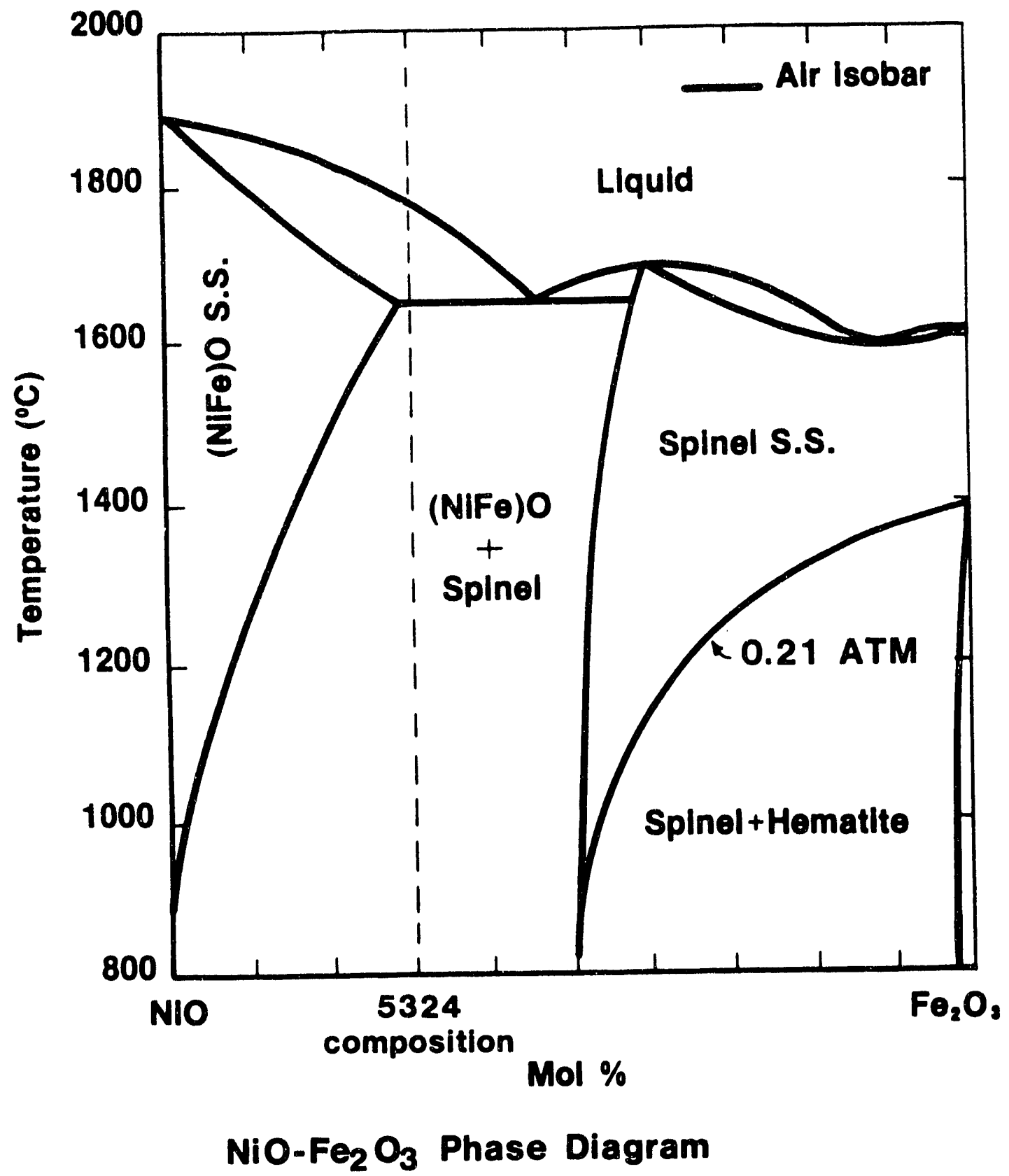

Eigure 71. 


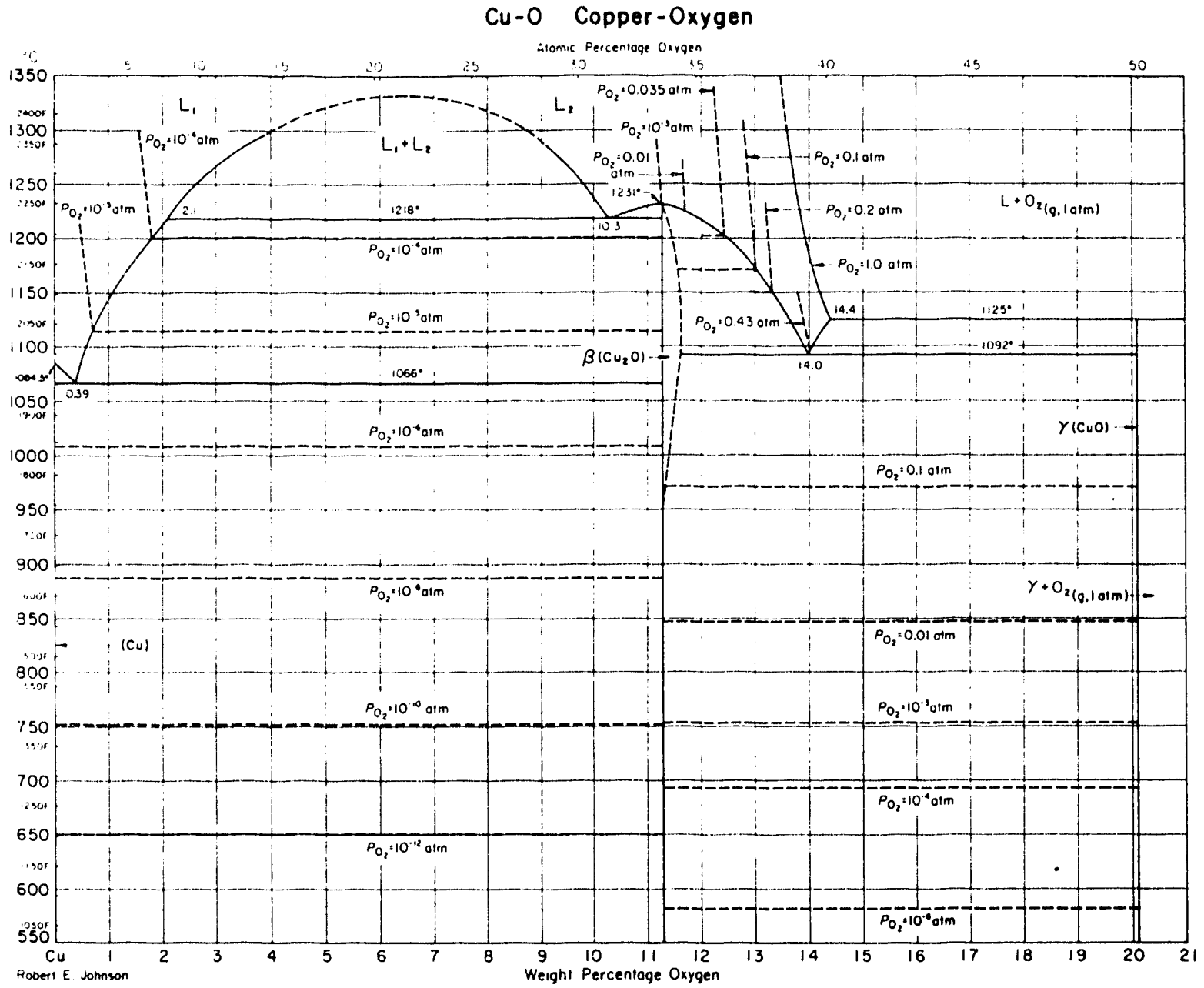

Eigure 72. Cu-O phase diagram as a function of $\mathrm{PO}_{2}$ and temperature. 


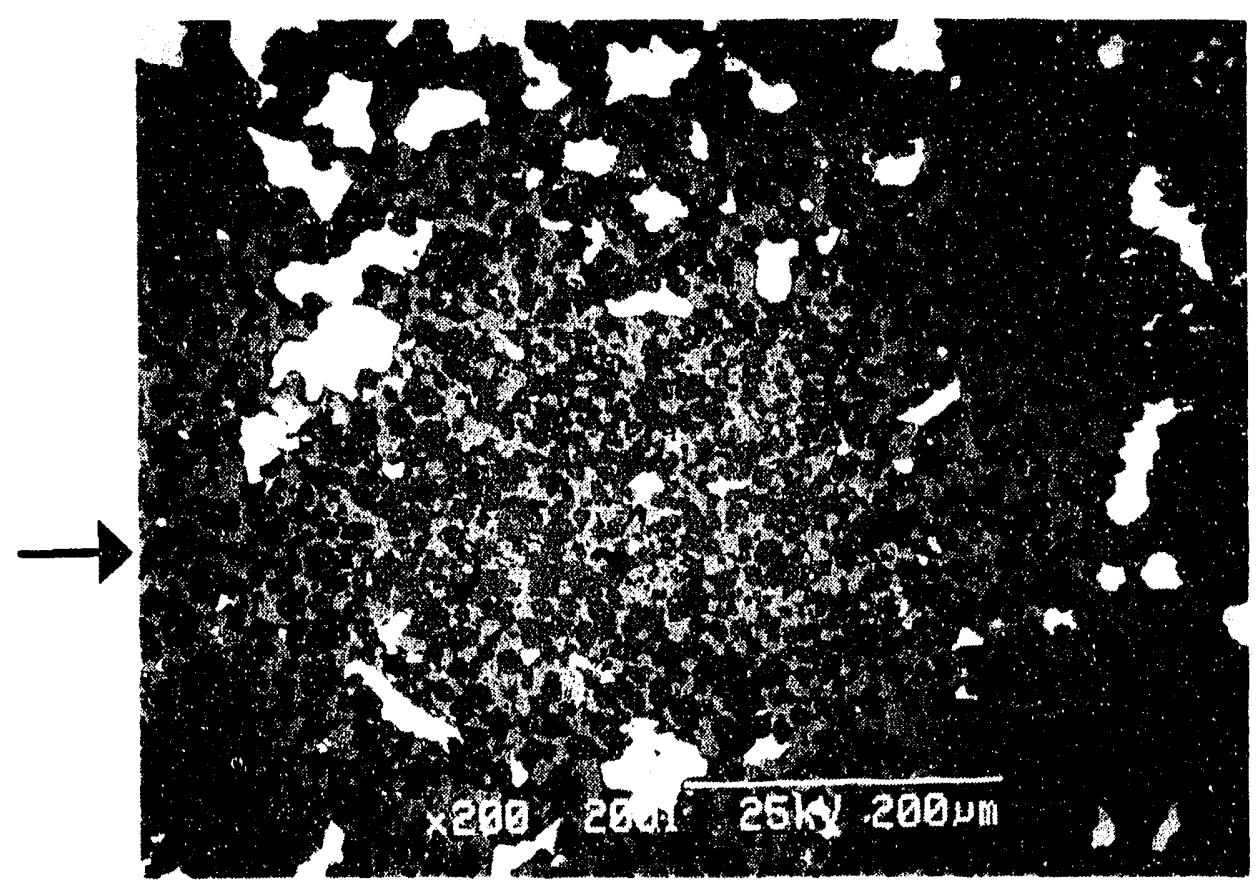

Figure 73. A copper depletion seam is shown within the untested cermet (arrow). 
macroscopically. Eigure 73 shows a seam that is $200 \mu \mathrm{m}$ wide; they have been observed to be up to several $\mathrm{cm}$ long.

Although the electrical conductivity of these particular anodes were not measured, many measurements have been performed in the past on the $\mathrm{NiO}-\mathrm{NiFe}_{2} \mathrm{O}_{4}$-Cu cermet composition. 3,6,14 This composition does not behave like a classical cermet material. The electrical conductivity of this material occurs by a $k$-type semiconducting mechanism while the Alcoa reaction sintered $\mathrm{Fe}-\mathrm{Ni}$ cermet with a continuous nickel metal bonding phase conducts metallically. The conductivity of the PNL laboratory cermet is $50(\mathrm{ohm}-\mathrm{cm})^{-1}$ at $\sim 900^{\circ} \mathrm{C}$, while ELTECH has shown that the conductivity of their $\mathrm{Cu}$ cermet at $\sim 1000^{\circ} \mathrm{C}$ ranges from 60 to $160(0 \mathrm{hm}-\mathrm{cm})^{-1}$, depending on the preparation and sintering procedures. ELTECH has also shown that (depending on the preparation procedure) not only will the room temperature and $1000^{\circ} \mathrm{C}$ conductivity change, but the character of the conductivity (more metallic or more semiconductive) changes. ${ }^{6}$ The conductivity of pure $\mathrm{Cu}$ metal decreases as the temperature and amount of impurities (especially iron and oxygen) increases, while the conductivity of $\mathrm{Cu}_{2} \mathrm{O}$ (a $\mathrm{p}$-type conducting material) is $\sim 3(\mathrm{ohm}-\mathrm{cm})^{-1}$ at $900^{\circ} \mathrm{C}$ and $\mathrm{PO}_{2}=10^{-3}$ atm. ${ }^{15}$

PNL has performed an extensive study on the mechanical behavior of this cermet material, both before and after testing. " They have shown that the mechanical properties are also not typical of a cermet (low fracture toughness, $\sim 2.7 \mathrm{MPa} / \mathrm{m}^{1 / 2}$, at room temperature) and that the untested cermet has a low strength (110 MPa, at room temperature). These results suggest this material should be approached, not as a classical metal-phase bonded cermet material (metal matrix composite) but instead as a ceramic matrix composite.

\section{Microstructures of the Tested Anodes}

Anode B1 - $1 \mathrm{~h}$

Anode BI was online for one hour before removal because of cracking. A section from the bottorn corner of the west side of the anode (the side that faced the carbon anode) was mounted and polished, and a macroscopic photograph of the section is shown in Eigure 74. This section of the anode has four distinct microstructural layers, with three of these layers occurring within the substrate. A BEI of the outer surface (Figure 75) shows three of the four regions. The dark region (D) is frozen cryolite from the bath. No CEROX coating (typically bright in BEI) was present because the CEROX coating did not form during the first $12 \mathrm{~h}$ of the test (Subsection 3.2). The bright features within the cryolite was found to be a $\mathrm{Cu}$ oxide phase.

The central region (C) of Figure 75 shows that a $500 \mu m$ thick reaction layer has formed on the outer surface of the substrate. Figure 76 (a) and (b) shows higher magnification micrographs of 


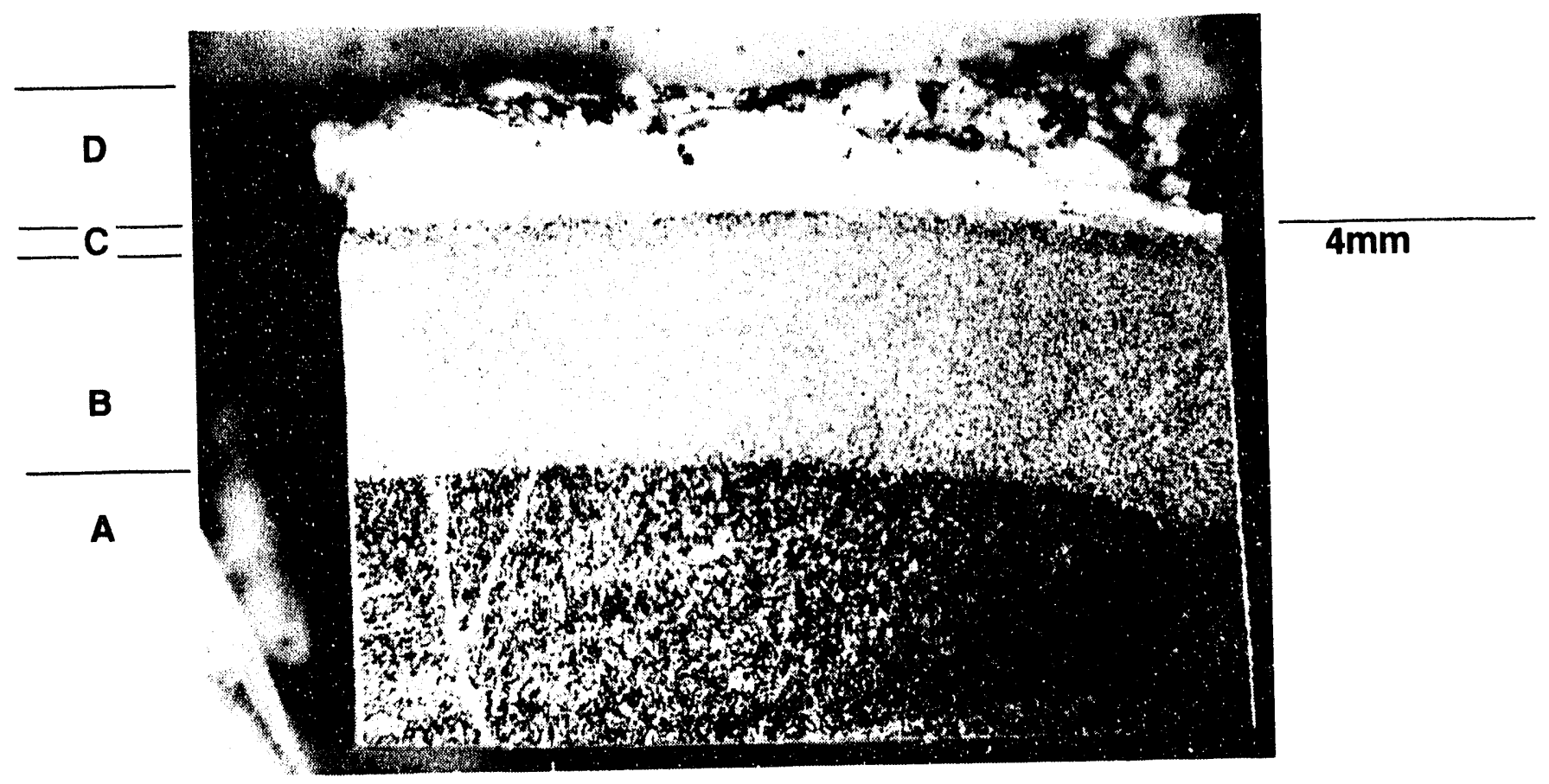

Figure 74. Exterior bottom corner of Anode B1.

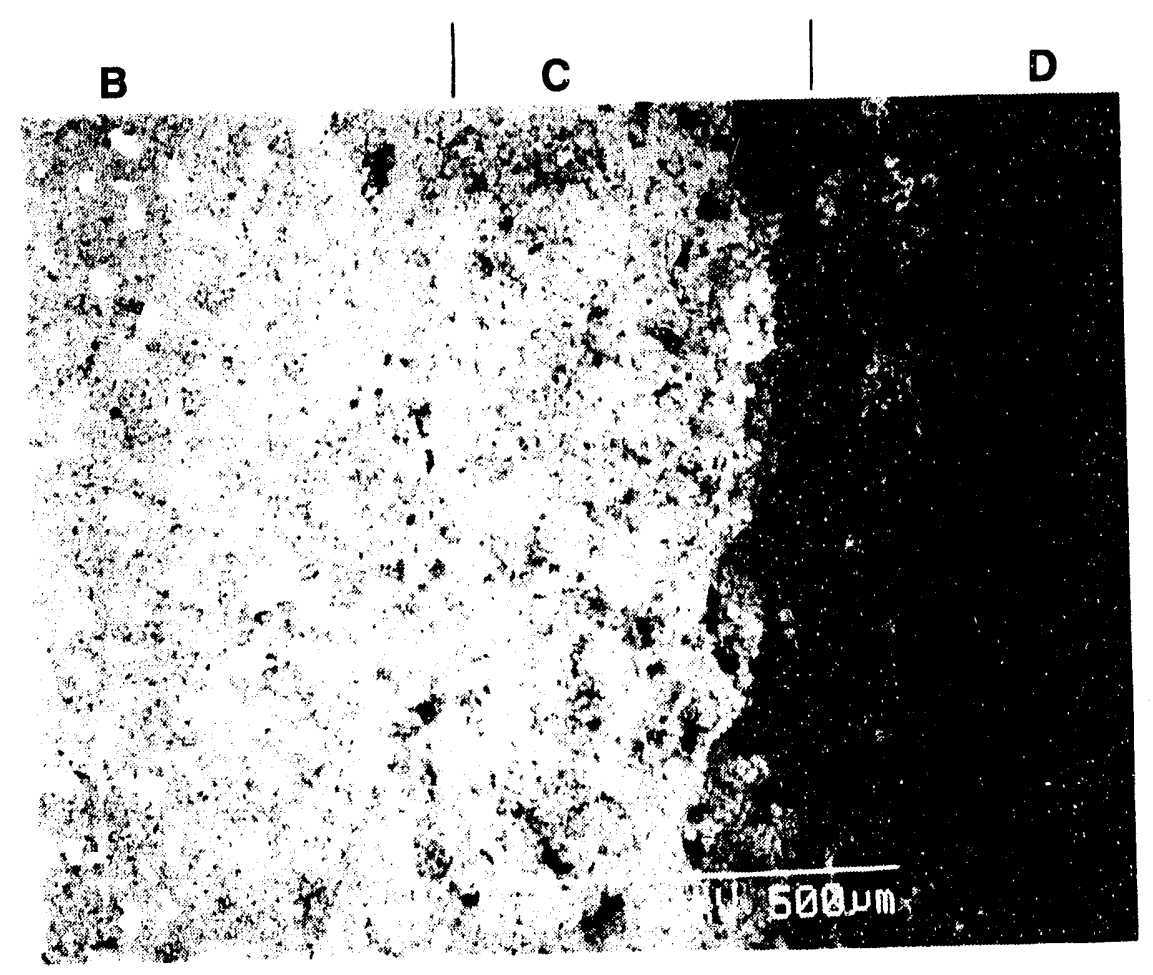
Figure 75. Outer edge of $\mathrm{B} 1$, tested for $1 \mathrm{~h}$. $\mathrm{D}=$ cryolite, $\mathrm{C}=\mathrm{Cu}$
depleted layer, $\mathrm{B}=$ porous region with $\mathrm{Cu}$ metal. 


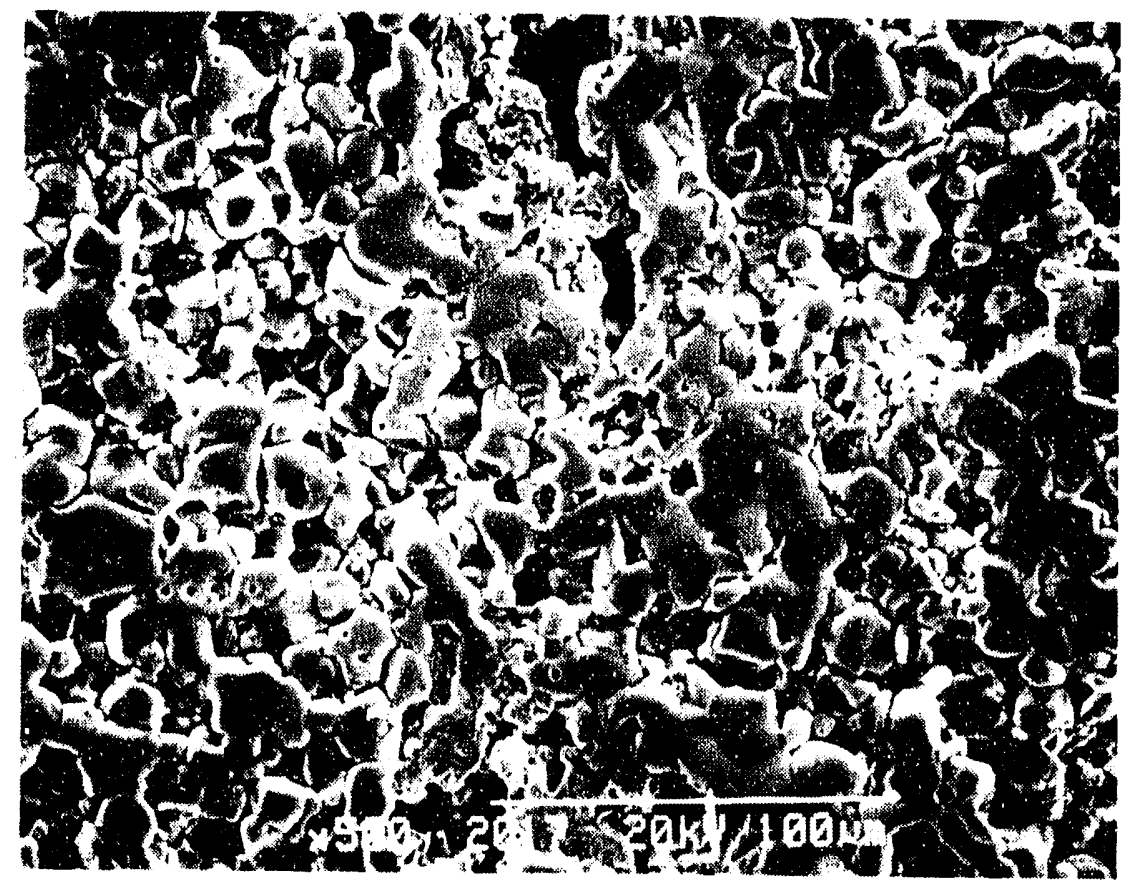

Figure 76a. SEI of the porous $\mathrm{Cu}$ depleted layer in Anode B1 (Layer $\mathrm{C}$ in Figure 75).

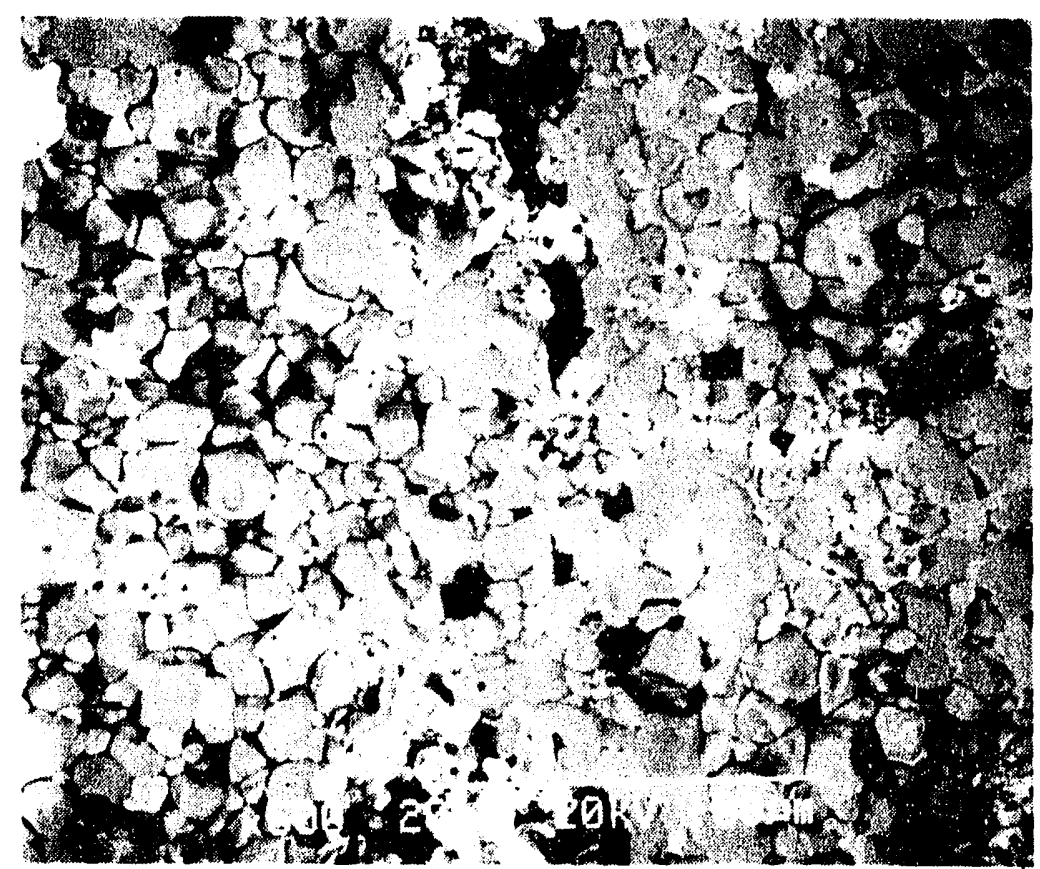

Figure $76 \mathrm{~b}$. BEI of the same area as $76 \mathrm{a}$. The rate light grains are Cu-rich phases. 
the inner boundary of this reaction layer. The bright features in Layer $\mathrm{B}$ are a $\mathrm{Cu}$ alloy phase and these are obviously missing in the reaction layer (Layer $C$ ). Electron probe microanalysis (EPMA) was performed at $500 x$ in Layer $C$ to estimate a bulk composition of the cermet, and it was found that this region was $\mathrm{Cu}$ depleted, containing 8.3 molo $\mathrm{Cu}$ as compared to the starting bulk cermet with $19.9 \% \mathrm{Cu}, 42.8 \% \mathrm{Ni}$ and $37.4 \% \mathrm{Fe}$ (all compositions are given in molo). The $\mathrm{Ni} / \mathrm{Fe}$ ratio was 1.133 , which is very close to the batched ratio of 1.142 . Thus, $\mathrm{Cu}$ is preferentially removed in this region. Most of the grain boundaries and triple grain junctions are rounded from corrosion with the cryolite and porosity is increased compared to the untested material. EPMA spot analysis on the ferrite grains showed that their composition is changed and they are now nearly stoichiometric $\mathrm{NiFe}_{2} \mathrm{O}_{4}$. Thus, $\mathrm{Fe}$ was removed from the ferrite grains.

The boundary between Layers $A$ and $B$ (Figure 74) are shown in Figure 77. This boundary occurred $4.2 \mathrm{~mm}$ in from the outer surface of the substrate. Higher magnification micrographs of the Layer A (inner) and Layer B (outer) regions are presented in Figures 78 and 79 . Layer A (Eigure 78) shows that the microstructure is very similar to the untested anode (see Figure 69). In contrast, Layer $B$ (Eigure 79) is very porous, probably because of grain boundary attack of the substrate. EPMA analysis showed that there is no significant difference in the overall composition of the two regions. It cannot be determined if the grains in the outer porous region were removed during operation of the anode (by dissolution) or if a grain boundary phase (cryolite) weakened the grain boundaries, causing pullout during the metallographic preparation procedure. The important conclusion is that the grain boundaries in this region were weakened during the initial stages of operation of the anode. Because all anodes underwent the same preheat procedure, it is expected that all of the anodes had a similar weakening during the preheat and early stages of testing.

Because the porous zone was $\sim 4.2 \mathrm{~mm}$ in from the outer edge of the sample, and because the anode operated for only $1 \mathrm{~h}$, the average penetration velocity of this front was $1.2 \times 10^{-4} \mathrm{~cm} / \mathrm{s}$. The diffusion coefficient, $D$, of the penetrating species was estimated using the equation $x^{2}=D t$ and to give a value of $D=5 \times 10^{-5} \mathrm{~cm}^{2} / \mathrm{s}$. This value is over 2 orders of magnitude greater than the diffusion coefficient of $\mathrm{Cu}$ in $\mathrm{Cu}_{2} \mathrm{O}$ and six orders magnitude greater than the diffusion coefficient of $\mathrm{Ni}$ in $\mathrm{NiO}^{15}$ so it is very doubtful that solid state diffusion is responsible for this microstructure. A more likely explanation would be the penetration of liquid cryolite along any existing open pores and along grain boundaries. The presence of this porous zone emphasizes the need to fabricate completely dense anodes to prevent or slow the rapid penetration and weakening of the cermet by cryolite. If the anode was immersed in molten cryolite for longer than an hour (during the heat-up period), more time might have been available for diffusion into 


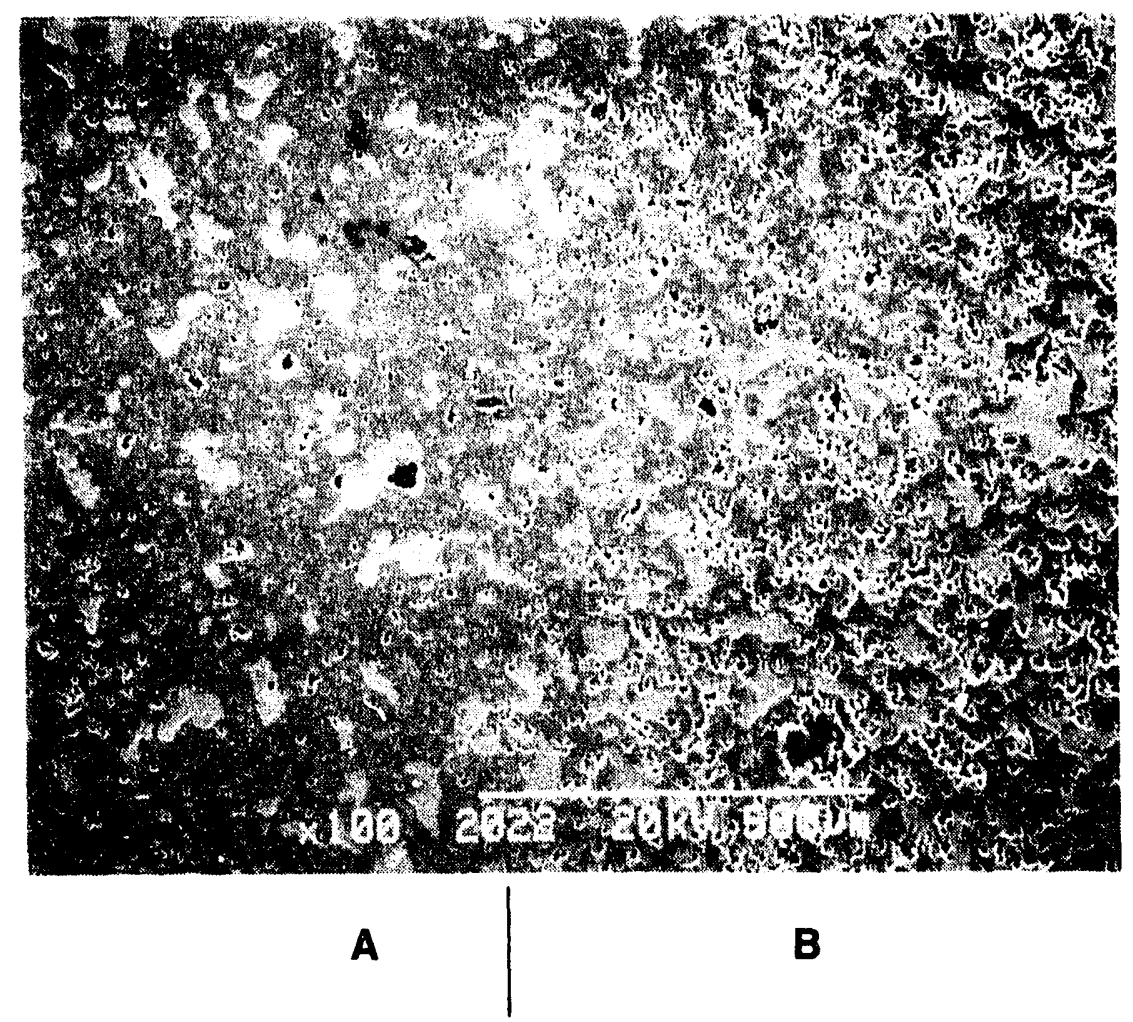

Figure 77. Anode $\mathrm{B} 1$, showing the boundary between the porous zone (B) and the dense zone (A) is $\sim 4.2 \mathrm{~mm}$ into the sample. 


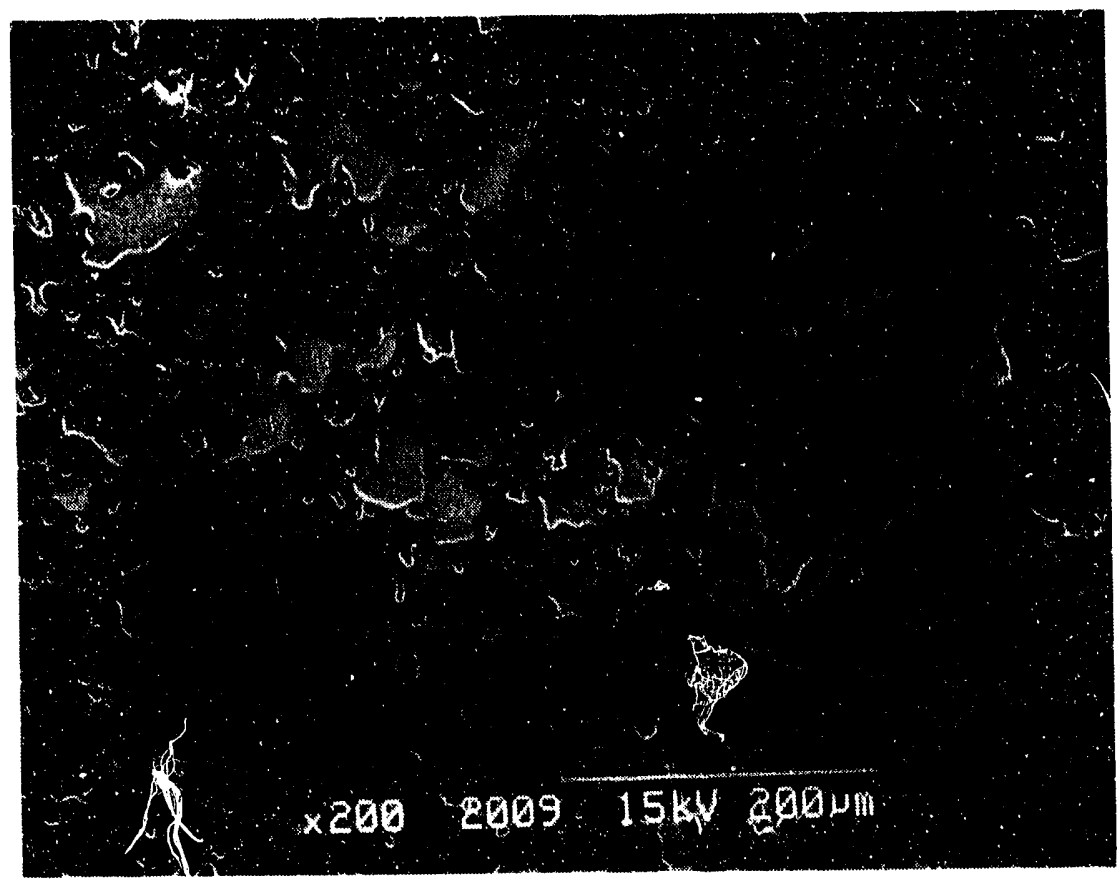

Figure 78. Inner dense zone (A) of Anode B1.

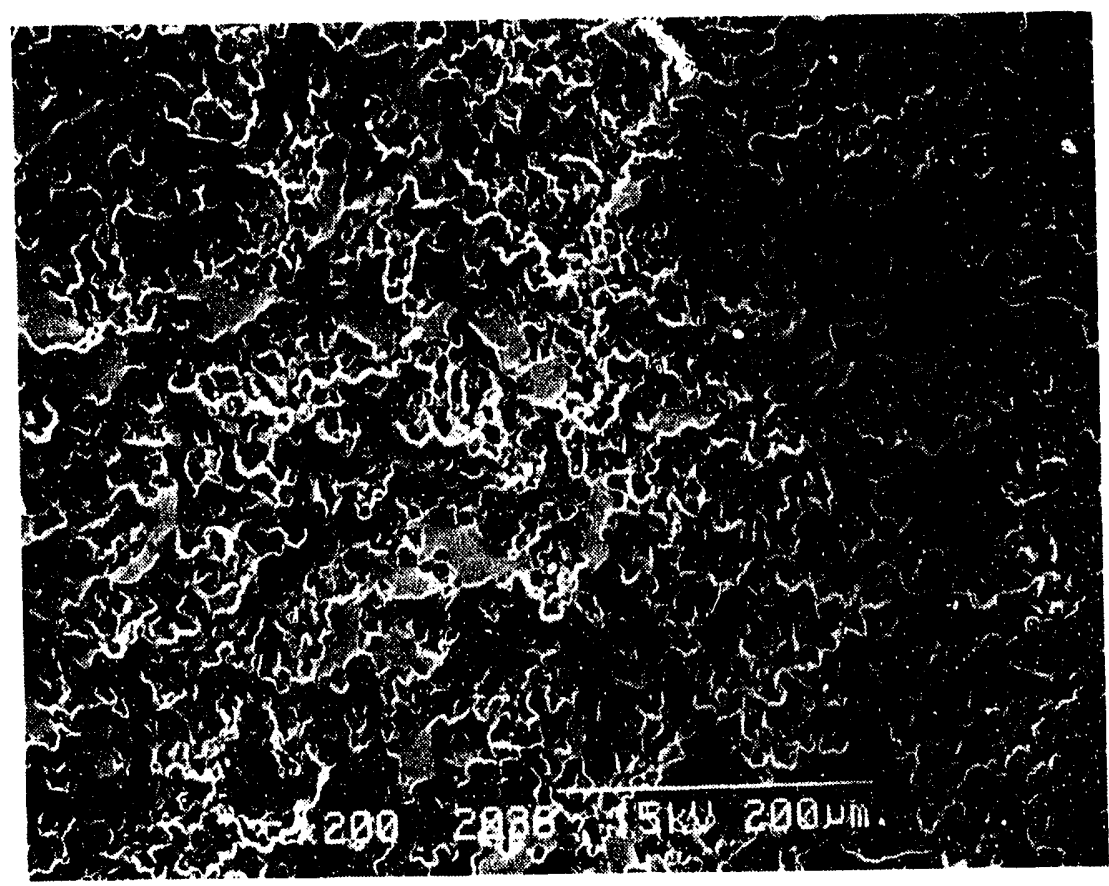

Figure 79. Outer porous zone (B) of Anode B1. 
the sample.

Several observations were made on the changes in chemical composition of the individual phases. As mentioned above, some or the ferrite grains in the outer reaction layer had the stoichiometric $\mathrm{NiFe}_{2} \mathrm{O}_{4}$ composition ( $\mathrm{Ee} / \mathrm{Ni}=2$ ) but, although the $\mathrm{Fe} / \mathrm{Ni}$ ratio in the ferrite phase increased with distance into the anode, it did not reach the ratio of the untested sample,

$\mathrm{Ee} / \mathrm{Ni}=2.57$. This is presented graphically in Eigure 80 which shows that the stoichiometric Fe/Ni ratio of 2 is present up to 1 $\mathrm{mm}$ in from the outer surface and increases to a value of 2.45 at $4.65 \mathrm{~mm}$ into the sample. The boundary between layer $A$ and $B$ occurred at $4.2 \mathrm{~mm}$. Thus, although the microstructure of the anode within layer $A$ is very similar to the untested microstructure, changes in the chemical composition have occurred in this area.

Also shown in Figure 80 is a plot of the $\mathrm{Cu} / \mathrm{Ni}$ ratio in the $\mathrm{Cu}-\mathrm{Ni}$ alloy phase with distance into the anode. The $\mathrm{Cu} / \mathrm{Ni}$ ratio decreases with distance into the anode, approaching the ratio in the untested anode (5.61). The $\mathrm{Cu}$ phases present in the outer $\mathrm{Cu}$ depleted reaction zone (layer $\mathrm{C}$ ) had $\mathrm{Cu} / \mathrm{Ni}$ ratios ranging from 10.5 to 27.5 . Outside of this reaction zone, the $\mathrm{Cu} / \mathrm{Ni}$ ratio decreased from a value of 7.18 at $1.6 \mathrm{~mm}$ into the anode to 6.28 at $4.65 \mathrm{~mm}$. The iron content in the $\mathrm{Cu}$ alloy remained unchanged in this region.

These results are consistent with reported corrosion data on this system. Alcoa originally used nickel metal as the bonding phase but they found that nickel is electrochemically corroded when it is in the metallic state and it is preferentially removed from $\mathrm{Cu}-\mathrm{Ni}$ alloys. ${ }^{3}$ This appears to be evident in the $\mathrm{Cu}-\mathrm{Ni}-\mathrm{Fe}$ alloys in $\mathrm{Bl}$.

The Nio composition was essentially unchanged throughout the outer region. The only change in the composition occurred at $4.65 \mathrm{~mm}$ where one grair was slightly lower in $\mathrm{Ni}$, containing 87 molo $\mathrm{Ni}$ $(\mathrm{Ni} / \mathrm{Fe}=6.7)$ compared to 89 to $90 \mathrm{~mol} 8(\mathrm{Ni} / \mathrm{Fe}=8.1$ to 10$)$ in the other areas of the anode and in the untested anode.

\section{Anode $\mathrm{Al}$ and $\mathrm{C1}, 213$ and $275 \mathrm{~h}$, respectively.}

Anodes $A 1$ and $C 1$ were operated in an electrolyte that had an average $\mathrm{BR}$ of 1.44 and averaged $\sim 708 \mathrm{Al}_{2} \mathrm{O}_{3}$ saturation (6.9 wto ). A sample from section 40 of anode $A 1$ was taken from the northwest side of the anode (thin CEROX side) while a sample from section 43 of this anode was taken from the northeast side (thick CEROX side).

The sample of anode Cl was taken from section 40 on the west side of the anode. These samples were mounted and polished and they represent the bottom corners of the anodes. 


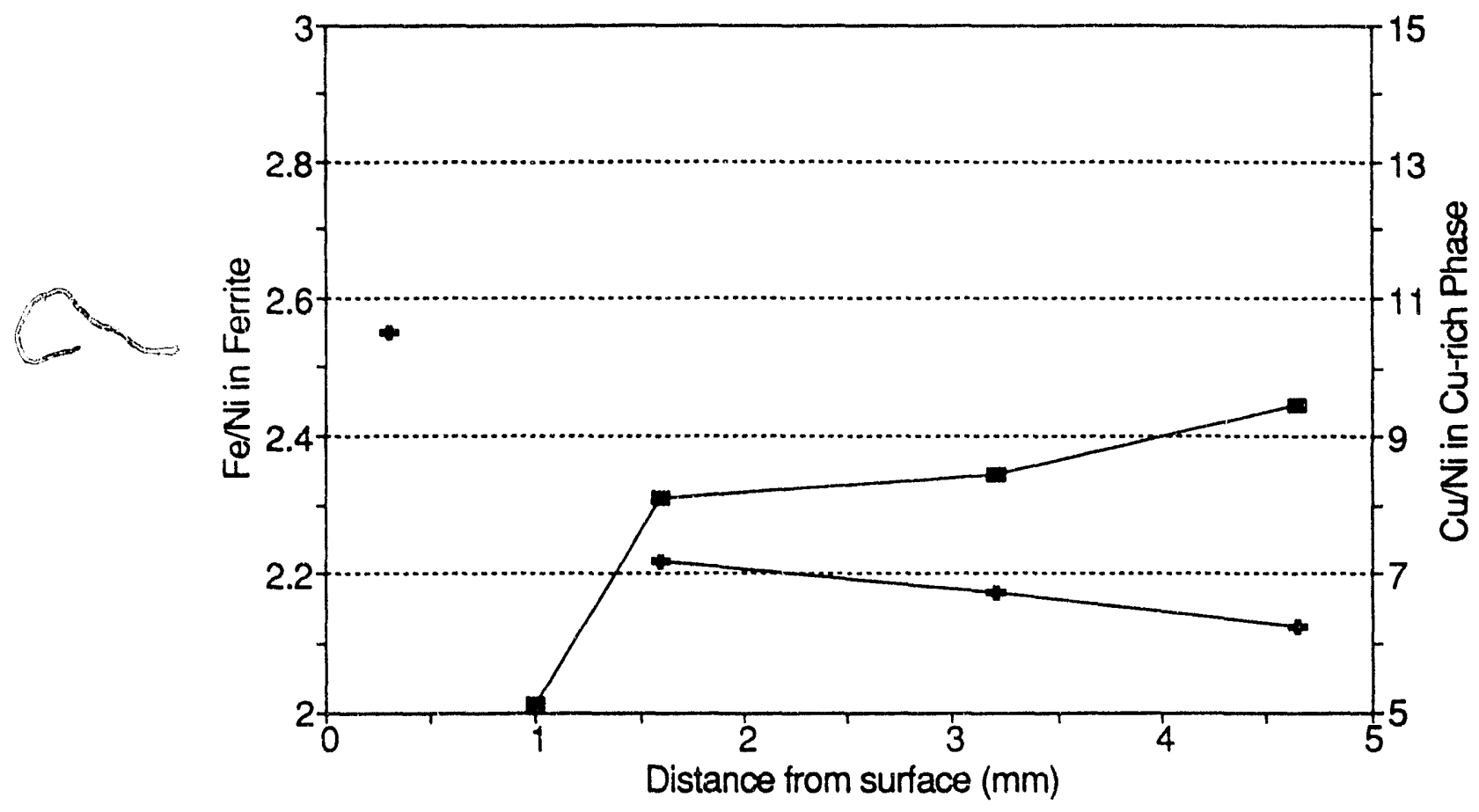

$-\mathrm{Fe} / \mathrm{Ni}-\mathrm{Cu} / \mathrm{Ni}$

Eigure 80. Composition of ferrite and $\mathrm{Cu}$ alloy phase in anode $\mathrm{B} 1$. 
Macroscopic photographs of the polished cross sections of the samples taken from Sections 40 and 43 of Anode Al are presented in Figures 81 and 82 , respectively, while a photograph of Anode C1 is shown in Eigure 83. These figures show that the resultant oxidation zones for the sections of anode A1 were 5 to $6 \mathrm{~mm}$ thick compared to 2 to $2.5 \mathrm{~mm}$ for the C1 sample. However, the thickness of the oxidation zone cannot be used as a quantifiable parameter for this experiment because the thickness also varied within each particular section. The thickness of the zone varied from 1 to $5 \mathrm{~mm}$ for section 40 (northwest) of Anode Al while the thickness of Section 43 (northeast) ranged from 5 to $10 \mathrm{~mm}$. The thickness of Section 40 of Anode C1 (west) varied from 1 to $5.5 \mathrm{~mm}$. It was decided to examine the microstructures of these particular samples because they showed features and reaction layers that were characteristic of other regions in the anodes.

There are many similarities but also some dirferences between these three sections. All anodes have a unique microstructure near the substrate/CEROX interface and these differences will be discussed beginning at the bottom of page 93. However, the composition and structure of the anodes away from this interface are very similar between the anodes. These samples all exhibit a porous $\mathrm{Cu}$ depletion zone that is $\sim 500 \mu \mathrm{m}$ to $1 \mathrm{~mm}$ thick, starting at the edge of the unique surface structure and extending into the substrate. At this point, the copper reappears in the form of a Cu-rich oxide phase. This phase forms an oxidation zone that is black to the naked eye and these zones are marked by the 0 in Figures 81 through 83. Further into the center of the anode, this black zone converts to a $\mathrm{Cu}$ colored structure that is present throughout the remainder of the anode. The change in color from black to copper signifies a phase transition from a $\mathrm{Cu}$ oxide (probably $\mathrm{Cu}_{2} \mathrm{O}$ ) to a $\mathrm{Cu}$ metal alloy.

Figure 84 (Anode $A 1$ ) shows an example of the $\mathrm{Cu}$ depleted region (N). The CEROX coating is to the left (C) and the region containing Cu-oxide is to the right (0). Within the Cu depleted region $\mathrm{NiO}, \mathrm{NiFe}_{2} \mathrm{O}_{4}$, and porosity occur. In the oxidized zone, NiO, $\mathrm{NiFe}_{2} \mathrm{O}_{4}$, and porosity occur, along with $\mathrm{Cu}$ oxide (the bright phase within the oxidized zone, Figure 84). A typical interface between the $\mathrm{Cu}$ metal and $\mathrm{Cu}$ oxide region is shown in Figure 85 (Anode $\mathrm{C} 1$ ). The boundary is usually sharp and san be seen in Figure 85 by the transition from the medium gray $\mathrm{Cu}$-oxide to the slightly brighter $\mathrm{Cu}$ metal (in BEI). The shape of the $\mathrm{Cu}$ oxide and $\mathrm{Cu}$ grains are similar but the $\mathrm{Cu}$ oxide is more likely to be present in places as a grain boundary phase.

The chemical composition of the $\mathrm{NiO}$ and $\mathrm{NiFe}_{2} \mathrm{O}_{4}$ phases remain fairly constant throughout the $\mathrm{Cu}$ depletion zone, oxidation zone and the unoxidized region. The compositions are also the same for both anodes. The ferrite phase transforms from being slightly Ni deficient (in the untested) to a nearly stoichiometric composition. As reported in the $B 1$ section, it was shown that the stoichiometric 


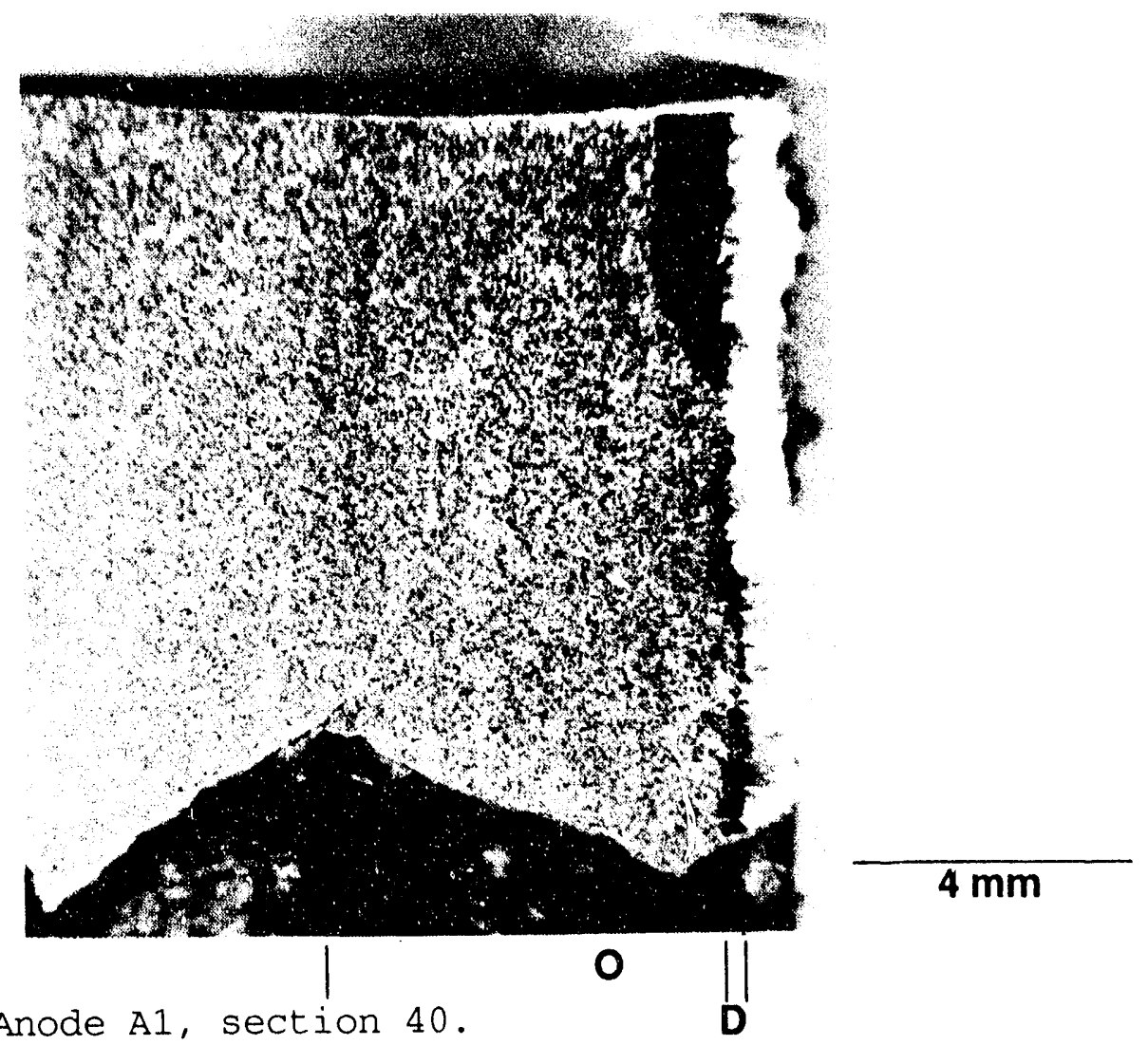

Figure 81. Anode $A 1$, section 40.

$4 \mathrm{~mm}$

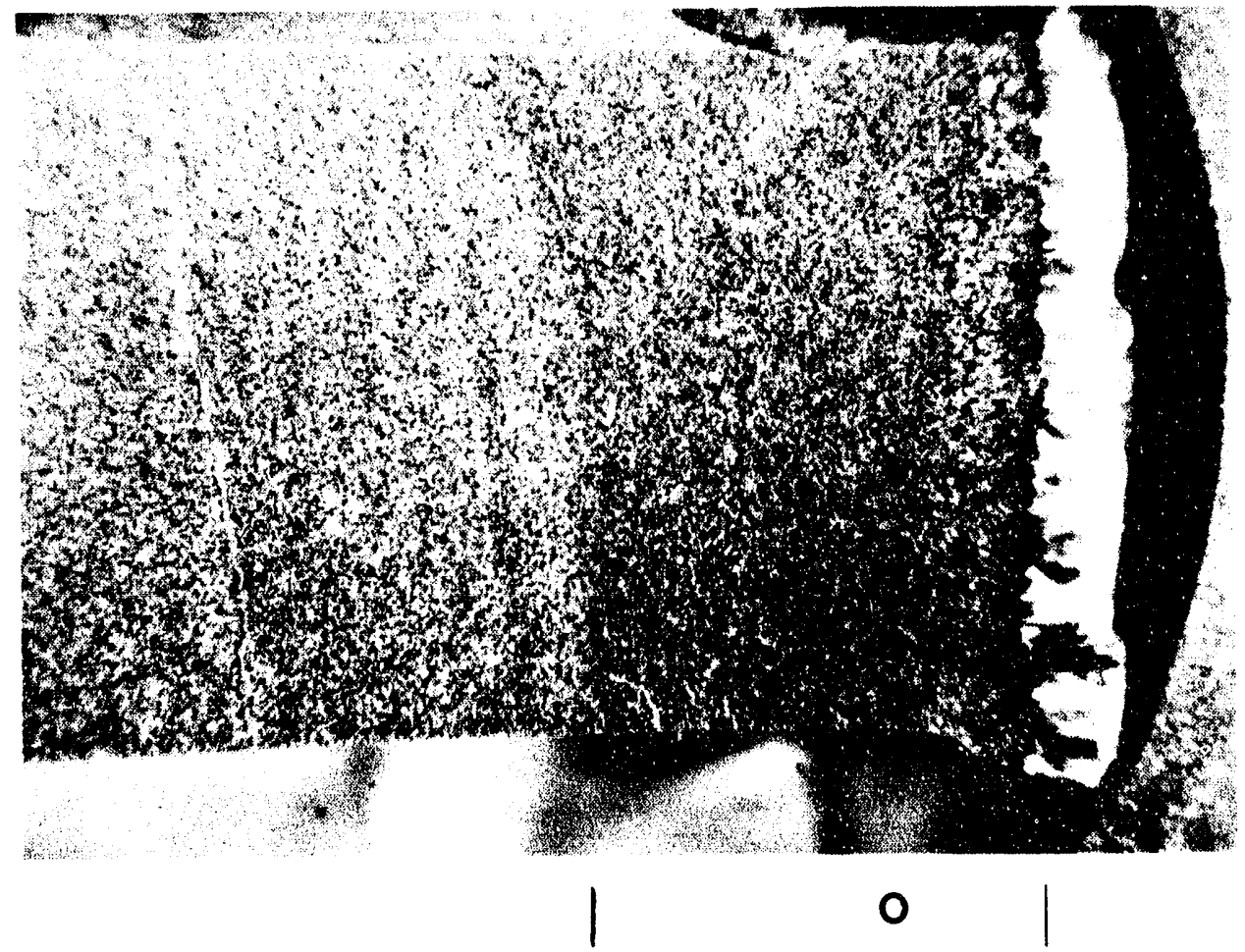

Figure 82. Anode A1, section 43 . 


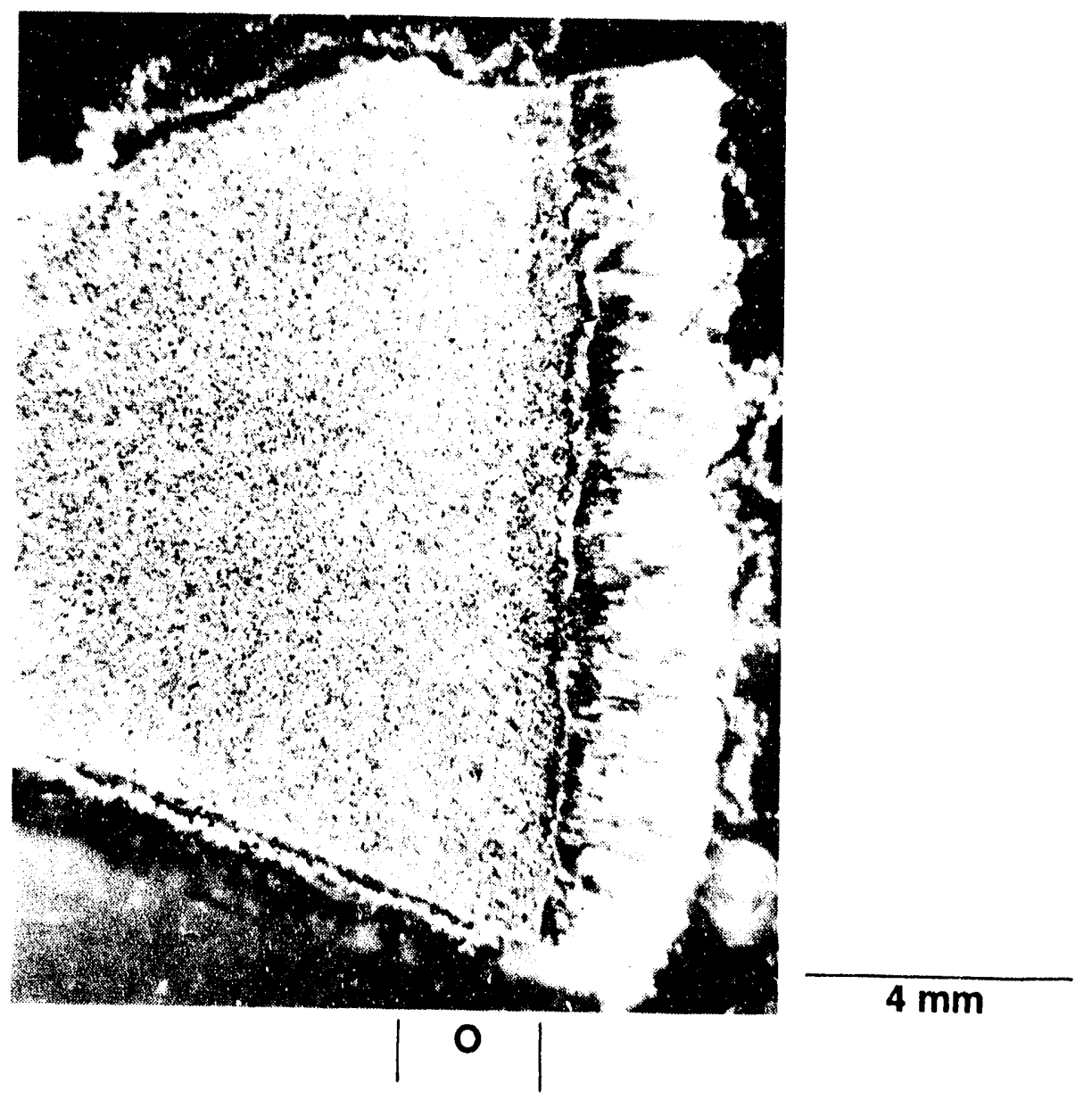

Figure 83. Anode C1, section 40. 


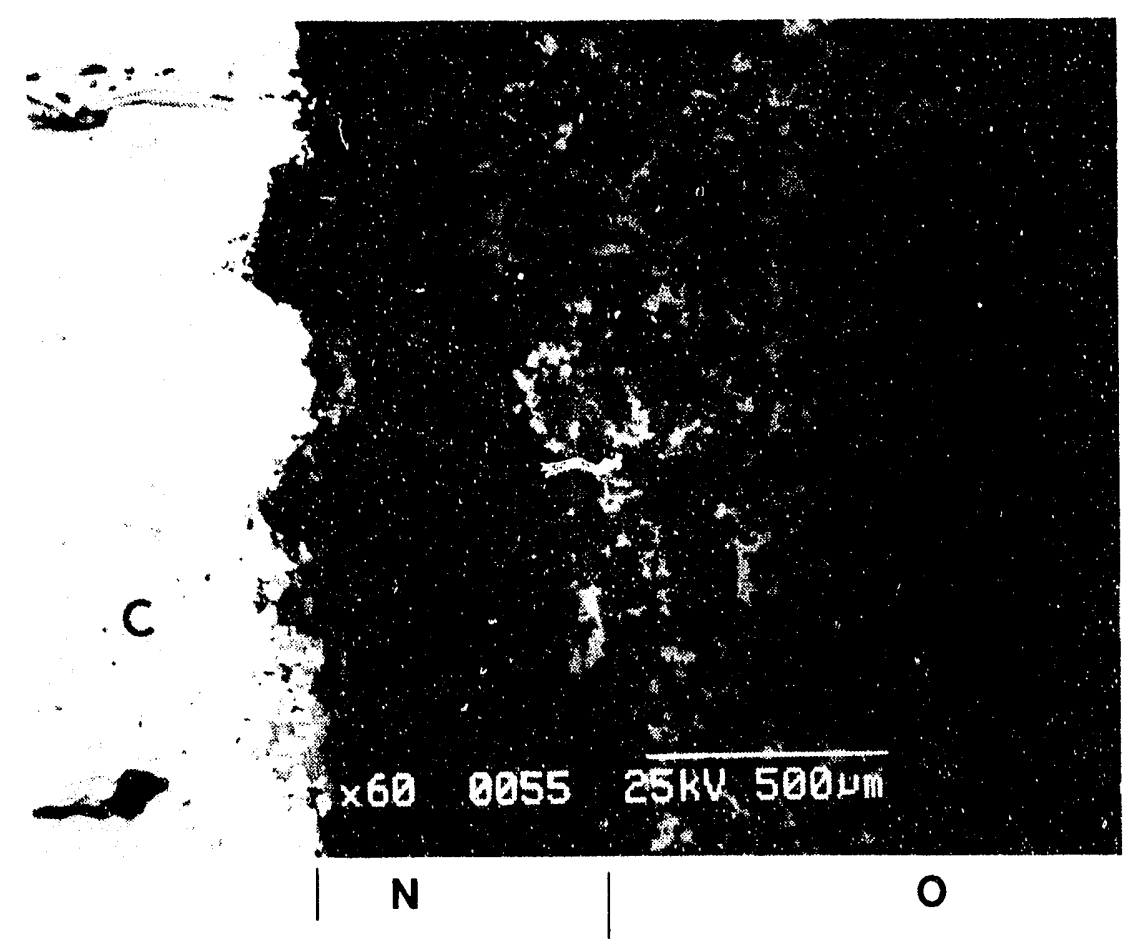

Figure 84. Anode $\mathrm{A} 1$, section 43. $\mathrm{O}=\mathrm{oxidized}$ region, $\mathrm{N}=\mathrm{Cu}$ depleted region, $\mathrm{C}=$ Cerox.

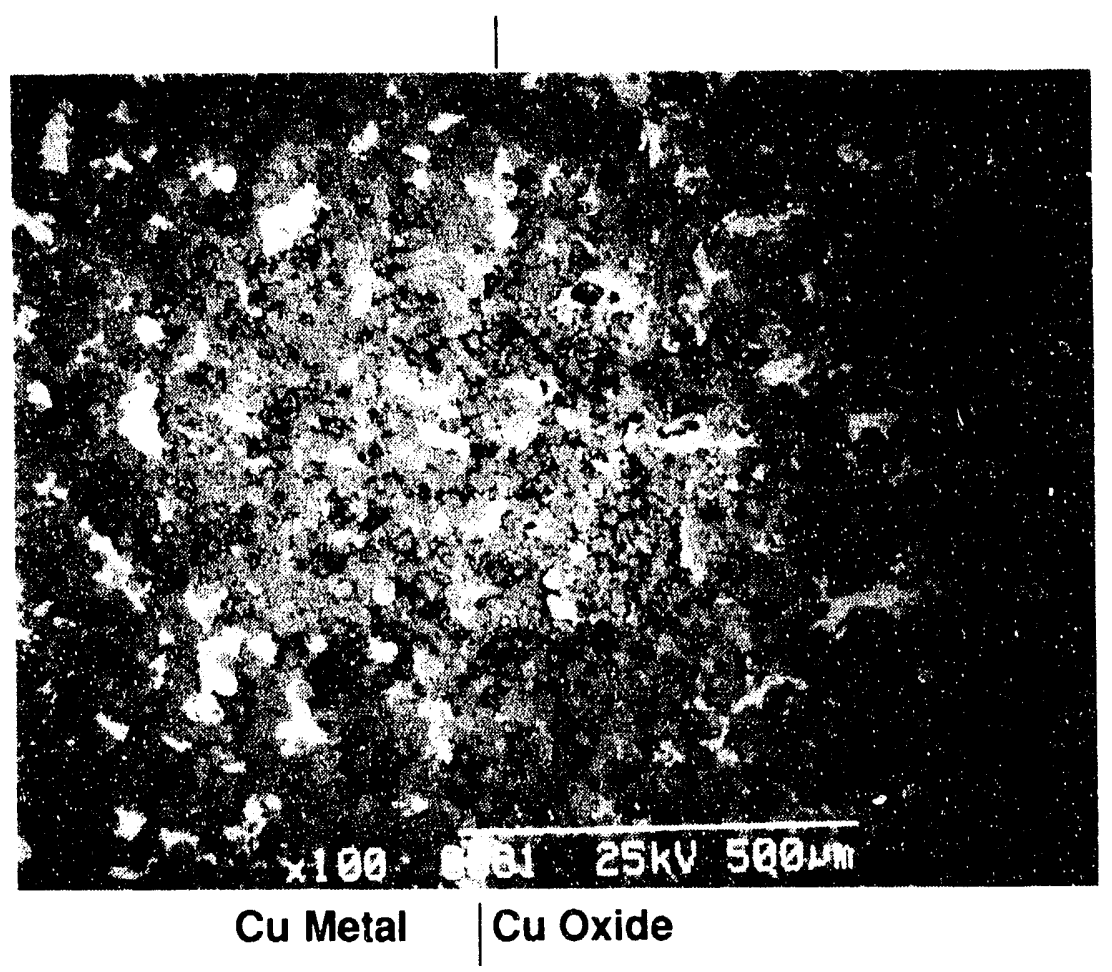

Figure 85. Anode C1, section 40. Boundary between $\mathrm{Cu}$ metal ard $\mathrm{Cu}-\mathrm{O}$ zones. 
ferrite composition, $\mathrm{NiFe}_{2} \mathrm{O}_{4}$, was detected in the surface reaction zone after only $1 \mathrm{~h}$ of operation. Therefore, it is not surprising to observe this composition in these anodes. The composition of the NiO does not significantly change from its original composition of $89.5 \mathrm{~mol}$ \& $\mathrm{Ni}$ anci $10.5 \mathrm{~mol} \% \mathrm{Fe}$. The only change observed is that quite often, minor amounts of $\mathrm{Al}$ and $\mathrm{Cu}$ are detected ( $<2$ molo each) in the ferrite and NiO phases. Al and $\mathrm{Cu}$ tend to substitute for $\mathrm{Fe}$ and $\mathrm{Ni}$ (respectively) in the ferrite phase while they substitute for $\mathrm{Fe}$ in the NiO phase.

These anodes probably underwent an oxygen chemical potential gradient across them such that the activity of oxygen decreased with distance into the sample. The inner areas would be expected to have a lower oxygen activity while the outer areas should have a higher activity. The composition of the ferrite phase can be explained using the phase equilibria for the $\mathrm{Ni}-\mathrm{Fe}-\mathrm{O}$ system. The phase diagram for this system at $1004^{\circ} \mathrm{C}$ as a function of $\mathrm{PO}_{2}$ is presented in Figure 86. This diagram shows that as the oxygen pressure of the system increases, the equilibrium concentration of the ferrite becomes more stoichiometric (less $\mathrm{Fe}$ ) and the $\mathrm{Fe}$ content in the Nio should also decrease. The trend from $\mathrm{Fe}$ rich ferrite to a stoichiometric $\mathrm{Ni}$ ferrite was observed in al.I the anodes after testing. However, there was little change in the composition of the NiO within the $\mathrm{Cu}$ depleted, $\mathrm{Cu}$ oxidized, central $\mathrm{Cu}$ metal region (tested), and the untested anodes, although the phase diagram predicts that the $F e$ content should decrease at higher $\mathrm{PO}_{2}$.

One very interesting observation is that the cation composition of the Cu-rich phase is the same in the $\mathrm{Cu}_{2} \mathrm{O}$ oxidation and $\mathrm{Cu}$ metallic zones. The composition is $\sim 95$ to $96 \% \mathrm{Cu}, 1$ to $1.5 \% \mathrm{Ni}, 1$ to $3 \% \mathrm{Fe}$, and 0 to $28 \mathrm{Al}$ (all mols).

The compositions of the ferrite, $\mathrm{NiO}$, and $\mathrm{Cu}$ rich phases in regions outside of the surface copper depletion zones for Anodes A1 and C1 are summarized in Table 7. These compositions are representative of both the copper oxidation and copper metal zones. Table 6 lists the compositions of the untested material and a comparison of Tables 6 and 7 readily shows that the $\mathrm{Ni}$ is depleted from the $\mathrm{Cu}$ rich phases. Also, the ferrite phase becomes more stoichiometric $\mathrm{NiFe}_{2} \mathrm{O}_{4}$ during operation because the $\mathrm{Fe}$ content decreases from 72 to $\sim 64$ molo. Table 7 suggests that the ferrite phase may be slightly $\mathrm{Fe}$ deficient. This is possible because Al, and a small amount of $\mathrm{Ni}$, can substitute for ferric iron $(+3)$ in the lattice of the spinel. Finally, these tables show that the composition of the Nio phases do not significantly change.

The microstructure at the substrate/CEROX interfacial region differs between the three samples. In section 40 of Anode A1, Figure 81 shows that a dark dense patchy region (D) is present at the substrate/CEROX interface, within the substrate. In Figure 87 , the CEROX coating (C) is at the right of the micrograph and the 


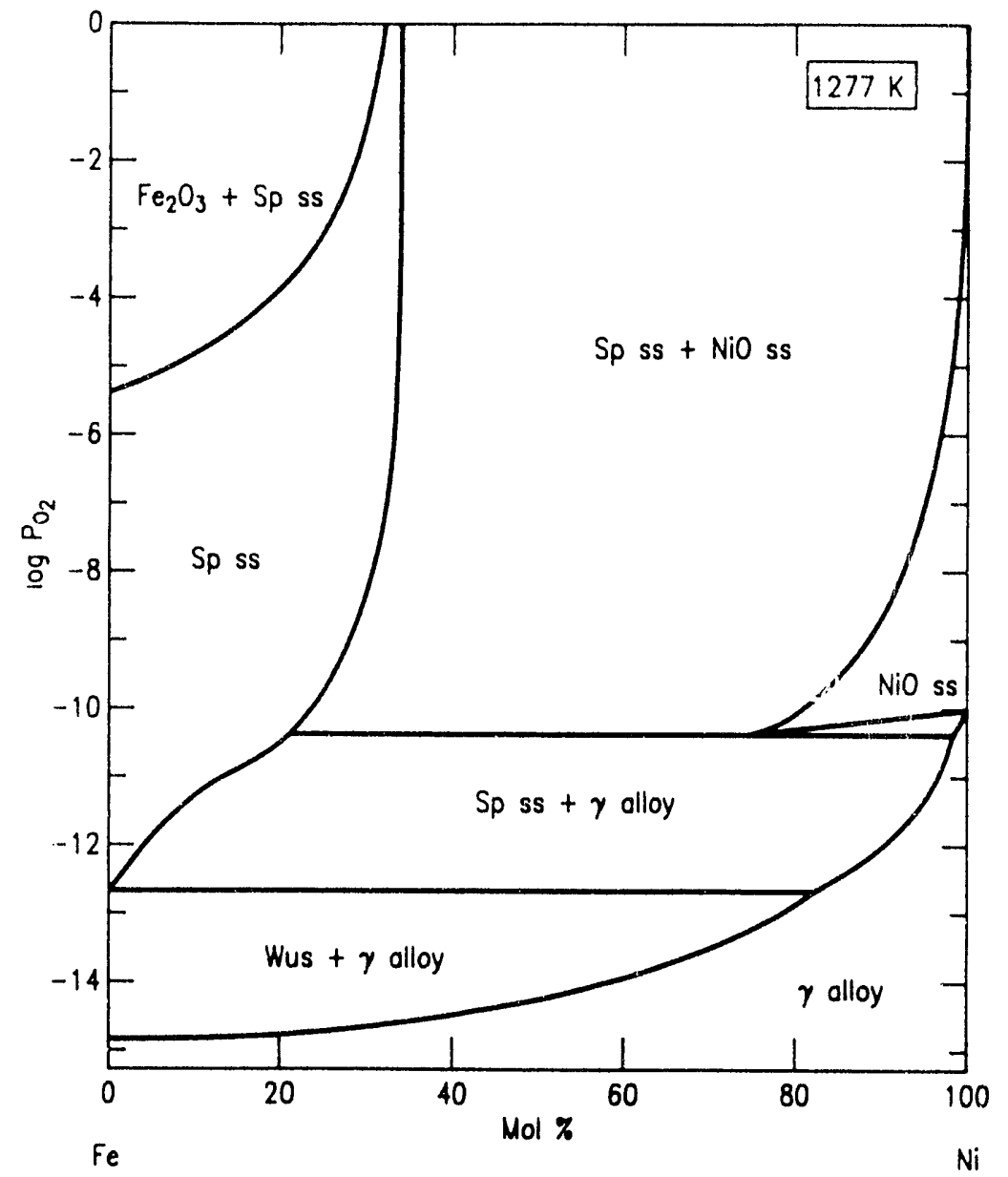

Eigure 86. Fe-Ni-O phase diagram at $1277 \mathrm{~K}$. 
Table 7. Average phase compositions in $\mathrm{Cu}$ metal and $\mathrm{Cu}$ oxide regions in Anodes $\mathrm{A} 1$ and $\mathrm{Cl}$ (in molo).

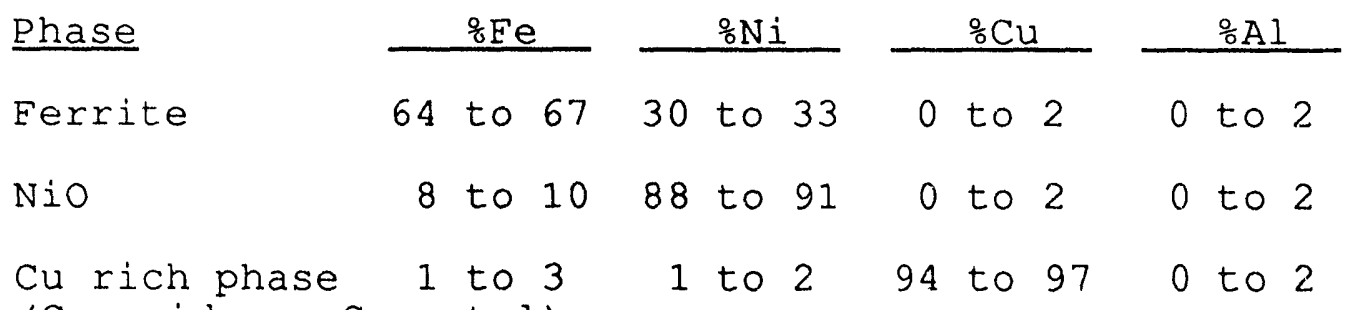

(Cu oxide or Cu metal) 


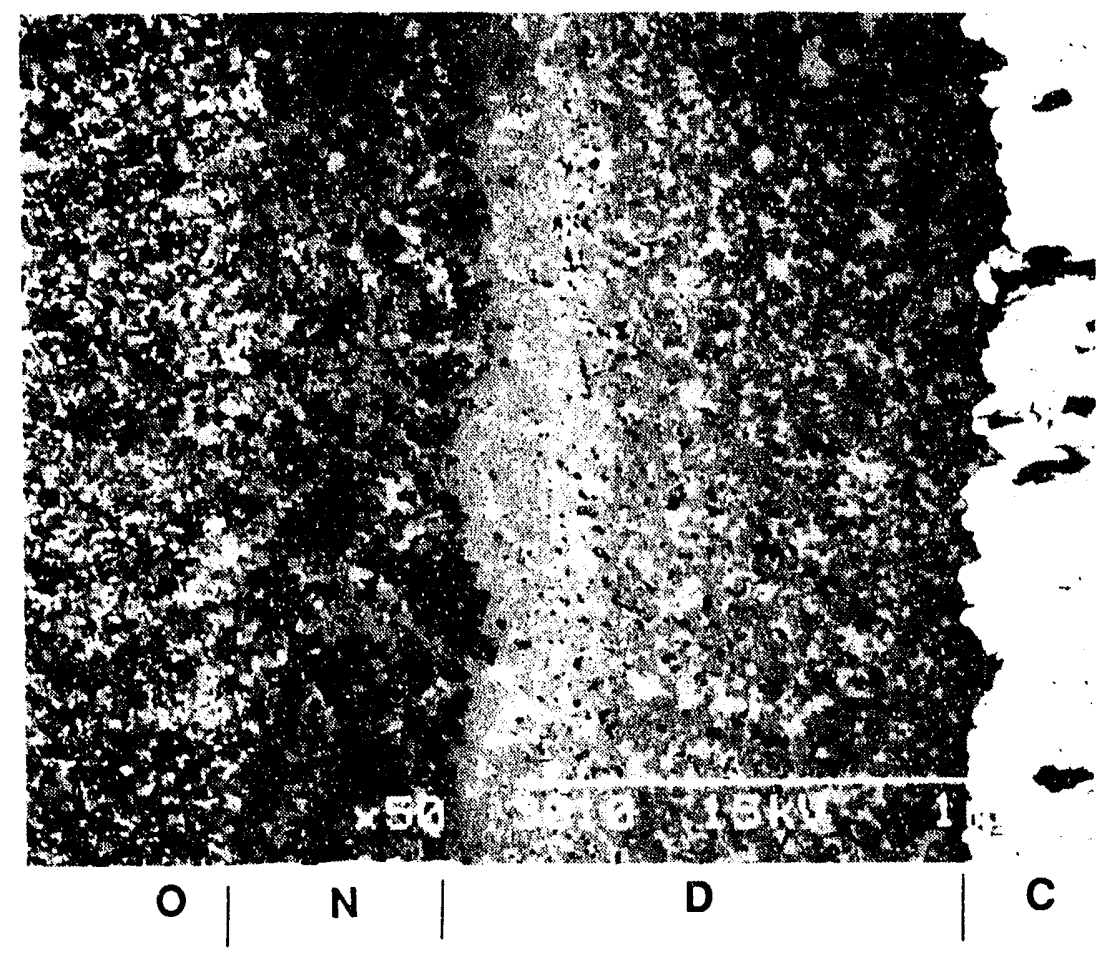

Figure 87. Exterior section of Anode $A 1$, section 40. $D=$ dense region, $\mathrm{N}=\mathrm{Cu}$ depleted zone, $\mathrm{O}=\mathrm{Cu}$ oxide region, $\mathrm{C}=$ Cerox.

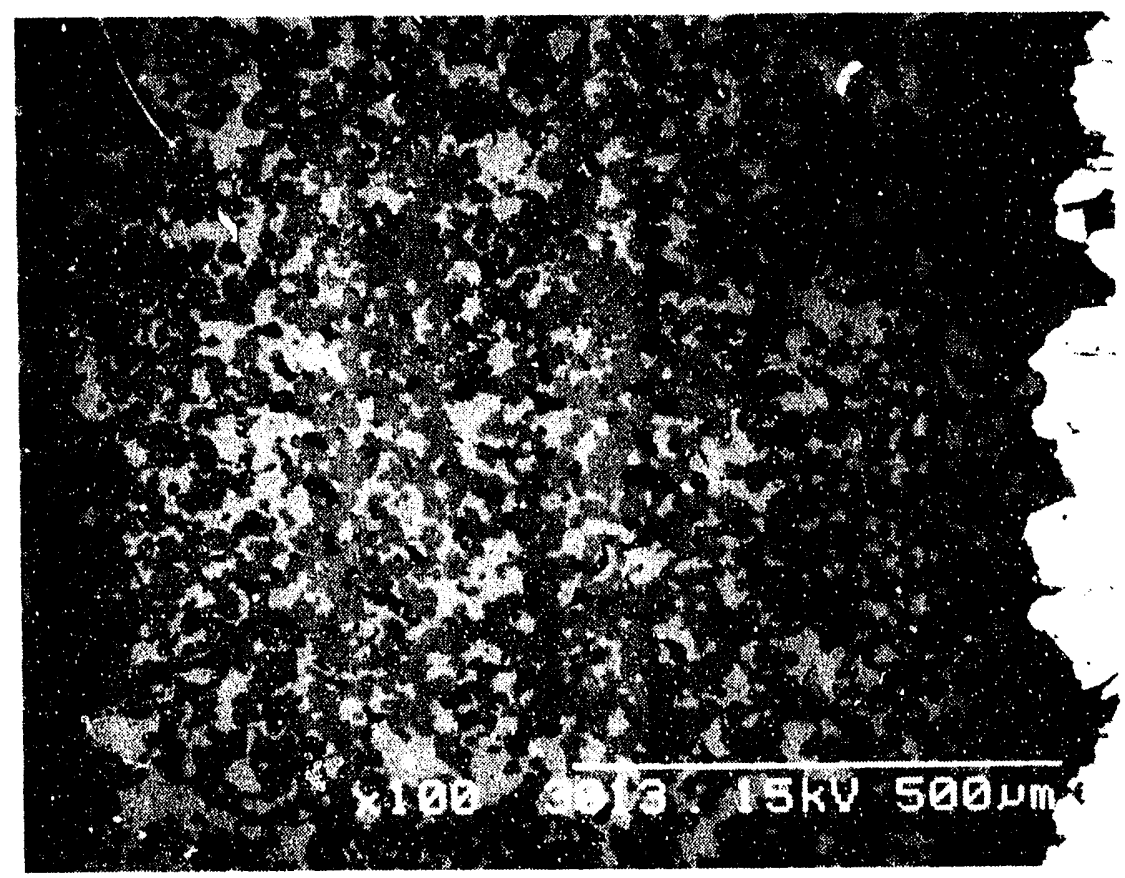

Figure 88. Higher magnification BEI of the dense area in Figure 87 (Anode A1, section 40 ). 
dense surface region (D) lies next to it. The Cu clepleted zone (N) is the dark porous band adjacent to the dense region and on the far left is the oxidation zone (0) where the individual bright features are $\mathrm{Cu}_{2} \mathrm{O}$ grains.

Figure 88 is a higher magnification BEI of the dense surface region. Although the region is denser than the surrounding substrate, pores (the black spots) are still present. The dense region consists of $\mathrm{NiO}$ (light gray) and the $\mathrm{Ni}$ ferrite (dark gray). The chemical compusition of the NiO phase near the outer surface is $71 \% \mathrm{Ni}, 7 \frac{8}{8} \mathrm{Fe}, 2.5 \% \mathrm{Al}$, and $19.5 \% \mathrm{Cu}$ but gradually changes to $64 \%$ $\mathrm{Ni}, 10.58 \mathrm{Fe}, 1.5 \% \mathrm{Al}$, and $248 \mathrm{Cu}$ near the $\mathrm{Cu}$ depletion zone (all values in molof). Similarly, the composition of the ferrite changed from $51 \% \mathrm{Fe}, 29 \% \mathrm{Ni}, 17 \% \mathrm{Al}$, and $3 \% \mathrm{Cu}$ near the surface to 63\% $\mathrm{Fe}$, $30 \% \mathrm{Ni}, 38 \mathrm{Al}$, and $48 \mathrm{Cu}$ near the $\mathrm{Cu}$ depletion zone. Thus, significant amounts of $\mathrm{Cu}$ is dissolved in the NiO phase while Al is dissolved in the ferrite phase.

No $\mathrm{Cu}$ metal or Cu-rich oxide phase is present in this region. Rather, the majority of the $\mathrm{Cu}$ that is present in this layer exists as the $\mathrm{Cu}^{2+}$ ion in the Nio phase. This can be considered to be a solid solution of NiO-CuO because the solubility limit of CuO in pure $\mathrm{NiO}$ is 28 to 35 molo CuO. ${ }^{16,17}$ However, it is possible that this solubility limit could be lower in the presence of 7 to 10 molo FeO. Knowledge of the phase behavior of the $\mathrm{Cu}$ allows us to estimate the oxygen activity gradient within the anode. This can be accomplished by following the transformation of the copper from $(\mathrm{Ni}, \mathrm{Cu}) \mathrm{O}$ (ss) $\rightarrow \mathrm{Cu}_{2} \mathrm{O} \rightarrow \mathrm{Cu}$ metal. The activity of $\mathrm{CuO}$ in $(\mathrm{Ni}, \mathrm{Cu}) \mathrm{O}$ solid solutions at $1000^{\circ} \mathrm{C}$ has been measured in ${ }^{16}$ and the thermodynamic data for the $\mathrm{Cu}-\mathrm{O}$ system has been published ${ }^{12}$. Using these two sources, it was calculated that the reaction $\mathrm{Ni}_{0.76} \mathrm{Cu}_{0.24} \mathrm{O}$ $\rightarrow \mathrm{Cu}_{2} \mathrm{O}$ occurs at an oxygen activity of $\sim 5 \times 10^{-2} \mathrm{~atm}$ while $\mathrm{Cu}_{2} \mathrm{O} \rightarrow \mathrm{Cu}$ (metal) occurs at an oxygen activity of $4 \times 10^{-7}$ atm.

Significant amounts of aluminum were found in the ferrite phase near the substrate/CEROX interface, but the Al content decreased further into the substrate within the dense region. Alcoa also observed diffusion of Al into the ferrite phase of their Cu-cermet anodes. ${ }^{3}$ The phase diagram of the $\mathrm{Fe}-\mathrm{Al}-\mathrm{O}$ system (constructed from 1280 to $\left.1500^{\circ} \mathrm{C}\right)^{18}$ shows that $\mathrm{Ee}_{3} \mathrm{O}_{4}$ and $\mathrm{FeAl}_{2} \mathrm{O}_{4}$ can form a complete solid solution. In addition, up to 20 mols $A l$ can be easily dissolved in $\mathrm{Fe}_{3} \mathrm{O}_{4}$ over 6 orders of magnitude of oxygen pressure. The $\mathrm{Ni}-\mathrm{Al}-\mathrm{O}$ phase diagram ${ }^{19}$ shows that $\mathrm{NiAl}_{2} \mathrm{O}_{4}$ and $\mathrm{NiO}$ coexist as the stable phases at $980^{\circ} \mathrm{C}$ and $\mathrm{PO}_{2}>5 \times 10^{-6}$ atm. Thus, it is not surprising to observe Al in the fe-rite phase, especially because a large driving force exists for aluminum diffusion into the material because of the aluminum concentration gradient that exists at the surface.

A $10 \mu \mathrm{m}$ thick reaction layer exists between the dense region and the CEROX coating. A BEI of this layer is presented in Figure 89, 


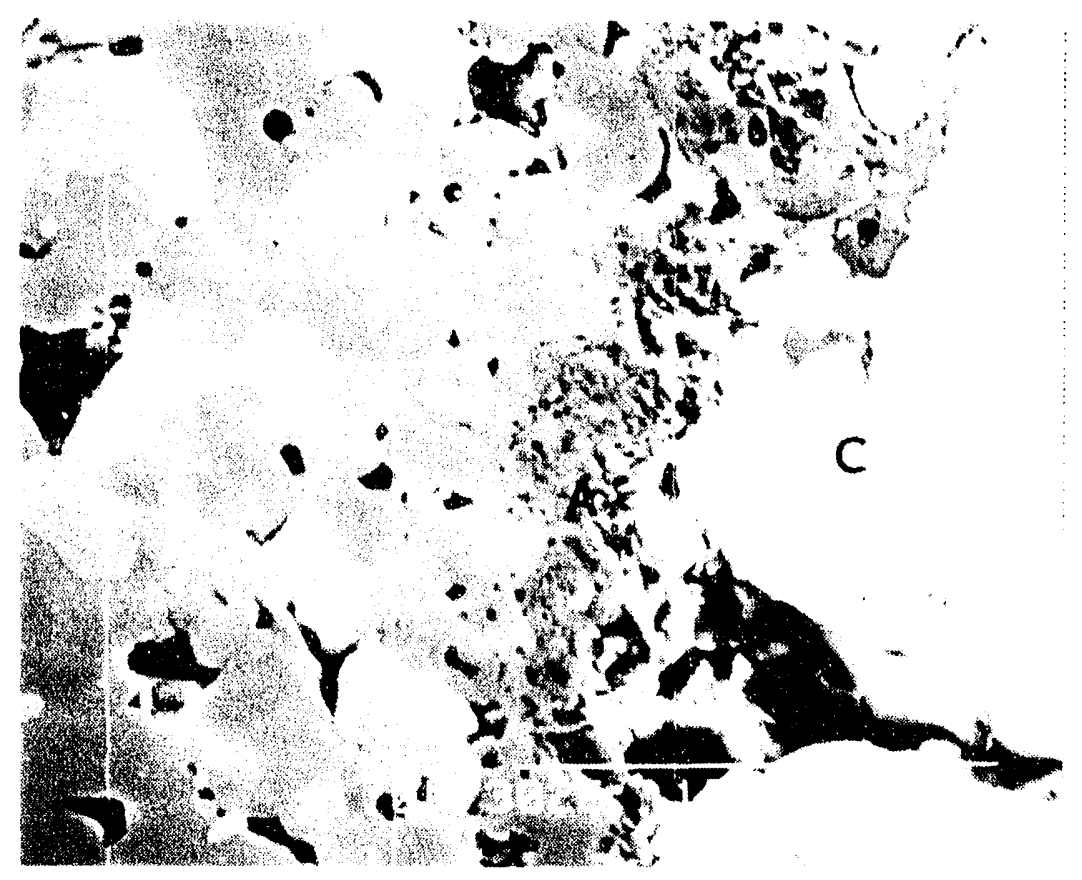

Figure 89. A porous $10 \mu \mathrm{m}$ thick aluminate layer (A) is between the Cerox (C) and the substrate. 
which shows that this layer appears to be porous. EPMA was performed in two spots of this layer and both spots had a composition that is $\sim 67 \% \mathrm{Al}, 11.5 \% \mathrm{Fe}, 18 \% \mathrm{Ni}$, and $2.5 \% \mathrm{Cu}$ (molo). The light element window was used in the analysis and a large oxygen peak was detected. This EPMA coupled with the above discussion suggests that the layer is a mixed aluminate with the composition, ( $\mathrm{Ee}, \mathrm{Ni}) \mathrm{Al}_{2} \mathrm{O}_{4}$. However, $\mathrm{x}$-ray diffraction was not performed to confirm this hypothesis.

The microstructure at the outer surface of Section 43 of Anode Al is shown in Figures 90 and 91 . Figure 90 is a low magnification SEI that shows that a dense surface layer (D) lies between the CEROX coating and the porous copper depletion layer. The layer in this section is thinner and less continuous than that observed in Anode Al Section 40. Figure 91 shows the substrate/CEROX interface in more detail. In a few isolated areas at the interface, $1.5 \mu \mathrm{m}$ thick interlayers exist that are an oxide containing 96.7 molo Cu and $3.3 \mathrm{~mol} 8 \mathrm{Al}$. However, it was mentioned above that the composition of $\mathrm{Cu}$ in the $\mathrm{Cu}$ rich phases in the bulk of the material is typically 96 molo so it cannot be determined if the microstructure of this feature is strictly because of surface effects.

The top of Figure 91 shows a $10 \mu \mathrm{m}$ thick layer at the interface that is very similar in structure and composition to the Al rich layer that was shown in Figure 89. The NiO within the dense region, however, unlike section 40, contained no significant amounts ( $>2$ molo) of $\mathrm{Cu}$. The remaining behavior of this sample outside of the surface region is very similar to that of section 40 .

Eigures 92 and 93 shows two BEI of the interfacial region for Section 40 of Anode $\mathrm{Cl}$. These micrographs show that the interface of this sample is distinctly different than the samples from anode A1. This interface has a columnar duplex structure that is comprised of a $\mathrm{Ce}$ fluoride (F) and a $\mathrm{Cu}$ oxide (O). The CEROX coating $(C)$ is the bright layer that appears similar in contrast to the ce fluoride grains (the bright lines in the SEM photo are an artifact of the carbon coating applied to the sample to make it conductive for SEM analysis). In the CEROX coating, only cerium is detected but in the Ce fluoride, calcium is found in addition to $\mathrm{Ce}$ and $F$. The $C u$ phase in the duplex region is similar to $\mathrm{Cu}$ oxide in the bulk of the sample because it contains 98 molo $\mathrm{Cu}$ and minor amounts of $\mathrm{Al}, \mathrm{Ni}$, and $\mathrm{Ee}$, in addition to oxygen.

On the left of the duplex layer in Figure 93 is a denser area consisting of the ferrite phase. The composition of the ferrite phase in this layer is $22 \% \mathrm{Al}, 46.5 \% \mathrm{Fe}, 27.5 \frac{8}{8} \mathrm{Ni}$, and $48 \mathrm{Cu}$ (molo). At lower magnification (Figure 92) the dark region to the left of the ferrite layer is the beginning of the copper depletion zone. The ferrite phases within this region (at $500 \mu \mathrm{m}$ into the anode) becomes nearly stoichiometric. Similarly, the Nio phase 


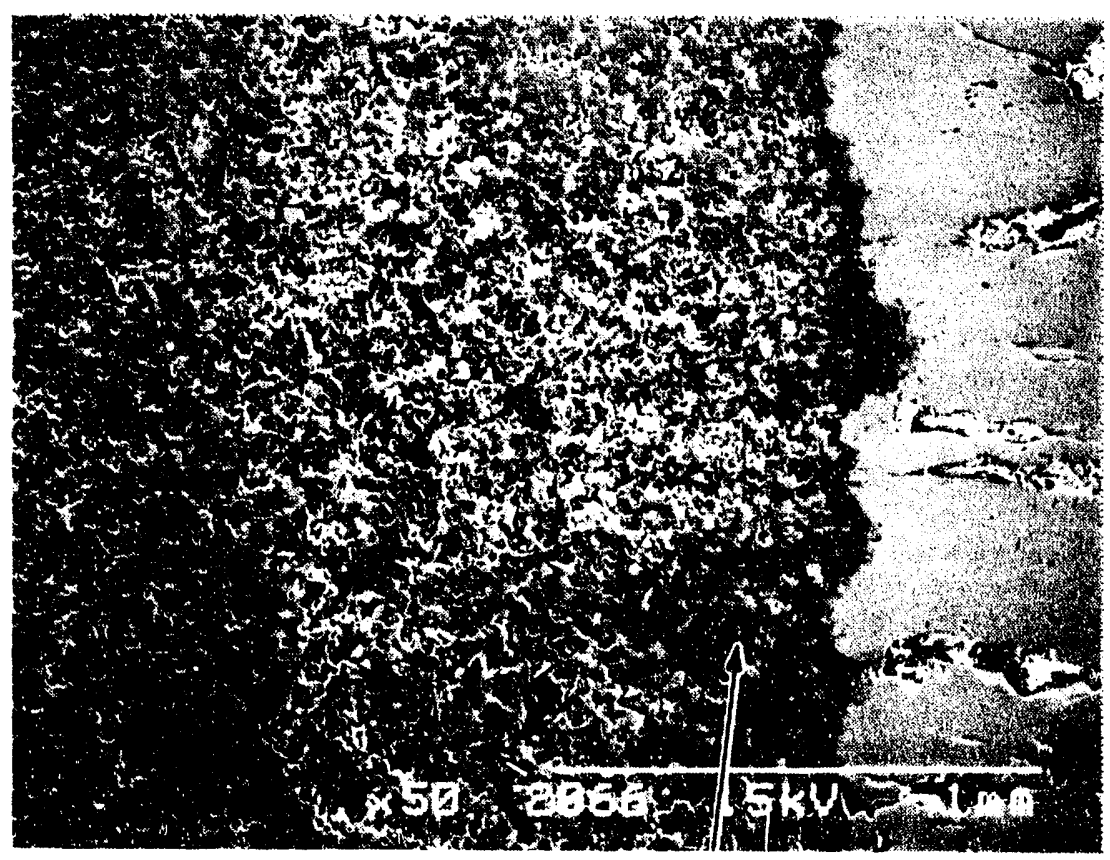

D

Figure 90. Anode $A 1$, section 43 (SEI) showing the dense region (D) next to the cerox coating.

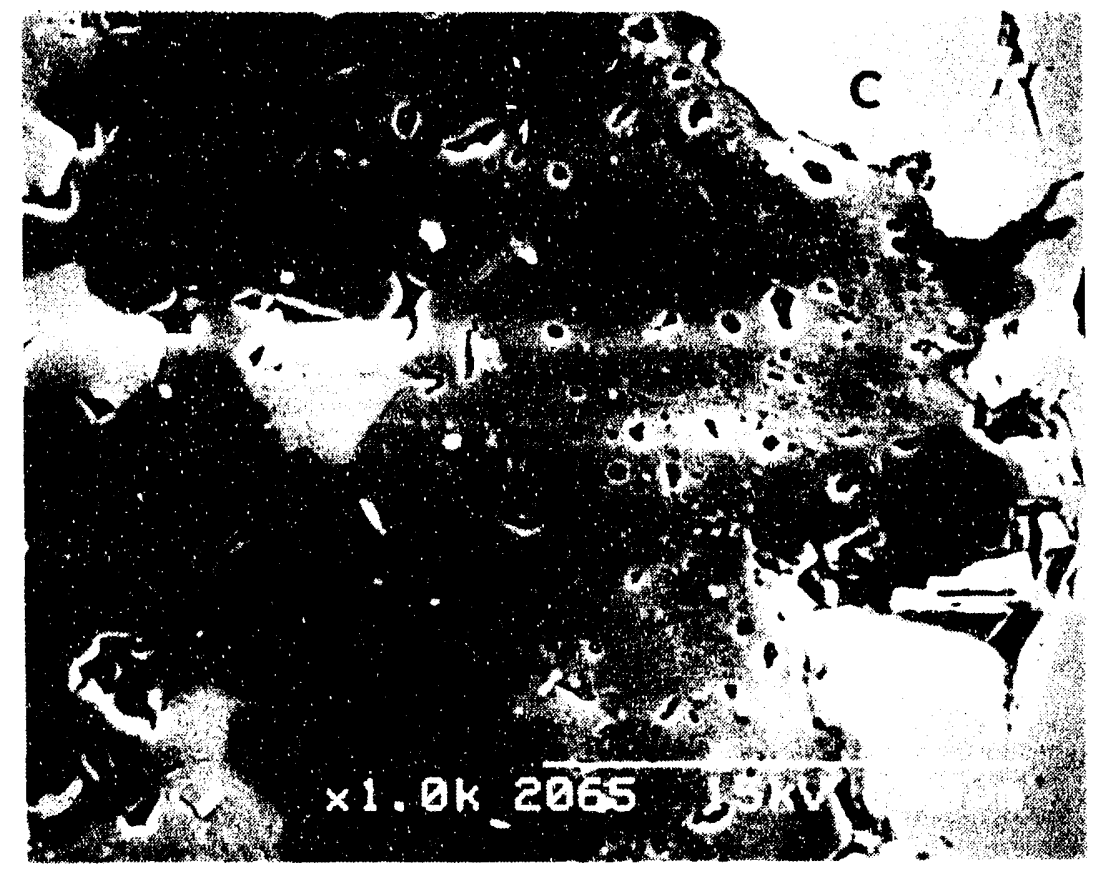

Figure 91. Anode A1, section 43, at the cerox-substrate interface. 


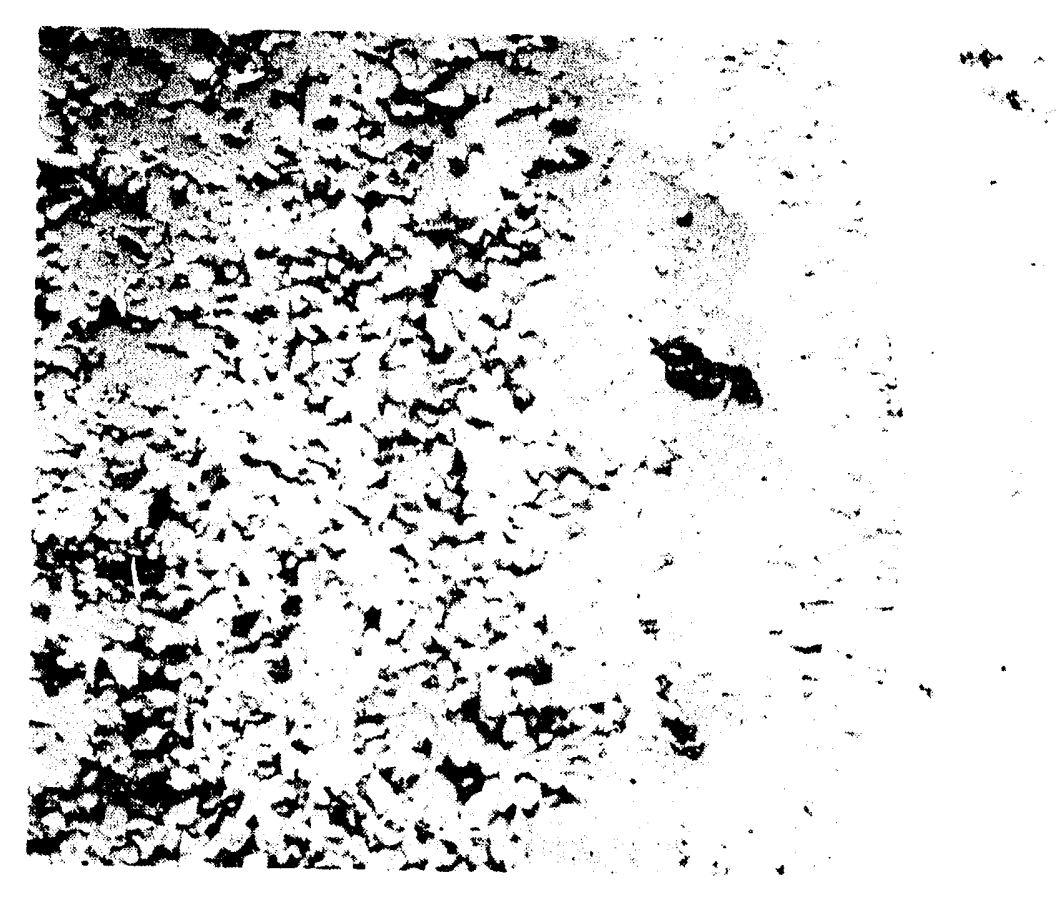

Figure 92. Anode $\mathrm{C1}$, section 40, interface between the cerox coating (far right) and the substrate (left).

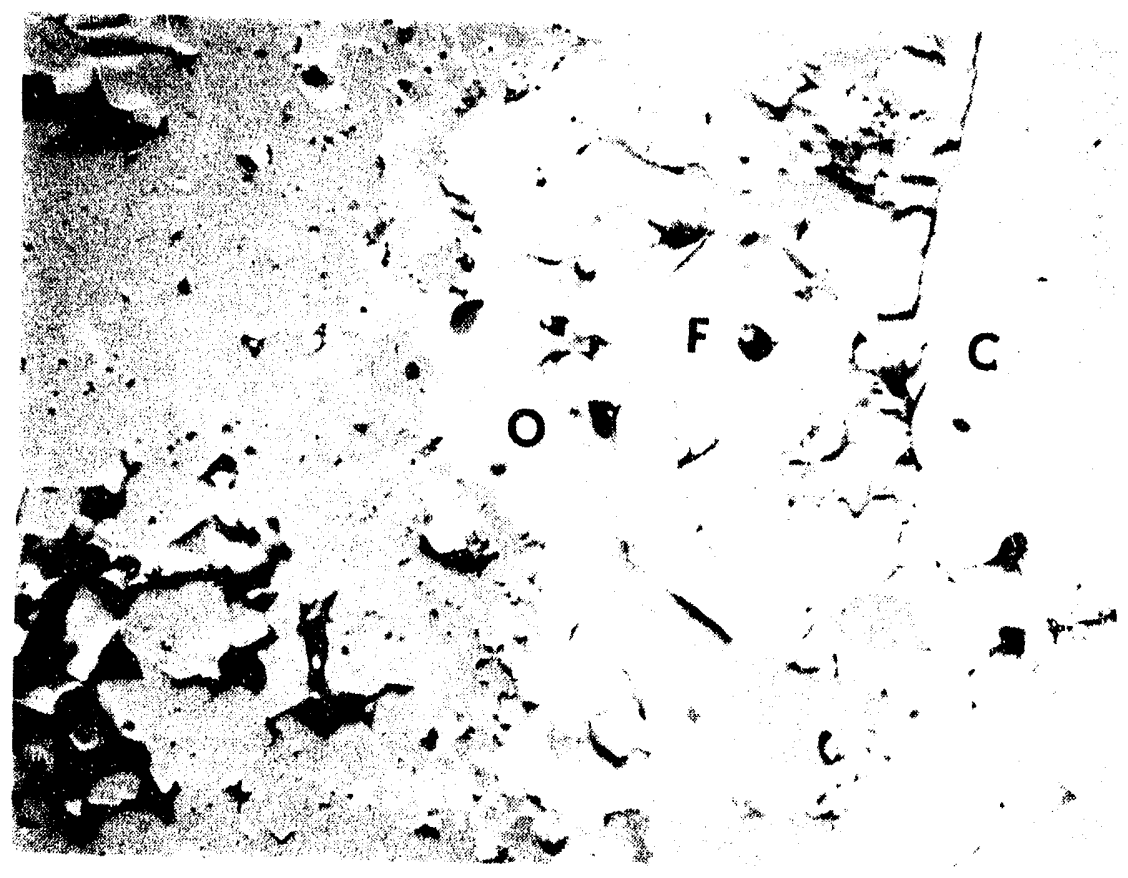

Figure 93. Anode $\mathrm{C} 1$, section 40, duplex structure next to the Cerox (C), consisting of Ce Fluoride (F) and Cu oxide (O) . 
near the surface is $1.28 \mathrm{Al}, 6.9 \% \mathrm{Fe}, 78.3 \% \mathrm{Ni}$, and $13.6 \% \mathrm{Cu}$ (mol\%), but the $\mathrm{Cu}$ content rapidly decreases and the Nio composition approaches its original composition of 90 molo $\mathrm{Ni}$, $8 \mathrm{~mol} \frac{\mathrm{Fe}}{\mathrm{Fe}}$ (with the remainder being $\mathrm{Al}$ and $\mathrm{Cu}$ ).

Anode E1-614 h

Anode El was run in the cell for the entire test and operated under a range of $C D$, bath composition, and temperature. The section examined was taken from the corner of the northeast side of the anode. The oxidation zone in this section was $17 \mathrm{~mm}$ thick and two metallographic mounts were needed to prepare a complete cross section from the exterior into the region where $\mathrm{Cu}$ metal was present.

A macroscopic photograph of the polished cross section near the CEROX/substrate surface of anode El is shown in Figure 94. The macroscopic color differences were helpful in distinguishing the different zones in the anode. The CEROX coating located at the top of the photo is $8 \mathrm{~mm}$ thick. A large pore in the right side of the CEROX is filled with the polymer mounting medium (M). The vertical line in Figure 94 shows the path along which the microstructure was evaluated with the SEM/EDX. A crack exists in the anode $\sim 2$ to 2.5 $\mathrm{mm}$ from the surface. The top part of this crack is red (macroscopically) and red specks are observed in a zone below it.

Secondary electron micrographs of the outer $2 \mathrm{~mm}$ of the substrate are shown in Figures 95 and 96. The right side of Figure 96 overlaps with the left side of Figure 95. Fi.yure 95 shows that a dense zone exists at the substrate/CEROX interface and this zone extends $\sim 1 \mathrm{~mm}$ into the substrate. This feature corresponds to the dark band that is present below the CEROX coatirig in Figure 94 . It was found that this region is very similar to the dense region that exists near the surface of Section 40 in Anode A1 (see Figure 87). Like Al, the composition of the NiO phase (in molor) in El contains 18 to $21 \% \mathrm{Cu}$, however, the $\mathrm{Fe}$ content of this region is only 1 to 6\% compared to 7 to $9 \%$ in Anode Al. The $\mathrm{Ni}$ content in the NiO is 71 to $78 \%$ while the Al content is 1 to $2 \%$. In Section 40 of Anode Al, the $\mathrm{Ni}$ content of the $\mathrm{NiO}$ phase was 66 to $71 \%$.

Significant amounts of $\mathrm{Al}$ were detected in the ferrite phase but the composition of this ferrite is slightly different from other ferrite phases in the other samples. This phase contains 4 to 8 mol\% $\mathrm{Cu}$ and 19 to $61 \mathrm{~mol} \% \mathrm{Al}$. Thus, the ferrite in this region of the sample contains more $C u$ then the ferrite phases in section 40 Anode A1. It appears that the Al in the ferrite preferentially substitutes for $\mathrm{Fe}$ (as Al content goes up, Fe content goes down), as was also observed in the other samples.

Like the other anodes examined, this anode also has a copper depletion zone $\sim \mathrm{mm}$ into the substrate (Eigure 96, layer D). The composition of the $\mathrm{NiO}$ phase in the copper depletion zone is the 


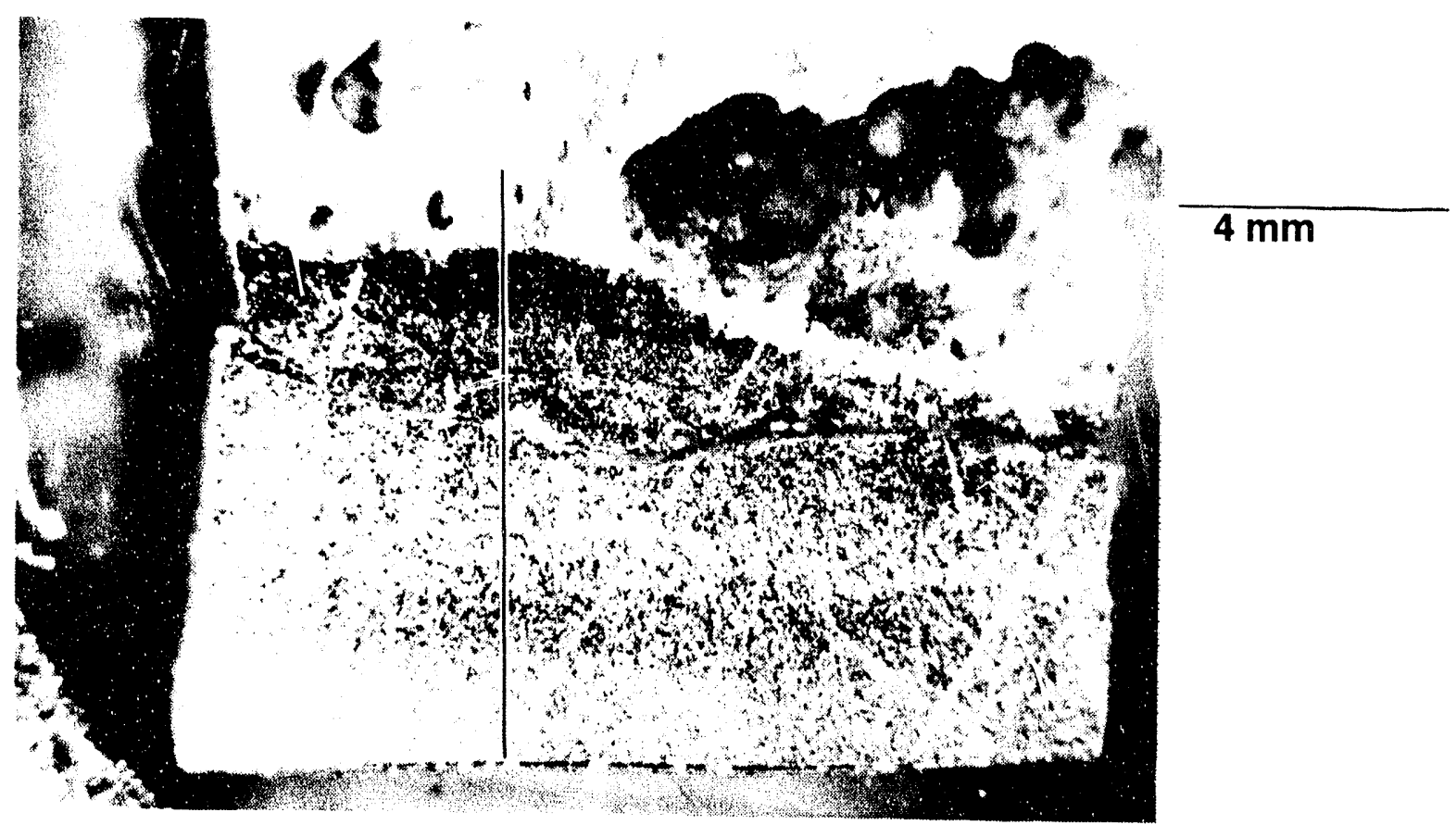

Figure 94. Macroscopic section of Anode E1 from the northeast side. 


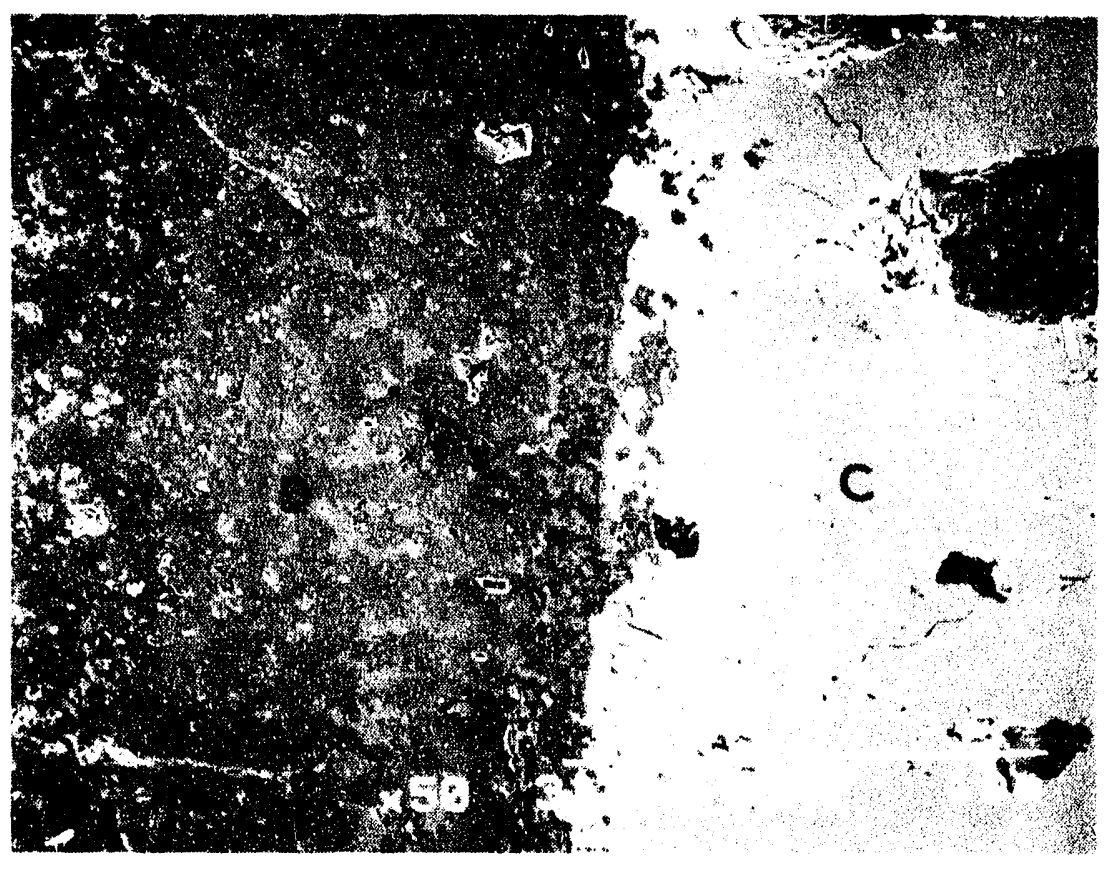

Figure 95. Intertace between the cerox and substrate in Anode E1. $C=$ Cerox, $D=$ dense, $C u$ depleted zone.

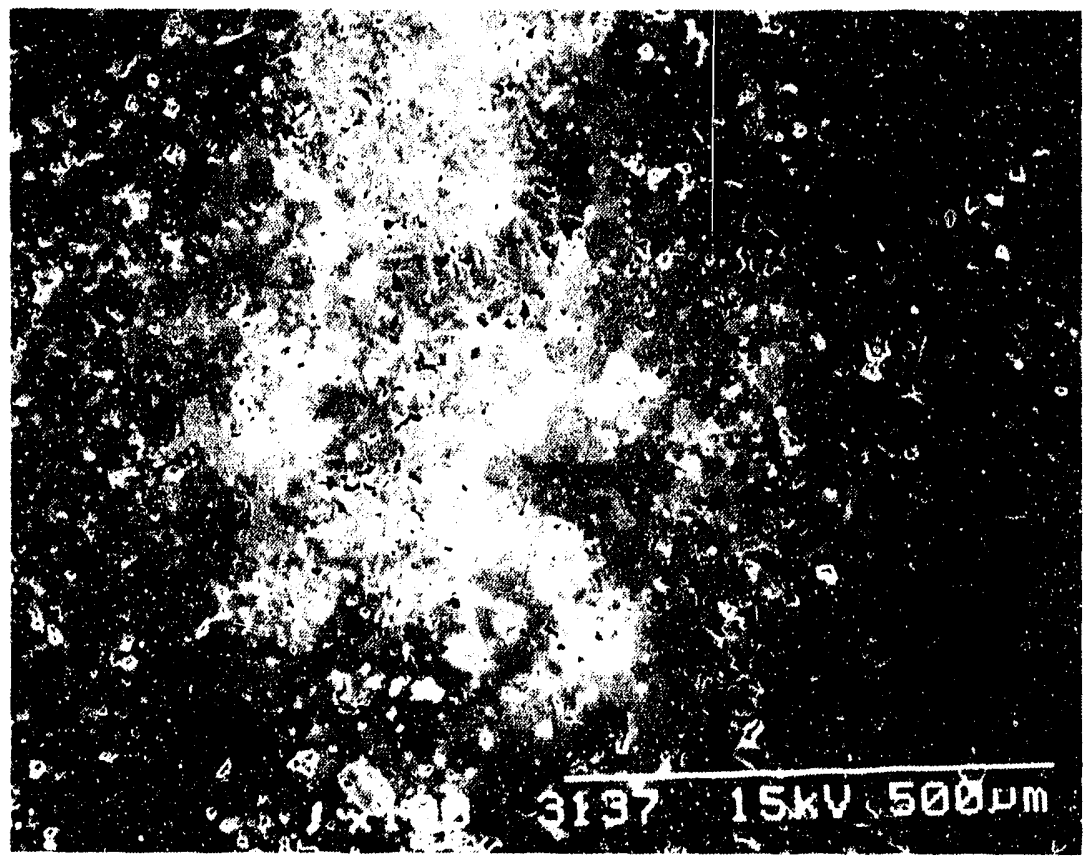

Figure 9E. Porous zone between $\mathrm{Cu}$ depletion zone (D) and the $\mathrm{Cu}$ O region further into the interior of $\mathrm{EI}$. 
same as the composition of the $\mathrm{NiO}$ in the dense region. The ferrite in the $\mathrm{Cu}$ depletion zone is nearly stoichiometric $\mathrm{NiFe}_{2} \mathrm{O}_{4}$, as was noted in the other anodes. The composition of the ferrite phase remains fairly constant ( 1 mol\% Al, 64.5 mol\% Fe, 33.5 mol\% $\mathrm{Ni}$, and 1 mols $\mathrm{Cu}$ ) throughout the rest of the anode.

Figure 94 shows that a crack exists 2 to $2.5 \mathrm{~mm}$ into the substrate. Figures 97 and 98 are BEI micrographs of both sides of the crack. Figure 97 shows the region to the right (exterior) of the crack, including the $\mathrm{Cu}$ depletion zone $(\mathrm{N})$. The isolated bright spots present in the $\mathrm{Cu}$ depletion zone are a Ce fluoride. Minor amounts ( $<3 \mathrm{~mol} \%$ ) of the Ce fluoride (with some $\mathrm{Ca}$ ) are present throughout the anode.

The large light colored band next to the crack in Figure 97 corresponds to the red zone that was macroscopically observed in Figure 94. EDS analysis shows that this feature is a Cu oxide (97 mol: $\mathrm{Cu}$ with 3 molo of $\mathrm{Fe}+\mathrm{Ni}$ ). Because $\mathrm{Cu}_{2} \mathrm{O}$ often has a red color, which is caused by internal reflections within its structure ${ }^{20}$, the red phase on both sides of the crack is probably $\mathrm{Cu}_{2} \mathrm{O}$ instead of $\mathrm{CuO}$.

As shown in Eigure 97, there are alternating layers of Cu depletion (N) and "normal" oxidized (O) microstructure ( 250 $\mu \mathrm{m}$ wide). All layers contain $\mathrm{NiO}$ and $\mathrm{NiFe}_{2} \mathrm{O}_{4}$, but only the oxidized zone also contains $\mathrm{Cu}$ oxide (light in BEI micrographs). The Nio contains little $\mathrm{Cu}$ within the oxidized and the second (left) $\mathrm{Cu}$ depletion zone. The composition of the NiO phase in those layers becomes

$1 \mathrm{~mol} \div \mathrm{Al}, 3 \mathrm{~mol} \% \mathrm{Fe}, 93 \mathrm{~mol} \% \mathrm{Ni}$ and $3 \mathrm{~mol} \% \mathrm{Cu}$ as compared to 18 to $21 \mathrm{~mol} \% \mathrm{Cu}$ in the $\mathrm{NiO}$ in the outer dense and $\mathrm{Cu}$ depleted region. on the other side of the crack (Figure 98) there is a Cu depletion zone $300 \mu \mathrm{m}$ thick and then a "normal" oxidized region containing $\mathrm{NiFe}_{2} \mathrm{O}_{4}$, NiO, and $\mathrm{Cu}_{2} \mathrm{O}$. Therefore, $\mathrm{Cu}_{2} \mathrm{O}$ is concentrated along the crack while a $\mathrm{Cu}$ depleted zone is present on either side of the $\mathrm{Cu}_{2} \mathrm{O}$ layer.

Figures 99 and 100 show the microstructure progressing from Figure 98 into the interior of the metallographic mount. Throughout the region $\mathrm{NiO}, \mathrm{NiFe}_{-} \mathrm{O}_{4}$, and $\mathrm{Cu}_{2} \mathrm{O}$ are present. The only differences in the composition of the three phases compared to the compositions described above is in the $\mathrm{NiO}$ phase. The $\mathrm{Al}$ and $\mathrm{Fe}$ content does not change but the $\mathrm{Ni}$ content decreases from 93 mol\% near the crack to 85 mol\% at the interior edge of the mount while the copper content increases from 3 to 11 molo.

The dark gray regions between the individual grains in Figures 98,99, and 100 is a two-phase mixture of frozen cryolite and a solid solution of nickel and aluminum fluoride. EPMA was performed on two spots of the frozen fluoride feature where the spots were separated by a distance of only $15 \mu \mathrm{m}$. The cation composition of the cryolite phase was $43.4 \mathrm{~mol} \% \mathrm{Al}, 52.8 \mathrm{~mol} \% \mathrm{Na}, 1.5 \mathrm{~mol} \% \mathrm{Ca}$ and $<1$ molo each of $\mathrm{Fe}, \mathrm{Ni}$, and $\mathrm{Cu}$. Converting these to weight 


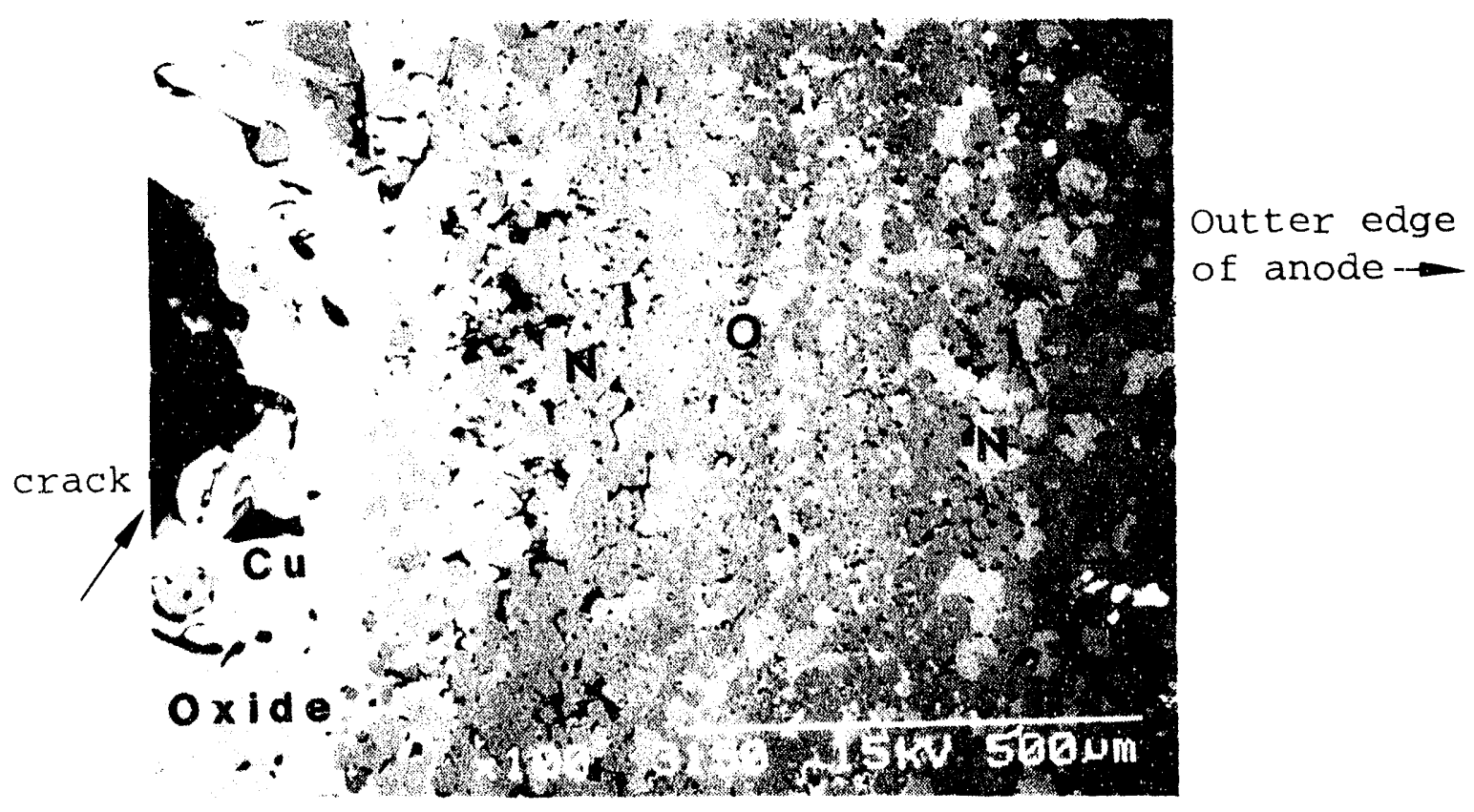

Figure 97. Anode E1 next to a crack. Alternating layers of $\mathrm{Cu}$ depleted zones (N) and oxidized zones (O) are present. Cu oxide occurs along the crack.

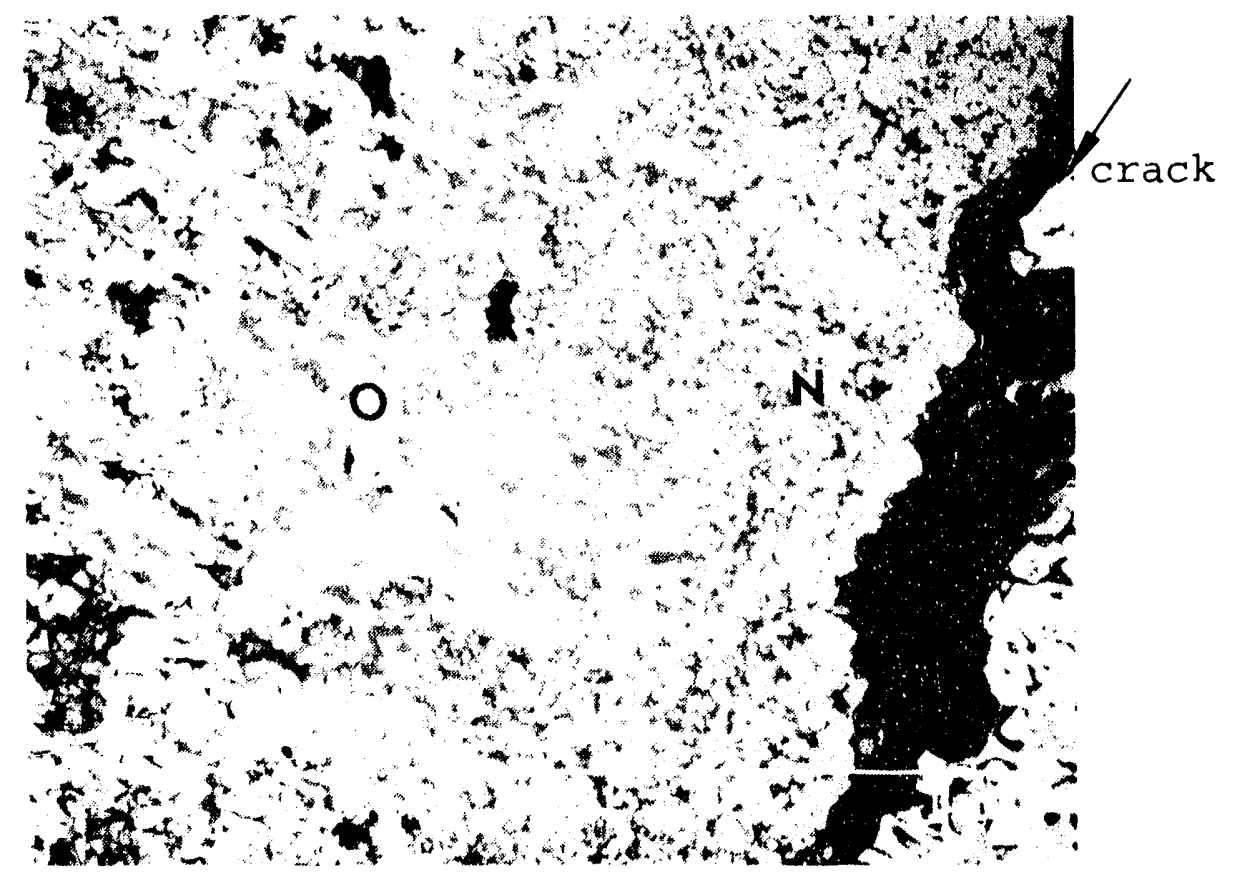

Figure 98. Anode E1, on the left (interior) side of the crack in Figure 97. A Cu depleted zone (N) occurs next to the crack while further into the interior $\mathrm{Cu}$ oxide (O) is present with $\mathrm{NiO}$ and $\mathrm{NiFe}_{2} \mathrm{O}_{4}$. 


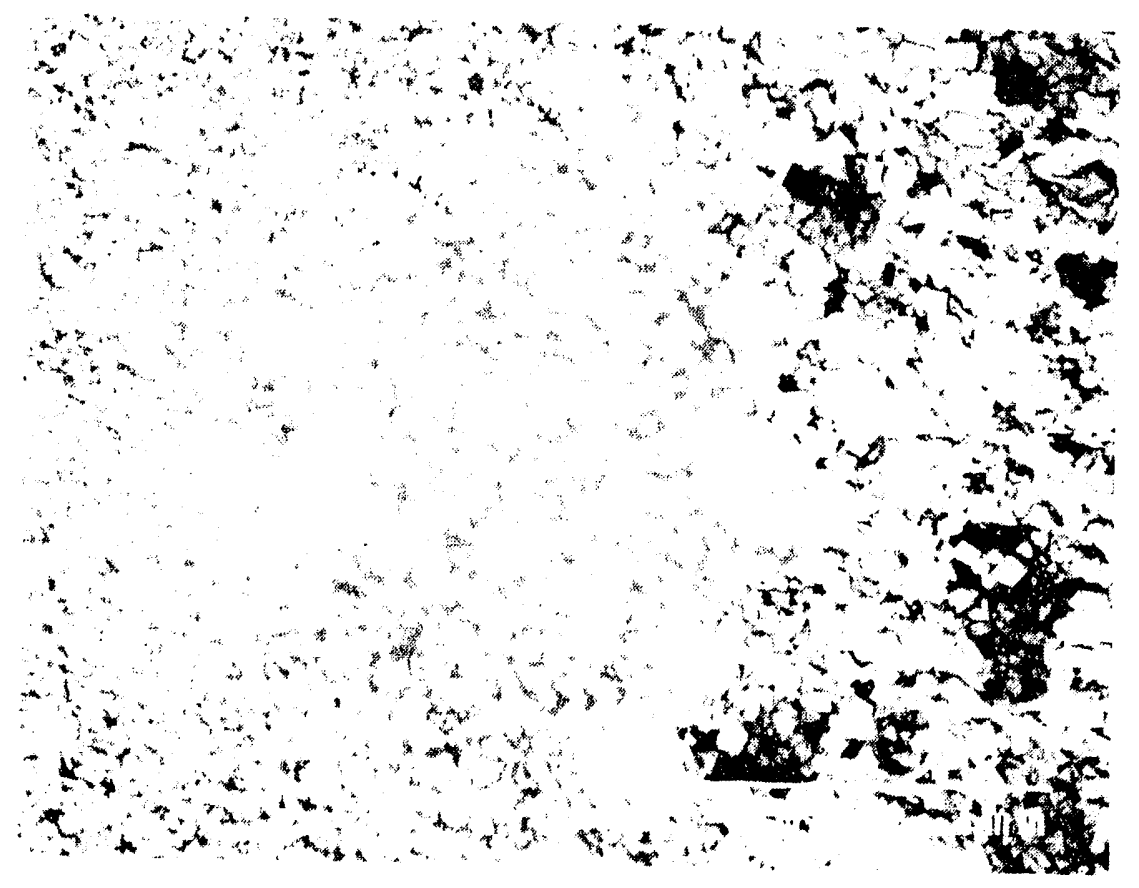

Figure 99. Interior of the oxidized zone in Anode E1.

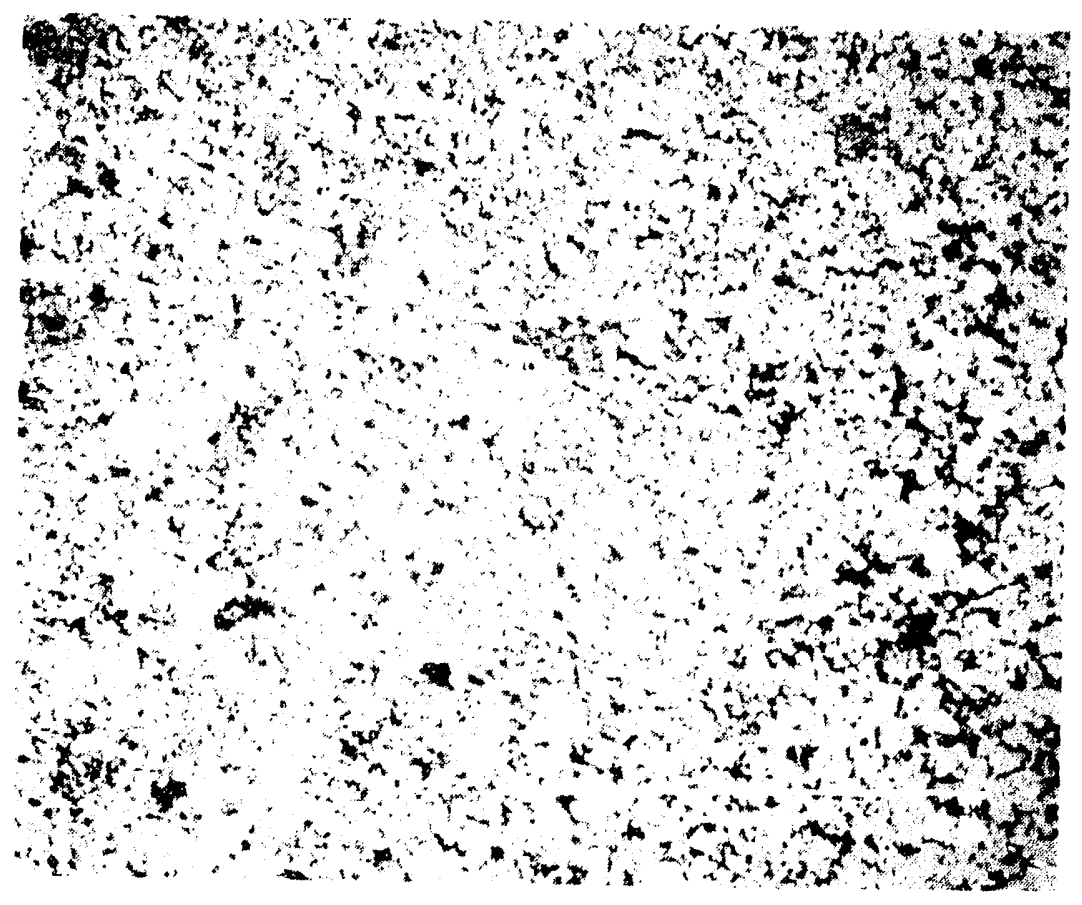

Figure 100. Further into the interior of the oxidized zone in E1. 
percents gives 45.4 wto $\mathrm{Al}, 47.1$ wto $\mathrm{Na}$, and 2.3 wto $\mathrm{Ca}$. This corresponds to a BR of 0.61. This BR is much lower than the measured ratio of the electrolyte in the pilot study, which ranged from 1.1 to 1.8. A second fluoride phase was found <15 $\mu \mathrm{m}$ from this cryolite phase and EPMA found that it contained 24.8 molo $\mathrm{Ni}$, $43.1 \mathrm{~mol} \% \mathrm{Al}, 27.8 \mathrm{~mol} 8 \mathrm{Na}$, and $<2$ molo each of $\mathrm{Fe}$, $\mathrm{Cu}$, and $\mathrm{Ca}$. This corresponds to a BR of 0.32 . Thus, this second fluoride phase contains a large amount of $\mathrm{Ni}$ and $\mathrm{Al}$ with a lower level (compared to typical bath compositions) of $\mathrm{Na}$.

BEI micrographs of the second metallographic mount of this section of Anode E1 are presented in Figures 101 through 107. Figures 101 and 102 are low magnification images of the outer surface of this mount. The outer surface of this mount was next to the inner surface of the previous mount. Therefore, the structure in the center and right side of Figure 101 is the same structural zone as the left side of Figure 100. Figure 102 (which is further into the interior than Figure 101) shows a different structural zone where the bright features ( $\mathrm{Cu}$ oxide) of Figure 101 are absent in Figure 102. Higher magnification micrographs of the area in Figure 102 are presented in Eigure 103. EDS analysis of the area in Figure 103 (in which the $\mathrm{Cu}$ oxide was absent) gave an overall composition of $42.7 \mathrm{~mol} \% \mathrm{Fe}, 45.1 \mathrm{~mol} \% \mathrm{Ni}, 5.8 \mathrm{~mol} \% \mathrm{Cu}$, and 6.4 molo $\mathrm{Al}$ showing the region is Cu depleted. The thickness of this depletion zone is $\sim 2 \mathrm{~mm}$ thick. This is much larger than the thickness of the $\mathrm{Cu}$ depletion zones that were observed in the untested material (see Figure 73) so it is probably the result of chemical reactions that are occurring within the anode.

A higher magnification BEI of Figure 103 is presented in Figure 104. EPMA was performed at the spots designated by the letters in Figure 104 and the results are summarized in Table 8 . According to Table 8, $\mathrm{NiO}(\mathrm{A}), \mathrm{Ni}$ ferrite (B), and $\mathrm{Ni}$ fluoride (C,D) coexist in the structure. It should be stressed that these three phases are the dominant phases in this region of the anode and they are not present in trace amounts. The concentration of $\mathrm{Ni}$ in the NiO phase is 79 molo but the $\mathrm{Cu}$ concentration is increased to 15.6 mol\%. Thus, the $\mathrm{Cu}$ concentration in the $\mathrm{NiO}$ phase is increasing with penetration distance into the sample. The NiO contained 3 molo $\mathrm{Cu}$ near the crack (see Eigure 97), 11 molo at the edge of the first mount (Figure 100), and to 15.6 molo in this region as shown in Eigure 102. The Ni rich fluoride phase is primarily Ni with some $\mathrm{Mg}$ as the cation constituents.

The black patches in this region (Eigure 104, spot E) is a solution of frozen $\mathrm{Ni}, \mathrm{Al}$, and $\mathrm{Na}$ fluoride. The $\mathrm{Ni}$ content is $37.5 \mathrm{~mol} \%$ while $\mathrm{Cu}$ and $\mathrm{Fe}$ combine to account for an additional 6 molo. The $\mathrm{Na}$ and $\mathrm{Al}$ contents in this phase are equivalent to a BR of 0.26 , which also is much lower than the ratio of the electrolyte (1.1 to 


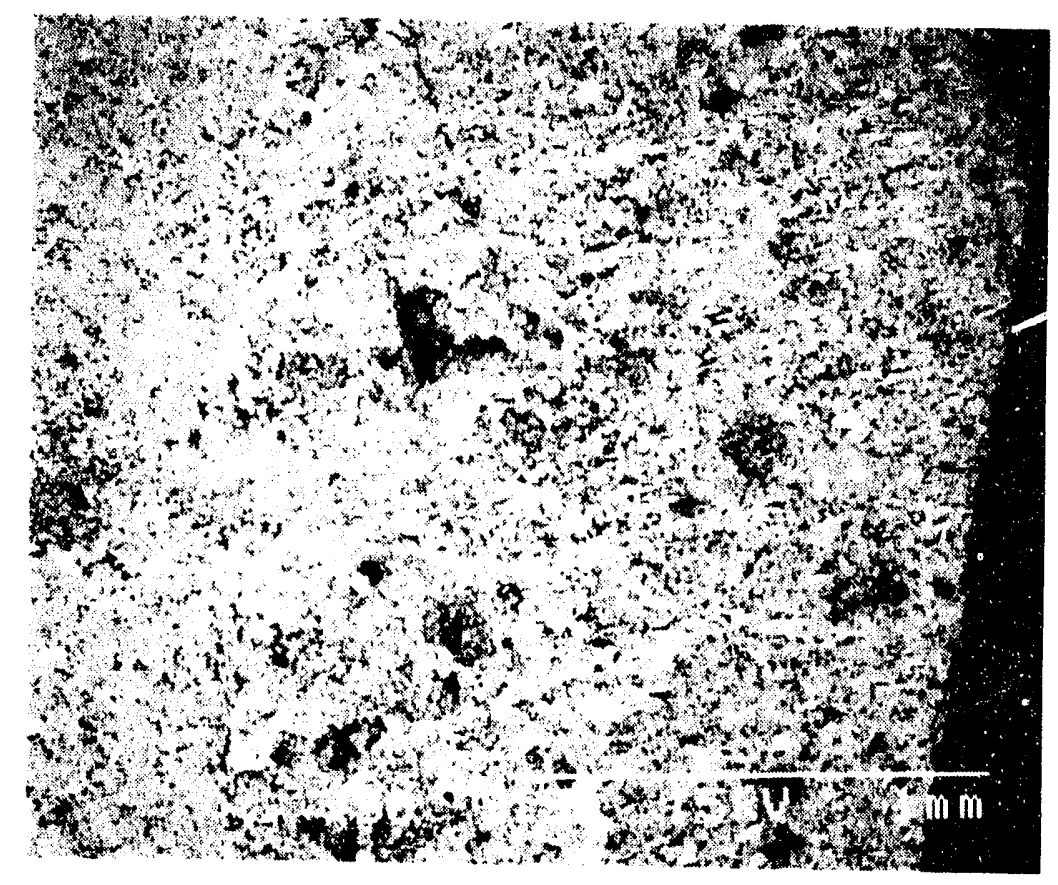

Figure 101. Anode E1, further into the interior of the Anode than Figure 100 .

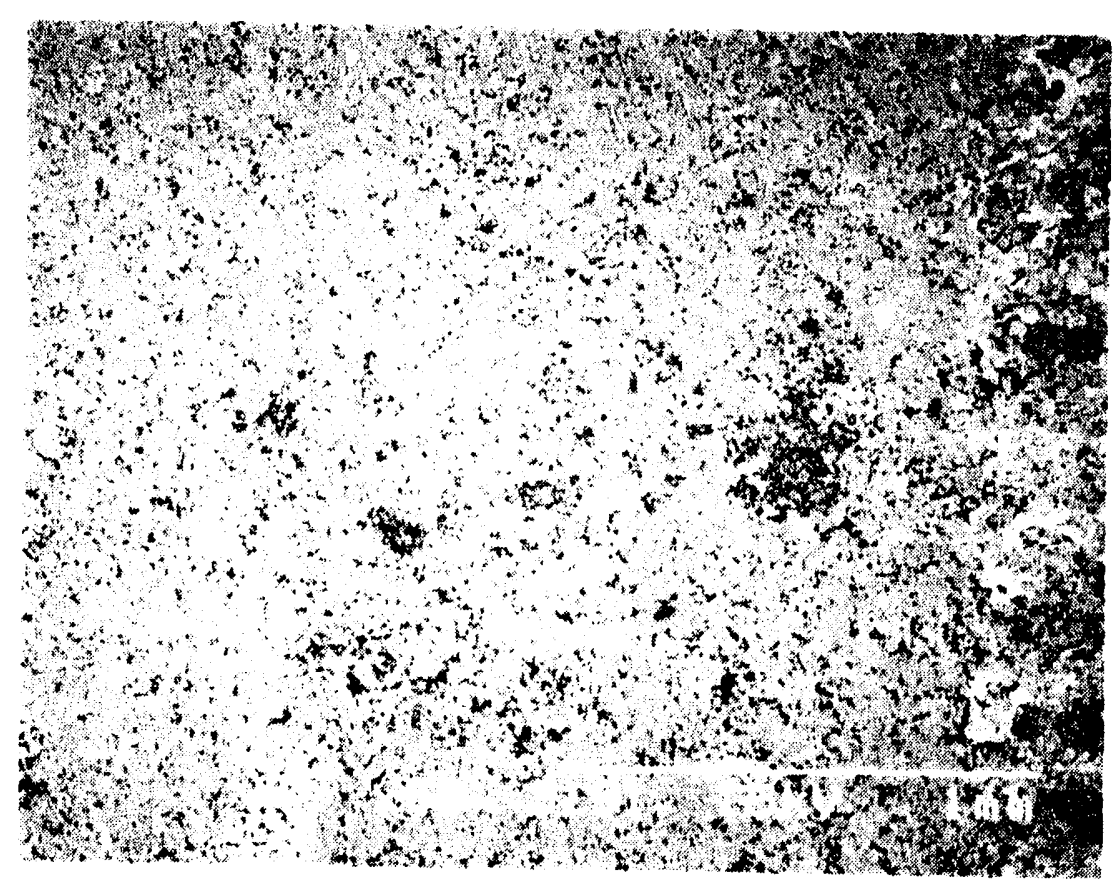

Figure 102. Anode E1, further into the interior than in Figure 101. 


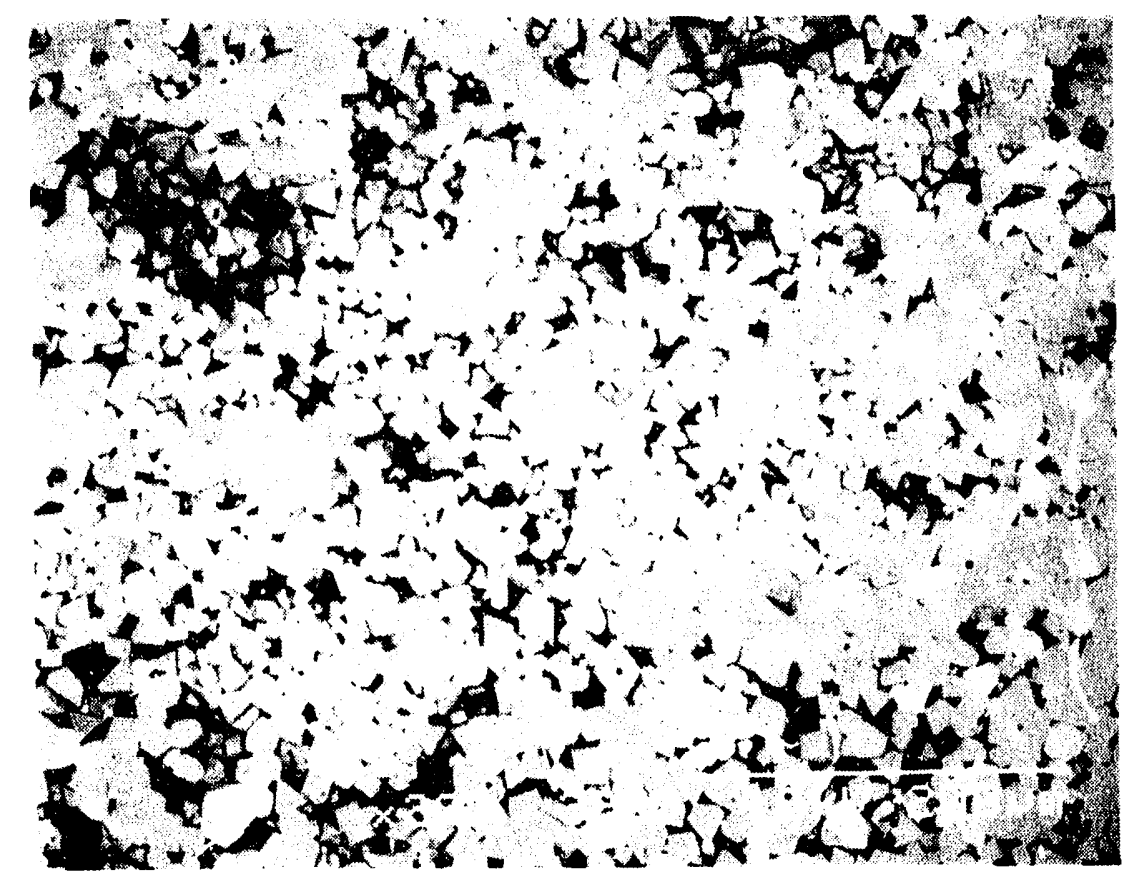

Figure 103. Higher magnification on the $\mathrm{Cu}$ depleted zone in Figure 102, Anode E1.

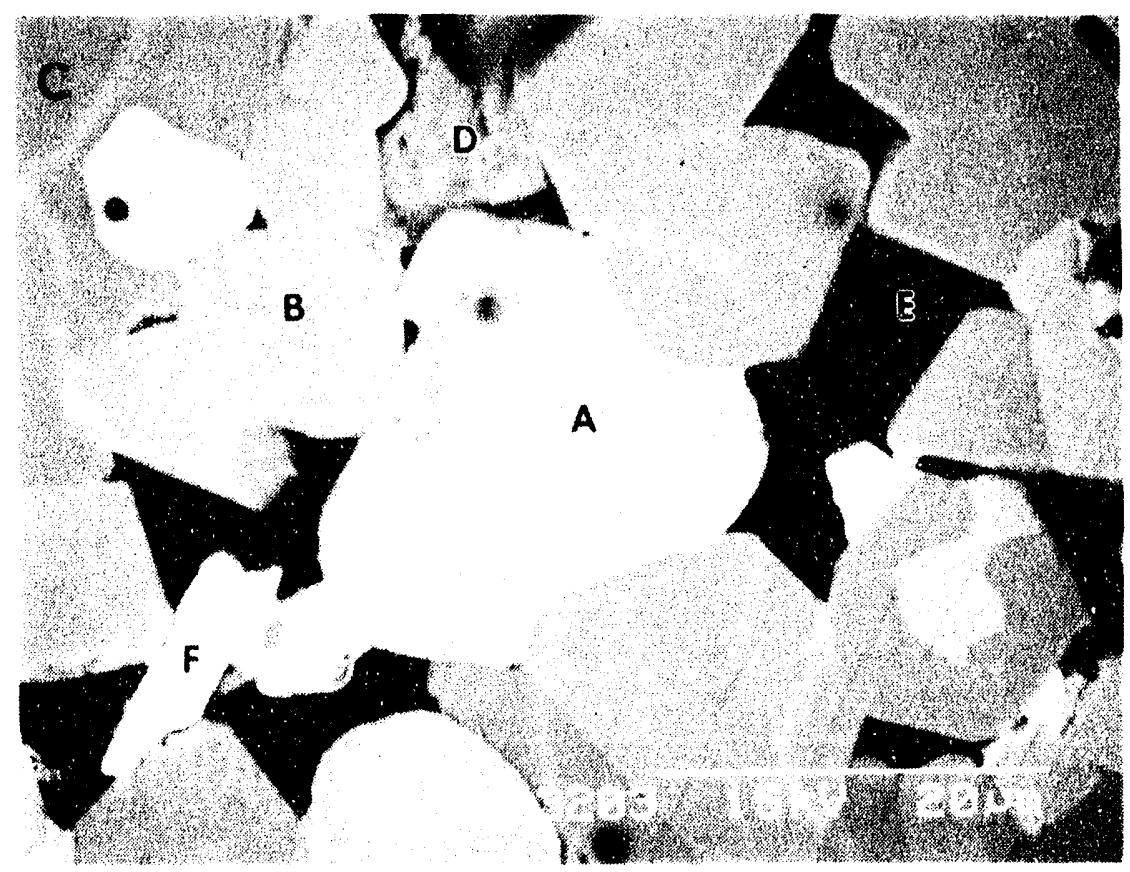

Figure 104. BEI of Figure 103, Anode E1, showing the individual phases from Table 8 . 


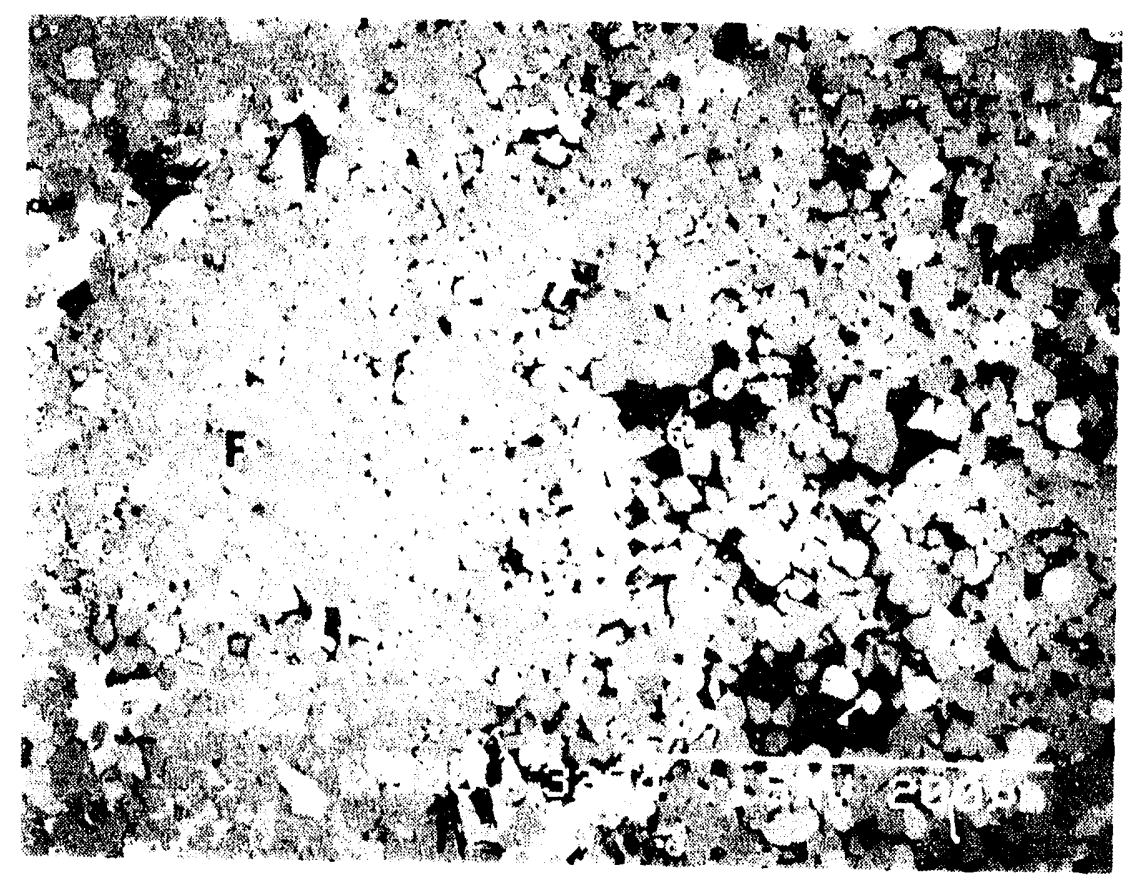

Figure 105. Further into the irterior of $\mathrm{E1}$, showing the boundary between the fluoride-containing region (F) and the $\mathrm{Cu}$ depletion region. 


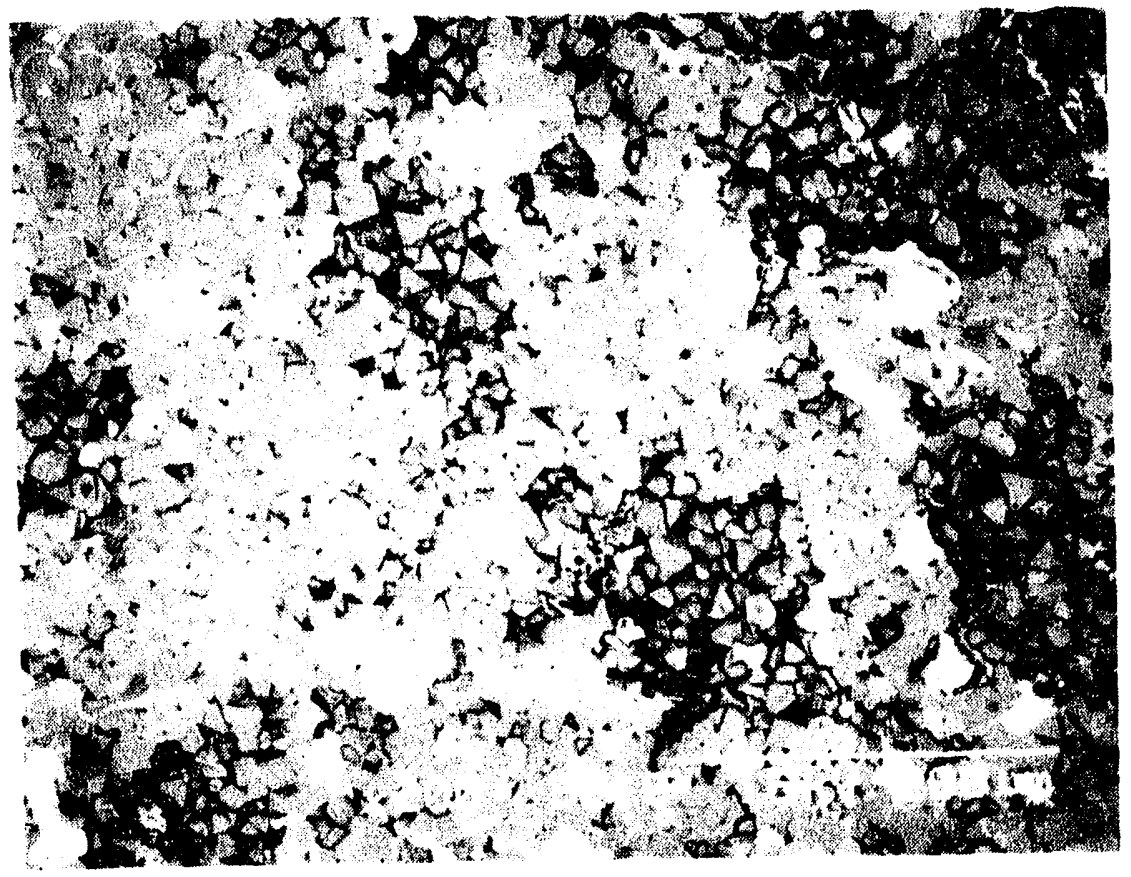

Figure 106. 19 mm into the center of Anode E1, where Cu metal occurs (bright phases).

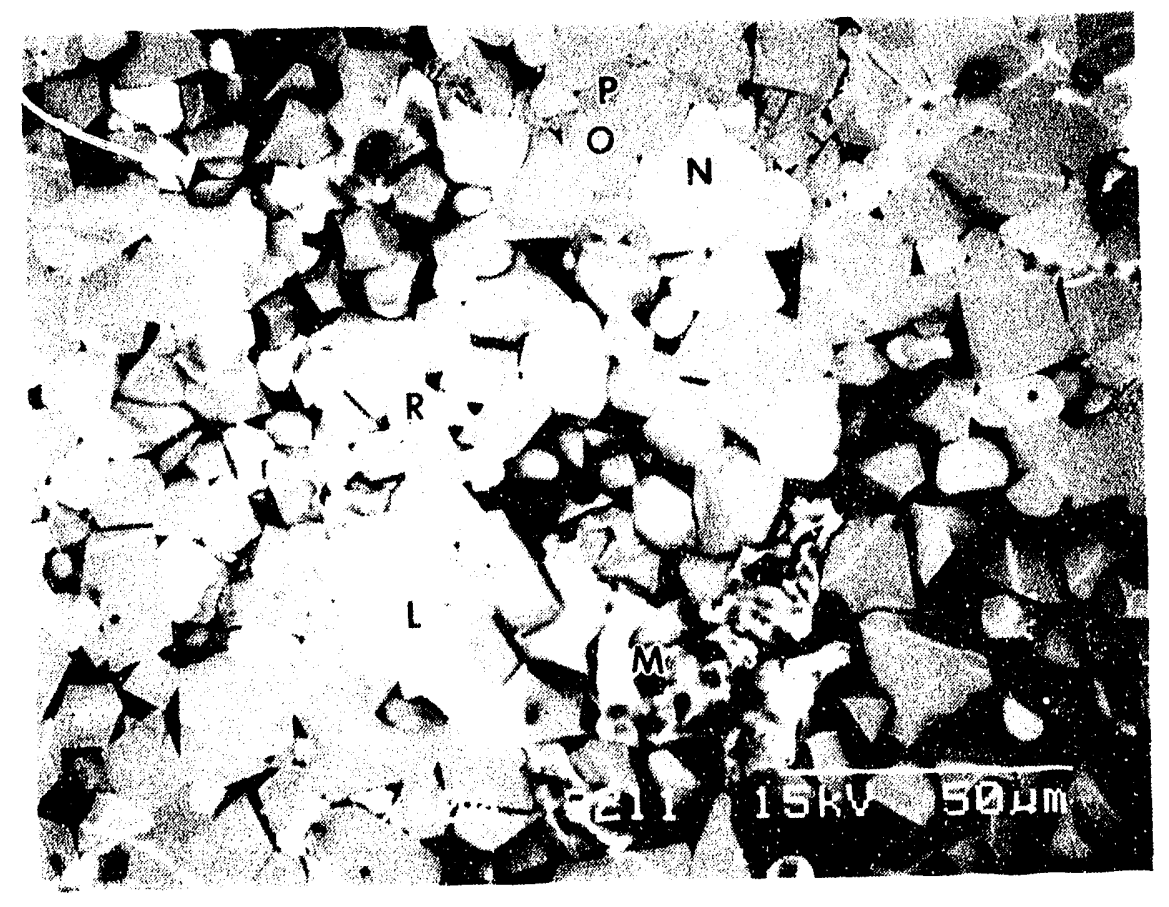

Figure 107. Higher magnification of Figure 106. 
Table 8. Compositions of the phases (mol\%) in the various regions in Figure 104.

\begin{tabular}{|c|c|c|c|c|c|c|}
\hline Spot & Phase & $8 \mathrm{Fe}$ & 定 $\mathrm{Ni}$ & $\frac{8}{8} \mathrm{Cu}$ & $\frac{8}{8} \mathrm{Al}$ & Others $\left(\frac{8}{8}\right)$ \\
\hline $\begin{array}{l}\text { Overall } \\
\mathrm{A}\end{array}$ & NiO & $\begin{array}{r}42.7 \\
4.6\end{array}$ & $\begin{array}{l}45.1 \\
79.2\end{array}$ & $\begin{array}{r}5.8 \\
15.6\end{array}$ & $\begin{array}{l}6.4 \\
0.6\end{array}$ & \\
\hline B & Ferrite & 64.2 & 33.3 & 1.2 & 1.3 & \\
\hline $\mathrm{C}$ & Fluoride & 3.8 & 76.8 & 4.1 & 3.0 & $12.38 \mathrm{Mg}$ \\
\hline$D$ & Eluoride & 4.7 & 76.4 & 3.1 & 1.9 & $13.98 \mathrm{Mg}$ \\
\hline$E$ & Fluoride & 3.9 & 37.5 & 2.0 & 35.8 & $\begin{array}{r}18.78 \mathrm{Na} \\
2.0 \% \mathrm{Ca}\end{array}$ \\
\hline $\mathrm{Ce}$ & Fluoride & 4.3 & 4.4 & 0.8 & 3.0 & $\begin{array}{r}84.98 \mathrm{Ce} \\
2.68 \mathrm{Ca}\end{array}$ \\
\hline a. Over & II composi & on taken & from $\mathrm{E}$ & e 103 & & \\
\hline
\end{tabular}


1.8), so this phase is also $A l$ rich versus Na. The composition of this fluoride phase is very similar to the $\mathrm{Ni}-\mathrm{Al}-\mathrm{Na}$ fluoride that was described earlier (Figures 98 through 100). Ce fluoride grains (Eigure 104, spot F) are also dispersed within the pores.

Further into the sample, next to the $\mathrm{Cu}$ depletion layer in Figure 102, there is a dense layer, $\sim 300 \mu \mathrm{m}$ thick. A BEI of the boundary between these two regions is shown in Figure 105. The dense zone lies to the left in Figure 105 and marks the last zone within the macroscopically black oxidation zone. EDS analysis at 500x on this area shows that the overall composition is very similar to the nominal batched composition in Table 6. However, the phase composition is different. The dense layer contains $\mathrm{Cu}$ oxide, $\mathrm{Ni}$ fluoride, $\mathrm{Ni}$ ferrite, and no NiO. The composition of the $\mathrm{Cu}$ oxide phase is very similar to the composition given in Table 7 . The EPMA composition of the $\mathrm{Ni}$ fluoride phase is very similar to the compositions that are listed in Table 8 . However, the intensity of $M g K_{\alpha}$ is qualitatively less dominant in this fluoride phase as compared to the $\mathrm{Ni}$ fluorides of $\mathrm{Table} 8$. No compositional changes are observed in the ferrite phase and its composition is similar to the compositions that are reported in Tables 7 and 8 .

The final microstructural region of this anode is presented in Figures 106 and 107 (again, the bright lines in the SEM photograph are an artifact of the carbon coating). This region lies further into the interior of the anode than in Figure 105. In this region, $\mathrm{Cu}$ is present in the metallic state. EPMA was performed at the various spots indicated in Figure 107. The composition of the $\mathrm{Cu}$ (spot L), and ferrite (spot O) phases are the same as the ones reported in Table 7. The composition of the NiO phase 'spot N) is $94.3 \mathrm{~mol} 8 \mathrm{Ni}, 4.5 \mathrm{~mol} \% \mathrm{Fe}$, and $1.2 \mathrm{~mol} \% \mathrm{Al}$. Comparison cf this NiO composition with the compositions of the Nio phases in the unoxidized regions of Anodes Al and C1 (see Table 7) shows that less $\mathrm{Fe}$ and more $\mathrm{Ni}$ is present in this anode.

The region in Eigures 107 has two additional microstructural features. The first one is spot $M$ of Eigure 107, which shows a particle that appears to have been reacted. However, the EPMA composition of this feature falls within the compositional range for a $\mathrm{Cu}$ rich particle in Table 7. No fluorine or other impurities were detected. This feature appears reacted but the exact nature of the reaction cannot be determined.

The second feature is a grain boundary $\mathrm{Ni}$ fluoride phase that is designated by spot $P$ in Figure 107. A pronounced Mg peak was detected in the EPMA spectrum and the $F \in$ content was higher than the values reported in Table 8 . However, the higher Fe content is probably an artifact of the EPMA process because of excitation of the surrounding ferrite phase. This $\mathrm{Ni}$ fluoride phase is found along the grain boundaries of both the NiO and ferrite phases. 
The microstructure of Anode El can be summarized as follows. Many distinct microstructural zones were found in this anode and each zone is comprised of a unique combination of phases. A dense outer zone, $\sim 1 \mathrm{~mm}$ thick, exists below the CEROX coating. This zone consists of ferrite and Nio phases. The ferrite phase has high Al (19 to $61 \mathrm{~mol} 8$ ) and $\mathrm{Cu}$ ( 4 to 8 molo) contents and $\mathrm{Al}$ tends to substitute for $\mathrm{Fe}$ in the ferrite. The NiO phase contains 18 to 21 molo $\mathrm{Cu}$ (presumably present as the oxidized $\mathrm{Cu}^{2+}$ ion) but only 1 to 6 molq $\mathrm{Fe}$. A porous $\mathrm{Cu}$ depletion zone lies next to the dense region. The composition of the Nio phase is the same as in the dense layer but the ferrite phase becomes nearly stoichiometric and the composition of the ferrite is the same for the remainder of the anode interior.

A macroscopic crack exists 2 to $2.5 \mathrm{~mm}$ into the body of the anode. A dense copper oxide layer, probably $\mathrm{Cu}_{2} \mathrm{O}$, lies on the outer edge of the crack and a $\mathrm{Cu}$ depletion zone lies on both sides of the $\mathrm{Cu}_{2} \mathrm{O}$ layer.

The next inward zone is $\sim 1 \mathrm{~mm}$ thick and the ferrite, $\mathrm{NiO}$, and $\mathrm{Cu}_{2} \mathrm{O}$ phases coexist in this region. The only change in composition occurs in the Nio phase, where the $\mathrm{Cu}$ content increases from 3 to 11 molo. Also, a two-phase fluoride mixture is present at the grain boundaries of the oxides. This fluoride mixture consists of a cryolite phase that has $a$ BR of 0.61 , and $a$ ( $N i, N a$, and $A l) E_{x}$ phase that contains 24.8 molo $\mathrm{Ni}$ and the $\mathrm{Na}$ to Al ratio is equivalent to a BR of 0.32 .

Further penetration into the anode reveals a $\mathrm{Cu}$ depletion $z$ one. This region is $\sim 2 \mathrm{~mm}$ thick so it is probably not an artifact of the untested material but rather is formed during operation of the anode. Four phases are observed in the microstructure: ferrite, $\mathrm{NiO}$, nickel fluoride, and $(\mathrm{Ni}, \mathrm{Na}, \mathrm{Al}) \mathrm{F}_{\mathrm{x}}$. Thus, two oxides and two fluorides coexist in this region and all compounds contain at least $33 \mathrm{~m} \% \mathrm{Ni}$ (see Table 8).

Finally, a dense layer of $\sim 300 \mu \mathrm{m}$ thick lies next to the $\mathrm{Cu}$ depletion zone and this layer represents the last oxidation zone in the anode. NiO is not found in this zone but $\mathrm{Ni}$ fluoride is present in addition to the ferrite and $\mathrm{Cu}$ oxide. In all regions interior to this zone, $\mathrm{Cu}$ is present in the metallic state. $\mathrm{Cu}$ metal, $\mathrm{NiFe}_{2} \mathrm{O}_{4}$, and $\mathrm{NiO}$ coexist in the interior and $\mathrm{Ni}$ fluoride is also present. Porosity is higher than in the untested anode.

The thickness of the entire oxidation zone (including dense, oxidized, and $\mathrm{Cu}$ depleted regions) is $\sim 17 \mathrm{~mm}$ and fluoride phases were detected throughout the section. Ce fluoride was found up to $15 \mathrm{~mm}$ into the interior. 


\subsubsection{Microstructure of the Inconel Rod}

Inconel 601 rods were used to supply the electrical current to the anodes. The nominal composition of Inconel 601 is presented in Table $9 .{ }^{21}$ The quantitative analyses that will be presented in this section will be on a weight percent (wt\%) basis and will only include $\mathrm{Ni}, \mathrm{Cr}, \mathrm{Fe}$ and $\mathrm{Al}$ in the compositions. Ni 200 [99.5 wt: $\mathrm{Ni}, 0.06 \%$ (max) C] rods were used by PNL in their pilot test (before our test) as current collectors. The Ni rods failed during their test leading to the use of the Inconel 601 instead of the $\mathrm{Ni}$ in the ELTECH test.

The electrical connection between the rod and anode was made by simply screwing the rod into the anode. The rods were 18 in. long, 1 in. in diameter, and they were tapped with male 1-8 threads. The microstructure of the threaded region is presented in Figures 108 and 109, where Figure 108 represents the region near the tip of the thread and Figure 109 represents the base of the thread. The rod is the brighter feature that lies to the left side of the images. The figures clearly show that the rod was severely attacked and corroded by the local environment. Specifically, the rod underwent pronounced corrosion at the grain boundaries suggesting an enhanced stress corrosion cracking mechanism. A detailed discussion of the corrosion behavior of the rod will be presented, starting at the center of the rod and moving toward the outer surface.

Figure $1: 0$ shows BEI micrographs of a section from $\sim 10 \mathrm{~mm}$ into the center of the rod. Figure 111 shows that the grain boundaries near the center of the rod contain a Cr-rich second phase (C). At $\sim 6 \mathrm{~mm}$ in from the edge of the rod there is a reaction zone (Figures 112 and 113). Figure 112 shows how the rod is preferentially attacked along the grain boundaries. The outer surface of the rod lies to the right of Figures 112 and 113. The dark grain boundary phase in the right side of Figure 113 is $A_{1} F_{3}$ (A), which is penetrating into the center of the rod along the grain boundaries. It appears to react with or dissolve the $\mathrm{Cr}$ rich boundary phase (C) in the left of Figure 113. No $\mathrm{Na}$ or $\mathrm{Ca}$ was detected in the penetrating $\mathrm{AlF}_{3}$. The compositions near the centers of the grains in both regions fall within the compositional range of Table 9 .

Higher magnification BEI micrographs of the rod, near the base of the thread of Figure 109, are presented in Figures 114 and 115 . In each, the brighter phases are the metallic phases. Location $A$ of Figure 114 is $\mathrm{AlF}_{3}$, but below this phase is a lighter feature that is designated $C$. EPMA of $C$ shows that it is a fluoride that contains Al, $\mathrm{Cr}$, and $\mathrm{Ti}$. Ti is not listed in Table 9 as a constituent of Inconel 601 and it is not known how it entered the system. EPMA determined the atomic Cr:Al ratio in the fluoride to be $\sim 4: 5$; however, it is possible that Al was detected from the surrounding $\mathrm{AlF}_{3}$ phase. Location $\mathrm{B}$ is a reaction phase that 
Table 9. Limiting chemical composition (in wt8) of Inconel 601.

Element

Nickel

Chromium

Iron

Aluminum

Carbon

Manganese

Sulfur

Silicon

Copper
Content

$$
58.0 \text { to } 63.0
$$

21.0 to 25.0

Remainder

1.0 to 1.7

$0.10 \max$.

$1.00 \mathrm{max}$

$0.015 \max$.

$0.50 \mathrm{max}$.

$1.00 \max$. 


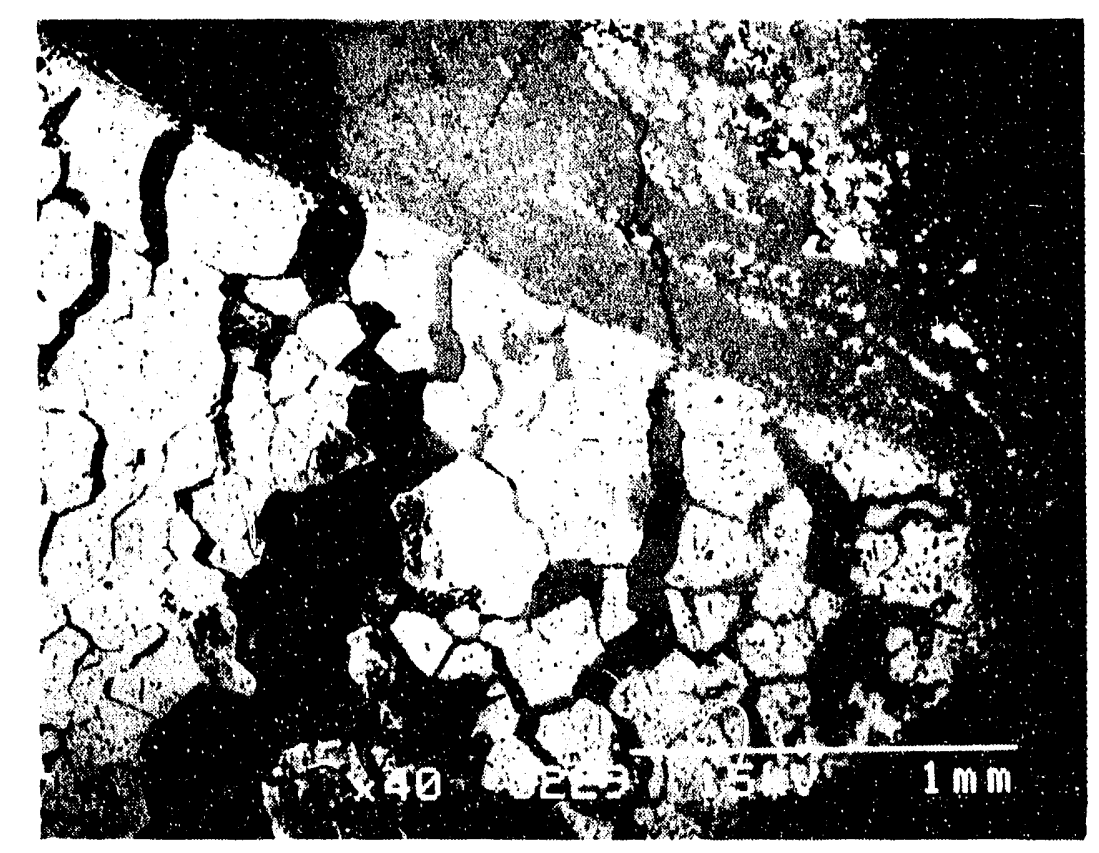

Figure 108. Tip of one of the threads on the Inconel 601 connector rod within the $\mathrm{Cu}$ cermet.

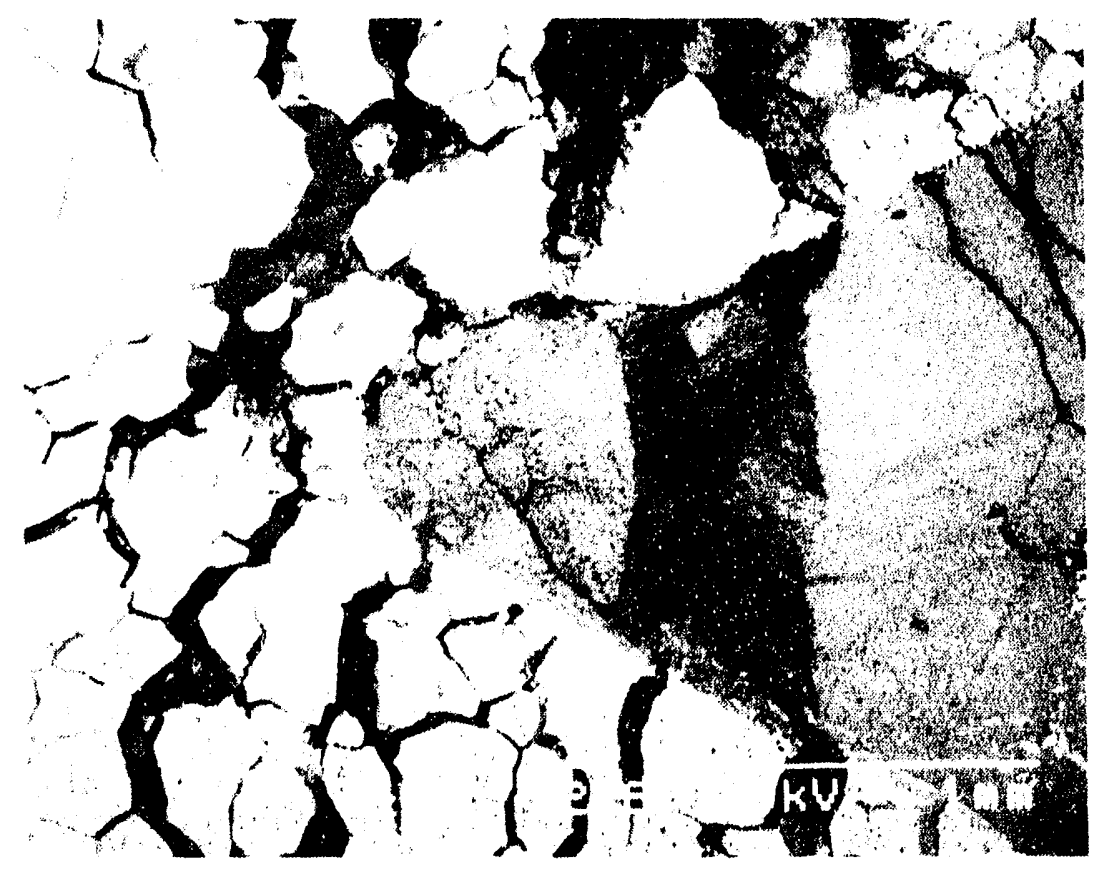

Figure 109. Base of one of the Inconel 601 threads within the $\mathrm{Cu}$ cermet. 


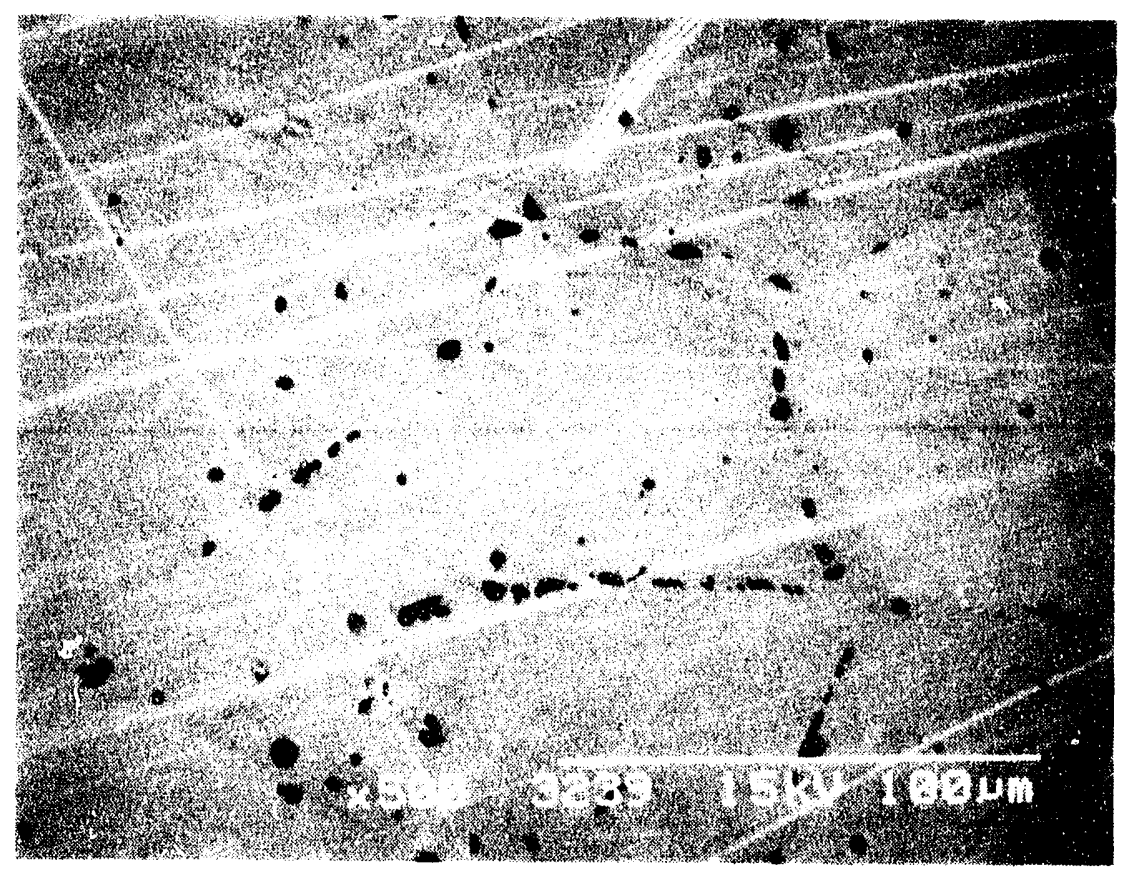

Figure 110. BEI micrograph of the Inconel 601 collector rod near the center.

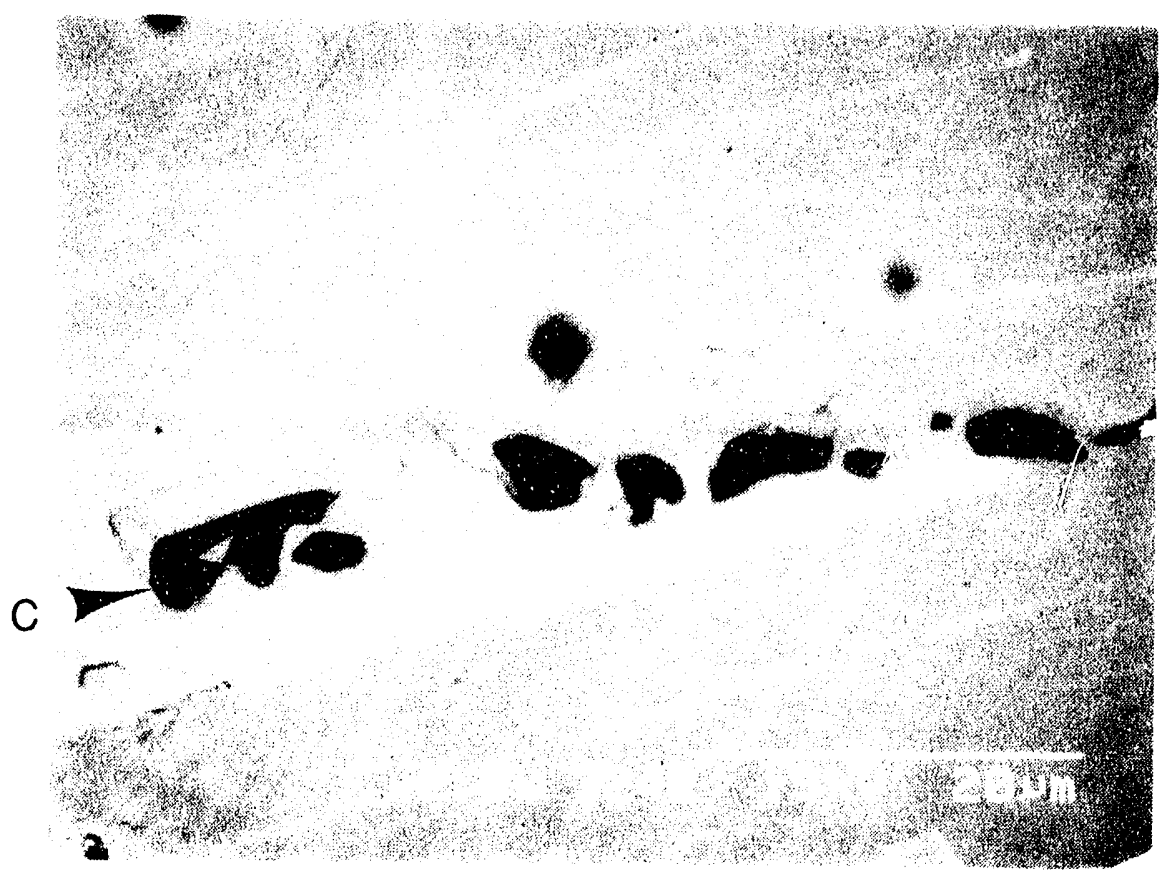

Figure 111. Close-up of the Cr-rich grain boundary inclusions in Figure 110. 


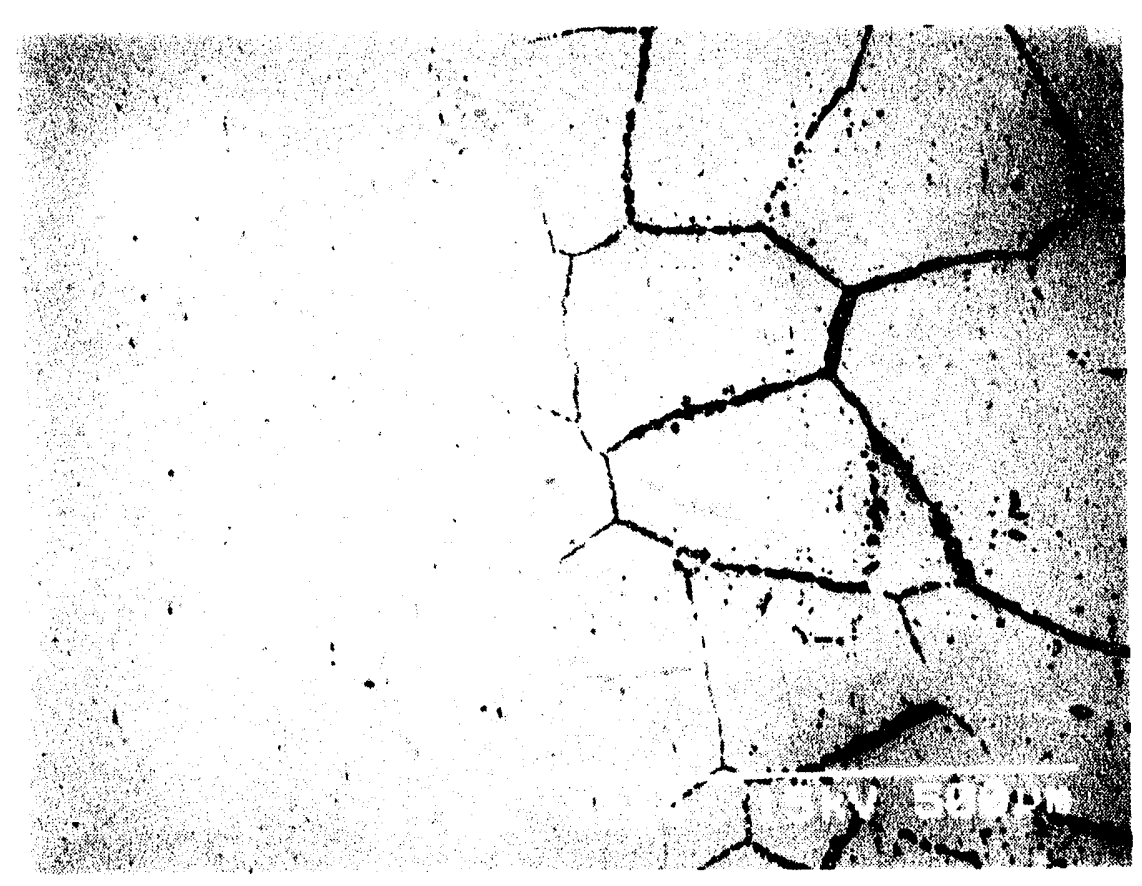

Figure 112. Edge of the reaction zone within the Inconel rod, 6 $\mathrm{mm}$ into the rod.

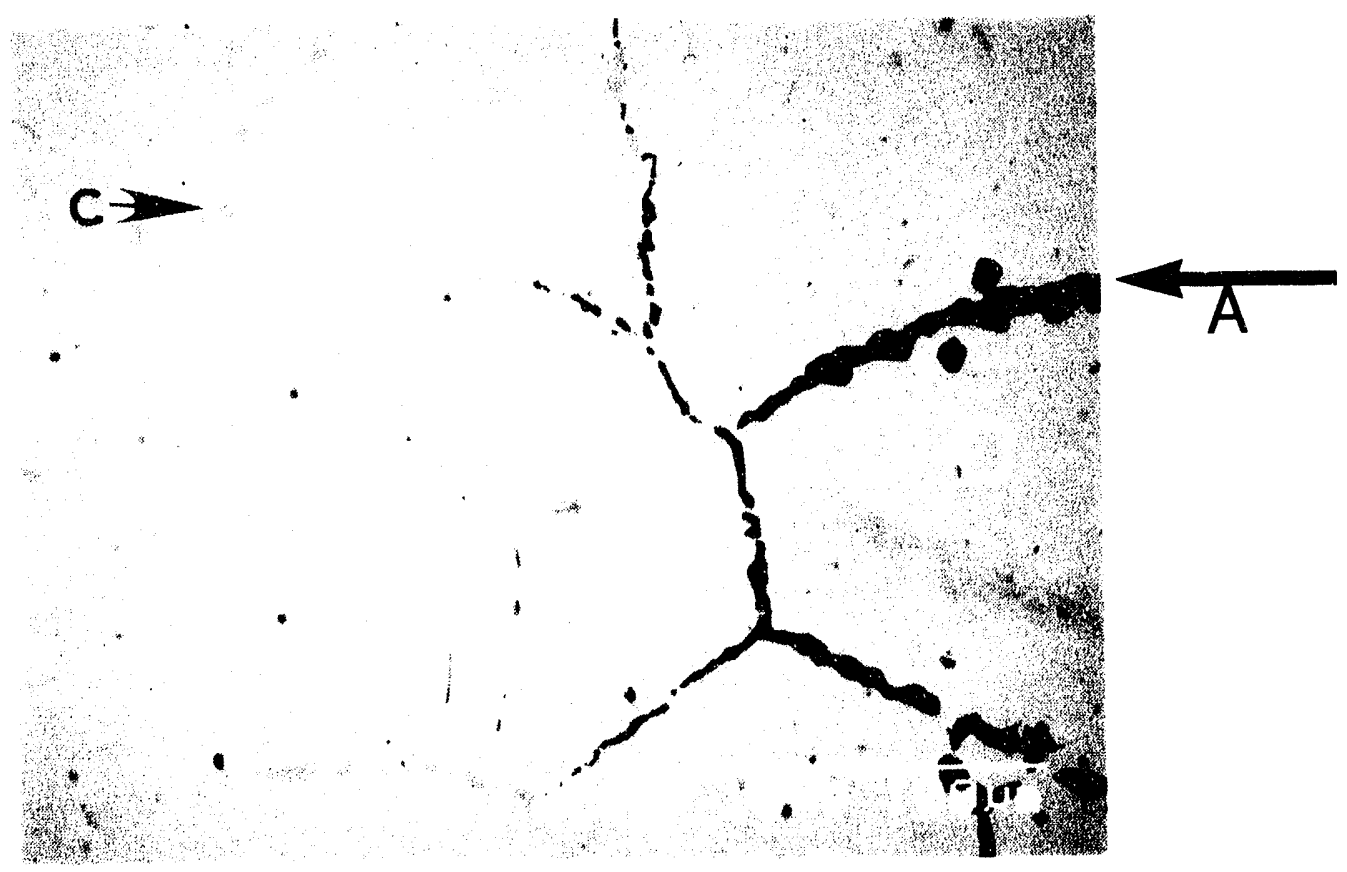

Figure 113. Higher magnification of Figure 112. $A=A l F_{3}, C=C r-r i c h$ phase. 


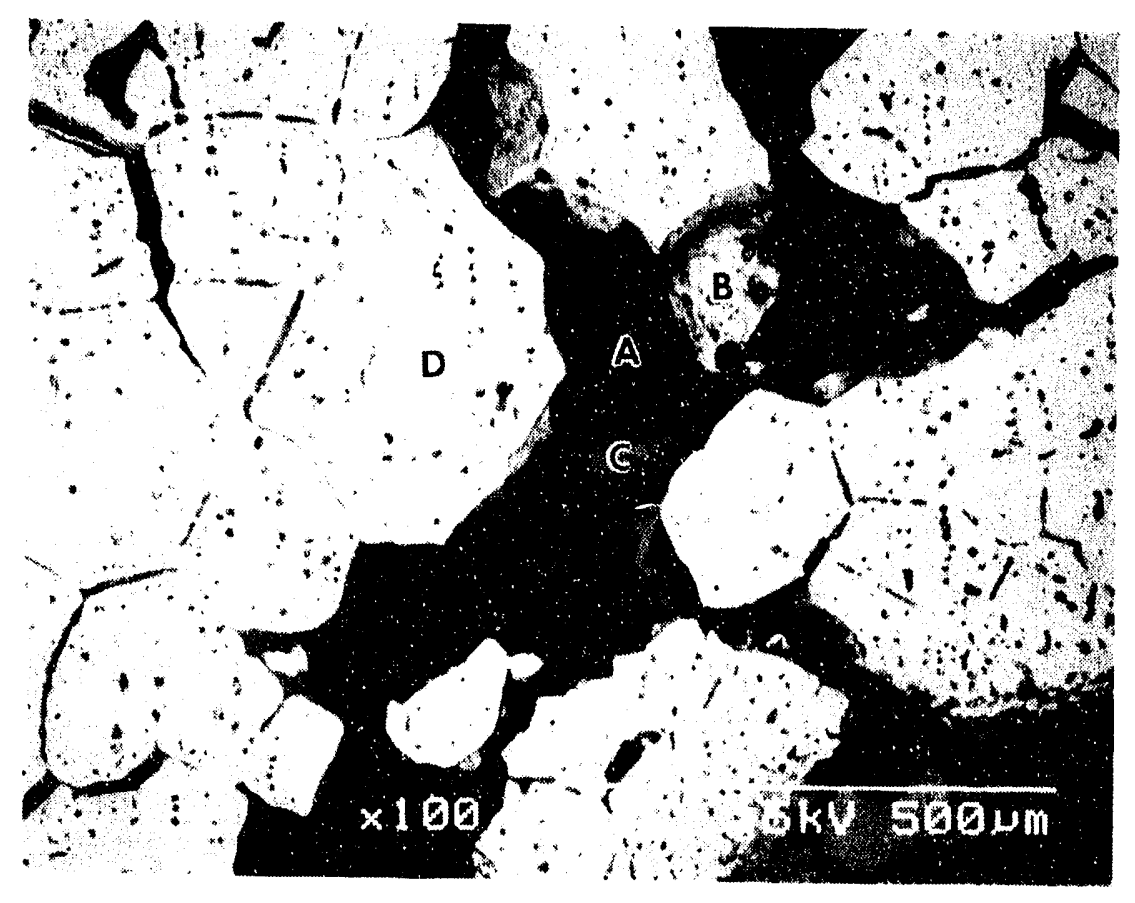

Figure 114. Region of corroded Inconel showing the $A_{1 F}$ grain boundary phase (A).

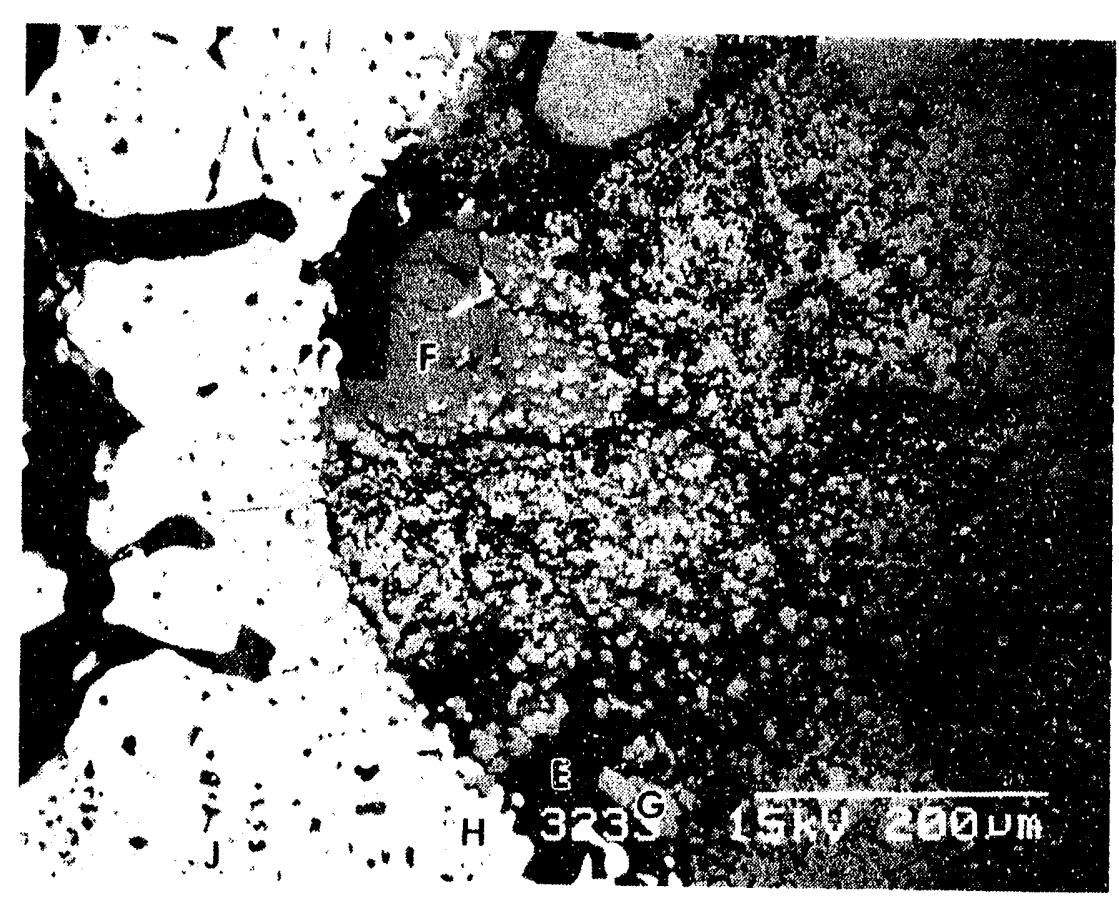

Figure 115. Edge of the Inconel rod at the base of the thread. 
contains 70 wto $\mathrm{Ni}, 20$ wto $\mathrm{Fe}, 7.7$ wto $\mathrm{Al}$, and 2.3 wto $\mathrm{Cr}$. It is difficult to determine if it is an oxide, or a metallic phase that is severely depleted in $\mathrm{Cr}$. Location $\mathrm{D}$ in the center of a large metal grain has the composition 67.5 wto $\mathrm{Ni}, 19.7$ wto $\mathrm{Cr}, 12$ wt\% $\mathrm{Fe}$, and 0.8 wto Al. According to Table 9, this region of the alloy has become depleted in $\mathrm{Cr}$ and $\mathrm{Al}$ and has a higher $\mathrm{Ni}$ content.

Fi.gure 115 shows the microstructure of a different area of Figure 109. EPMA was performed at five different spots in Figure 115 and the locations are designated by the various letters in the image. A higher magnification BEI micrograph of the central lower region of Figure 115 is presented in Figure 116. Location $J$ is located in the center of a large alloy grain and it is at least $200 \mu \mathrm{m}$ from a grain boundary. However, the $\mathrm{Cr}$ and $\mathrm{Al}$ contents of the alloy at location $J$ are only 14.5 and 0.4 wto, respectively while the corresponding $\mathrm{Ni}$ is 72.4 wto . According to Table 9, $\mathrm{Cr}$ and $\mathrm{Al}$ are depleted from this region causing the $\mathrm{Ni}$ concentration to increase. Location $\mathrm{H}$ is $\sim 30 \mu \mathrm{m}$ from the surface and the $\mathrm{Cr}$ concentration at this spot is only 2.9 wt $\%$. Thus, the alloy is severely depleted in Cr at the edge.

Locations $E, F$, and $G$ lie in an area that should contain the threads of the anode substrate material. However, EPMA analysis of these spots shows that they are not the ferrite, Nio, or Cu rich phases that are typically observed in the substrate material. Instead, they are rich in $\mathrm{Cr}$ or $\mathrm{Al}$ or both. Table 10 lists the compositions of these three spots.

Table 10 shows that locations $E$ and $F$ are fluorides while $G$ is an oxide phase. Also, minor amounts of $\mathrm{Ca}$ and $\mathrm{Ti}$ were detected in the material. Figures 109 and 116 show that location $E$ is at the exterior of the Inconel and along the grain boundaries of two Inconel grains. As had been found in the interior, $E$ was an $A l$ rich ( 86.9 wt\%) fluoride phase. Because $A_{1 F}$ was previously found along the grain boundaries, it was expected that this phase would be rich in $\mathrm{Al}$ and this was observed (86.9 wto $\mathrm{Al}$ ). However, the $\mathrm{Cr}$ content of the fluoride phase significantly increases from

10.3 wto at location $\mathrm{E}$ to 54.9 wto at $\mathrm{F}$. Location $\mathrm{G}$ is a $\mathrm{Cr}$ rich ( 96.9 wto $)$ oxide phase surrounded by the $\mathrm{AlF}_{3}$ phase.

A mechanism for the formation of these $\mathrm{Al}$ and $\mathrm{Cr}$ rich phases can be formulated from the above discussions. It is clearly demonstrated that $\mathrm{AlF}_{3}$ preferentially attacks the $\mathrm{Cr}$ in the alloy by corroding $\mathrm{Cr}$ rich inclusions at the grain boundaries and dissolving $\mathrm{Cr}$ from the bulk of the lattice. The dissolved $\mathrm{Cr}$ is than transported to the surface of the rod through the liquid $\mathrm{AlF}_{3}$ grain boundary phase. Locations E, F, and G of Figure 115 are evidence that the amount of $\mathrm{Cr}$ that was removed from the alloy and the transport rate of $\mathrm{Cr}$ through the molten $\mathrm{AlF}_{3}$ grain boundary phase is large enough to form $\mathrm{Cr}$ rich phases elsewhere in the microstructure. 


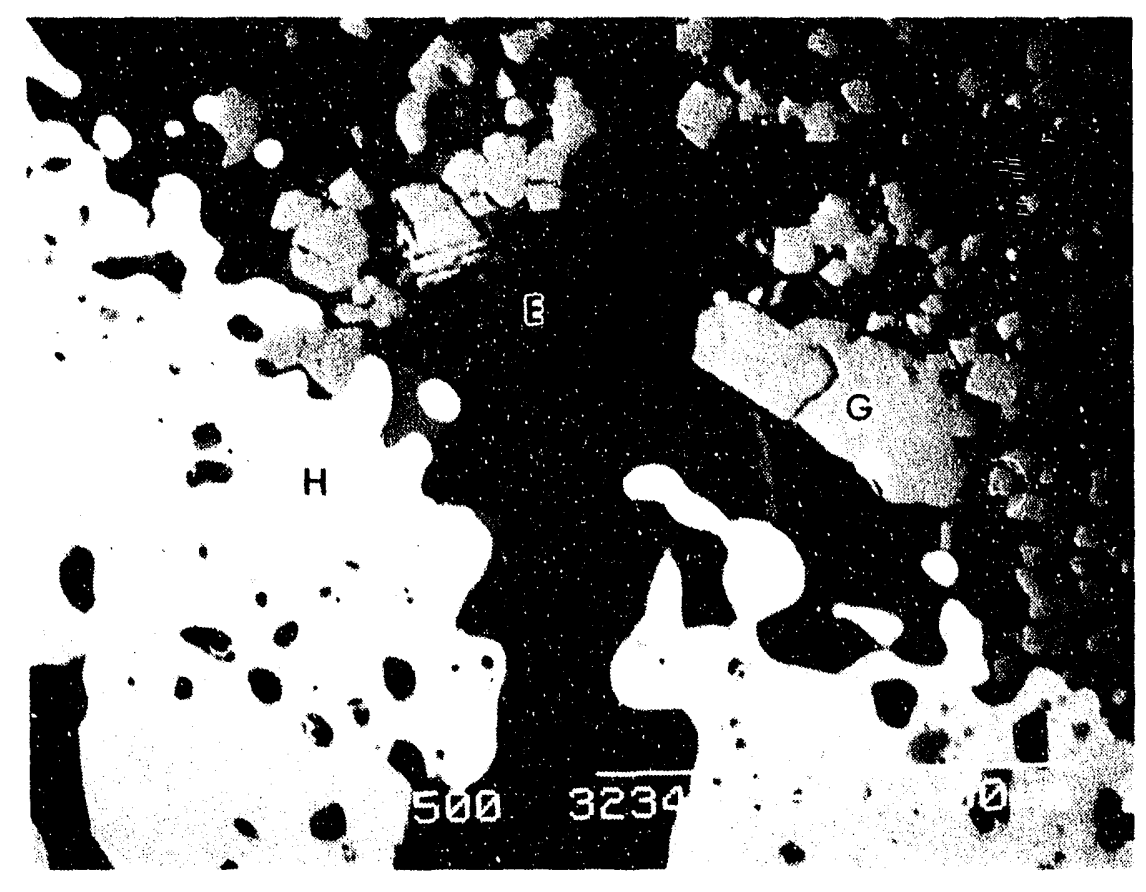

Figure 116. Higher magnification of Figure 115. 
Table 10. Compositions (in wto) of $\mathrm{Cr}$ and $\mathrm{Al}$ reaction phases from Figure 115.

\begin{tabular}{|c|c|c|c|c|c|}
\hline Location & Phase & $\frac{\circ}{6} \mathrm{Cr}$ & $\frac{\circ}{0 A 1}$ & $\frac{\circ}{0} \mathrm{~T}$ & $\frac{\circ \mathrm{Ca}}{2}$ \\
\hline $\mathrm{E}$ & Fluoride & 10.3 & 86.9 & 2.1 & 0.7 \\
\hline $\mathrm{F}$ & Eluoride & 54.9 & 43.3 & 0.7 & 1.1 \\
\hline G & Oxide & 96.9 & 1.5 & 1.2 & 0.4 \\
\hline
\end{tabular}


The discussion of this section describes how Inconel 601 undergoes severe stress corrosion cracking when it is exposed to the molten cryolite environment. However, it must by emphasized that no anodes failed because of corrosion of the rod in this pilot test while $25 \%$ of the anodes that were run in the PNL pilot test failed because of the severe corrosion of the $\mathrm{Ni} 200$ rods. ' Thus, Inconel 601 is a superior connector rod material compared to $\mathrm{Ni} 200$. 


\section{Conclusions}

Conclusions from the testing are divided into four areas involving the CEROX coating, the corrosion rates, the pilot cell operation, and the $\mathrm{Cu}$ cermet substrate and connector. The test was successful in demonstrating that inert anodes could be coated and operated with a CEROX coating in a pilot cell for up to $614 \mathrm{~h}$. However, the test was unsuccessful in showing exactly what the performance advantage is of a CEROX-coated cermet over an uncoated cermet.

\section{CEROX Coating}

- The CEROX coating could be deposited and maintained in a pilot cell. At "optimum" conditions (BR 1.6, CD of $0.5 \mathrm{~A} / \mathrm{cm}^{2}$ ) the coating was dense and 1 to $3 \mathrm{~mm}$ thick.

- On the sides of adjacent cermet anodes, where CD was low, the CEROX coating was not deposited or was very thinly deposited. There was no macroscopic evidence of increased corrosion on the uncozted sides.

- The anodes that were CEROX coated at "optimum" conditions and then tested at higher CD $\left(0.65 \mathrm{~A} / \mathrm{cm}^{2}\right)$ and then lower $\mathrm{BR}$ (1.15) had a more irregular and thinner CEROX coating. It could not be determined from the impurities in the metal if the change in the character of the coating led to a change in the corrosion rates.

- The CEROX coating can grow a short distance into cracks in the cermets.

- The Ce in the bath and the metal can be controlied if the pilot cell is operating smoothly. If the cell is experiencing mucking or crusting/melting periods, the $\mathrm{Ce}$ level is more difficult to control and the coating may undergo deposition/dissolution periods that correspond to the changing Ce concentration in the bath. This may not be detrimental as long as the Ce concentration remains high enough to maintain a CEROX coating.

- The CEROX coating did not grow on the sides of cermets that were very close to the carbon anode. This may be caused by the low current density on that side or the presence (absence) of $\mathrm{CO}_{2}\left(\mathrm{O}_{2}\right)$ or both.

- A CEROX coating was present in the areas where cryolite froze around the anodes, however, the coating became very thick and porous. This condition must be avoided in order to maintain a good CEROX coating and good current distribution to the anodes. 
- Testing could not determine the influence of the introduction and the CEROX coating of new anodes while old CEROX-coated anodes were operating.

\section{Corrosion Rates}

- The corrosion rates calculated from the impurity levels in the zluminum were $0.075 \mathrm{lb} / \mathrm{d} \mathrm{Cu}, 0.13 \mathrm{lb} / \mathrm{d} \mathrm{Ni}$, and $0.30 \mathrm{lb} / \mathrm{d}$ $\mathrm{Fe}$. Some of the $\mathrm{Fe}$ is probably because of contamination from Fe tools. An adjusted Fe corrosion of $0.12 \mathrm{lb} / \mathrm{d}$ was calculated. These rates are half of those calculated for uncoated anodes from the PNL testing.

- Due to the cracking problems with the anodes and the difficulties with cell operation, neither these nor the PNL corrosion rates are indicative of the real corrosion levels that could be achieved in an industrial cell.

- The calculated surface area loss was $0.1 \mathrm{~mm} / \mathrm{d}(3.65 \mathrm{~cm} / \mathrm{y})$, half that of the uncoated anodes. This is too high a corrosion for an inert anode material. Again, because of the cracking, this may not be a realistic estimate of the surface cermet anode wear.

- The operation at slightly higher $C D$ and lower BR did not significantly change the corrosion rate as determined by the impurities in the aluminum metal.

\section{Pilot Cell Operation}

- Operation near alumina saturation resulted in muck accumulating in the cell. This led to a decrease in the cell volume and a large temperature giadient $\left(30\right.$ to $\left.50^{\circ} \mathrm{C}\right)$ from top to bottom as the muck accumulated on the bottom. In addition, the muck led to uneven anodes rurrent.

- The lack of individual current control to each cermet anode led to varying $C D$ on the anodes with time and with location in the cell. This made it very difficult to draw any conclusions based on $C D$ to an anode.

- The low $C D$ on the cermet ancdes (and consequently low heat) led to crusting around the anodes furthest from the carbon anode, which was supplying most of the heat to the cell. This may be a continued difficulty in a self-heated cell with inert anodes at low $C D$ unles: an auxiliary heat source is available or a different cell design is used.

- Operation of inert anodes and carbon anodes together in a cell is possible. However, the current efficiency of each cannot be calculated individually. In addition, the aluminum formed from the carbon anode dilutes the impurities 
in the aluminum formed from the cermet anodes. Thus, the impurity levels in the aluminum will not be indicative of those that could be achieved with cermet anodes.

Calculations of the loss of the material from the inert anodes from the impurity levels should still give an idea of the wear rate of the inert anodes.

\section{$\mathrm{Cu}$ Cermet Substrates and Inconel Rod}

- The cracking of the $\mathrm{Cu}$ cermet substrates and the loss of chips or pieces in the bath resulted in corrosion rates that are not useful for predicting impurity levels or wear of the anodes.

- The cracking was the result of thermal shock on introduction of the cermets into the test cell. The design of the metal current connector within the machined cermet probably contributed to the formation of the cracks.

- There is probably some open porosity in the starting material that may have allowed initial penetration of the cryolite into the anode. The cryolite formed a porous corroded zone over $4 \mathrm{~mm}$ thick in an anode that had been operated for only $\mathrm{Ih}$.

- Cu in the metallic form was not present in the outer layers of any of the anodes. The depth of oxidation in the anodes ranged from 3 to $18 \mathrm{~mm}$ thick. Within the oxidized zone there existed $\mathrm{Cu}$ depletion zones, $\mathrm{Cu}$ oxidized zones, and unique outer surface zones.

- A Cu depletion zone exists near the surface in all anodes. This zone typically begins within $1 \mathrm{~mm}$ from the outer surface of the substrate and is up to $1 \mathrm{~mm}$ wide. Although $\mathrm{Cu}$ depleted seams were observed in the untested material, the presence of these zones consistently near the exterior surface of the anode, and the observation of $\mathrm{Cu}$ oxide stringers in the cryolite in B1, suggest that this particular feature is a result of operation in the cell.

- The composition of the ferrite and $\mathrm{Cu}-r i c h$ phases remain fairly constant from the copper depletion zone to areas inward in all anodes and are the same for all anodes. The NiO composition is fairly constant from the $\mathrm{Cu}$ depletion zone inward for anodes $\mathrm{Al}$ and $\mathrm{C} 1$. In anode $\mathrm{E} 1$, the $\mathrm{Cu}$ in solid solution within the $\mathrm{NiO}$ phase increases with depth into the anode.

- Within the $\mathrm{Cu}$ depleted, oxidized, and $\mathrm{Cu}$ metal containing regions in tested anodes there was an increase in porosity. Bath components could be found in some anodes throughout the sections examined. Bath mixtures in the pores had a lower 
$\mathrm{Na}: \mathrm{Al}$ ratio than was present in the bath.

- At the surface of the anode, next to the CEROX coating, unique surface structures were observed. These layers varied within an anode and from anode to anode. In some areas, the surface structure was a dense zone that contained $\mathrm{NiO}$ and $\mathrm{Ni}$ ferrite of different composition from the rest of the sample. In the ferrite, Al substituted for the $\mathrm{Fe}$ and small amounts of $\mathrm{Cu}$ were present as well. In that region, a $\mathrm{Cu}$ oxide phase was generally absent but $C u$ was present in the +2 state as part of a (Fe, $\mathrm{Ni}, \mathrm{Cu}) \mathrm{O}$ solid solution. The $\mathrm{PO}_{2}$ within the anode can be estimated based on the $\mathrm{Cu}$ oxidation reactions.

- In some areas, a dense Ce fluoride and $\mathrm{Cu}$ oxide layer lies between the CEROX coating and the ferrite substrate. In addition (in some anodes), Ce fluoride was noted as small isolated grains within the interior oxidized region, up to $15 \mathrm{~mm}$ into the sample (E1). The Ce fluoride within the sample may simply be the result of dissolved $\mathrm{Ce}$ in the cryolite penetrating the grain boundaries and freezing there upon removal from the cell. However, the dense and thick layers of mixed $\mathrm{Ce}$ fluoride and $\mathrm{Cu}$ oxide cannot yet be explained.

- Two different $\mathrm{Ni}$ fluoride phases were observed within the sample. One phase was a $\mathrm{Ni}$ rich $\mathrm{NiF}_{2}$ while the other contained $\mathrm{Ni}, \mathrm{Al}$, and $\mathrm{Na}$ as a $(\mathrm{Ni}, \mathrm{Na}, \mathrm{Al}) \mathrm{F}_{\mathrm{x}}$. Cryolite and $(\mathrm{Ni}, \mathrm{Na}, \mathrm{Al}) \mathrm{F}_{\mathrm{x}}$ coexist as separate phases. It is unknown if these compounds phase separate at cell operating conditions or if they separate upon cooling. It is not known why $\mathrm{NiF}_{2}$ is present in certain layers, while Nio coexists with $\mathrm{AlF}_{3}$ in other layers.

- The above conclusions indicate that this $\mathrm{Cu}$ cermet material as currently produced is not a stable material as a long term inert anode. The increase in porosity and the changes in phase composition show that the material composition was not stable under the conditions of penetrating $\mathrm{AlF}_{3}$ and cryolite. The $\mathrm{Cu}$ depletion in some areas, and the reaction of $\mathrm{Cu}$ metal to $\mathrm{Cu}_{2} \mathrm{O}$ and to $\mathrm{Cu}^{2+}$ in the $\mathrm{NiO}$ solid solution may lead to a loss of electrical conductivity in the anode. The oxidation thickness appears to increase with the length of time tested, which may yield a finite lifetime on an anode.

- The Inconel 601 microstructure exhibits signs of stress corrosion cracking. Cr rich precipitates at the grain boundaries in the center of the alloy were preferentially attacked by $\mathrm{AlF}_{3}$ and $\mathrm{Cr}$ was depleted within the grains. $\mathrm{Cr}$ fluorides and oxides were observed as reaction products. However, no rods failed and this material is superior to $\mathrm{Ni}$ 200 for this application. 


\section{Recommendations}

Based on the pilot cell testing recommendations can be made on ways to improve future pilot cell testing of inert anodes. In addition, recommendations are made on the substrate material and CEROX coating.

- In future pilot cell testing with inert anodes, the pilot cell should ideally contain all cermet anodes so that real estimates of current efficiency and corrosion can be made. In addition, the current to each inert anode should be individually controlled and monitored.

- Modeling and testing should be performed on the inert anode and current connector design in order to prevent any thermal stress cracking of the anodes.

- Low inert anode $C D$ will make it difficult to control the heat balance in a self-heated pilot cell. The cell should be carefully designed to take this problem into account.

- Mucking of the cell by excess undissolved alumina led to operation problems. Careful design of the anode or cell may help to operate at high alumina concentrations. If this is not possible, inert anode materials that are less affected by low alumina concentrations should be employed.

- A longer alumina sheath on the current connector is needed such that it extends above the crust. This should prevent corrosion of Inconel 601 stems above the meltiine. Rods within the anode may still be in contact with $\mathrm{AlF}_{3}$.

Additional experiments to determine a better (more corrosion resistant, more conductive, and cheaper) connector material may be necessary. The reaction of $\mathrm{AlF}_{3}$ with $\mathrm{Cr}$ suggests a lower $\mathrm{Cr}$ contents may be desirable.

- This Cu cermet material, as currently fabricated is not an acceptable material for a long term inert anode. Research on either improving this cermet (increase density, change composition or processing) or on a new material, with and without a CEROX coating, should be performed.

- Because the development of the CEROX coating as a protective coating for an anode substrate is at the pilot cell level, for future commercialization of the technology removal of Ce from the aluminum (to acceptable levels) should be demonstrated.

Based on the observations in this test, another pilot cell test is not recommended at this time with the present $\mathrm{Cu}$ cermet substrate material. Rather, materials research and small-scale testing of alternative ceramic or cermet materials is recommended before 
longer term testing. The present $\mathrm{Cu}$ cermet would be useful in short-term pilot cell tests in order to further develop a pilot cell that is adequate for longer term controlled testing of inert anode materials. In addition, the cermet is also adequate for other engineering studies, such as testing different shapes of anodes, if the cracking thermal shock problem is remedied. 


\section{REFERENCES}

1. Grjotheim, K; Krohn, C.; Molinovsky, M.; Matiasovsky, K. and Thonstad, J.; Aluminum Electrolysis Eundamentals of the HallHeroult Process, 2nd Edition, Aluminum-Verlag, Dusseldorf, 1982 .

2. Billehaug, K. and Oye, H.A.; "Inert Anodes for Aluminum Electrolysis in Hall-Heroult Cells," Aluminum 57 (2), 1980, pp. 146-150.

3. Weyand, J.D.; Ray, S.P.; Baker, F.W.; DeYoung, D.H.; and Tarcy, G.P.; "Inert Anodes for Aluminum Smelting," Final Report, February 1986; DOE/CS/40158-20.

4. Strachan, D.M.; Marschman, S.C.; Davis, N.C.; Friley, F.R.; and Schilling, C.H.; "Inert Electrodes Program Fiscal Year 1988 Annual Report," October 1989; PNL-7106/UC-313.

5. Strachan, D.M.; Windisch, C.F., Jr.; Koski, O.H.; Morgan, L.G.; Peterson, R.D.; Richards, N.E.; and Tabereaux, A.T.; "Results from Electrolysis Test of a Prototype Inert Anode," May 1990; PNL-7345/UC-313.

6. Gregg, J.S. and Frederick, M.S.; "Evaluation of Cerium Oxide Coated $\mathrm{Cu}$ Cermets as Inert Anodes For Aluminum Electrowinning," March 1992; DOE/ID/12949.

7. Windisch, C.P., Jr.; Strachan, D.M.; Henager, C.H., Jr.; Greenwell, E.N.; and Alcorn, T.R.; "Results from a Pilot Cell Test of Cermet Anodes," May 1992.

8. Skybakmoen, E.; Solheim, A.; and Sterten, A.; "Phase Diagram Data in the System $\mathrm{Na}_{3} \mathrm{AlF}_{6}-\mathrm{Li}_{3} \mathrm{AlF}_{6}-\mathrm{AlF}_{3}-\mathrm{Al}_{2} \mathrm{O}_{3}$ Part II: Alumina Solubility," Light Metals 1990, C.M. Bickert (ed.), The Minerals, Metals, \& Materials Society, Warrendale, PA, 1990.

9. Pelton, A.D.; Schmalzried, H.; and Sticher, J.; "ComputerAssisted Analysis and Calculation of Phase Diagrams of the $\mathrm{Fe}-\mathrm{Cr}-\mathrm{O}, \mathrm{Fe}-\mathrm{Ni}-\mathrm{O}$, and $\mathrm{Cr}-\mathrm{Ni}-\mathrm{O}$ Systems," J. Phys. Chem. Solids, 40 (12), 1979, pp. 1103-1122.

10. Dalvi, A.D. and Sridhar, R.; "Thermodynamics of the Ee-Ni-O and $\mathrm{Fe}-\mathrm{Ni}$ Systems at $1065 \mathrm{~K}$ to $1380 \mathrm{~K}, "$ Can. Metall. Q., 15 (4), 1976, pp. 349-357.

11. Thompson, W.T.; Bale, C.W.; and Pelton, A.D.; "F*A*C*T (Facility for the Analysis of chemical Thermodynamics) Guide to Operations," MCGill University Computing Centre, Montreal, 1985. 
12. Schmid, R., "A Thermodynamic Analysis of the Cu-O system with an Associated Solution Model," Metall. Trans. B, 14B (5), 1983, pp. 473-481.

13. Metals Handbook, Volume 8, T. Lyman, Ed., The American Society For Metals, Metals Park, Ohio, 8th Edition, 1973.

14. Windisch, C.F., Jr.; Strachan, D.M.; Davis, N.C.; Morgan, L.G.; Shade, J.W.; Stice, N.D.; and Westerman, R.E., "Inert Electrodes Program Fiscal Year 1990 Annual Report," August 1991; $\mathrm{PNL}-7777 / \mathrm{UC}-313$.

15. Kingery, W.D.; Bowen, H.K.; and Uhlmann, D.R., Introduction to Ceramics, 2nd Edition, John Wiley \& Sons, New York, New York, 1976.

16. Bularzik, J.; Davies, P.K.; and Navrotsky, A., "Thermodynamics of Solid-Solution Formation in NiO-CuO," J. Amer. Ceram. Soc., 69 (6), 1986; pp. 453-457.

17. Eric, H. and Timucin, M., "Equilibrium Relations in the System Nickel Oxide-Copper Oxide," Metall. Trans. B, 10B (6), 1979; pp. 561-563.

18. Meyers, C.E.; Mason, T.O.; Petuskey, W.T.; Halloran, J.W.; and Bowen, H.K.; "Phase Equilibria in the System Fe-Al-O", J. of the Amer. Cer. Soc., 63 (11-12), 1980; pp. 659-663.

19. Elrefaie, F.A. and Smeltzer, W.W., "Thermodynamics of NickelAluminum-oxygen System Between 900 and $1400 \mathrm{~K}, " \mathrm{~J}$. Electrochem. Soc., 128 (10), 1981; pp. 2237-2242.

20. Craig, J.R. and Vaughan, D.J., ore Microscopy and Ore Petrography, John Wiley \& Sons, New York, New York, 1981.

21. "Inconel 601," Inco Alloys International, Huntington, West Virginia. 
Appendix 1

Reynolds Manufacturing Technology Laboratory (MTL) Report 
MTL Report 1073

TIC 43-2411

\section{Manufacturing Technology Laboratory \\ ELTECH CERMET ANODE \\ PILOT CELL TEST \\ Project J-006-001 \\ Subcontract to DOE Contract \\ DE-FC07-9 OID12940}

Tom R. Alcorn January 28, 1992

Submitted By:

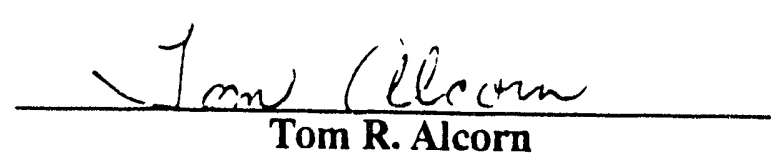

Tom R. Alcorn

Approved By:

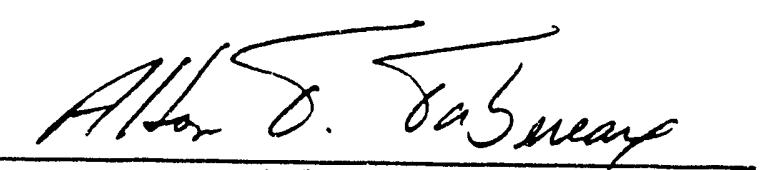

A. T. Tabereaux

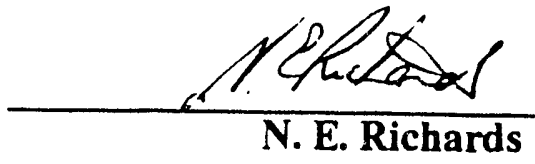




\section{ELTECH CERMET ANODE}

PILOT CELL TEST

Table of Contents

Page

I. SUMMARY …................................................................................................ 1

II. INTRODUCTION ..................................................................................... 3

III. CONCLUSIONS _........................................................................................ 4

IV. EXPERIMENTAL DESIGN AND PROCEDURES ........................................... 5

V. RESULTS …................................................................................

VI. DISCUSSION

VII. APPENDICES …..................................................................................................... 16

Appendix A - Bath Composition

Appendix B - Metal Impurities

Appendix C - Bath Impurities 


\section{SUMMARY}

The effectiveness of cerium oxide coating technology developed by ELTECH for cermet anodes was evaluated in a pilot aluminum reduction cell operated at Reynolds Metals' Manufacturing Technology Laboratory. 'This was the second test of a module of six cermet anodes in the pilot reduction cell, with the first being with uncoated cermet anodes with Battelle's Pacific Northwest Laboratory (PNL). Individual cermet anodes were in continuous operation for as long as 614 hours (26 days) during the test with ELTECH and were intact upon removal.

The cermet anodes were operated for the majority of the test period at an anode current density of $0.5 \mathrm{amp} / \mathrm{cm}^{2}$ and with the alumina content of the electrolyte near saturation. These conditions resulted in muck buildup in the cell bottom reducing available cell liquid volumes. Minor changes in the test parameters were made near the end of the test period with a slightly higher anode current density $\left(0.65 \mathrm{amp} / \mathrm{cm}^{2}\right)$ and lower bath ratio (1.25 versus 1.50$)$. No measurable effect on cermet anode performance or cell condition (muck buildup) was observed as a result of these changes.

Material problems, which occurred during the previous PNL cermet anode test, were greatly reduced during the ELTECH test. Inconel 600 was used as the material for the anode stem conductor, which proved to be an improvement over Nickel 200 used initially in the PNL test. The thermal stress cracking of the cermet anodes still remained a significant problem with this particular design of the cermet anode. However, through minimizing disturbances and movement of the cermet anodes, only two anodes were removed prematurely due to cracking or breakage.

Corrosion rates of the cermet anodes with a "Cerox" coating, as determined by the rate of metal impurity (iron, nickel, copper) increase in the aluminum metal, was approximately half that experienced in the previous PNL test with uncoated cermet anodes as shown below.

\begin{tabular}{|lll|}
\hline & PNL & ELTECH \\
\hline Iron increase, lb/day & $0.31(0.21)$ & $0.30(0.12)$ \\
Nickel increase, lb/day & 0.26 & 0.13 \\
Copper increase, lb/day & 0.13 & 0.075 \\
Surface area loss, mm/day & 0.2 & 0.1 \\
\hline
\end{tabular}

The rate of iron increase in the aluminum metal pad was affected by other sources than the cermet anodes, such as tapping and sampling. The values for iron in parenthesis are the quantity which can be attributed to the cermet anodes.

It was observed that for some anodes the variability in the current gradients around the surface of individual cermet anodes greatly affected the "Cerox" coating thickness. Individual anodes were observed to have "Cerox" coating thickness varying from approximately $1 / 8$ inch thick to none, where no, or very limited, current flow occurred from the anode surface. It is uncertain as to what effect these uncoated areas of the cermet anodes had on the corrosion rates of the anode material.

Maintaining the desired thickness of cerium oxide coating on the cermet anodes required maintaining cerium in the electrolyte through the routine additions of $\mathrm{CeF}_{3}$. The resulting equilibrium concentrations of cerium in the bath and metal are as follows: 


\begin{tabular}{|ll|}
\hline Cerium in the bath & $0.44 \%$ \\
Cerium in the metal & $3.23 \%$ \\
\hline
\end{tabular}

This high concentration of cerium in the metal will require that an economical technology be proven feasible for reducing the cerium concentration in the primary metal to an acceptable level ( $<1 \mathrm{ppm}$ ) before the "Cerox" technology would be accepted by industry. Advances in the cermet anode technology must also occur. Additional material characterization needs to occur as well as innovations in cell/anode design which will minimize the problems associated with the thermal stress cracking, low anode current density operation, and reduction cell operation with high alumina concentration in the electrolyte. 


\section{INTRODUCTION}

ELTECH Research Corporation has developed the technology to form and maintain a cerium oxide coating on cermet anodes during the operation of an aluminum reduction cell. As part of a Department of Energy contract (cost shared), Reynolds Metals Company operated a pilot reduction cell at its Manufacturing Technology Laboratory to allow larger scale testing of this "Cerox" coating technology. This was the second test of a module of six cermet anodes conducted in the pilot cell, with the first being with Battelle's Pacific Northwest Laboratories (PNL). Both tests used cermet anodes manufactured by Ceramic Magnetics, Fairfield, New Jersey.

The objective of the pilot cell test was to evaluate the performance and determine the corrosion rate of the cermet anodes with the "Cerox" coating in an industrial size application and compare that data with the similar operation of the cermet anodes without the "Cerox" coating during the previous PNL test. Corrosion rates were primarily determined through the rate of increase of metal impurities (iron, nickel, and copper) in the aluminum metal pad. Material evaluations of the removed cermet anodes will be reported separately by ELTECH.

Primary evaluation of the cermet anodes was conducted under pilot cell test conditions of $0.5 \mathrm{amp} / \mathrm{cm}^{2}$, alumina saturation, and a bath ratio of 1.5 . Additional evaluations were conducted at a slightly higher anode current density $\left(0.65 \mathrm{amp} / \mathrm{cm}^{2}\right)$ and at a lower bath ratio (1.25). 


\section{CONCLUSIONS}

Major conclusions from the operation of the reduction pilot cell with cermet anodes using ELTECH's "Cerox" coating are:

1. Major design problems exist with the cermet anodes as manufactured for the pilot cell test as demonstrated by the thermal stress causing cracking and breaking of the anodes. The actual breakage of the anodes, which was experienced in the previous PNL test, was minimized by adopting a policy of not disturbing the cermet anodes once installed. Only two cermet anodes were removed prematurely due to cracking/breaking.

2. Use of Inconel 600 for the anode stem conductor rod, along with a ceramic barrier just above the anode top, proved to be satisfactory for the duration of the pilot cell test.

3. Corrosion rates of the cermet anodes as determined by metal impurity increases in the aluminum metal pad were:

\begin{tabular}{|ll|}
\hline Copper & $0.075 \mathrm{lb} /$ day \\
Nickel & $0.13 \mathrm{lb} /$ day \\
Iron & $0.30 \mathrm{lb} /$ day \\
\hline
\end{tabular}

The iron corrosion rate is inflated due to contamination from other sources and should be $0.12 \mathrm{lb} /$ day based upon the ratio of materials in the anode and the rate of corrosion of copper and nickel.

4. These corrosion rates result in a surface area loss of $0.1 \mathrm{~mm} /$ day, based on uniform loss from all six anodes. This corrosion rate is approximately one half of that determined during the previous testing of similarly manufactured cermet anodes without "Cerox" coating for PNL.

5. Operation of the cermet anodes with slightly higher anodic current density and/or lower bath ratio did not significantly change the corrosion rates as determined by metal impurity increases in the aluminum metal pad.

6. Continuous operation of the cell near alumina saturation resulted in extreme mucking conditions which reduced the cell liquid volumes of bath and metal. This condition also resulted in a $30-50^{\circ} \mathrm{C}$ temperature gradient vertically in the bath.

7. Uneven current flow from the surfaces of individual cermet anodes resulted in uneven "Cerox" coating formation with some areas without any coating. This current flow imbalance was caused by the effects of the adjacent carbon anode which operated at a considerably higher amperage and voltage, and the location of other cermet anodes.

8. Average equilibrium levels of cerium in the pilot reduction cell were:

\begin{tabular}{|ll|}
\hline Cerium in the bath & $0.44 \%$ \\
Cerium in the metal & $3.23 \%$ \\
\hline
\end{tabular}

Higher temporary concentrations of cerium (approximately $0.8 \%$ in the bath) were needed during the actual coating process to be effective. 


\section{EXPERIMENTAL DESIGN AND PROCEDURES}

\section{A. Pilot Aluninum Reduction Cell Design}

MTL's pilot reduction cell, as shown in Figure 1, is a small, self-heated cell with the capacity for running two industrial-size carbon anodes. Figures 2 - 3 show schematics of the pilot cell design. Key features of this design include the following.

1. Two $15.5 " \mathrm{n}$ 21.5" anodes located 4 inches apart, centered over two standard amorphous cathode blocks.

2. Sidewall construction consisting of rammed carbon, prebake carbon blocks, and TR-19 vermiculite insulation to minimize heat losses.

3. Alumina feed through a point feed system located between the two anodes.

4. A cell cavity $44^{\prime \prime} \times 33^{\prime \prime} \times 17^{\prime \prime}$ deep. A 5 inch gap exists between the edge of the anode on two sides and a 6 inch gap on the other two sides. Metal tapping is normally done using a vacuum crucible between the two anodes.

Special modifications were done to the system to accommodate the testing of the vermet anodes. One of the carbon anodes (east) was replaced by an inert anode cluster consisting of six cermet anodes in a 2 by 3 arrangement as shown in Figures 4 and 5 . The identification (A-F) of the anode positions is shown in Figure 4 and will be used throughout this report. The holder system allowed for removal of each individual anode. Current was supplied to the anode cluster by means of cables connected to the top of each stem. Current was monitored to each cermet anode by means of a calibrated current shunt located near the top of the superstructure. The shunts were calibrated at $100 \mathrm{mv}$ being equal to 500 amps. Each of the anodes was electrically isolated from the holder by means of an alumina insulator. Current to the cermet anode cluster was isolated from the adjacent carbon anode, allowing individual control of current or voltage of the carbon anode and cermet anode cluster. This allowed operation of the carbon anode under such conditions to provide sufficient heat for maintaining a proper thermal balance in the cell.

\section{B. Cermet Anode Design}

The cermet anodes of the type $\mathrm{NiO}-\mathrm{NiFe}_{2} \mathrm{O}_{4}-\mathrm{Cu}$ were manufactured by Ceramic Magnetics Inc., Fairfield, N.J. These anodes contained approximately $42.9 \% \mathrm{NiO}, 40.1 \%$ $\mathrm{Fe}_{2} \mathrm{O}_{3}$, and $17 \% \mathrm{Cu}$. The cermet anode is shown in Figure 6. The anodes were cylindrical with a radius of 3 inches and a height of 3 inches with an additional 1 inch lip extending above the top face of the cylinder. The bottom edges of the anodes were rounded with a radius of curvature of 1.5 inch. An 18 inch long, 1 inch diameter Inconel 600 connector rod was screwed into the center of each cermet anode. A 1.25 inch diameter alumina sleeve was placed over the rod, extending 3 inches up from the top of the cermet anode, to serve as a chemical protection to the rod. This sleeve was then packed with an alumina castable.

\section{Testing Procedures}

Test data was routinely collected from the cell in order to monitor the performance of the anodes and control the cell operation. These items were recorded on a log sheet during each of the three daily shifts as shown in Figure 7. In addition to this, current of each 


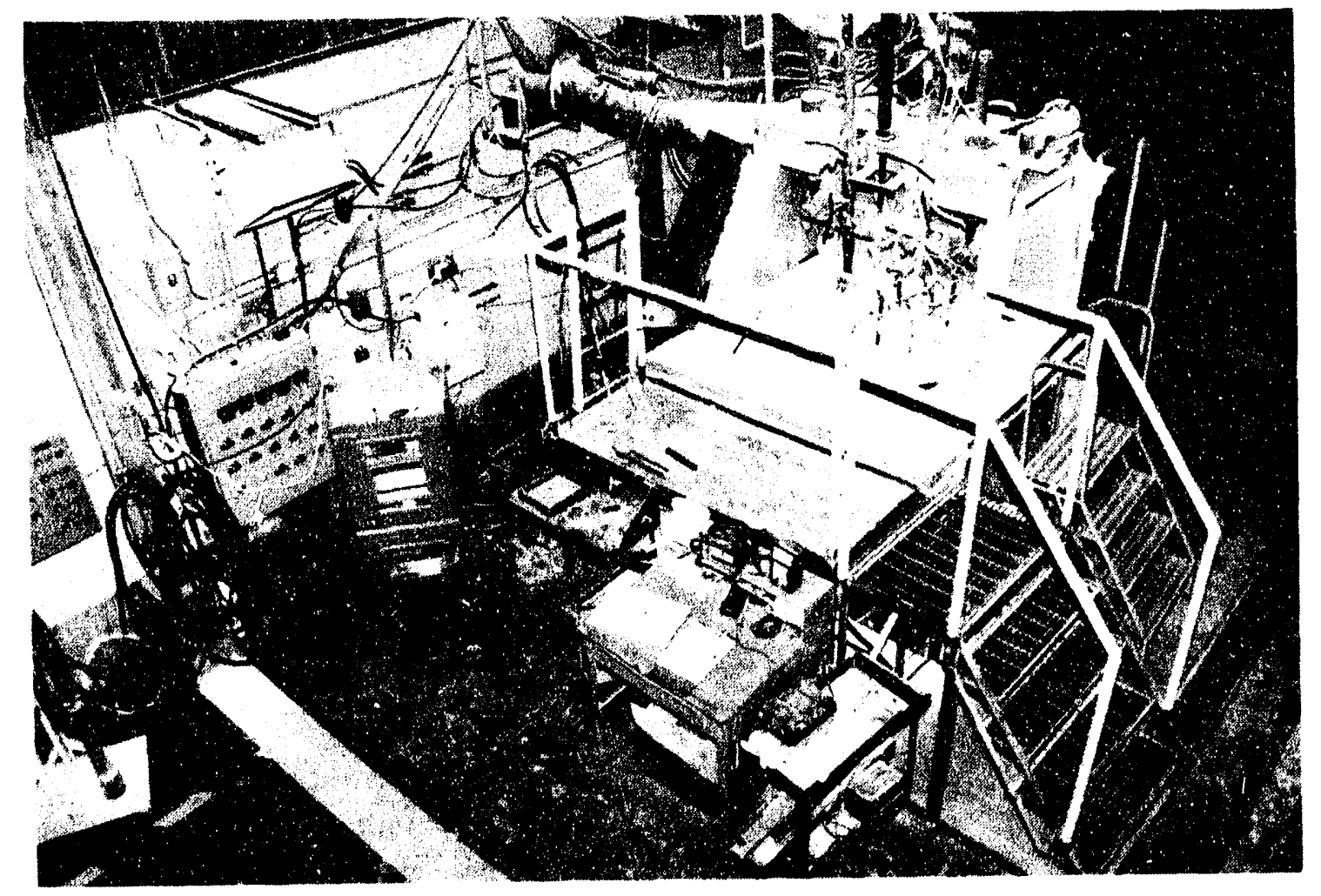

Figure 1. MTL's Pilot Reduction Cell 


\section{Pilot Cell Design Plan View}

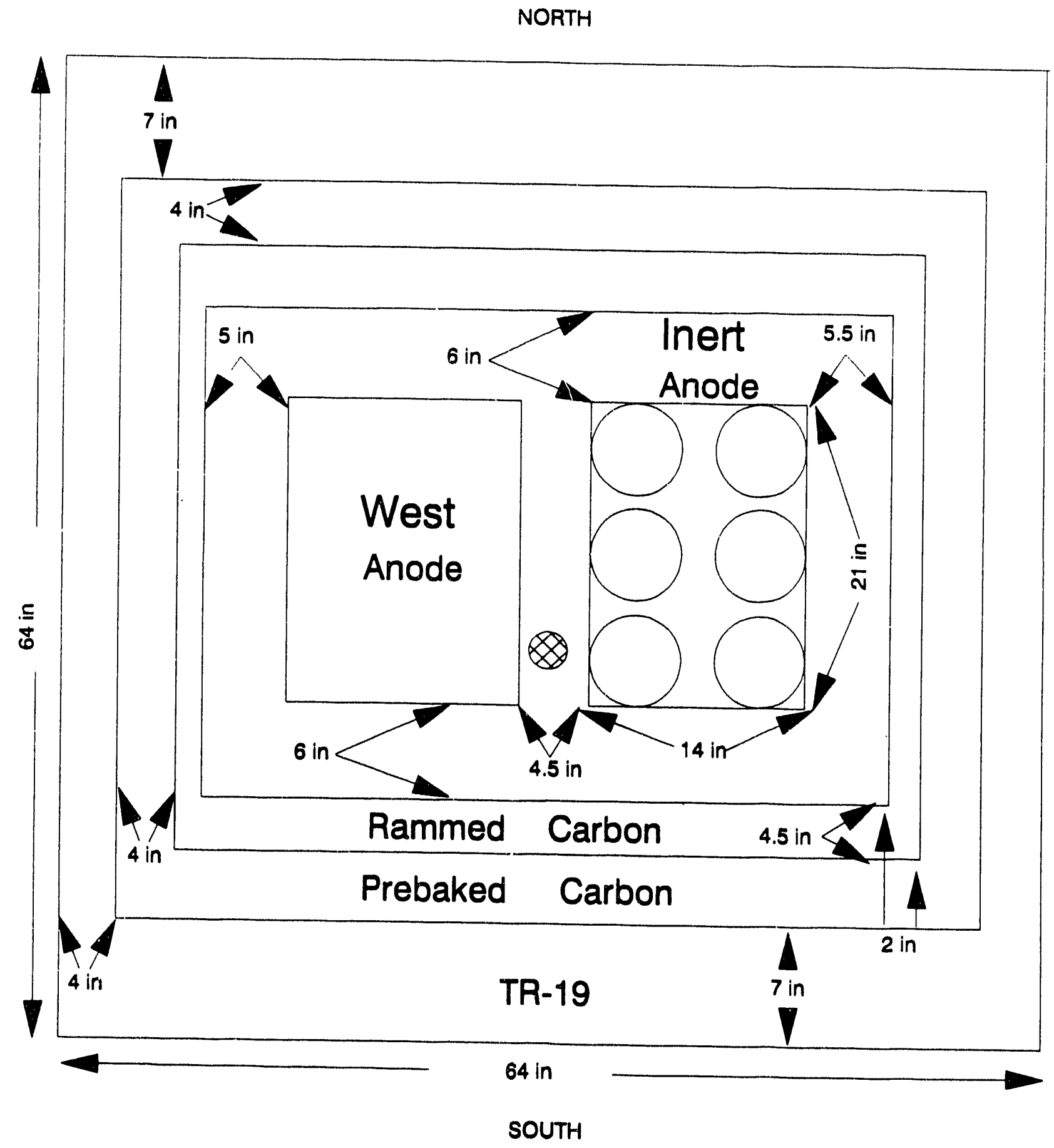

Figure 2

- 7 - 


\section{PILOT REDUCTION CELL DESIGN}

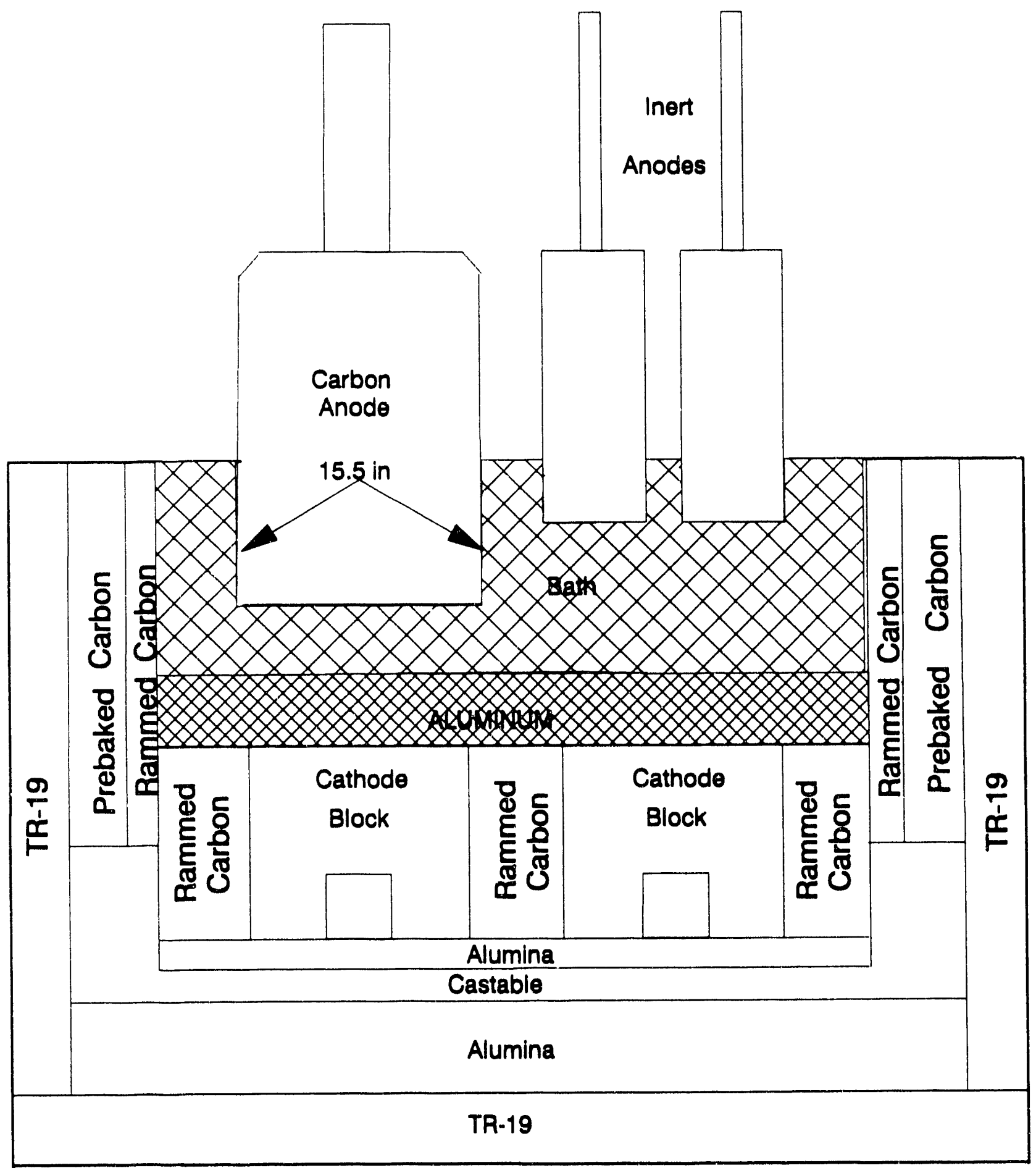

Figure 3 


\section{Inert Anode Layout}

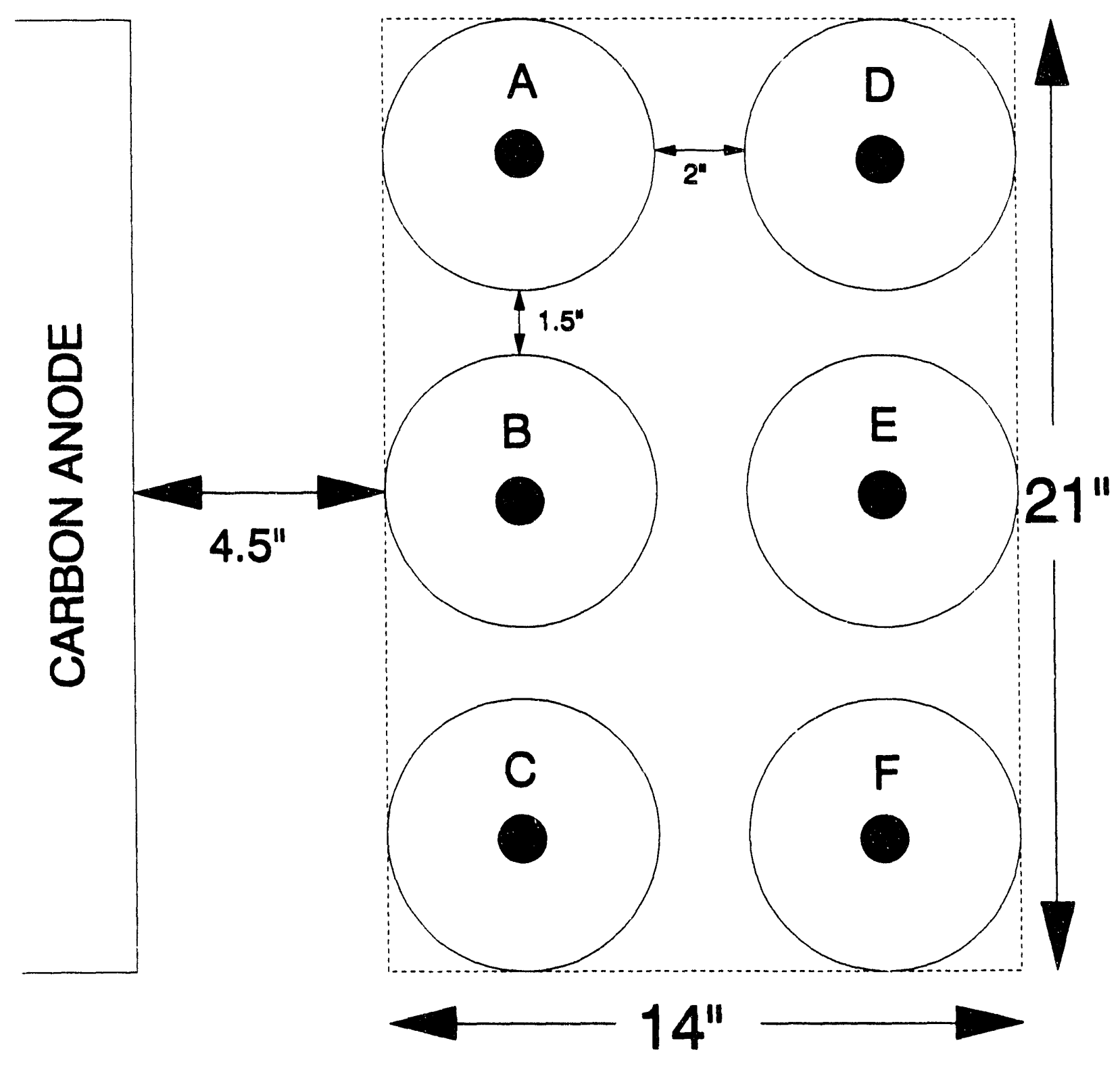

Figure 4 

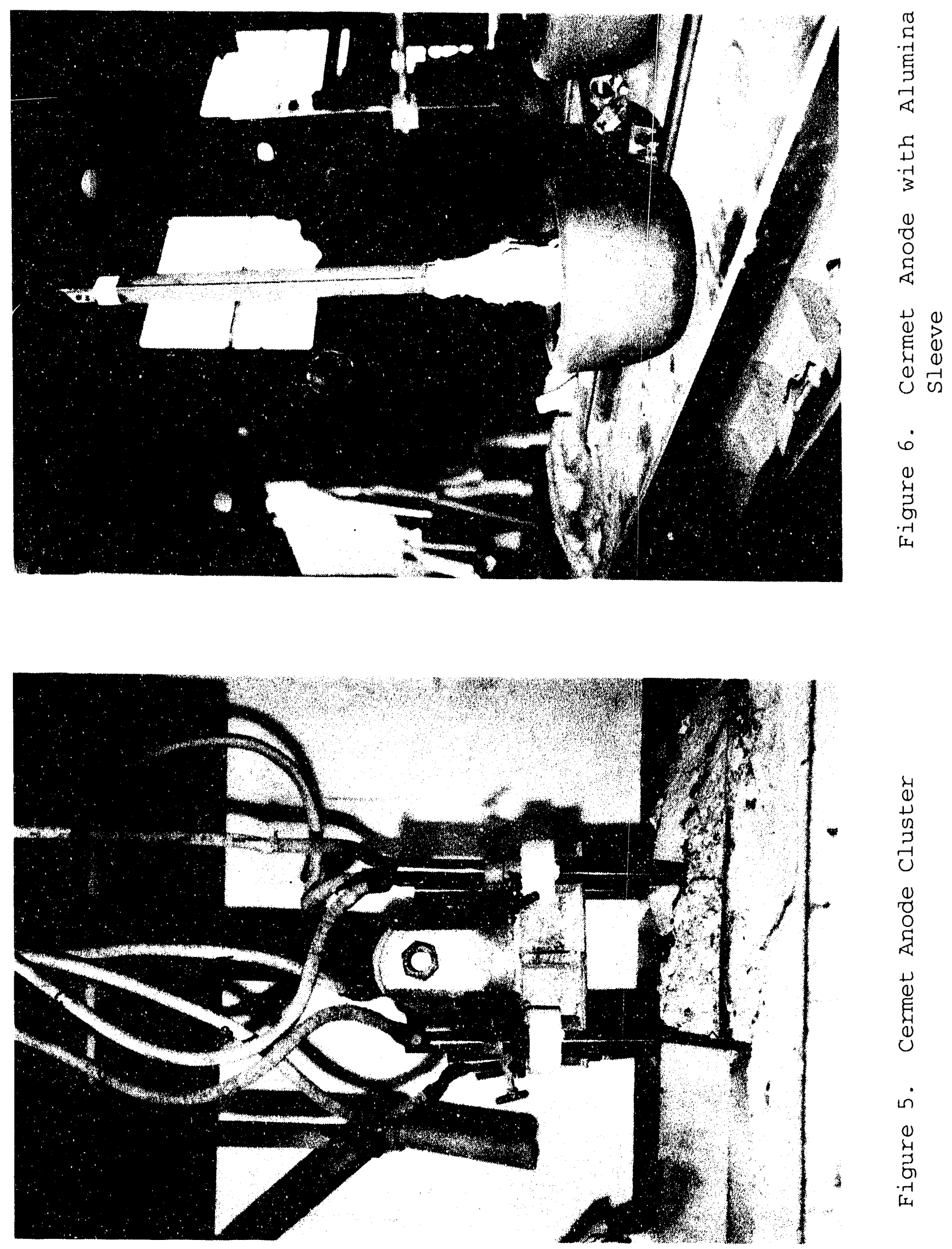


\section{Pilot Reduction Cell Inert Anode Test}

Date

Operators

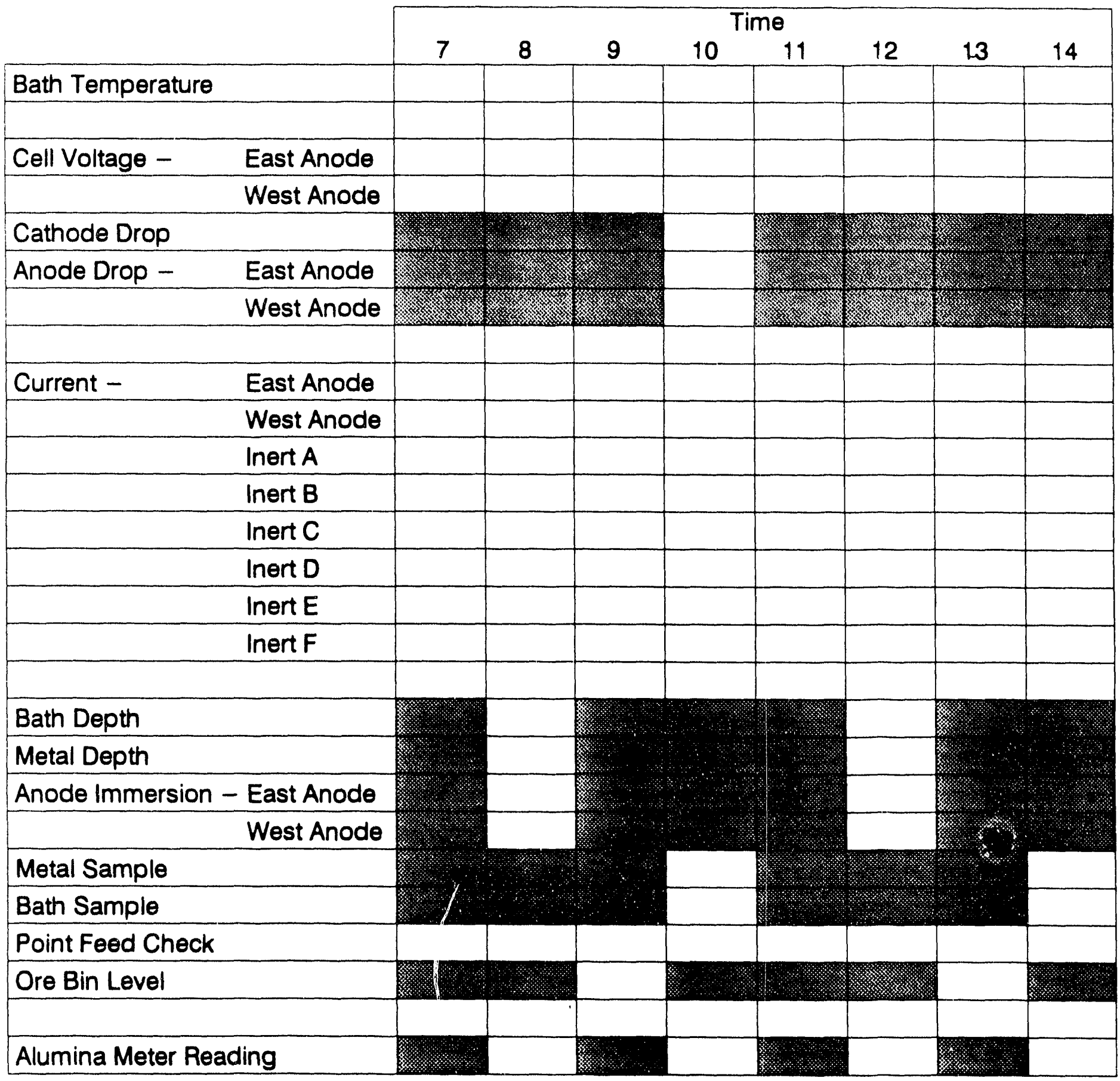

Comments:

Figure 7 
cermet anode, voltage of the east and west anodes, and total current to each anode (or cluster) was logged every 30 seconds by means of a Dianachart data acquisition system and a personal computer. Non-routine data and activities were recorded in log books. 


\section{RESULTS}

\section{A. Cell Preparation}

Following the completion of the PNL pilot cell test in August, the cermet anodes were replaced with a standard carbon anode and the cell was operated for a time to return the cell to a normal operating condition. Primary emphasis was in achieving a clean cathode, free of muck, and to reduce the major metal (iron, copper, and nickel) impurities' concentrations to normal, baseline levels. Target baseline concentration levels were:

\begin{tabular}{|ll|}
\hline Iron & $0.380 \%$ \\
Copper & $0.050 \%$ \\
Nickel & $0.003 \%$ \\
\hline
\end{tabular}

The metal pad was tapped low (2-3 inch) and numerous anode effects were forced to enhance the return to normal operating conditions. The cell bottom was essentially muckfree by September 3; however, additional time was required to obtain the stable, lower concentration levels of the major impurities in the metal. Figures $8-10$ show the impurity levels during this time period. On September 11, $100 \mathrm{lb}$ of pure aluminum was added to the cell to dilute and thus lower the levels of metal impurities. By September 14, the impurity levels had stabilized at sufficiently low levels to begin the test of the cermet anodes with the "Cerox" coating. Only nickel had not returned to the initial low level, as shown below.

\begin{tabular}{|ll|}
\hline Iron & $0.440 \%$ \\
Copper & $0.020 \%$ \\
Nickel & $0.030 \%$ \\
\hline
\end{tabular}

\section{B. Preheating and Installation of Cermet Anodes}

The cermet anodes were heated on the cell, similar to procedures developed during the previous PNL test. The cermet anodes were placed on the deck plate and covered with a kaowool blanket on September 8 (4:00 p.m.), where they remained until September 13 (11:30 a.m.), at which time they were placed in the "six-pack" holder over the crust, as shown in Figure 11. A kaowool blanket was then placed over the cermet anodes, and they were gradually lowered onto the crust and into the bath. The anodes were moved into the bath at 1:30 p.m. on September 14 and began to conduct current. Figure 12 shows the heatup of the cermet anodes during this period as measured by thermocouples located on top of the anodes. As this plot indicates, the anodes were heated to $130-230^{\circ} \mathrm{C}$ when placed over the cell crust, then gradually heated to $600-650^{\circ} \mathrm{C}$, prior to contacting the molten bath.

This procedure appeared to work reasonably well; however, the anode in position B developed a noticeable crack through the center of the anode shortly after installation and was removed at 5:00 p.m. on September 14.

An identical heatup procedure was used for installation of the 3 replacement anodes used during the testing on September 26 and 27. 


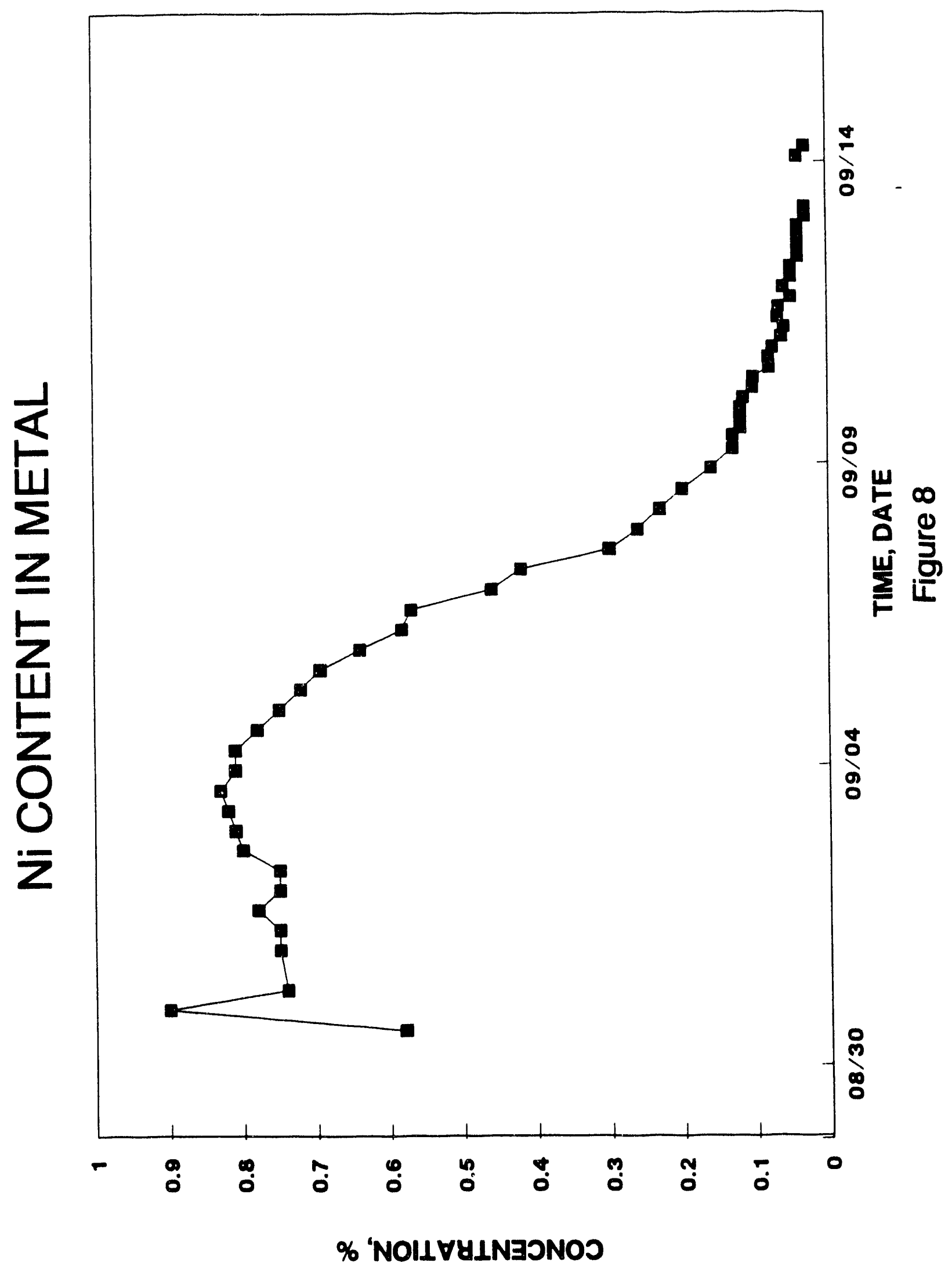

- 14 - 


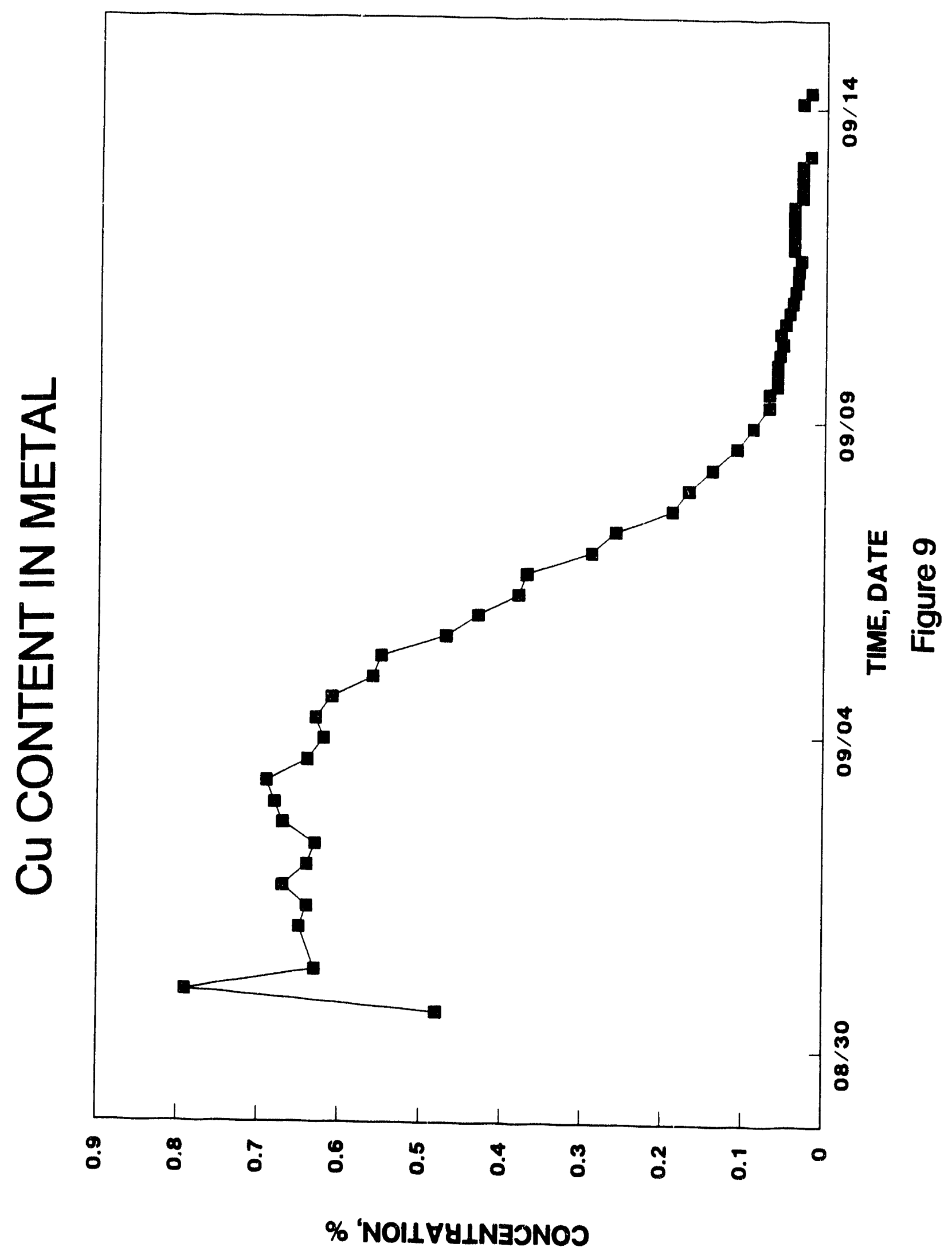

- 15 - 


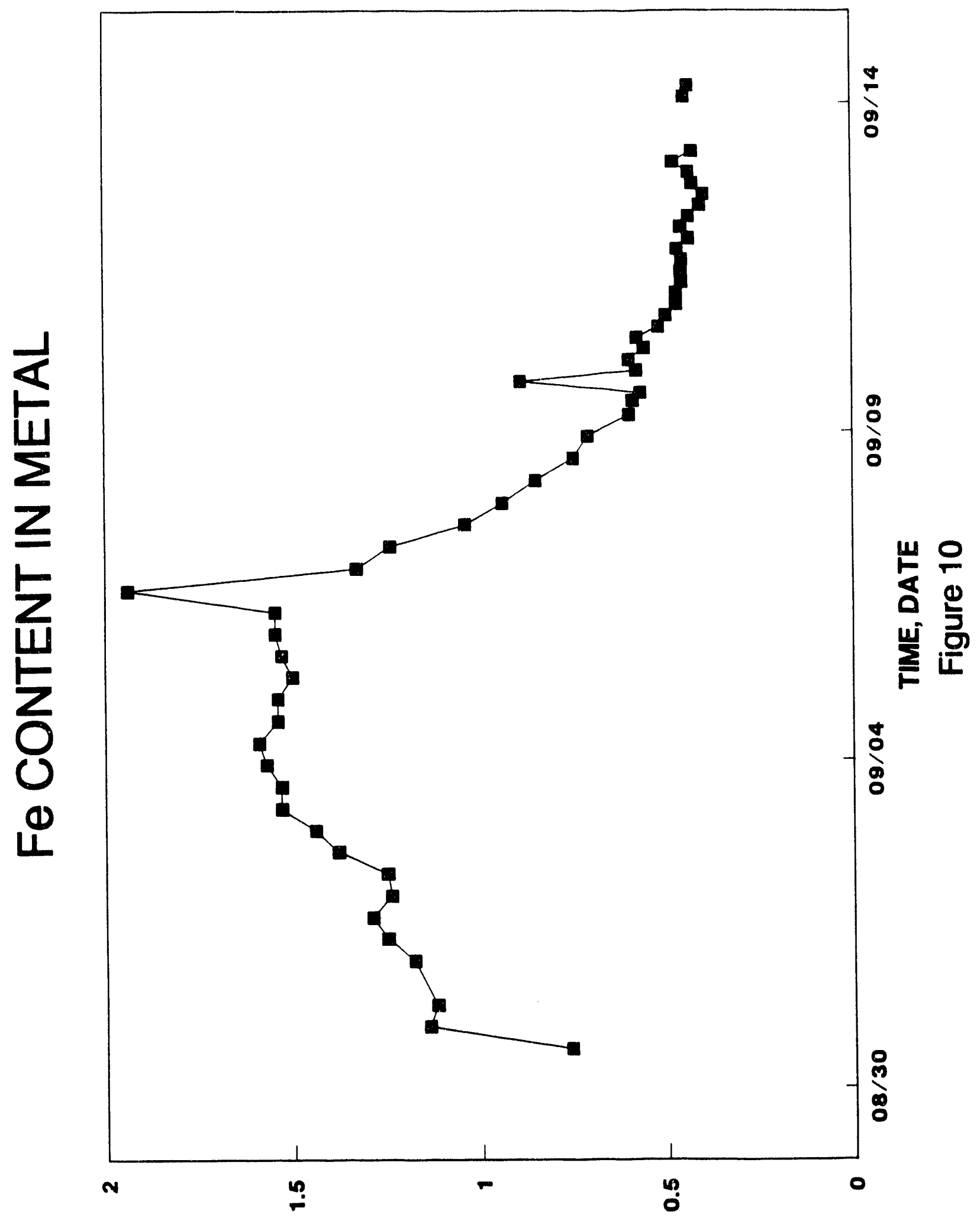

\% 'NOIL $\forall Y \perp N \exists D N O S$

-16 - 


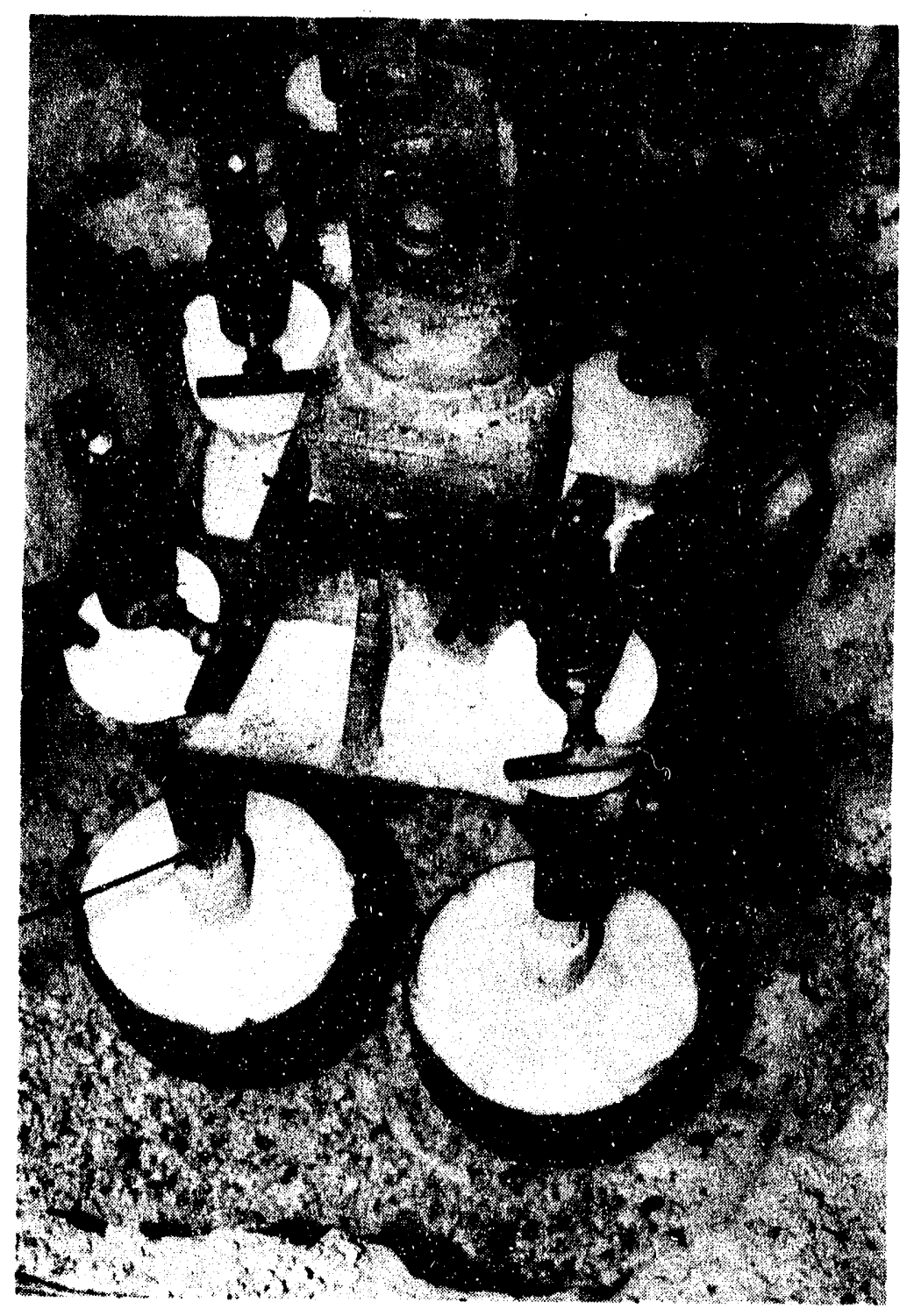

Figure 11. Cermet Anode Cluster preheating over Cryolite Crust 


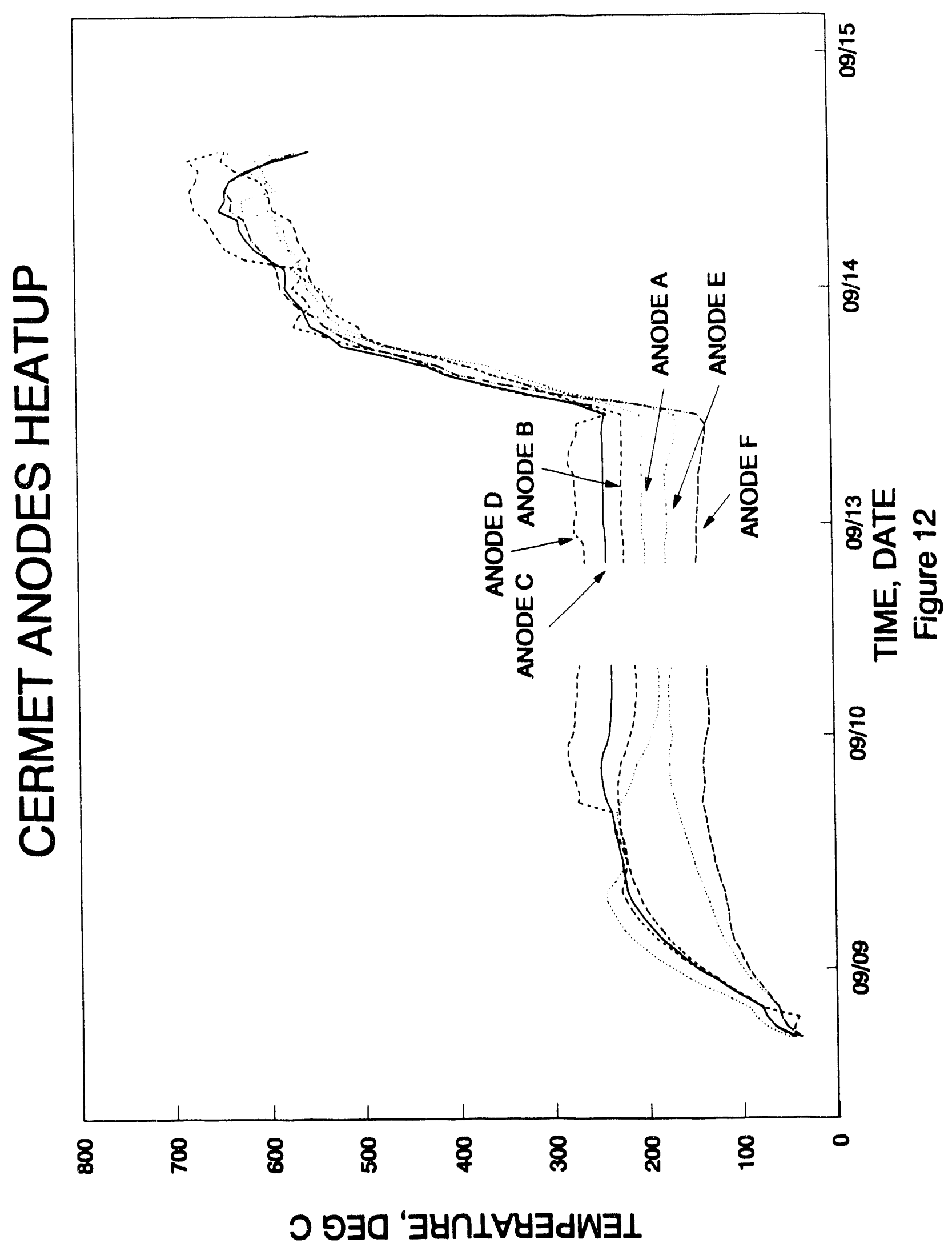



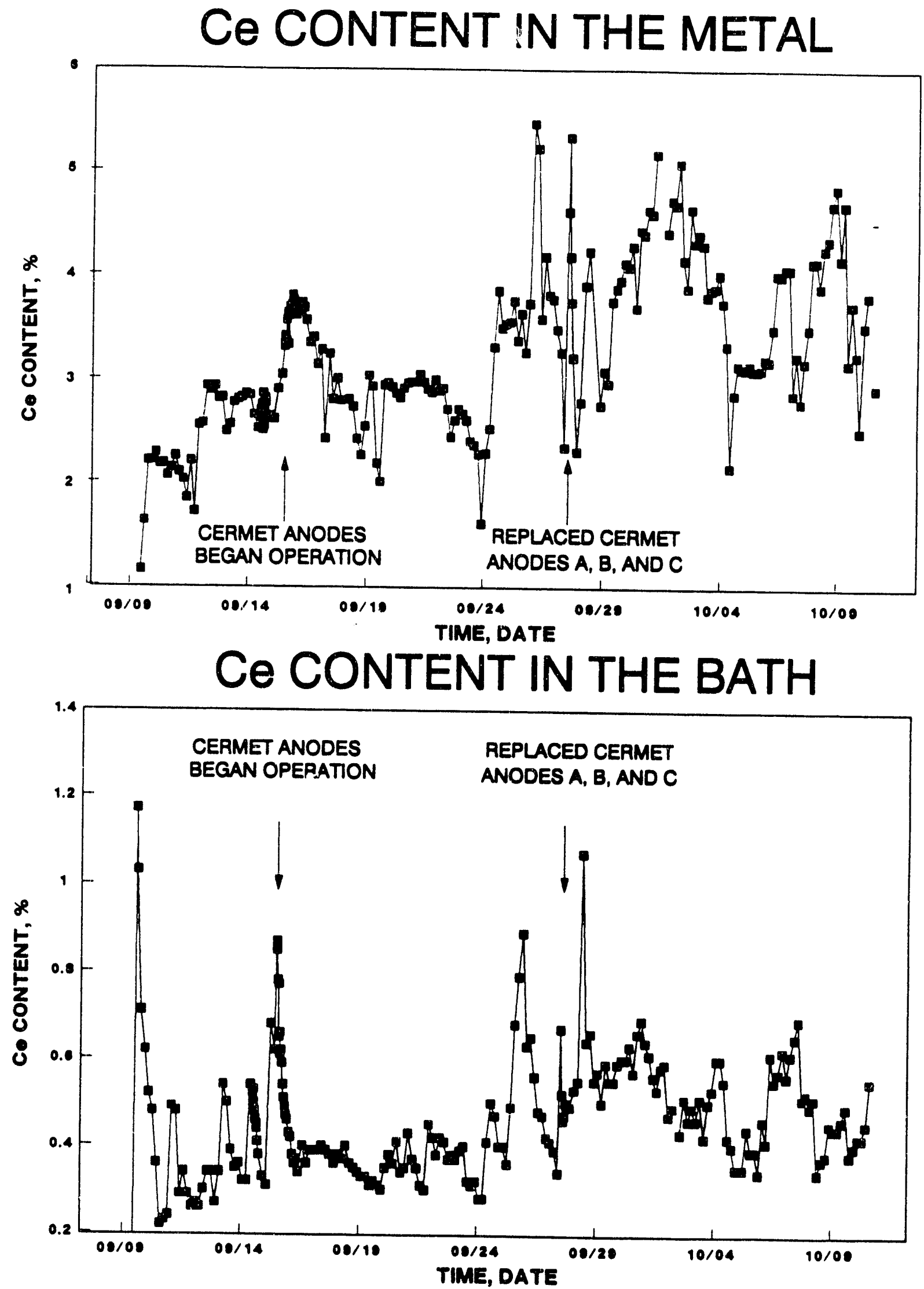

Figure 13 


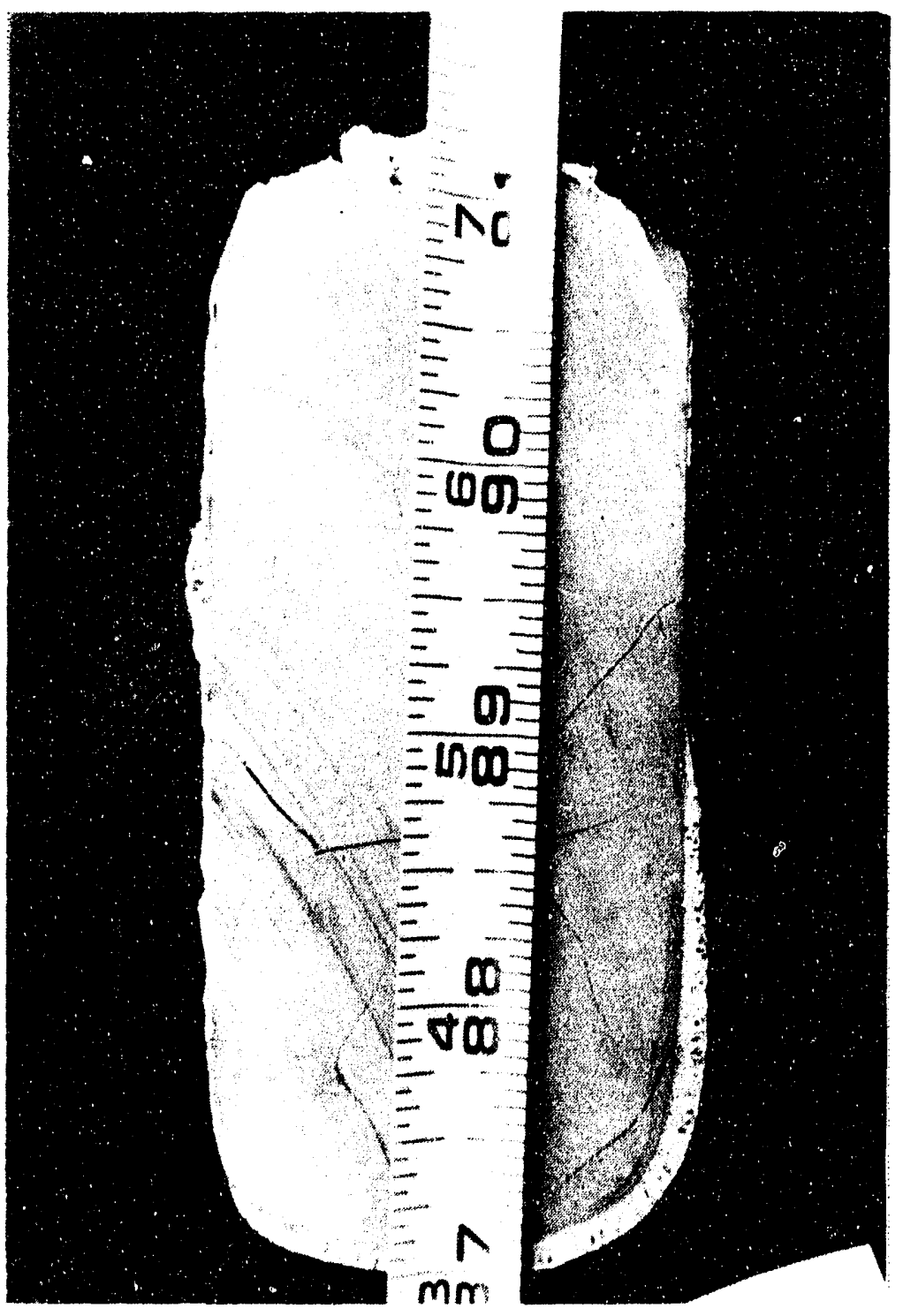

Figure 14. Reference Cermet Anode cross-section showing "Cerox" coating 


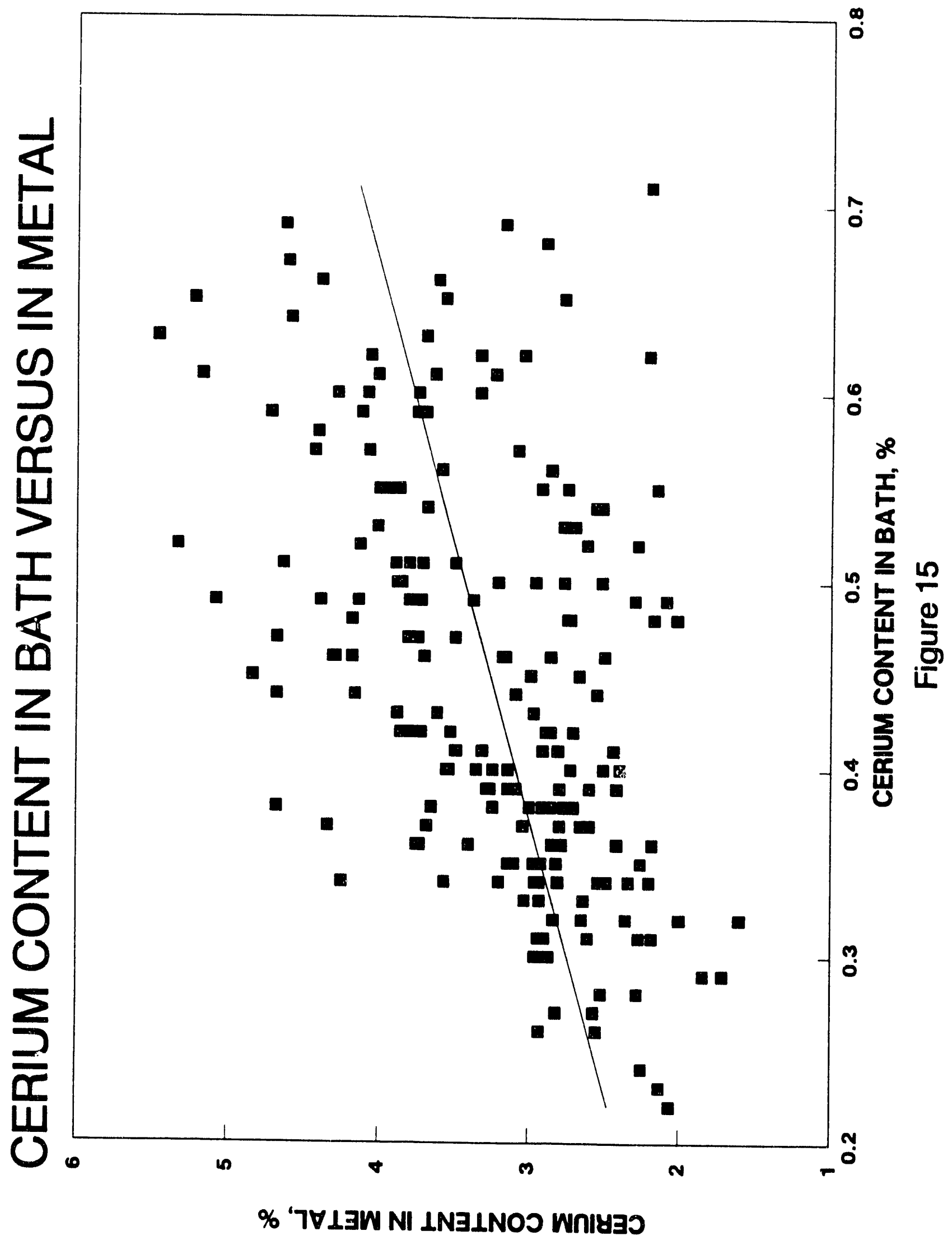




\section{Cerox Cermet Anode Coating Procedure}

The cermet anodes were coated with cerium oxide in the pilot reduction cell by controlling the additions of cerium fluoride $\left(\mathrm{CeF}_{3}\right)$ to the electrolyte. For the coating to occur properly, it is critical to have sufficient concentrations of cerium fluoride in the cell bath. The majority of the cerium added to the bath reported to the aluminum metal pad. These values for cerium are shown in Figure 13. Typical equilibrium concentration values for the distribution of cerium between the bath and aluminum are as follows:

\begin{tabular}{|ll|}
\hline Cerium in bath & $0.44 \%$ \\
Cerium in metal & $3.23 \%$ \\
\hline
\end{tabular}

At the time (September 15 and September 26) of the initial coating of the anodes, increased amounts of $\mathrm{CeF}_{3}$ were added to the cell, temporarily achieving higher levels of cerium in the bath. A separate, small (reference) cermet anode (1.5" diameter) was placed into the electrolyte, operating on a separate power supply, to evaluate the cerium coating process. The anode operated for a few hours and then was removed to evaluate the coating. The first evaluation was on September 13 at 3:30 p.m. in which no coating was observed on the cermet anode upon removal 5 hours later. A second evaluation was made on September 14 and again little or no cerium coating of the cermet anode occurred. On September 15, after increased amounts of $\mathrm{CeF}_{3}$ were added to the cell, a coating was observed to have formed on the anode. This anode and its coating is shown in Figure 14. As these photographs show, a significant coating did occur, approximately $1 / 8^{\prime \prime}$ thick, on a portion of the cermet anode. The side of the cermet anode next to the carbon anode did not form a coating, as minimal current flow occurred from this area of the cermet anode.

After obtaining the initial coating, a maintenance $(25-60 \mathrm{~g} / \mathrm{hr})$ amount of $\mathrm{CeF}_{3}$ was added to the cell to compensate for the cerium removed in the aluminum metal being produced. Figure 15 shows the distribution between cerium in the bath and that in the metal. As this plot indicates, the cerium in the bath will normally remain in the $0.3-0.6 \%$ range with the excess amounts reporting to the metal.

A question did arise concerning the cerium coating procedures and process for the replacement anodes installed on September 26. It was uncertain what effect the high levels of cerium, required to coat the new anodes, would have on the three remaining cermet anodes with a coating already applied. Analysis and evaluation of the three removed anodes by ELTECH may provide information regarding this aspect of the coating process.

\section{Cermet Anodes Operation}

Operation of the cermet anodes in the pilot cell began on September 15 and continued through October 10 . The cermet anodes actually operated for a time (12 hours) on September 14, but current was interrupted after determination that insufficient cerium existed in the electrolyte for coating to occur. After adding more cerium to the electrolyte, the anodes were restarted on September 15 at 1:00 p.m. The majority of the test period was directed toward evaluation of the cermet anodes under "normal" test conditions; that is, a nominal anodic current density of $0.5 \mathrm{amp} / \mathrm{cm}^{2}$ and alumina saturation. Target test conditions for this phase of cell operation were as follows: 


\begin{tabular}{|ll|}
\hline Date & Sept $15-30$ \\
\hline Maximum individual anode current & $90 \mathrm{amp}$ \\
$\mathrm{Bath}_{\text {Ratio }}$ & $1.4-1.6$ \\
$\mathrm{CaF}_{2}$ & $4-6 \mathrm{wt} \%$ \\
$\mathrm{Al}_{2} \mathrm{O}_{3}(100 \%$ saturation $)$ & $8-10 \mathrm{wt} \%$ \\
\hline
\end{tabular}

On September 30, the test target operating condition was changed such that maximum current to an individual cermet anode was increased to $115 \mathrm{amp}$. An additional change was made on October 6 with the target ratio being lowered to 1.2.

\section{Electrolyte Chemistry}

\section{Bath Additives}

Figures 16 and 17 show the primary components of the bath. Actual results are contained in Appendix A. Large variations in bath ratio were found to occur whenever rapid changes in bath volume occurred in the cell due to freezing and melting of the ledges caused by large bath temperature variations. $\mathrm{The}^{\mathrm{CaF}} 2$ was generally controlled within target limits of $4-5 \%$. Trace amounts of $\operatorname{LiF}(<0.3 \%)$ and $\mathrm{MgF}_{2}(<0.15 \%)$ were also present in the electrolyte, along with the $\mathrm{CeF}_{3}$.

\section{Bath Temperature}

The electrolyte temperature measured on an hourly basis is shown in Figure 18. A very large variability in the bath temperature occurred as the dynamics of the pilot cell is such that quick response in temperature occurs with disturbances to the cell alumina crust cover or changes in the cell energy input. Thick muck developed in the cell bottom as the pilot cell operation progressed due to requirements to overfeed the cell with alumina in order to maintain alumina in the bath near saturation. As a result, extreme temperature gradients developed vertically in the bath. Temperatures near the top of the bath would be as much as $40-50^{\circ} \mathrm{C}$ higher than near the cathode bottom. The reported bath temperatures were measured approximately 2 inches into the bath and represent the higher bath temperature of the cell. Operating temperatures were controlled at high temperatures (above $1000^{\circ} \mathrm{C}$ ) during the later periods of the test to minimize freezing of bath on the bottom of the cell.

\section{Alumina Concentration}

One of the key operating parameters was to maintain alumina content in the bath as close to saturation as possible. Bath samples were taken every 4 hours for alumina analysis and the alumina content in the bath was monitored every two hours with the Reynolds' Mark V alumina meter. Generally, the bath samples were taken between the east anode cluster and the west carbon anode. The results of the measured alumina content in the bath and the calculated alumina saturation throughout the test are shown in Figures 19 and 20. The calculated values for percent alumina saturation were obtained using the formula developed by Skybakmoen, et al., presented in Light Metals 1990. The calculated percent alumina saturation is greatly influenced by the operating bath temperature as shown in Figure 21. This plot also indicates the problem operating near saturation in a reduction cell which can experience great swings in bath temperature such as the pilot cell. Significant amounts of alumina are deposited on the cell bottom when a cell is operating near 


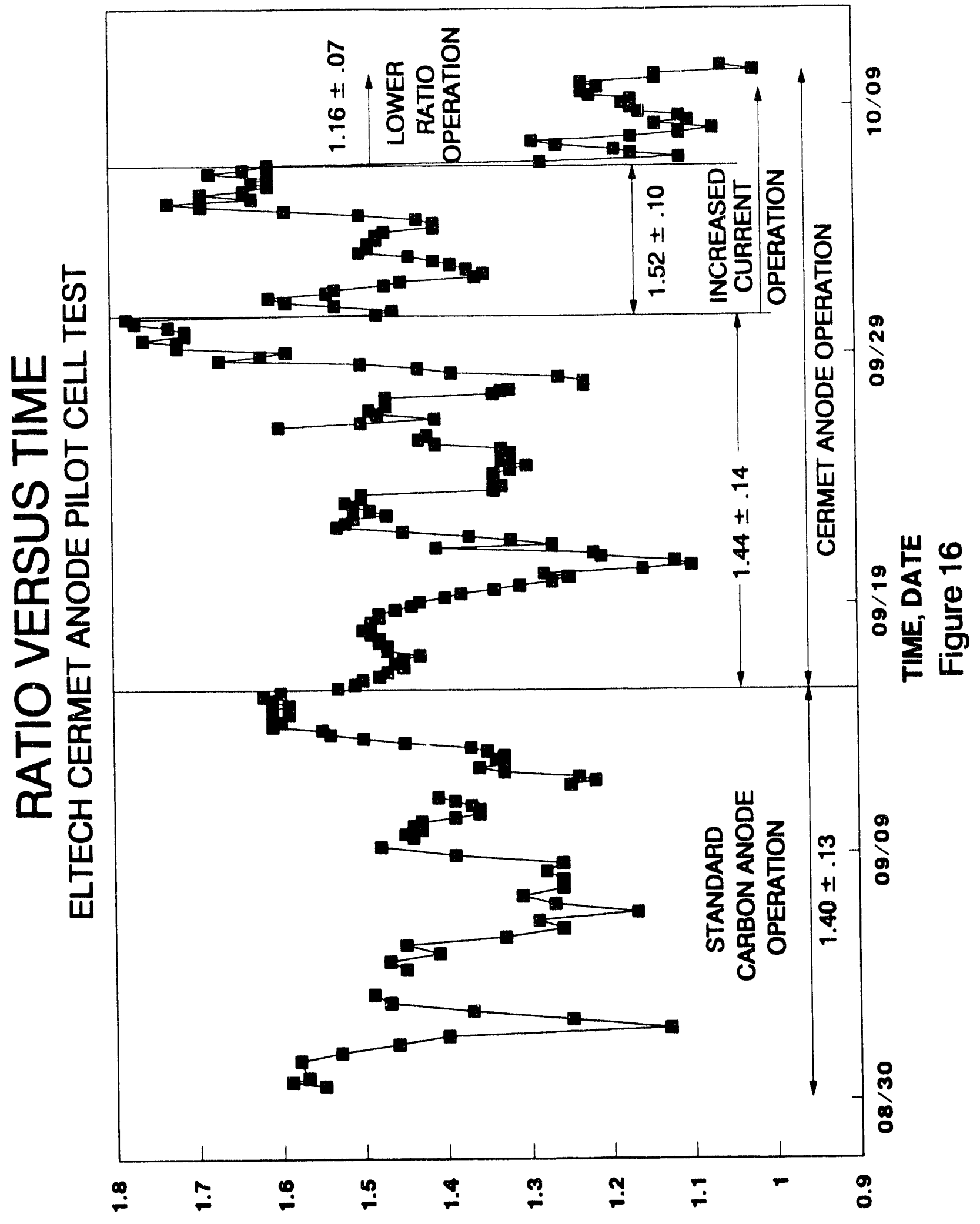

0118'y 


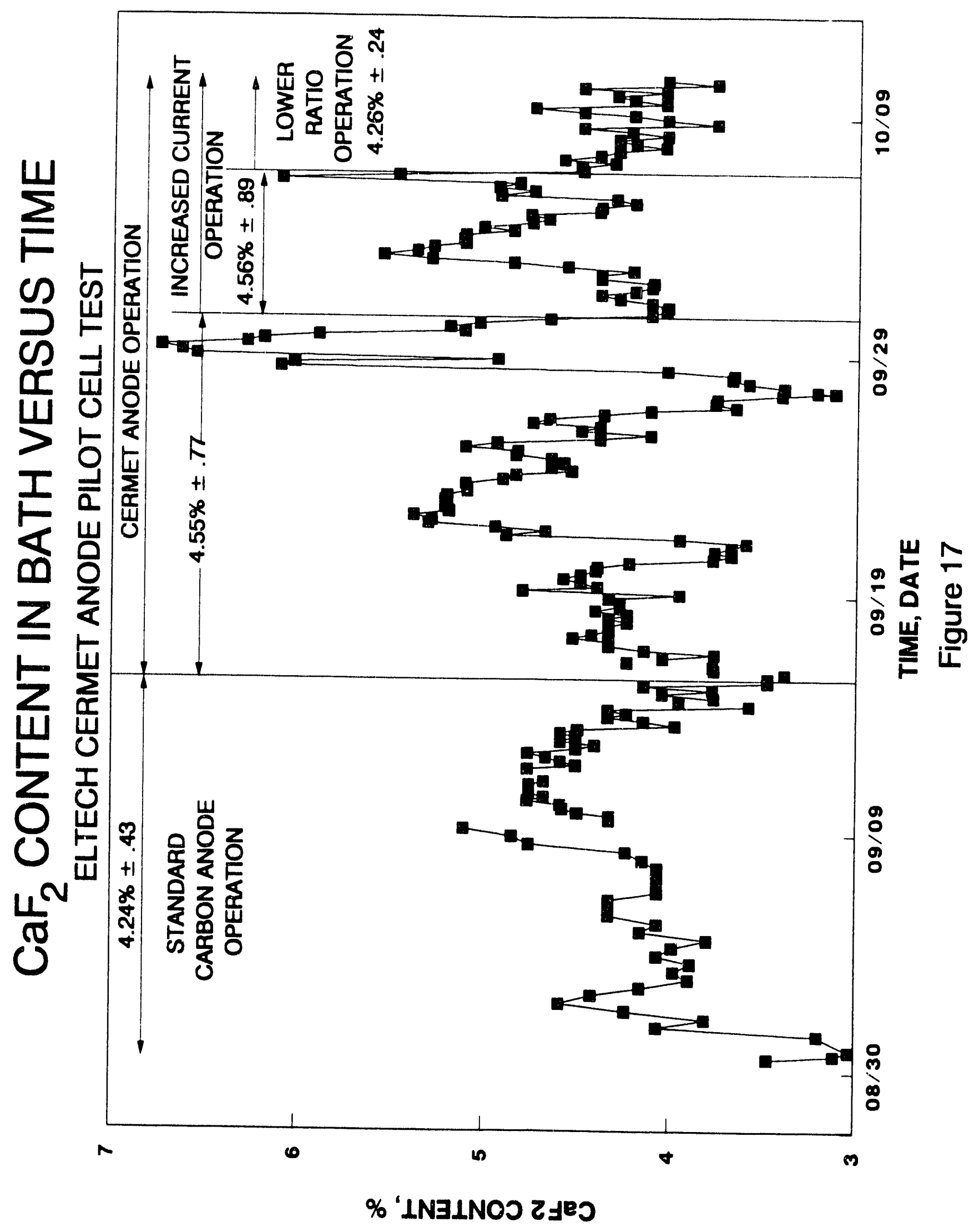




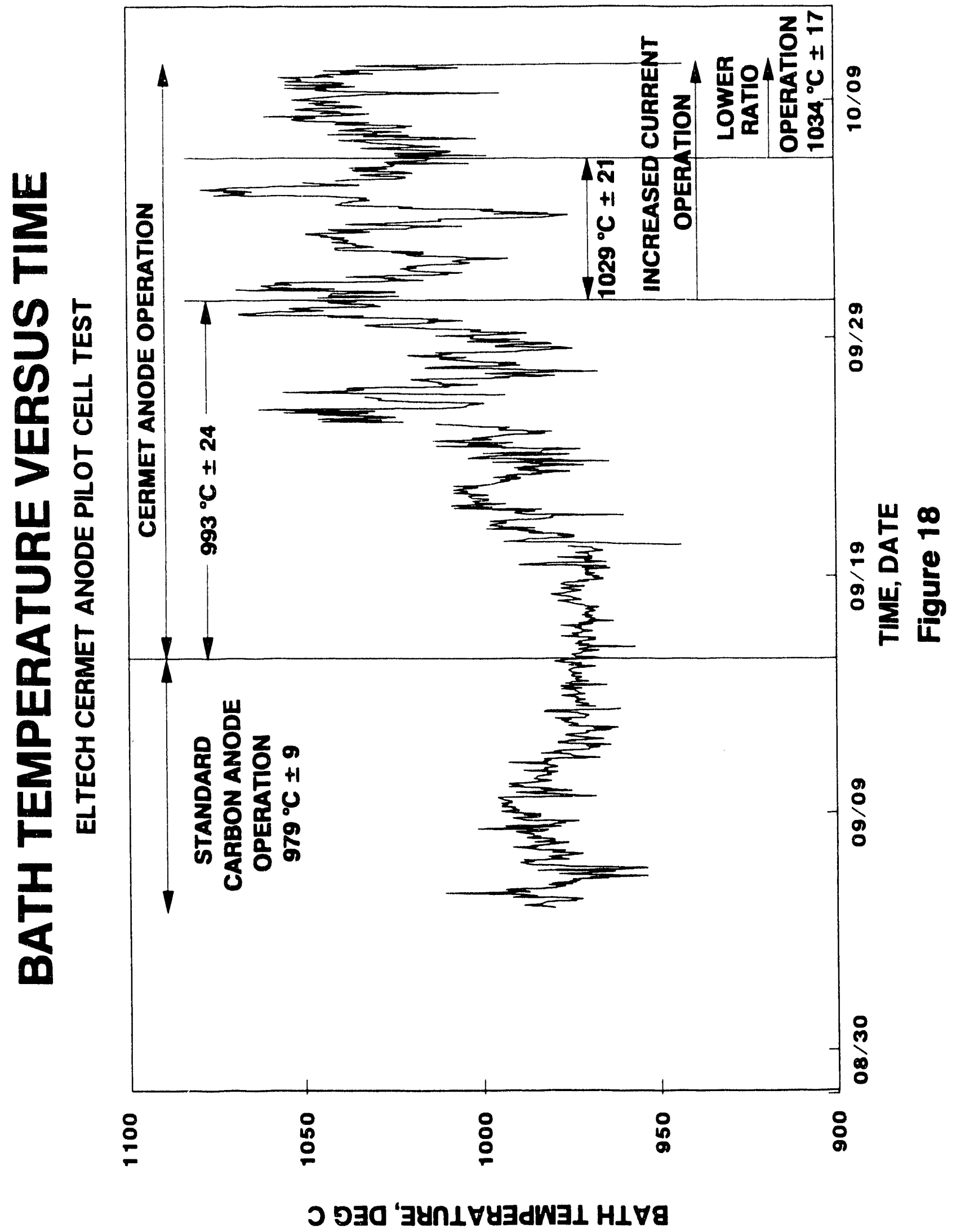




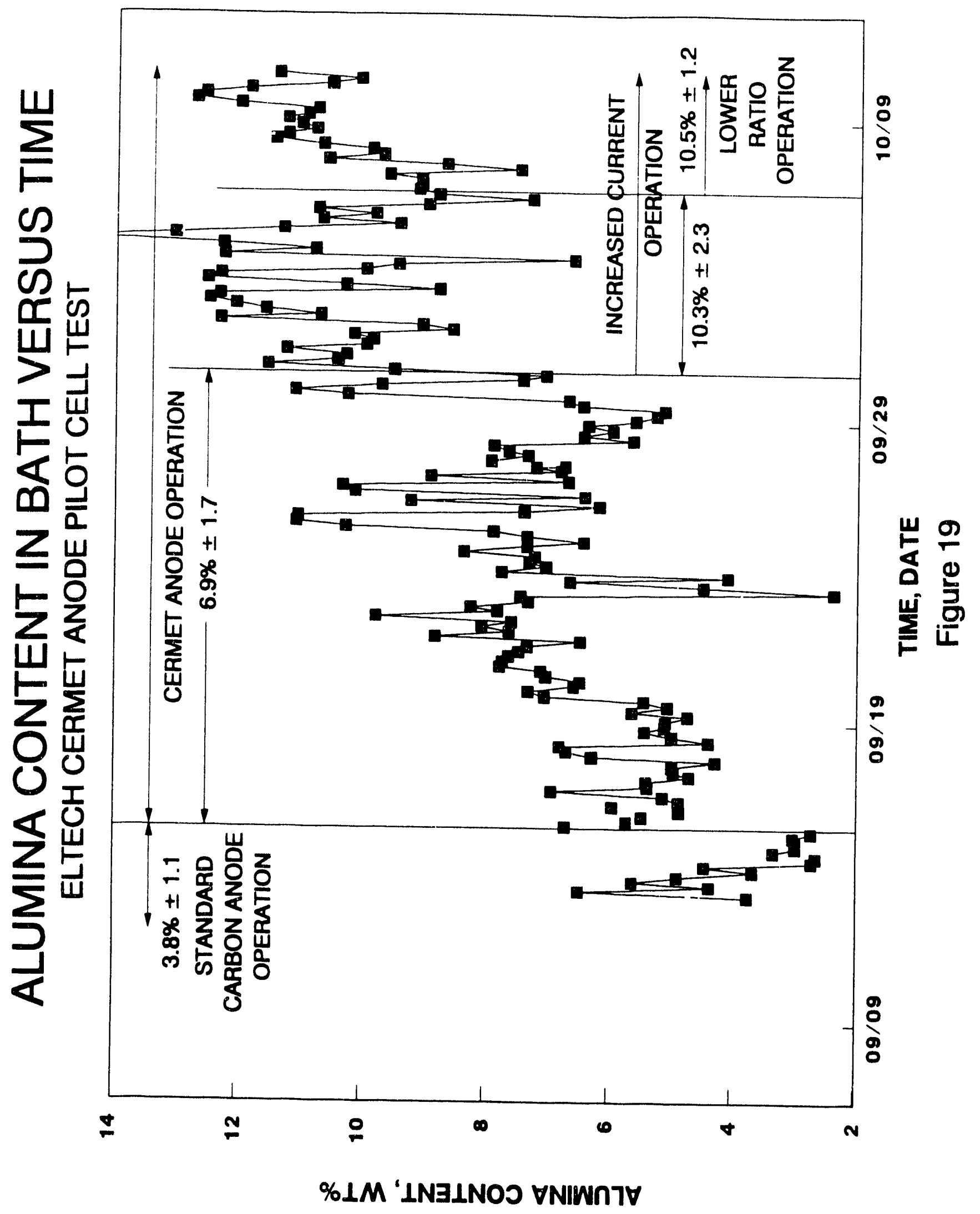

- 27 . 


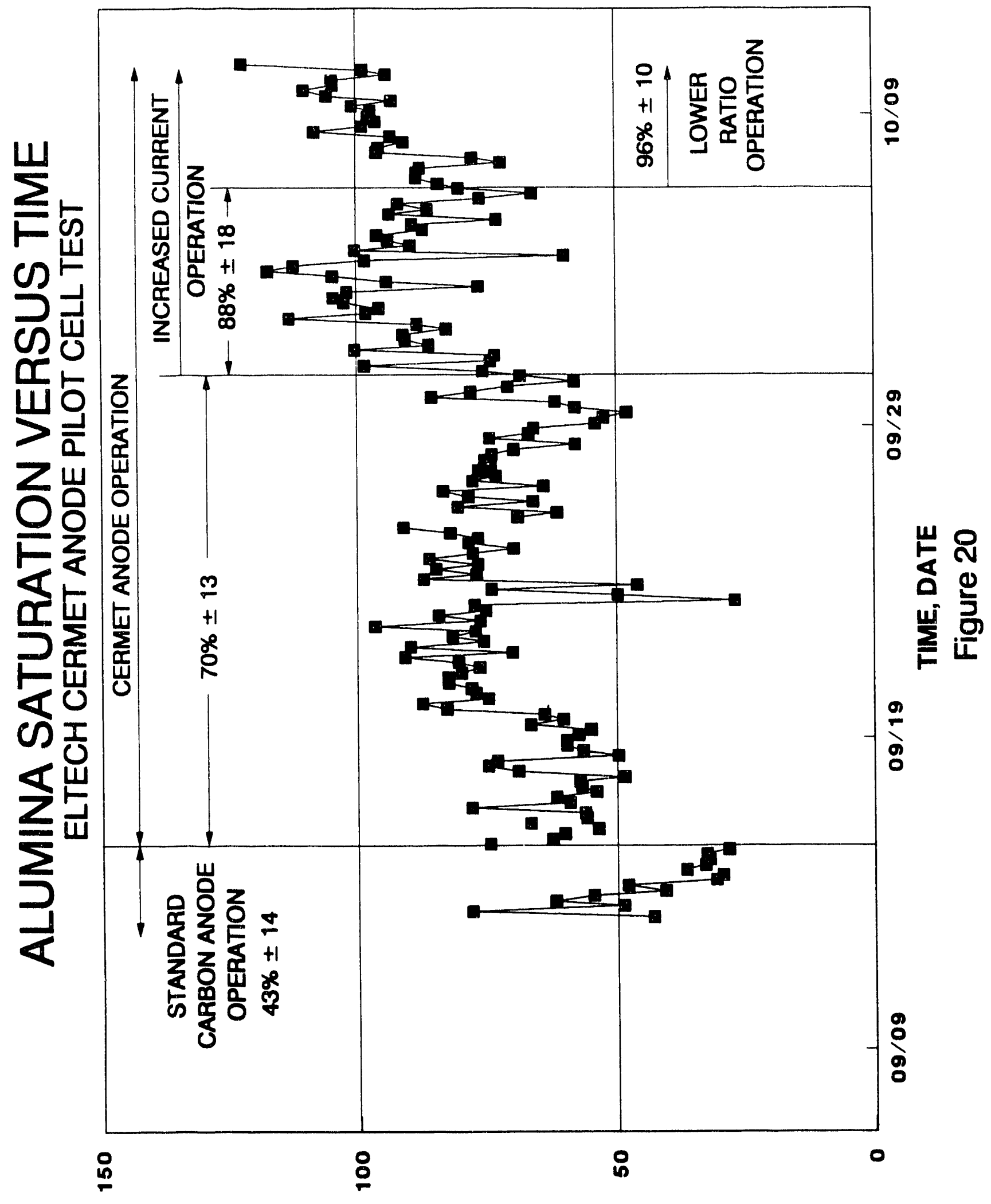

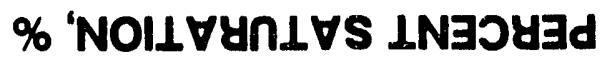




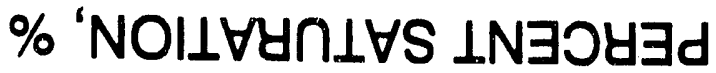

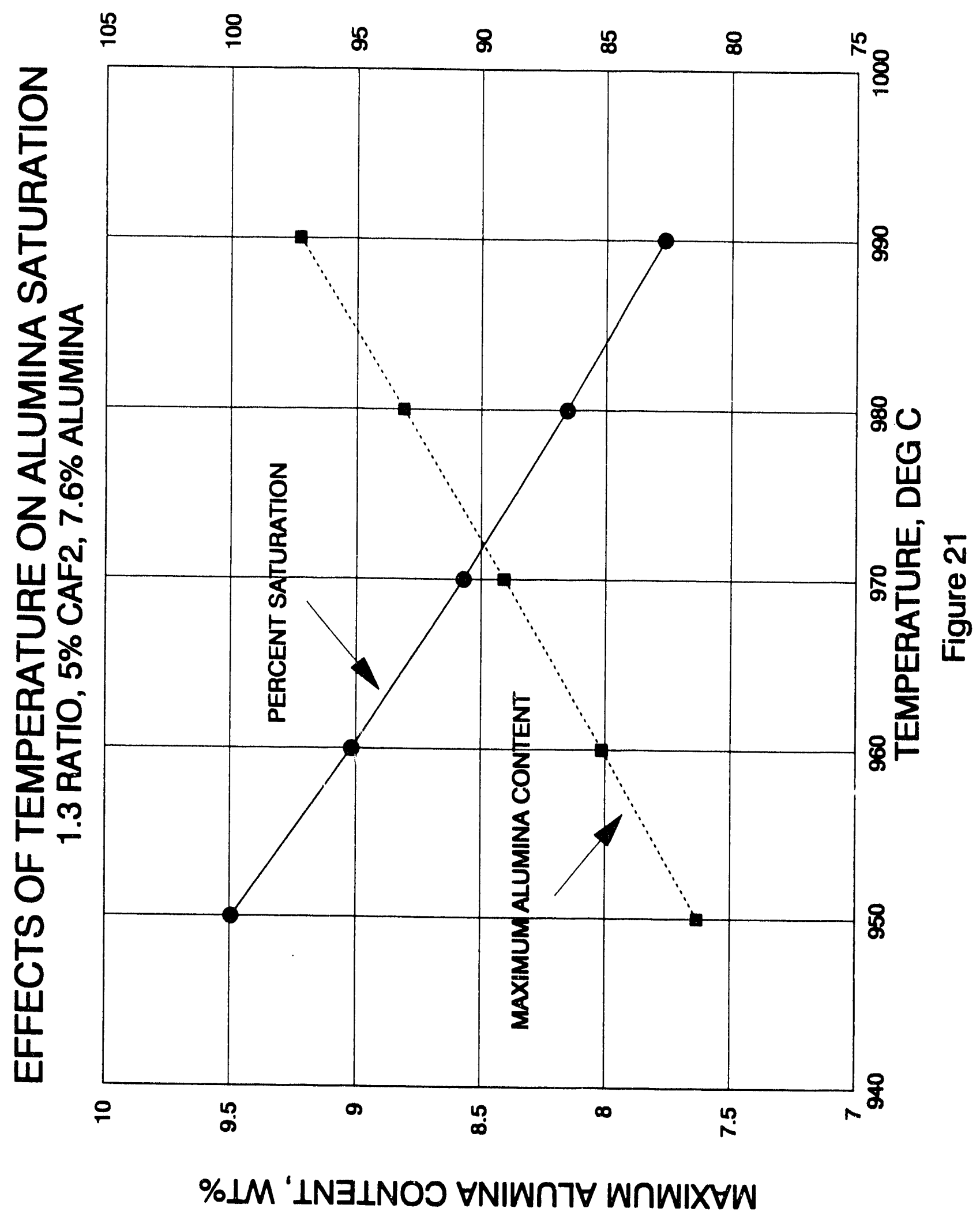


saturation and experiences an upset condition resulting in a $20-30^{\circ} \mathrm{C}$ drop in bath temperature.

Average operating parameters determined for the various phases of the test are presented below.

\begin{tabular}{|lllll|}
\hline Date & Sept 1-15 & Sept 15-30 & Sept 30-Oct 6 & Oct 6-10 \\
\hline Current & Carbon anode & Max 90 amp & Max 115 amp & Max 115 amp \\
Ratio & 1.40 & 1.44 & 1.52 & 1.16 \\
$\mathrm{CaF}_{2}$ & $4.24 \%$ & $4.55 \%$ & $4.56 \%$ & $4.26 \%$ \\
$\mathrm{CeF}_{3}$ &..-- & $0.47 \%$ & $0.50 \%$ & $0.49 \%$ \\
$\mathrm{Temp}$. & $979{ }^{\circ} \mathrm{C}$ & $993^{\circ} \mathrm{C}$ & $1029^{\circ} \mathrm{C}$ & $1034^{\circ} \mathrm{C}$ \\
$\mathrm{Al}_{2} \mathrm{O}_{3}$ & $3.8 \mathrm{wt} \%$ & $6.9 \mathrm{wt} \%$ & $10.3 \mathrm{wt} \%$ & $10.5 \mathrm{wt} \%$ \\
$\%$ Sat. & $43 \%$ & $70 \%$ & $88 \%$ & $96 \%$ \\
\hline
\end{tabular}

\section{Liquid Level Control}

An initial operational target was to maintain the anodes' immersion in the bath at 2-3 inches, and to minimize any movement of the anodes. Frequent dipping of metal in small increments $(5-20 \mathrm{lb})$ from the cell and occasional dipping of the bath was required to maintain the anodes at the immersion target. Figure 22 shows the anode immersion levels throughout the run. The initial coating of the anodes on September 15 was done with a high cermet anode immersion level ( 3.5 inch), with the levels during the remaining operation generally remaining below this ievel. On September 26 , when anodes in positions $A, B$, and $C$ were replaced, they were set at 1 inch less immersion than $D, E$, and $F$. All values plotted represent the levels of $D$ through $F$.

Throughout the operation, the bath level dropped from an initial level of 7-9 inch to 3-5 inch as shown in Figure 23. This change was a result of reduced available cathode cavity volume due to muck build-up on the bottom of the cell. The resulting anode-cathode distances are shown in Figure 2 The anode-cathode distance was reduced from the initial level of 5-6 inch to that of 1 inch as a result of the reduction in bath level.

Aluminum metal inventory was measured on two separate occasions to determine metal production rates. The results of metal dilution analysis using manganese were as follows:

\begin{tabular}{|ll|}
\hline \hline September 23, 8:00 a.m. & $208 \mathrm{lb}$ aluminum \\
October 10, 8:00 a.m. & $199 \mathrm{lb}$ aluminum \\
\hline
\end{tabular}

Based on these aluminum inventory values and the weighed aluminum metal tapped during this period, an average aluminum metal production rate of $38.2 \mathrm{lb} /$ day was calculated. Figure 25 shows the predicted aluminum metal inventory based on this rate with the metal tapped being included. This plot indicates the aluminum inventory was maintained between 150 and $250 \mathrm{lb}$. 


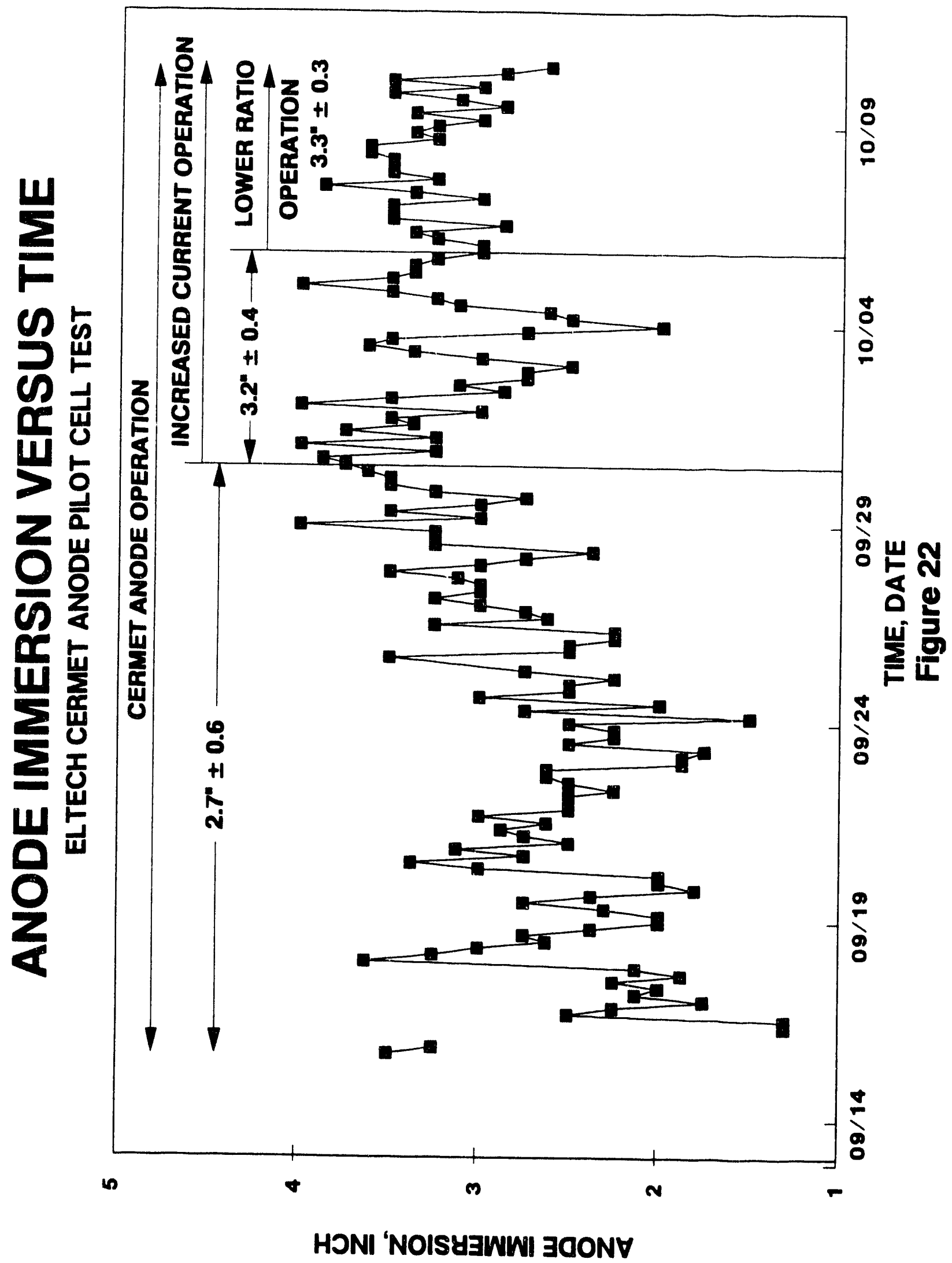




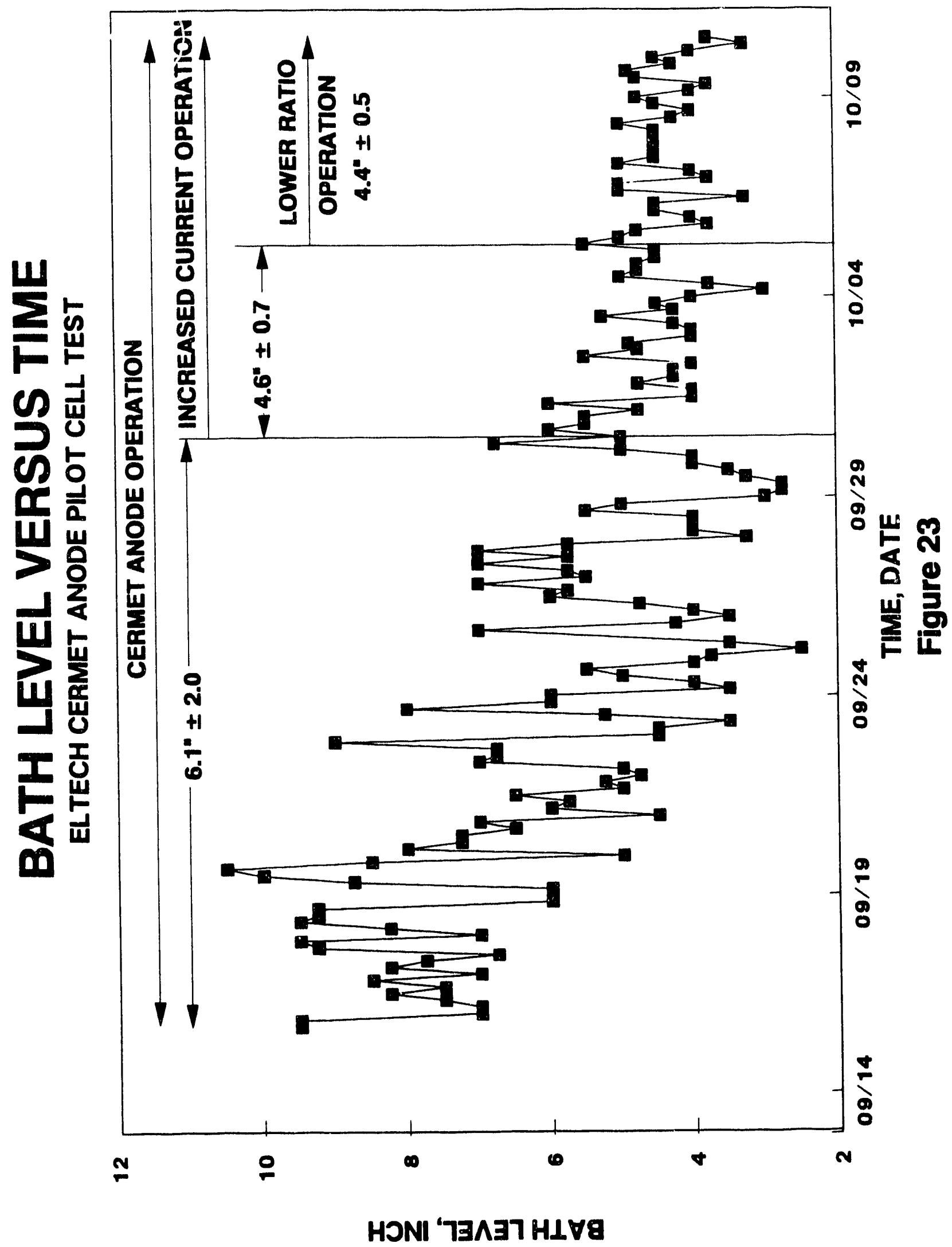




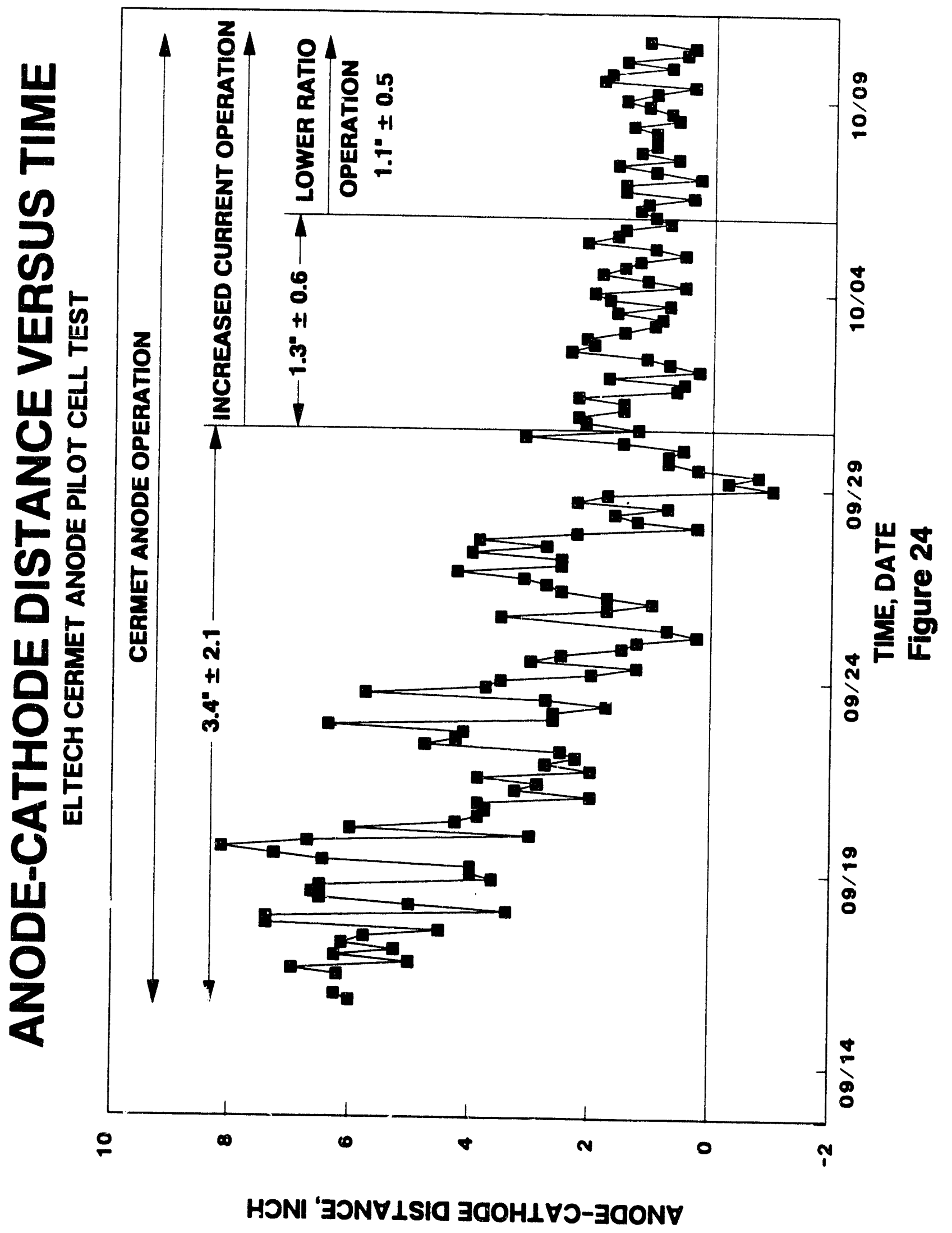




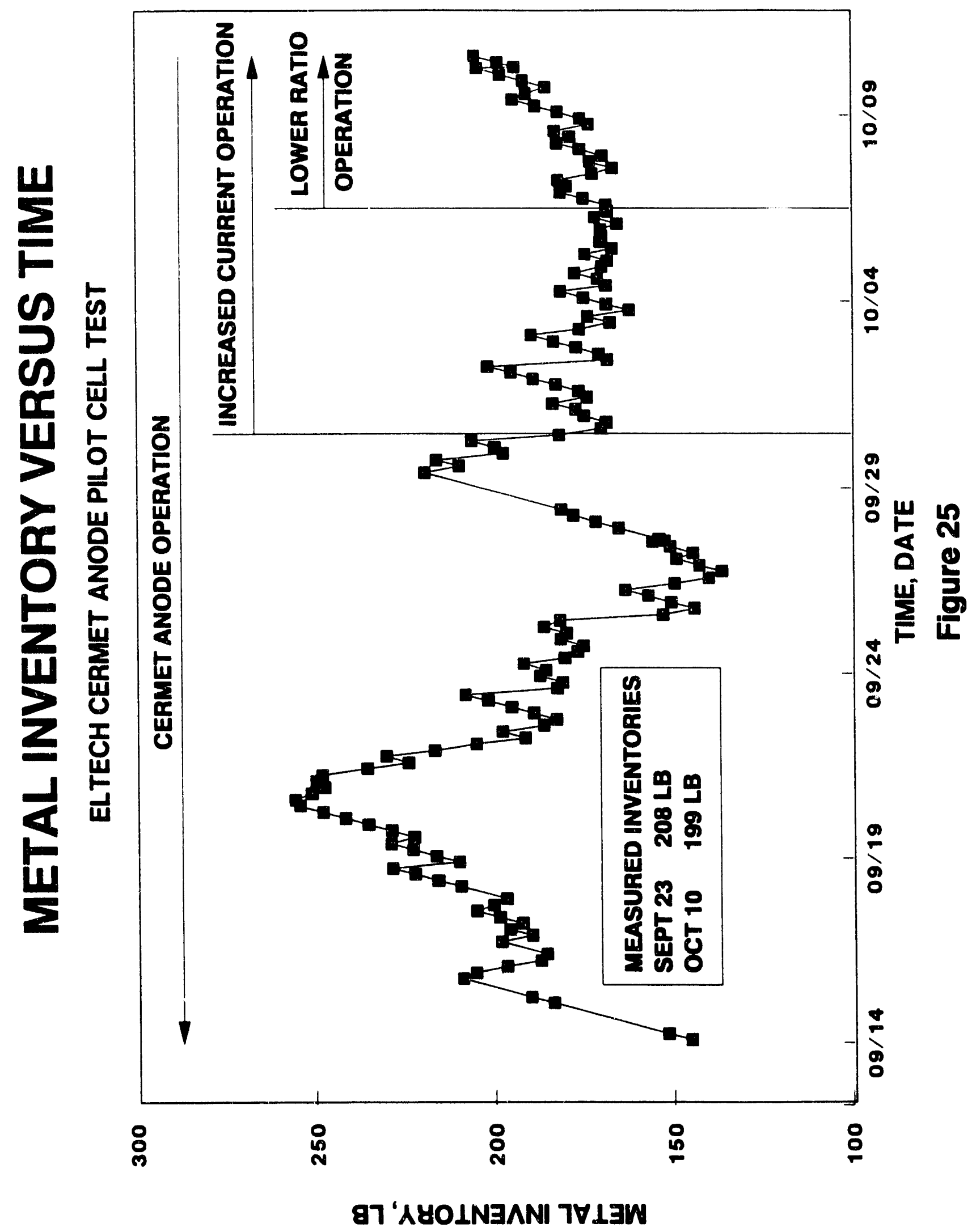




\section{Anode Current Distribution}

Nine cermet anodes were used during the pilot cell operation. The anodes were identified as 1 through 9. Table I summarizes the life of each of the anodes and Figures 26 31 show graphically the current carried by the anodes according to cell position. Anodes 4 6 , located in positions $D, E$, and F, remained in operation for the entire test, 614 hours. Only anodes 1 (position $A$ ) and 2 (position B) were removed early due to breakage. Every effort was made to minimize the movement and disturbances to the anodes during the reduction cell operation. This probably contributed to the reduced breakage of the anodes as compared with that experienced during the previous PNL testing as well as the use of improved stem material and ceramic protectors.

The electrical current distribution among the six cermet anodes varied throughout the cell operation as shown in Figure 32. Generally, the current distribution was better than that experienced in the previous PNL testing. This can be attributed to operating with a narrower anode-cathode distance which lessened the effects of the adjacent carbon anode and sidewall conduction. As the cell operation continued, it can be seen that the current conducted by the anodes in positions $\mathrm{D}, \mathrm{E}$, and $\mathrm{F}$ was reduced while the current conducted by $\mathrm{A}, \mathrm{B}$, and $\mathrm{C}$ increased correspondingly. It is believed this was due to muck building under the cermet anodes, minimizing any metal inventory under them, such that the current path was through the bath to metal pooled under the carbon anode. This resulted in an extremely resistive path for those cermet anodes furthest away from the carbon anode.

\section{Voltage Distribution}

The voltage of the module of six cermet anodes varied considerably throughout the run as shown in Figure 33. This variation was due to a number of variables including cell condition (muck formation and metal level) and carbon anode condition (voltage and current). The average voltage of the cermet anodes was 6.49 volt with a total current to the anode cluster of $0.32 \mathrm{kA}$.

The cathode drop (voltage from the metal pad to negative metering point) of the cell increased from an initial value of 0.6 volt to about 1.5 volt, and then decreased to 0.8 volt after increasing of cermet anode current density shown in Figure 34 . The high cathode drops were an indication of the extreme mucking conditions in the cell. Extremely high cathode drops and cermet anode voltages also existed during the period in which only the cermet anodes in positions $\mathrm{D}, \mathrm{E}$, and $\mathrm{F}$ were operating.

Anode drops were not routinely measured on the cermet anodes in an effort to minimize any possibility of breaking the anodes. Drops were measured on October 10, prior to shutdown, using a tantalum wire encased in a quartz tube. These results indicated the following drops:

\begin{tabular}{|lcccccc||}
\hline Anode & $\mathrm{A}$ & $\mathrm{B}$ & $\mathrm{C}$ & $\mathrm{D}$ & $\mathrm{E}$ & $\mathrm{F}$ \\
Current, amp & 113 & 104 & 80 & 17 & 20 & 49 \\
Drop to top of stem, v & 0.78 & 0.53 & 0.23 & 0.10 & 0.06 & 0.31 \\
Drop to top rf anode, v & 1.77 & 1.85 & & & & \\
Drop to bottom of anode, v & 2.70 & 2.52 & & & & \\
\hline
\end{tabular}

Due to the nature of the current paths, it is impossible to determine a more exact breakdown of the cermet anodes voltages. The changing of the current distributions within this run, as 
Table I

\section{ANODE SUMMARY}

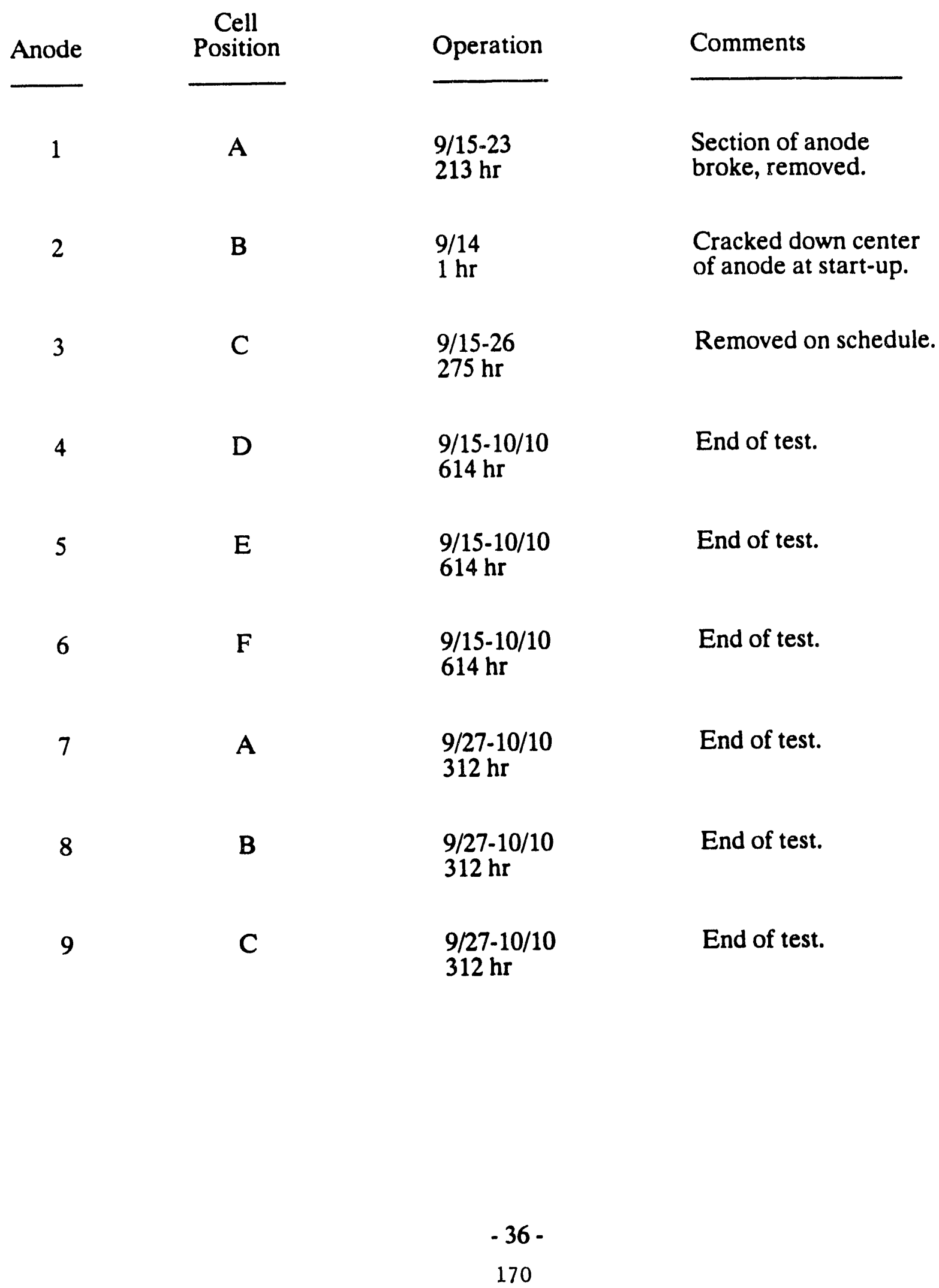




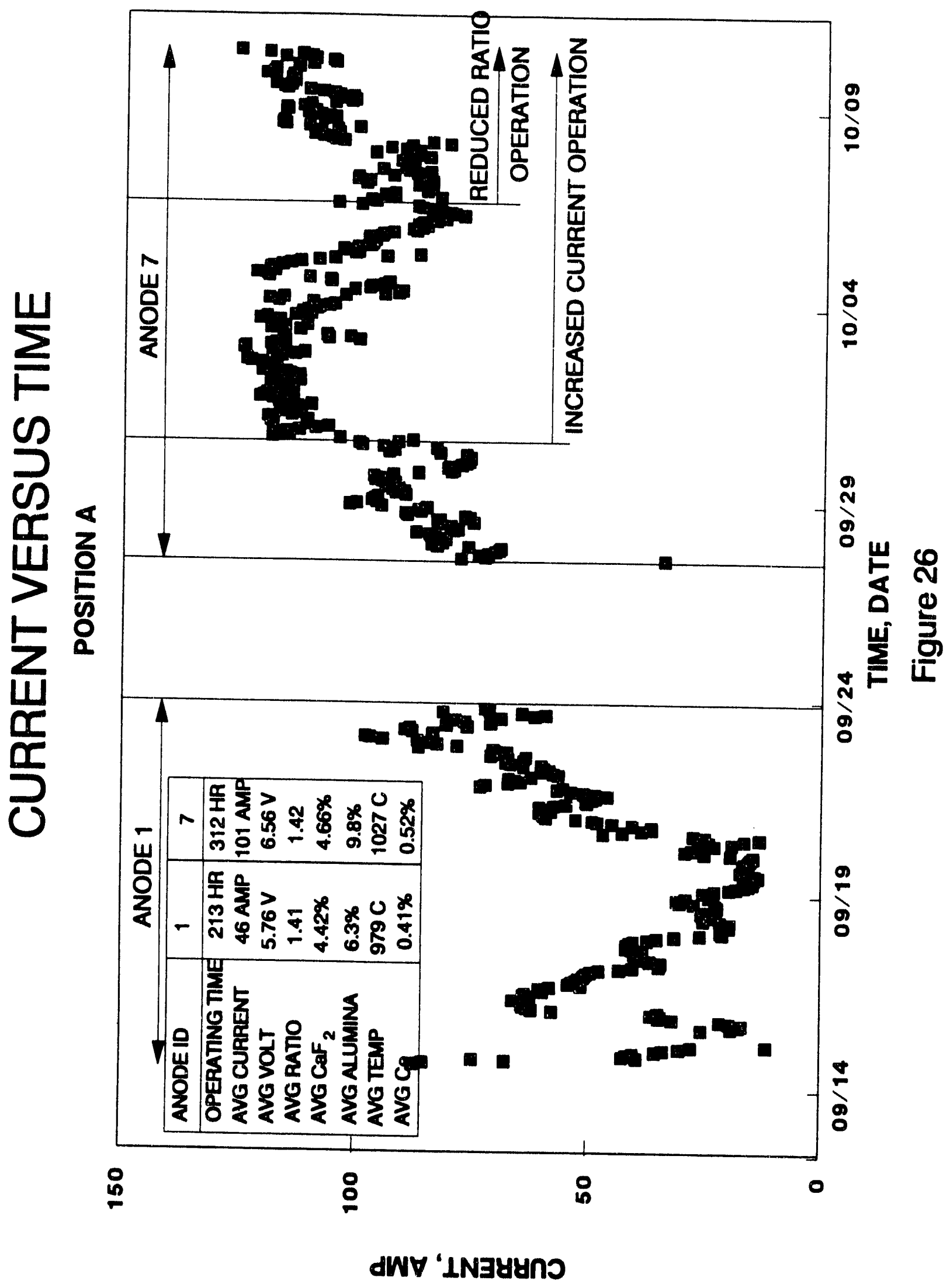




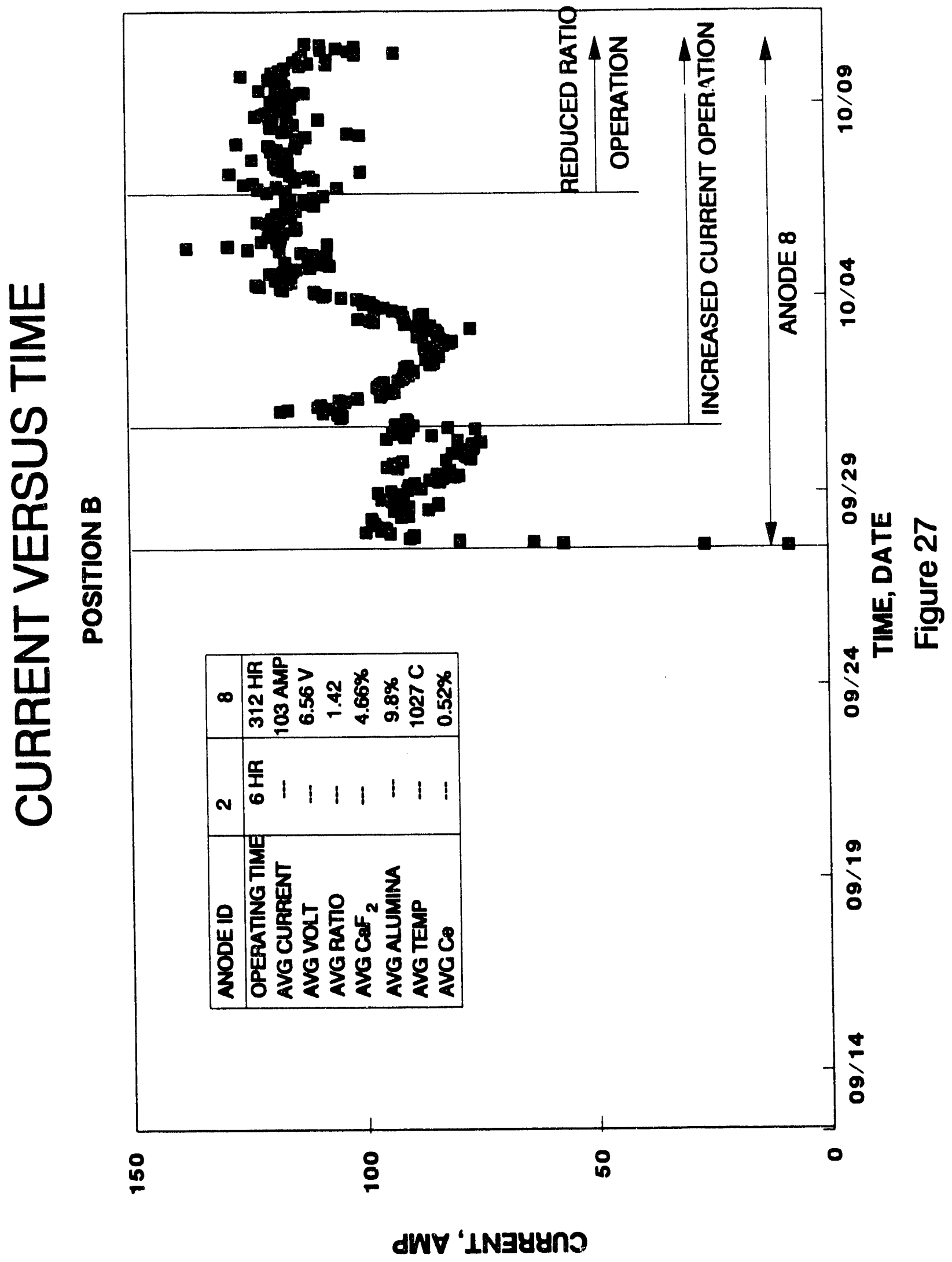




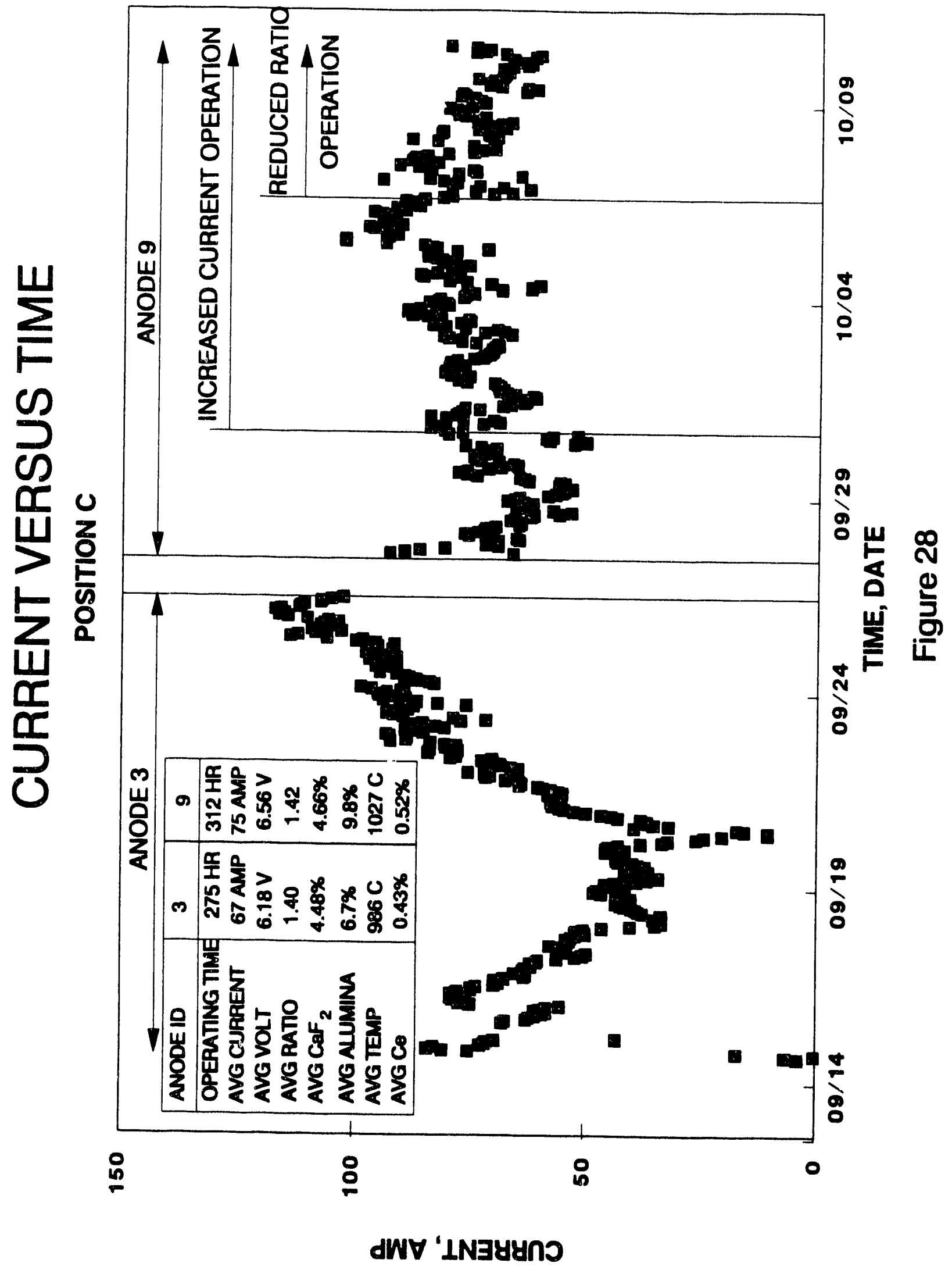




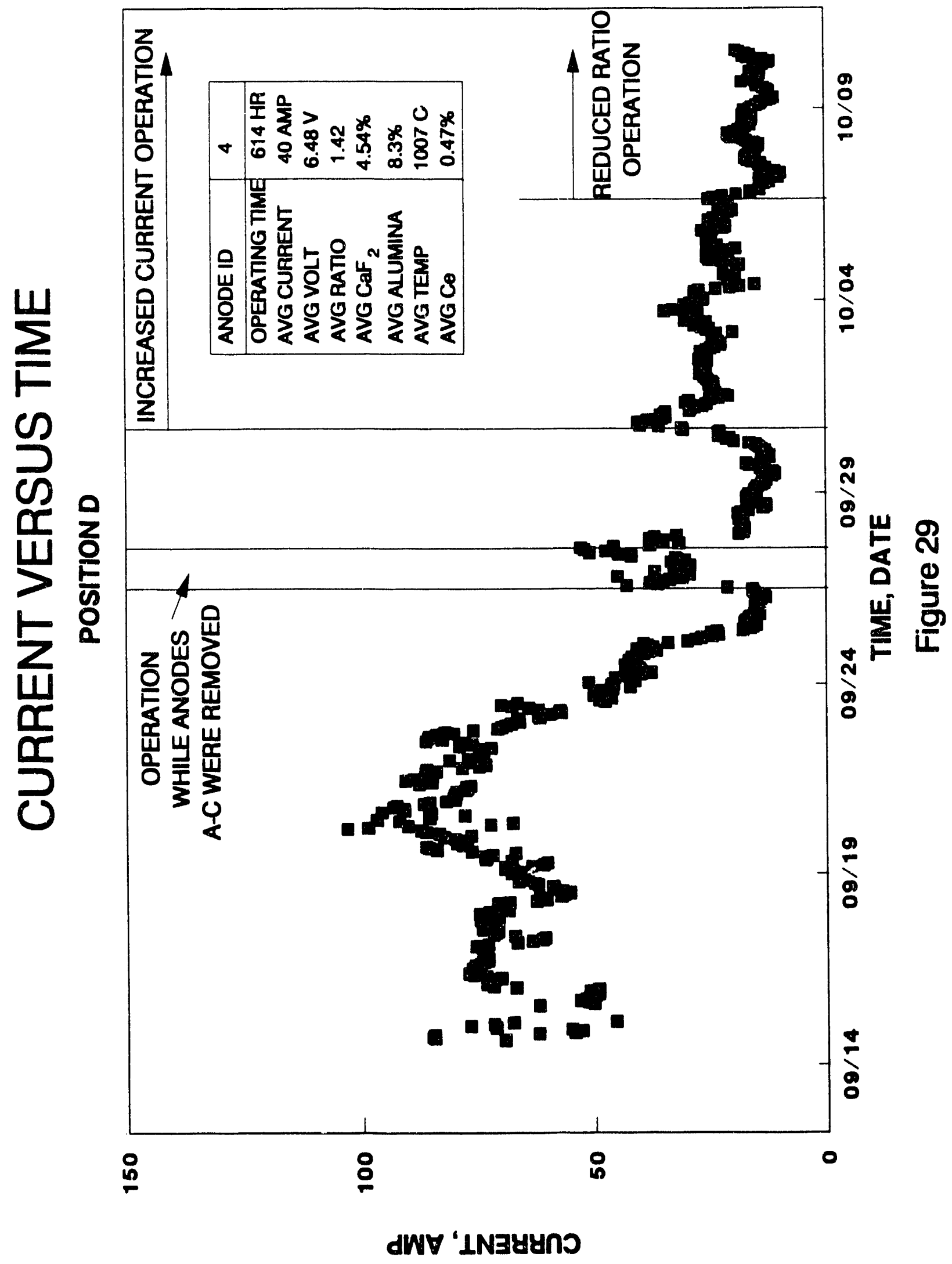




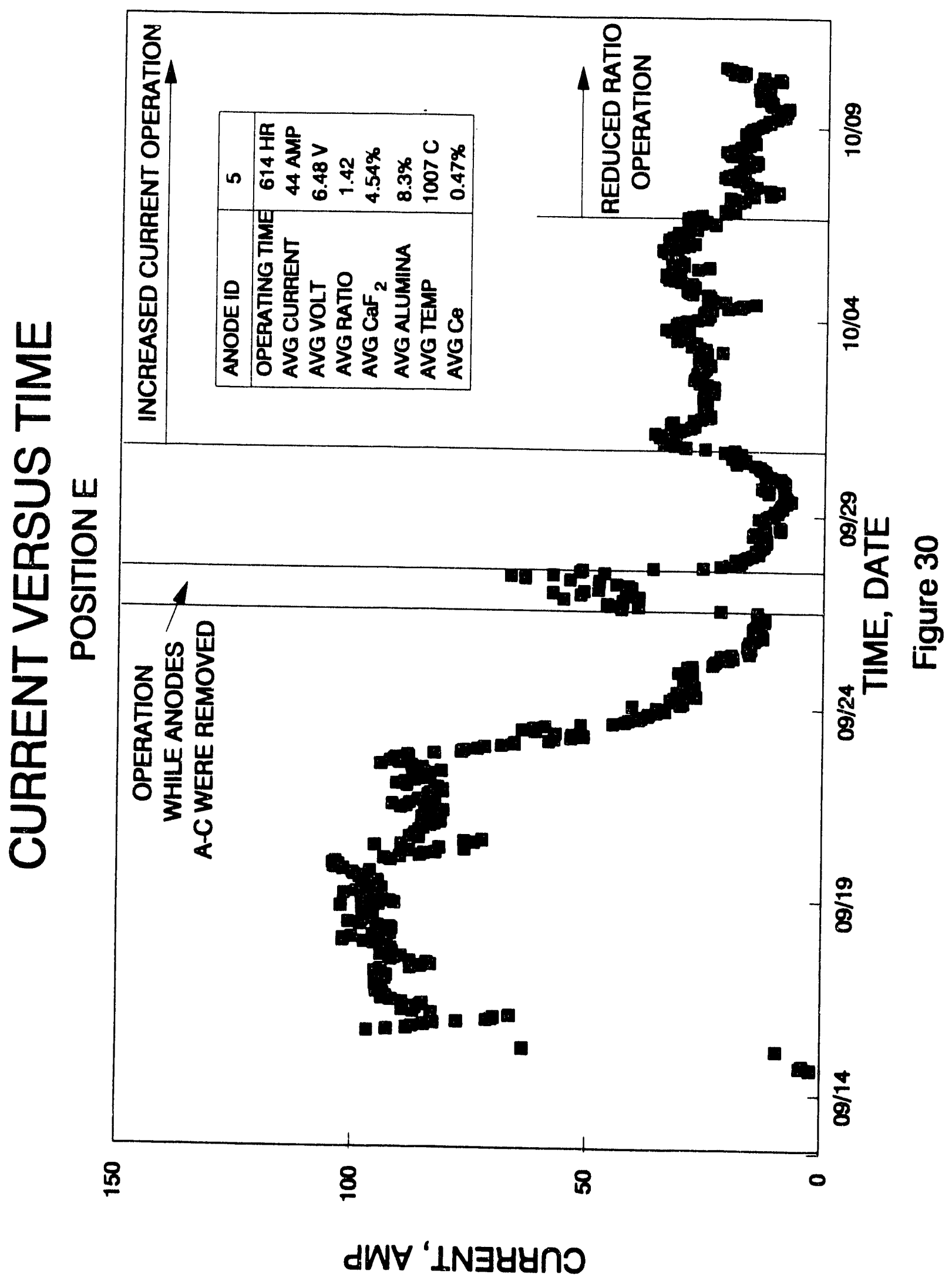




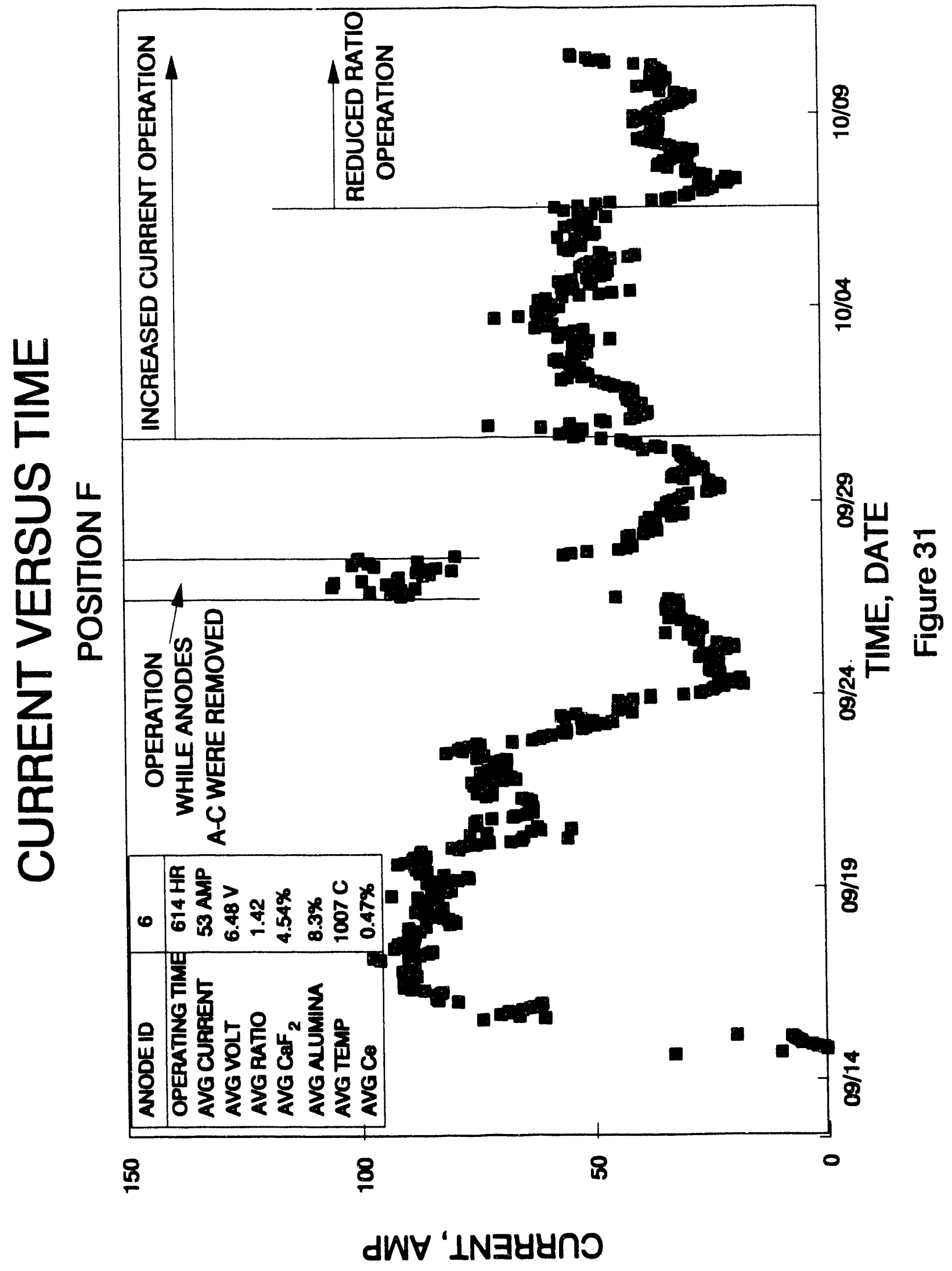




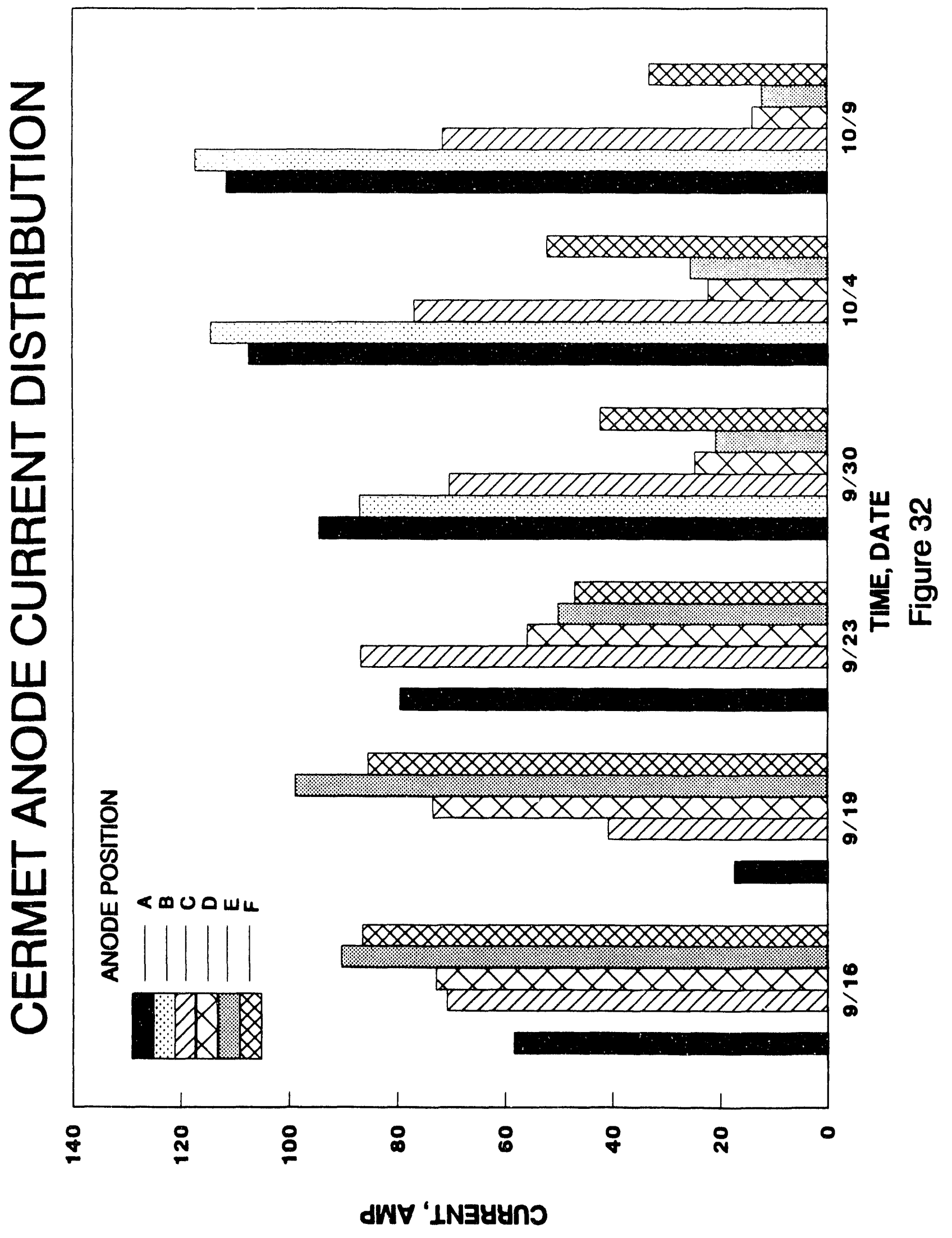




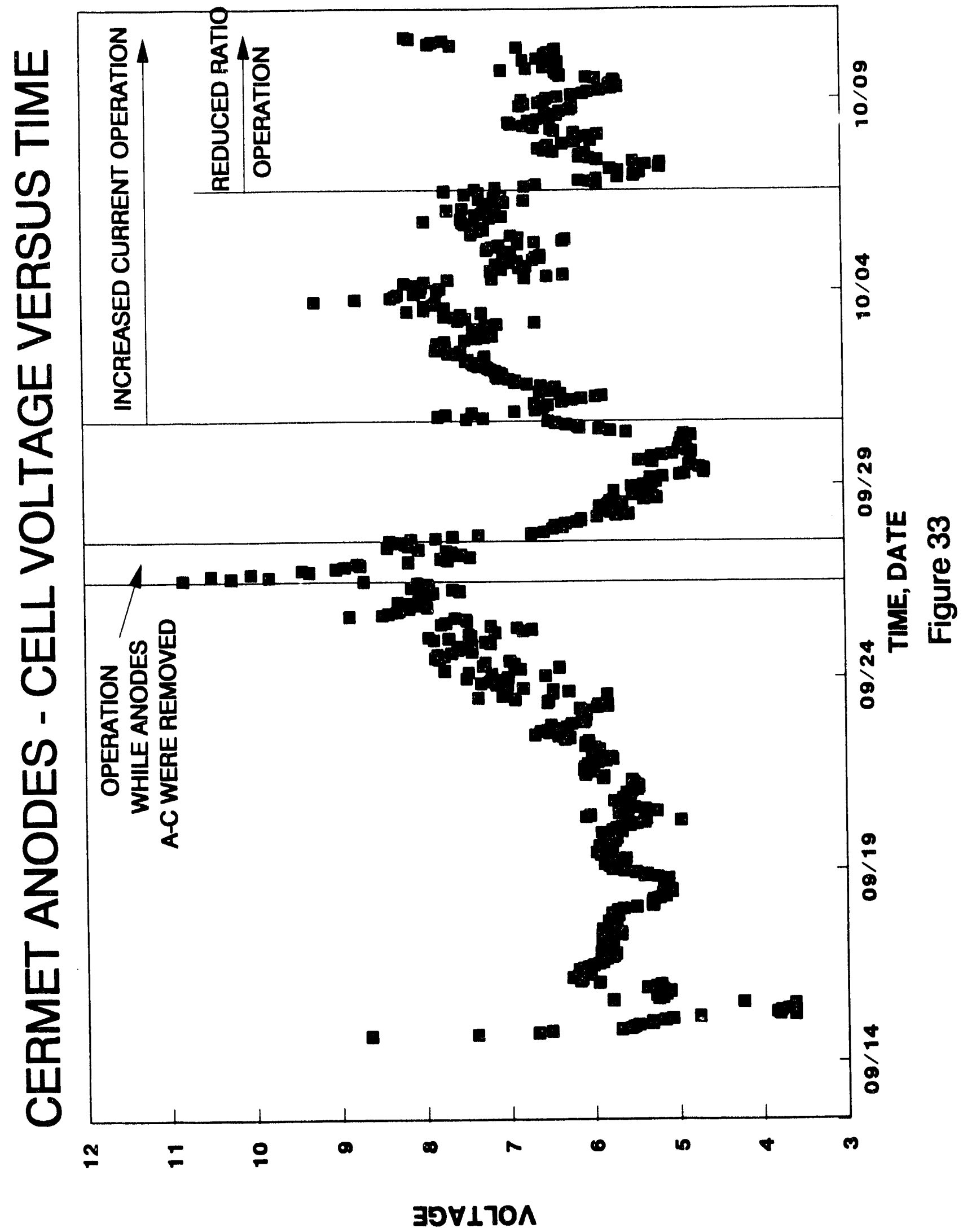

.44 - 


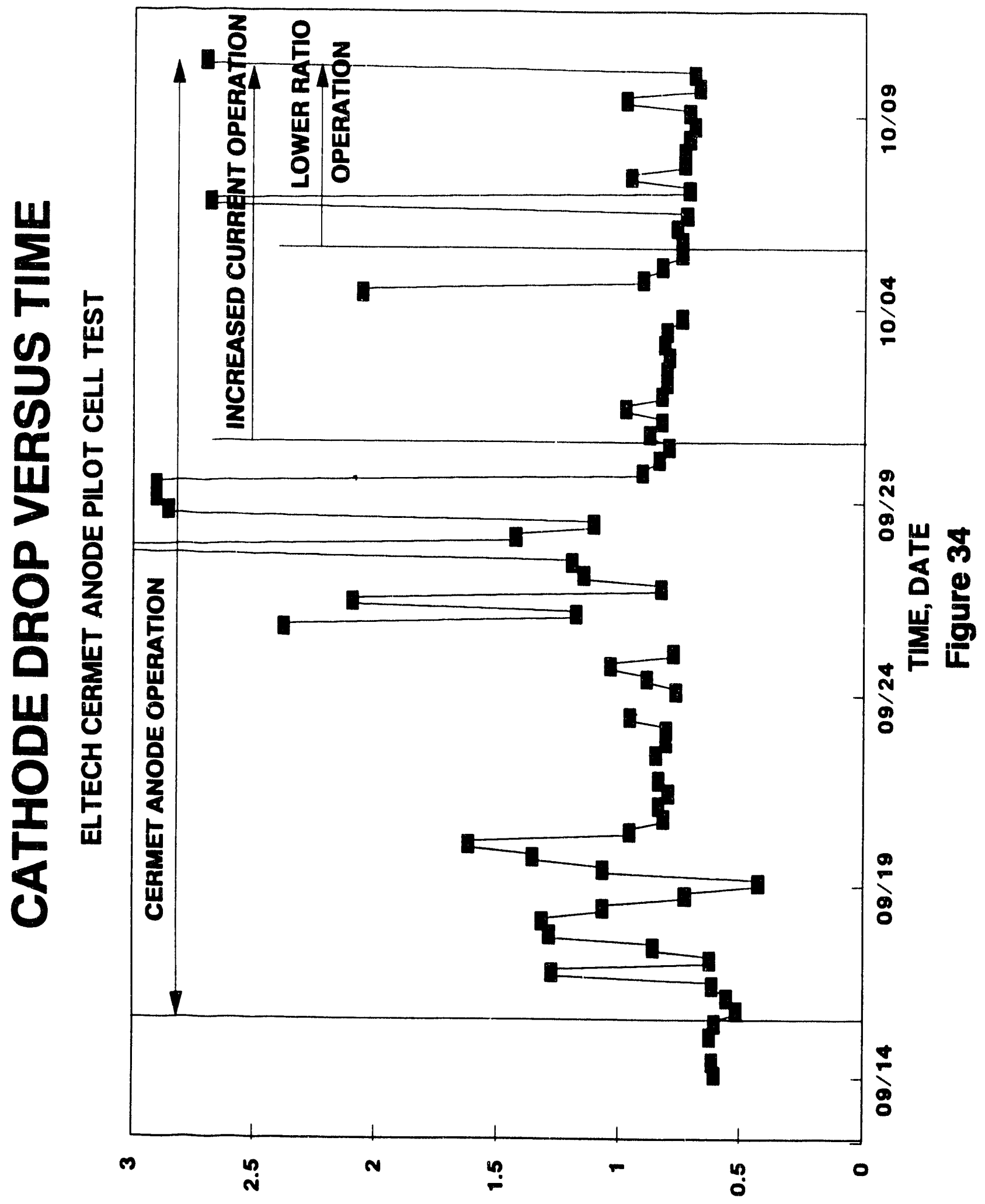

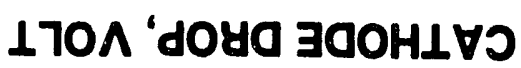


well as in comparison to the previous run with the PNL cermet anodes, makes it impossible to reliably predict the voltage penalty incurred by the "Cerox" coating.

\section{Material Problems}

The major problems experienced with the cermet anodes during the previous PNL test included (a) anode stems breaking and (b) the cermet anodes cracking and breaking. These problems were greatly reduced during the ELTECH test period.

(a) Anode Stem Material

As described earlier Inconel 600 was used for the anode stem conductor rod material in the ELTECH test rather than the Nickel 200 used for the PNL test. In addition to the change of material, the 3 inches extending out of the anode were protected by use of an alumina sleeve, filled with an alumina castable refractory. This combination of materials provided a satisfactory stem for the test period. None of the Inconel stems broke during the test. Additional evaluations of the stems will be conducted and reported by ELTECH.

\section{(b) Anode Breakage}

Only two cermet anodes were removed prematurely due to cracking or breakage during the total test period. The first was anode No. 2, position B, which was removed shortly after the initial installation on September 14. A crack down the center of the anode was first observed and it was then decided to remove the anode prior to its complete breakage which might cause contamination of the metal pad. Anode No. 2 is shown in Figure 35. The second anode was anode No. 1, position A, which was removed on September 23, after 213 hours of operation. Approximately $1 / 4$ of the anode had broken and fallen to the bottom of the cell. The broken piece, ak ng with the rest of the anode, was then removed from the cell. Anode No. 1 is shown in Figure 36.

All other cermet anodes were removed as scheduled. The six cermet anodes, upon removal at the end of the test period, are shown in Figures 37 and 38. These anodes were all removed together as a unit. As can be seen, numerous cracks did exist in the anodes, but the anodes were removed in one piece. Additional evaluation of each of these anodes will be conducted and reported by ELTECH.

\section{6. "Cerox" Coating Evaluation}

Analysis of the coatings formed on the cermet anodes will be performed by ELTECH. Observation of the $r$ emoved anodes (both small test anode and larger anodes) indicated that they were not uniformly coated. There appeared to be sections with no coating. These sections were facing either the carbon anode or adjacent cermet anodes, thus emphasizing the uneven current distribution on individual anodes. It appears that anodes may be better suited to a "pre-coating" operation in which the anodes are actually coated outside the operating cell, in which uniform current distribution can occur on the anode.

\section{Bath and Metal Impurities}

The primary indicator of the corrosion rate of the cermet anodes was the rate of increase of nickel, copper, and iron impurity content in the aluminum metal during cell 

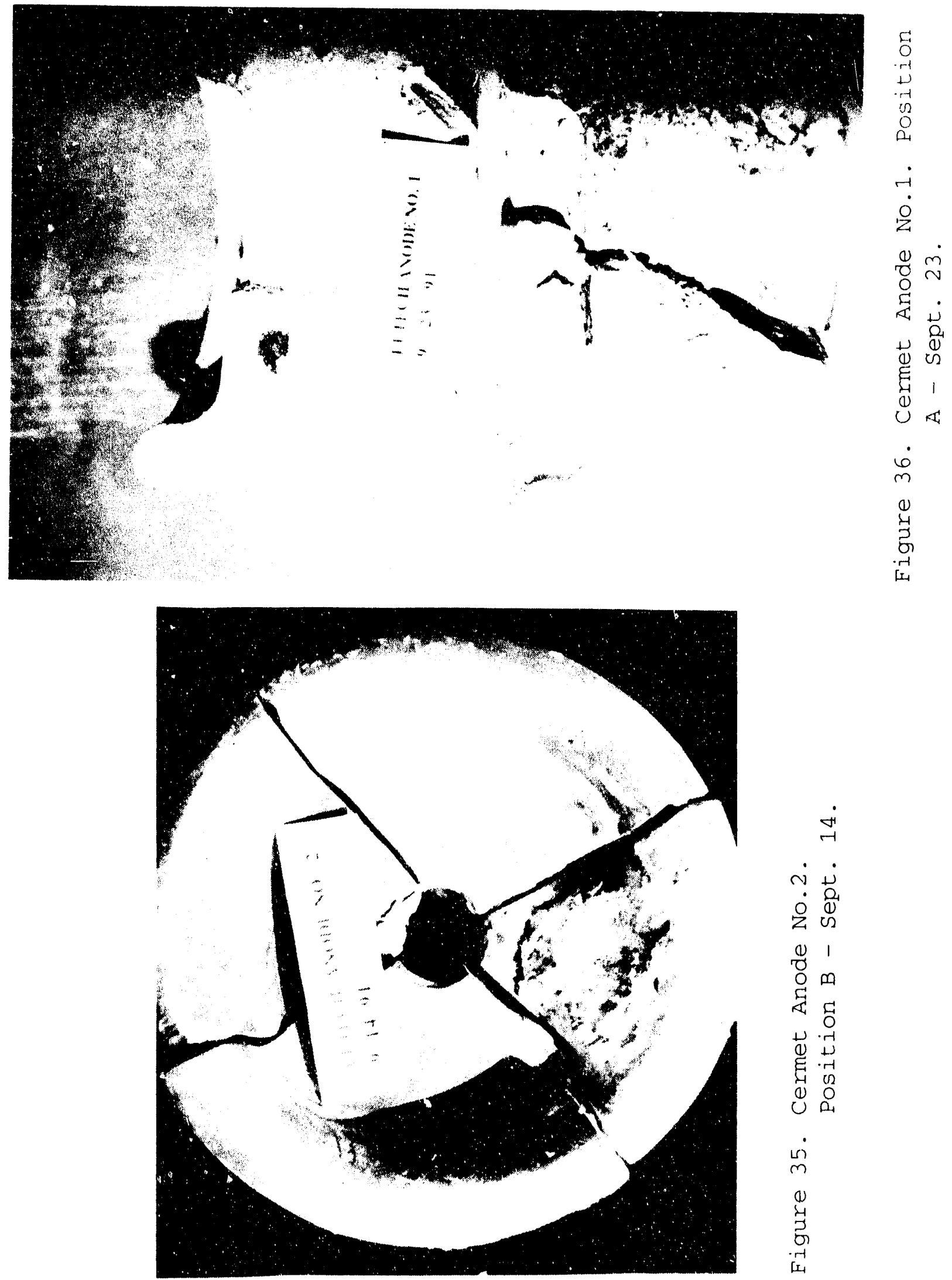

$-47-$ 


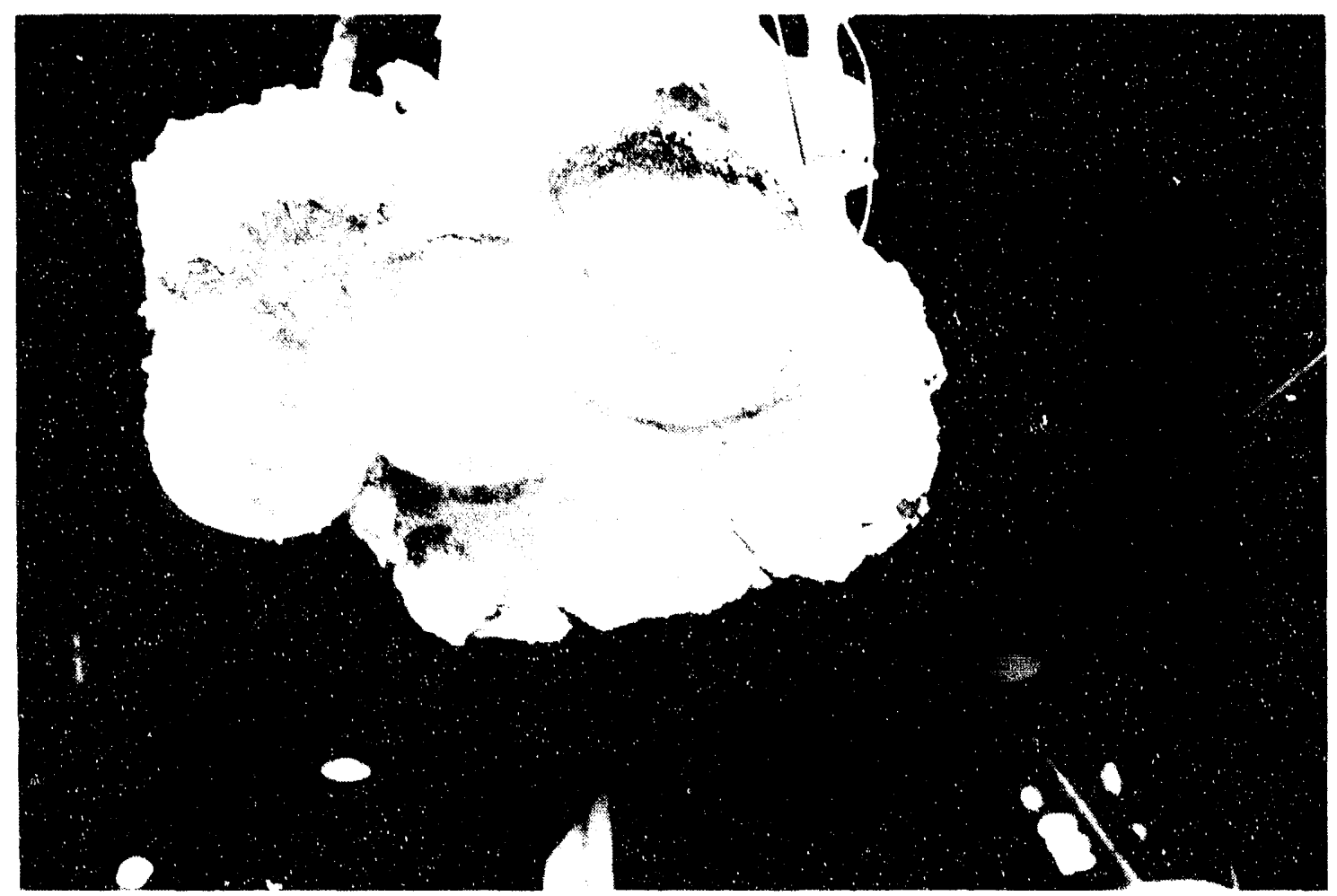

Figure 37. Cermet Anodes upon removal - Oct. 10

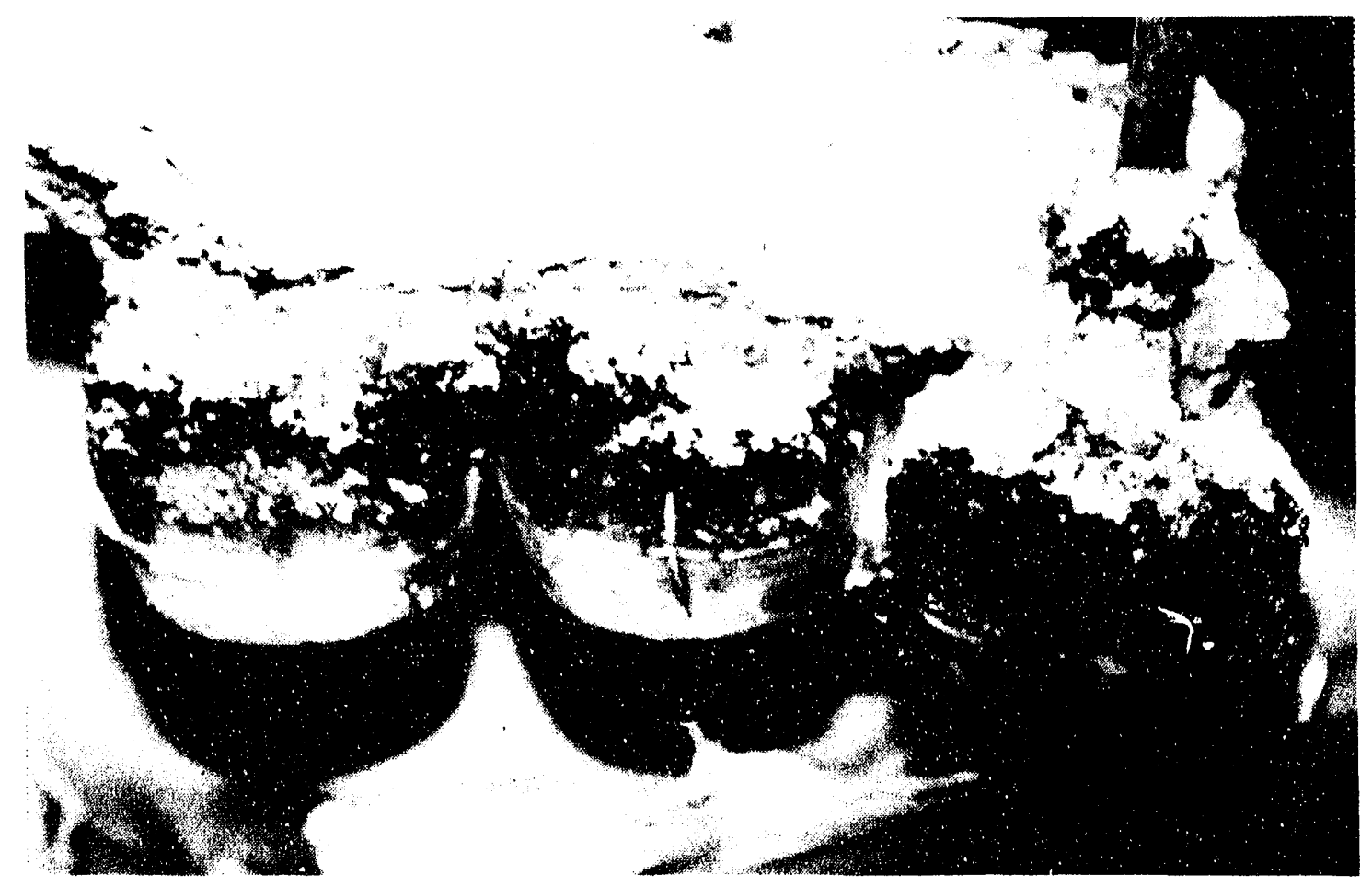

Figure 38. Cermet. Anodes upon removal - Oct. 10

-48 - 
operation. Metal samples were collected every four hours to track the concentration of these elements. The results from these analyses are presented in Appendix B and Figures 39 - 41. Impurities from other sources were minimized during the operation of the cell (in particular that of copper and nickel). As previously discussed, the impurity levels were allowed to reach equilibrium prior to introducing the cermet anodes into the cell.

The data shows an initial increase in impurity levels with the introduction of the cermet anodes, but then a stabilization of the concentrations. It should be noted that the concentrations were much more sensitive to change than in the previous PNL testing as the cell was operating at a greatly reduced metal inventory (200 lb versus $750 \mathrm{lb}$ ). The data shows several spikes in the impurity concentrations which can possibly be attributed to segregation of the metal pad within the cell preventing obtaining representative analysis of the metal. The data does not clearly indicate any significant changes in corrosion rates with the changes in cell operation (increased current and lower ratio).

In an effort to quantify the corrcsion rates, a model was constructed estimating the metal impurity concentrations based upon a fixed amount of each component (iron, nickel, and copper) reporting to the metal on a daily basis. This model accounts for the changing metal inventory in the cell, both through production and tapping. Using the following fixed amounts, concentrations were calculated and compared with the actual values as shown in Figures 42 - 44.

\begin{tabular}{|ll|}
\hline $\mathrm{Cu}$ & $0.075 \mathrm{lb} /$ day \\
$\mathrm{Ni}$ & $0.13 \mathrm{lb} /$ day \\
$\mathrm{Fe}$ & $0.30 \mathrm{lb} /$ day \\
\hline
\end{tabular}

As these plots show, the model fits the actual data reasonably well, with the exception of the period from September 24-30. It was during this period that fewer anodes were in the cell (4 anodes through September 27) and then initial operation and recoating of the replacement anodes.

The relative ratio of these impurities in the anodes are (Cu:Ni:Fe) $1: 1.98: 1.65$. The calculated metal losses result in a ratio of $1: 1.74: 4$. It is not surprising that the iron losses appears to be significantly higher than what would be expected from the anode, as frequent dipping of the metal from the cell was done with iron ladles. Based upon the composition of the anode and the rate of copper and nickel losses to the metal pad, the iron losses from the anode should be at the rate of $0.12 \mathrm{lb} /$ day. Based upon these rates, a total loss of material from the cermet anodes (assuming the losses are actually $\mathrm{Cu}, \mathrm{NiO}$, and $\mathrm{Fe}_{2} \mathrm{O}_{3}$ ) was 0.41 $\mathrm{lb} /$ day. This corresponds to a volumetric loss of $31.0 \mathrm{~cm}^{3}$, based on an anode density of 6 $\mathrm{g} / \mathrm{cm}^{3}$. Applying this loss uniformly from all the anodes, it would indicate a surface loss of $0.1 \mathrm{~mm} /$ day. These losses are approximately $1 / 2$ that found during the PNL test, using a similar analysis procedure.

While only a limited number of cermet anodes were observed at MTL, it was noticed that the coating was not uniform on the anodes, with some sections not having any observable coating. The effect of the uncoated sections of the anodes on the corrosion rate is not defined, but it is expected to result in a higher corrosion rate.

The $\mathrm{Fe}, \mathrm{Ni}$, and $\mathrm{Cu}$ levels were also monitored in the bath throughout the operation. These values are presented in Appendix $C$ and shown graphically in Figures 45 - 47 . As shown in these plots, little change in the levels of these impurities existed throughout the run. 


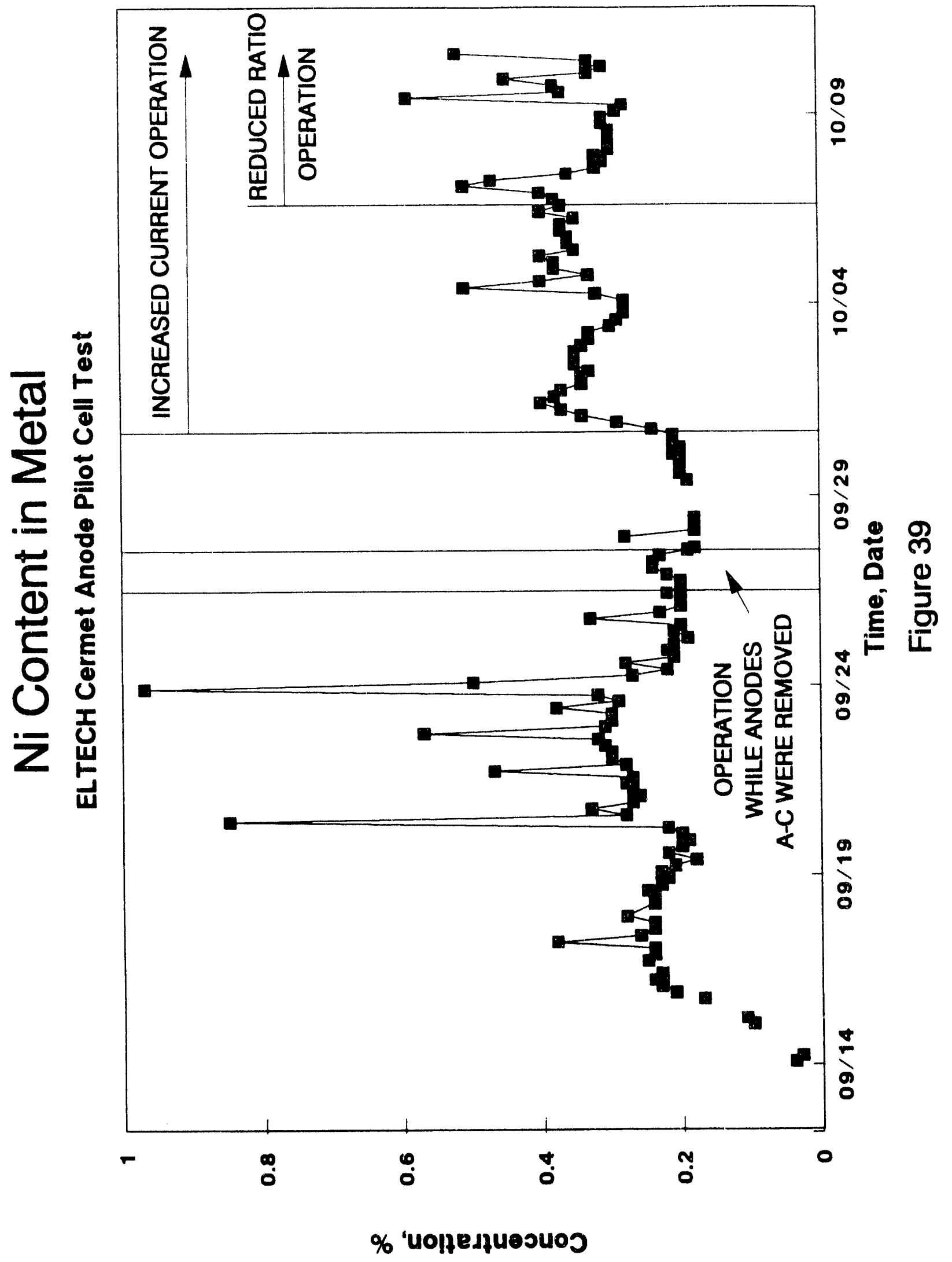




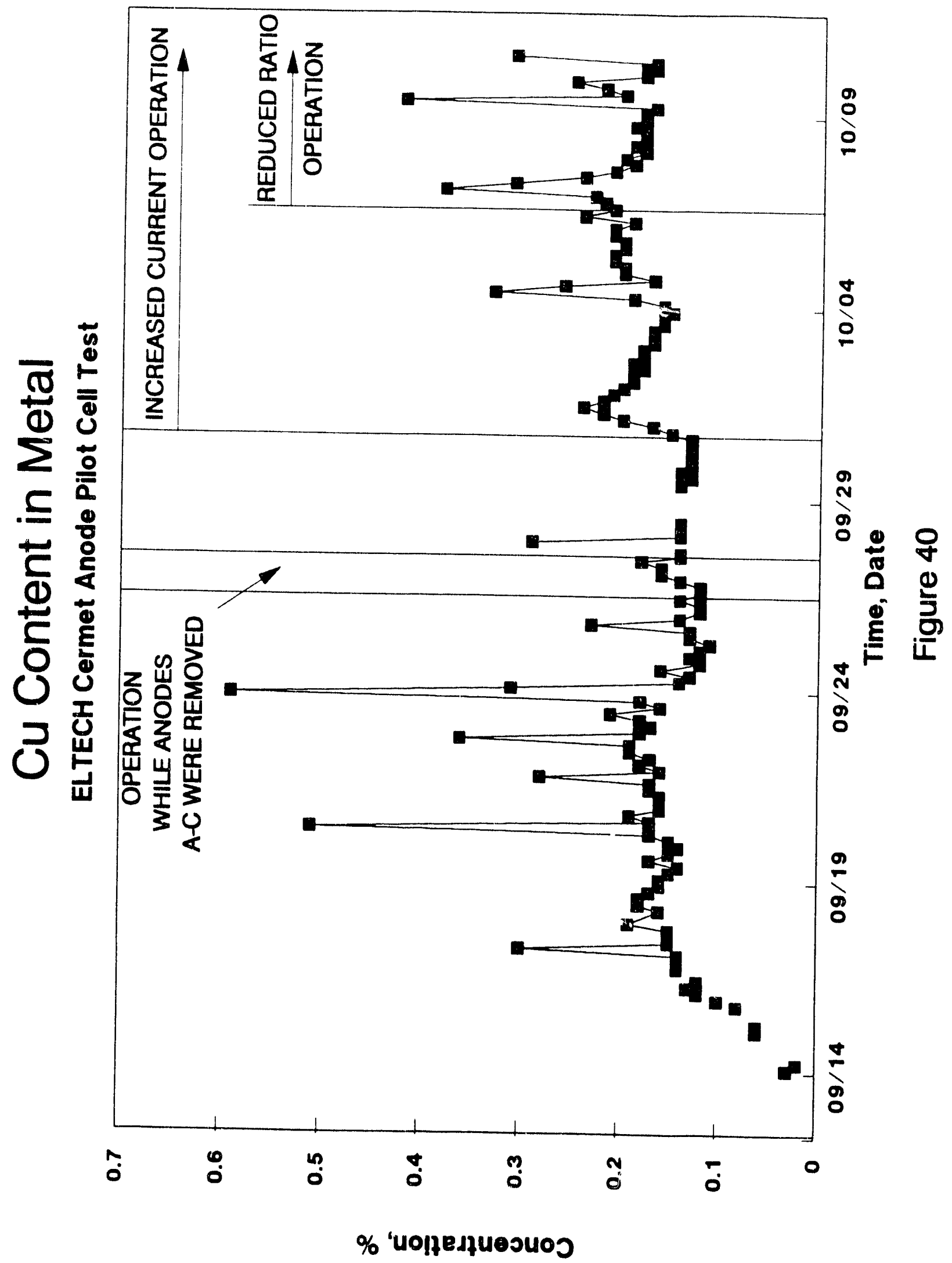




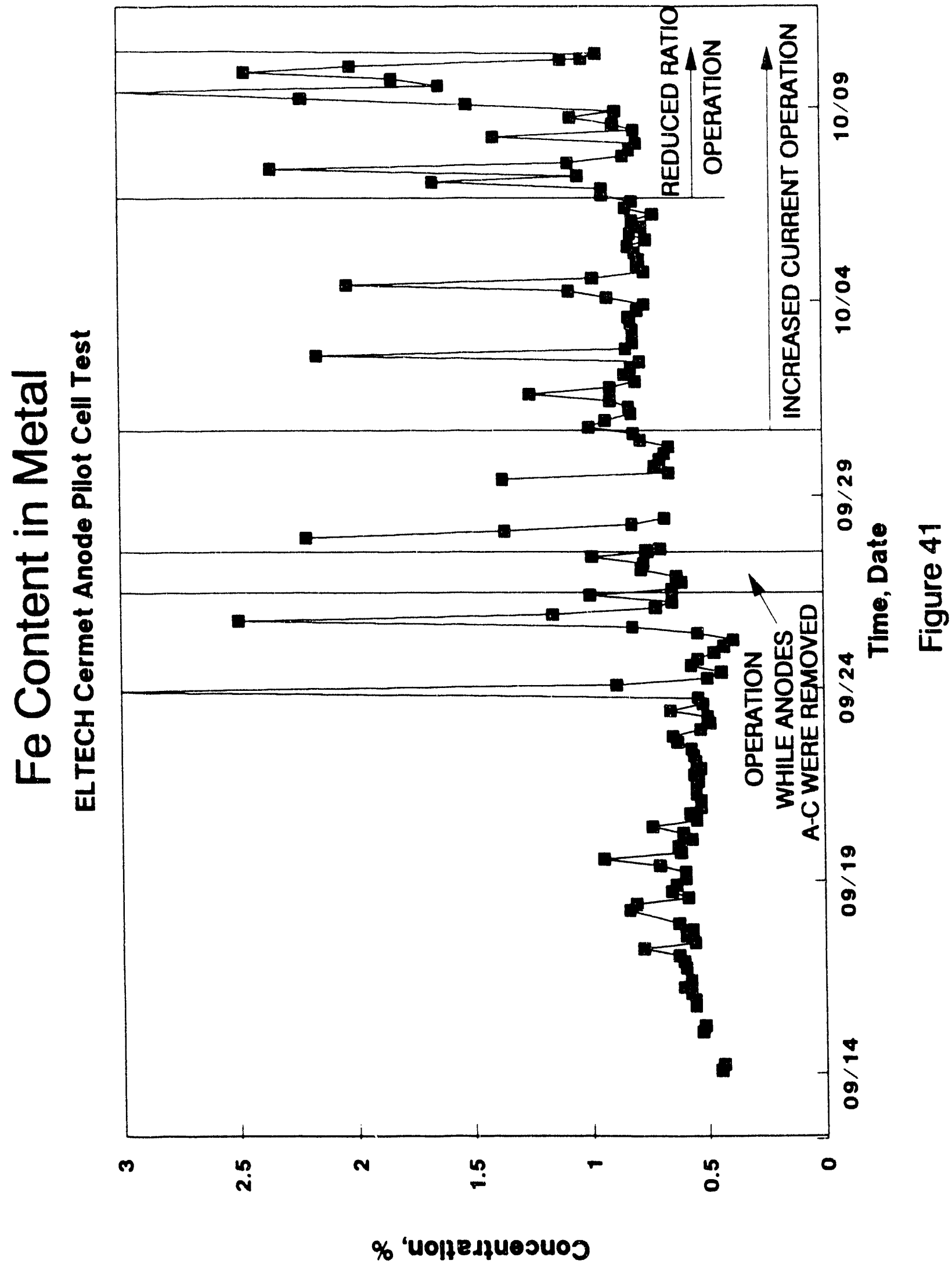




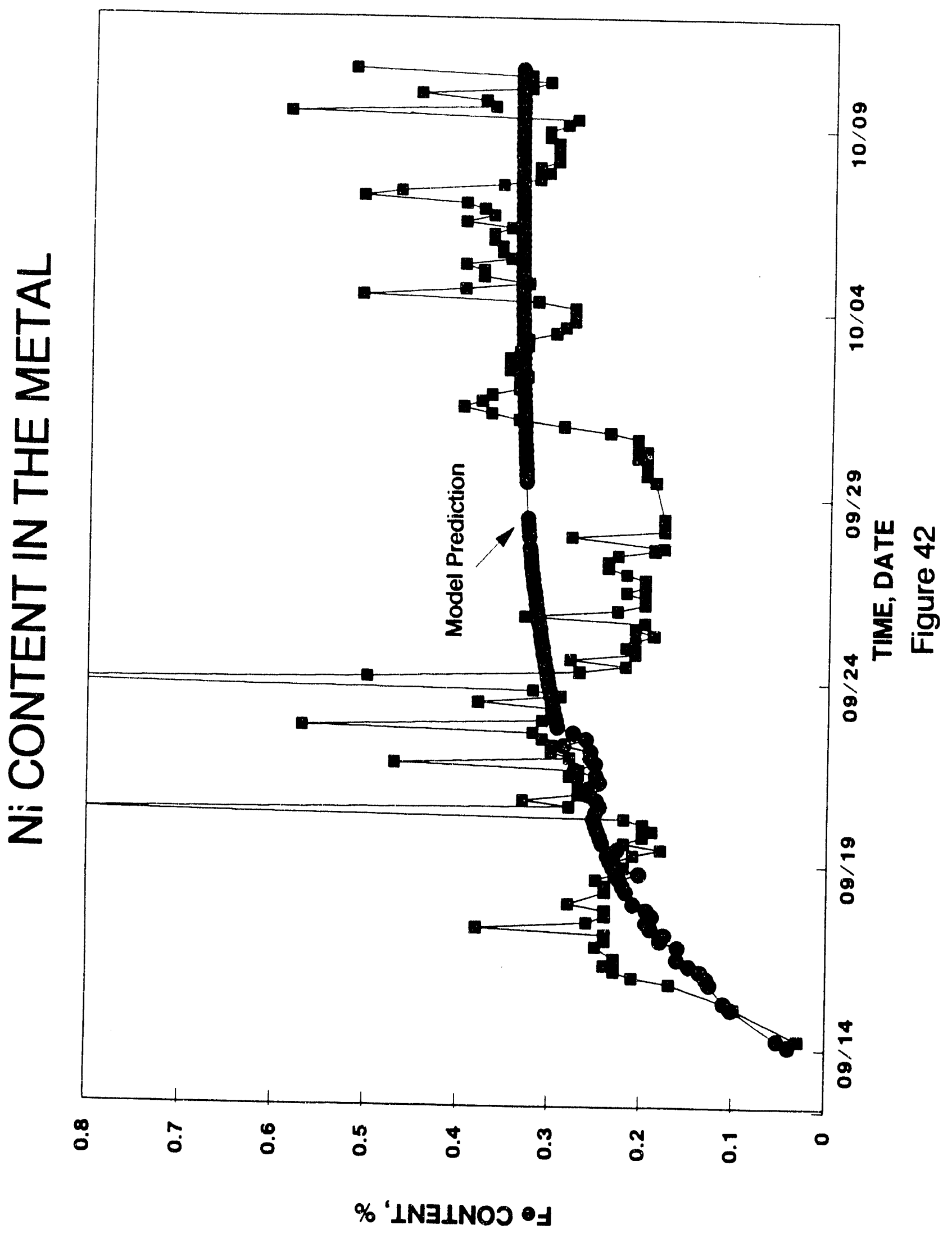




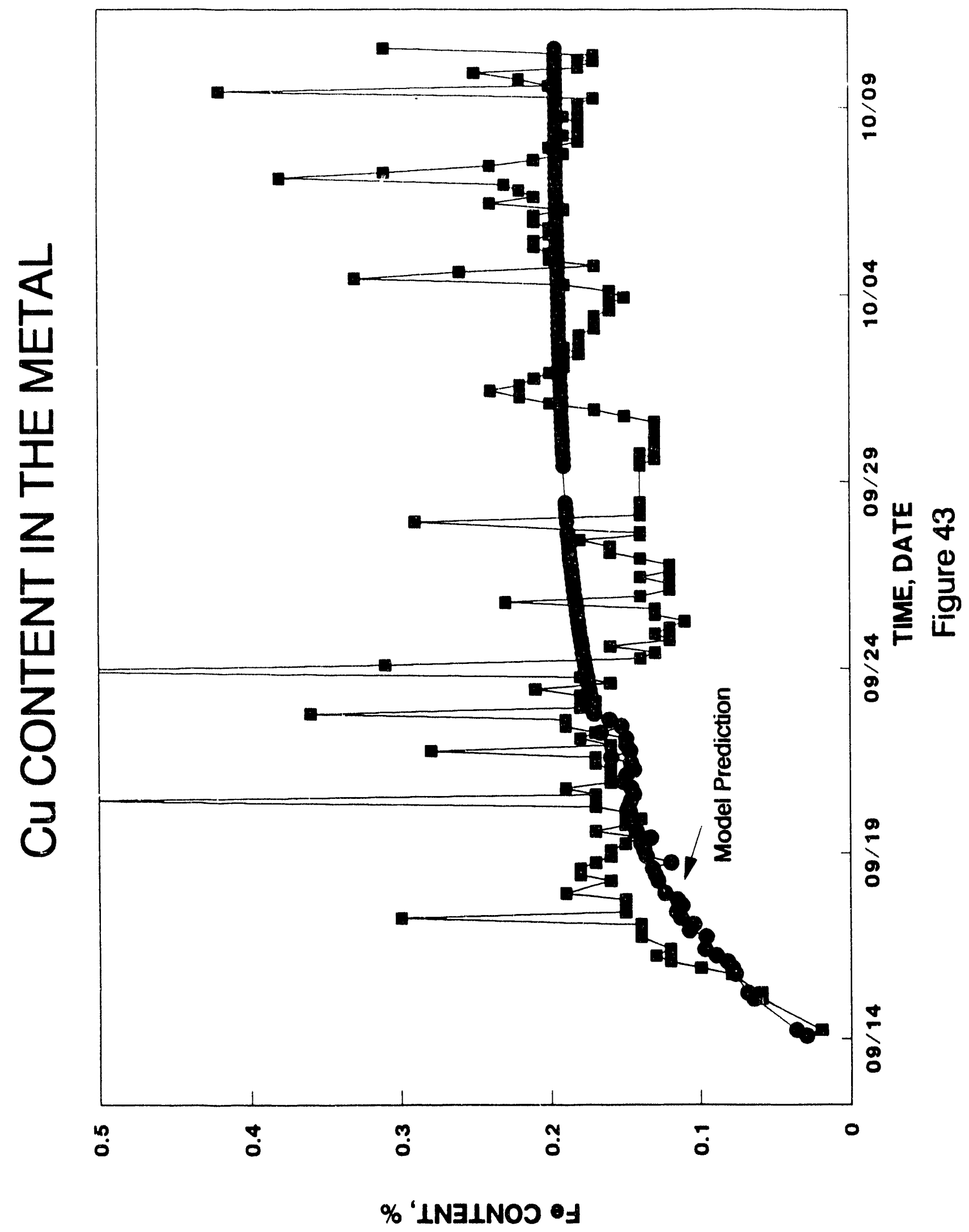




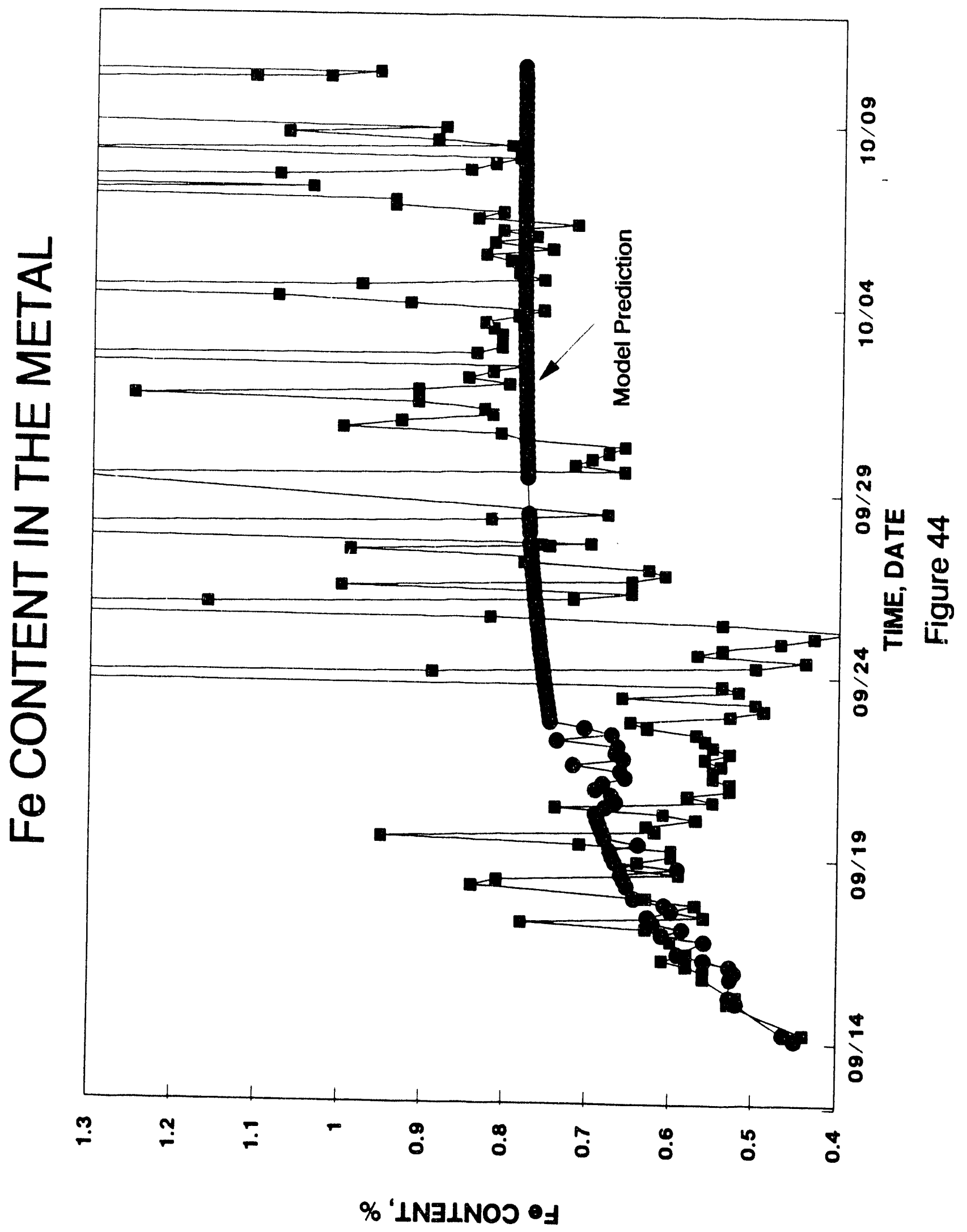




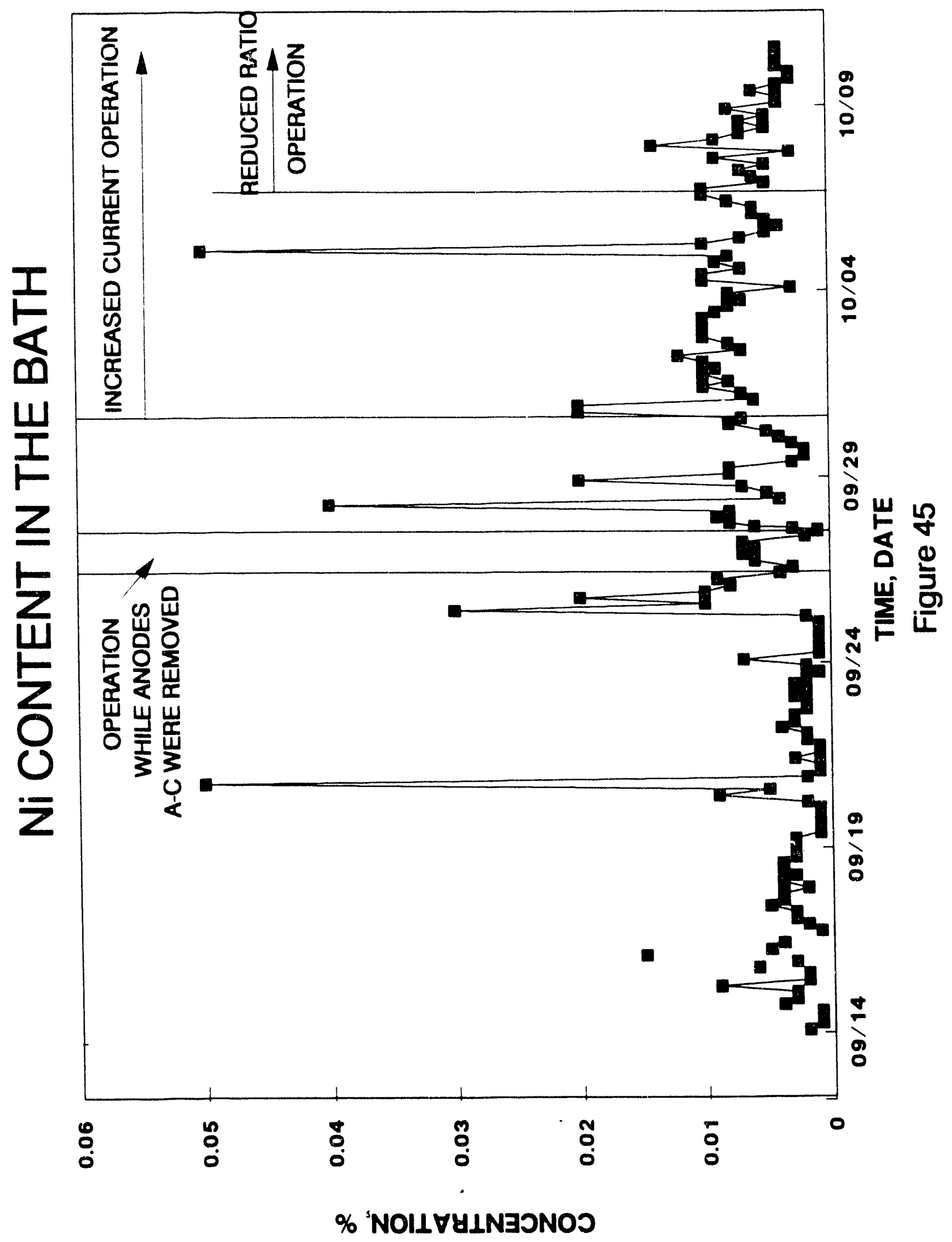

-56 - 


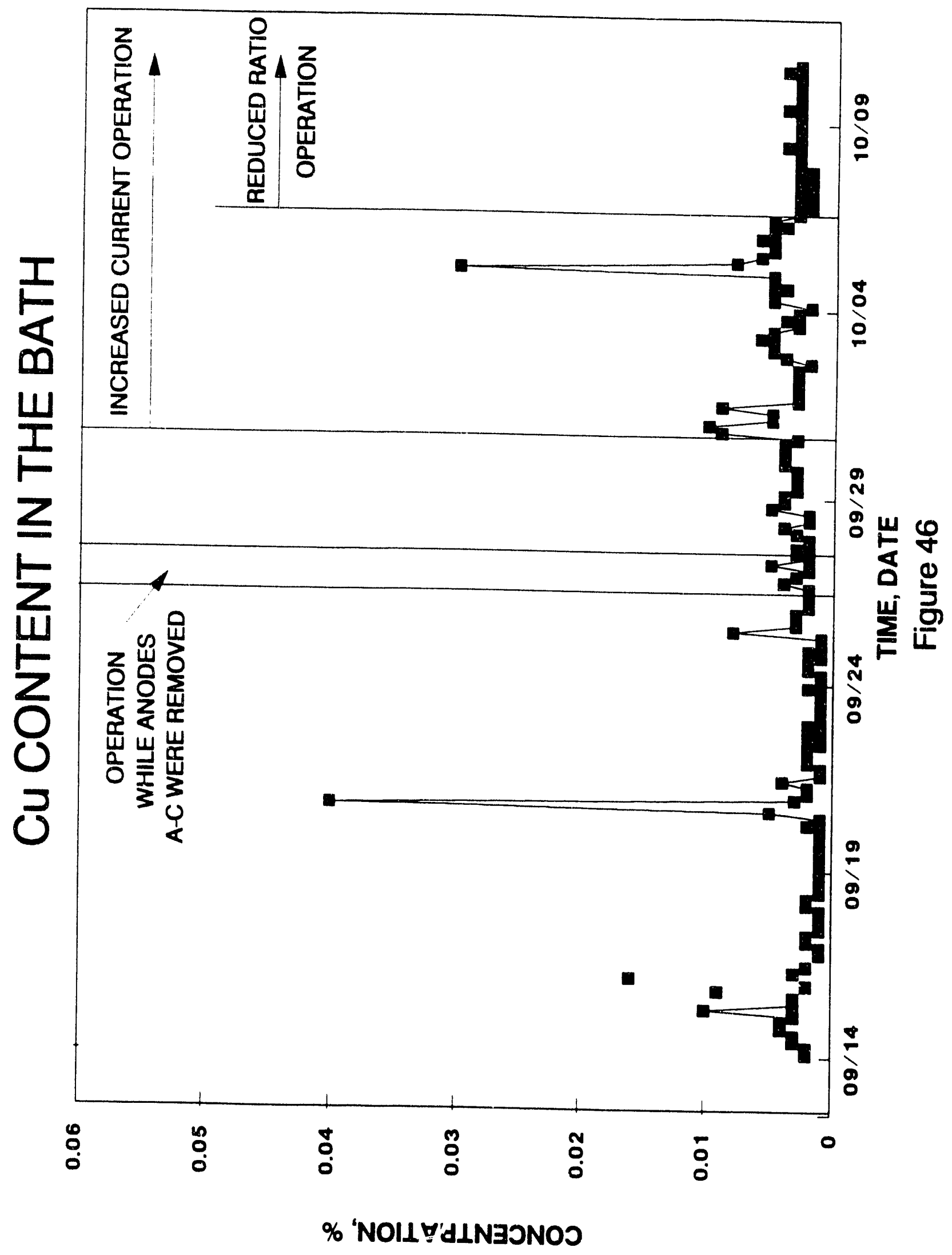

- 57 . 


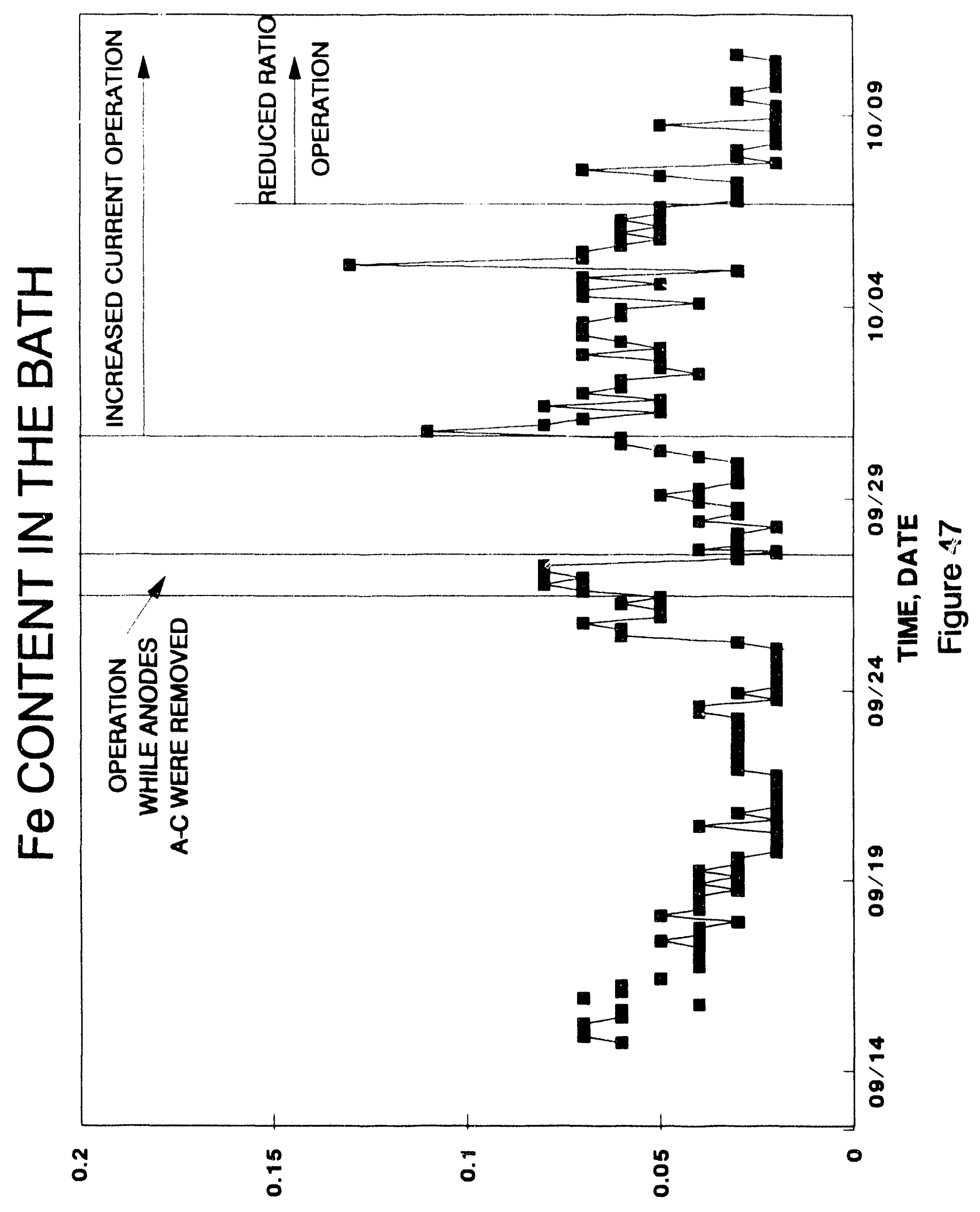

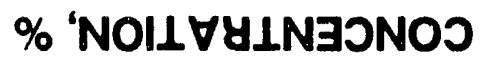




\section{DISCUSSION}

The operation of the aluminum reduction pilot cell with cermet anodes using ELTECH's "Cerox" technology was successful in that individual anodes remained in continuous operation for as long as 600 hours and, upon removal, were basically intact. Corrosion rates, as determined from the metal impurities in the metal, were approximately half that experienced during operation of the cell with cermet anodes without the "Cerox" coating (PNL testing), but still higher than desired for an acceptable commercial operation.

Similar problems were encountered with cracking of the cermet anodes as was experienced during the previous PNL testing. A number of concerns about the cermet anode technology as well as with the "Cerox" coating technology were emphasized during this pilot reduction cell test.

These concerns about the cermet technology were basically the same seen during the PNL testing without the "Cerox" coating. These include:

a) Cermet Anode Cracking and Srem Breakage

While the anode conductor stem breakage did not occur in this testing as experienced during the PNL testing, due to a change in material, significant wear was observed on the stems, indicating that an improved connector material or protection of the stem is needed.

The the imal stress cracking of the cermet anodes still remained a significant problem with this particular design of the anode. Even though the pre-mature failure of anodes due to breakage was not a significant problem, as experienced during the PNL testing, it was still very much evident and requires further investigation.

b) Operation at Low Anode Current Density

The apparent need to operate cermet anodes at low anode current density indicates the need for a revised anode design, allowing significant increase in anode area with sufficient current conduction for 1) the thermal stability of the aluminum reduction cell and 2) maintaining the commercial cell productivity.

c) Operation at Alumina Saturation

It is essentially impossible to operate for long periods at saturated alumina conditions in a conventional reduction cell due to increasing muck build-up which results in increasing cathode drop and reduced availability of liquid volume in the cell cathode cavity.

The developrnent of innovative anode and cell design is required to address these problems. Further development in cermet materials may still be required even with design changes, such that a suitable corrosion rate is achieved.

In addition to these general problems with the cermet anode technology, implementation of the "Cerox" coating adds some additional challenges. 
a) Anode Current Distribution

To achieve uniform coating of the anode it is necessary to have a uniform current density on the anode. While this is a concern with any design, it is especially critical with the Cerox technology.

b) Replacement of Anodes

To achieve the initial coating on the cermet anode it is necessary to operate at elevated cerium fluoride concentrations in the electrolyte. It is unclear as to the effects this will have on anodes in the cell which already have a "Cerox" coating installed. It may be better to develop a procedure for pre-coating the anodes prior to actual installation in an operating cell. It is also not clear as to the dynamics of the coating when placed in the bath and not under electrolysis.

c) Liquid Level Control

As the coating is applied in the cell while elevated levels of cerium exist in the bath, it is necessary to be sure that the coating is applied while anode immersion is the maximum, otherwise uncoated areas of the anode will be exposed later in the operation.

d) Cerium Levels in the Metal

A major disadvantage to the "Cerox" technology is that the cerium concentrations in the metal are in the 3-4\% range. An economical technology must be proven to reduce these concentrations to an acceptable level $(<1 \mathrm{ppm})$ before it would be accepted by industry. 
VII. APPENDICES

APPENDIX A

Bath Composition

\author{
APPENDIX B \\ Metal Impurities
}

\author{
APPENDIX C \\ Bath Impurities
}


APPENDIX A

Bath Composition

$-62$. 


\section{ELTECH BATH ANALYSIS}

\begin{tabular}{|c|c|c|c|c|c|c|c|c|}
\hline SAMPLE ID & DATE & TIME & RATIO & $\mathrm{CaF}_{2}$ & $\mathrm{Al}_{2} \mathrm{O}_{3}$ & EXCESS ALF $_{3}$ BATH TEMP & ALUMINA & $\begin{array}{c}\mathrm{CeF}_{3} \\
\%\end{array}$ \\
\hline & & & & $\%$ & & $\%$ & SAT \% & \\
\hline $2687-30 A$ & & 1400 & & 3.47 & & & & \\
\hline $2687-31 C$ & & 1800 & & 3.11 & & & & \\
\hline $2687-31 A$ & & 2200 & & 3.03 & & & & \\
\hline $2687-32 B$ & AUG 31 & 1400 & & 3.20 & & & & \\
\hline $2687-33 A$ & & 2200 & & 4.07 & & & & \\
\hline $2687-34 B$ & SEPT 1 & 600 & & 3.81 & & & & \\
\hline $2687-35 A$ & & 1400 & & 4.24 & & & & \\
\hline $2687-36 B$ & & 2200 & 1.13 & 4.59 & & & & \\
\hline $2687-37 B$ & SEPT 2 & 600 & 1.25 & 4.42 & & & & \\
\hline $2687-38 C$ & & 1400 & 1.37 & 4.16 & & & & \\
\hline $2687-38 D$ & & 2200 & 1.47 & 3.90 & & & & \\
\hline $2687-39 B$ & SEPT 3 & 600 & 1.49 & 3.98 & & & & \\
\hline $2687-39 D$ & & 1400 & & 3.89 & & & & \\
\hline $2687--40 A$ & & 2200 & & 4.07 & & & & \\
\hline $2687-41 B$ & SEPT 4 & 600 & 1.45 & 3.99 & & & & \\
\hline $2687-41 D$ & & 1400 & 1.47 & 3.80 & & & & \\
\hline $2687-42 B$ & & 2200 & 1.41 & 4.16 & & & & \\
\hline $2687-42 \mathrm{D}$ & SEPT 5 & 600 & 1.45 & 4.07 & & & & \\
\hline $2687-43 B$ & & 1400 & 1.33 & 4.33 & & & & \\
\hline $2687-43 D$ & & 2200 & 1.26 & 4.33 & & & & \\
\hline $2687-44 B$ & SEPT 6 & 600 & 1.29 & 4.33 & & & & \\
\hline $2687-44 D$ & & 1400 & 1.17 & 4.07 & & & & \\
\hline $2687-45 B$ & & 22.00 & 1.27 & 4.07 & & & & \\
\hline $2687-45 D$ & SEPT 7 & 600 & 1.31 & 4.07 & & & & \\
\hline $2687-46 B$ & & 1400 & 1.26 & 4.07 & & & & \\
\hline $2687-46 D$ & & 2200 & 1.26 & 4.15 & & & & \\
\hline $2687-47 B$ & SEPT 8 & 600 & 1.28 & 4.24 & & & & \\
\hline $2687-47 D$ & & 1400 & 1.26 & 4.76 & & & & \\
\hline $2687-48 B$ & & 2200 & 1.39 & 4.85 & & & & \\
\hline $2687-49 B$ & SEPT 9 & 600 & 1.48 & 5.11 & & & & \\
\hline $2687-50 A$ & & 1100 & & & & & & 0.01 \\
\hline $2687-50 C$ & & 1300 & & & & & & 1.17 \\
\hline $2687-50 E$ & & 1400 & 1.44 & 4.33 & & & & 1.03 \\
\hline $2687-51 \mathrm{H}$ & & 1800 & 1.45 & 4.33 & & & & 0.71 \\
\hline $2687-52 A$ & & 2200 & 1.43 & 4.50 & & & & 0.62 \\
\hline $2687-52 C$ & SEPT 10 & 200 & 1.44 & 4.58 & & & & 0.52 \\
\hline $2687-53 A$ & & 600 & 1.43 & 4.59 & & & & 0.48 \\
\hline $2687-53 C$ & & 1000 & 1.39 & 4.77 & & & & 0.36 \\
\hline $2687-53 E$ & & 1400 & 1.36 & 4.68 & & & & 0.22 \\
\hline $2687-54 \mathrm{E}$ & & 1800 & 1.36 & 4.76 & & & & 0.23 \\
\hline $2687-54 G$ & & 2200 & 1.37 & 4.76 & & & & 0.24 \\
\hline $2687-55 B$ & & 200 & 1.39 & 4.76 & & & & 0.49 \\
\hline $2687-55 \mathrm{D}$ & & 600 & 1.41 & 4.68 & & & & 0.48 \\
\hline $2687-56 A$ & & 1000 & & & & & & 0.29 \\
\hline $2687-56 D$ & & 1400 & & & & & & 0.34 \\
\hline
\end{tabular}




\section{ELTECH BATH ANALYSIS}

SAMPLE ID DATE TIME RATIO $\mathrm{CaF}_{2} \mathrm{Al}_{2} \mathrm{O}_{3} \quad$ EXCESS ALF $_{3}$ BATH TEMP ALUMINA $\mathrm{CeF}_{3}$

$\% \quad \% \quad$ DEGC $\quad$ SAT $\% \quad \%$

\begin{tabular}{|c|c|c|c|c|c|c|c|c|c|}
\hline $2687-57 E$ & & 1800 & 1.25 & 4.77 & & & & & 0.29 \\
\hline $2687-57 \mathrm{G}$ & & 2200 & 1.22 & 4.51 & & & & & 0.26 \\
\hline $2687-58 \mathrm{~B}$ & SEPT 12 & 200 & 1.24 & 4.59 & & & & & 0.27 \\
\hline $2687-58 \mathrm{D}$ & & 600 & 1.33 & 4.67 & & & & & 0.26 \\
\hline $2687-59 E$ & & 1000 & 1.36 & 4.77 & & & & & 0.30 \\
\hline $2687-60 A$ & & 1400 & 1.33 & 4.51 & & & & & 0.34 \\
\hline $2687-60 D$ & & 1800 & 1.34 & 4.41 & & & & & 0.34 \\
\hline $2687-61 B$ & & 2200 & 1.33 & 4.59 & & & & & 0.27 \\
\hline $2687-61 \mathrm{D}$ & SEPT 13 & 200 & 1.35 & 4.51 & & & & & 0.34 \\
\hline $2687-61 F$ & & 600 & 1.37 & 4.59 & 3.76 & 3.33 & 973 & 43.2 & 0.54 \\
\hline $2687-61 \mathrm{H}$ & & 1000 & 1.45 & 4.50 & 6.49 & 1.20 & 961 & 78.4 & 0.50 \\
\hline $2687-62 A$ & & 1400 & 1.50 & 3.98 & 4.37 & 0.00 & 971 & 49.1 & 0.39 \\
\hline $2687-63 B$ & & 1800 & 1.54 & 4.15 & 5.62 & -0.94 & 974 & 62.2 & 0.35 \\
\hline $2687-63 D$ & & 2200 & 1.55 & 4.34 & 4.90 & -1.18 & 973 & 54.8 & 0.36 \\
\hline $2687-64 B$ & SEPT 14 & 200 & 1.61 & 4.24 & 3.68 & -2.57 & 973 & 40.8 & 0.32 \\
\hline $2687-65 B$ & & 600 & 1.60 & 4.34 & 4.45 & -2.33 & 978 & 48.2 & 0.32 \\
\hline $2687-65 C$ & & 1000 & 1.61 & 3.58 & 2.72 & -2.62 & 965 & 30.9 & 0.54 \\
\hline $2687--65 E$ & & 1200 & & & & & & & 0.52 \\
\hline $2687-66 A$ & & 1300 & & & & & & & 0.53 \\
\hline $2687-66 C$ & & 1330 & & & & & & & 0.50 \\
\hline $2687-66 \mathrm{C}$ & & 1400 & 1.59 & 3.96 & 2.65 & -2.15 & 970 & 29.7 & 0.48 \\
\hline $2687-66 \mathrm{E}$ & & 1430 & & & & & & & 0.48 \\
\hline $2687-67 B$ & & 1500 & & & & & & & 0.46 \\
\hline $2687-67 \mathrm{D}$ & & 1530 & & & & & & & 0.46 \\
\hline $2687-67 F$ & & 1600 & & & & & & & 0.45 \\
\hline $2687-67 \mathrm{H}$ & & 1630 & & & & & & & 0.44 \\
\hline $2687-68 B$ & & 1730 & & & & & & & 0.41 \\
\hline $2687-68 D$ & & 1800 & 1.61 & 3.77 & 3.34 & -2.60 & 972 & 36.7 & 0.38 \\
\hline $2687-68 \mathrm{~F}$ & & 2200 & :.59 & 4.05 & 2.98 & -2.14 & 972 & 33.1 & 0.33 \\
\hline $2687-68 \mathrm{H}$ & SEPT 15 & 200 & 1.61 & 3.78 & 2.98 & -2.61 & 975 & 32.2 & 0.31 \\
\hline $2687-69 B$ & & 600 & 1.62 & 4.15 & 3.02 & -2.82 & 976 & 32.8 & 0.68 \\
\hline $2687-69 D$ & & 1000 & 1.60 & 3.48 & 2.73 & -2.39 & 980 & 28.4 & 0.62 \\
\hline $2687-69 E$ & & 1200 & & & & & & & 0.87 \\
\hline $2687-70 B$ & & 1245 & & & & & & & ก 85 \\
\hline $2687-70 \mathrm{D}$ & & 1330 & & & & & & & -8 \\
\hline $2687-70 F$ & & 1400 & 1.53 & 3.48 & 6.72 & -0.71 & 969 & 74.8 & 0.77 \\
\hline $2687-70 \mathrm{H}$ & & 1430 & & & & & & & 0.65 \\
\hline $2687-70 \mathrm{~J}$ & & 1500 & & & & & & & 0.66 \\
\hline $2687-70 \mathrm{~L}$ & & 1530 & & & & & & & 0.61 \\
\hline $2687-70 \mathrm{~N}$ & & 1600 & & & & & & & 0.62 \\
\hline $2687-71 B$ & & 1700 & & & & & & & 0.59 \\
\hline $2687-71 D$ & & 1800 & 1.51 & 3.39 & 5.73 & -0.24 & 972 & 62.7 & 0.54 \\
\hline $2687-71 F$ & & 1900 & & & & & & & 0.51 \\
\hline $2687-71 \mathrm{H}$ & & 2000 & & & & & & & 0.49 \\
\hline $2687-711$ & & 2100 & & & & & & & 0.47 \\
\hline
\end{tabular}


ELTECH BATH ANAL.YSIS

SAMPLE ID DATE TIME RATIO $\mathrm{CaF}_{2} \quad \mathrm{Al}_{2} \mathrm{O}_{3} \quad$ EXCESS ALF $_{3} \mathrm{BATH}$ TEMP ALUMINA $\mathrm{CeF}_{3}$ $\% \quad \% \quad$ DEG C $\quad$ SAT \% $\%$

\begin{tabular}{|c|c|c|c|c|c|c|c|c|c|}
\hline $2687-72 B$ & & 2200 & 1.50 & 3.77 & 5.47 & 0.00 & 973 & 60.3 & 0.46 \\
\hline $2687-72 D$ & SEPT 16 & 0 & & & & & & & 0.43 \\
\hline $2687-72 F$ & & 200 & 1.48 & 3.78 & 4.87 & 0.49 & 973 & 53.8 & 0.42 \\
\hline $2687-73 B$ & & 400 & & & & & & & 0.38 \\
\hline $2687-73 D$ & & 600 & 1.47 & 4.24 & 5.96 & 0.72 & 973 & 66.9 & 0.36 \\
\hline $2687-73 F$ & & 800 & & & & & & & 0.37 \\
\hline $2687-73 \mathrm{H}$ & & 1000 & 1.45 & 4.05 & 4.88 & 1.23 & 968 & 56.0 & 0.34 \\
\hline $2687-73 \mathrm{~J}$ & & 1400 & 1.46 & 3.77 & 5.14 & 0.98 & 975 & 56.3 & 0.40 \\
\hline $2687-74 B$ & & 1800 & 1.45 & 4.15 & 6.95 & 1.20 & 972 & 78.4 & 0.36 \\
\hline $2687-74 \mathrm{D}$ & & 2200 & 1.43 & 4.34 & 5.38 & 1.72 & 978 & 59.3 & 0.39 \\
\hline $2687-75 B$ & SEPT 17 & 200 & 1.47 & 4.34 & 5.41 & 0.73 & 970 & 61.9 & 0.39 \\
\hline $2687-75 \mathrm{D}$ & & 600 & 1.47 & 4.53 & 4.71 & 0.73 & 970 & 54.2 & لي. \\
\hline $2687-75 E$ & & 1000 & 1.48 & 4.43 & 4.97 & 0.48 & 970 & 57.0 & 0.40 \\
\hline $2687-75 \mathrm{G}$ & & 1400 & 1.48 & 4.34 & 4.99 & 0.48 & 969 & 57.4 & 0.39 \\
\hline $2689-1 A$ & & 1800 & 1.49 & 4.34 & 4.29 & 0.24 & 971 & 48.8 & 0.38 \\
\hline $2689-2 A$ & & 2200 & 1.50 & 4.24 & 6.29 & 0.00 & 976 & 69.3 & 0.36 \\
\hline $2689-2 C$ & SEPT 18 & 200 & 1.49 & 4.34 & 6.71 & 0.24 & 974 & 75.1 & 0.38 \\
\hline $2689-2 D$ & & 600 & 1.49 & 4.24 & 6.82 & 0.24 & 981 & 73.3 & 0.37 \\
\hline $2689-2 G$ & & 1000 & 1.48 & 4.41 & 4.40 & 0.49 & 972 & 49.9 & 0.40 \\
\hline $2689-3 B$ & & 1400 & 1.48 & 4.28 & 5.00 & 0.49 & 971 & 56.8 & 0.36 \\
\hline $2689-3 D$ & & 1800 & 1.46 & 4.28 & 5.43 & 0.97 & 977 & 59.9 & 0.35 \\
\hline $2689-4 B$ & & 2200 & 1.44 & 4.34 & 5.11 & 1.48 & 966 & 59.9 & 0.34 \\
\hline $2689-4 D$ & SEPT 19 & 200 & 1.43 & 3.96 & 5.10 & 1.74 & 971 & 57.6 & 0.33 \\
\hline $2689-4 F$ & & 600 & 1.40 & 4.80 & 4.74 & 2.50 & 971 & 55.1 & 0.33 \\
\hline $2689-4 \mathrm{H}$ & & 1000 & 1.38 & 4.40 & 5.64 & 3.01 & 965 & 66.9 & 0.31 \\
\hline $2689-5 B$ & & 1400 & 1.34 & 4.49 & 5.07 & 4.10 & 965 & 60.5 & 0.32 \\
\hline $2689 \cdot-5 D$ & & 1800 & 1.31 & 4.58 & 5.45 & 4.91 & 969 & 64.2 & 0.31 \\
\hline $2689-5 F$ & & 2200 & 1.27 & 4.49 & 7.07 & 5.94 & 970 & 83.1 & 0.30 \\
\hline $2689-6 B$ & SEPT 20 & 200 & 1.25 & 4.41 & 7.33 & 6.50 & 966 & 87.7 & 0.35 \\
\hline $2689-6 D$ & & 600 & 1.28 & 4.40 & 6.59 & 5.69 & 976 & 75.0 & 0.38 \\
\hline $2689-6 E$ & & 1000 & 1.16 & 4.23 & 6.49 & 9.32 & 969 & 77.5 & 0.36 \\
\hline $2689-6 \mathrm{H}$ & & 1400 & 1.10 & 3.78 & $\% .05$ & 11.26 & 987 & 78.3 & 0.41 \\
\hline $2689-7 B$ & & 1800 & 1.12 & 3.68 & 7.13 & 10.60 & 974 & 82.7 & 0.34 \\
\hline $2689-7 D$ & & 2200 & 1.21 & 3.77 & 7.79 & 7.69 & 990 & 82.8 & 0.35 \\
\hline $2689-8 B$ & SEPT 21 & 200 & 1.22 & 3.68 & 7.75 & 7.41 & 995 & 80.2 & 0.43 \\
\hline $2689-8 D$ & & 600 & 1.41 & 3.60 & 7.65 & 2.20 & 993 & 76.7 & 0.37 \\
\hline $2689-8 E$ & & 1000 & 1.27 & 3.96 & 7.49 & 5.95 & 985 & 80.8 & 0.35 \\
\hline $2689-9 A$ & & 1400 & 1.32 & 4.89 & 7.35 & 4.51 & 960 & 91.2 & 0.31 \\
\hline $2689-9 D$ & & 1800 & 1.37 & 4.68 & 6.48 & 3.23 & 985 & 70.4 & 0.30 \\
\hline $2689-9 F$ & & 2200 & 1.45 & 4.95 & 8.83 & 1.17 & 997 & 90.1 & 0.45 \\
\hline $2689-10 B$ & SEPT 22 & 200 & 1.53 & 5.31 & 7.64 & -0.68 & 1002 & 75.9 & 0.42 \\
\hline $2689-10 \mathrm{D}$ & & 600 & 1.52 & 5.29 & 8.08 & -0.46 & 998 & 82.0 & 0.38 \\
\hline $2689-11 B$ & & 1000 & 1.51 & 5.39 & 7.60 & -0.23 & 998 & 77.5 & 0.42 \\
\hline $2689-11 D$ & & 1400 & 1.47 & 5.20 & 9.79 & 0.68 & 1004 & 96.9 & 0.41 \\
\hline \multirow[t]{2}{*}{$2689-11 F$} & & 1800 & 1.49 & 5.22 & 7.83 & 0.23 & 1001 & 78.5 & 0.37 \\
\hline & & & & & $-65-$ & & & & \\
\hline
\end{tabular}




\section{ELTECH BATH ANALYSIS}

SAMPLE ID DATE TIME RATIO $\quad \mathrm{CaF}_{2} \quad \mathrm{Al}_{2} \mathrm{O}_{3} \quad$ EXCESS ALF $_{3}$ BATH TEMP ALUMINA CeF $\% \quad \% \quad \% \quad$ DEGC $\quad$ SAT \% $\%$

\begin{tabular}{|c|c|c|c|c|c|c|c|c|c|}
\hline $2689-11 \mathrm{H}$ & & 2200 & 1.51 & 5.21 & 8.26 & -0.23 & 996 & 84.6 & 0.38 \\
\hline $2689-12 B$ & SEPT 23 & 200 & 1.52 & 5.22 & 7.34 & -0.46 & 990 & 77.4 & 0.37 \\
\hline $2689-12 D$ & & 600 & 1.50 & 5.21 & 7.46 & 0.00 & 993 & 77.7 & 0.39 \\
\hline $2689-12 F$ & & 1000 & 1.50 & 5.10 & 2.38 & 0.00 & 975 & 27.1 & 0.40 \\
\hline $2689-13 B$ & & 1400 & 1.34 & 5.10 & 4.49 & 4.10 & 984 & 49.9 & 0.32 \\
\hline $2689-13 D$ & & 1800 & 1.33 & 5.11 & 6.65 & 4.27 & 983 & 74.3 & 0.31 \\
\hline $2689-14 B$ & & 2200 & 1.34 & 4.91 & 4.10 & 4.12 & 980 & 46.2 & 0.32 \\
\hline $2689-14 D$ & SEPT 24 & 200 & 1.34 & 4.84 & 7.76 & 3.96 & 979 & 87.5 & 0.28 \\
\hline $2689-14 \mathrm{~F}$ & & 600 & 1.34 & 4.54 & 7.05 & 4.01 & 983 & 77.3 & 0.28 \\
\hline $2689-15 B$ & & 1000 & 1.32 & 4.65 & 7.32 & 4.53 & 993 & 77.1 & 0.41 \\
\hline $2689-15 \mathrm{D}$ & & 1400 & 1.30 & 4.58 & 7.23 & 5.08 & 991 & 77.0 & 0.50 \\
\hline $2689-16 B$ & & 1800 & 1.33 & 4.65 & 8.37 & 4.21 & 997 & 86.4 & 0.47 \\
\hline $2689-16 \mathrm{D}$ & & 2200 & 1.32 & 4.84 & 7.36 & 4.52 & 993 & 78.0 & 0.40 \\
\hline $2689-16 \mathrm{~F}$ & SEPT 25 & 200 & 1.32 & 4.83 & 6.43 & 4.56 & 980 & 72.4 & 0.40 \\
\hline $2689-17 B$ & & 600 & 1.33 & 5.11 & 7.36 & 4.23 & 992 & 78.9 & 0.36 \\
\hline $2689-17 \mathrm{C}$ & & 1000 & 1.41 & 4.94 & 7.90 & 2.16 & 1015 & 74.5 & 0.49 \\
\hline $2689-17 F$ & & 1400 & 1.43 & 4.39 & 10.28 & 1.63 & 1046 & 82.3 & 0.68 \\
\hline $2689-18 B$ & & 1800 & 1.42 & 4.12 & 11.08 & 1.86 & 1038 & 91.4 & 0.79 \\
\hline $2689-18 D$ & & 2200 & & 4.49 & 11.05 & & & & 0.89 \\
\hline $2689-19 b$ & SEPT 26 & 200 & 1.60 & 4.39 & 7.41 & -2.25 & 1006 & 69.2 & 0.63 \\
\hline $2689-19 D$ & & 600 & 1.50 & 4.75 & 6.19 & 0.00 & 999 & 61.6 & 0.65 \\
\hline $2689-19 F$ & & 1000 & 1.41 & 4.66 & 9.23 & 2.13 & 1029 & 80.9 & 0.56 \\
\hline $268^{\prime} 9-20 B$ & & 1400 & 1.48 & 4.37 & 6.42 & 0.48 & 1030 & 54.6 & 0.48 \\
\hline $2689-20 D$ & & 1800 & 1.49 & 4.12 & 10.13 & 0.23 & 1047 & 78.8 & 0.47 \\
\hline $2689-21 B$ & & 2200 & 1.47 & 3.66 & 10.33 & 0.69 & 1036 & 83.7 & 0.42 \\
\hline $2689-21 D$ & SEPT 27 & 200 & 1.47 & 3.77 & 6.69 & 0.72 & 1012 & 60.9 & 0.41 \\
\hline $2689-22 B$ & & 600 & 1.47 & 3.76 & 8.91 & 0.70 & 1020 & 78.0 & 0.39 \\
\hline $2689-22 C$ & & 1000 & 1.34 & 3.41 & 6.81 & 4.07 & 979 & 73.4 & 0.34 \\
\hline $2689-22 F$ & & 1300 & 1.33 & 3.12 & 7.22 & 4.34 & 984 & 75.4 & 0.67 \\
\hline $2689-23 B$ & & 1400 & 1.32 & 3.22 & 6.75 & 4.63 & 967 & 76.8 & 0.52 \\
\hline $2689-23 C$ & & 1500 & & & & & & & 0.46 \\
\hline $2689-23 E$ & & 1600 & & & & & & & 0.47 \\
\hline $2689-24 B$ & & 1800 & 1.23 & 3.40 & 7.94 & 7.12 & 1016 & 74.4 & 0.50 \\
\hline $2689-24 D$ & & 2200 & 1.23 & 3.59 & 7.35 & 7.15 & 995 & 75.7 & 0.49 \\
\hline $2689-25 B$ & SEPT 28 & 200 & 1.26 & 3.68 & 7.66 & 6.24 & 1008 & 74.2 & 0.53 \\
\hline $2689-25 D$ & & 600 & 1.39 & 3.67 & 7.90 & 2.70 & 1021 & 69.9 & 0.55 \\
\hline $2689-26 \mathrm{~A}$ & & 1000 & 1.43 & 4.03 & 5.64 & 1.73 & 990 & 58.0 & 1.07 \\
\hline $2689-27 A$ & & 1400 & 1.50 & 6.10 & 6.44 & 0.00 & 978 & 74.6 & 0.64 \\
\hline $2689-27 D$ & & 1800 & 1.67 & 6.03 & 5.98 & -3.71 & 980 & 67.1 & 0.66 \\
\hline $2689-28 B$ & & 2200 & 1.62 & 4.94 & 6.37 & -2.69 & 989 & 66.1 & 0.55 \\
\hline $2689-28 \mathrm{D}$ & SEPT 29 & 200 & 1.59 & 6.55 & 5.60 & -2.02 & 1013 & 54.2 & 0.57 \\
\hline $2689-28 \mathrm{~F}$ & & 600 & 1.72 & 6.63 & 5.26 & -4.72 & 1003 & 52.6 & 0.50 \\
\hline $2689-29 B$ & & 1000 & 1.72 & 6.74 & 5.14 & -4.72 & 1016 & 48.1 & 0.59 \\
\hline 2689-29D1 & & 1400 & 1.76 & 6.28 & 6.45 & -5.45 & 1019 & 58.1 & 0.55 \\
\hline $2689-29 \mathrm{D} 2$ & & 1800 & 1.71 & 6.19 & 6.69 & -4.47 & 1015 & 61.9 & 0.55 \\
\hline
\end{tabular}


ELTECH BATH ANALYSIS

\begin{tabular}{|c|c|c|c|c|c|c|c|c|c|}
\hline SAMPLE ID & DATE & TIME & RATIO & $\begin{array}{c}\mathrm{CaF}_{2} \\
\%\end{array}$ & $\begin{array}{c}\mathrm{Al}_{2} \mathrm{O}_{3} \\
\%\end{array}$ & $\begin{array}{c}\text { EXCESS ALF } \\
\%\end{array}$ & $\begin{array}{r}\text { BATH TEMP } \\
\text { DEG C }\end{array}$ & $\begin{array}{r}\text { ALUMINA } \\
\text { SAT \% }\end{array}$ & $\begin{array}{c}\mathrm{CeF}_{3} \\
\%\end{array}$ \\
\hline $2689-30 B$ & & 2200 & 1.71 & 5.90 & 10.26 & -4.31 & 1033 & 85.8 & 0.59 \\
\hline $2689-30 D$ & SEPT 30 & 200 & 1.73 & 5.12 & 11.10 & -4.68 & 1061 & 78.3 & 0.60 \\
\hline $2689-30 \mathrm{~F}$ & & 600 & 1.77 & 5.20 & 9.71 & -5.50 & 1052 & 71.0 & 0.60 \\
\hline $2689-31 B$ & & 1000 & 1.78 & 5.04 & 7.44 & -5.84 & 1037 & $\underline{58.3}$ & 0.63 \\
\hline $2689-31 D$ & & 1400 & 1.48 & 4.66 & 7.07 & 0.47 & 1004 & 68.7 & 0.57 \\
\hline $2689-32 B$ & & 1800 & 1.46 & 4.12 & 3.51 & 0.93 & 1043 & 75.9 & 0.66 \\
\hline $2689-32 D$ & & 2200 & 1.53 & 4.04 & 11.55 & -0.66 & 1024 & 98.8 & 0.69 \\
\hline $2689-33 B$ & OCT 1 & 200 & 1.59 & 4.03 & 10.43 & -1.97 & 1059 & 74.4 & 0.64 \\
\hline $2689-33 D$ & & 600 & 1.61 & 4.12 & 10.29 & -2.39 & 1058 & 73.6 & 0.61 \\
\hline $2689-34 \mathrm{~A}$ & & 1000 & 1.54 & 4.29 & 11.25 & -0.88 & 1016 & 100.7 & 0.56 \\
\hline $2689-34 C$ & & 1400 & 1.53 & 4.39 & 9.97 & -0.67 & 1024 & 86.3 & 0.53 \\
\hline $2689-35 B$ & & 1800 & 1.47 & 4.21 & 9.86 & 0.69 & 1012 & 91.0 & 0.58 \\
\hline $2689-35 D$ & & 2200 & 1.45 & 4.12 & 10.17 & 1.16 & 1018 & 91.3 & 0.59 \\
\hline $2689-36 B$ & OCT 2 & 200 & 1.36 & 4.11 & 8.57 & 3.43 & 1006 & 82.9 & 0.47 \\
\hline $2689-36 D$ & & 600 & 1.35 & 4.39 & 9.06 & 3.66 & 1006 & 88.6 & 0.49 \\
\hline $2689-36 E$ & & 1000 & 1.37 & 4.39 & 12.31 & 3.03 & 1018 & 113.4 & \\
\hline $2689-36 \mathrm{H}$ & & 1400 & 1.39 & 4.22 & 10.70 & 2.60 & 1016 & 98.5 & 0.43 \\
\hline $2689-37 B$ & & 1800 & 1.41 & 4.57 & 11.59 & 2.07 & 1041 & 96.0 & 0.51 \\
\hline $2689-37 D$ & & 2200 & 1.44 & 4.86 & 12.07 & 1.35 & 1035 & 102.8 & 0.46 \\
\hline $2689-38 B$ & OCT 3 & 200 & 1.50 & 5.30 & 12.49 & 0.00 & 1038 & 104.8 & 0.49 \\
\hline $2689-38 D$ & & 600 & 1.49 & 5.56 & 12.33 & 0.22 & 1043 & 102.2 & 0.46 \\
\hline $2689-38 F$ & & 1000 & 1.49 & 5.38 & 8.80 & 0.23 & 1031 & 76.7 & 0.51 \\
\hline $2689-38 \mathrm{H}$ & & 1400 & 1.48 & 5.29 & 10.30 & 0.45 & 1020 & 94.5 & 0.42 \\
\hline $2689-39 B$ & & 1800 & 1.48 & 5.12 & 12.52 & 0.44 & 1038 & 105.0 & 0.50 \\
\hline $2689-39 D$ & & 2200 & 1.47 & 5.13 & 12.31 & 0.66 & 1011 & 117.5 & 0.53 \\
\hline $2689-39 F$ & OCT 4 & 200 & 1.41 & 0.12 & 0.98 & 2.45 & 379 & 9.4 & 0.60 \\
\hline $2689-40 B$ & & 600 & 1.41 & 4.86 & 9.45 & 2.12 & 993 & 98.6 & 0.60 \\
\hline $2689-40 C$ & & 1000 & 1.43 & 5.02 & 6.62 & 1.69 & 1023 & 60.1 & 0.55 \\
\hline $2689-40 F$ & & 1400 & 1.50 & 4.76 & 12.26 & 0.00 & 1039 & 100.7 & 0.42 \\
\hline $2689-41 B$ & & 1800 & 1.59 & 4.67 & 10.79 & -1.95 & 1031 & 89.9 & 0.40 \\
\hline $2689-41 D$ & & 2200 & 1.69 & 4.77 & 12.28 & -3.88 & 1044 & 94.2 & 0.35 \\
\hline $2689-42 B$ & OCT 5 & 200 & 1.73 & 4.40 & 14.70 & -4.52 & 1072 & 96.3 & 0.35 \\
\hline $2689-43 B$ & & 600 & 1.63 & 4.39 & 13.05 & -2.70 & 1073 & 87.4 & 0.35 \\
\hline $2689-43 D$ & & 1000 & 1.69 & 4.21 & 11.31 & -3.95 & 1034 & 89.5 & 0.44 \\
\hline $2689-43 F$ & & 1400 & 1.64 & 4.31 & 9.44 & -3.03 & 1041 & 73.1 & 0.39 \\
\hline $2689-44 A$ & & 1800 & 1.61 & 4.93 & 10.68 & -2.36 & 1021 & 93.9 & 0.39 \\
\hline $2689-44 D$ & & 2200 & 1.63 & 4.75 & 9.83 & -2.80 & 1019 & 86.5 & 0.34 \\
\hline $2689-45 B$ & OCT 6 & 200 & 1.61 & 4.94 & 10.75 & -2.35 & 1026 & 92.2 & 0.41 \\
\hline $2689-45 D$ & & 600 & 1.68 & 4.83 & 8.98 & -3.84 & 1024 & 76.4 & 0.41 \\
\hline $2689-45 F$ & & 1000 & 1.64 & 6.10 & 7.31 & -3.04 & 1021 & 66.3 & 0.61 \\
\hline $2689-45 \mathrm{H}$ & & 1400 & 1.61 & 5.48 & 8.82 & -2.39 & 1017 & 80.5 & 0.55 \\
\hline $2689-46 B$ & & 1800 & 1.28 & 4.49 & 9.14 & 5.52 & 1024 & 84.3 & 0.57 \\
\hline $2689-46 D$ & & 2200 & 1.11 & 4.50 & 9.07 & 10.59 & 1025 & 88.5 & 0.62 \\
\hline $2689-47 B$ & OCT 7 & 200 & 1.17 & 4.32 & 9.10 & 8.73 & 1018 & 88.6 & 0.56 \\
\hline $2689-47 D$ & & 600 & 1.19 & 4.59 & 9.61 & 8.05 & 1034 & 88.0 & 0.61 \\
\hline
\end{tabular}




\section{ELTECH BATH ANALYSIS}

\begin{tabular}{|c|c|c|c|c|c|c|c|c|c|}
\hline \multirow[t]{2}{*}{ SAMPLE ID } & \multirow[t]{2}{*}{ DATE } & \multirow[t]{2}{*}{ TIME } & \multirow[t]{2}{*}{ RATIO } & \multirow{2}{*}{$\begin{array}{c}\mathrm{CaF}_{2} \\
\%\end{array}$} & \multirow{2}{*}{$\begin{array}{c}\mathrm{Ab}_{2} \mathrm{O}_{3} \\
\%\end{array}$} & \multicolumn{2}{|c|}{ EXCESS ALF ${ }_{3}$ BATH TEMP } & \multirow{2}{*}{$\begin{array}{r}\text { ALUMINA } \\
\text { SAT \% }\end{array}$} & \multirow{2}{*}{$\begin{array}{c}\mathrm{CeF}_{3} \\
\%\end{array}$} \\
\hline & & & & & & $\%$ & DEG C & & \\
\hline $2689-47 F$ & & 1000 & 1.26 & 4.40 & 7.51 & 6.20 & 1015 & 72.3 & 0.65 \\
\hline $2689-48 B$ & & 1400 & 1.29 & 4.30 & 8.69 & 5.29 & 1029 & 77.8 & 0.69 \\
\hline $2689-48 D$ & & 1800 & 1.17 & 4.05 & 10.59 & 8.60 & 1033 & 96.3 & 0.51 \\
\hline $2689-48 \mathrm{~F}$ & & 2200 & 1.11 & 4.21 & 9.71 & 10.55 & 1019 & 95.9 & 0.52 \\
\hline $2689-49 B$ & OCT 8 & 200 & 1.07 & 4.30 & 9.89 & 11.81 & 1044 & 91.1 & 0.49 \\
\hline $2689-49 D$ & & 600 & 1.14 & 4.04 & 10.68 & 9.51 & 1046 & 93.6 & 0.51 \\
\hline $2689-49 E$ & & 1000 & 1.10 & 4.23 & 11.45 & 10.64 & 1031 & 108.4 & 0.34 \\
\hline $2689-49 G$ & & 1400 & 1.11 & 4.49 & 11.25 & 10.32 & 1052 & 99.1 & 0.37 \\
\hline $2689-50 B$ & & 1800 & 1.16 & 3.77 & 10.79 & 8.91 & 1036 & 96.5 & 0.38 \\
\hline $2689-50 \mathrm{D}$ & & 2200 & 1.17 & 4.04 & 11.03 & 8.56 & 1039 & 97.9 & 0.45 \\
\hline $2689-50 F$ & OCT 9 & 200 & 1.18 & 4.22 & 11.26 & 8.22 & 1046 & 97.5 & 0.44 \\
\hline $2689-51 B$ & & 600 & 1.17 & 4.49 & 10.93 & 8.52 & 1032 & 101.1 & 0.44 \\
\hline $2689-51 D$ & & 1000 & 1.22 & 4.75 & 10.77 & 7.06 & 1046 & 93.4 & 0.46 \\
\hline $2689-51 F$ & & 1400 & 1.23 & 4.05 & 12.02 & 6.73 & 1035 & 106.0 & 0.49 \\
\hline $2689-51 \mathrm{H}$ & & 1800 & 1.21 & 4.22 & 12.72 & 7.22 & 1042 & 110.4 & 0.38 \\
\hline $2689-51 \mathrm{~J}$ & & 2200 & 1.23 & 4.31 & 12.57 & 6.67 & 1051 & 104.8 & 0.40 \\
\hline $2689-52 B$ & OCT 10 & 200 & 1.14 & 4.05 & 11.86 & 9.37 & 1043 & 104.9 & 0.42 \\
\hline $2689-52 D$ & & 600 & 1.14 & 4.49 & 10.55 & 9.47 & 1044 & 94.5 & 0.42 \\
\hline $2689-52 G$ & & 1000 & 1.02 & 3.77 & 10.09 & 13.57 & 1029 & 98.9 & 0.45 \\
\hline $2689-53 B$ & & 1400 & 1.06 & 4.04 & 11.40 & 11.97 & 1000 & 122.4 & 0.55 \\
\hline
\end{tabular}


APPENDIX B

Metal Impurities

-69 . 
METAL ANALYSIS

\begin{tabular}{|c|c|c|c|c|c|c|}
\hline Sample ID & Date & Time & $\mathrm{Ni}, \%$ & $\mathrm{Fe}, \%$ & $\mathrm{Cu}, \%$ & $\mathrm{C} \theta, \%$ \\
\hline $2687-30 \mathrm{~B}$ & & 1400 & 0.58 & 0.76 & 0.48 & \\
\hline $2687-31 B$ & & 2200 & 0.90 & 1.14 & 0.79 & \\
\hline $2687-31 D$ & AUG 31 & 600 & 0.74 & 1.12 & 0.63 & \\
\hline $2687-33 B$ & & 2200 & 0.75 & 1.18 & 0.65 & \\
\hline $2687-34 A$ & SEPT 1 & 600 & 0.75 & 1.25 & 0.64 & \\
\hline $2687-35 B$ & & 1400 & 0.78 & 1.29 & 0.67 & \\
\hline $2687-36 A$ & & 2200 & 0.75 & 1.24 & 0.64 & \\
\hline $2687-37 A$ & SEPT 2 & 600 & 0.75 & 1.25 & 0.63 & \\
\hline $2687-38 A$ & & 1400 & 0.80 & 1.38 & 0.67 & \\
\hline $2687-38 D$ & & 2200 & 0.81 & 1.44 & 0.68 & \\
\hline $2687-39 A$ & SEPT 3 & 600 & 0.82 & 1.53 & 0.69 & \\
\hline $2687-39 c$ & & 1400 & 0.83 & 1.53 & 0.64 & \\
\hline $2687-40 B$ & & 2200 & 0.81 & 1.57 & 0.62 & \\
\hline $2687-41 A$ & SEPT 4 & 600 & 0.81 & 1.59 & 0.63 & \\
\hline $2687-41 C$ & & 1400 & 0.78 & 1.54 & 0.61 & \\
\hline $2687-42 A$ & & 2200 & 0.75 & 1.54 & 0.56 & \\
\hline $2687-42 D$ & SEPT 5 & 600 & 0.72 & 1.50 & 0.55 & \\
\hline $2687-43 A$ & & 1400 & 0.69 & 1.53 & 0.47 & \\
\hline $2687-43 C$ & & 2200 & 064 & 1.55 & 0.43 & \\
\hline $2687-44 A$ & SEPT 6 & 600 & 0.58 & 1.55 & 0.38 & \\
\hline $2687-44 C$ & & 1400 & 0.57 & 1.94 & 0.37 & \\
\hline $2687-45 A$ & & 2200 & 0.46 & 1.33 & 0.29 & \\
\hline $2687-45 C$ & SEPT 7 & 600 & 0.42 & 1.24 & 0.26 & \\
\hline $2687-46 A$ & & 1400 & 0.30 & 1.04 & 0.19 & \\
\hline $2687-46 C$ & & 2200 & 0.26 & 0.94 & 0.17 & \\
\hline $2687-47 A$ & SEPT 8 & 600 & 0.23 & 0.85 & 0.14 & \\
\hline $2687-47 C$ & & 1400 & 0.20 & 0.75 & 0.11 & \\
\hline $2687-48 A$ & & 2200 & 0.16 & 0.71 & 0.09 & \\
\hline $2687-49 A$ & SEPT 9 & 600 & 0.13 & 0.60 & 0.07 & \\
\hline $2687-50 B$ & & 1100 & 0.13 & 0.59 & 0.07 & 1.15 \\
\hline $2687-50 F$ & & 1400 & 0.12 & 0.57 & 0.06 & 1.62 \\
\hline $2687-5 i G$ & & 1800 & 0.12 & 0.89 & 0.06 & 2.20 \\
\hline $2687-52 B$ & & 2200 & 0.12 & 0.58 & 0.06 & 2.21 \\
\hline $2687-52 D$ & SEPT 10 & 200 & 0.12 & 0.60 & 0.06 & 2.28 \\
\hline $2687-53 B$ & & 600 & 0.10 & 0.56 & 0.05 & 2.17 \\
\hline 2687-53D & & 1000 & 0.10 & 0.58 & 0.06 & 2.18 \\
\hline $2687-53 F$ & & 1400 & 0.08 & 0.52 & 0.05 & 2.06 \\
\hline $2687-54 F$ & & 1800 & 0.08 & 0.50 & 0.05 & 2.13 \\
\hline $2687-54 \mathrm{H}$ & & 2200 & 0.08 & 0.47 & 0.04 & 2.25 \\
\hline $2687-55 A$ & SEPT 11 & 200 & 0.06 & 0.47 & 0.04 & 2.09 \\
\hline $2687-55 C$ & & 600 & 0.06 & 0.46 & 0.04 & 2.02 \\
\hline $2687-56 B$ & & 1000 & 0.07 & 0.46 & 0.03 & 1.84 \\
\hline $2687-56 C$ & & 1400 & 0.07 & 0.46 & 0.03 & 2.20 \\
\hline $2687-57 F$ & & 1800 & 0.05 & 0.47 & 0.04 & 1.71 \\
\hline $2687-57 \mathrm{H}$ & & 2200 & 0.06 & 0.44 & 0.04 & 2.55 \\
\hline $2687-58 A$ & SEPT 12 & 200 & 0.05 & 0.46 & 0.04 & 2.57 \\
\hline
\end{tabular}


METAL ANALYSIS

\begin{tabular}{|c|c|c|c|c|c|c|}
\hline Sample ID & Date & Time & $\mathrm{Ni}, \%$ & Fe, \% & $\mathrm{Cu}, \%$ & $\mathrm{Ce}, \%$ \\
\hline $2687-58 C$ & & 600 & 0.05 & 0.44 & 0.04 & 2.93 \\
\hline $2687-59 A$ & & 1000 & 0.04 & 0.41 & 0.04 & 2.89 \\
\hline $2687-60 B$ & & 1400 & 0.04 & 0.40 & 0.03 & 2.93 \\
\hline $2687-60 C$ & & 1800 & 0.04 & 0.43 & 0.03 & 2.81 \\
\hline $2687-61 A$ & & 2200 & 0.04 & 0.44 & 0.03 & 2.82 \\
\hline $2687-61 C$ & SEPT 13 & 200 & 0.03 & 0.48 & 0.03 & 2.49 \\
\hline $2687-61 E$ & & 600 & 0.03 & 0.43 & 0.02 & 2.56 \\
\hline $2687-61 G$ & & 1000 & & & & 2.77 \\
\hline $2687-62 B$ & & 1400 & & & & 2.80 \\
\hline $2687-63 A$ & & 1800 & & & & 2.82 \\
\hline $2687-63 C$ & & 2200 & & & & 2.85 \\
\hline $2687-64 A$ & SEPT 14 & 200 & 0.04 & 0.45 & 0.03 & 2.84 \\
\hline $2687-65 A$ & & 600 & 0.03 & 0.44 & 0.02 & 2.65 \\
\hline $2687-65 D$ & & 1000 & & & & 2.52 \\
\hline $2687-65 F$ & & 1200 & & & & 2.62 \\
\hline $2687-66 \mathrm{~B}$ & & 1300 & & & & 2.70 \\
\hline $2687-66 D$ & & 1330 & & & & 2.52 \\
\hline $2687-66 \mathrm{D} 1$ & & 1400 & & & & 2.75 \\
\hline $2687-66 \mathrm{~F}$ & & 1430 & & & & 2.73 \\
\hline $2687-67 A$ & & 1500 & & & & 2.50 \\
\hline $2687-67 C$ & & 1530 & & & & 2.86 \\
\hline 2687-67E & & 1600 & & & & 2.67 \\
\hline $2687-67 G$ & & 1630 & & & & 2.55 \\
\hline $2687-67 \mid$ & & 1640 & & & & 2.72 \\
\hline $2687-67 \mathrm{~J}$ & & 1640 & & & & 2.74 \\
\hline $2687-67 \mathrm{~K}$ & & 1640 & & & & 2.76 \\
\hline $2687-67 L$ & & 1640 & & & & 2.76 \\
\hline $2687-68 A$ & & 1730 & & & & 2.81 \\
\hline $2687-68 C$ & & 1800 & & & & 2.77 \\
\hline $2687-68 E$ & & 2200 & & & & 2.64 \\
\hline $2687-68 G$ & SEPT 15 & 200 & 0.10 & 0.53 & 0.06 & 2.61 \\
\hline $2687-69 A$ & & 600 & 0.11 & 0.52 & 0.06 & 2.90 \\
\hline $2687-69 C$ & & 1000 & & & & 3.04 \\
\hline $2687-69 F$ & & 1200 & & & & 3.31 \\
\hline $2687-70 A$ & & 1245 & & & & 3.36 \\
\hline $2687-70 \mathrm{C}$ & & 1330 & & & & 3.41 \\
\hline $2687-70 E$ & & 1400 & & & & 3.36 \\
\hline $2687-70 G$ & & 1430 & & & & 3.56 \\
\hline $2687-701$ & & 1500 & & & & 3.61 \\
\hline $2687-70 K$ & & 1530 & & & & 3.63 \\
\hline $2687-70 M$ & & 1600 & & & & 3.33 \\
\hline $2687-71 A$ & & 1700 & & & & 3.69 \\
\hline $2687-71 C$ & & 1800 & 0.17 & 0.56 & 0.08 & 3.68 \\
\hline $2687-71 E$ & & 1900 & & & & 3.71 \\
\hline $2687-71 G$ & & 2000 & & & & 3.80 \\
\hline $2687-71 \mathrm{~J}$ & & 2100 & & & & 3.75 \\
\hline
\end{tabular}


METAL ANALYSIS

\begin{tabular}{|c|c|c|c|c|c|c|}
\hline Sample ID & Date & Time & $\mathrm{Ni}, \%$ & $\mathrm{Fe}, \%$ & $\mathrm{Cu}, \%$ & $\mathrm{Ce}, \%$ \\
\hline $2687-72 A$ & & 2200 & 0.21 & 0.56 & 0.10 & 3.70 \\
\hline $2687-72 C$ & SEPT 16 & 0 & & & & 3.61 \\
\hline $2687-72 E$ & & 200 & 0.23 & 0.58 & 0.12 & 3.72 \\
\hline $2687-73 A$ & & 400 & & & & 3.65 \\
\hline $2687-73 C$ & & 600 & 0.24 & 0.61 & 0.13 & 3.73 \\
\hline $2687-73 E$ & & 800 & & & & 3.68 \\
\hline $2687-73 G$ & & 1000 & 0.23 & 0.58 & 0.12 & 3.56 \\
\hline $2687-731$ & & 1400 & & & & 3.35 \\
\hline $2687-74 A$ & & 1800 & 0.25 & 0.60 & 0.14 & 3.40 \\
\hline $2687-74 C$ & & 2200 & 0.24 & 0.61 & 0.14 & 3.14 \\
\hline $2687-75 A$ & SEPT 17 & 200 & 0.24 & 0.63 & 0.14 & 3.28 \\
\hline $2687-75 C$ & & 600 & 0.38 & 0.78 & 0.30 & 2.42 \\
\hline $2687-75 F$ & & 1000 & 0.26 & 0.56 & 0.15 & 3.24 \\
\hline $2687-75 \mathrm{H}$ & & 1400 & 0.24 & 0.60 & 0.15 & 2.80 \\
\hline $2689-1 B$ & & 1800 & 0.24 & 0.57 & 0.15 & 3.00 \\
\hline $2689-2 B$ & & 2200 & 0.28 & 0.63 & 0.19 & 2.79 \\
\hline $2689-2 E$ & SEPT 18 & 600 & 0.24 & 0.84 & 0.16 & 2.80 \\
\hline $2689-2 F$ & & 1000 & 0.24 & 0.81 & 0.18 & 2.73 \\
\hline $2689-3 A$ & & 1400 & 0.25 & 0.59 & 0.18 & 2.42 \\
\hline $2689-3 C$ & & 1800 & 0.23 & 0.66 & 0.17 & 2.26 \\
\hline $2689-4 A$ & & 2200 & 0.22 & 0.64 & 0.16 & 2.54 \\
\hline $2689-4 C$ & SEPT 19 & 200 & 0.23 & 0.60 & 0.16 & 3.03 \\
\hline $2689-4 E$ & & 600 & 0.21 & 0.60 & 0.15 & 2.93 \\
\hline $2689-4 G$ & & 1000 & 0.18 & 0.71 & 0.14 & 2.18 \\
\hline $2689-5 A$ & & 1400 & 0.22 & 0.95 & 0.17 & 2.00 \\
\hline $2689-5 C$ & & 1800 & 0.20 & 0.62 & 0.15 & 2.94 \\
\hline $2689-5 E$ & & 2200 & 0.19 & 0.63 & 0.14 & 2.96 \\
\hline $2689-6 A$ & SEPT 20 & 200 & 0.20 & 0.57 & 0.15 & 2.92 \\
\hline $2689-6 C$ & & 600 & 0.22 & 0.61 & 0.17 & 2.86 \\
\hline $2689-6 F$ & & 1000 & 0.85 & 0.74 & 0.51 & 2.82 \\
\hline $2689-6 G$ & & 1400 & 0.28 & 0.55 & 0.17 & 2.91 \\
\hline $2689-7 A$ & & 1800 & 0.33 & 0.58 & $0 .: 9$ & 2.96 \\
\hline $2689-7 C$ & & 2200 & 0.27 & 0.53 & 0.16 & 2.97 \\
\hline $2689-8$ & SEPT 21 & 200 & 0.26 & 0.53 & 0.16 & 2.97 \\
\hline $2689-8 C$ & & 600 & 0.27 & 0.55 & 0.16 & 3.04 \\
\hline $2689-8 F$ & & 1000 & 0.28 & 0.55 & 0.17 & 2.97 \\
\hline $2689-9 B$ & & 1400 & 0.27 & 0.54 & 0.17 & 2.90 \\
\hline $2689-9 C$ & & 1800 & 0.47 & 0.56 & 0.28 & 2.87 \\
\hline $2689-9 E$ & & 2200 & 0.28 & 0.53 & 0.16 & 2.99 \\
\hline $2689-10 A$ & SEPT 22 & 200 & 0.30 & 0.55 & 0.18 & 2.89 \\
\hline $2689-10 C$ & & 600 & 0.30 & 0.56 & 0.17 & 2.91 \\
\hline $2689-11 A$ & & 1000 & 0.31 & 0.57 & 0.19 & 2.71 \\
\hline $2689-11 C$ & & 1400 & 0.32 & 0.63 & 0.19 & 2.44 \\
\hline 2689-\{1E & & 1800 & 0.57 & 0.65 & 0.36 & 2.60 \\
\hline $2689-11 G$ & & 2200 & 0.31 & 0.53 & 0.18 & 2.71 \\
\hline $2689-12 A$ & SEPT 23 & 200 & 0.30 & 0.49 & 0.17 & 2.66 \\
\hline
\end{tabular}


METAL ANALYSIS

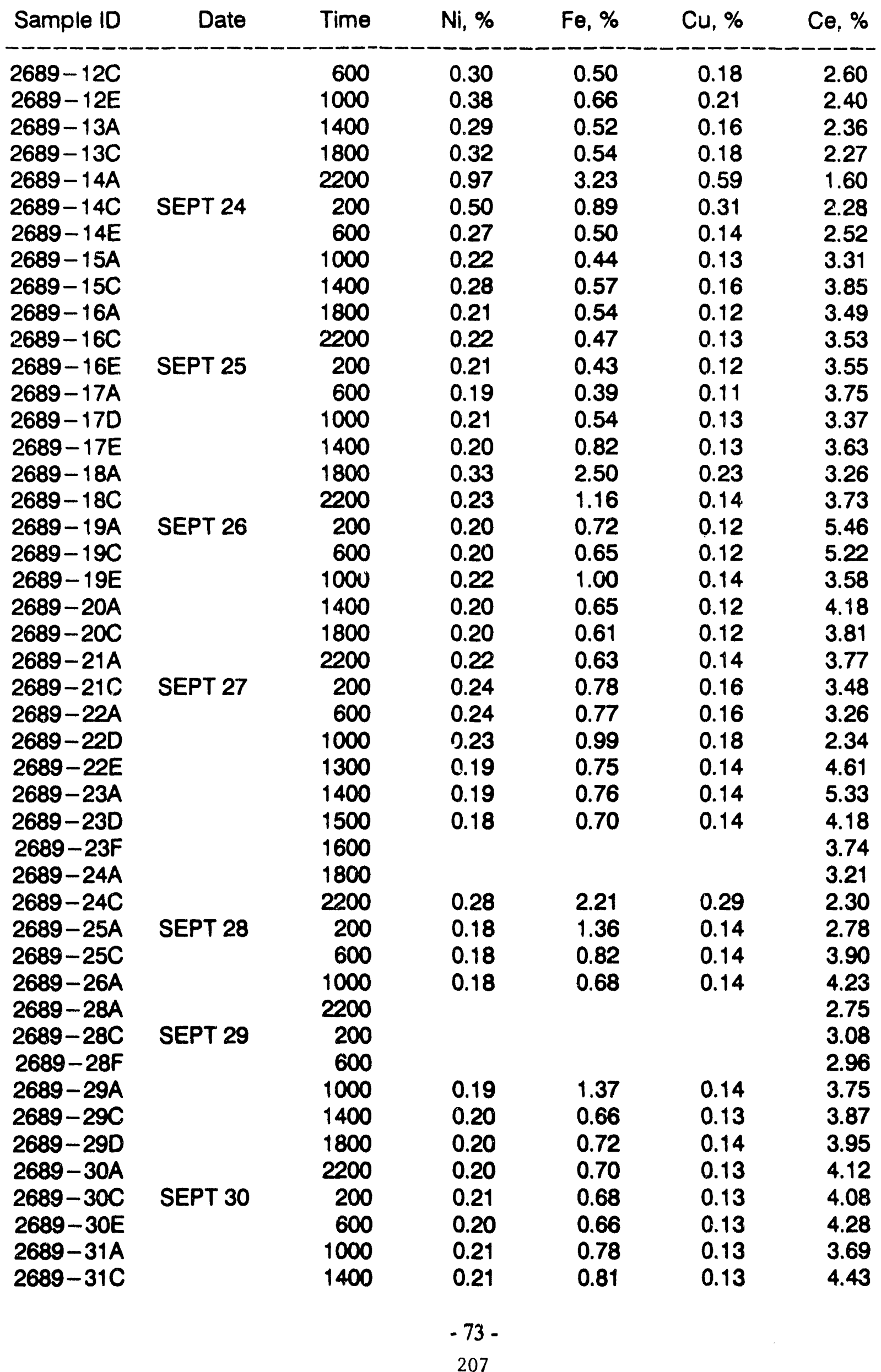


METAL ANALYSIS

\begin{tabular}{lrrrrrr} 
Sample ID & Date & Time & Ni, \% & Fe, \% & Cu, \% & Ce, \% \\
\hline $2689-32 A$ & & 1800 & 0.24 & 1.00 & 0.15 & 4.39 \\
$2689-32 C$ & & 2200 & 0.29 & 0.93 & 0.17 & 4.63 \\
$2689-33 A$ & OCT 1 & 200 & 0.34 & 0.82 & 0.20 & 4.59 \\
$2689-33 C$ & & 600 & 0.37 & 0.83 & 0.22 & 5.17 \\
$2689-34 B$ & & 1000 & 0.40 & 0.91 & 0.24 & \\
$2689-34 D$ & & 1400 & 0.38 & 1.25 & 0.22 & \\
$2689-35 A$ & & 1800 & 0.37 & 0.91 & 0.21 & 4.41 \\
$2689-35 C$ & & 2200 & 0.34 & 0.80 & 0.20 & 4.72 \\
$2689-36 A$ & OCT 2 & 200 & 0.34 & 0.85 & 0.19 & 4.68 \\
$2689-36 C$ & & 600 & 0.33 & 0.82 & 0.19 & 5.08 \\
$2689-36 F$ & & 1000 & 0.35 & 0.78 & 0.18 & 4.15 \\
$2689-36 G$ & & 1400 & 0.35 & 2.16 & 0.19 & 3.88 \\
$2689-37 A$ & & 1800 & 0.35 & 0.84 & 0.18 & 4.64 \\
$2689-37 C$ & & 2200 & 0.34 & 0.81 & 0.18 & 4.31 \\
$2689-38 A$ & OCT 3 & 200 & 0.33 & 0.81 & 0.17 & 4.39 \\
$2689-38 C$ & & 600 & 0.33 & 0.81 & 0.17 & 4.29 \\
$2689-38 E$ & & 1000 & 0.30 & 0.82 & 0.17 & 3.80 \\
$2689-38 G$ & & 1400 & 0.29 & 0.83 & 0.16 & 3.86 \\
$2689-39 A$ & & 1800 & 0.28 & 0.79 & 0.16 & 3.88 \\
$2689-39 C$ & & 2200 & 0.28 & 0.76 & 0.15 & 4.01 \\
$2689-39 E$ & OCT 4 & 200 & 0.28 & 0.92 & 0.16 & 3.74 \\
$2689-40 A$ & & 600 & 0.32 & 1.08 & 0.19 & 3.33 \\
$2689-40 D$ & & 1000 & 0.51 & 2.03 & 0.33 & 2.15 \\
$2689-40 E$ & & 1400 & 0.40 & 0.98 & 0.26 & 2.86 \\
$2689-41 A$ & & 1800 & 0.33 & 0.76 & 0.17 & 3.14 \\
$2689-41 C$ & & 2200 & 0.38 & 0.79 & 0.20 & 3.11 \\
$2689-42 A$ & OCT 5 & 200 & 0.38 & 0.78 & 0.20 & 3.10 \\
$2689-43 A$ & & 600 & 0.40 & 0.80 & 0.21 & 3.14 \\
$2689-43 C$ & & 1000 & 0.35 & 0.83 & 0.21 & 3.09 \\
$2689-43 E$ & & 1400 & 0.36 & 0.75 & 0.20 & 3.09 \\
$2689-44 B$ & & 1800 & 0.36 & 0.82 & 0.20 & 3.10 \\
$2689-44 C$ & & 2200 & 0.37 & 0.77 & 0.21 & 3.20 \\
$2689-45 A$ & OCT 6 & 200 & 0.37 & 0.81 & 0.21 & 3.18 \\
$2689-45 C$ & & 600 & 0.35 & 0.72 & 0.19 & 3.49 \\
$2689-45 E$ & & 1000 & 0.40 & 0.84 & 0.24 & 4.01 \\
$2689-45 G$ & & 1400 & 0.37 & 0.81 & 0.21 & 4.00 \\
$2689-46 A$ & & 1800 & 0.38 & 0.94 & 0.22 & 4.07 \\
$2689-46 C$ & & 2200 & 0.40 & 0.94 & 0.23 & 4.06 \\
$2689-47 A$ & OCT 7 & 200 & 0.51 & 1.66 & 0.38 & 2.86 \\
$2689-47 C$ & & 600 & 0.47 & 1.04 & 0.31 & 3.23 \\
$2689-47 E$ & & 1000 & 0.36 & 2.35 & 0.24 & 2.78 \\
$2689-48 A$ & & 1400 & 0.32 & 1.08 & 0.21 & 3.17 \\
$2689-48 C$ & & 1800 & 0.31 & 0.85 & 0.19 & 3.49 \\
$2689-48 E$ & & 2200 & 0.32 & 0.82 & 0.20 & 4.13 \\
$2689-49 A$ & OCT 8 & 200 & 0.30 & 0.79 & 0.18 & 4.14 \\
$2689-49 C$ & & 600 & 0.30 & 1.40 & 0.19 & 3.89
\end{tabular}


METAL ANALYSIS

\begin{tabular}{ccccccc} 
Sample ID & Date & Time & $\mathrm{Ni}, \%$ & $\mathrm{Fe}, \%$ & $\mathrm{Cu}, \%$ & $\mathrm{Ce}, \%$ \\
\hline $2689-49 \mathrm{~F}$ & & 1000 & 0.30 & 0.80 & 0.18 & 4.25 \\
$2689-49 \mathrm{H}$ & & 1400 & 0.30 & 0.89 & 0.18 & 4.34 \\
$2689-50 \mathrm{~A}$ & & 1800 & 0.31 & 1.07 & 0.19 & 4.68 \\
$2689-50 \mathrm{C}$ & & 2200 & 0.31 & 0.88 & 0.18 & 4.84 \\
$2689-50 \mathrm{E}$ & OCT 9 & 200 & 0.29 & 1.51 & 0.18 & 4.16 \\
$2689-51 \mathrm{~A}$ & & 600 & 0.28 & 2.22 & 0.17 & 4.68 \\
$2689-51 \mathrm{C}$ & & 1000 & 0.59 & 3.02 & 0.42 & 3.16 \\
$2689-51 \mathrm{E}$ & & 1400 & 0.37 & 1.63 & 0.20 & 3.72 \\
$2689-51 \mathrm{G}$ & & 1800 & 0.38 & 1.83 & 0.22 & 3.24 \\
$2689-511$ & & 2200 & 0.45 & 2.46 & 0.25 & 2.51 \\
$2689-52 \mathrm{~A}$ & OCT 10 & 200 & 0.33 & 2.01 & 0.18 & 3.52 \\
$2689-52 \mathrm{C}$ & & 600 & 0.31 & 1.11 & 0.17 & 3.81 \\
$2689-52 \mathrm{E}$ & & 700 & 0.33 & 1.02 & 0.18 & \\
$2689-52 \mathrm{~F}$ & & 1000 & 0.33 & 0.96 & 0.17 & \\
$2689-53 \mathrm{~A}$ & & 1400 & 0.52 & 5.36 & 0.31 & 2.92
\end{tabular}




\section{APPENDIX C}

\section{Bath Impurities}

$-70$.

210 
BATH IMPURITIES

\begin{tabular}{|c|c|c|c|c|c|}
\hline Sample ID & Date & Time & $\mathrm{Cu}, \%$ & $\mathrm{Ni}, \%$ & $\mathrm{Fe}, \%$ \\
\hline $2687-30 A$ & & 1400 & 0.005 & 0.017 & 0.060 \\
\hline $2687-31 C$ & & 1800 & 0.011 & 0.032 & 0.047 \\
\hline $2687-31 A$ & & 2200 & 0.002 & 0.009 & 0.025 \\
\hline $2687-32 B$ & AUG 31 & 1400 & 0.006 & 0.015 & 0.034 \\
\hline $2687-33 A$ & & 2200 & 0.003 & 0.008 & 0.048 \\
\hline $2687-34 B$ & SEPT 1 & 600 & 0.002 & 0.007 & 0.029 \\
\hline $2687-35 A$ & & 1400 & 0.002 & 0.007 & 0.029 \\
\hline $2687-36 B$ & & 2200 & 0.002 & 0.004 & 0.032 \\
\hline $2687-37 B$ & SEPT 2 & 600 & 0.002 & 0.007 & 0.029 \\
\hline $2687-38 C$ & & 1400 & 0.001 & 0.006 & 0.015 \\
\hline $2687-38 D$ & & 2200 & 0.001 & 0.007 & 0.019 \\
\hline $2687-39 B$ & SEPT 3 & 600 & 0.001 & 0.006 & 0.036 \\
\hline $2687-39 D$ & & 1400 & & & \\
\hline $2687-40 A$ & & 2200 & & & \\
\hline $2687-41 B$ & SEPT 4 & 600 & 0.001 & 0.005 & 0.016 \\
\hline $2687-41 D$ & & 1400 & & & \\
\hline $2687-42 B$ & & 2200 & & & \\
\hline $2687-42 D$ & SEPT 5 & 600 & 0.001 & 0.006 & 0.028 \\
\hline $2687-43 B$ & & 1400 & & & \\
\hline $2687-43 D$ & & 2200 & & & \\
\hline $2687-44 B$ & SEPT 6 & 600 & 0.001 & 0.005 & 0.031 \\
\hline $2687-44 D$ & & 1400 & & & \\
\hline $2687-45 B$ & & 2200 & & & \\
\hline 2687-45D & SEPT 7 & 600 & 0.001 & 0.006 & 0.032 \\
\hline $2687-46 B$ & & 1400 & & & \\
\hline $2687-46 D$ & & 2200 & & & \\
\hline $2687-47 B$ & SEPT 8 & 600 & 0.001 & 0.020 & 0.130 \\
\hline $2687-47 D$ & & 1400 & & & \\
\hline $2687-48 B$ & & 2200 & & & \\
\hline $2687-49 B$ & SEPT 9 & 600 & 0.001 & 0.005 & 0.023 \\
\hline $2687-50 A$ & & 1100 & & & \\
\hline $2687-50 C$ & & 1300 & & & \\
\hline $2687-50 E$ & & 1400 & & & \\
\hline $2687-51 \mathrm{H}$ & & 1800 & & & \\
\hline $2687-52 A$ & & 2200 & & & \\
\hline $2687-52 C$ & SEPT 10 & 200 & & & \\
\hline $2687-53 A$ & & 600 & & & \\
\hline $2687-53 C$ & & 1000 & & & \\
\hline $2687-53 E$ & & 1400 & & & \\
\hline $2687-54 E$ & & 1800 & & & \\
\hline $2687-54 G$ & & 2200 & & & \\
\hline 2687-55B & & 200 & & & \\
\hline 2687-55D & & 600 & & & \\
\hline $2687-56 A$ & & 1000 & & & \\
\hline $2687-56 D$ & & 1400 & & & \\
\hline 2687-57E & & 1800 & & & \\
\hline
\end{tabular}


BATH IMPURITIES

\begin{tabular}{|c|c|c|c|c|c|}
\hline Sample ID & Date & Time & $\mathrm{Cu}, \%$ & $\mathrm{Ni}, \%$ & $\mathrm{Fe}, \%$ \\
\hline $2687-57 G$ & & 2200 & & & \\
\hline $2687-58 B$ & SEPT 12 & 200 & & & \\
\hline $2687-58 D$ & & 600 & & & \\
\hline $2687-59 E$ & & 1000 & & & \\
\hline $2687-60 A$ & & 1400 & & & \\
\hline $2687-60 D$ & & 1800 & & & \\
\hline $2687-61 B$ & & 2200 & & & \\
\hline $2687-61 D$ & SEPT 13 & 200 & & & \\
\hline $2687-61 F$ & & 600 & & & \\
\hline $2687-61 H$ & & 1000 & & & \\
\hline $2687-62 A$ & & 1400 & & & \\
\hline $2687-63 B$ & & 1800 & 0.002 & 0.001 & 0.210 \\
\hline $2687-63 D$ & & 2200 & 0.002 & 0.001 & 0.210 \\
\hline $2687-64 B$ & SEPT 14 & 200 & 0.002 & 0.002 & 0.420 \\
\hline $2587-65 B$ & & 600 & 0.002 & 0.001 & 0.290 \\
\hline $2687-65 C$ & & 1000 & 0.003 & 0.001 & 0.210 \\
\hline $2687-65 E$ & & 1200 & & & \\
\hline $2687-66 A$ & & 1300 & & & \\
\hline $2687-66 C$ & & 1330 & & & \\
\hline $2687-66 C$ & & 1400 & 0.003 & 0.001 & 0.210 \\
\hline $2687-66 E$ & & 1430 & & & \\
\hline $2687-67 B$ & & 1500 & & & \\
\hline 2687-67D & & 1530 & & & \\
\hline $2687-67 F$ & & 1600 & & & \\
\hline $2687-67 \mathrm{H}$ & & 1630 & & & \\
\hline $2687-68 B$ & & 1730 & & & \\
\hline $2687-68 D$ & & 1800 & 0.004 & 0.004 & 0.060 \\
\hline $2687-68 F$ & & 2200 & 0.004 & 0.003 & 0.070 \\
\hline $2687-68 \mathrm{H}$ & SEPT 15 & 200 & 0.003 & 0.003 & 0.070 \\
\hline $2687-69 B$ & & 600 & 0.010 & 0.009 & 0.070 \\
\hline $2687-69 D$ & & 1000 & 0.003 & 0.002 & 0.060 \\
\hline $2687-69 E$ & & 1200 & & & \\
\hline $2687-70 B$ & & 1245 & & & \\
\hline $2687-70 D$ & & 1330 & & & \\
\hline $2687-70 F$ & & 1400 & 0.003 & 0.002 & 0.060 \\
\hline $2687-70 \mathrm{H}$ & & 1430 & & & \\
\hline $2687-70 \mathrm{~J}$ & & 1500 & & & \\
\hline $2687-70 \mathrm{~L}$ & & 1530 & & & \\
\hline $2687-70 \mathrm{~N}$ & & 1600 & & & \\
\hline $2687-71 B$ & & 1700 & & & \\
\hline $2687-71 D$ & & 1800 & 0.009 & 0.006 & 0.040 \\
\hline $2687-71 F$ & & 1900 & & & \\
\hline $2687-71 \mathrm{H}$ & & 2000 & & & \\
\hline $2687-711$ & & 2100 & & & \\
\hline $2687-72 B$ & & 2200 & 0.002 & 0.003 & 0.070 \\
\hline $2687-72 D$ & SEPT 16 & 0 & & & \\
\hline
\end{tabular}


BATH IMPURITIES

\begin{tabular}{|c|c|c|c|c|c|}
\hline Sample ID & Date & Time & $\mathrm{Cu}, \%$ & $\mathrm{Ni}, \%$ & $\mathrm{Fe}, \%$ \\
\hline $\begin{array}{l}2687-72 F \\
2687-73 B\end{array}$ & & $\begin{array}{l}200 \\
400\end{array}$ & 0.016 & 0.015 & 0.060 \\
\hline $\begin{array}{l}2687-73 D \\
2687-73 F\end{array}$ & & $\begin{array}{l}600 \\
800\end{array}$ & 0.003 & 0.005 & 0.060 \\
\hline $2687-73 \mathrm{H}$ & & 1000 & 0.002 & 0.004 & 0.050 \\
\hline $2687-73 \mathrm{~J}$ & & 1400 & & & \\
\hline $2687-74 B$ & & 1800 & 0.001 & 0.001 & 0.040 \\
\hline $2687-74 D$ & & 2200 & 0.001 & 0.002 & 0.040 \\
\hline $2687-75 B$ & SEPT 17 & 200 & 0.002 & 0.003 & 0.040 \\
\hline $2687-75 D$ & & 600 & 0.002 & 0.003 & 0.040 \\
\hline $2687-75 E$ & & 1000 & 0.001 & 0.005 & 0.050 \\
\hline $2687-75 G$ & & 1400 & 0.001 & 0.004 & 0.040 \\
\hline $2689-1 A$ & & 1800 & 0.001 & 0.004 & 0.040 \\
\hline $2689-2 A$ & & 2200 & 0.001 & 0.002 & 0.030 \\
\hline $2689-2 C$ & SEPT 18 & 200 & 0.002 & 0.004 & 0.050 \\
\hline $2689-2 D$ & & 600 & 0.002 & 0.003 & 0.040 \\
\hline $2689-2 G$ & & 1000 & 0.001 & 0.004 & 0.040 \\
\hline $2689-3 B$ & & 1400 & 0.001 & 0.004 & 0.040 \\
\hline $2689-3 D$ & & 1800 & 0.001 & 0.003 & 0.030 \\
\hline $2689-4 B$ & & 2200 & 0.001 & 0.003 & 0.040 \\
\hline $2689-4 D$ & SEPT 19 & 200 & 0.001 & 0.003 & 0.030 \\
\hline $2689-4 F$ & & 600 & 0.001 & 0.003 & 0.040 \\
\hline $2689-4 H$ & & 1000 & 0.001 & 0.001 & 0.030 \\
\hline $2689-5 B$ & & 1400 & 0.001 & 0.001 & 0.030 \\
\hline $2689-5 D$ & & 1800 & 0.001 & 0.001 & 0.020 \\
\hline $2689-5 F$ & & 2200 & 0.001 & 0.001 & 0.020 \\
\hline $2689-6 B$ & SEPT 20 & 200 & 0.001 & 0.001 & 0.020 \\
\hline $2689-6 D$ & & 600 & 0.002 & 0.002 & 0.020 \\
\hline $2689-6 E$ & & 1000 & 0.001 & 0.009 & 0.040 \\
\hline $2689-6 H$ & & 1400 & 0.005 & 0.005 & 0.020 \\
\hline $2689-7 B$ & & 1800 & 0.040 & 0.050 & 0.030 \\
\hline $2689-7 D$ & & 2200 & 0.003 & 0.002 & 0.020 \\
\hline $2689-8 B$ & SEPT 21 & 200 & 0.002 & 0.001 & 0.020 \\
\hline $2689-8 D$ & & 600 & 0.002 & 0.001 & 0.020 \\
\hline $2689-8 E$ & & 1000 & 0.004 & 0.003 & 0.020 \\
\hline $2689-9 A$ & & 1400 & 0.001 & 0.001 & 0.020 \\
\hline $2689-9 D$ & & 1800 & 0.001 & 0.001 & 0.020 \\
\hline $2689-9 F$ & & 2200 & 0.002 & 0.002 & 0.030 \\
\hline $2689-10 B$ & SEPT 22 & 200 & 0.002 & 0.002 & 0.030 \\
\hline $2689-10 D$ & & 600 & 0.002 & 0.004 & 0.030 \\
\hline $2689-11 B$ & & 1000 & 0.001 & 0.003 & 0.030 \\
\hline $2689-11 D$ & & 1400 & 0.002 & 0.003 & 0.030 \\
\hline $2689-11 F$ & & 1800 & 0.001 & 0.002 & 0.030 \\
\hline $2689-11 H$ & & 2200 & 0.002 & 0.002 & 0.030 \\
\hline $2689-12 B$ & SEPT 23 & 200 & 0.001 & 0.003 & 0.030 \\
\hline $2689-12 D$ & & 600 & 0.001 & 0.002 & 0.030 \\
\hline
\end{tabular}


BATH IMPURITIES

\begin{tabular}{|c|c|c|c|c|c|}
\hline Sample ID & Date & Time & $\mathrm{Cu}, \%$ & $\mathrm{Ni}, \%$ & $\mathrm{Fe}, \%$ \\
\hline $2689-12 F$ & & 1000 & 0.001 & 0.003 & 0.040 \\
\hline $2689-13 B$ & & 1400 & 0.001 & 0.002 & 0.040 \\
\hline $2689-13 D$ & & 1800 & 0.001 & 0.001 & 0.020 \\
\hline $2689-14 B$ & & 2200 & 0.002 & 0.002 & 0.030 \\
\hline $2689-14 D$ & SEPT 24 & 200 & 0.001 & 0.007 & 0.020 \\
\hline $2689-14 F$ & & 600 & 0.001 & 0.001 & 0.020 \\
\hline $2689-15 B$ & & 1000 & 0.002 & 0.001 & 0.020 \\
\hline $2689-15 D$ & & 1400 & 0.002 & 0.001 & 0.020 \\
\hline $2689-16 B$ & & 1800 & 0.001 & 0.001 & 0.020 \\
\hline $2689-16 D$ & & 2200 & 0.002 & 0.001 & 0.020 \\
\hline $2689-16 F$ & SEPT 25 & 200 & 0.001 & 0.001 & 0.020 \\
\hline $2689-17 B$ & & 600 & 0.001 & 0.002 & 0.030 \\
\hline $2689-17 C$ & & 1000 & 0.008 & 0.030 & 0.060 \\
\hline $2689-17 F$ & & 1400 & 0.003 & 0.010 & 0.060 \\
\hline $2689-18 B$ & & 1800 & 0.003 & 0.020 & 0.070 \\
\hline $2689-18 D$ & & 2200 & 0.003 & 0.010 & 0.050 \\
\hline $2689-19 B$ & SEPT 26 & 200 & 0.002 & 0.008 & 0.050 \\
\hline $2689-19 D$ & & 600 & 0.002 & 0.009 & 0.060 \\
\hline $2689-19 F$ & & 1000 & 0.002 & 0.004 & 0.050 \\
\hline $2689-20 B$ & & 1400 & 0.002 & 0.003 & 0.070 \\
\hline $2689-20 D$ & & 1800 & 0.004 & 0.006 & 0.080 \\
\hline $2689-21 B$ & & 2200 & 0.003 & 0.007 & 0.070 \\
\hline $2689-21 D$ & SEPT 27 & 200 & 0.002 & 0.006 & 0.080 \\
\hline $2689-22 B$ & & 600 & 0.005 & 0.007 & 0.080 \\
\hline $2689-22 C$ & & 1000 & 0.002 & 0.002 & 0.030 \\
\hline $2689-22 F$ & & 1300 & 0.003 & 0.001 & 0.030 \\
\hline $2689-23 B$ & & 1400 & 0.003 & 0.001 & 0.020 \\
\hline $2689-23 C$ & & 1500 & 0.002 & 0.003 & 0.020 \\
\hline $2689-23 E$ & & 1600 & 0.003 & 0.006 & 0.040 \\
\hline $2689-24 B$ & & 1800 & 0.002 & 0.008 & 0.030 \\
\hline $2689-24 D$ & & 2200 & 0.002 & 0.009 & 0.030 \\
\hline $2689-25 B$ & SEPT 28 & 200 & 0.003 & 0.008 & 0.030 \\
\hline $2689-25 D$ & & 600 & 0.004 & 0.040 & 0.020 \\
\hline $2689-26 A$ & & 1000 & 0.002 & 0.004 & 0.040 \\
\hline $2689-27 A$ & & 1400 & 0.002 & 0.005 & 0.030 \\
\hline $2689-270$ & & 1800 & 0.005 & 0.007 & 0.030 \\
\hline $2689-28 B$ & & 2200 & 0.004 & 0.020 & 0.040 \\
\hline $2689-28 D$ & SEPT 29 & 200 & 0.004 & 0.008 & 0.050 \\
\hline $2689-28 F$ & & 600 & 0.003 & 0.008 & 0.040 \\
\hline $2689-29 B$ & & 1000 & 0.003 & 0.003 & 0.030 \\
\hline 2689-29D1 & & 1400 & 0.003 & 0.002 & 0.030 \\
\hline $2689-2902$ & & 1800 & 0.003 & 0.002 & 0.030 \\
\hline $2689-308$ & & 2200 & 0.004 & 0.003 & 0.030 \\
\hline $2689-30 D$ & SEPT 30 & 200 & 0.004 & 0.004 & 0.040 \\
\hline $2689-30 F$ & & 600 & 0.004 & 0.005 & 0.050 \\
\hline $2689-31 B$ & & 1000 & 0.004 & 0.008 & 0.060 \\
\hline
\end{tabular}


BATH IMPURITIES

\begin{tabular}{|c|c|c|c|c|c|}
\hline Sample ID & Date & Time & $\mathrm{Cu}, \%$ & $\mathrm{Ni}, \%$ & $\mathrm{Fe}, \%$ \\
\hline $\begin{array}{l}2689-31 D \\
2689-32 B\end{array}$ & & $\begin{array}{l}1400 \\
1800\end{array}$ & $\begin{array}{l}0.003 \\
0.009\end{array}$ & $\begin{array}{l}0.007 \\
0.020\end{array}$ & $\begin{array}{l}0.060 \\
0.110\end{array}$ \\
\hline $2689-32 D$ & & 2200 & 0.010 & 0.020 & 0.080 \\
\hline $2689-33 B$ & OCT 1 & 200 & 0.005 & 0.006 & 0.070 \\
\hline $2689-33 D$ & & 600 & 0.005 & 0.007 & 0.050 \\
\hline $2689-34 A$ & & 1000 & 0.009 & 0.010 & 0.080 \\
\hline $2689-34 C$ & & 1400 & 0.003 & 0.008 & 0.050 \\
\hline $2689-35 B$ & & 1800 & 0.003 & 0.010 & 0.070 \\
\hline $2689-35 D$ & & 2200 & 0.003 & 0.009 & 0.060 \\
\hline $2689-368$ & OCT 2 & 200 & 0.003 & 0.010 & 0.060 \\
\hline $2689-36 D$ & & 600 & 0.003 & 0.012 & 0.040 \\
\hline $2689-36 E$ & & 1000 & 0.003 & 0.007 & 0.050 \\
\hline $2689-36 \mathrm{H}$ & & 1400 & 0.002 & 0.008 & 0.050 \\
\hline $2689-37 B$ & & 1800 & 0.004 & 0.010 & 0.070 \\
\hline $2689-37 D$ & & 2200 & 0.005 & 0.010 & 0.050 \\
\hline $2689-38 B$ & OCT 3 & 200 & 0.005 & 0.010 & 0.060 \\
\hline $2689-380$ & & 600 & 0.006 & 0.010 & 0.070 \\
\hline $2689-38 F$ & & 1000 & 0.005 & 0.009 & 0.070 \\
\hline $2689-38 H$ & & 1400 & 0.003 & 0.008 & 0.070 \\
\hline $2689-398$ & & 1800 & 0.004 & 0.007 & 0.060 \\
\hline $2689-39 D$ & & 2200 & 0.003 & 0.008 & 0.060 \\
\hline $2689-39 F$ & OCT 4 & 200 & 0.002 & 0.003 & 0.040 \\
\hline $2689-40 B$ & & 600 & 0.005 & 0.010 & 0.070 \\
\hline $2689-40 C$ & & 1000 & 0.005 & 0.010 & 0.070 \\
\hline $2689-40 F$ & & 1400 & 0.004 & 0.007 & 0.050 \\
\hline $2689-41 B$ & & 1800 & 0.005 & 0.009 & 0.070 \\
\hline $2689-41 D$ & & 2200 & 0.005 & 0.008 & 0.030 \\
\hline $2689-42 B$ & OCT 5 & 200 & 0.030 & 0.050 & 0.130 \\
\hline $2689-43 B$ & & 600 & 0.008 & 0.010 & 0.070 \\
\hline $2689-43 D$ & & 1000 & 0.006 & 0.007 & 0.070 \\
\hline $2689-43 F$ & & 1400 & 0.005 & 0.005 & 0.060 \\
\hline $2689-44 A$ & & 1800 & 0.005 & 0.004 & 0.050 \\
\hline $2689-44 D$ & & 2200 & 0.006 & 0.005 & 0.060 \\
\hline $2689-45 B$ & OCT 6 & 200 & 0.005 & 0.006 & 0.050 \\
\hline $2689-45 D$ & & 600 & 0.004 & 0.006 & 0.060 \\
\hline $2689-45 F$ & & 1000 & 0.005 & 0.008 & 0.050 \\
\hline $2689-45 H$ & & 1400 & 0.003 & 0.010 & 0.050 \\
\hline $2689-46 B$ & & 1800 & 0.002 & 0.010 & 0.030 \\
\hline $2689-46 D$ & & 2200 & 0.003 & 0.005 & 0.030 \\
\hline $2689-47 B$ & OCT 7 & 200 & 0.002 & 0.006 & 0.030 \\
\hline $2689-47 D$ & & 600 & 0.003 & 0.007 & 0.030 \\
\hline $2689-47 F$ & & 1000 & 0.002 & 0.005 & 0.050 \\
\hline $2689-48 B$ & & 1400 & 0.003 & 0.009 & 0.070 \\
\hline $2689-48 D$ & & 1800 & 0.002 & 0.003 & 0.020 \\
\hline $2689-48 F$ & & 2200 & 0.003 & 0.014 & 0.030 \\
\hline $2689-49 B$ & OCT 8 & 200 & 0.003 & 0.009 & 0.030 \\
\hline
\end{tabular}


BATH IMPURITIES

\begin{tabular}{|c|c|c|c|c|c|}
\hline Sample ID & Date & Time & $\mathrm{Cu}, \%$ & $\mathrm{Ni}, \%$ & $\mathrm{Fe}, \%$ \\
\hline $2689-49 D$ & & 600 & 0.003 & 0.007 & 0.020 \\
\hline $2689-49 E$ & & 1000 & 0.004 & 0.005 & 0.020 \\
\hline $2689-49 G$ & & 1400 & 0.003 & 0.007 & 0.020 \\
\hline $2689-50 B$ & & 1800 & 0.003 & 0.005 & 0.050 \\
\hline $2689-50 D$ & & 2200 & 0.003 & 0.008 & 0.020 \\
\hline $2689-50 F$ & OCT 9 & 200 & 0.003 & 0.004 & 0.020 \\
\hline $2689-51 B$ & & 600 & 0.003 & 0.004 & 0.020 \\
\hline $2689-51 D$ & & 1000 & 0.004 & 0.006 & 0.030 \\
\hline $2689-51 F$ & & 1400 & 0.003 & 0.004 & 0.030 \\
\hline $2689-51 \mathrm{H}$ & & 1800 & 0.003 & 0.003 & 0.020 \\
\hline $2689-51 J$ & & 2200 & 0.003 & 0.003 & 0.020 \\
\hline $2689-52 B$ & OCT 10 & 200 & 0.003 & 0.004 & $0.02 C$ \\
\hline $2689-52 D$ & & 600 & 0.003 & 0.004 & 0.02 \\
\hline $2689-52 G$ & & 1000 & 0.004 & 0.004 & 0.020 \\
\hline $2689-53 B$ & & 1400 & 0.003 & 0.004 & 0.03 \\
\hline
\end{tabular}



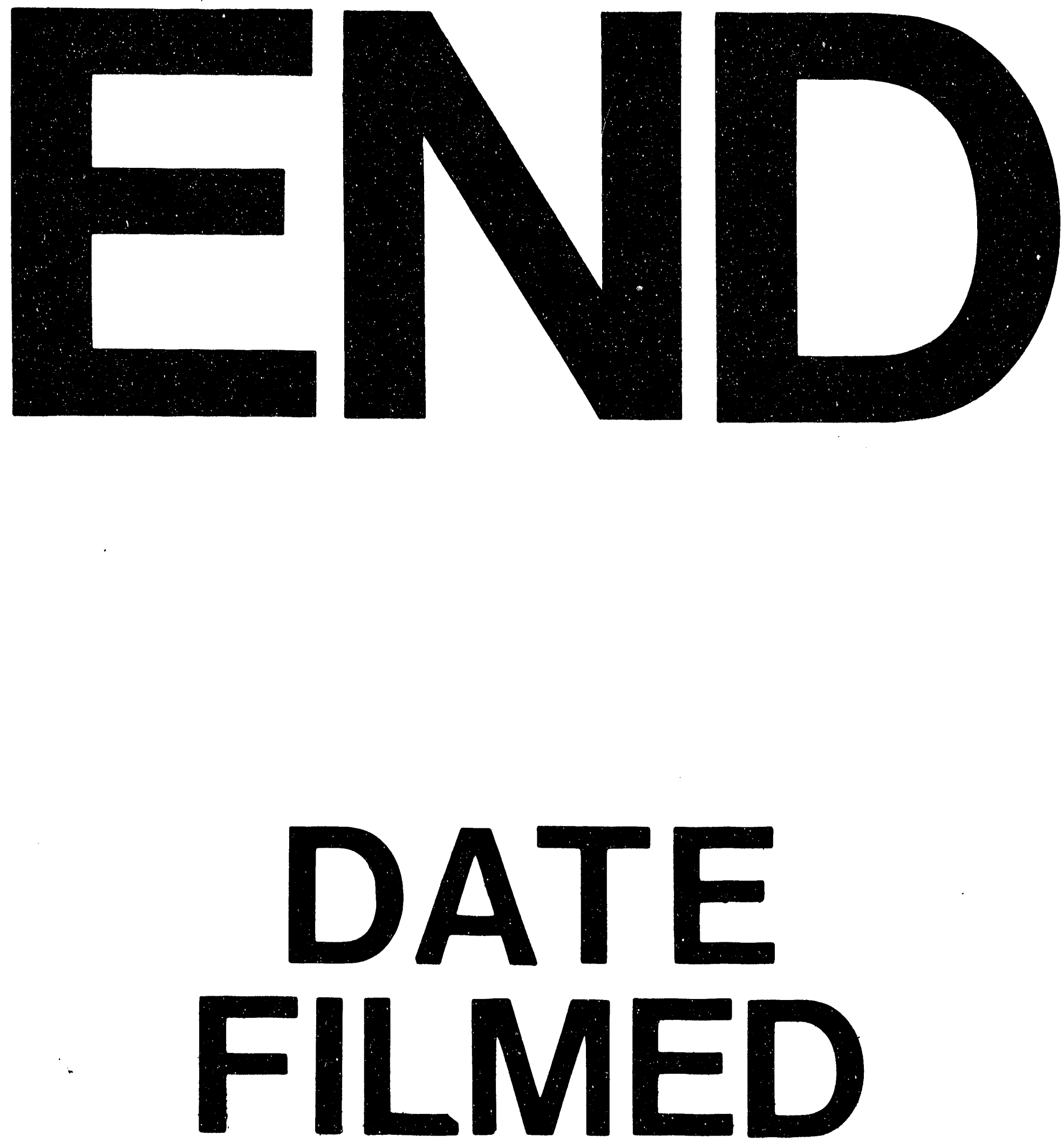

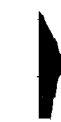
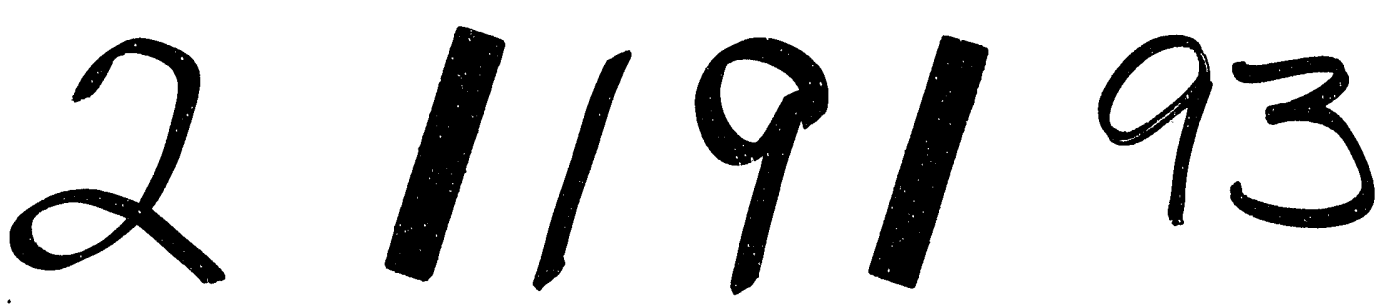
